\title{
PERIGLACIAL PRECONDITIONING OF DEBRIS FLOWS \\ IN THE SOUTHERN ALPS, NEW ZEALAND
}

by

Katrin Sattler

\begin{abstract}
A thesis submitted to
Victoria University of Wellington

in fulfilment of the requirements for the degree of

Doctor of Philosophy in Physical Geography
\end{abstract}

Victoria University of Wellington

Te Whare Wānanga o te Ūpoko o te Ika a Māui

2014 



\section{ABSTRACT}

The lower boundary of alpine permafrost extent is considered to be especially sensitive to climate change. Ice loss within permanently frozen debris and bedrock as a consequence of rising temperature is expected to increase the magnitude and frequency of potentially hazardous mass wasting processes such as debris flows. Previous research in this field has been generally limited by an insufficient understanding of the controls on debris flow formation. A particular area of uncertainty is the role of environmental preconditioning factors in the spatial and temporal distribution of debris flow initiation in high-alpine areas. This thesis aims to contribute by investigating the influence of permafrost and intensive frost weathering on debris flow activity in the New Zealand Southern Alps. By analysing a range of potential factors, this study explores whether debris flow systems subjected to periglacial influence are more active than systems outside of the periglacial domain.

A comprehensive debris flow inventory was established for thirteen study areas in the Southern Alps. The inventory comprises 1534 debris flow systems and 404 regolithsupplying contribution areas. Analysis of historical aerial photographs, spanning six decades, identified 240 debris flow events. Frequency ratios and logistic regression models were used to explore the influence of preconditioning factors on the distribution of debris flows as well as their effect on sediment reaccumulation in supply-limited systems. The preconditioning factors considered included slope, aspect, altitude, lithology, Quaternary sediment presence, neo-tectonic uplift rates (as a proxy for bedrock fracturing), permafrost occurrence, and frost-weathering intensity. Topographic and geologic information was available in the form of published datasets or was derived from digital elevation models. The potential extent of contemporary permafrost in the Southern Alps was estimated based on the statistical evaluation of 280 rock glaciers in the Canterbury region. Statistical relationships between permafrost presence, mean annual air temperature, and potential incoming solar radiation were used to calculate the spatially distributed probability of permafrost occurrence. Spatially distributed frost-weathering intensities were estimated by calculating the number of annual freeze-thaw cycles as well as frost-cracking intensities, considering the competing frost-weathering hypotheses of volumetric ice expansion and segregation ice growth. 
Results suggest that the periglacial influence on debris flow activity is present at high altitudes where intense frost weathering enhances regolith production. Frost-induced debris production appears to be more efficient in sun-avert than sun-facing locations, supporting segregation ice growth as the dominant bedrock-weathering mechanism in alpine environments. No indication was found that permafrost within sediment reservoirs increases slope instability. Similarly, the presence of permanently frozen bedrock within the debris flow contribution areas does not appear to increase regolith production rates and hence debris flow activity. Catchment topography and the availability of unconsolidated Quaternary deposits appeared to be the cardinal non-periglacial controls on debris flow distribution.

This thesis contributes towards a better understanding of the controls on debris flow formation by providing empirical evidence in support of the promoting effect of intense frost weathering on debris flow development. It further demonstrates the potential and limitations of debris flow inventories for identifying preconditioning debris flow controls. The informative value of regional-scale datasets was identified as a limitation in this research. Improvement in the spatial parameterisation of potential controls is needed in order to advance understanding of debris flow preconditioning factors. 


\section{ACKNOWLEDGEMENTS}

Numerous people have accompanied me on this $\mathrm{PhD}$ journey and have in some way contributed to the completion of this thesis.

I especially would like to thank my supervisors Andrew Mackintosh, Kevin Norton, Brian Anderson, and Mairéad de Róiste for their support, advice, and feedback on endless drafts. Throughout my journey, all have had an open door for questions and constructive discussions, helping me to regain order when ideas and thoughts were all over the place. A special thank you goes to Brian for sharing his knowledge of and experience in the Southern Alps, which was vital in planning and accomplishing my permafrost fieldwork in the Ben Ohau Range. I also greatly appreciate Brian's support and patience in all things modelling, including provision of the temperature interpolations, which represent a vital part of this research. A big thanks to Dalice Sim who patiently talked me through the intricacies of interpreting logistic regression outputs. A special thank you to Sam McColl for his support and boundless enthusiasm in planning and executing fieldwork, but also for opening his Canterbury home for me and other field assistants to wait when the weather did not play along. I would also like to thank Michael Guggenmos, Robert Williams, Leonhard Gerd, Angelika Riegler, and Rory Hart for their help in the field. A big thank you to Malcolm Ingham and Gillian Turner who offered their geotechnical experience in a last attempt to make the geoelectric surveys work. I would further like to acknowledge the Department of Conservation and Environment Canterbury for financial support towards fieldwork expenses. Thank you also to my examiners Michael Crozier, Stefan Winkler, and Martin Hoelzle for their constructive comments, suggestions, and effort, which are greatly appreciated. I'd particularly like to acknowledge Nick Preston, who secured the Victoria Vice Chancellor's Strategic Research PhD Scholarship for this project, supervised and mentored the first stages of my research, and welcomed me into his home for the first weeks settling in New Zealand. I hope he would enjoy reading through these pages and seeing what the original project has developed into.

I'd also like to thank the Spatial Forestry and Land Operations Team at the Ministry for Primary Industries, who facilitated part-time employment over the last two years to finance the last stretches of my PhD journey. I truly enjoyed showing up to work every Monday morning and applying GIS in areas completely contrary to the barren high-alpine landscape 
of my research. To be surrounded by a great team of people who are fun to work with, kept me sane and provided a much appreciated distraction from my thesis.

Heartfelt thanks to all my friends inside and outside university, who celebrated with me the highs and supported me through the lows of this journey, but more importantly, were part of all the amazing non-thesis adventures and activities that have made the last five years in New Zealand the fantastic experience they have been.

Lastly, l'd like to thank Will and my family for their boundless support over these years. Will, thank you for being at my side, celebrating with me the milestones and steering me through the times when everything just got a bit too much. My love goes to my family, who have been incredibly understanding and put up with my decision to study and live on the other side of the world. Mama und Papa, thank you for making it possible for me to follow my dreams; this thesis is dedicated to you. 


\section{TABLE OF CONTENTS}

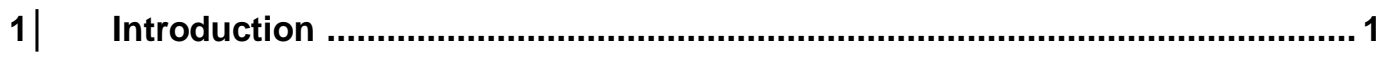

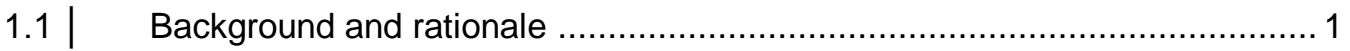

1.2 Study aims and objectives ............................................................ 4

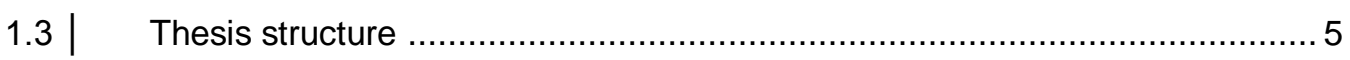

2| The Southern Alps …...................................................................... 7

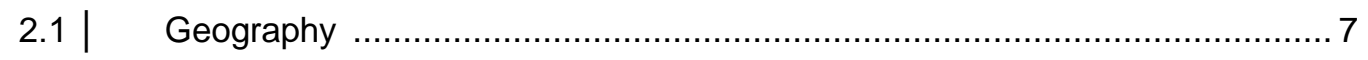

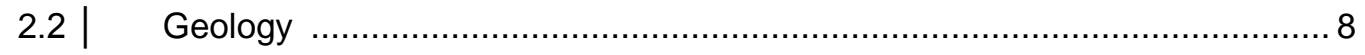

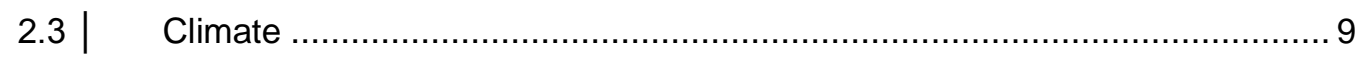

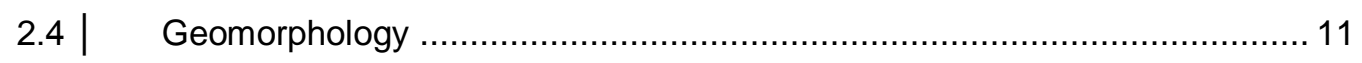

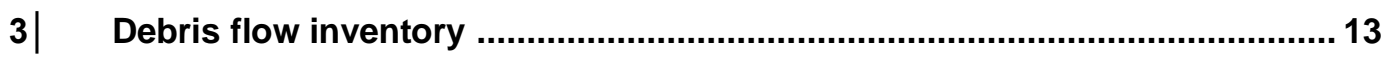

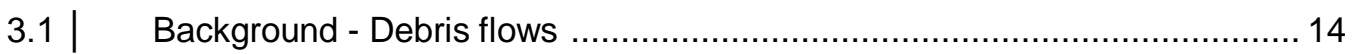

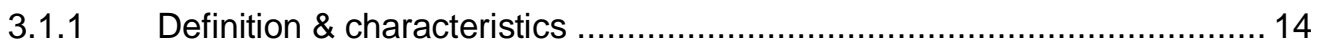

3.1.2 Factors controlling debris flow initiation .......................................... 19

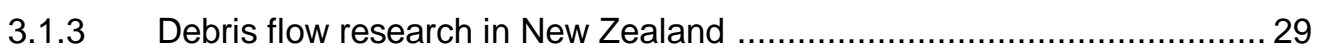

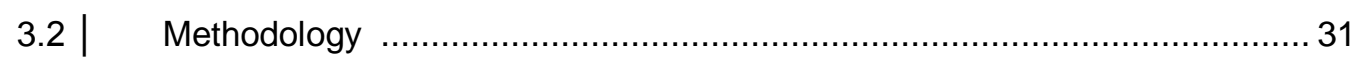

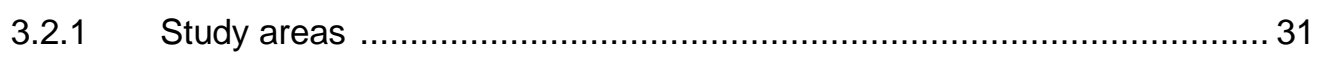

3.2.2 Assessment of debris flow activity in the selected study areas ............... 37

3.2.3 Delineation of debris flow contribution areas ...................................... 44

3.2.4 Delineation of steep rock surfaces ................................................ 46

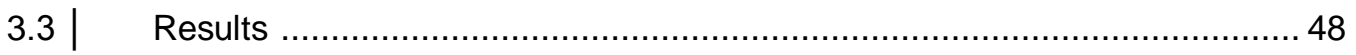

3.3.1 General debris flow activity in study areas .................................... 48

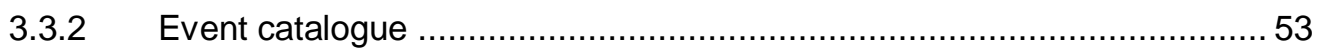




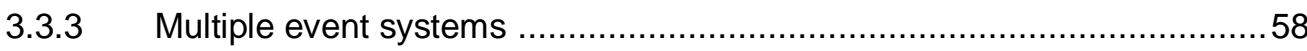

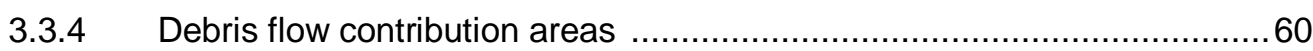

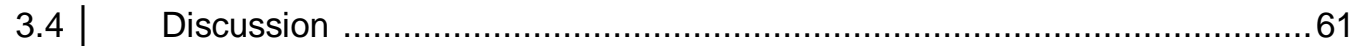

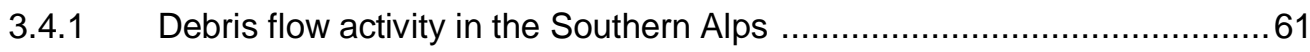

3.4.2 Debris flow activity according to debris flow type .................................... 62

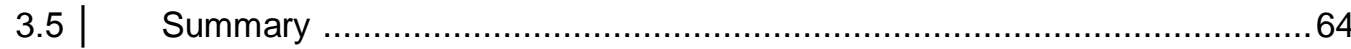

4 An estimate of alpine permafrost distribution in the Southern Alps ............65

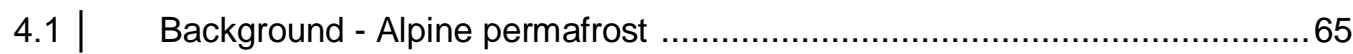

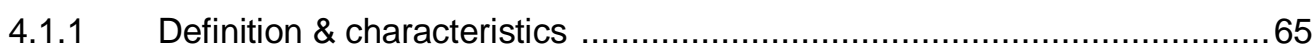

4.1.2 Indicators, prospecting methods, and distribution modelling

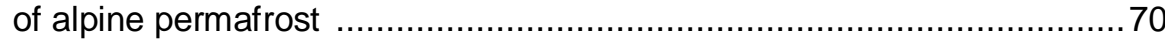

4.1.3 Permafrost research in New Zealand's Southern Alps ..........................75

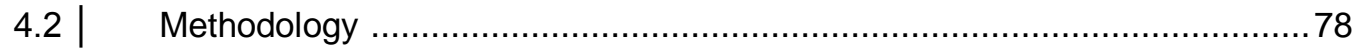

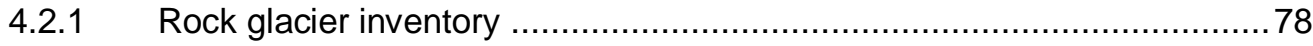

4.2.2 Present-day permafrost distribution estimate ....................................... 83

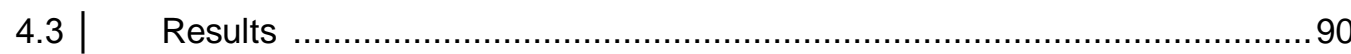

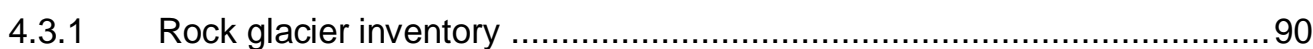

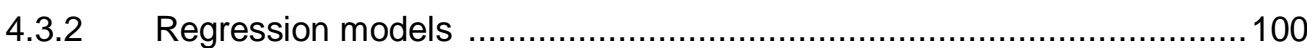

4.3.3 Permafrost distribution estimate for the Southern Alps ........................109

4.3.4 Local evaluation of the permafrost distribution estimate .......................114

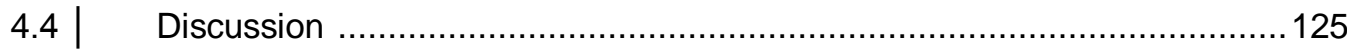

4.4.1 Rock glacier distribution and derived permafrost extent

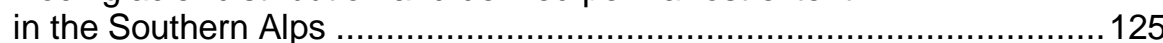

4.4.2 Applicability of the BTS method for permafrost prospecting

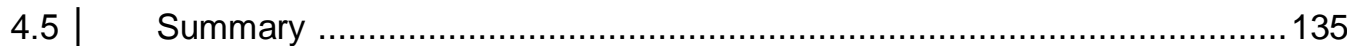

5| Statistical analysis of debris flow preconditioning factors .......................137

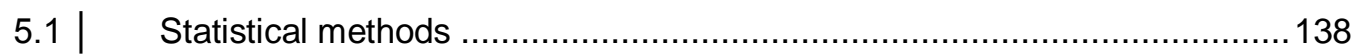

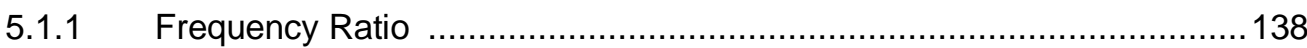

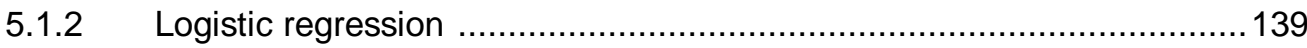




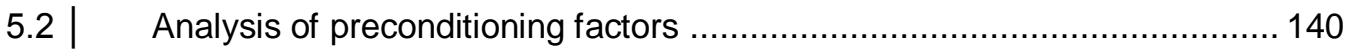

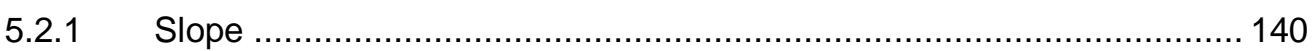

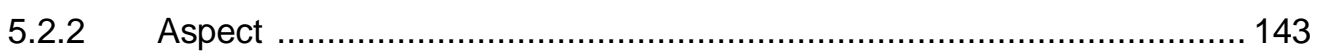

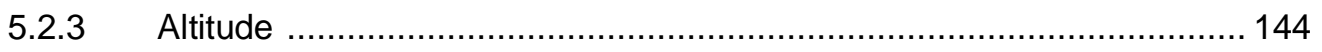

5.2.4 Lithology \& Quaternary deposits ................................................. 146

5.2.5 Neo-tectonic uplift rates ............................................................... 150

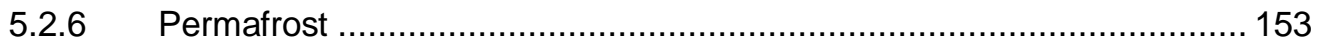

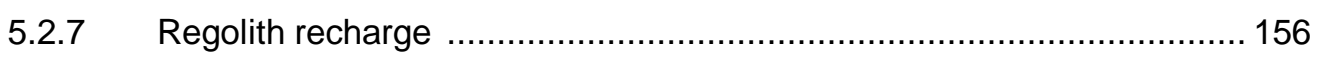

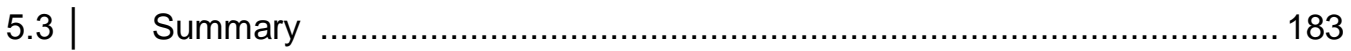

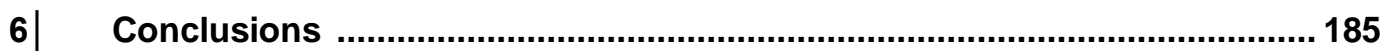

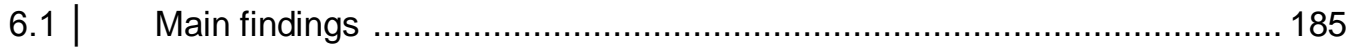

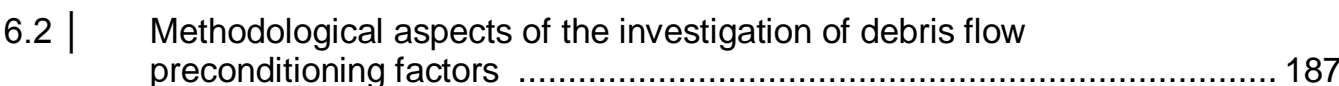

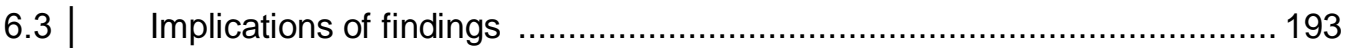

6.4 Recommendations for future research ............................................. 195

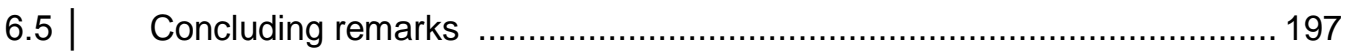

References 199

Appendices

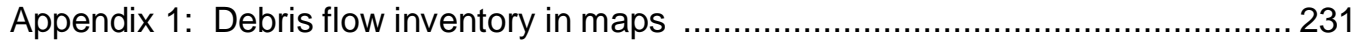

Appendix 2: List of aerial photographs used for debris flow event mapping .............. 245

Appendix 3: Regional characteristics of debris flow activity in the study areas ........ 247

Appendix 4: Debris flow activity in study areas through time …............................ 254

Appendix 5: Regional characteristics of debris flow events in the study areas ......... 256

Appendix 6: Climate stations used for temperature interpolations .......................... 262

Appendix 7: Preliminary permafrost distribution estimate for the Irishman Stream Valley, central Ben Ohau Range

Appendix 8: Modelled permafrost extent and frost-weathering intensities in the study areas

Appendix 9: Variance inflation factors for regression analyses ............................ 279 
EA 1: Debris flow inventory

EA 2: Debris flow contribution areas

EA 3: Rock glacier inventory

EA 4: Ground surface temperature time series

EA 5: Extended versions of frequency ratio tables 


\section{ABBREVIATIONS}

\begin{tabular}{ll}
\multicolumn{2}{l}{ Study Regions } \\
AP & Arthur's Pass region \\
KR & Kaikoura ranges \\
MA & Mount Aspiring region \\
MC & Mount Cook region \\
TT & Two Thumb Range
\end{tabular}

Study Areas

BBS Black Birch Stream valley

CC Camp Creek

CHFS Castle Hill \& Foggy Stream valley

DC Denas Creek

ES Enys Stream valley

FC Forest Creek

GB Glacier Burn valley

KCET Kay Creek eastern tributary

LDS Lower Dart Stream valley

MSV Middlehead Stream valley

SSV Stony Stream valley

TSV Trolove Stream valley

USCT Upper Stony Creek tributary

Debris flow types

SIT Slide-initiated debris flow

RIT Runoff-generated debris flow

COMB Combined-type debris flow ( slide-related)

Other

AICc Corrected Akaike Information Criterion

AUC Area under the Receiver-Operating-Characteristics (ROC)-Curve 


\begin{tabular}{ll} 
BTS & Bottom temperature of the winter snow cover \\
CCR & Correct classification rate \\
DEM & Digital Elevation Model \\
DF & Debris flow \\
EA & Electronic Appendix \\
EPV & Events per predictor variable \\
GST & Ground surface temperature \\
GWR & Geographically weighted regression \\
LiDAR & Light detecting and ranging \\
MAAT & Mean annual air temperature \\
N & Number \\
NZ & New Zealand \\
P & Probability \\
PF & Permafrost \\
PFM & Permafrost model \\
PISR & Potential incoming solar radiation \\
RG & Rock glacier \\
RILA & Rock glacier initiation line altitude \\
RQ & Research question \\
SS & Sediment supply \\
Ta & Annual temperature variations \\
VIF & Variance inflation factor \\
& \\
\hline
\end{tabular}




\section{LIST OF FIGURES}

Figure 1.1 Schematic diagram illustrating the spatial relation of the analysed preconditioning factors.

Figure 2.1 New Zealand's Southern Alps from space, Inset A) Tectonic setting of New Zealand, Inset B) Approximate area above $2000 \mathrm{~m}$ elevation, illustrating the distribution of high-alpine areas in the Southern Alps.

Figure 2.2 Simplified basement geology of New Zealand's South Island. ....................... 9

Figure 2.3 Transect across the Southern Alps. ..................................................... 10

Figure 3.1 Longitudinal profile of a debris flow.

Figure 3.2 Overlapping levées with clear inverse sorting left by multiple surges at Mount Fitzwilliam, Liebig Range, central Southern Alps.

Figure 3.3 Slide-initiated debris flows generated by Cyclone Bola 1988 in the Waipaoa catchment, NZ North Island.

Figure 3.4 Runoff-generated debris flows underneath Mt Blackburn, Tasman Valley, NZ South Island. 18

Figure 3.5 Graphical depiction of the concept of disposition for debris flow formation. .... 19

Figure 3.6 Graphical depiction of the difference in supply conditions for debris flow initiation.

Figure 3.7 Location of the thirteen study areas selected for the multi-temporal debris flow analysis.

Figure 3.8 Example of mapped debris flow features and attributes. 38

Figure 3.9 Aerial photograph coverage for the individual study areas. 40

Figure 3.10 Example of an aerial photo pair indicating debris flow occurrences between 1986 and 1998.

Figure 3.11 Example of a delineated debris flow contribution area. 45

Figure 3.12 Example of runoff-generated debris flow systems underneath small rock outcrops, where the extent of debris contributing area is not clearly recognisable. 
Figure 3.13 Slope angle distribution curves for selected talus and rock surface areas in Denas Creek, Camp Creek and the Kay Creek tributary.

Figure 3.14 Graphical representation of percentage distribution data listed in Table 3.3 for the entire inventory (column a), active systems (column c), and multiple event systems (column d).

Figure 3.15 Debris flow density in the individual study areas as well as combined per region.

Figure 3.16 Time of occurrence of observed debris flow events. .53

Figure 3.17 Absolute number of events mapped in the individual study areas. 54

Figure 3.18 Debris flow activity in the study areas and regions calculated as proportion of mapped debris flow systems showing activity during the investigation period.

Figure 3.19 Debris flow activity levels in the study areas through time. 56

Figure 3.20 Time of occurrence of debris flow events in multiple event systems according to study areas.

Figure 4.1 Examples of alpine permafrost. A) Permafrost body exposed in debris flow initiation area B) Ice lens underneath blocky scree in the rooting zone of an active rock glacier.

Figure 4.2 Schematic representation of permafrost occurrence in regolith with corresponding temperature profile

Figure 4.3 Relationship between permafrost distribution and other climatically-controlled limits as a function of continentality and elevation.

Figure 4.4 A) Schematic representation of an active talus-derived rock glacier in the Irishman Stream Valley, Ben Ohau Range B) Oblique view of the talus-derived rock glacier illustrated in A. C) Oblique view of a moraine-derived rock glacier of unknown activity close to Mt Glenmary.

Figure 4.5 Morphological model of talus-derived rock glacier development. ....................79

Figure 4.6 Examples of rock glacier initiation line locations. 80

Figure 4.7 Example of the S-shaped relationship between the conditional probability of the outcome $Y$ being 1 and the continuous independent variable $X_{n}$ before logarithmic transformation of $P(Y=1)$.

Figure 4.8 Rock glacier inventory for the Canterbury Region. .....................................91

Figure 4.9 Rock glacier distribution according to rock glacier type. 91

Figure 4.10 Rock glacier distribution according to activity status overall and differentiated by region. 94

Figure 4.11 Rock glacier distribution according to mean rock glacier altitude. .................95

Figure 4.12 Altitudinal zone of rock glacier in the individual study regions. .95 
Figure 4.13 Relationship between modelled mean annual air temperature (MAAT) and rock glacier initiation line altitude (RILA) of the mapped rock glaciers.

Figure 4.14 Rock glacier distribution according to aspect.

Figure 4.15 Rock glacier distribution in study regions according to initiation line altitude (RILA) and aspect.

Figure 4.16 Relationship between the modelled potential incoming solar radiation in snow-free months and rock glacier orientation.

Figure 4.17 Relationship between modelled mean annual air temperature (MAAT) and modelled potential incoming solar radiation in snow-free months for the active and relict talus-derived rock glaciers used for calibration of the permafrost distribution model.

Figure 4.18 Example of complete separation in values of the predictor variable $X_{n}$ for the outcome $Y$.

Figure 4.19 Results of PFM III: A) Local $\mathrm{R}^{2}$; B) Significance of coefficient estimates for MAAT and PISR at location $i ; 1=p \leq .05,0=p>.05$, inferred from absolute t-values $</> \pm 1.96$; C) Coefficient estimates for MAAT at location $i$; D) Coefficient estimates for PISR at location $i$.

Figure 4.20 Scatterplot of local coefficient estimates for MAAT and PISR.

Figure 4.21 ROC curves of the models PFM I and PFM II BOR for the area Ben Ohau Range and all other areas combined.

Figure 4.22 Permafrost probability map for the permafrost study regions, delineating the modelled contemporary permafrost extent in central Canterbury.

Figure 4.23 Permafrost probability map for the Inland Kaikoura Range delineating the modelled contemporary permafrost extent.

Figure 4.24 Extent of permafrost probability classes in the permafrost study regions. ... 113

Figure 4.25 Continuous ground surface measurement sites in the central Ben Ohau Range.

Figure 4.26 A) Data logger setup on rock glacier site RG \#2 B) Example of a data logger used in this study.

Figure 4.27 Examples of three ground surface temperature (GST) profile types

(B, C, D), and corresponding air temperatures recorded March 2010 - Feb 2011

in the Irishman Stream area, central Ben Ohau Range.

Figure 4.28 GST profile types and BTS values for the winter 2010 and 2011 . 120

Figure 4.29 Twenty-three month record of GST development at site E \#5.

Figure 4.30 Comparison of the modelled permafrost extent and the distribution of determined BTS values for A) winter 2010 and B) winter 2011.

Figure 4.31 Comparison of modelled permafrost extent and late-summer snow patch distribution, as mapped in February 2006. 
Figure 4.32 Relationship between rock glacier front altitude and latitude in the Canterbury Region for active features and intact and relict features.

Figure 4.33 Altitudinal distribution limits of active rock glaciers according to aspect, taken from a selection of published international rock glacier inventories.

Figure 4.34 Comparison of modelled mean annual air temperature (MAAT) at active rock glacier sites in the Southern Alps to other international datasets.

Figure 4.35 Profile of the Ben Ohau Range, illustrating the spatial and altitudinal distribution of active and fossil rock glaciers mapped by Brazier et al. (1998).

Figure 4.36 Comparison of the modelled potential permafrost extent in the central Ben Ohau Range (top) and the northern Two Thumb Range (bottom) to the model results by Gruber (2012).

Figure 5.1 Debris flow activity, calculated as proportion of mapped systems showing activity during the investigation period, in the topographic categories debris, rock/debris interface, and rock wall.

Figure 5.2 Frequency of debris flow systems and events in the individual lithology classes.

Figure 5.3 Debris flow density (overall inventory) in the individual lithology classes.

Figure 5.4 Uplift rates for New Zealand's South Island after Wellman (1979) overlain by modelled exhumation rates for the last $1 \mathrm{Ma}$.

Figure 5.5 Percent frequency distribution of mapped debris flow systems and events in the individual permafrost probability classes.

Figure 5.6 Spatial distribution of mean annual frost cycles in the Camp Creek Valley, northern Two Thumb Range.

Figure 5.7 Predicted depth-integrated frost-cracking intensity values for a range of MAAT, based on annual temperature variations $\left(T_{a}\right)$ of $6^{\circ} \mathrm{C}$.

Figure 5.8 Spatial distribution of frost-cracking intensity in the Camp Creek Valley, northern Two Thumb Range.

Figure 5.9 Relationship between modelled frost-cracking intensities and mean annual frost cycles for high-altitude locations in the Camp Creek catchment, Two Thumb Range. 


\section{LIST OF TABLES}

Table 3.1 Information on geographic location, relief characteristics, geology, and climate for the individual study areas.

Table 3.2 Summary of features and attributes mapped for analysing debris flow activity in the study areas.

Table 3.3 Percent frequency distribution of process-related and topographic parameters for the entire debris flow inventory.

Table 3.4 Average reactivation intervals in multiple event systems according to system type and sediment supply.

Table 3.5 Topographic characteristics of mapped debris flow contribution areas according to study regions.

Table 3.6 Likelihood of events occurring during the investigation period according to debris flow types.

Table 4.1 Summary of attributes mapped in conjunction with the rock glacier initiation line location.

Table 4.2 Visual diagnostics for rock glacier activity classification.

Table 4.3 Comparison of this study's rock glacier dataset to published regional inventories.

Table 4.4 Rock glacier density according to study regions. 93

Table 4.5 Regression results and dataset characteristics of the three model designs.

Table 4.6 Regression results for PFM I calculated with standardised predictor variables ZMAAT and ZPISR.

Table 4.7 Modelled permafrost extent in the permafrost study regions.

Table 4.8 Elevation summary for locations with permafrost probability between 0.6 and 0.7 according to aspect classes as well as averaged over all orientations. 
Table 5.1 Frequency ratios for slope categories according to initiation type and activity count.

Table 5.2 Frequency ratios for aspect categories according to initiation type and activity count.

Table 5.3 Frequency ratios for altitude categories according to initiation type and activity count.

Table 5.4 Frequency ratios values for lithology classes according to initiation type and activity count.

Table 5.5 Frequency ratios for Quaternary deposits and lithology classes separately according to process type and activity count.

Table 5.6 Frequency ratios for uplift rate categories according to process type and activity count.

Table 5.7 Modelled permafrost extent in the individual study areas. 154

Table 5.8 Frequency ratios for permafrost probability categories according to initiation type and activity count.

Table 5.9 Mean annual temperature cycles $\left(\mathrm{T}_{\mathrm{a}}\right)$, calculated for the period 1971-2000, at climate stations close to the study areas.

Table 5.10 Activity counts according to debris flow study regions and grouped analysis regions.

Table 5.11 Results of the logistic regression for the analysis region 'South' using debris flow systems' activity during the investigation period as dependent variable and calculated frost-cracking intensities and mean annual frost cycles as independent variable.

Table 5.12 Activity counts according to debris flow study regions for frost cracking intensity data and frost cycle data.

Table 5.13 Activity counts in the Mt Aspiring region according to individual and grouped aspect classes.

Table 5.14 Results of the logistic regression model, exploring the orientationdependent effect of frost weathering on debris flow activity in the Mt Aspiring region.

Table 5.15 Activity counts in all study areas according to lithology classes and grouped rock type.

Table 5.16 Results of the logistic regression using debris flow systems' activity during the investigation period as dependent variable and lithology in the debris flow initiation area as independent variable.

Table 5.17 Results of the logistic regression using debris flow systems' activity during the investigation period as dependent variable and the principal type of lithology in the debris flow initiation area as independent variable. 
Table 5.18 Activity counts in the Mt Aspiring region according to lithology classes.

Table 5.19 Results of the logistic regression, exploring the lithology-dependent effect of frost- weathering activity on debris flow occurrence in the Mt Aspiring region.

Table 5.20 Results of the logistic regression, exploring the lithology-dependent effect of frost-weathering activity on debris flow occurrence in all study areas. .. 176

Table 5.21 Results of the logistic regression, exploring the lithology-dependent effect of frost-weathering activity on debris flow occurrence in all study areas. .. 177

Table 5.22 Results of the logistic regression, analysing the lithology-dependent effect of frost-weathering activity on debris flow occurrence in the Mt Aspiring region.

Table 5.23 Sample count for all study areas according lithology class and uplift rate.

Table 5.24 Result of the logistic regression, exploring the effect of uplift rates on general sediment production in greywacke catchments.

Table 5.25 Activity count for study areas in greywacke according to study area and uplift rate.

Table 5.26 Activity count according to permafrost presence in the debris flow contribution areas for all study regions. Figures in brackets give proportion of events/ non-events within permafrost category. 181

Table 5.27 Results of the logistic regression, analysing the effect of permafrost in the contribution areas on debris flow occurrence.

Table 5.28 Findings of the statistical analysis of factors influencing debris flow activity in the Southern Alps. 


\section{1| INTRODUCTION}

\subsection{BACKGROUND AND RATIONALE}

High-mountain areas are currently in focus of the geosciences due to the contemporary and anticipated effects of global warming at high altitudes (Beniston, 2003; Christensen et al., 2007; Warburton, 2007; Knight and Harrison, 2009). Of particular concern is the degradation of permanently frozen ground (permafrost), which is expected to promote an increase in magnitude and frequency of potentially hazardous mass wasting processes (e.g. Haeberli, 1992; Haeberli et al., 1997; Haeberli and Gruber, 2009; Huggel et al., 2012). While our understanding of the effect of atmospheric warming on bedrock stability and hence rockfall susceptibility has significantly advanced in recent years (see e.g. Gruber and Haeberli, 2007, Harris et al., 2009, and Stoffel and Huggel, 2012, for reviews), a possible link between permafrost degradation and increased debris flow activity still remains largely theoretical. Field observations illustrating the expected relationship are rare (e.g. Jomelli et al., 2004; M. Curtaz in Zischg et al., 2011). They are hindered by insufficient knowledge of fine-scale permafrost distribution, spatial and temporal occurrence of debris flow events, and the timescale involved in the reaction of permafrost to atmospheric warming (cf. Harris, 2005; Sattler et al., 2011). The lower boundary of the contemporary permafrost distribution is thought to be especially sensitive to climate warming. Studies at a regional scale interpreted the occurrence of conspicuous debris flow activity at this margin as an indicator of a causal relationship (e.g. Zimmermann and Haeberli, 1992; Stötter, 1994; Felderer, 2008; Sattler et al., 2011). Yet, these studies do not adequately consider the baseline debris flow activity in alpine periglacial areas, i.e. high-altitude areas subjected to seasonal or perennial frost (cf. French and Thorn, 2006; French, 2007). Activity is likely to be innately high in these areas due to the combination of steep slopes, high regolith production rates owing to intense frost weathering, and the presence of permafrost (cf. Van Steijn et al., 1995; Berthling and Etzelmüller, 2011). However, the role of periglacial influences on debris flow activity in high-alpine areas has so far not been systematically investigated. Knowledge of baseline debris flow activity and its natural variability in high mountain areas is needed to adequately evaluate potential indicators of geomorphic responses to atmospheric warming (cf. Marchi et al., 2008; Huggel et al., 2012). 
This study analyses debris flow activity in the alpine areas of the Southern Alps, New Zealand, during the last six decades. It focuses on determining debris flow preconditioning factors, i.e. the environmental conditions within source areas that facilitate debris flow development. By analysing a wide range of potential factors, including topography, lithology, and geomorphic legacy (e.g. the presence of Quaternary deposits), this study aims to determine whether debris flow systems subjected to periglacial influences, i.e. intense frost weathering and the presence of permafrost, are more active than systems outside the periglacial realm. A periglacial influence on debris flow activity is expected to include an altitudinal component, since both frost weathering and permafrost occurrence are primarily temperature- and hence elevation controlled, with the zone of significant frost-weathering activity extending to lower altitudes than permafrost occurrences (Figure 1.1). This characterisation of recent debris flow activity at high altitudes may be used as a baseline record for future studies on the geomorphic impact of anticipated climate change in New Zealand's Southern Alps.

The control of preconditioning factors on the spatial distribution of debris flows is well acknowledged (e.g. Innes, 1983; Bovis and Jakob, 1999; Jomelli et al., 2007; Carrara et al., 2008). However, so far only few studies have systematically analysed environmental conditions within source areas to determine their relative importance for debris flow development (e.g. Rieger, 1999; Lorente et al., 2002; Jomelli et al., 2003). The statistical evaluation of preconditioning factors requires an extensive debris flow inventory in order to capture variations in environmental factors. This regional scale of analysis is in stark

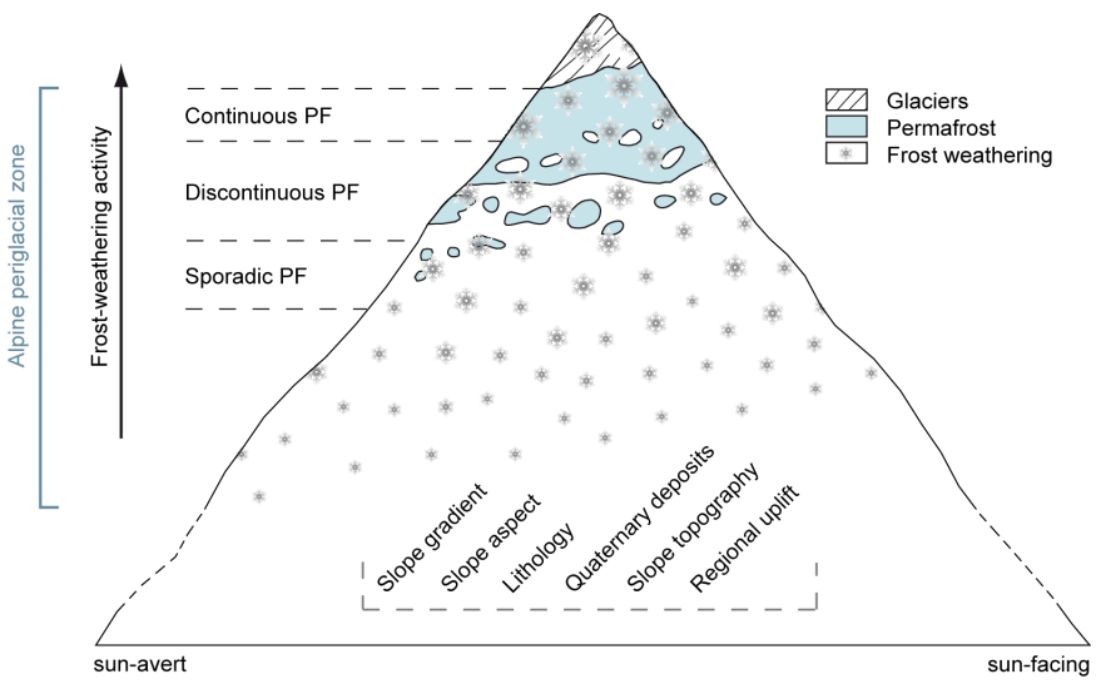

Figure 1.1

Schematic diagram illustrating the spatial relation of the analysed preconditioning factors. The extent of areas potentially underlain by permafrost (adapted from French, 2007, p.4; permafrost distribution types are further discussed in Chapter 4 of this thesis) is smaller than the extent of areas potentially affected by significant frost weathering. The distribution of the non-periglacial factors (dashed bracket) is altitude and aspect-independent. 
contrast to the local scale of factors influencing debris flow initiation (e.g. Blijenberg, 1998; Bovis and Jakob, 1999; Brayshaw and Hassan, 2009; Schneuwly-Bollschweiler and Stoffel, 2012). Local topography, volume of sediment reservoirs, as well as the mechanical and hydraulic properties of debris accumulations, are decisive factors for debris flow initiation. However, their field assessment at representative sample sites is problematic due to the remote and often hazardous location of debris flow starting zones, which makes large datasets difficult to realise. Similarly, the determination and implementation of rainfall-trigger thresholds in mountainous areas remain challenging (cf. Blijenberg, 1998; Bollschweiler and Stoffel, 2010). Complex mountain topography and scarce availability of high altitude rain gauges significantly complicate the spatial interpolation of precipitation distributions (e.g. Sevruk and Mieglitz, 2002; Kerr, 2009). Allowance for the change of rain to snow at high altitudes or the hydrological effect of rain on snow provide further challenges for modelling of discharge and hence the evaluation of triggering events for debris flow initiation areas (cf. Brayshaw and Hassan, 2009). These fundamental methodological constraints impede a holistic analysis of the role of preconditioning factors for debris flow initiation. Yet, all new information on causal relationships will contribute to our presently still inadequate understanding of the spatial distribution of debris flows and may further our ability to evaluate the sensitivity of specific debris flow systems to climate change.

New Zealand's Southern Alps are thought especially suited for this study. The combination of steep topography, high denudation rates, and relatively frequent high intensity rainfall events creates an ideal environment for debris flow development. Debris flow tracks are common features throughout the Southern Alps, and, given the high sediment production rates (e.g. Whitehouse and Pearce, 1992), activity levels are expected to be high. Of special advantage is the widespread occurrence of geomorphologically simple debris flow systems, i.e. systems associated with open-slope instabilities or short low-order torrential systems. The simple structure of these systems facilitates the mapping of debris flow initiation areas and related characteristics as well as the identification of events via aerial photo interpretation. Furthermore, the bedrock geology of the Southern Alps is fairly homogenous over large areas. Climatic gradients and their landscape expressions have a relatively straightforward distribution due to the more or less constant strike of the Main Divide, blocking prevailing westerly weather systems. These environmental conditions increase the potential for statistically significant relationships between predisposing controls and debris flow events to be found within a regional debris flow inventory. Additionally, extensive areas of the Southern Alps experience mean air temperatures at or below $0^{\circ} \mathrm{C}$ for several months a year (cf. Soons and Price, 1990) and hence are likely subjected to intense frost-weathering activity. Rock temperature measurements by Allen et al. (2009) as well as intact rock glaciers east of the main divide suggest the presence of permafrost within highaltitude rockwalls and debris slopes. However, local-observation based estimates of the contemporary extent of permafrost in the Southern Alps have so far only been established 
for the Mt Cook area and Ben Ohau Range (Brazier et al., 1998; Allen et al., 2008). Results of a recent high-resolution (1 km) global permafrost zonation model (Gruber, 2012) have yet to be locally evaluated. Consequently, the creation of a regional local-data based permafrost distribution estimate for the Southern Alps is a main objective of this study.

\subsection{STUdY AIMS AND OBJECTIVES}

The primary aim of this study is to evaluate the role of periglacial preconditioning factors, i.e. intense frost weathering and the presence of permafrost, on debris flow activity in the Southern Alps, New Zealand.

To achieve this, the following research questions will be addressed:

1) Are debris flow systems within the permafrost zone more active than those at lower altitudes?

To answer this question, the objectives are:

- Establish a debris flow inventory for selected study areas across the Southern Alps.

- Assess debris flow activity in these study areas.

- Estimate the potential permafrost extent in the Southern Alps.

- Compare the activity in debris flow systems within the permafrost zone to the activity in debris flow systems below the permafrost zone.

2) Are debris flow systems subjected to intense frost-weathering regimes more active than those at lower altitudes?

To answer this question, additional objectives are:

- Estimate frost-weathering intensities in the study areas.

- Compare debris flow activity in comparatively intense and less intense frostweathering regimes.

3) Which non-periglacial preconditioning factors influence debris flow activity in the Southern Alps?

To answer this question, additional objectives are:

- Review published literature on factors that promote debris flow initiation. 
- Analyse the explanatory power of non-periglacial factors for spatial variability in debris flow activity by means of uni- and multivariate statistics.

\section{3 | THESIS STRUCTURE}

This thesis is divided into six interrelated chapters. Following on from this introductory chapter, Chapter 2 introduces the Southern Alps, which form the geographic setting of this study. An overview of general topographic characteristics of the Southern Alps is followed by a brief outline of geologic, climatic, and geomorphologic attributes. Chapter 2 is intended as a general introduction to the Southern Alps; detailed descriptions of this research's study areas are given in Chapter 3 .

Chapter 3 presents background information to and results of the established debris flow inventory, which forms the core data of this research (research question (RQ) 1 to 3 ). The chapter starts by introducing the geomorphic process 'debris flow', followed by an extensive literature review on the environmental factors known to influence debris flow formation (RQ 3) and a summary of previous work on debris flows in New Zealand. This first part of Chapter 3 provides the conceptual context of this research. Chapter 3 further outlines the methodology used for establishing the debris flow inventory, including the criteria for study site selection and details on the selected study areas (RQ 1 to 3 ). It describes the strategies for mapping debris flow systems and events, and for semi-automatically delineating the regolith-providing debris flow contribution areas. The chapter further presents the established debris flow inventory according to process-related and topographic attributes. Chapter 3 ends with a discussion of derived information on debris flow activity in the Southern Alps.

Chapter 4 presents a permafrost distribution estimate for the Southern Alps inferred from topoclimatic conditions at rock glacier sites (RQ 1). The model was developed as part of this study to allow comparing debris flow activity within the potential permafrost zone to activity at lower altitudes. The chapter starts with a general introduction to alpine permafrost, its distribution characteristics, and a review of current spatial modelling approaches. It further outlines the methodology used for mapping rock glaciers in the Canterbury Region and describes the statistical evaluations underlying the developed spatially-distributed permafrost estimate. The chapter further details the evaluation of the model results by two independent permafrost indicator datasets (bottom temperature of the snow cover and perennial snow patches) from a site in the Ben Ohau Range, central Southern Alps. The chapter ends with a discussion of the distribution of rock glaciers in the Southern Alps and the inferred permafrost extent in the context of published literature. 
Chapter 5 represents the principal analysis chapter of this thesis (RQ 1 to 3 ). Univariate and multivariate statistics are used to relate mapped debris flow densities and debris flow activity to potentially process promoting environmental factors. Frequency ratios are used to investigate spatial variations in debris flow system and event density according to slope, aspect, altitude, lithology, presence of Quaternary debris reservoirs, neo-tectonic uplift rates, and permafrost occurrence within the debris initiation areas. A series of logistic regression models is used to analyse the effect of frost weathering, aspect, lithology, uplift rates (as a proxy for bedrock fracture density), and bedrock permafrost on regolith reaccumulation in supply-limited debris flow systems. Chapter 5 differs in structure from the previous chapters as it does not include a dedicated discussion section. Instead the statistical results are discussed along with the analyses. A summary of the main findings on predisposing factors of debris flow activity in the Southern Alps is given at the end of Chapter 5.

This thesis concludes in Chapter 6 by addressing the three central research questions stated in the introduction. It further discusses methodological aspects of the investigation of debris flow preconditioning factors, outlines implications of this study's findings for the field of debris flow research, and gives recommendations for future research efforts. 


\section{2| THE SOUTHERN ALPS}

New Zealand's Southern Alps superficially appear especially suited for the investigation of predisposing debris flow controls. The steep topography, extensive regolith reservoirs, and relatively frequent high intensity rainfall events create an ideal environment for debris flow development. Debris flow tracks are common features throughout the Southern Alps, and, in view of documented high regolith production rates, activity levels are expected to be high. This chapter provides a general introduction to the Southern Alps. The following sections briefly outline the geography, geology, climate, and geomorphology of the Southern Alps. The focus of this chapter is the Southern Alps in general; a detailed description of the individual debris flow study areas follows in Chapter 3.

\subsection{GEOGRAPHY}

The Southern Alps are an elongated, southwest-trending mountain chain on New Zealand's South Island (hatched area, Figure 2.1, Inset A). The mountain belt, created by the oblique collision of the Pacific and Australian plates, is approximately $800 \mathrm{~km}$ long, $60 \mathrm{~km}$ wide and consists of a series of ranges and basins (Barrell et al., 2011). Its sharp northwest margin is formed by the escarpment of the Alpine Fault. Severe earthquakes occur on the Alpine Fault and its associated faults approximately every 100 to 300 years (e.g. Cowan and McGlone, 1991; Sutherland et al., 2007; Berryman et al., 2012). The Southern Alps' drainage divide, referred to as the Main Divide, runs parallel to and approximately $20 \mathrm{~km}$ southeast of the Alpine Fault. Many mountains along the Main Divide rise above $2500 \mathrm{~m}$ a.s.l. and 23 peaks exceed $3000 \mathrm{~m}$ a.s.l., including New Zealand's highest Mountain, Aoraki/ Mt Cook (3724 m) (Dennis, 2012; Sirguey, 2014). The Southern Alps are sparsely populated and have limited economic development. Only three mountain road passes connect the eastern foreland with its western counterpart.

The extent of the Southern Alps has not been officially defined. In this thesis, the geographic name refers to all South Island mountain ranges related to the orogen along the continental plate boundary, including the Kaikoura ranges in the north (see Figure 2.1, Inset B). The following sections briefly summarise geologic (Section 2.2), climatologic (Section 2.3) and geomorphologic characteristics (Section 2.4) of the Southern Alps. 


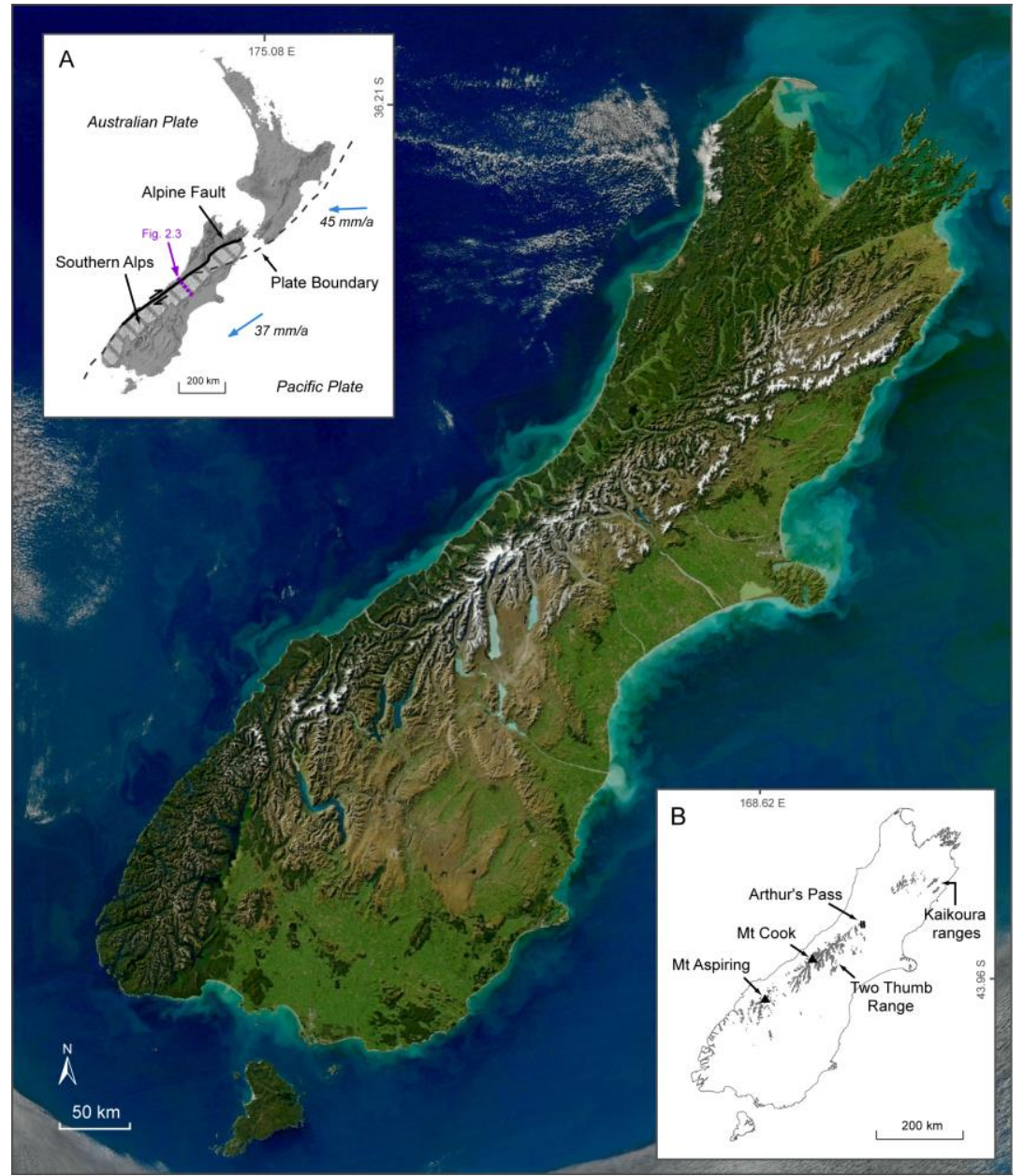

Figure 2.1

New Zealand's Southern Alps from space, captured by NASA's Aqua satellite on 29/04/2011

(source: www. oceancolor.gsfc.nasa.gov). Inset A) Tectonic setting of New Zealand (adapted from McColl, 2012).

Blue arrows indicate inferred inter-plate velocities during the last three million years (cf. Norris and Cooper, 2001).

The dashed purple line marks the approximate location of the transect depicted in Figure 2.3. Inset B)

approximate area above 2000 m elevation, illustrating the distribution of high-alpine areas in the Southern Alps.

\subsection{GeOLOGY}

The geology of the Southern Alps is dominated by well-indurated sedimentary rocks and their metamorphosed equivalents. The northern and central Southern Alps are comprised of hard quartzo-feldspatic sandstones (greywacke) and mudstones (argillite) of the Torlesse Composite terrane (Figure 2.2), which are derived from submarine sediments eroded from the ancient Gondwana continent (Coates, 2002; Mortimer, 2004). This geologic terrane, stratified by age into Rakaia (Older Torlesse) and Pahau (Younger Torlesse), is the largest by area and lithologically fairly monotonous. Towards the Main Divide, the sedimentary rocks are progressively replaced by schist (Haast Schist) of increasing metamorphic grade, with the highest-grade metamorphic rocks exposed in the vicinity of the Alpine Fault 


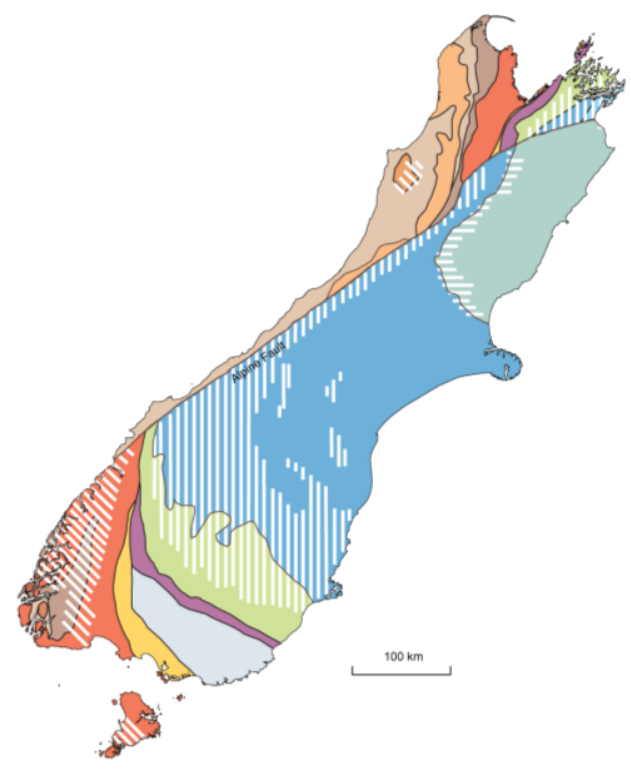

SEDIMENTARY AND VOLCANIC ROCKS

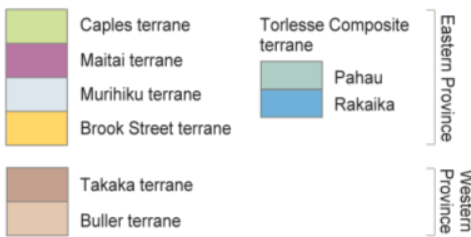

PLUTONIC ROCKS

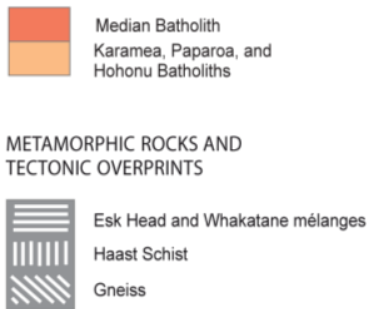

Figure 2.2

Simplified basement geology of New Zealand's South Island (adapted from Mortimer, 2004, in Cox and Barrell, 2007).

(Coates, 2002; Cox and Barrell, 2007). Metamorphic rocks can also be found towards the south, in the Otago Region, where Otago Schist occurs at the contact of the Rakaia terrane with the volcaniclastic rocks of the Caples terrane (Mortimer, 2004). The southern-most ranges of the Southern Alps, the Fiordland Mountains, comprise plutonic rocks associated with the ancient Gondwana continent, including granites, diorites and orthogneisses (Turnbull et al., 2010).

\section{$2.3 \mid$ CLIMATE}

The Southern Alps form a topographic barrier for the prevailing, moisture-laden westerly winds, creating a strong orographic precipitation regime with a steep negative rainfall gradient towards the east (Figure 2.3). Annual precipitation is highest on the western flank near the Main Divide (up to $14 \mathrm{~m} \mathrm{a}^{-1}$, Henderson and Thompson, 1999). Significant rainfall is also recorded immediately east of the Main Divide due to orographic spillover (cf. Sinclair et al., 1997; Chater and Sturman, 1998). Further eastwards, rainfall totals drop progressively to less than $1000 \mathrm{~mm}$ on the eastern plains and in the drier inland mountain basins (Griffiths and McSaveney, 1983). The proportion of snow increases with elevation. Persistent winter snow cover forms above $1200 \mathrm{~m}$ to $1500 \mathrm{~m}$; permanent surface ice exists in shaded locations above $1600 \mathrm{~m}$ west and above $2200 \mathrm{~m}$ east of the Main Divide (cf. Chinn, 1995; Barrell et al., 2011). The modern glacial equilibrium line altitude in the Inland Kaikoura 


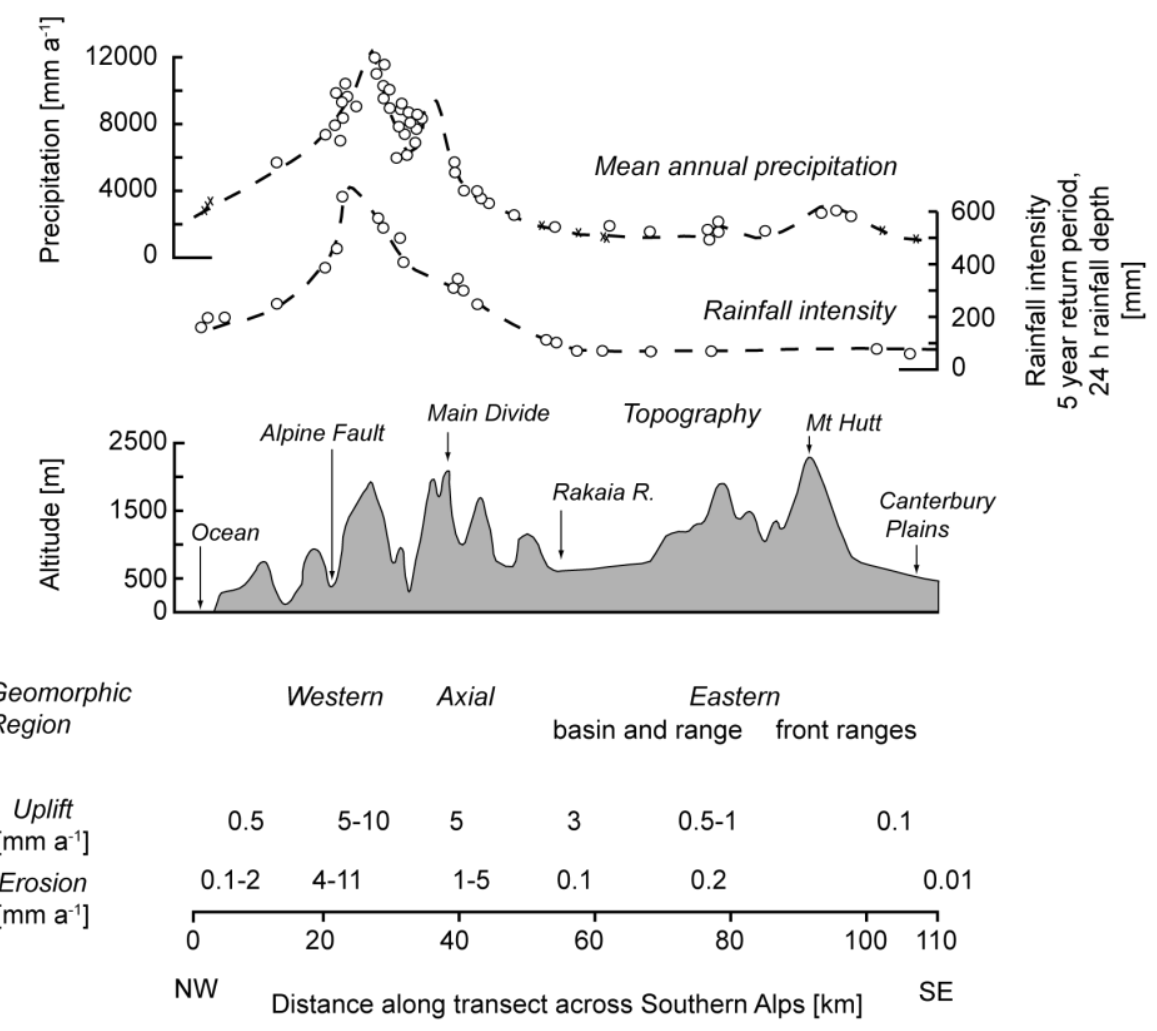

Figure 2.3

Transect across the Southern Alps (adapted from Whitehouse, 1988, based on mean annual precipitation from Griffiths and McSaveney (1983), rainfall intensity from Whitehouse (1985), uplift rates from Wellman (1979), and erosion rates calculated from the relationship between sediment yield and rainfall in Griffiths (1981)). The approximate location of the transect is marked as a purple dashed line in Figure 2.1, Inset A.

Range lies at about $2500 \mathrm{~m}$ (Chinn, 1995; Bacon et al., 2001). Overall, more than 3000 glaciers larger than 1 ha, covering approximately $1150 \mathrm{~km}^{2}$, were mapped in the Southern Alps from aerial photographs taken 1978 (Chinn, 2001). However, many of these have been retreating or thinning since that time (Chinn et al., 2012).

Annual to multi-annual climatic variations in the Southern Alps are influenced by largescale atmospheric circulation variations associated with the EI Niño - Southern Oscillation (ENSO) phenomena (Sturman and Wanner, 2001; Mullan et al., 2008). Related change in the dominant wind direction causes variations in the movement of synoptic weather systems across the region. Enhanced south-westerly air flow in El Niño years leads to higher than normal precipitation and cooler air temperatures in the Southern Alps. Conversely, in La Niña years, the predominant wind direction changes to north-east, leading to generally warmer conditions, increased precipitation in the north-eastern Alps, and less rainfall in the southern and western ranges (Salinger and Mullan, 1999; Lorrey et al., 2007). The Interdecadal Pacific Oscillation (IPO) is thought to modulate ENSO-related climate variability on an interdecadal scale, leading to more frequent and more prolonged El Niño events during its positive phase and vice versa (Salinger et al., 2001). During the most recent positive phase (1977 - 1999) several major El Niño events occurred in comparatively short 
succession, including the exceptionally strong 1997/1998 event (Mullan et al., 2008). The Southern Annular Mode (SAM) influences the Southern Alps on a shorter time scale of several weeks (e.g. Renwick and Thompson, 2006). The SAM is a ring of pressure anomalies centred over the South Pole that produces alternating meridional shifts in the subpolar westerly winds. In a positive phase, the westerly zone is displaced towards higher latitudes $\left(50^{\circ}-70^{\circ}\right)$, resulting in calmer and more settled weather over New Zealand, including warmer temperatures and less rainfall in the Southern Alps (Renwick and Thompson, 2006). In a negative phase, the belt of westerly winds moves over New Zealand, resulting in lower temperatures and increased rainfall for the Southern Alps.

New Zealand's high natural climatic variability partly obscures signals of ongoing global climate change. However, continuous temperature records since the late 1800 s indicate that mean temperatures have increased in the South Island by about $0.7^{\circ} \mathrm{C}$ since the $1940 \mathrm{~s}$ (e.g. Salinger and Mullan, 1999; Mullan et al., 2001). There is reasonable statistical evidence that global warming is already causing a rise in mean temperatures in New Zealand (e.g. Dean and Stott, 2009). Furthermore, an increase in positive phases of SAM since the 1940s has been linked to increased greenhouse gas levels and ozone depletion (e.g. Arblaster and Meehl, 2006; Abram et al., 2014), likely contributing to the positive temperature trend observed in New Zealand. Future projections estimate an increase in temperature of about $2^{\circ} \mathrm{C}$ from 1990 to 2090 (Mullan et al., 2008). The warmer atmosphere will be able to hold more moisture. A projected general increase in annual precipitation in the Southern Alps (up to 12\% from 1990 to 2090) will thus be likely accompanied by a significant increase in frequency and magnitude of heavy rainfall events (Mullan et al., 2008).

\section{4 | GeOMORPHOLOGY}

The topography of the Southern Alps is the expression of modern tectonic uplift, high orographic precipitation, and past glaciations (cf. Whitehouse, 1988; Whitehouse and Pearce, 1992; Fitzsimons and Veit, 2001; Barrell et al., 2011). The mountain ranges are deeply dissected by glaciated valleys. The relief is generally steep and intensely eroded. The location of the Main Divide towards the west of the mountain chain creates an asymmetrical cross-profile. Westwards-draining catchments have consequently overall steeper gradients than eastwards-draining catchments. The high relief on the western flank, in combination with exceptionally high contemporary uplift and rainfall rates (see Figure 2.3), produces catchment sediment yields that are among the highest in the world (Whitehouse and Pearce, 1992). Uplift, rainfall and subsequently erosion rates decrease towards the east; with them the landscape transitions to more depositional environments. 
Whitehouse (1988, see also Whitehouse and Pearce, 1992) differentiates three geomorphological regions in the Southern Alps based on characteristic landforms and erosional processes (Figure 2.3): The western Alps are intensely fluvially dissected and experiences rapid uplift and erosion. The steep topography is maintained by constant fluvial downcutting and frequent rockslides (Hovius et al., 1997; Korup, 2005). Comprehensive regolith storages are rare, and erosional landforms dominate. The axial Alps exhibit the highest elevations and steepest relief. Many of the valleys are still glacierised, and both modern and historic glacial features, such as moraines or cirques, are frequent. Valley slopes are characterised by bare bedrock, snow and ice with prominent talus slopes at lower altitudes. Rockfalls and debris flows are widespread. The eastern Alps comprise the drier eastern ranges, intermontane basins, and front ranges. Where elevations are still high, but rainfall insufficient to sustain glaciers, intact and relict rock glaciers are frequent. The relief decreases progressively towards the east. Valley flanks are increasingly rectilinear with scree and frost-rubble sheets extending up to the ridge crests. Uplift and erosion rates are low. Depositional features dominate the landscape and small-scale rockfalls, debris flows, and debris slides are, aside from water floods, the predominant erosional processes. 


\section{3| DEBRIS FLOW INVENTORY}

An inventory of 1534 debris flow systems and 240 related debris flow events, established for thirteen study areas by aerial photo interpretation, represents the core data of this research. The mapped debris flow systems (described by debris flow initiation zones and corresponding regolith-supplying catchments) serve as the spatial analysis units for the statistical evaluation of predisposing controls for debris flow formation in Chapter 5. Mapped events are interpreted as indicating debris flow systems particularly susceptible to debris flow development. The present chapter provides basic information on debris flows, describes the selected study sites, outlines the methodological approach used for mapping debris flow systems and events, describes the established debris flow inventory, and discusses inferred aspects of debris flow activity in the Southern Alps.

The chapter is divided into five parts: Section 3.1 provides an introduction to debris flows by defining the geomorphic process, describing morphologic characteristics, and reviewing factors that control debris flow initiation. It summarises the current scientific knowledge and hence conceptual framework that this research is based on. The section ends with a review of debris flow research in New Zealand. Section 3.2 represents the core methodology section of this thesis. It outlines the criteria used for study site selection and gives a short characterisation of the study areas. It presents the methodology used for mapping debris flow systems and for identifying debris flow events during the investigation period as well as explains the procedures used for delineating debris flow contribution areas and rockwall surfaces. Section 3.3 describes process-related and topographic attributes of the established debris flow inventory by summarising general and regional characteristics of the overall inventory, the event inventory, as well as of systems with multiple events during the investigation period. Inferences about general levels of debris flow activity in the Southern Alps are discussed in Section 3.4. The chapter's key points are summarised in Section 3.5. 


\subsection{BACKGROUND - DEBRIS FLOWS}

\subsubsection{Definition \& characteristics}

Debris flows are mass movements, intermediate between landslides and sediment-laden water floods (Iverson, 2003a). They consist of a mixture of fine material (sand, silt, and clay), coarse material (gravel, boulders, and organic matter), and water, which forms a muddy slurry that moves as a viscoplastic mass in a non-Newtonian laminar manner downslope (Corominas et al., 1996; Blair and McPherson, 2009). The ratios of the different components comprising the debris flow mass can vary widely, and with them the flow properties of the moving mass (Costa, 1984; Selby, 1993; Hungr et al., 2001; Iverson, 2003b; Iverson, 2005). However, debris flows are generally characterised by high velocity, high bulk density, high discharge, and a potential for long runout distances (cf. Pierson, 1980b; Innes, 1983; Costa, 1984; Selby, 1993; Corominas et al., 1996; Hungr, 2005; Takahashi, 2007). With these attributes, debris flows are not only effective erosion and sediment transport mechanisms in mountainous areas (e.g. Rapp, 1960; Beylich and Sandberg, 2005), but also constitute significant hazards for infrastructure and human lives in affected areas (e.g. Costa, 1984; Corominas et al., 1996; Jakob and Hungr, 2005; Takahashi, 2007).

Debris flows generate when saturated, poorly sorted sediment becomes unstable and liquefies, transforming into a cohesive slurry which resembles wet concrete (Iverson, 1997; Blair and McPherson, 2009). The initial movement is generally caused by shallow slide failures, commonly triggered by soil oversaturation following heavy rainfall (cf. Wieczorek, 1996; Crozier, 1997) or by concentrated overland flow. In the case of landslide initiation, the remoulding, disaggregation, and dilatancy of the failing mass as well as the undrained loading of saturated sediment downslope can elevate pore water pressures beyond effective stress levels, triggering the transition from a sliding to a flowing movement (Iverson et al., 1997; Sassa and Wang, 2005). Concentrated storm runoff, on the other hand, can instigate debris flow development by progressively entraining already saturated sediment within existing drainage channels, also referred to as sediment bulking (Berti et al., 1999; Tognacca, 1999; Hungr et al., 2005; Godt and Coe, 2007; Welcker, 2011). Alternatively, the high runoff can prompt the sudden failure of accumulated colluvium at the exit of steep rock channels (known as 'firehose effect', Johnson and Rodine, 1984; Larsen et al., 2006).

Debris flows are essentially defined by their rheologic behaviour, which differentiates them from the end-member processes landslides and water floods. Despite having sediment concentrations comparable to those of static soil, debris flows are able to flow fluidly (Iverson, 2003a; Iverson, 2005). This fluidity results from the liquefaction of the saturated sediment. After the onset of the initial movement, transient stress increases the intergranular 
pore water pressure to a level sufficient to support the weight of the overlying particles. At this point, cohesion is reduced to zero. This allows particles to move smoothly past each other and results in the characteristic viscoplastic, yet very fluid flow behaviour (Iverson, 1997, 2003a). Liquefaction persists in the moving debris flow mass as silt and clay particles impede pore-pressure dissipation, even if the fine-grain content normally comprises only a few percent (Costa, 1984; Iverson, 2003a, b). During the debris flow motion, a longitudinal sorting of particles develops (Figure 3.1), with larger particles being pushed upwards in the flowing mass and subsequently moved to the front due to higher velocities at the surface (Takahashi, 1980). High permeability of the coarse material at the debris flow head leads to rapid dissipation of the pore pressure at the front. The suddenly highly resistant flow head gets consequently pushed aside from the ensuing, still liquefied, finer-grained debris flow mass (Iverson, 2003b), forming the characteristic, roughly inverse-sorted lateral ridges, called levées (Figure 3.2). The levées confine the following flow, hinder sideward spreading and thus increase the runout distance (Pierson, 1980b; Iverson, 2003b). Debris flows stop once they are depleted of material (e.g. lost in the formation of levées) or once internal friction exceeds pore pressure due to the decrease in velocity on gentler gradients or loss of water (Pierson, 1980b; Costa, 1984). Low-viscosity debris flows generally spread out fan-like once lateral confinement ceases. More viscous debris flows, on the other hand, can leave characteristic convex tongues or boulder trains with sharply defined margins (Corominas et al., 1996; Blair and McPherson, 2009).

Debris flow events often comprise multiple surges, with large boulders forming the wave front followed by a liquid slurry which passes into a diluted trail (Pierson, 1986; Hungr, 2000; Figure 3.1). The individual surges can develop out of the longitudinal sorting, with the large particles moved to the front during the debris flow motion. Alternatively, surges can also be caused by the temporally offset release of sediment into or within the channel by instabilities of channel banks or the breaching of temporary dams or obstructions (Corominas et al.,

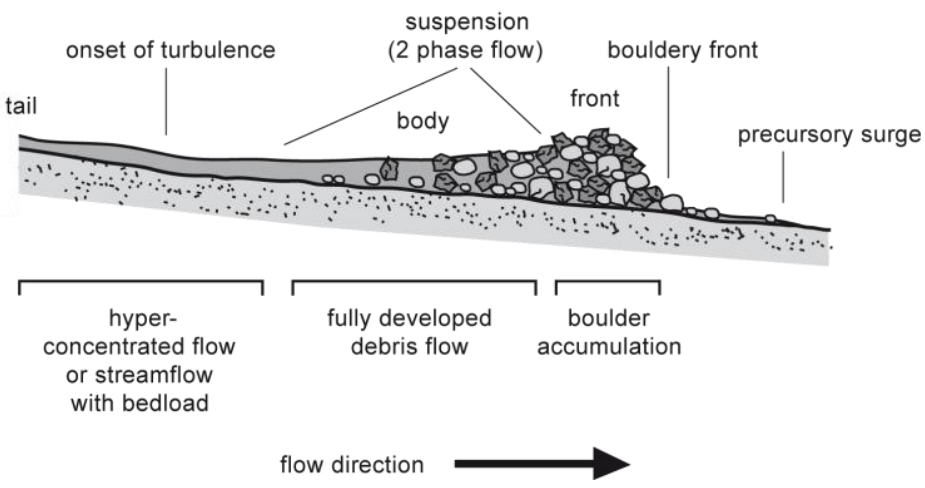

Figure 3.1

Longitudinal profile of a debris flow surge (adapted from Hübl et al., 2002, after Pierson, 1986, p.279). 


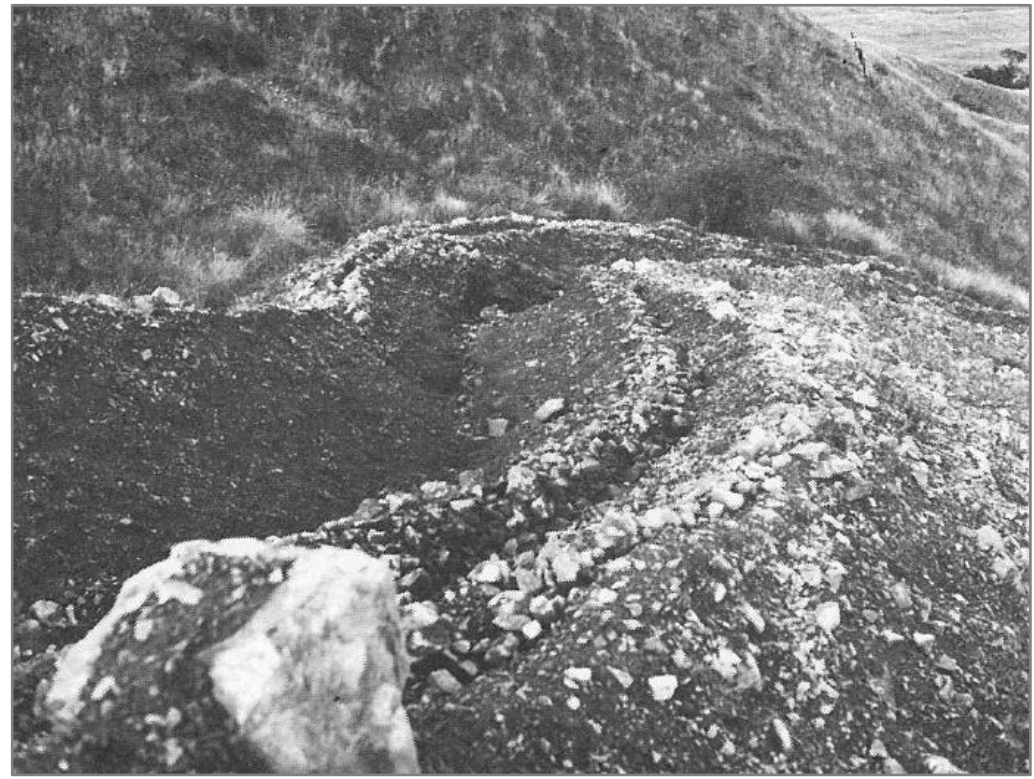

Figure 3.2

Overlapping levées with clear inverse sorting left by multiple surges at Mount Fitzwilliam, Liebig Range, central Southern Alps. (Source: Pierson, 1980b, p.10).

1996; Hungr, 2005). The blockage of channels by deposits of previous surges can lead in topographically unconfined areas, such as on debris fans, to sudden channel abandonment and re-direction of the subsequent debris surge, creating distributary channels (Hungr, 2005). Debris flow fans are formed by recurrent events with potentially multiple surges and generally display a distinctive uneven surface, created by generations of individual, slightly meandering levées and deposition lobes (cf. Figure 3.4). However, as debris flows occur in or create new channels, their tracks are also drainage pathways. Debris flow deposits within or below the channels can therefore be significantly reworked by intermittent storm-water runoff (Bovis, 1993; Hungr, 2005; Davies and McSaveney, 2008).

Defined essentially by their kinematic behaviour, the characteristics of individual debris flows, such as erosive power, run-out distances, and deposit appearance, can vary widely. Variations arise from differences in materials involved, water content, or initiation mechanism. In order to facilitate a scientific discourse, numerous classifications and corresponding terminologies have been suggested (e.g. Varnes, 1978; Brunsden, 1979; Takahashi, 1981; Hutchinson, 1988; Haeberli et al., 1991; Coussot and Meunier, 1996; Cruden and Varnes, 1996; Hungr et al., 2001; Takahashi, 2007). A comprehensive review of common classification schemes can be found in Hungr et al. (2001) and Hungr (2005).

In the present study, the term debris flow is used in accordance with the basic kinematic definition stated above, referring to any type of gravitational mass movements which displays geomorphic signs of rapid, viscoplastic, non-Newtonian flow of debris. This usage is generic and in contrast to some classification schemes (e.g. Varnes, 1978; Hungr et al., 
2001) independent of solid fractions, material type, viscosity, or moment and mechanism of liquefaction. However, debris flow systems, defined as a spatial unit including all the process relevant areas (i.e. regolith-supplying contribution area, initiation zone, process track, and deposition area), are differentiated according to the predominant initiation mechanism inferred from aerial photography. Assuming that recurring events within these systems are instigated by the same mechanism, events are correspondingly differentiated into slideinitiated debris flows and runoff-generated debris flows.

Slide-initiated debris flows (Figure 3.3), corresponding to the debris avalanches of Varnes (1978) and Hungr et al. (2001), the hillslope debris flows of Hutchinson (1988) and Brunsden (1979), and the landslide type debris flows of Takahashi (1981), are generally initiated by shallow landslides on steep, commonly grass-covered slopes. Source areas consequently show crescent-shaped head scarps typical for translational slides or rotational failures. Depending on the water content and thus viscosity of the flowing mass, slideinitiated debris flows have been described as non-erosive to moderately erosive (cf. Selby, 1993; Godt and Coe, 2007), hence displacing mainly the volume of material mobilised in the source area. As the flowing mass is moving downslope, unconfined by established channels, material is lost in the creation of levées. Slide-initiated debris flows stop once their initial volume is depleted, or the low-gradient valley bottom is reached.

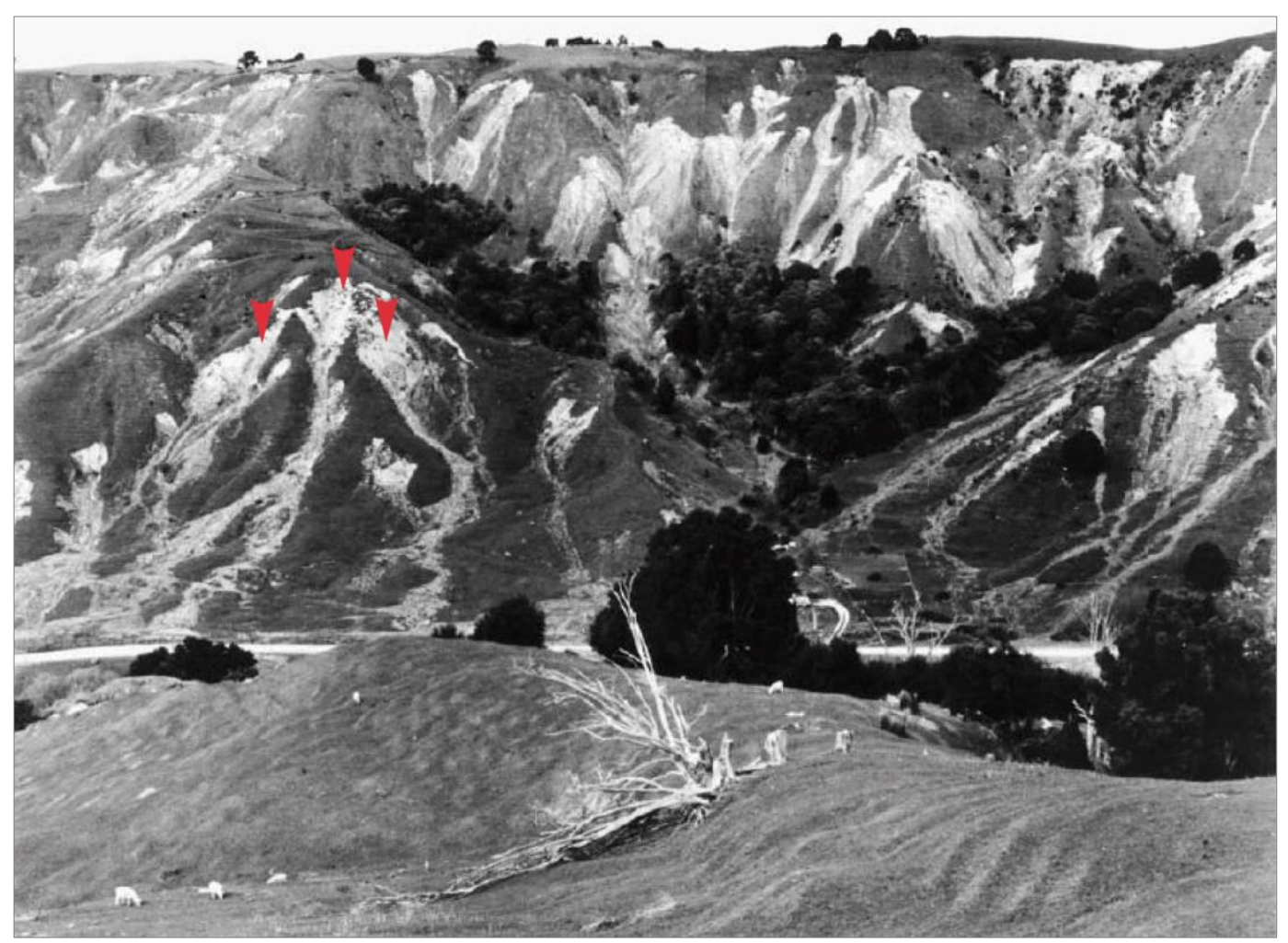

Figure 3.3

Slide-initiated debris flows generated by Cyclone Bola 1988 in the Waipaoa catchment, NZ North Island. The red arrows indicate examples of slide-initiated debris flow systems (Source: Reid and Page, 2003, p.75). 
Runoff-generated debris flows (Figure 3.4), corresponding to the debris flows of Varnes (1978) and Hungr et al. (2001), the valley-confined flows of Hutchinson (1988) and Brunsden (1979), and the mobilised-type debris flows of Takahashi (1981), on the other hand, are initiated by excessive water discharge and hence occur in established channels or generally unvegetated locations subject to ephemeral concentrated overland flow. This type of debris flow is common below the exit of steep rock channels and slope concavities or below rock outcrops. The existing channels and rills confine the flow and allow the mass to retain its water content, reducing the material lost to levée building and increasing runout distances (cf. Pierson, 1980b; Blair and McPherson, 2009). Concentrated within the channels, runoff generated debris flows show increased erosive power, deepening their tracks and thus increasing their volume as they travel downslope (cf. Pierson, 1980b; Godt and Coe, 2007). These debris flow systems are hence characterised by markedly incised mid-slope sections followed below by the typical depositional landforms once confinement ceases or the slope decreases.

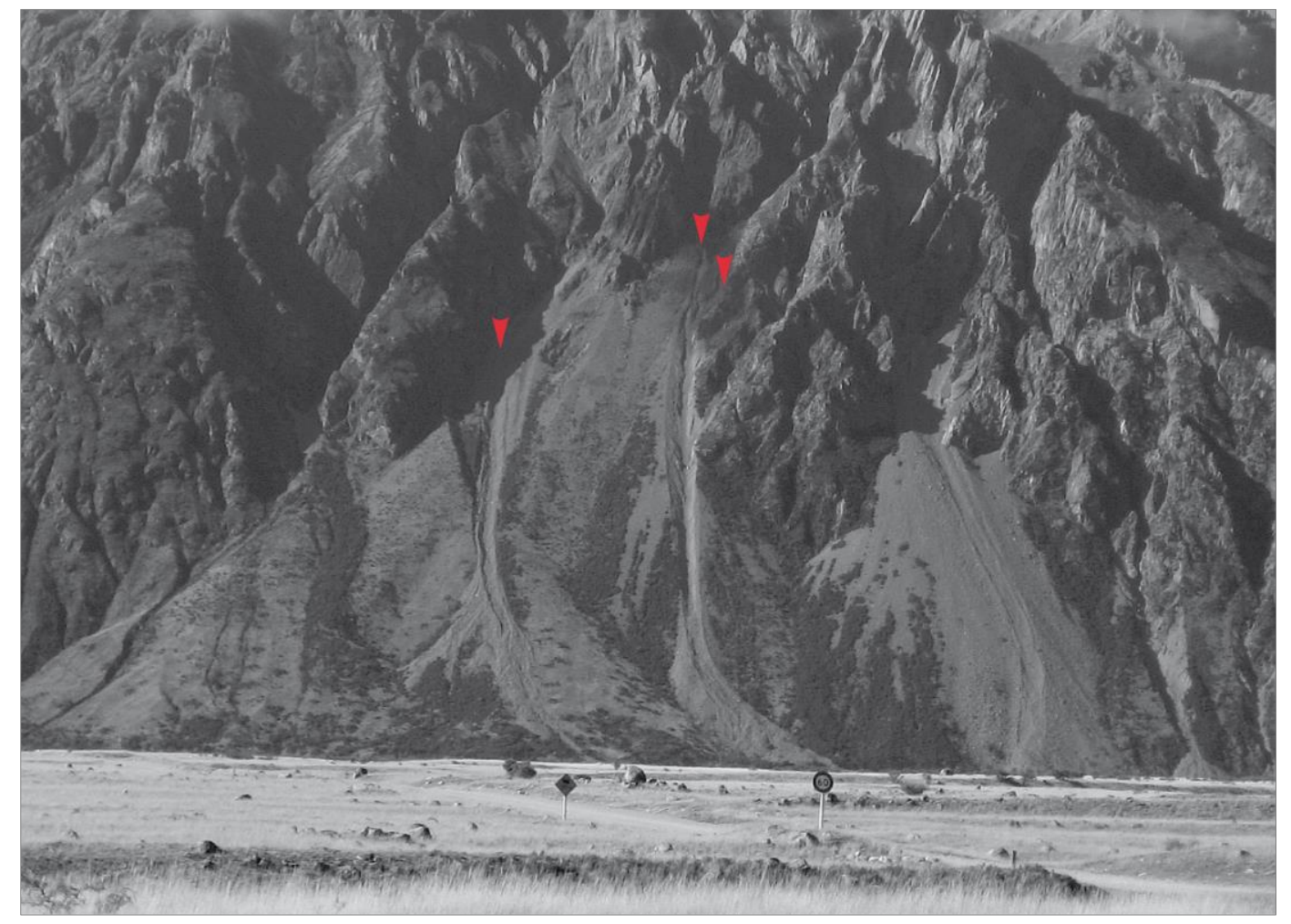

Figure 3.4

Runoff-generated debris flows underneath Mt Blackburn, Tasman Valley, NZ South Island. The red arrows indicate examples of runoff-generated debris flow systems (Source: K. Sattler, 2012). 


\subsubsection{Factors controlling debris flow initiation}

The occurrence of debris flows is the result of a complex interaction of various hydrological, geological, and topographical parameters (Costa, 1984). The 'concept of disposition' for debris flow formation (cf. Kienholz, 1995; Zimmermann et al., 1997a, b; Kaitna et al., 2013) allows the classification of the numerous controlling factors according to their temporal efficacy into basic susceptibility, variable susceptibility, and triggering events. It thereby offers a framework for systematically analysing the importance of the individual factors for debris flow initiation as well as potential interdependencies.

The susceptibility of a debris flow source area describes its physical inclination or tendency for debris flow formation at a given point it time. It corresponds to a system's resistance against external stresses. The total susceptibility is the sum of long-term (basic susceptibility) and medium-term (variable susceptibility) conditions within the source area (Figure 3.5). Triggering events are short-term external stresses which exceed the system's internal threshold and hence lead to an event. If the system's susceptibility for debris flow initiation is high, comparatively low stresses are required for initiation. Whereas, if the general susceptibility is low, even high external loading might fail to instigate a debris flow event.

The following characterisation of factors influencing debris flow initiation focuses on debris flows in temperate mountainous areas. The relevance of individual factors or interrelations may vary in other climates.

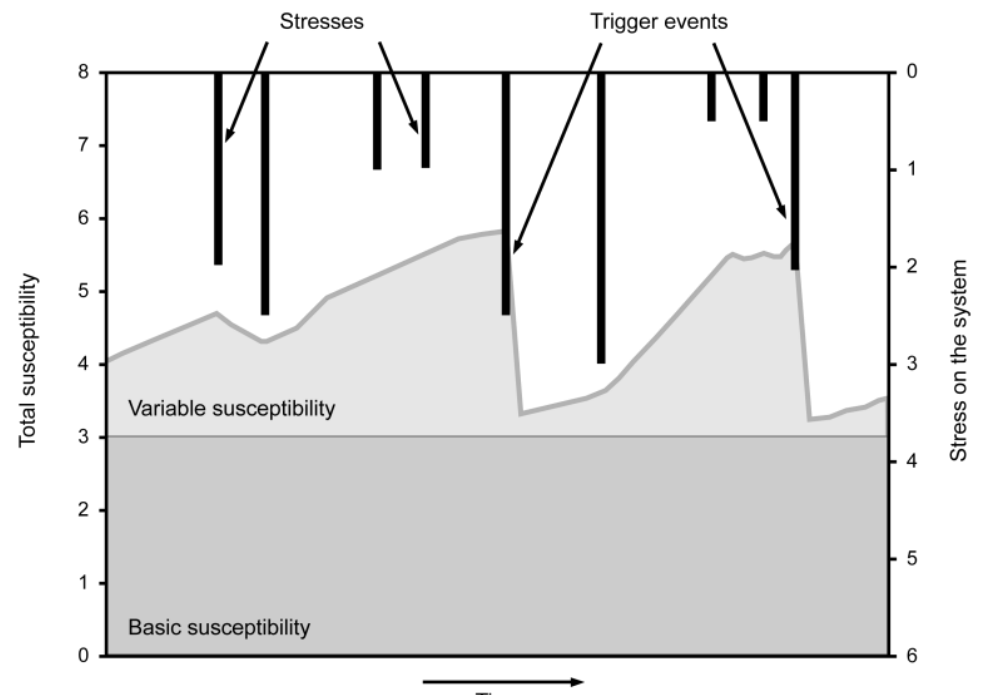

Figure 3.5

Graphical depiction of the concept of disposition for debris flow formation (adapted from Zimmermann et al. (1997b) and Kaitna et al. (2013)). 


\section{Basic susceptibility}

The basic susceptibility describes the general geomorphic susceptibility of a location for debris flow development. It determines the spatial occurrence of debris flows as well as their magnitude. The basic susceptibility is mainly controlled by topography, the type of sediment reservoir, and the reservoir's physical characteristics. These factors are generally constant over time or change only gradually over extended periods such as decades or centuries. Examples for such slow changes are climate-induced changes in weathering intensities, vegetation cover, or ground ice content (Zimmermann et al., 1997b).

\section{Topography}

Adequate slope gradients within the source area are, besides sediment availability and water, a main prerequisite for debris flow development (Pierson, 1980b; Costa, 1984; Lewin and Warburton, 1994). Costa (1984) defines $15^{\circ}-20^{\circ}$ as a common lower threshold for debris flow initiation. Observed slope angles generally range between $20^{\circ}$ and $45^{\circ}$, with $20^{\circ}$ to $40^{\circ}$ being most common (cf. Corominas et al., 1996). These observations reflect the theoretical upper limit of event initiation defined by the angle of repose, which is for scree commonly assumed to be $45^{\circ}$ (cf. Kleinhans et al., 2011). Slopes steeper than this threshold are generally covered with debris too thinly or too locally restricted to be susceptible to failure (Hungr, 2005). Larsson (1982) further emphasises slope geometry as an important factor, controlling the spatial location of debris flow development. Similar to earlier observations of Williams and Guy (1971), many of the new slide-initiated instabilities analysed in Larsson's (1982) study in Spitsbergen occurred at slope breaks where the upper convex slope changes to the gentler gradient of the lower concave part of the hillslope profile. An oversaturation of soil in these locations during rainfall events due to the concentration of interflow (i.e. subsurface flow within soil layer, cf. Ahnert, 1998, p. 115 f.) at the break change is capable of reducing the soil's shear strength to such a degree that failure can also occur on gentle $\left(<15^{\circ}\right)$ slopes (cf. Brunsden, 1979; Sidle and Ochiai, 2006). Similarly, debris flows emanating from a sudden mobilisation of channel infill or those instigated by dam breaches within the channels can develop at lower gradients (cf. Haeberli et al., 1991).

The topographic parameters altitude and aspect do not directly influence debris flow formation but are main controls on other influential factors (cf. Rieger, 1999). With increasing altitude above sea level, air temperature decreases and precipitation falls increasingly as snow in cold weather periods. In combination with incoming solar radiation, these climatic factors are decisive for frost-weathering intensities, vegetation cover, or the existence of permafrost in subsurface material. All of these factors influence debris availability and stability within the debris flow initiation areas. 
Although the underlying mechanical processes of frost weathering are still debated (cf. McGreevy, 1981; Hales and Roering, 2007; Matsuoka and Murton, 2008; Hall and Thorn, 2011; see Section 5.2.7, Question II, for details), ice-growth in solid rock is widely acknowledged as an efficient weathering mechanism in high alpine areas and as a major factor in regolith production and landscape evolution (Murton et al., 2006; Hales and Roering, 2007). Studies by Coutard and Francou (1989) and Sass (2005b) in the European Alps showed that rockfall activity is up to three times higher in north-facing than south-facing locations, implying that also sediment production rates are higher in sun-avert locations. Coutard and Francou (1989) attribute the difference to more constant water supply and longer and more intense periods of uninterrupted frost at depth in sun-averted rockwalls. Production of material occurred in north-facing locations due to block separation along deepfrost related, ice-filled macro-fissures. In south-facing aspects, on the other hand, superficial freeze-thaw cycles produced only small particle falls. Sass's (2005b) analysis of more than 60 debris collectors in alpine environments showed no correlation between regolith production and elevation up to an altitude of $2500 \mathrm{~m}$. Above, the presence of permafrost within rockwalls was thought to positively affect regolith production rates.

In the context of debris flows, regolith production through frost weathering is mainly of importance for event initiation in supply-limited systems (Bovis and Jakob, 1999; Jakob et al., 2005; see also below). In these systems, which are abundant in high-alpine areas and generally occur just below the rock-debris interface or within debris-filled rock couloirs, the debris reservoir must be sufficiently replenished by rockfall or in-situ weathering before an event can be triggered. Jomelli et al. (2003) used the cumulative number of freezing days since the last debris flow event to incorporate frost-weathering intensity into their analysis of debris flow activity in the French Alps. Frost action and the number of days above a rainfall threshold described the study's observed debris flow frequencies best. Similarly, Glade (2005) found that sediment reservoirs in twelve catchments in western Iceland were not replenished fast enough by rockfall and solifluction for a debris flow event to occur at the next potentially triggering rainfall event. Jomelli et al. (2004) identified a connection between the decrease in debris flow activity in lower altitudes and the reduction in freezing days, resulting from the increase in annual and seasonal air temperatures in the French Alps in the late $20^{\text {th }}$ century. Despite the theoretical link between regolith production through frost weathering and debris flow activity, empirical evidence remains rare so far. However, these studies highlight the role of contemporary frost action as a significant preconditioning factor for supply-limited debris flows, which are a common debris flow type in high-alpine areas. 


\section{Debris supply conditions}

The availability of readily-mobilised sediment within the initiation area is another essential prerequisite for debris flow development (cf. Innes, 1983; Jomelli et al., 2004). Debris supply conditions in the initiation area are often related to the type of debris reservoir. Based on the presence or absence of present-day replenishment, two main types of debris reservoirs can be distinguished (cf. Stiny, 1931):

Active debris reservoirs are continuously replenished by weathering processes, mass movements, or fluvial bedload transport. Common examples in high-alpine areas are active scree slopes below rockwalls or sediment deposits in low-order drainage channels. Active debris reservoirs are generally poorly consolidated and close to the angle of repose and are hence particularly susceptible to instabilities. However, the volume of material available to be mobilised is generally limited, and debris flows emanating from these debris reservoirs are typically of low magnitude. Furthermore, these storages are commonly depleted in the course of an event. Since sediment has to reaccumulate before the next event can occur, event frequencies are generally low. Debris flow systems originating in active debris reservoirs are generally supply-limited (cf. Jakob, 2003; Figure 3.6).

\section{Supply-limited system}

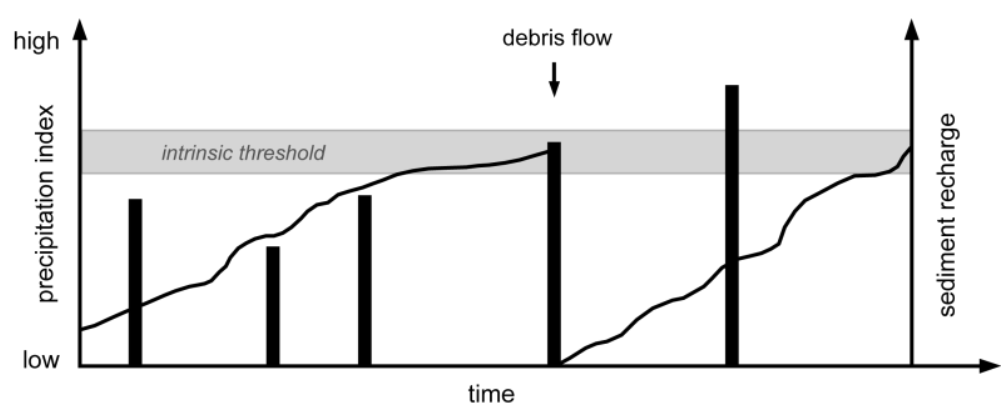

Supply-unlimited system

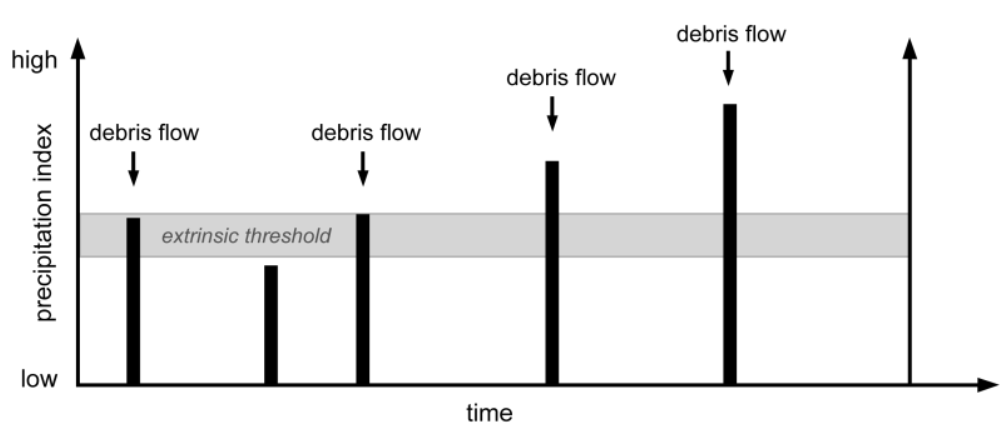

Figure 3.6

Graphical depiction of the difference in supply conditions for debris flow initiation (after Bovis and Jakob (1999)). 
Relict debris reservoirs, on the other hand, are sediment accumulations that are not replenished by contemporary processes. Common examples in alpine environments are moraines, fluvial terraces, or landslide deposits. Some of these sediment reservoirs formed over long periods and under more extreme climatic conditions than today. They are frequently of large volume and represent a nearly limitless supply of sediment for debris flow formation. As a result, large magnitude events can occur at high frequency until the sediment supply is exhausted. Debris flow systems situated in relict debris storages are therefore often supply-unlimited (cf. Jakob, 2003; Figure 3.6).

Due to the abundance of sediment, relict debris reservoirs can be viewed as an element of the basic susceptibility for debris flow development (cf. Figure 3.5). In contrast, the susceptibility of active debris reservoirs for debris flow formation changes through time. The volume of active reservoirs is, therefore, an element of the variable susceptibility (see below).

Bovis and Jakob (1999) considered debris supply conditioning in their analysis of debris flow activity in the Canadian Coast Mountains. They found that differentiating between supply-limited and supply-unlimited watersheds significantly improved their prediction models. Similarly, varying response of debris flow systems to an observed increase in meteorological triggering events in the French Alps was attributed by Jomelli et al. (2007) to differences in debris supply conditions in the debris flow source areas.

\section{Physical properties of sediment reservoirs}

The physical properties of sediment reservoirs, such as particle size distribution, permeability, and shear strength, influence the susceptibility of debris bodies for instability and debris flow initiation. These properties are partly controlled by the lithology of the parent rock. Coarser-grained lithologies, such as coarse granites and certain types of sandstone, tend to produce on weathering high quantities of coarse sand particles and deposits are poorly sorted with bigger clasts embedded in a coarse grained sandy matrix (Ballantyne, 1986). Such deposits have been found to be especially susceptible to debris flows (e.g. Innes, 1982, cited in Ballantyne, 1986; Milne and Davies, 2007), as the coarse sand particles have high infiltration rates which allow a rapid rise in pore-water pressures during rainfall events, promoting saturation-type slope failure. Finer-grained lithologies, such as basalt and types of schist and dolomite, produce debris with much higher proportions of fine sand, silt, and clay (Ballantyne, 1986). These deposits are characterised by low infiltration rates, which obviate sudden oversaturation and hence instability during rainfall events (cf. Rieger, 1999). However, Griffiths et al. (2004) found that in the Grand Canyon debris flows emanate almost exclusively from shales or other fine-grained formations. They conclude that a high content of clay-sized particles is necessary to transform the initially generally dry mass movements into a fluid-supported debris flow. Thus, sediment reservoirs' 
propensity for debris flow initiation depends on the initiation mechanism in question. Despite such observations, empirical evidence for a lithological influence on debris flow initiation is still rare. Other studies (e.g. Rickenmann and Zimmermann, 1993; Blijenberg, 1998; Rieger, 1999; Larsen et al., 2006; Carrara et al., 2008) found no indications for a link between geology and debris flow activity. The role of parent rock lithology in debris flow occurrence thus seems to be subordinate. Yet, according to laboratory experiments, significant differences exist in regolith production by frost weathering between different lithologies, with sedimentary rocks producing 35 times more debris than crystalline rocks (André, 2003). In natural environments, factors such as joint density, tectonic wear by uplift and folding, and dip direction influence debris production rates (cf. Sass, 2005b). Consequently, differences might hence not be as accentuated in field observations. It can, however, be assumed that geology has some effect on debris flow formation for supply-dependent debris flows via debris production rates and in general as a relief-forming factor, e.g. where rock strength is decisive for the formation of steep rock faces vs. gently sloping debris covered hillslopes (cf. Augustinus, 1995; Lorente et al., 2002; Griffiths et al., 2004).

Further factors that can effectively influence the physical properties of sediment reservoirs are the presence of permafrost at depth or the presence of continuous vegetation cover on the surface. In high-alpine areas, the presence of interstitial ice within the debris increases internal cohesion and can armour sediment bodies against mobilisation (Zimmermann and Haeberli, 1992). The permafrost body can, however, also act as an aquiclude and thus facilitate the oversaturation of overlying or adjacent debris and therefore promote slope failure (e.g. Zimmermann, 1990; Del Longo et al., 2001; Kneisel, 2010; Bardou, 2011). Saturation-type detachment slides are common in fine-grained soils in arctic permafrost areas (cf. Larsson, 1982; Lewkowicz and Harris, 2005), but are less observed on coarser, generally better drained debris slopes in alpine areas (cf. Zimmermann and Haeberli, 1992; Rist, 2007; Bommer et al., 2012). In runoff-generated systems, frozen debris in the source areas can impede the effective infiltration at times of excessive water input, promoting the mobilization of the overlying active-layer material. The influence of permafrost occurrence on debris flow initiation is, however, strongly seasonal. Particulars are thus described in more detail in the context of the variable susceptibility factors below. At lower elevation, a continuous vegetation cover can effectively increase the stability of debris reservoirs. Plants are generally beneficial for slope stability by providing root cohesion to the regolith, by decreasing surface runoff, and by enhancing infiltration and water storage capacity (although the additional mass of trees and their susceptibility to wind-throw might have a detrimental effect in some cases) (cf. Rieger, 1999; Greenwood et al., 2004; Sidle, 2005). As such, vegetation cover is especially influential in the case of saturation-type debris flows where the root cohesion is to some extent capable of counteracting the destabilising effect of sudden oversaturation during rainfall events. Reports of increased landslide activity after forest harvesting, land use change, or bushfires are numerous (e.g. Glade, 2003; 
Imaizumi et al., 2008; Sass et al., 2012; García-Ruiz et al., 2013; Riley et al., 2013). For the development of runoff-generated debris flows, vegetation cover within the initiation area is generally subordinate. Water drainage during non-catastrophic rainfall events hinder the development of an effective plant cover in these locations. However, the percentage of vegetation cover in the contributing areas has been found to be a significant factor for the magnitude and frequency of debris flows. Rieger (1999) observed in the European Alps that catchments without vegetation cover produced debris flows of significantly larger magnitude than vegetated catchments of a similar size. He attributes the increase in magnitude to higher discharge peaks and higher erosive power in non-vegetated catchments. Furthermore, sediment production from channel walls through slumps, sheet wash, or ravelling is higher on non-vegetated slopes (cf. Pellerin, 2001), thus providing more material for debris flow initiation or event propagation.

Factors determining the basic susceptibility of a location for debris flow initiation are generally constant or change only gradually over extended periods of time. Yet, sometimes natural events, such as earthquakes (see below), bushfires, wind throw of trees, or human impact, can alter the susceptibility of slopes for mass wasting over relative short time periods. Examples for increased erosion after ground cover changes have already been cited above. Other examples arise from the increasing development of high-alpine areas for recreation purposes by changing catchments' drainage configurations (e.g. Koscielny et al., 2009) or altering thermal subsurface conditions by constructing ski lifts and buildings in permafrost areas (e.g. Schnalstal; E. Nollett, Schnalstaler Gletscherbahnen, pers. comm., 2006).

\section{Variable susceptibility}

The variable susceptibility describes shorter-term, often seasonal or cyclic fluctuations of a system's propensity for debris flow initiation. It is decisive for the temporal occurrence of events. Temporal fluctuations in a location's susceptibility for debris flow initiation arise from hydrometeorological variations (days to weeks) as well as from sediment recharge rates in supply-limited systems (years) (Zimmermann et al., 1997b).

\section{Season}

Debris flows generally develop in summer and autumn (e.g. Rebetez et al., 1997; Marchi et al., 2002). Not only are triggering events more common during the warmer periods, but also sediments are more likely to be frozen during the colder months and hence the availability of debris is significantly restricted during that time. Furthermore, in high-altitude areas, precipitation falls during cold months predominantly in the form of snow, which obviates a potential oversaturation of regolith and thus instabilities. 
During the warmer seasons, prolonged rainfall or snow melt can lead to a significant increase in pore water pressure within sediment reservoirs. Within days to weeks, this antecedent moisture can reduce the effective strength of slope material to a critical level and hence considerably elevate a system's susceptibility for debris flow initiation. The significant role of antecedent rainfall and snowmelt in landslide and debris flow initiation has been reported globally (see Wieczorek and Glade, 2005, for review). However, the effect of antecedent moisture conditions depends on the porosity and water storage capacity of the local regolith (cf. Crozier, 1999; Glade, 2000; Schneuwly-Bollschweiler and Stoffel, 2012). Hence, antecedent moisture input is less important in well-draining open-work talus than, for example, in moisture retaining fine-grained till or talus with high fine content (cf. Clow et al., 2003).

In permafrost areas, the temporal occurrence of debris flows is strongly controlled by active layer development (cf. Section 4.1.1). Activity peaks thus tend to occur later in the year (cf. Stoffel et al., 2006; Rist, 2007). Slow top-down thawing of the frozen near-surface material during the summer months progressively releases material until the annually-varying maximum depth is reached by late summer to early autumn. By then, permafrost slopes are particularly prone to instability, as the permafrost table at depth acts as an aquiclude and thus promotes oversaturation, or acts as a potential failure plane during periods of elevated pore pressure (cf. McRoberts and Morgenstern, 1974; Larsson, 1982; Zimmermann, 1990). Laboratory experiments suggest that the stability of permafrost soils is reduced by $21 \%$ during summer as opposed to winter (Nater et al., 2008). Furthermore, comparisons of meteorological triggering events indicate that critical thresholds seem to be significantly lower in permafrost than non-permafrost areas (cf. André, 2003; SchneuwlyBollschweiler and Stoffel, 2012). Recent experimental research has contributed to the physical understanding of permafrost slopes' propensity to failure. Nater et al. (2008) modelled the redistribution of strength parameters in permafrost soils during seasonal thawing and demonstrated the careful balance between the decreasing cohesive forces of ice bonding and the forming friction between the soil particles during melting. By conducting stability simulations in a climate chamber, Rist (2007) found that permafrost soils are less likely to fail in consequence to soil saturation during snowmelt, as large amounts of the percolating water refreezes in the still cold active layer which stabilises the slope material. However, the quantity of ice formed during snowmelt influences the active layer's water content during thawing and thus effects the slope's susceptibility for failure in summer.

\section{$\underline{\text { Sediment recharge }}$}

In supply-limited debris flow systems, the availability of sediment for event initiation varies through time (cf. debris supply conditions above). Debris reservoirs in these systems are commonly exhausted after a debris flow event or when reaccumulating debris is flushed 
out by floods between individual debris flow events. Immediately after such events the susceptibility for debris flow development is markedly lowered (cf. Figure 3.6). Sediment has first to reaccumulate through rockfall or in situ weathering before an event of similar magnitude can recur. Some debris flow systems in the European Alps show remarkable periodicity in events of similar magnitude (e.g. Zimmermann et al., 1997b, p. 39; events of similar magnitude occurred roughly every 30 years), indicating a strong sediment supply control. The cyclic pattern is likely to be caused by the time necessary to refill the debris reservoir under constant weathering rates. If meteorological triggers are the dominant control, a more irregular pattern would be expected due to the high temporal variability of heavy rainfall events.

\section{Triggering events}

Triggering events are transitory extrinsic stresses on the debris flow system, leading to an exceptional presence of water, which, in the case of a sufficiently high level of the system's susceptibility, initiate debris flow events (cf. Figure 3.5). They can be rainfallrelated or rainfall-unrelated, such as sudden drainage of water pockets or earthquakes, and are generally of high temporal variability (minutes to days) (Zimmermann et al., 1997b).

\section{Rainfall-related}

Debris flows are most commonly triggered by rainfall events, such as high-intensity short-duration rainstorms or low-intensity long-duration precipitation events (cf. Innes, 1983; Corominas et al., 1996; Rickenmann, 1999). This strong link between precipitation and debris flow occurrence is of particular interest for hazard assessment and management. Triggering rainfall thresholds have therefore been calculated for many different climates and regions worldwide. Recent reviews of the literature can be found in Guzzetti et al. (2007) and Wieczorek and Glade (2005). The establishment of global (eg. Caine, 1980; Guzzetti et al., 2008) and regional (eg. Glade, 2000; Jakob and Weatherly, 2003) rainfall thresholds facilitate our understanding of debris flow initiation (e.g. the influence of certain preconditioning factors, such as sediment supply and permafrost for event formation). Empirical rainfall thresholds are also valuable tools for debris flow warning systems (see examples in Wieczorek and Glade, 2005). However, inferred critical values cannot be used to characterise debris flow activity on a local scale as the status of a system's susceptibility is strongly site-dependent. Furthermore, rainfall thresholds vary not only spatially but also seasonally. Schneuwly-Bollschweiler and Stoffel (2012) showed that critical rainfall thresholds for debris flow development in periglacial catchments in the Swiss Alps were significantly lower earlier in the debris flow season than towards the end. The authors attribute the observed seasonality to increased antecedent moisture during spring snowmelt 
and to the presence of permafrost within the source sediments. During the summer months, high-intensity short-duration rainfall events were sufficient to elevate pore pressures to critical values within the still comparatively shallow active layer. In autumn, on the other hand, low-intensity long-duration precipitation events were necessary to achieve oversaturation in the well-developed active layer.

\section{$\underline{\text { Rainfall-unrelated }}$}

Other hydrological processes known for triggering debris flows are rapid snowmelt, and the drainage of landslide- or moraine-dammed lakes or glacial water pockets. Snowmelt related triggering events are generally rare. However, marked debris flow activity has been reported to occur in dry weather conditions after significant rises in air temperature (e.g. Sharp and Nobles, 1953; Decaulne et al., 2005), warm rain-on-snow events (e.g. Wondzell and King, 2003), or after volcanic eruptions (e.g. Pierson et al., 1990). Other debris flows, emanating from glacierised areas in sunny weather conditions but without apparent linkage to hydrometeorologic events, have been attributed to sudden emptying of proglacial lakes or englacial water pockets (e.g. Chiarle et al., 2007; SchneuwlyBollschweiler and Stoffel, 2012).

In tectonically active mountain regions, debris flows can also be triggered by seismic shaking during strong earthquakes. The cyclic loading and unloading of regolith as a consequence of ground acceleration in response to the passage of seismic waves can raise pore water pressures to critical levels and hence promote instabilities (Holzer et al., 1989; Sidle and Ochiai, 2006). The liquefaction and consequent mobilisation of regolith requires moderate to high earthquake intensities (cf. Hancox et al., 1997) and debris flows are thus less frequently triggered by earthquakes than other mass movements such as rockfalls or deep-seated slumps (cf. Keefer, 1984; Korup, 2005). Furthermore, antecedent water content is thought to be an influential factor in the effect of ground shaking on slide initiation (cf. Wieczorek and Glade, 2005; Lin et al., 2006). For example, in 2007, the $M_{W} 6.7$ George Sound earthquake off the coast of New Zealand's South Island occurred shortly after a storm event and triggered numerous instabilities, whereas landslide activity was much lower following the stronger $M_{W}$ 7.6 Dusky Sound Earthquake in 2009. A dry weather spell before the 2009 earthquake is thought to have lowered the variable susceptibility of slopes, resulting in the differing geomorphic response (S. Cox, pers. comm. July 2010). A similar phenomenon was observed in connection with the $M_{\llcorner} 5.4$ Lake Rotoehu earthquake and swarm of July 2004 (Hancox et al., 2004).

Despite the subordinate role of earthquakes as actual debris flow trigger events, their indirect effect on debris flow formation is nonetheless crucial. Large seismic events have considerable effects on sediment production via initiating rockfalls or weakening slope structures (e.g. Mikoš et al., 2006; Chen, 2011; Vanmaercke et al., 2014) and can locally 
change catchments' topography and drainage conditions lastingly. As such earthquakes can effectively influence debris flow systems' susceptibility for event initiation.

\subsubsection{Debris flow research in New Zealand}

Debris flows in New Zealand have received surprisingly little scientific attention despite being a widespread phenomenon on both North and South Island. This is because they occur predominantly in remote areas with low population densities and hence generally distant from settlements or major infrastructure. Furthermore, there are multiple other meteorologic and geologic hazards present in New Zealand which pose a significant hazard to extensive parts of the country. New Zealand's debris flow environments, therefore, received far less attention than those in more populated mountainous areas such as in the European Alps, the Coast Mountains of British Columbia, Japanese Alps, or Taiwan (cf. McSaveney and Davies, 2005).

Pierson (1980b) was one of the first to highlight the geomorphic importance of debris flows as erosive processes in New Zealand's steepland areas. Field observations of a debris flow event in the Bullock Creek catchment, Canterbury, in 1978 facilitated a detailed, still often cited, description of debris flow material properties and the characteristic surging flow behaviour (Pierson, 1980a, 1981). Further laboratory studies on the rheology of debris flows in this catchment were carried out by Phillips and Davis (1991). Whitehouse and McSaveney (1992) and Paterson (1996) addressed debris flows among other processes in their qualitative hazard assessments for State Highway 73 around Arthur's Pass, one of the only three transit routes across the Southern Alps. Other studies, focusing on storm-induced or seismically-triggered hillslope erosion and sediment yields (e.g. Selby, 1976; Hayward, 1980; Whitehouse, 1982; Beschta, 1983; Hancox et al., 1997; Hancox et al., 2003), analysed debris flow events within the wider context of gully erosion or landslide activity. Noteworthy in this context are the landslide studies in the aftermath of Cyclone Bola in 1988 (e.g. Page et al., 1994; Preston, 1996; Glade, 1997). This cyclone had a devastating impact on the soft-rock hill country of the Hawke's Bay and Gisborne East Cape regions, where extensive conversion to pastoral farming land left hillslopes especially susceptible to landslides and debris flow formation (cf. Figure 3.3). Triggering mechanisms and flow behaviour of debris flows emanating from volcanic source areas, so-called lahars (see Neall, 2003), have been studied at Mt Ruapehu, North Island (e.g. Cronin et al., 1997; Hodgson and Manville, 1999; Carrivick et al., 2009).

With the increasing development of remote and secluded alluvial fans for both residential and tourism purposes, the identification and management of active debris flow environments is attracting growing interest from scientists, engineers and regional councils in New 
Zealand. De Scally and Owens (2004), De Scally et al. (2010) and Welsh and Davies (2011) used catchment-based morphometric variables to identify alluvial fans which are susceptible to debris flow activity. Thurston (2009) examined climatic triggering events for alluvial fan activity in the Makarora valley and concluded that the sediment availability within the catchments was a key factor for the observed spatial variability in debris flow occurrence on the investigated fans. Examples of recent hazard and risk assessments are the Otago Alluvial Fan Project (Barrell et al., 2009) and assessments for Mt Cook Village, Canterbury (Whitehouse and McSaveney, 1990; McSaveney et al., 1995; Skermer et al., 2002; Hufschmidt, 2008), the town Matata, Bay of Plenty (McSaveney et al., 2005), the town Thames, Waikato (McSaveney and Beetham, 2006), and an undisclosed rural property in the Southern Alps (Bowman and Davies, 2008). Reviews of these assessments as well as further New Zealand-based case studies are included in McSaveney and Davies (2005) and Davis and McSaveney (2008). 


\subsection{Methodology}

The focus of this study lies on the identification of process-promoting environmental conditions in debris flow source areas. The main analysis units are, therefore, individual debris flow systems (described by the debris flow initiation zone and the upslope regolith contribution areas) and their activity in the recent past ( 60 years). The following sections outline the procedures for mapping debris flow systems and the assessment of debris flow activity. Furthermore, the approaches for delineating corresponding regolith contribution areas and steep rock surfaces are described.

\subsubsection{Study areas}

A prime criterion for the selection of suitable study areas was their location within or close to the periglacial zone in order to examine possible periglacial influences, such as permafrost and frost weathering, on debris flow activity. Furthermore, the selected areas had to be well-distributed over the Southern Alps to capture the likely presence of spatial variability in environmental conditions.

At the time of the site selection process, the spatial extent of the contemporary permafrost zone (cf. Chapter 4) and the occurrence of intense frost weathering (cf. Chapter 5) across the Southern Alps was not yet available. Hence, Brazier et al.'s (1998) suggested value of $2000 \mathrm{~m}$ elevation as the lower distribution limit of permafrost in the Southern Alps was adapted as the preliminary lower threshold of the altitudinal zone of interest. Subsequently, the search for suitable study areas by means of Google Earth imagery and aerial photograph catalogues was restricted to the Southern Alps' high mountain ranges with significant land proportions above this threshold, i.e. the Kaikoura ranges, the Two Thumb Range, the mountain ranges in the vicinity of Arthur's Pass and Mt Cook, and the Mount Aspiring region (cf. Figure 2.1, Inset B). Potential study sites were evaluated against the following criteria:

- Sufficient temporal resolution of aerial photograph coverage since $\sim 1950$.

- Altitudinal range up into the postulated periglacial zone, i.e. above $2000 \mathrm{~m}$ elevation (altitudinal information: 25 m DEM (Barringer et al., 2002)).

- High density of unchannelised first-order debris flow systems as opposed to multiorder gully systems to increase the likelihood of event identification (cf. Section 3.2.2 below).

- Whole catchments for a wide sample range of aspect, altitude, and slope.

- Existing literature on debris flows or related processes for the respective area. 
Eventually thirteen study areas, clustered in five regions and stretching the entire Southern Alps, were selected (Figure 3.7). The clustering of study sites was chosen to increase sample populations for a regional comparison of debris flow activity levels. Information on geographical location, relief characteristics, geology, and climate is listed for each site in Table 3.1. Topographic maps of the individual study areas are included in Appendix 1. A brief description of notable features follows below.

No suitable study areas were found in the western Southern Alps. As a consequence of the frequent high-intensity rainfall events at the West Coast, the steep alpine slopes west of

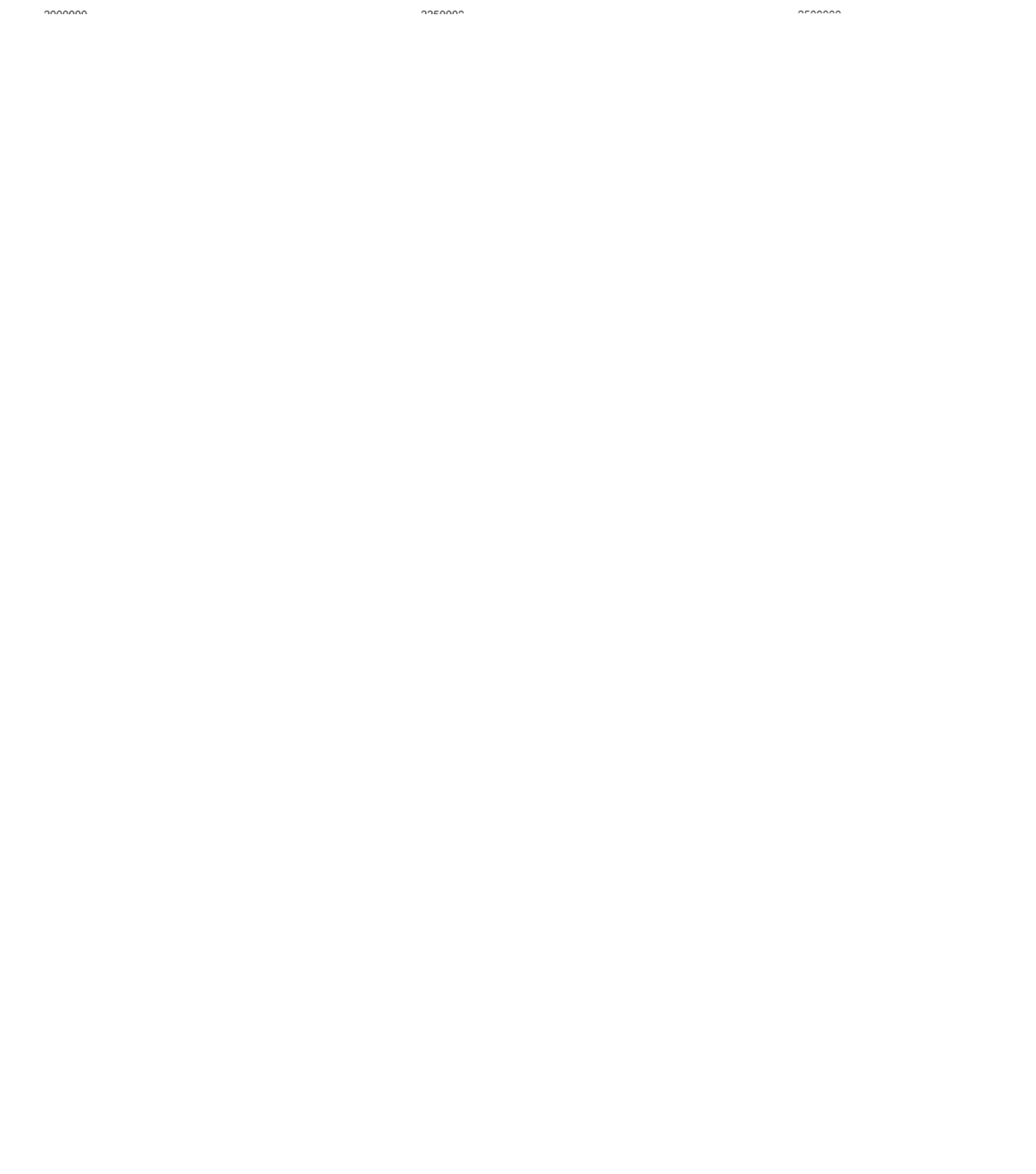

Figure 3.7 Location of the thirteen study areas selected for the multi-temporal debris flow analysis. 
Table 3.1 Information on geographic location, relief characteristics, geology, and climate for the individual study areas.

\begin{tabular}{|c|c|c|c|c|c|c|}
\hline $\begin{array}{l}\text { General Information } \\
\text { Region }\end{array}$ & Study area & Abbrevation & Mountain Range & Size $\left[\mathrm{km}^{2}\right]$ & $\begin{array}{c}\text { Valley } \\
\text { direction }\end{array}$ & $\begin{array}{l}\text { Centroid coordinates } \\
\text { [long/lat decdeg] }\end{array}$ \\
\hline Kaikoura ranges (KR) & $\begin{array}{l}\text { Trolove Stream valley } \\
\text { Dart Stream valley (lower part) } \\
\text { Middlehead Stream valley }\end{array}$ & $\begin{array}{l}\text { TSV } \\
\text { LDS } \\
\text { MSV }\end{array}$ & $\begin{array}{l}\text { Inland Kaikoura Range } \\
\text { Inland Kaikoura Range } \\
\text { Seaward Kaikoura Range }\end{array}$ & $\begin{array}{l}3.29 \\
2.71 \\
2.47\end{array}$ & $\begin{array}{l}\text { SE } \\
\text { SE } \\
\text { SE }\end{array}$ & $\begin{array}{l}173.675,-42.031 \\
173.655,-42.042 \\
173.575,-42.268\end{array}$ \\
\hline Arthur's Pass region (AP) & $\begin{array}{l}\text { Denas Creek } \\
\text { Enys Stream valley } \\
\text { Castle Hill - Foggy Stream valleys }\end{array}$ & $\begin{array}{l}\text { DC } \\
\text { ES } \\
\text { CHFS }\end{array}$ & $\begin{array}{l}\text { Shaler Range } \\
\text { Craigieburn Range } \\
\text { Torlesse Range }\end{array}$ & $\begin{array}{l}4.80 \\
6.54 \\
7.21\end{array}$ & $\begin{array}{l}\text { W } \\
E \\
\text { SE }\end{array}$ & $\begin{array}{l}171.362,-43.000 \\
171.658,-43.243 \\
171.770,-43.272\end{array}$ \\
\hline Two Thumb Range (TT) & $\begin{array}{l}\text { Camp Creek } \\
\text { Forest Creek }\end{array}$ & $\begin{array}{l}\mathrm{CC} \\
\mathrm{FC}\end{array}$ & $\begin{array}{l}\text { Two Thumb Range (North) } \\
\text { Two Thumb Range (South) }\end{array}$ & $\begin{array}{l}2.83 \\
8.35\end{array}$ & $\underset{\mathrm{E}}{\mathrm{NW}}$ & $\begin{array}{l}170.664,-43.535 \\
170.736,-43.814\end{array}$ \\
\hline Mt Cook region (MC) & $\begin{array}{l}\text { Black Birch Stream valley } \\
\text { Stony Stream valley (E fork) }\end{array}$ & $\begin{array}{l}\text { BBS } \\
\text { SSV }\end{array}$ & $\begin{array}{l}\text { Sealy Range } \\
\text { Ben Ohau Range }\end{array}$ & $\begin{array}{l}4.69 \\
6.22\end{array}$ & $\begin{array}{l}E \\
S\end{array}$ & $\begin{array}{l}170.080,-43.744 \\
170.031,-43.985\end{array}$ \\
\hline Mt Aspiring region (MA) & $\begin{array}{l}\text { Upper Stony Creek NE tributary } \\
\text { Glacier Burn valley } \\
\text { Kay Creek E tributary }\end{array}$ & $\begin{array}{l}\text { USCT } \\
\text { GB } \\
\text { KCET }\end{array}$ & $\begin{array}{l}\text { Richardson Mountains } \\
\text { Humboldt Mountains } \\
\text { Humboldt Mountains }\end{array}$ & $\begin{array}{l}6.44 \\
6.56 \\
4.48\end{array}$ & $\begin{array}{l}\text { SW } \\
E \\
W\end{array}$ & $\begin{array}{l}168.599,-44.790 \\
168.303,-44.823 \\
168.264,-44.817\end{array}$ \\
\hline
\end{tabular}

General Information (cont.)

\begin{tabular}{|c|c|c|c|c|c|c|}
\hline \multirow[b]{2}{*}{ Study Area } & \multicolumn{3}{|c|}{ Elevation $^{1}$} & \multirow{2}{*}{$\begin{array}{c}\text { Mean } \\
\text { slope }\left[{ }^{\circ}\right]^{\prime}\end{array}$} & \multirow{2}{*}{$\begin{array}{c}\text { Basin } \\
\text { relief ratio }^{2}\end{array}$} & \multirow{2}{*}{$\begin{array}{r}\text { Rock surface } \\
\text { extent }[\%]^{3}\end{array}$} \\
\hline & $\min$ & $\max$ & total relief & & & \\
\hline TSV & 978 & 2160 & 1183 & 25.5 & 0.6 & 0 \\
\hline LDS & 881 & 2238 & 1357 & 32.7 & - & 19 \\
\hline MSV & 1064 & 2146 & 1082 & 35.2 & 0.5 & 24 \\
\hline$D C$ & 990 & 2403 & 1413 & 34.9 & 0.3 & 36 \\
\hline ES & 861 & 2193 & 1332 & 29.3 & 0.3 & 0 \\
\hline CHFS & 772 & 1995 & 1222 & 31.7 & 0.4 & 4 \\
\hline CC & 1448 & 2255 & 807 & 31.8 & 0.3 & 18 \\
\hline FC & 1399 & 2293 & 894 & 26.1 & 0.2 & 5 \\
\hline BBS & 745 & 2203 & 1457 & 37.6 & 0.4 & 56 \\
\hline SSV & 1210 & 2426 & 1216 & 30.8 & 0.3 & 9 \\
\hline USCT & 890 & 2179 & 1289 & 34.1 & 0.3 & 28 \\
\hline GB & 508 & 2319 & 1811 & 35.5 & 0.3 & 56 \\
\hline KCET & 768 & 2309 & 1541 & 33.9 & 0.4 & 33 \\
\hline
\end{tabular}

derived from $15 \mathrm{~m}$ DEM (Columbus et al., 2011)

${ }^{2}$ calulated as the ratio between total relief and basin length (cf. Strahler, 1957)
${ }^{3}$ derived from manual mapping (cf. Section 3.2.4)

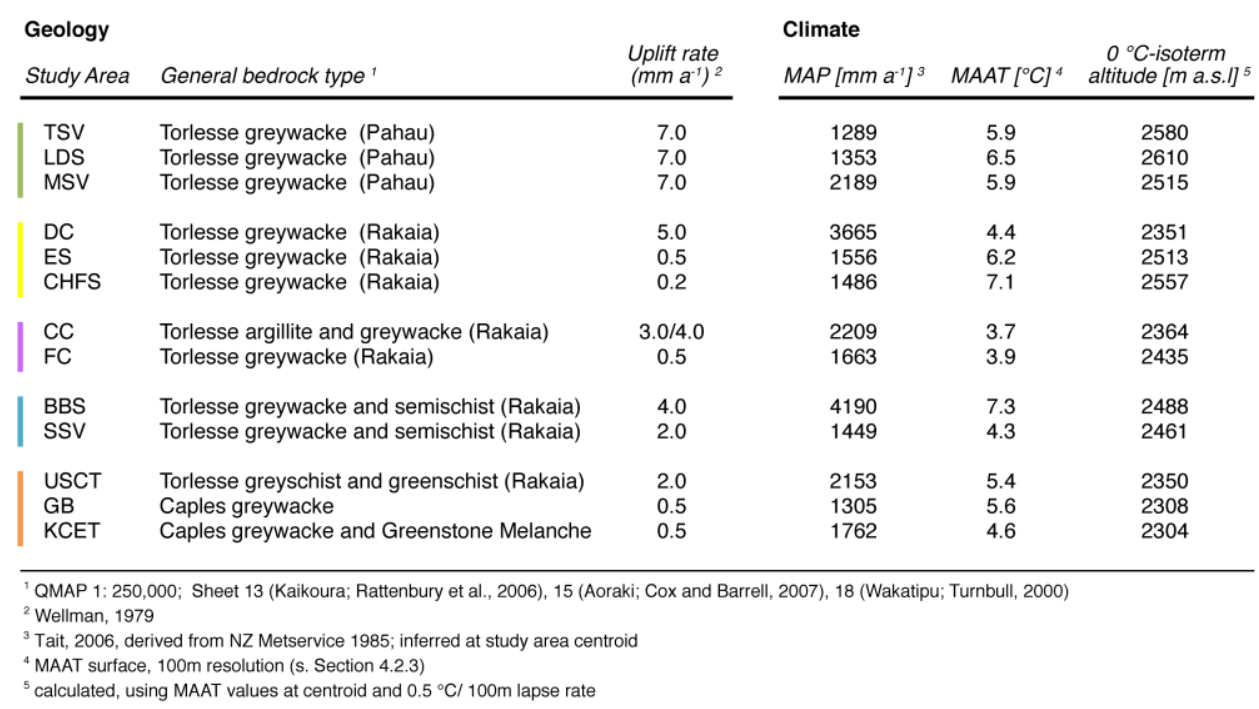


the Main Divide are generally stripped bare of regolith and significant debris taluses suitable for open-slope debris flow development are rare (cf. Whitehouse, 1988; Hales and Roering, 2005). Debris flows occur in the western ranges within the steep, deeply incised gully systems or, more commonly, at lower altitudes (cf. Hovius et al., 1997; Korup, 2005).

Furthermore, only a few sites that featured in previous hillslope erosion studies (cf. Section 3.1.3) were suitable locations for the present study (see below). Especially the Makarora valley catchments, investigated by Thurston (2009), would have been interesting sites, since results on conditions and developments within debris source areas would have been complementary to Thurston's fan-based interpretations. However, these catchments comprise steep, deeply incised, multi-order gully systems and are consequently unsuited for event identification based on aerial photo interpretation.

\section{Noteworthy features in the selected study areas}

Catchments in the Kaikoura ranges are generally very steep and especially in the Seaward Kaikoura Range deeply incised into bedrock. This is a geomorphic expression of the high neotectonic activity in this region, with uplift rates estimated to range between $6-10 \mathrm{~mm} \mathrm{a}^{-1}$ in the Seaward Kaikoura Range (Van Dissen and Yeats, 1991) and $4-8 \mathrm{~mm} \mathrm{a}^{-1}$ in the Inland Kaikoura Range (Bacon et al., 2001). Both the lower part of the Dart Stream valley (LDS) and the Middlehead Stream valley (MHS) feature signs of the ongoing tectonic landscape adjustment in the form of relict taluses that have been undercut by markedly incised drainage lines. These large, seemingly supply-unlimited sediment reservoirs show a high density of instabilities at their oversteepened toes. The Trolove Stream valley (TSV) has the highest basin relief ratio of all investigated study areas, demonstrating the exceptional steepness of this unusually short valley, which is situated directly on the imposing scarp of the Clarence Fault (cf. GNS, 2004). Numerous debris flow systems have formed underneath the moderate rocky outcrops on the northern flank of this otherwise exceptionally debris-rich catchment. The steep topography in the Kaikoura ranges impeded the selection of suitable study areas. Debris flows are abundant in both the Inland and Seaward Kaikoura Range; however, they commonly enter steep channels, which is unfavourable for event identification (cf. Section 3.2.2 below). The glacial valleys surrounding Mt Tapuae-o-Uenuku appeared most suitable for debris flow mapping due to the presence of extensive taluses. Yet, these valleys are all significantly larger than the other study areas selected for this study. As a compromise, only the lower part of the Dart Stream Valley, adjacent to the Trolove Stream catchment, was chosen as the third study site in the Kaikoura ranges.

The study areas selected in the Arthur's Pass region are diverse. Denas Creek (DC), situated closest to the actual Arthur's Pass mountain pass, is a hanging valley, flanked to 
both sides by steep rock cliffs with large scree slopes below. The valley is still glacierised; however, only small glacier remnants occur at the valley's head wall. Small moraines can be found at the head of the wide valley floor. Both Enys Stream valley (ES) and the Castle Hill Foggy Stream valleys (CHFS) are located at significantly lower altitude in the eastern front ranges of the Southern Alps. The relief in this area can be described as rolling with gentle, debris-mantled slopes, flat-topped ridges and only few isolated rock cliffs and outcrops. The mostly rectilinear slopes are strewn with active erosion areas. The Castle Hill - Foggy Stream catchments were primarily chosen because of a previous study by Beschta (1983) on sediment sources and pattern of long-term sediment movement in the wider Upper Kowai Basin.

Camp Creek (CC), in the northern Two Thumb Range, is the only catchment among the study areas that opens towards the north. It is characterised by long talus slopes below comparatively small rock outcrops. Numerous, barely incised debris flow tracks with welldeveloped depositional heads and levées are visible on the taluses. Their distinct full forms indicate the absence of post-event modification by fluvial erosion and facilitate event identification. Catchments in the northern Two Thumb Range were glaciated more often and for longer durations in the past than those in the southern areas (Brook et al., 2008). The difference in glacial history reflects a transition in the present-day valley topography from glacial troughs in the north (e.g. Camp Creek) to fluvial cross-profiles in the south. Forest Creek (FC), in the southern Two Thumb Range, is an example of a catchment intermittent between these two states (cf. Herman and Braun, 2006; Brook et al., 2008). It is a wide valley with comparatively low total relief. Given the lack of documented structural geologic features in this area (cf. Cox and Barrell, 2007), it appears that fluvial erosion has been the dominant process in the recent geologic past, cutting into the tectonically uplifting valley floor and creating a raised bench floor (cf. Kirkbride and Mathews, 1997). The dry environment at high altitude promoted the development of large nowadays relict rock glaciers within the sun-averted tributary cirques. The catchment is in general debris depleted. However, numerous short debris flow tracks are visible on the high-altitude taluses as well as below the bench floor escarpment. A small number of debris flow systems emanate from relict rock glacier deposits.

The study areas for the Mt Cook region are situated south of Aoraki/ Mt Cook in the Sealy Range and its southern extension, the Ben Ohau Range. Analogous to the Two Thumb Range, this north-south stretching range complex shows a distinct transition from glacial valleys in the north to fluvially shaped catchments in the south (Kirkbride and Mathews, 1997), accompanied by an increase in the occurrence of both intact and relict rock glaciers. The Black Birch Stream (BBS) catchment is located in the northern range, above Mt Cook Village. The lower north-facing slope of this very steep glacierised catchment has been previously studied by Whitehouse (1982), who conducted a multi-temporal analysis of slope instabilities based on oblique historic photographs taken between 1897 and 1980. The 
area investigated by Whitehouse (1982) is the location of a suspected landslide which probably occurred between 9 and 18 ka ago (D. Barrell, pers. comm. November 2012). Although its presence has yet to be scientifically verified, and disagreement exists in literature on the origin of the actual slope material (cf. Burrows, 1980; Whitehouse, 1982; Gellatly et al., 1988), satellite imagery shows the presence of a large volume of unconsolidated material which is currently remobilised by debris flows and gully erosion. The Stony Stream valley (SSV) is situated in the central Ben Ohau Range. The presence of an intact rock glacier as well as the observation of patterned ground and solifluction lobes in the neighbouring Irishman Stream valley (cf. Section 4.3.4), indicated that a significant part of the catchment is situated within the periglacial zone. Given the large number of debris flows originating at comparatively high altitude underneath rockwalls or rocky outcrops, it was expected that some debris flow systems are situated within or have at least their contribution areas in potential permafrost areas.

The axial mountain ranges of the Mt Aspiring region are characterised by steeply-flanked catchments, forming the hanging tributaries of the wide glacial troughs in between. Significant high-altitude debris accumulations are largely restricted to the Humboldt Mountains in the south. The Glacier Burn (GB) catchment and the unnamed eastern tributary of the Kay Creek (KCET) are back-to-back valleys below Mt Bonpland. In both catchments, high rock cliffs with scree slopes beneath form the northern flank. While the head area of the Glacier Burn catchment is still covered by the Bryant glacier, long taluses have developed underneath the nowadays almost ice-free headwall of the Kay Creek tributary. Numerous debris flow tracks on both valleys' scree slopes suggest recurrent debris flow activity. On the lower north-facing slope of the Kay Creek tributary, comparatively young looking slide-initiated debris flows are visible in recent satellite imagery from 2006 . The also unnamed Upper Stony Creek tributary (USCT) is situated only a short distance of $\sim 20 \mathrm{~km}$ to the east of the Glacier Burn catchment in the Richardson Mountains. Over this distance, the bedrock transforms from greywacke to schist, resulting in a distinct change in topography. The Upper Stony Creek tributary is markedly dissected and the relief extremely rugged. The slopes of the steep catchment appear at least to some degree influenced by the basement rocks' foliation (cf. Turnbull et al., 1975; Whitehouse, 1988), as long dip-slopes form the south-eastern valley flank. Small glaciers close to the northern ridge have formed steep moraines above a heavily dissected rock cliff. Below the cliff, debris flow tracks can be seen on vegetated scree slopes. The lower half of the catchment is characterised by steep bedrock-incised gullies. Small colluvial fans at their exits also show signs of debris flow activity. 


\subsubsection{Assessment of debris flow activity in the selected study areas}

\section{Mapping of debris flow systems}

Debris flow systems in the study areas were mapped based on a digital colour orthophotograph mosaic with $0.75 \mathrm{~m}$ resolution, collated by Terralink International Ltd from aerial photographs taken between 2005 and 2008. Georeferenced scans of historic aerial photographs (see following section) as well as Google Earth imagery (available early 2011) were consulted for clarification of details and for mapping of a small area outside the orthophotograph coverage (Black Birch Stream valley, Mt Cook region). Debris flow initiation areas, flow paths, and the spatial extent of deposits (symbolised by endpoints) were digitised in ArcMap 9.3 (ESRI, 2009b), using the orthophotograph at a scale of 1: 3,000 as generalisation guideline. Features were purposely mapped based on the rectified orthophotograph, where available, to minimise potential inaccuracies in feature location due to residual geometric distortions in the aerial photographs (cf. below).

Debris flow initiation areas were mapped as point features at the highest position where signs of marked erosion were visible on slopes or within channels (cf. Pierson, 1980b; Godt and Coe, 2007; see also Figure 3.8). Where the actual origin of a debris flow was not clear (e.g. wide landslide scarps or steep dendritic source areas), the initiation area was mapped at the highest position common to the possible flow paths. Only one flow path per debris flow system was recorded as line feature. In the case of multiple flow paths, created by consecutive surges or independent events, the track with the furthest runout distance was mapped, regardless of the relative age of deposits. The furthest reach of visible debris flow deposits was marked with an endpoint. The lack of visible deposits at the end of a debris flow track indicates that the event continued into a higher-order drainage channel, or, more likely, deposits have been significantly reworked by fluvial erosion. In such systems, the number of debris flow events identified is likely underestimated.

Additional to the location of initiation zones and the extent of flow paths, the type of initiation mechanism, the debris supply conditions in the source areas, and the level of confinement of the debris flow track were recorded as supplementary attributes (see also Table 3.2):

Debris flow initiation areas were differentiated according to the initiation mechanism (cf. Section 3.1.1) into slide-initiated debris flows (SIT) and runoff-generated debris flows (RIT). However, an unambiguous attribution was not always possible, especially in systems, where instabilities on gully walls could serve over time both as initiation sites and as a supplier of material into the channel for later runoff-generated debris flows (cf. Brayshaw and Hassan, 2009). At these locations, a determination based solely on aerial 

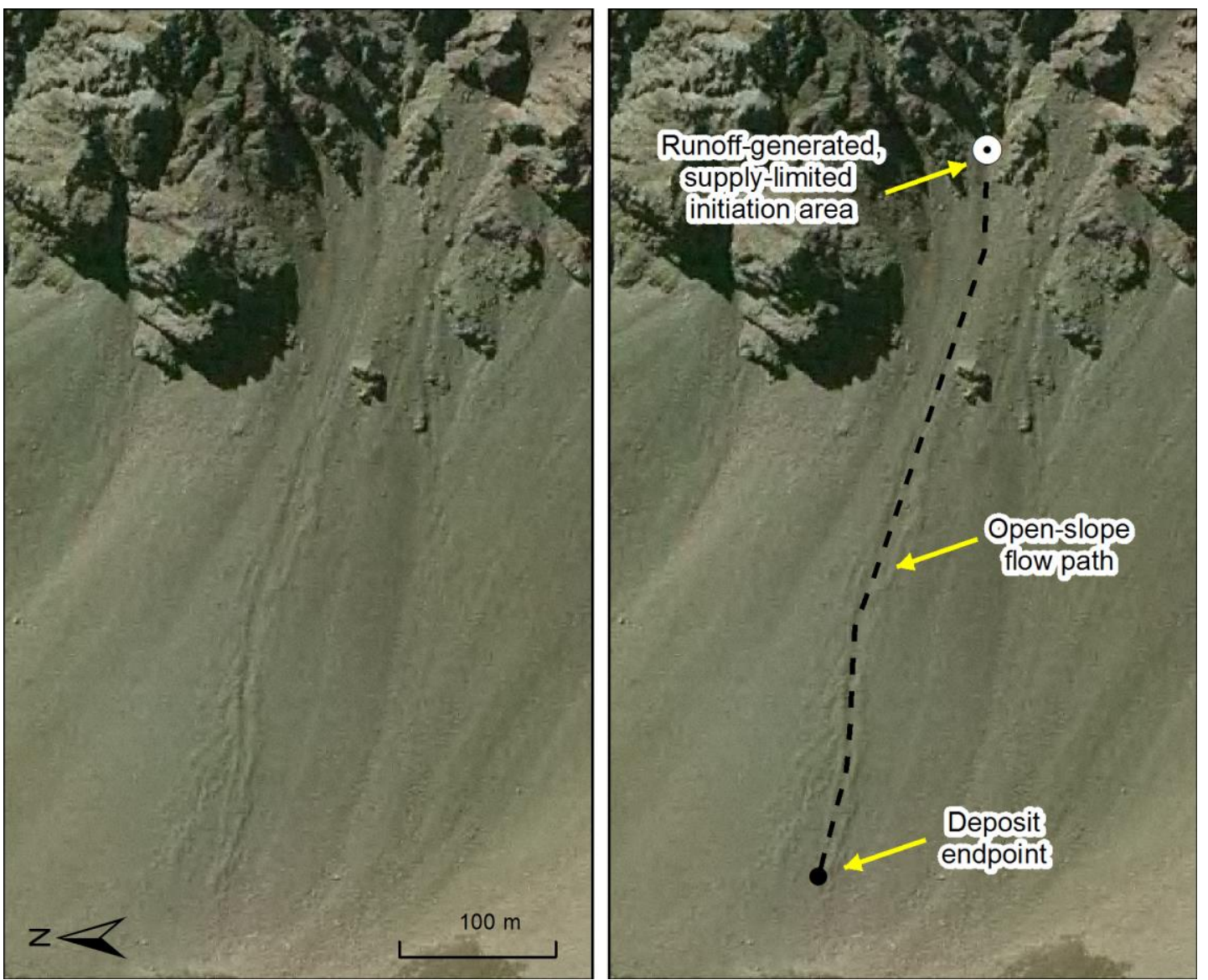

Figure 3.8

Example of mapped debris flow features and attributes (DF ID 120011, Camp Creek, Two Thumb Range). Basemap: Orthophotograph (Terralink, 2005-2008).

photo interpretation was not possible. Such systems were therefore categorised as an additional combined initiation type (COMB).

Debris supply conditions in the source areas were categorised as limited or unlimited (cf. Section 3.1.2). The attribution was based on the interpretation of the amount of easily mobilised sediment visible in the initiation area in remotely sensed imagery. Source areas were categorised as unlimited only where distinct signs of erosion in loose material were apparent.

Debris flow tracks were differentiated according to the level of confinement into openslope flow paths and channelised flow paths. Open-slope tracks are largely unconfined features on open hillslopes, created by a single or a small number of low-magnitude, moderately-erosive events. Their well-developed lateral and frontal deposits are easily discernable in aerial photographs and events are readily recognised by image comparison. Deposits of debris flows occurring within or entering markedly incised channels, on the other hand, are not as easily recognised. Besides less developed levées within the confining channel walls (cf. Section 3.1.1), channel floors are frequently obscured in aerial 
photographs due to shadows or optical overexposure. Furthermore, rills and channels act as preferred drainage lines for storm water runoff. Deposits within channelised flow paths are, therefore, commonly removed by fluvial erosion soon after deposition. Potential debris flow tracks that appeared to be influenced by fluvial sediment transport were mapped as 'debrisflow-capable drainage lines'. If the topography at the channel head or fan suggested debris flow activity, a runoff-generated initiation zone was added at the top.

Table 3.2 Summary of features and attributes mapped for analysing debris flow activity in the study areas.

\begin{tabular}{|c|c|c|}
\hline Features & Attributes & Subtypes \\
\hline \multicolumn{3}{|l|}{ Debris flow systems } \\
\hline \multirow[t]{2}{*}{ Initiation zone $(p)$} & Mechanism & Slide-initiated (SIT); runoff-generated (RIT); combined (COMB) \\
\hline & Supply conditions & Limited; unlimited \\
\hline Flow path (I) & Type & Open-slope, channelised \\
\hline \multicolumn{3}{|l|}{ Endpoint $(p)$} \\
\hline \multicolumn{3}{|l|}{ Other } \\
\hline Drainage system (I) & Type & Debris-flow-capable; water; intermittent \\
\hline
\end{tabular}

(p) point feature, (I) line feature

\section{Evaluation of the mapping process}

The identification of debris flow systems and their initiation areas was based on the interpretation of the geomorphology in remotely sensed imagery. Due to the good resolution of the available imagery (e.g. colour orthophoto mosaic $0.75 \mathrm{~m}$ cell size), the spatial error in positioning the initiation points at the determined location is estimated to be in most cases within $10 \mathrm{~m}$ (horizontal accuracy of the orthophoto mosaic varies among the study areas between \pm 3 and $\pm 12 \mathrm{~m}$, Terralink 2005-2008). This is considered acceptable, given that the highest resolution of the raster datasets available for the analysis of preconditioning factors is $15 \mathrm{~m}$ (cf. Section 3.3 and 5.2).

The attribution of initiation mechanism and supply conditions within the identified source areas was also based on remotely sensed imagery interpretation only. Uncertainties stemming from lack of field validation must therefore be considered in the interpretation of results.

\section{Aerial photographs}

A chronological set of aerial photographs was chosen for each study area (Figure 3.9 and Appendix 2). A target of ten-year increments was aimed for but was not always possible. Irregular survey intervals or poor-quality images, taken after snowfall, above 


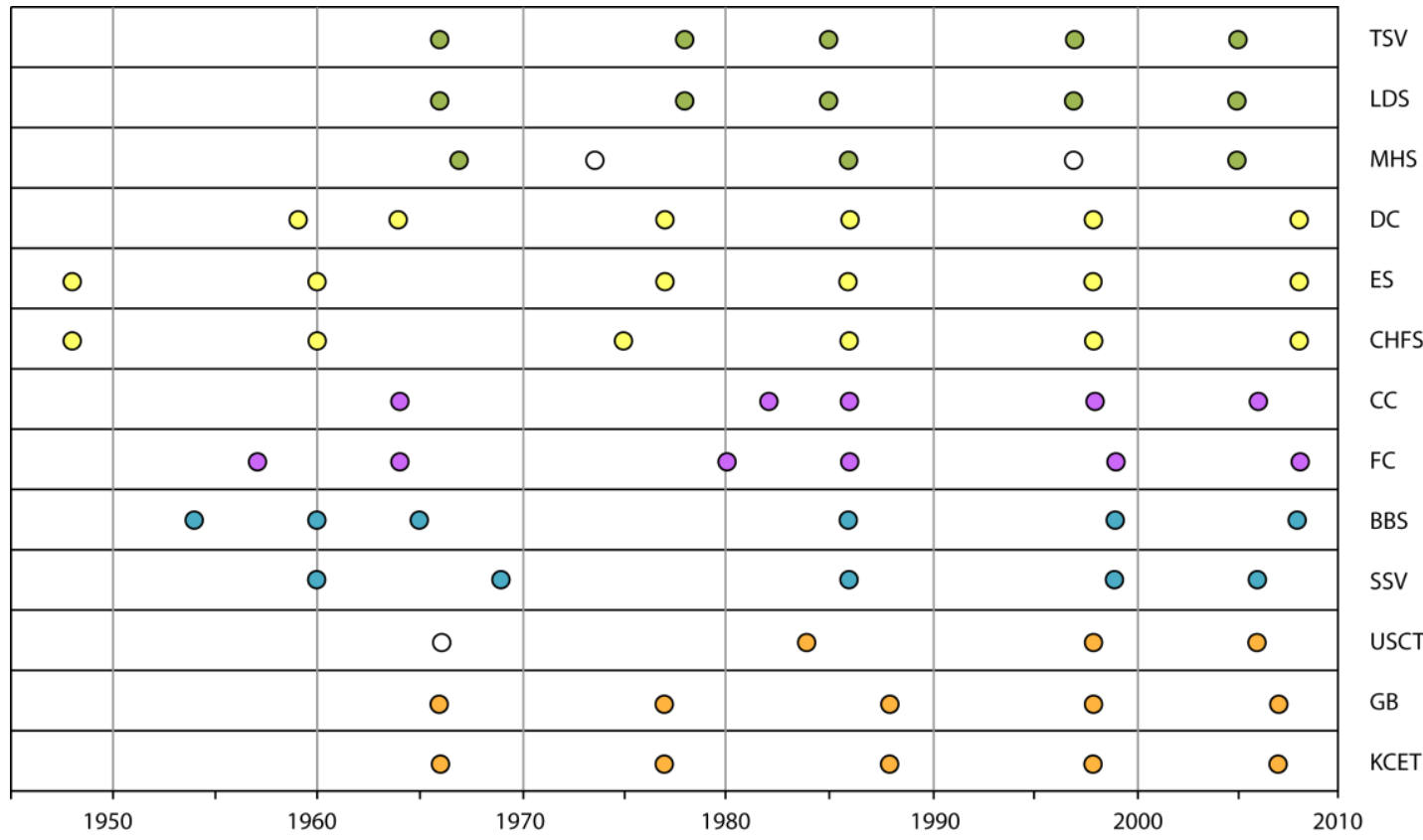

Figure 3.9

Aerial photograph coverage for the individual study areas. The colouring signifies the study region (cf. Table 3.1); white circles indicate that the quality of the available image was insufficient for event analysis. Details on the individual images are listed in Appendix 2.

significant cloud cover, or from high altitudes, resulted for some catchments in significantly longer intervals between consecutive images.

All aerial photographs were scanned from hard copies at a high resolution (1200 dpi) and visually enhanced, using ENVI's (ITT Cooperation, 2009) 5-kernel high-pass filter, to improve the images' contrast by amplifying linear features such as debris flow tracks. An initial attempt to orthorectify the aerial photographs by using a $15 \mathrm{~m}$ DEM (Columbus et al., 2011a) and ENVI's (ITT Cooperation, 2009) 'Build RPCs' tool and 'Generic RPC orthorectification' tool had to be abandoned, since the rectified image visibly lacked spatial accuracy, probably stemming from DEM inaccuracies as well as errors introduced by the necessary manual placement of tie points. The aerial photographs were therefore manually georeferenced in ArcMap 9.3 (ESRI, 2009b), using the already rectified orthophotograph mosaic (Terralink, 2005-2008) as reference layer for correcting topography-induced displacements inherent in the aerial photographs. On average, 101 control points were set per image (cf. Appendix 2). The high density of control points allowed the use of the spline transformation as warping method, which optimises for local accuracy (ESRI, 2009a) and hence facilitates a controlled correction of relief displacement in the aerial photographs. The spline transformation is a true rubber sheeting method, i.e. source control points are exactly placed at target control points. Therefore, root mean square errors (RMS), used to evaluate the accuracy of polynomial transformations, cannot be calculated. In a last step, the 
georeferenced aerial photographs were rectified, using the cubic convolution for cell resampling and a cell size of $0.3-0.5 \mathrm{~m}$ as final raster resolution.

\section{Mapping of debris flow events}

The occurrence of debris flow events was analysed by visually comparing the appearance of debris flow systems in chronologic pairs of aerial photos in ArcMap 9.3 (ESRI, 2009b). The tool 'Swipe' in the 'Effects Toolbar' proved vital for this purpose. It allowed the interactive comparison of different images by 'rolling' the younger image back and forth over the next older image. Given the images' high spatial resolution and precise spatial registration (i.e. conformity with the orthophotograph as well as the other aerial photographs), event-indicating changes in initiation altitude, flow paths, deposition areas or changes in channel drainage patterns in response to high sediment input from tributaries, were easily recognised (Figure 3.10). Identified events were attributed to the
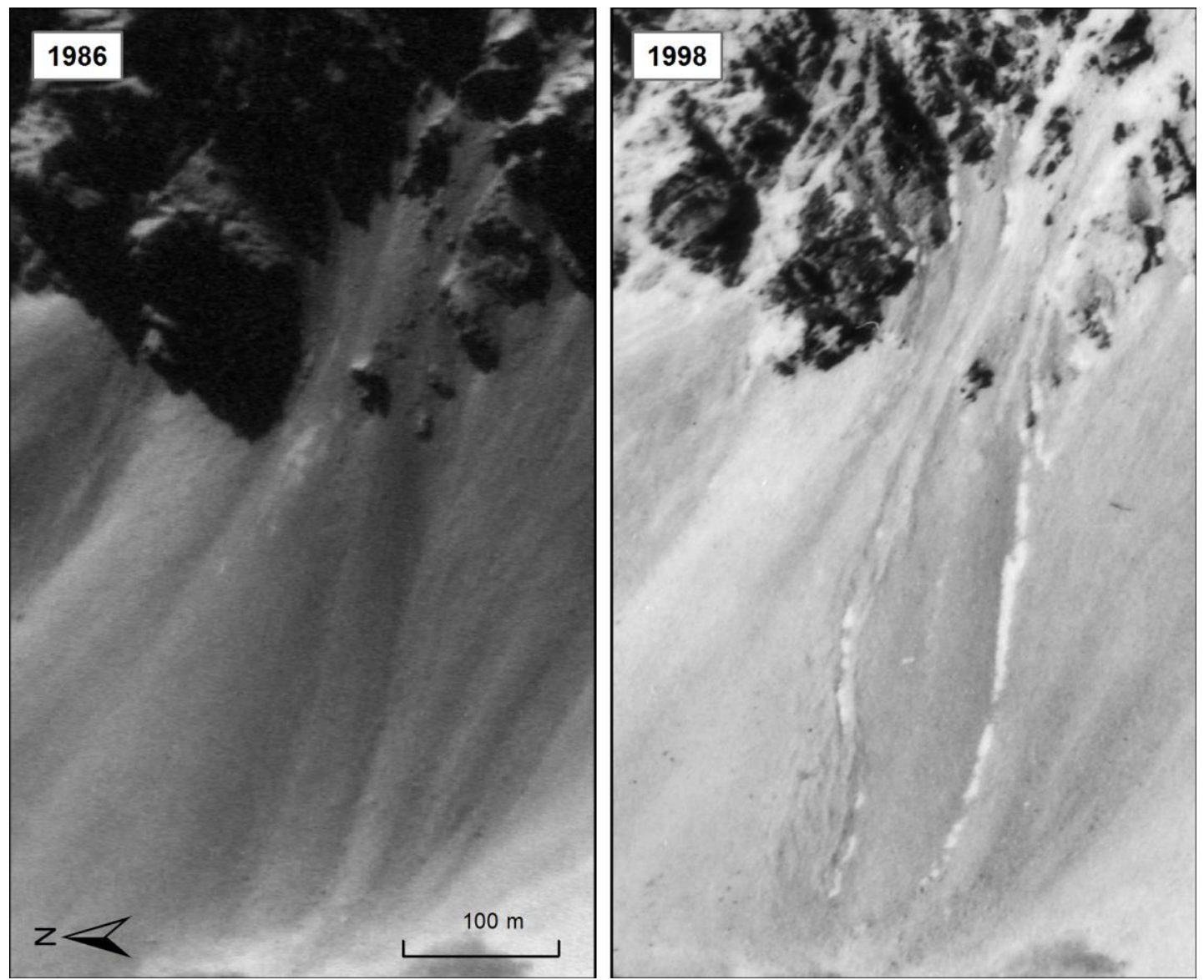

Figure 3.10

Example of an aerial photo pair indicating debris flow occurrences between 1986 and 1998 (DF ID 120011, Camp Creek, Two Thumb Range). The features of the earlier debris flow (1998, left track) are more eroded than the later one (1998, overriding towards right diverted track). This suggests that two independent events occurred in this system between 1986 and 1998. Photographs: SN8595 A18 (1986) and 506593 (1998). 
initiation areas via the younger photograph's year, i.e. the point in time when the event was recognised.

Although the comparison of aerial photographs revealed that certain debris flow system had been active since the older image was taken, it generally did not disclose how many events had occurred. Only in few open-slope cases, the presence of multiple new tracks in the deposition area indicated the occurrence of several surges, or, as in Figure 3.10, the occurrence of several independent events. To avoid a bias in event count due to the easier differentiation of individual events in open-slope systems, which tend to channel avulsion, any identified activity was registered as a single event count.

\section{Evaluation of event mapping}

The identification of debris flow events within the study areas was strongly dependent on the number of available aerial photo surveys and the quality of the respective images.

Publicly available aerial photographs for New Zealand's South Island date back to the 1930s. In the early years, only specific features, such as main roads, mountain passes, or river courses, were recorded. Spatially comprehensive image sets emerged for most regions in the 1950s and 1960s. Systematic nationwide resurveying started in the mid-1980s, resulting in more consistent time intervals between available photographs since that time (see Figure 3.9).

The lack of early images for the study areas in the Kaikoura ranges and the Mt Aspiring region significantly shortened the period investigated for these sites. Differing lengths of analysed periods complicates an interregional comparison of debris flow activity across the Southern Alps. The irregular number and dates of images available for the individual sites also introduces variations in the level of uncertainty involved in the mapping of debris flow events based on aerial photo interpretation. The longer the time interval between chronologic aerial photographs, the higher the risk that events went unnoticed, as deposits may had been reworked by fluvial erosion or, though less likely, covered by rockfall debris. The accuracy of the assessed event inventory differs therefore not only between the study areas but also between a study site's individual time steps. Furthermore, the accuracy of event identification also varies between the different flow path types, as events are more easily recognised in open-slope systems than in channelised systems.

A further constraint in the identification of debris flow events in the individual study areas was the quality of the available aerial photographs. Main factors impacting image comparison in this context were:

- Low ground resolution in small-scale, i.e. high-altitude, images.

- Lack of contrast as a result of low ground resolution or lack of texture of ground cover. 
- Optical overexposure of areas with scarce or no sediment cover.

- Extended shadows, snow, or cloud cover.

- Differing appearance of features due to variation in recording position and angles, affecting visibility, degree of shading, and colouring.

- Introduction of artificial texture, created by contact prints' paper during scanning.

In cases where the older image's quality impeded the visual comparison of debris flow systems, the next older photograph was consulted. If signs of activity were visible between the most recent and the oldest image, the three images were contrasted in detail to determine the period in which the event most likely occurred. Fortunately, the situation never arose where extended shadows obstructed the identification process.

Without extensive ground truthing or other independent evidence (e.g. archival records), the suitability of the mapping approach and consequently the quality of the assessed debris flow event inventory cannot be objectively evaluated. However, in an attempt to assess the methodological validity, the events mapped at the lower north-facing slope in the Black Birch Stream catchment were compared to Whitehouse's (1982) observations. Despite a significantly coarser temporal resolution, more events were identified in the present study by the use of aerial photographs than by Whitehouse's (1982) comparison of oblique photographs. The reactivation of numerous existing debris flow systems during the Boxing Day storm in 1957 (cf. also Hufschmidt, 2008) went unnoticed by Whitehouse (1982), as they were not accompanied by the formation of new instabilities or the marked enlargement of existing scars.

In summary, the mapping of debris flow events based on the visual comparison of georeferenced aerial photographs in a GIS environment is evaluated as a useful approach to assess debris flow activity on a catchment scale. However, it is expected that the event inventory underestimates the actual activity in the study areas by an unknown amount. The event catalogue is most likely biased towards larger, open-slope events, since small debris flows, not reaching beyond the extent of existing deposits, or events occurring in channelised systems are more likely to go unnoticed. The long time intervals between the available historic aerial photographs are a significant shortcoming in the present mapping approach. Increments of often more than ten years allow only a very rough dating of the identified events. The temporal information is hence insufficient for the analysis of debris flow triggers or spatial variations in the timing of debris flow occurrence. However, the coarse temporal resolution can also be seen as a trade-off for the regional scale of the assessed event data set, potentially enabling the interregional comparison of environmental conditions promoting debris flow formation. 


\subsubsection{Delineation of debris flow contribution areas}

The analysis of the effect of sediment production rates on debris flow activity in supplylimited systems requires information on the extent of the sediment contribution areas, i.e. the catchments above debris flow initiation areas that actively provide debris via rockfall or other sediment transport processes (cf. Bovis and Jakob, 1999; Godt and Coe, 2007, see Figure 3.11). The debris flow contribution areas were calculated for runoff-generated, supply-limited debris flow systems by means of flow accumulation calculations within the open-source GIS Whitebox GAT 1.0.7 (a newer version of the software is available at http://www.uoguelph.ca/ hydrogeo/Whitebox/index.html) and a $15 \mathrm{~m}$ DEM (Columbus et al., 2011a). Slide-initiated and combined systems were not considered as debris supply in these systems is controlled by the stability of backscarps or gully walls and therefore completely or, as in the case of combined systems, to some extent independent from upslope sediment production.

Flow direction and flow accumulation raster were calculated in Whitebox GAT using the random eight-node (rho8) algorithm. The rho8 algorithm is like the commonly used eightdirection (D8) flow algorithm (e.g. ArcGIS 9.3) a single-flow-direction method where "all flow is passed to the neighbour with the steepest downslope gradient [...] resulting in eight possible drainage directions" (Gruber and Peckham, 2009). However, the rho8 algorithm introduces a degree of randomness into the flow-direction calculations (Wilson and Gallant, 2000). The stochastic computation approach breaks up parallel flow paths on smooth hillslopes and reduces the number of linear upslope pixel chains encountered when using the strongly grid-biased D8 algorithm. Additionally, Whitebox GAT bases flow accumulations on the specific catchment area (SCA, unit: area per unit contour length), which is less affected by grid resolution (cf. Goodwin and Tarboton, 2003; Lindsay, 2010).

In a second step, the debris flow initiation areas, i.e. the pour points for the catchment delineation process, were snapped within ArcGIS 9.3 to the modelled flow lines described by the flow accumulation raster, using the 'snap pour point' tool. ArcGIS allowed using the point features directly as input which minimised the amount of spatial displacement required. In the raster-based GIS Whitebox GAT pour points have to be converted into raster format before they can be snapped to the nearest high flow accumulation cell. In a trial run, this conversion introduced in numerous cases significant positional inaccuracies in the location of the pour points (up to $31 \mathrm{~m}$ ), which in the worst cases led to the calculation of unintended adjacent contribution areas.

Debris flow contribution areas were eventually delineated in Whitebox GAT using the 'unnest basins' tool. In contrast to the watershed tool in ArcGIS 9.3, the unnest basins tool identifies and processes different layers of watersheds and thus allows the delineation of low-order basins 'nested' within the contributing area of downslope initiation zones. To accommodate for the difference between water drainage and sediment accumulation 
(e.g. debris might be stored in extensive low-gradient areas within a hydrological basin), areas below the empirically assessed angle of $40^{\circ}$ (cf. Section 3.2.4) and a planar curvature value above -0.5 were excluded. To assure that the calculated polygons represented the individual contribution areas adequately, in a last step, the extent of each catchment was visually checked in the orthophotograph and if necessary manually corrected. Calculated polygons that did not represent regolith-supplying area above a mapped debris flow system or polygons where the calculated extent was questionable were deleted. Contribution areas were only manually re-mapped if the extent was clearly discernable in the orthophotograph.

\section{Evaluation of semi-automated delineation approach}

The suitability of the $15 \mathrm{~m}$ DEM as base data for local-scale flow accumulation calculations is debatable. Derived from the $20 \mathrm{~m}$ contours in the LINZ NZTopo database (see Columbus et al., 2011b), the $15 \mathrm{~m}$ grid is too coarse in resolution to adequately resolve the slope characteristics of dissected rockwalls or hillslopes (see cell size and rockwall topography in Figure 3.11). As a consequence, drainage area calculations for the numerous debris flow systems without distinct, funnel-shaped contribution areas yielded erroneous results. While in some cases, inaccuracies stemming from the topographic generalisation of

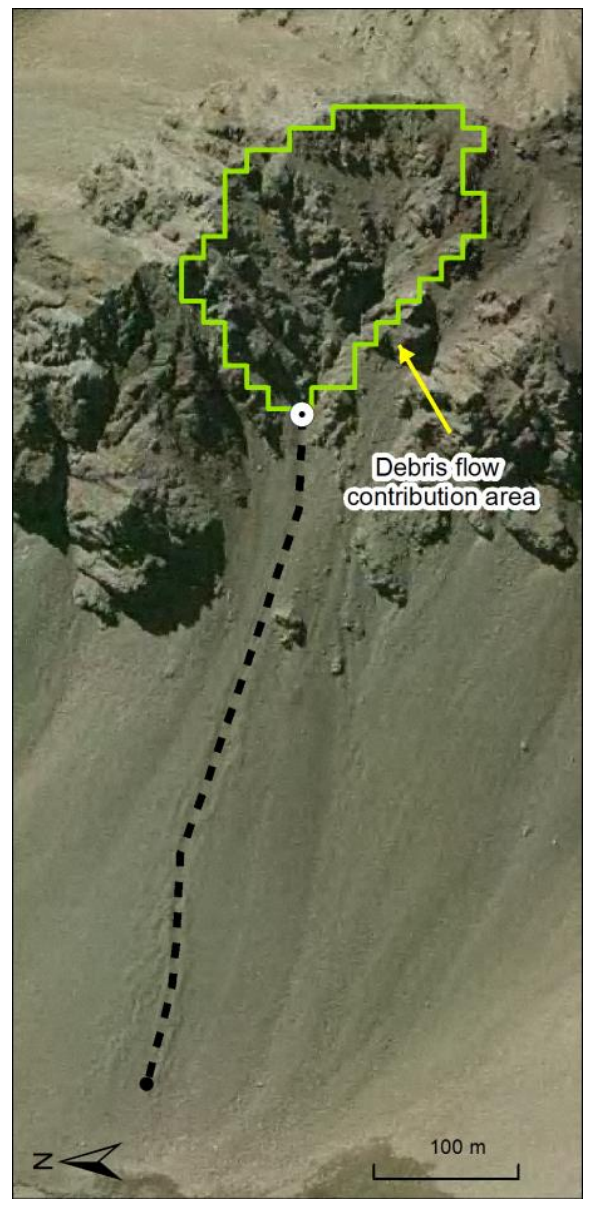

Figure 3.11

Example of a delineated debris flow contribution area (DF ID 120011, Camp Creek, Two Thumb Range); for symbology of other features see Fig. 3.8.

Basemap: Orthophotograph (Terralink, 2005-2008). 


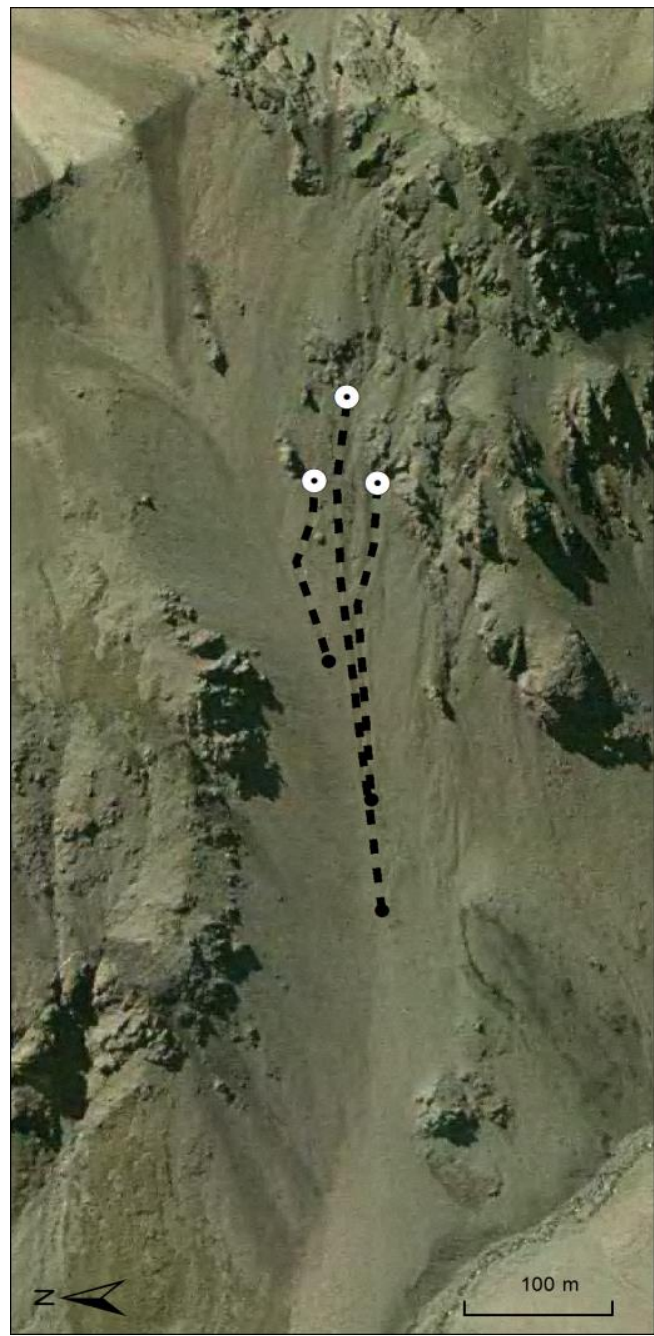

Figure 3.12

Example of runoff-generated debris flow systems underneath small rock outcrops, where the extent of debris contributing area is not clearly recognisable (DF ID 120069 - 120071, Camp Creek, Two Thumb Range); for symbology of other features see Fig. 3.8. Basemap: Orthophotograph (Terralink, 2005-2008).

the DEM could be easily corrected manually, in other cases, the actual extent of the contribution areas was difficult to identify in the available imagery (cf. Figure 3.12). Excluding these areas resulted in a significant reduction in the number of mapped contribution areas from potential 1216 (= number of run-off generated systems) to 404 .

At the time of the analysis, the $15 \mathrm{~m}$ DEM was the finest resolution dataset available among the countrywide digital elevation models. A manual mapping of the contribution areas would not have significantly improved either quality or size of the resulting dataset, given the difficulties in identifying the extent of not distinctly funnel-shaped contribution areas based on the available imagery.

\subsubsection{Delineation of steep rock surfaces}

Information on the extent of steep rock surfaces, i.e. slopes with gradients steeper than the angle of repose and hence not covered by debris-flow significant sediment accumulations, are useful not only for the general characterisation of a catchment's 
topography (Table 3.1) but also for the area-normalised statistical analysis of debris flow occurrences (Chapter 5). Novel approaches, using DEM derived slope and roughness information to automatically extract rock surfaces (e.g. Sappington et al., 2007; DiBiase et al., 2012) could not be adopted, since the $15 \mathrm{~m}$ DEM does not resolve the slope topography in sufficient detail (see Section 3.2.3 above). Similarly, an empirical approach, based on slope angle distributions (SAD) for rock surfaces and scree areas (Figure 3.13, see below), had to be dismissed, as the output did not achieve a satisfactory discrimination. As a result, rockwalls and marked outcrops were manually mapped in ArcGIS based on the orthophotograph mosaic and the georeferenced aerial photographs.

\section{Slope angle distribution approach for mapping rockwalls}

The empirical approach tested for rockwall delineation uses the value where slope angle distributions (SAD) of representative rockwall and scree areas intersect (Figure 3.13) to determine a $15 \mathrm{~m}$-DEM specific slope threshold for the automated extraction of steep rock surfaces in the study areas (cf. Loye et al., 2009). Based on the observation that pixels with gradients above $40^{\circ}$ are more likely to represent steep rock areas than scree areas, rock surfaces were extracted via raster calculation from a slope grid calculated in ArcMap. Isolated pixel smaller than $450 \mathrm{~m}^{2}$ and greater than one pixel length away from other rock pixels were removed.

Although this approach yielded acceptable results in catchments with distinctive rock cliffs, the classification was inadequate in debris-dominated catchments, where slopes are up to the ridges (even if only thinly) covered with debris or small rock outcrops can be found among significant debris accumulations. Misclassification around the $40^{\circ}$ slope threshold was common in these areas and corrections would have required extensive manual postprocessing. For this reason, automatic delineation was abandoned.

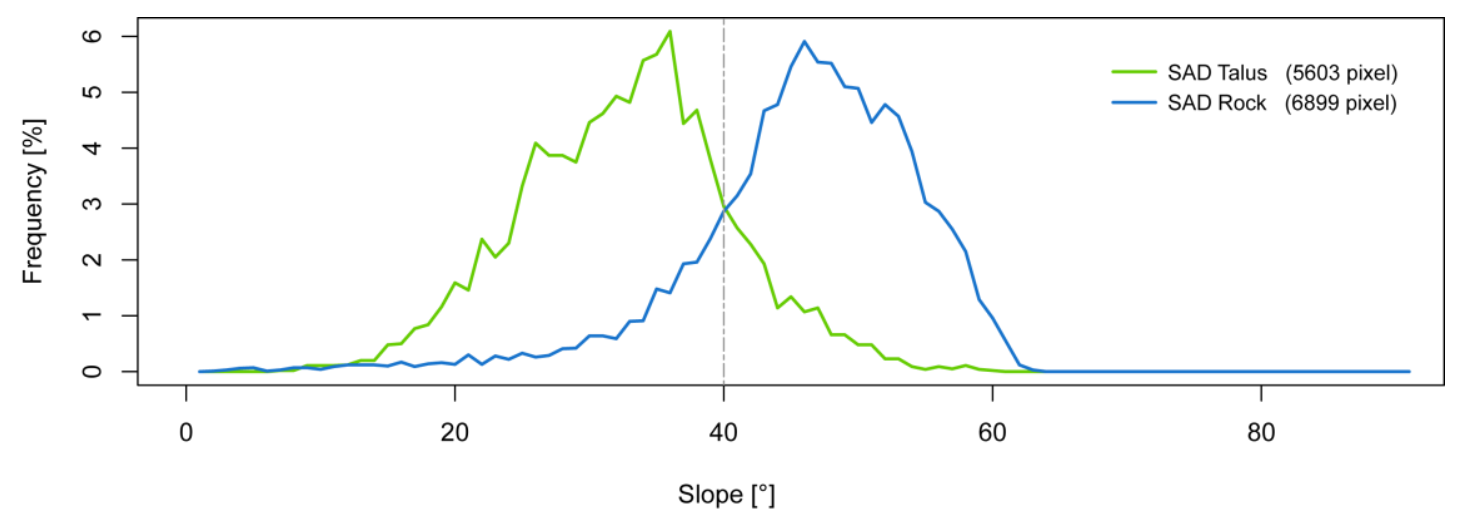

Figure 3.13

Slope angle distribution curves for selected talus and rock surface areas in Denas Creek, Camp Creek and the Kay Creek tributary. The dashed line marks the graphical crossing and thus the slope threshold chosen for the automated delineation of rock surfaces. 


\subsection{RESULTS}

In the following sections, process-related and topographic attributes of the compiled debris flow inventory (Section 3.3.1), mapped events (Section 3.3.2), and systems with multiple events during the investigation period (Section 3.3.3) are described. The general characterisations are based on data collocated in Table 3.3. Underlying data for the regional comparisons are given in Appendix 3 and Appendix 5. Morphometric information, such as elevation, slope, and aspect were derived from a $15 \mathrm{~m}$ DEM (Columbus et al., 2011a). The descriptions of the datasets are exclusively based on the frequency distribution of given attributes in the debris flow inventory. Observed patterns are normalised by the areal extent of attribute classes in Chapter 5. A table detailing the full debris flow inventory can be found in Electronic Appendix 1.

\subsubsection{General debris flow activity in study areas}

\section{General characteristics}

In total, 1534 debris flow systems were mapped in the thirteen study areas. The average debris flow density in the investigated areas is 23 initiation areas per $\mathrm{km}^{2}$.

The majority of the mapped debris flows were of the runoff-generated initiation type (79\%) and developed in locations with limited sediment supply conditions (94\%) (Table 3.3, column a; Figure $3.14 \mathrm{~A}-\mathrm{B})$. Only about a tenth of the assessed debris flows were of the 'slide-initiated' $(10 \%)$ or 'combined' type $(11 \%)$, respectively. These debris flow types also originated mainly in areas with limited sediment supply. Overall only $6 \%$ of the mapped debris flows initiated in abundant sediment reservoirs.

Debris flows occurred in the study areas at a wide range of elevations $(700 \mathrm{~m}-2300 \mathrm{~m})$ (Figure $3.14 \mathrm{C}$ ). Their overall distribution can be described as bell-shaped with more than half $(54 \%)$ of all debris flows emanating between 1200 and $1700 \mathrm{~m}$ a.s.l. Concerning relative altitudes, i.e. elevation above the lowest point of the individual catchments, debris flows were most common in the basins' mid-range (Figure $3.14 \mathrm{D}$ ). Almost half $(49 \%)$ of the mapped debris flows emanated between $300 \mathrm{~m}$ and $600 \mathrm{~m}$ above the catchment's exit. Debris flows occurred in the study areas in all aspect classes. However, more than a third $(39 \%)$ of the mapped debris flows originated on south or south-east facing slopes (Figure $3.14 \mathrm{E}$ ). Slope gradients in debris flow source areas also showed a bell-shaped distribution, ranging from $5^{\circ}$ to $60^{\circ}$ with a maximum occurrence between $35^{\circ}$ and $40^{\circ}$ (Figure 3.14 F). An analysis of variance (ANOVA) showed a statistically significant difference $(p=.01)$ in average slope angles between the debris flow types. The average inclination in initiation areas of runoff-generated debris flows $\left(37^{\circ}\right)$ is significantly higher than in the case of slide-initiated $\left(32^{\circ}\right)$ or combined type $\left(33^{\circ}\right)$ debris flows. 
Table 3.3 Percent frequency distribution of process-related and topographic parameters for the entire debris flow inventory (column a), the event inventory (column b-c), and the multiple event systems (column d). Categories for slope, altitude, and relative altitude include values $\geq X$ to $<\mathrm{Y}$ of the respective category.

\begin{tabular}{|c|c|c|c|c|}
\hline Parameter & \multirow{2}{*}{$\begin{array}{c}\text { DF systems } \\
a\end{array}$} & \multicolumn{2}{|c|}{ DF events } & \multirow{2}{*}{$\begin{array}{c}\begin{array}{c}\text { Multiple Event } \\
\text { Systems }\end{array} \\
d\end{array}$} \\
\hline & & $\begin{array}{c}b \\
\text { events } \\
\end{array}$ & $\begin{array}{c}c \\
\text { active } \\
\text { systems }\end{array}$ & \\
\hline DFsz N & 1534 & 240 & 219 & 18 \\
\hline A DF type & $\%$ & $\%$ & $\%$ & $\%$ \\
\hline $\begin{array}{l}\text { Slide-initiated } \\
\text { Runoff-generated } \\
\text { Combined }\end{array}$ & $\begin{array}{l}10 \\
79 \\
11\end{array}$ & $\begin{array}{l}15 \\
71 \\
13\end{array}$ & $\begin{array}{l}14 \\
74 \\
12\end{array}$ & $\begin{array}{l}33 \\
44 \\
22\end{array}$ \\
\hline B Sediment supp & & & & \\
\hline $\begin{array}{l}\text { Limited } \\
\text { Unlimited }\end{array}$ & $\begin{array}{c}94 \\
6\end{array}$ & $\begin{array}{l}87 \\
13\end{array}$ & $\begin{array}{l}90 \\
10\end{array}$ & $\begin{array}{l}56 \\
44\end{array}$ \\
\hline
\end{tabular}

C Altitude [m]

$500-600$

$600-700$

$700-800$

$800-900$

$900-1000$

$1000-1100$

$1100-1200$

$1200-1300$

$1300-1400$

$1400-1500$

$1500-1600$

$1600-1700$

$1700-1800$

$1800-1900$

$1900-2000$

$2000-2100$

$2100-2200$

$2200-2300$

$2300-2400$

$2400-2500$

\begin{tabular}{|cc|c|}
0 & 0 & 0 \\
0 & 0 & 0 \\
0 & 0 & 0 \\
3 & 3 & 6 \\
1 & 1 & 6 \\
7 & 6 & 17 \\
10 & 9 & 17 \\
18 & 17 & 33 \\
15 & 15 & 11 \\
10 & 11 & 0 \\
8 & 8 & 6 \\
8 & 8 & 6 \\
9 & 10 & 0 \\
6 & 6 & 0 \\
4 & 5 & 0 \\
2 & 2 & 0 \\
0 & 0 & 0 \\
0 & 0 & 0 \\
0 & 0 & 0 \\
0 & 0 & 0
\end{tabular}

D Relative Altitude [m] $0-100$

$100-200$

$200-300$

$300-400$

$400-500$

$500-600$

$600-700$

$700-800$

$800-900$

$900-1000$

$1000-1100$

$1100-1200$

$\mid$

$$
\begin{gathered}
0 \\
0 \\
0 \\
1 \\
3 \\
6 \\
9 \\
12 \\
12 \\
10 \\
9 \\
12 \\
9 \\
8 \\
6 \\
3 \\
1 \\
0 \\
0 \\
0
\end{gathered}
$$$$
\mid \begin{array}{r}
1 \\
13 \\
15 \\
18 \\
16 \\
11 \\
7
\end{array}
$$

\begin{tabular}{c|c}
1 & 1 \\
5 & 6 \\
13 & 10 \\
15 & 14 \\
18 & 19 \\
16 & 17 \\
11 & 13 \\
7 & 9 \\
7 & 5 \\
4 & 4 \\
2 & 1 \\
0 & 0
\end{tabular}

\begin{tabular}{cc|c}
1 & 1 & 0 \\
6 & 6 & 11 \\
10 & 8 & 22 \\
14 & 14 & 17 \\
19 & 19 & 17 \\
17 & 17 & 17 \\
13 & 13 & 11 \\
9 & 10 & 6 \\
5 & 6 & 0 \\
4 & 5 & 0 \\
1 & 1 & 0 \\
0 & 0 & 0
\end{tabular}

E Aspect

$\mathrm{N}$
$\mathrm{NE}$
$\mathrm{E}$
$\mathrm{SE}$
$\mathrm{S}$
$\mathrm{SW}$
$\mathrm{W}$
$\mathrm{NW}$

\begin{tabular}{c|c}
10 & 9 \\
11 & 10 \\
9 & 6 \\
19 & 23 \\
20 & 20 \\
9 & 6 \\
11 & 10 \\
12 & 16
\end{tabular}

\begin{tabular}{c|c}
9 & 11 \\
9 & 28 \\
6 & 6 \\
21 & 33 \\
22 & 0 \\
7 & 0 \\
11 & 6 \\
16 & 17
\end{tabular}




\begin{tabular}{|c|c|c|c|c|}
\hline F Slope $\left[^{\circ}\right]$ & & & & \\
\hline$<10$ & 0 & 0 & 0 & 0 \\
\hline $10-15$ & 0 & 0 & 0 & 0 \\
\hline $15-20$ & 1 & 0 & 0 & 0 \\
\hline $20-25$ & 3 & 5 & 5 & 11 \\
\hline $25-30$ & 9 & 9 & 9 & 11 \\
\hline $30-35$ & 26 & 24 & 24 & 28 \\
\hline $35-40$ & 35 & 37 & 37 & 33 \\
\hline $40-45$ & 18 & 16 & 17 & 6 \\
\hline $45-50$ & 5 & 5 & 5 & 6 \\
\hline $50-55$ & 1 & 3 & 3 & 6 \\
\hline $55-60$ & 0 & 0 & 0 & 0 \\
\hline$>60$ & 0 & 0 & 0 & 0 \\
\hline
\end{tabular}
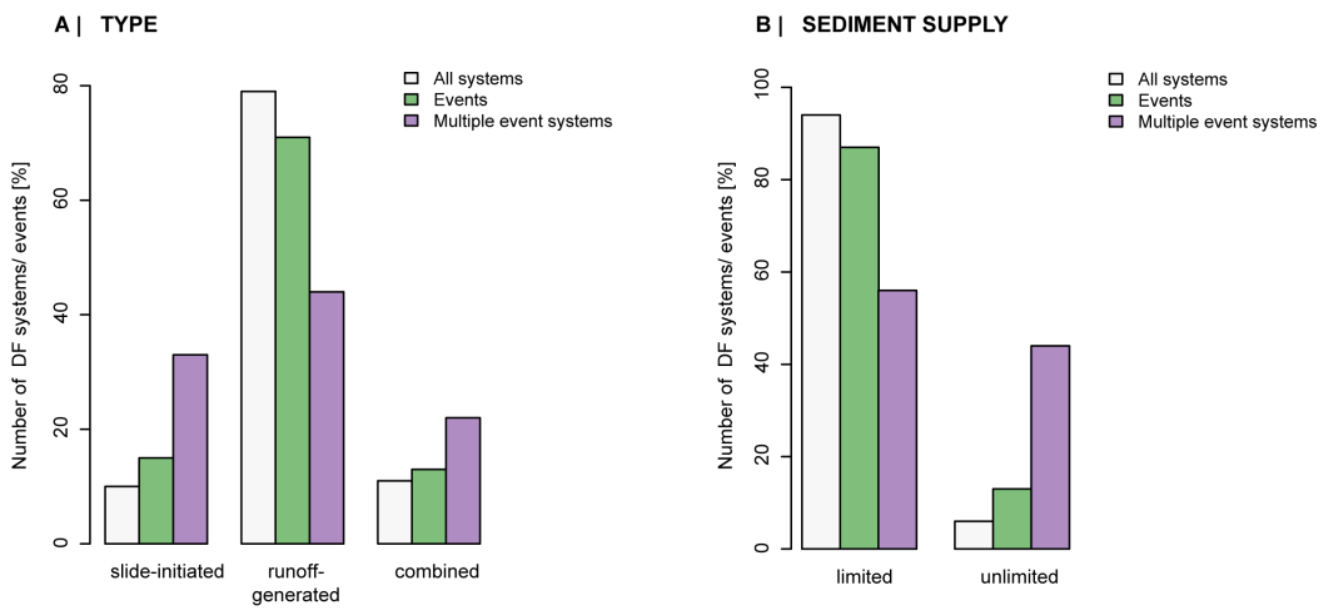

C| ALTITUDE (above sea level)

D| RELATIVE ALTITUDE (above catchment exit)
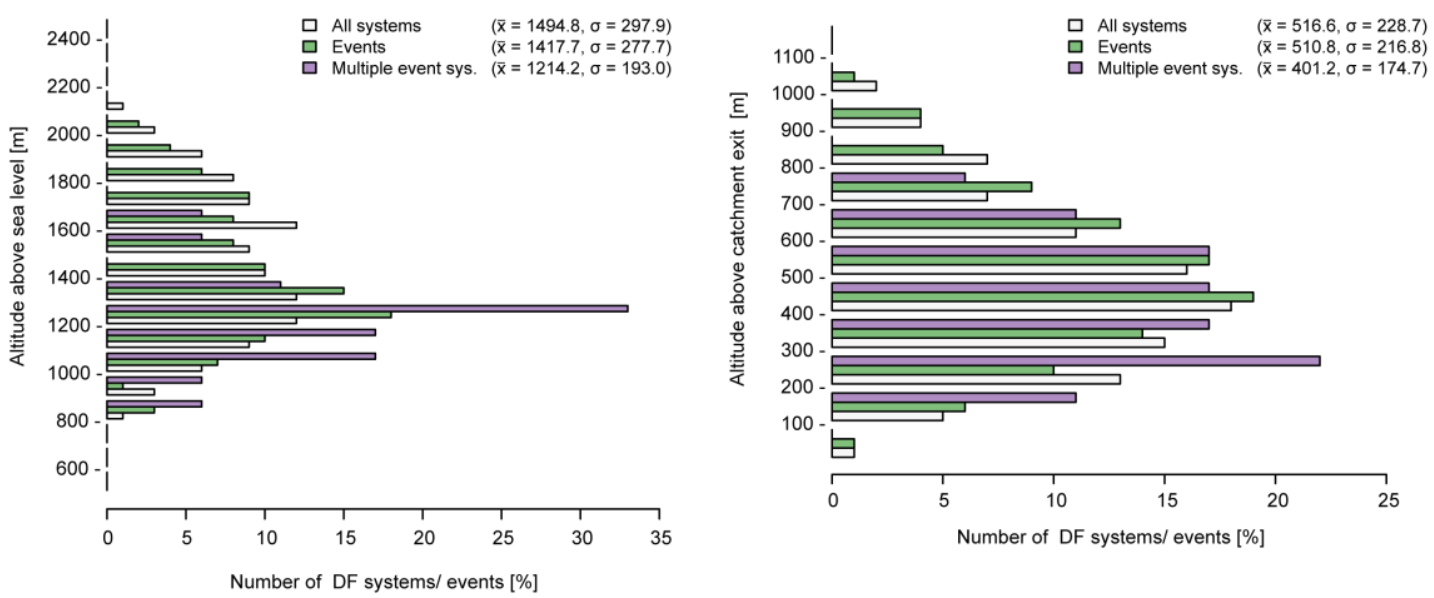

Figure 3.14

Graphical representation of percentage distribution data listed in Table 3.3 for the entire inventory (column a), event inventory (column b), and multiple event systems (column d).

- Figure continues on the next page - 

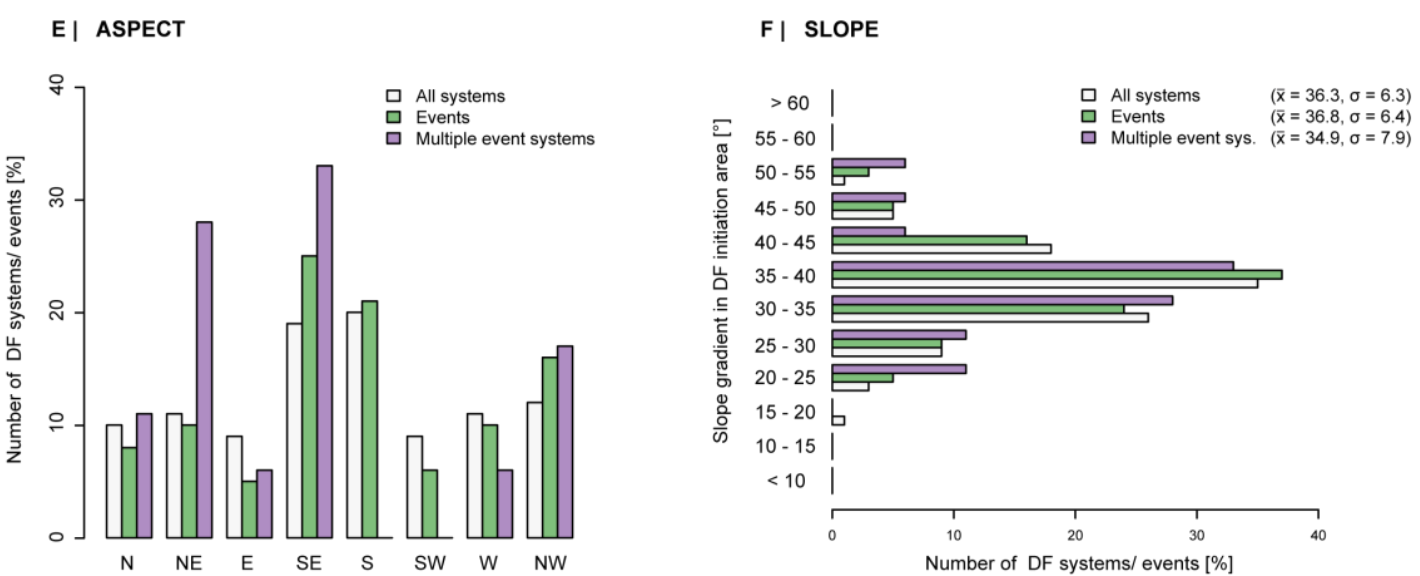

Figure 3.14 - Figure continued from previous page -

\section{Regional characteristics}

Debris flow densities varied significantly between the individual study areas (Figure 3.15). The lower Dart Stream valley (KR-LDS) and Middlehead Stream valley (KR-MHS), both in the Kaikoura ranges, showed relatively high density values (37 and 60 initiation zones per $\mathrm{km}^{2}$, respectively), raising the Kaikoura region's average debris flow density (36 DF km${ }^{-2}$ ) well above the overall mean. Other study areas with significantly above-average debris flow densities were the Camp Creek valley, Two Thumb Range (TT-CC; $42 \mathrm{DF} \mathrm{km}^{-2}$ ) and the Castle Hill - Foggy Stream valleys, Arthur's Pass region (AP-CHFS; $33 \mathrm{DF} \mathrm{km}^{-2}$ ). All other areas showed either close to or well below average densities. The lowest debris flow density

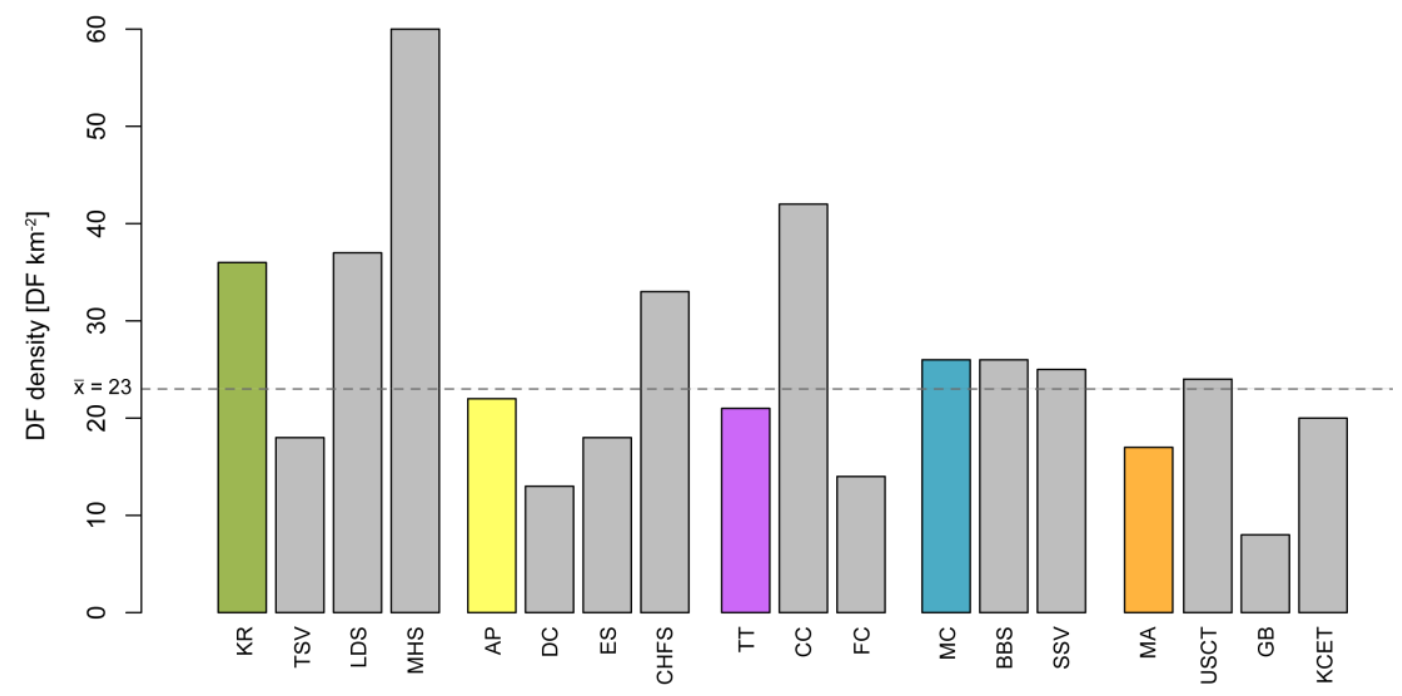

Figure 3.15

Debris flow density in the individual study areas as well as combined per region (coloured bars). The dashed line marks the overall mean debris flow density $(\bar{X})$ of 23 systems per $\mathrm{km}^{2}$. 
was observed in the Glacier Burn, Mt Aspiring region (MA-GB), where only eight initiation zones were mapped per $\mathrm{km}^{2}$.

Runoff-related sediment mobilisation was in all study areas the prevailing debris flow initiation type (Appendix 3.1). In the Trolove Stream valley, Inland Kaikoura Range (KR-TSV) and the Denas Creek, Arthur's Pass region (AP-DC), all debris flows seemed to have occurred in connection with concentrated overland flow. Marked numbers of slide-initiated debris flows were observed in areas in the Mt Cook region, the Mt Aspiring region, and the Kaikoura ranges. Debris flow systems where potentially both mechanisms might have led to event initiation were found in all areas except the Trolove Stream valley, Inland Kaikoura Range (KR-TSV), Denas Creek, Arthur's Pass region (AP-DC), and the Kay Creek tributary, Mt Aspiring region (MA-KCET).

Debris flows originating in unlimited sediment supply locations were observed in less than half of the investigated study areas (Appendix 3.2). They mainly occurred in the two Mt Cook study areas, in the Middlehead Stream valley, Seaward Kaikoura Range (KR-MHS), and the Kay Creek tributary, Mt Aspiring region (MA-KCET).

In terms of topographic attributes, the most striking differences between the individual study areas existed in the directional (Appendix 3.3) and the altitudinal (Appendix 3.5) distributions of recorded debris flow initiation zones. Both aspect and altitude are strongly pre-determined by the general topographic characteristics of the study areas. For example, observed variance in elevational ranges could to a large extent be explained by the general areal distribution in the individual study areas (Appendix 3.7). However, debris flow counts were not always proportional to the areal extent at a given altitude class (e.g. Black Birch Stream valley, Mt Cook region (MC-BBS), Kay Creek tributary, Mt Aspiring region (MA-KCET), Trolove Stream valley, Inland Kaikoura Range (KR-TSV)). This highlights the role of specific catchment characteristics in controlling the spatial distribution of debris flows. Since relative elevation is only a modification of absolute altitude, the regional variation in elevation above the local base level reflects the general altitudinal pattern above sea level (Appendix 3.6). However, the normalisation according to catchments' exit altitudes showed that while in most catchments debris flow initiation areas were most frequent in medium to lower reaches, the Glacier Burn valley, Mt Aspiring region (MA-GB), the Kay Creek tributary, Mt Aspiring region (MA-KCET), and the Trolove Stream valley, Inland Kaikoura Range (KR-TSV) showed also significant proportions in the catchments' higher areas. No marked variation existed between the study areas as to the most common slope angles in the debris flow initiation areas (Appendix 3.4). In almost all catchments, the majority of debris flows originated at slopes between $30^{\circ}$ to $40^{\circ}$, and hence close to the angle of repose. Glacier Burn, Mt Aspiring region (MA-GB), Upper Stony Creek, Mt Aspiring region (MA-USCT), and Denas Creek, Arthur's Pass region (AP-DC) had their maximum frequency in steeper gradient classes, whereas the Black Birch Stream, Mt Cook region (MC-BBS) showed a particularly wide range of slope angles in the recorded debris flow areas. 


\subsubsection{Event catalogue}

The multi-temporal analysis of historical aerial photographs of the study areas revealed 240 debris flow events. Overall, signs of activity, i.e. one or more recorded events, were observed in 219 of the investigated debris flow systems.

The following subsections focus on the general characteristics and regional distribution of the individual events $(N=240)$, i.e. they describe event characteristics irrespective of the number of events recorded in the corresponding debris flow system. Proportions are thus to some extent biased by debris flow systems with multiple events, as their characteristics were counted multiple times. Characteristics of multiple event systems are described in Section 3.3.3.

\section{General characteristics of identified events}

The majority of the recorded events occurred in either the 1980 s $(25 \%)$ or 1990 s $(33 \%)$ (Figure 3.16). Comparatively few events were identified in the 1970s (8\%). However, such a generalised side-by-side comparison is misleading due to the bias of the overall inventory by the gaps in the aerial photo coverage as well as spatially and temporally varying image quality (cf. Section 3.2.2).

Mapped events occurred predominantly $(71 \%)$ in debris flow systems of the runoffgenerated initiation type (Table 3.3, column b; Figure $3.14 \mathrm{~A}$ ), followed by slide-initiated systems (15\%) and the combined type (13\%). In terms of sediment supply, events originated generally in locations with limited sediment resources (87\%) (Figure $3.14 \mathrm{~B}$ ).

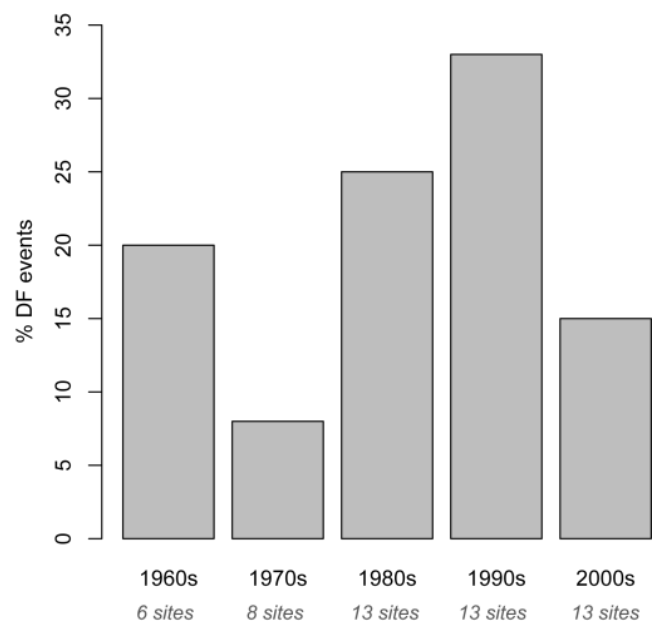

Figure 3.16

Time of occurrence of observed debris flow events. Grey text indicates number of study areas with aerial photograph coverage for the respective time period (cf. Figure 3.9). 
Debris flows events occurred within a wide range of altitudes $(800 m-2100 m$, Figure $3.14 \mathrm{C}$ ). However, events were especially frequent between $1200 \mathrm{~m}$ and $1400 \mathrm{~m}$. Half of the identified events occurred between $300 \mathrm{~m}$ and $500 \mathrm{~m}$ above the lowest point of the respective catchments (Figure $3.14 \mathrm{D}$ ). In terms of orientation, almost half of the identified events occurred on southeast (23\%) or south (20\%) facing slopes (Figure $3.14 \mathrm{E}$ ). Low numbers of events were recorded in eastern and south-western aspects (both 6\%). In terms of slope gradients, recorded events originated predominantly $(61 \%)$ at gradients close to the angle of repose (Figure 3.14 F).

\section{Regional distribution of identified events}

Debris flow events were identified in all but one study area during the investigation period. In Denas Creek, Arthur's Pass region (AP-DC), no indications were found for debris flow occurrences. The area is therefore excluded from the following characterisations.

In terms of absolute numbers, comparatively high activity ( $>25$ events) was observed in the Enys Stream valley (AP-ES) and the Castle Hill - Foggy Stream valleys (AP-CHFS) in the Arthur's Pass region, in the Camp Creek, Two Thumb Range (TT-CC), Black Birch Stream valley, Mt Cook region (MC-BBS), and in the Kay Creek tributary, Mt Aspiring region (MA-KCET) (Figure 3.17). Almost two thirds (63\%) of the mapped events were located in these five study areas.

In order to enable the comparison of debris flow activity between the study areas and thus between different topographic environments, activity levels were calculated as proportions of the overall number of debris flow systems mapped in the respective area. Activity levels varied between study areas (Figure 3.18) with no clear regional trend

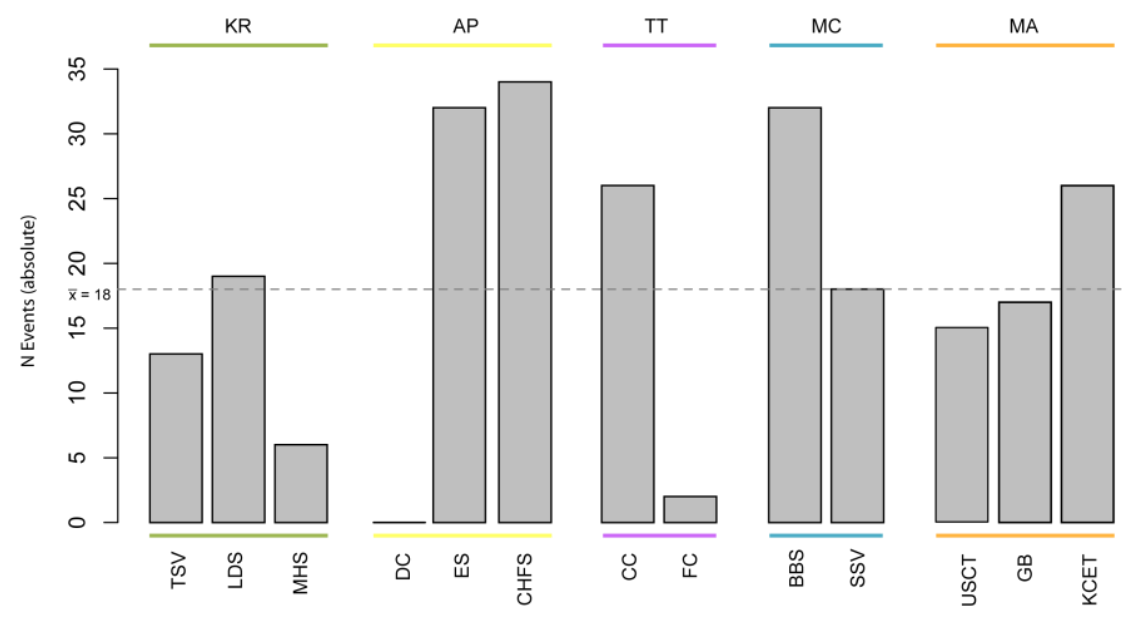

Figure 3.17

Absolute number of events mapped in the individual study areas. The dashed line marks the overall mean $(\overline{\mathbf{X}})$ of 18 identified events per study area. 


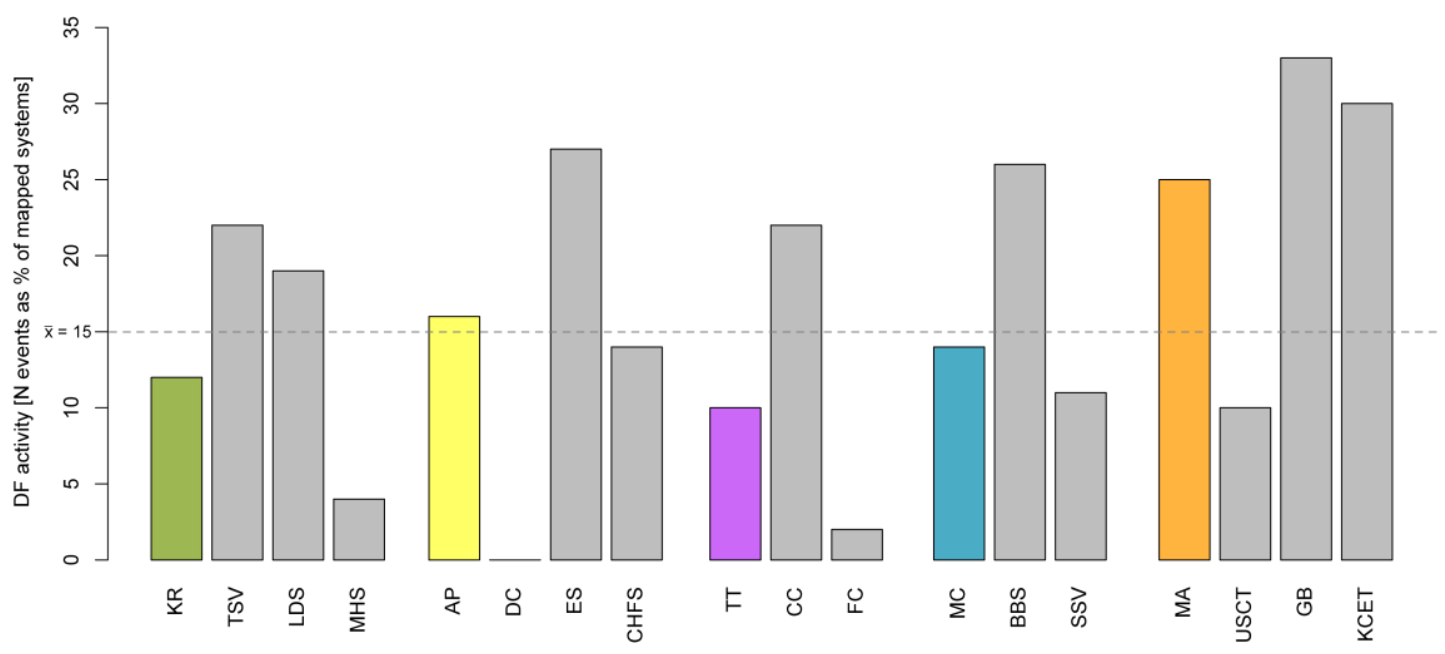

Figure 3.18

Debris flow activity in the study areas and regions calculated as proportion of mapped debris flow systems showing activity during the investigation period. The occurrence of multiple events in a single system is not considered. The dashed line marks the overall mean $(\bar{X})$ of $15 \%$ active debris flow systems per study area.

observable. All regions showed areas with relatively high as well as markedly low numbers of debris flow events. However, most events in relation to the general numbers of debris flow systems mapped in the respective study areas were observed in the adjacent areas Glacier Burn valley (MA-GB) and Kay Creek tributary (MA-KCET) in the Mt Aspiring region. Similarly, the two bordering catchments Trolove Stream (KR-TSV) and lower Dart Stream (KR-LDS) in the Inland Kaikoura Range showed both high activity levels. Comparatively low counts of events despite relative high numbers of mapped debris flow systems were observed in the Middlehead Stream valley, Seaward Kaikoura range (KR-MHS) and the Castle Hill - Foggy Stream valleys, Arthur's Pass region (AP-CHFS).

Similarities in intraregional activity levels emerged when the number of mapped events was considered in the context of time and study area size (Figure 3.19). All study areas in the Arthur's Pass region and Mt Cook region, respectively, displayed similarly low event frequencies $\left(\% \mathrm{a}^{-1} \mathrm{~km}^{-2}\right.$, i.e. percent active debris flow systems per year per square kilometre study area) over the course of the investigation period. Marked differences in the proportional numbers of active debris flow systems in these regions (Figure 3.18) hence appear to be rather the cumulative effect of slight deviations in activity levels than the presence of significant intraregional variations through time. Conversely, activity levels in most of the study areas of the Kaikoura ranges, Two Thumb Range, and Mt Aspiring region study areas fluctuated significantly through time and were generally higher than in the Arthur's Pass and Mt Cook region. Exceptionally high frequency values were observed in the Kay Creek tributary, Mt Aspiring region (MA-KCET) in $1998\left(0.48 \% \mathrm{a}^{-1} \mathrm{~km}^{-2}\right)$ and Trolove Stream valley, Inland Kaikoura Range (KR-TSV) in $1985\left(0.45 \% \mathrm{a}^{-1} \mathrm{~km}^{-2}\right)$. The timing of the Kay Creek maximum corresponded with the maximum activity levels in the lower Dart Stream valley, Inland Kaikoura Range (KR-LDS), the Camp Creek, Two Thumb Range 

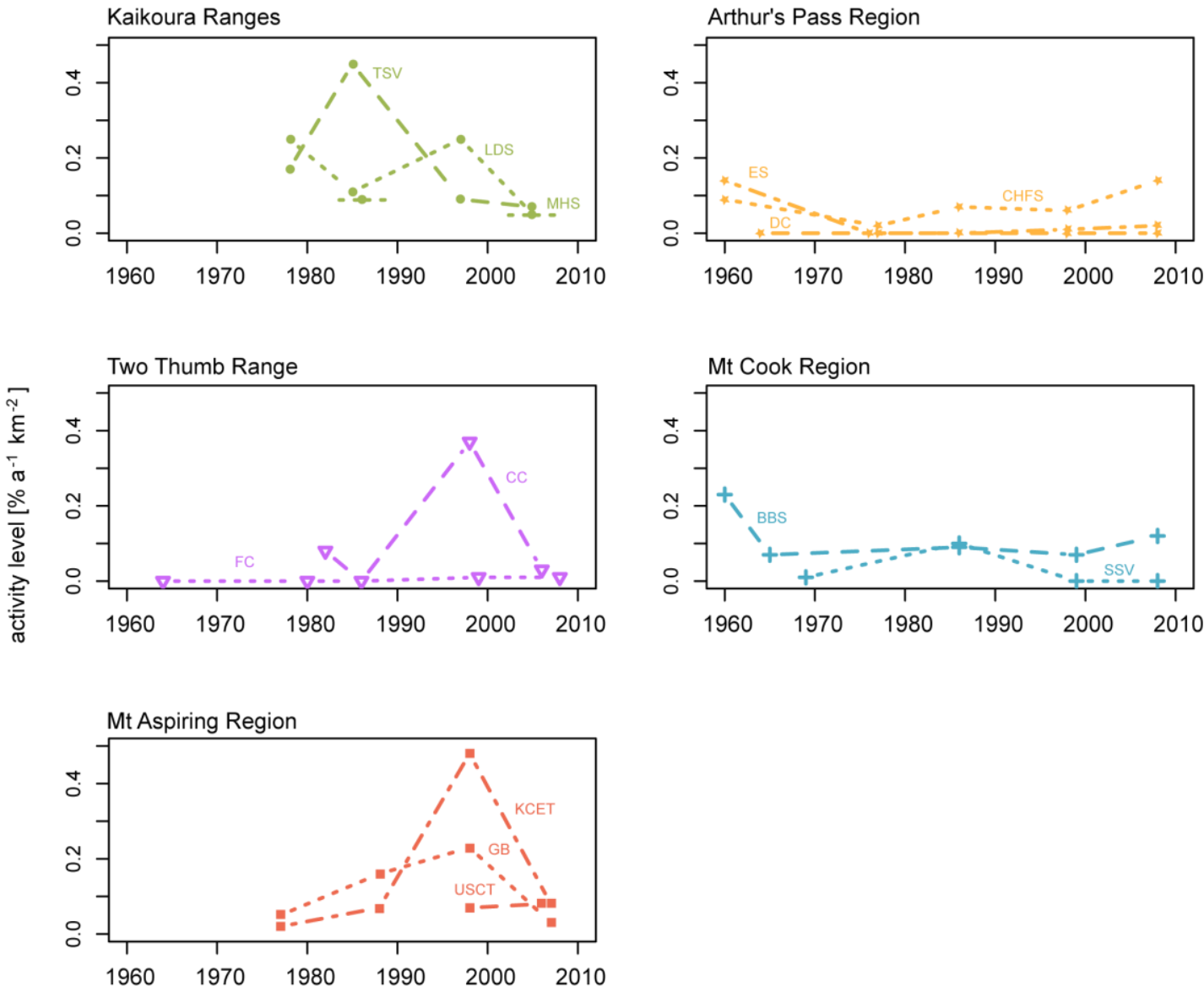

Figure 3.19

Debris flow activity levels in the study areas through time. Activity levels are normalised by year and catchment area to allow the comparison of the individual sites. Underlying data is listed in Appendix 4.

(TT-CC), and the Glacier Burn valley, Mt Aspiring region (MA-GB). Interestingly, the neighbouring catchments Kay Creek and Glacier Burn in the Mt Aspiring region had both their highest activity levels in 1998, whereas the adjacent catchments Trolove Stream (KR-TSV) and lower Dart Stream (KR-LDS) in the Inland Kaikoura Range showed asynchronous development of activity levels through time.

\section{Regional characteristics of identified events}

In almost all study areas, mapped debris flow events were predominantly instigated by concentrated runoff (Appendix 5.1). Only in the Forest Creek, Two Thumb Range (TT-FC), an equal proportion of events occurred in systems of the combined and mobilised initiation type. However, since this proportion is based on just two events, this exception can be ignored. Forest Creek is hence omitted from the following characterisation.

The prevalence of runoff-generated debris flow events is less pronounced in areas in the Mt Aspiring region, where significant proportions of events were slide-initiated. Interestingly, 
nine out of the twelve new slide instabilities that were identified during the investigation period occurred in this region. Marked numbers of slide-initiated debris flows were also observed in both catchments in the Mt Cook region as well as in the lower Dart Stream valley, Inland Kaikoura Range (KR-LDS). Events where both runoff and flank instabilities might have led to debris flow occurrence were found in all areas except the Trolove Stream valley, Inland Kaikoura Range (KR-TSV) and the Kay Creek tributary, Mt Aspiring region (MA-KCET). In the Enys Stream valley, Arthur's Pass region (AP-ES), combined-type events were almost as frequent as runoff-generated debris flow events.

In all study areas, the majority of mapped events emanated from locations with limited sediment availability (Appendix 5.2). Events initiated in unlimited sediment supply conditions occurred in six of the analysed study areas. In the Black Birch Stream valley, Mt Cook region (MC-BBS), close to half of the identified events occurred in locations where sediment availability appeared abundant. Also in the Kay Creek tributary, Mt Aspiring region (MA-KCET) more than a third of the mapped events occurred in unlimited sediment supply conditions.

The most obvious differences between the individual study areas exist again in the aspect (Appendix 5.3) and elevation (Appendix 5.5) of the mapped event initiation zones, which are both influenced by the catchments' topographic characteristics. Dissimilarities are also evident in the relative elevation of initiation zones above lowest point in the catchments. In the Enys Stream valley, Arthur's Pass region (AP-ES), Camp Creek, Two Thumb Range (TT-CC), and the Black Birch Stream valley, Mt Cook region (MC-BBS) mapped events occurred mainly in lower reaches of the respective catchment. In lower Dart Stream valley, Inland Kaikoura Range (KR-LDS), Castle Hill - Foggy Stream valleys, Arthur's Pass region (AP-CHFS), and the Stony Stream valley, Mt Cook region (MC-SSV) observed events commonly emanated in mid-altitudes, whereas in the Glacier Burn valley, Mt Aspiring region (MA-GB), and the Kay Creek tributary, Mt Aspiring region (MA-KCET) mapped debris flows originated mainly in higher catchment areas. No altitudinal trend in initiation areas was observed in the Trolove Stream valley, Inland Kaikoura Range (KR-TSV), Middlehead Stream valley, Seaward Kaikoura Range (KR-MHS) and the Upper Stony Creek tributary, Mt Aspiring region (MA-USCT). However, relatively low numbers of events were identified in these areas during the investigation period (cf. Figure 3.17), and the high local variability, therefore, likely due to the small event population. Slope gradients in the event initiation areas vary little between the study areas (Appendix 5.4). In almost all areas, identified events occurred most frequently between $30^{\circ}$ and $40^{\circ}$. Only in the Upper Stony Creek tributary (MA-USCT) and Glacier Burn valley in the Mt Aspiring Region, events occurred predominately in steeper slope classes. In both Mt Cook areas, a marked proportion of events $(>10 \%)$ also occurred at less inclined locations. 


\subsubsection{Multiple event systems}

\section{General characteristics of multiple event systems}

Eighteen debris flow systems showed more than one episode of activity during the investigation period (Table 3.3, column d). For 15 systems, two events were identified. The remaining three systems, all located in the Enys Stream valley, Arthur's Pass region (AP-ES), experienced three events during the investigation period. Given the small number of three-event systems and their close proximity to each other $(<300 \mathrm{~m})$, differences between two and three-event systems were not further analysed.

More than half of the multiple event systems were either of the slide-initiation type (33\%) or systems where slides or slips might have affected debris flow initiation (22\%) (Figure $3.14 \mathrm{~A}$ ). Almost half of the multiple event systems (44\%) were mapped as originating in locations with unlimited sediment supply (Figure 3.14 B).

The multiple event systems were located between $800 \mathrm{~m}$ and $1700 \mathrm{~m}$ altitude and were most common (33\%) between $1200 \mathrm{~m}$ and $1300 \mathrm{~m}$ a.s.I. (Figure $3.14 \mathrm{C}$ ). In terms of relative elevation, debris flow systems with multiple events occurred mainly in the lower to middle reaches of the catchments $(200-600 \mathrm{~m}$ ) (Figure 3.14 D). Multiple event systems are most frequent $(33 \%)$ on south-east facing slopes and are also numerous in north-west to northeast orientations (Figure $3.14 \mathrm{E}$ ). Almost two thirds (61\%) of the multiple event systems occurred in locations with slope gradients between $30^{\circ}$ and $40^{\circ}$ (Figure $3.14 \mathrm{~F}$ ).

\section{Regional distribution of multiple event systems}

Multiple event systems occur only in 7 of the 13 study areas (Figure 3.20). They are most frequent in the Enys Stream valley, Arthur's Pass region (AP-ES) (5) and the Black Birch Stream valley, Mt Cook region (MC-BBS) (5), but also the Glacier Burn valley (MA-GB) (2) and the Kay Creek tributary (MA-KCET) (3) show several systems with reoccurring events. Three-event systems were only found in the Enys Stream valley, Arthur's Pass region (AP-ES). No regional pattern was observed in debris flow type and supply conditions.

In three multiple event systems, the earliest mapped event was a new slide-instability in the respective location (Figure 3.20, denoted by ' $N$ '). In all these debris flow systems, reactivation occurred within the subsequent investigation period, i.e. signs of activity were visible in the next aerial photograph. In two of the three locations, the initial and subsequent events occurred in unlimited sediment-supply conditions. In Glacier Burn valley, Mt Aspiring region (MA-GB), the initial event was probably instigated by a shallow landslide which removed the soil layer. The subsequent event thus occurred in limited supply conditions by lateral enlargement of the erosion scar. 


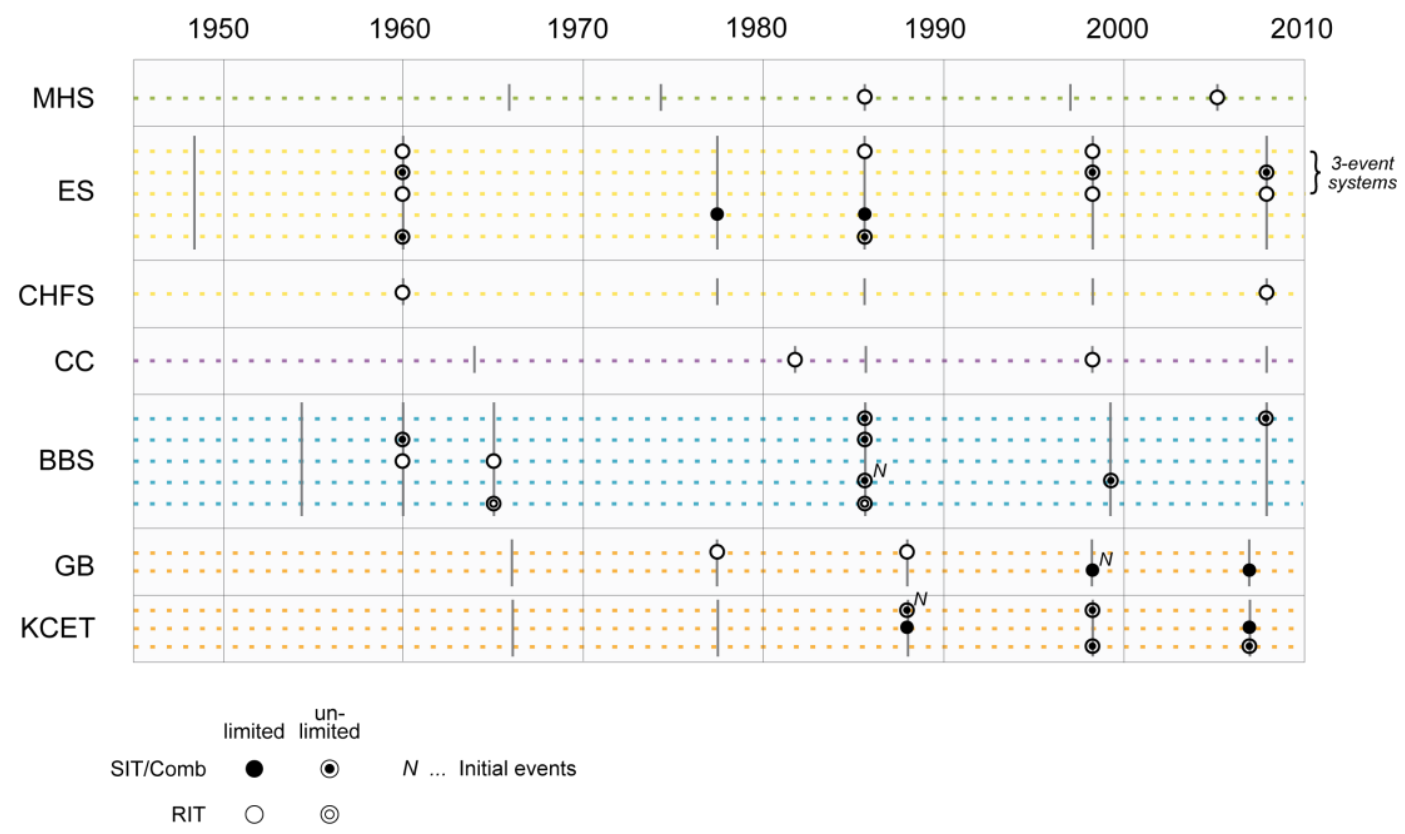

Figure 3.20

Time of occurrence (= time of documentation) of debris flow events in multiple event systems according to study areas. Vertical bars symbolise years of aerial photograph coverage; the colouring signifies the study region (cf. Table 3.1). The first bar in each area marks the year of the oldest image, which was used for comparison and hence has no events associated. Debris flow systems are represented according to debris flow type (SIT ... slide-initiated, Comb ... combined, and RIT ... runoff-generated) and sediment supply conditions (limited, unlimited).

The low number of multiple event systems identified in the study areas $(8 \%$ of active systems) and the short investigation period does not allow for a sensible calculation of recurrence intervals for the different debris flow types. However, average time intervals between events (Table 3.4) indicate shorter reactivation intervals in slide-initiated (SIT) or slide-related (Comb) systems than in systems where events are purely runoff-generated (RIT).

Table 3.4 Average reactivation intervals in multiple event systems according to system type and sediment supply (SS).

\begin{tabular}{lcc}
\hline Debris flow class & $\begin{array}{c}\text { Mean } \\
\text { time interval [a] }\end{array}$ & $\begin{array}{c}\text { Mean } \\
\text { per type [a] }\end{array}$ \\
\hline SIT/ Comb - limited SS & 13 & 16 \\
SIT/ Comb - unlimited SS & 19 & \\
RIT - limited SS & 20.5 & 21 \\
RIT - unlimited SS & $21^{*}$ & \\
\hline
\end{tabular}

* Based on a single observation.

Overall, the identified events in the multiple event systems are temporally clustered within the respective regions. This effect is partly due to the small number of time steps analysed in the individual study areas. However, especially in Enys Stream, Arthur's Pass region 
(AP-ES), the absence of activity in multiple event systems despite image coverage as well as the reactivation pattern in the 3-event systems (interval between first and second event were longer than between second and third event) suggests the presence of temporal patterns in debris flow activity.

\subsubsection{Debris flow contribution areas}

The semi-automatic mapping approach enabled the delineation of the sediment contribution areas for 404 debris flow systems. This equates to a third of the mapped runoffgenerated debris flow systems. For many of the small systems underneath rock outcrops, the upslope sediment contributing areas could not be determined.

Comparatively high numbers contribution areas were mapped in the Mt Aspiring region and the Kaikoura ranges, where the steep and dissected relief facilitated the delineation process (Table 3.5). The mean altitude for contribution areas in the Two Thumb Range is close to the $2000 \mathrm{~m}$ a.s.l., suggesting that a significant number of areas might extend into the periglacial zone.

Table 3.5 Topographic characteristics of mapped debris flow contribution areas according to study regions.

\begin{tabular}{|c|c|c|c|c|c|c|c|}
\hline \multirow[b]{2}{*}{ Study region } & \multirow[b]{2}{*}{$N$} & \multirow{2}{*}{$\begin{array}{c}\text { Mean } \\
\text { area [ha] }\end{array}$} & \multicolumn{4}{|c|}{ Elevation $[\mathrm{m}]^{1}$} & \multirow{2}{*}{$\frac{\text { Slope }\left[{ }^{\circ}\right]}{\text { mean } \mid \sigma}$} \\
\hline & & & $\min$ & $\max$ & mean $\mid \sigma$ & av. range & \\
\hline Kaikoura Ranges & 95 & 1.03 & 1056 & 2238 & $1591 \mid 32$ & 119 & $37 \mid 4$ \\
\hline Arthur's Pass Region & 63 & 0.67 & 925 & 2318 & $1496 \mid 29$ & 103 & $41 \mid 6$ \\
\hline Two Thumb Range & 32 & 0.73 & 1559 & 2258 & $1993 \mid 29$ & 107 & $41 \mid 5$ \\
\hline Mt Cook Region & 61 & 0.99 & 920 & 2385 & $1614 \mid 29$ & 107 & $41 \mid 6$ \\
\hline Mt Aspiring Region & 153 & 0.64 & 983 & 2132 & $1490 \mid 37$ & 130 & $44 \mid 5$ \\
\hline
\end{tabular}

${ }^{1}$ derived from $15 \mathrm{~m}$ DEM (Columbus et al., 2011a) 


\subsection{DISCUSSION}

In this section, debris flow activity in the Southern Alps is evaluated by comparing mapped debris flow densities in the study areas to international datasets (Section 3.4.1). Furthermore, the unexpectedly large discrepancy between numbers of mapped debris flow systems and identified events is reviewed. In Section 3.4.2, debris flow activity levels are examined separately for each debris flow type.

\subsubsection{Debris flow activity in the Southern Alps}

Debris flows are common in the Southern Alps and remnants of past events are abundant in both the lower hill areas and high-alpine catchments. Comparison of the mean debris flow density in the study areas (24 DF systems $/ \mathrm{km}^{2}$ ) to inventories from other mountain ranges is difficult since datasets differ in terms of landforms mapped, geologic settings, or the scale of mapping. European examples range from 56 systems $/ \mathrm{km}^{2}$ in the South Tyrolean Alps (schistose gneiss; Sattler, 2008), to 24 systems $/ \mathrm{km}^{2}$ in the Italian Dolomites (mixed lithology; Carrara et al., 2008), 13 systems $/ \mathrm{km}^{2}$ in the French Alps (sedimentary rock, Van Steijn, 1996), and 4 systems $/ \mathrm{km}^{2}$ in the Austrian Alps (mixed lithology; Rieger, 1999). However, given the Southern Alps' presumably favourable environmental conditions for debris flow occurrence, such as steep topography, high denudation rates, and relatively frequent high-intensity rainfall events (cf. Chapter 2), the observed debris flow density is likely high by global standards.

Given the considerable number of debris flow systems mapped in the study areas $(\mathrm{N}=1534)$, the number of events identified during the analysed six decades was surprisingly low $(\mathrm{N}=240)$. During the investigation period, only $14 \%$ of the debris flow systems showed signs of activity. These figures likely underestimate the real number of events during the investigation period due to methodological constraints (poor visibility into channelised debris flow tracks, long intervals between aerial photographs) or the lack of early or high-quality imagery in some regions (cf. Section 3.2.2). However, strongly channelised systems, where significant events might have gone unnoticed, were comparatively rare. The total of events potentially omitted due to poor visibility into debris flow tracks is therefore likely low. How many events, on the other hand, went unrecorded in the Kaikoura ranges, the Mt Aspiring region, and the Camp Creek valley due to the lack or insufficient quality of early aerial photographs is unknown. Given the high activity levels identified in these regions during the documented period, it is likely that several events occurred in these areas in the 1950s and early 1960s. The actual overall percentage of active systems in the study areas during the last six decades is, therefore, probably slightly higher than the documented $14 \%$. Omitted events in the Kaikoura ranges, the Mt Aspiring region, and the Camp Creek valley would 
further emphasise the differences in debris flow activity observed between the study regions. Conspicuously low activity levels in the Mt Cook region, Arthur's Pass region, and southern Two Thumb Range would, however, remain.

The general discrepancy between mapped debris flow densities and observed activity levels may be attributed to debris flow recurrence intervals exceeding the present study's investigation period. Van Steijn's (1996) demonstrated that even for geomorphologically simple debris flow systems return periods often exceed several decades. In the present study, the average time interval between reactivations in multiple event systems gives a basic indication for the time scales involved (Table 3.4). Assuming that the mapped multiple event systems represent the most active systems in the study areas, mean reactivation periods can be interpreted as minimum estimates of the average recurrence intervals. Debris flow events occurred in these 'highly active' systems on average 16 years (SIT/COMB) or 21 years (RIT) apart. It is hence reasonable to assume that reactivations in systems with longer recurrence intervals were not captured in this study's investigation period of five to six decades (depending on the study area).

\subsubsection{Debris flow activity according to debris flow type}

Slide-initiated (SIT) and slide-related (COMB) debris flow systems showed shorter average recurrence intervals than runoff-generated systems (RIT) (cf. above). This suggests that slide-initiated and slide-related debris flow systems are more active than runoffgenerated systems. The same was also indicated by the event frequency distribution according to debris flow type (Figure 3.14 A) with debris flow events in SIT and COMB being slightly more frequent than the representation of these two debris flow types in the overall inventory suggested.

Empirical probabilities allow the ranking of debris flow types according to their likelihood of producing one or several debris flow events during the investigation period (Table 3.6). Results support the higher susceptibility of slide-initiated and slide-related systems for debris flow formation indicated above. Debris flow activity (at least one event) was most likely during the investigation period in slide-initiated systems $(P=.201)$, followed by systems where both mechanisms might have led to debris flow initiation (COMB, $P=.165$ ). The same ranking applied for the likely occurrence of multiple events. However, differences between the probabilities were more significant in this category with multiple events being close to twice as likely in slide-initiated systems $(P=.039)$ compared to slide-related systems $(P=.024)$.

Slides, slips, and slumps occur as a consequence of a local strength disequilibrium within the regolith body, aiming at re-establishing the balance between movement promoting and movement resisting forces (cf. Carson and Kirby, 1972; Selby, 1993). While adjustment is to 
some extent achieved after the initial failure, the creation of steep backscarps often leads to subsequent secondary mass-wasting and a progressive enlargement of the original detachment area (cf. Pierson, 1980b; Crozier and Preston, 1999; Crozier, 2010). Hence the recurrence of slide-initiated debris flows within comparatively short time intervals is likely, as was observed in the present inventory in the case of the new slide instabilities which all experienced reactivation within the subsequent investigation period (cf. Figure 3.20). In contrast, runoff-generated debris flows are not the result of slope stability adjustment but represent the clearance of readily-mobilised regolith. Debris storages are commonly depleted in the course of an event. The time until reactivation therefore largely depends on the rate of reaccumulation of debris in the initiation area. As storages are generally replenished by rockfall or in-situ weathering, reaccumulation is generally slow. The low number of runoff-generated systems with multiple reactivations during the investigation period suggests that in the time span necessary for debris recharge in runoff-generated debris flow systems generally exceeds a few decades in the Southern Alps.

The comparatively high likelihood of events in slide-related debris flow systems (COMB, $\mathrm{P}=.165$ activity, $\mathrm{P}=.024$ multiple events) may stem from the possibility of either landslides or excessive storm runoff triggering debris flow events. Additionally, intermittent sediment delivery to the system by non-triggering gully flank instabilities may increase the potential for runoff-generated debris flow formation. However, interpretations of activity in combined-type systems have to be treated with reservation. The attribution of slide-related debris flow systems (COMB) was primarily based on their geomorphic characteristics fitting neither end member group of slide-initiated or runoff-generated debris flows. More in-depth site studies would be required to verify that indeed both initiation mechanism occur in the respective systems or that flank instabilities actually contribute material to these system.

The observed differences in activity levels between debris flow types affirm the need for differentiating debris flow initiation mechanisms in the analysis of debris flow inventories. In principle, debris flow formation in slide-initiated and runoff-generated debris flow systems is governed by different factors. Slide-initiated and runoff-generated debris flows, therefore, should be interpreted as different geomorphic processes.

Table 3.6 Likelihood of events occurring during the investigation period according to debris flow types (SIT ... slide-initiated, COMB ... combined, and RIT ... runoff-generated).

Probability of event occurring if ...

SIT $\quad .201$

RIT $\quad .132$

COMB $\quad .165$
Probability of multiple events occurring if ...

$\begin{array}{llr}\text { SIT } & .039 & \text { (6 systems/ } 154 \text { total) } \\ \text { RIT } & .007 & \text { (8 systems } 1216 \text { total) } \\ \text { COMB } & .024 & \text { (4 systems/ 164 total) }\end{array}$




\subsection{SUMMARY}

Debris flows are rapid mass movements, intermediate between landslides and sedimentladen water floods. They are characterised by a viscoelastic non-Newtonian flow behaviour, which leads to the creation of distinctive depositional landforms (levées and boulder trains) that are recognisable in remotely sensed imagery. The initiation of debris flows is the result of a complex interaction of various hydrological, geological, and topographical parameters. Slope and sediment availability are main prerequisites for debris flow development. Frostweathering activity, lithology, permafrost, and vegetation cover can influence the availability of regolith or the stability of debris accumulations and thus precondition debris flow activity.

For the statistical evaluation of debris flow preconditioning factors in the Southern Alps, 1534 debris flow systems were mapped by aerial photo interpretation in thirteen, mostly high-altitude study areas along the Southern Alps. For 404 debris flow systems, the regolith contributing area was mapped by semi-automatic catchment delineation. Visual comparison of historic aerial photographs, spanning six decades, identified 240 debris flow events in 219 systems. The established debris flow inventory represents the core data of this research. Environmental conditions at the initiation areas or within the regolith contributing areas of both active and inactive debris flow systems are statistically evaluated in Chapter 5 to identify factors promoting debris flow formation.

The number of debris flow events identified during the last six decades was unexpectedly low, considering the large number of debris flow systems mapped in the study areas. Analysis of recurrence intervals in debris flow systems with multiple events during the investigation period shows that the average return period in these particularly active systems is 16 to 21 years. Consequently, a possible reason for the low activity identified for the mapped debris flow systems is that recurrence intervals in the Southern Alps are generally longer than reactivations being captured during the investigation period. 


\section{4| AN ESTIMATE OF ALPINE PERMAFROST DISTRIBUTION IN THE SOUTHERN ALPS}

Investigating the effect of permafrost on debris flow activity requires information on the potential extent of present-day permafrost in high-alpine areas. This chapter documents the development of a regional permafrost distribution estimate for the Southern Alps based on the statistical evaluation of a rock glacier inventory for the Canterbury Region.

Section 4.1 provides background information on alpine permafrost and on characteristics of its spatial distribution with a focus on debris environments (as opposed to bedrock). The section further introduces surficial permafrost indicators (such as rock glaciers) and methods for local permafrost prospecting, as well as discusses different approaches for permafrost distribution modelling. The section ends with a summary of previous permafrost research in the Southern Alps. Section 4.2 describes the methodology used for rock glacier mapping in the Canterbury Region and provides details on the statistical inference of a regional permafrost distribution model from the established inventory. Characteristics of the rock glacier distribution in the Southern Alps, results of the permafrost distribution estimate, as well as findings from the model's local evaluation at a test site in the central Ben Ohau Range are presented in Section 4.3. Section 4.4 compares the distribution of rock glaciers and inferred permafrost distribution limits in the Southern Alps to other domestic and international studies and reviews the applicability of the BTS method (bottom temperature of the winter snow cover) in the Southern Alps. Section 4.5 summarises the chapter's main findings.

\subsection{Background - AlPINE PERMAFrost}

\subsubsection{Definition \& characteristics}

Permafrost is defined as 'ground (soil or rock and included ice and organic material) that remains at or below $0^{\circ} \mathrm{C}$ for at least two consecutive years' (Van Everdingen, 2005). The 
term 'alpine permafrost' is used to denominate permafrost occurrences in mountain areas. Alpine permafrost (also referred to as mountain or high-altitude permafrost) is characterised by a high spatial variability, as the steep mountain topography induces a strong spatial heterogeneity of controlling factors. Consequently, much less is known about the extent, evolution and climatic sensitivity of alpine permafrost than about its polar analogue (e.g. Gruber and Haeberli, 2009; Etzelmüller, 2013).

Per definition, the term 'permafrost' describes the thermal state of subsurface material. Contrary to its name, the presence of ice is not a conditional prerequisite of permafrost. Although natural occurrences are often cemented or even oversaturated by ice (Figure 4.1), permafrost can be almost entirely ice-free in exceptionally dry environments (cf. Bockheim and Tarnocai, 1998; French, 2007; Haeberli et al., 2010). Furthermore, moisture can exist in liquid form even at temperatures below $0^{\circ} \mathrm{C}$ where the freezing point is depressed by dissolved salts or pressure.

The vertical structure of permafrost is controlled by the thermal regime within the subsurface material (Figure 4.2). Seasonal temperature variations attenuate with depth, generally vanishing between 10 to $20 \mathrm{~m}$ below the ground surface (= depth of the zero annual amplitude), depending on local climatic conditions and terrain properties (Noetzli and Gruber, 2005; Van Everdingen, 2005). In response to the annual temperature oscillations, the surface-near ground layer thaws during the warm seasons. The thickness of this socalled active layer varies interannually but typically ranges in mountain areas between $0.5 \mathrm{~m}$ and $8 \mathrm{~m}$ (Gruber and Haeberli, 2009). Beneath the active layer lies the permafrost body, where temperatures remain at or below $0^{\circ} \mathrm{C}$ for consecutive years. The upper boundary of the permafrost body is termed the permafrost table, the lower boundary the permafrost base. In flat areas, the thickness of the permafrost body is controlled by climatic conditions above
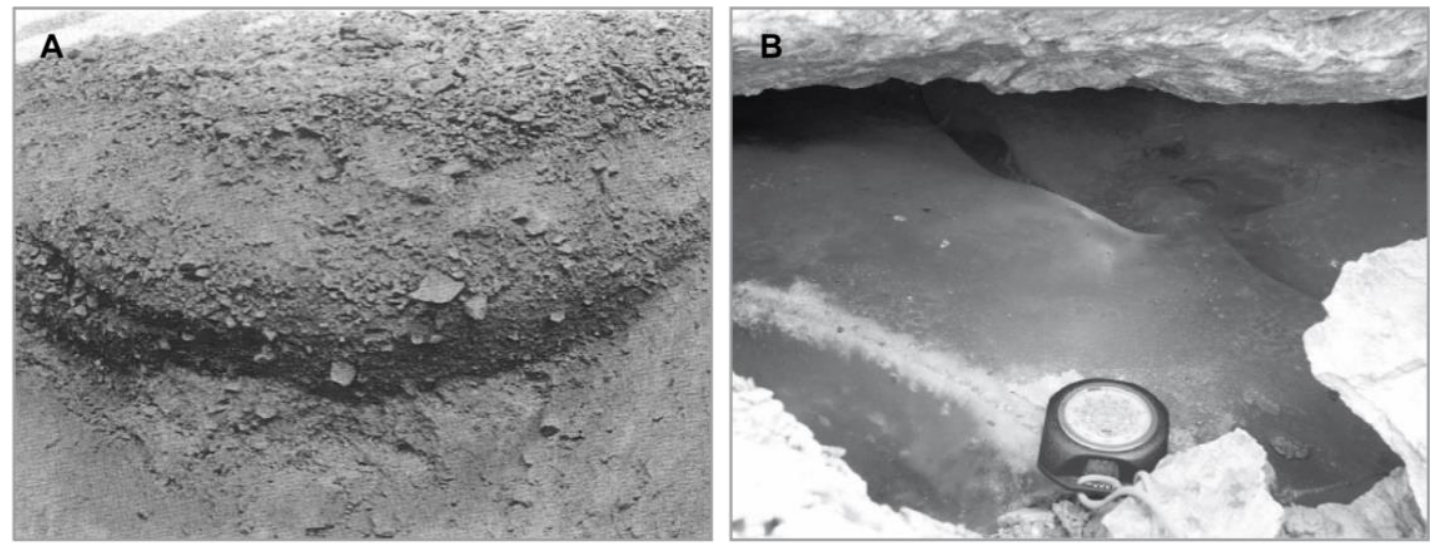

Figure 4.1

Examples of alpine permafrost. A) Permafrost body exposed in debris flow initiation area. Debris particles are cemented by ice, which prevents erosion. Larger blocks on surface are estimated to be 1 to 2 metres in diameter. Source: Zimmermann and Haeberli, 1992, p. 64. B) Ice lens underneath blocky scree in the rooting zone of an active rock glacier. Source: Nyenhuis, 2006, p. 22. 


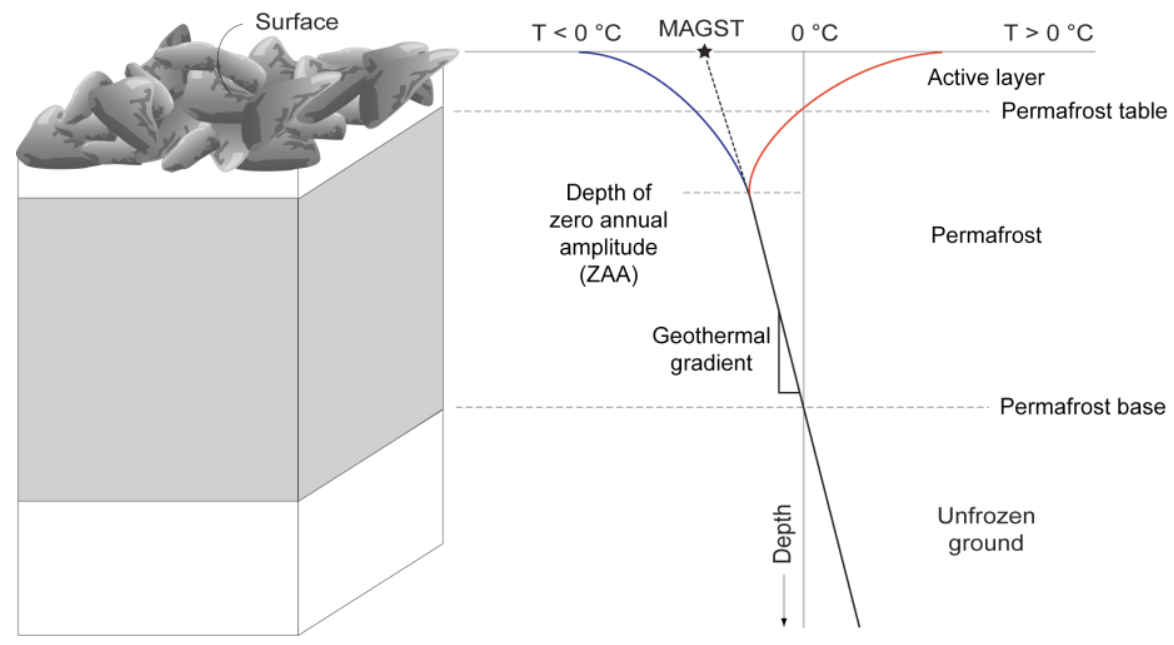

Figure 4.2

Schematic representation of permafrost occurrence in regolith with corresponding temperature profile. The red and blue curves indicate annual maximum and minimum temperatures. The star marks the mean annual ground surface temperature (MAGST); the dotted line illustrates the temperature distribution with depth. Adapted from Noetzli and Gruber, 2005, p. 112, and French, 2007, p. 84.

as well as the geothermal gradient within the ground $\left(1^{\circ} \mathrm{C}\right.$ per $30-60 \mathrm{~m}$ increase in depth; Lachenbruch, 1968). In mountain areas, lateral heat fluxes can be the dominant control (cf. Noetzli et al., 2007). Typical permafrost thickness observed in the European Alps range from tens of metres in regolith to several hundred metres in bedrock (Noetzli and Gruber, 2005). However, thickness and location of present-day permafrost occurrences do not always correspond with contemporary climatic conditions. Particularly occurrences at the lower elevation limits are thought to be remnants of past climatic conditions, such as the 'Little Ice Age' (e.g. Etzelmüller et al., 2001b).

The factors controlling the spatial distribution of alpine permafrost can be categorised based on the spatial scale of interest into three domains: climate, topography, and ground conditions (Gruber, 2005; Gruber and Haeberli, 2009). These domains are hierarchical, not exclusive. For example, on the lower scales, the influence of climate is modified by more local conditions but is still of importance. The hierarchical framework is useful for illustrating the diverse influences on alpine permafrost distribution, as well as for visualising limitations of common modelling approaches presented in Section 4.1.2.

On the global to continental scale (including large mountain ranges), suitable climatic conditions are the dominant control on permafrost occurrence in alpine areas (domain climate). The global permafrost distribution is closely related to air temperature and shows a strong latitudinal trend, following the increase in mean annual air temperatures towards the equator. In the North American Cordillera, for example, lower distribution limits rise from about $1000 \mathrm{~m}$ a.s.l. at $60^{\circ} \mathrm{N}$ to over $3000 \mathrm{~m}$ a.s.l in Colorado at around $40^{\circ} \mathrm{N}$ (Péwé, 1983). The strong link between air temperature and large-scale permafrost distribution is also expressed in a decrease in the spatial extent of permafrost with decreasing altitude. Based 
on the proportional extent of permafrost, three distribution types are distinguished: continuous permafrost $\left(>80 \%\right.$ of area, MAAT $<-8^{\circ} \mathrm{C}$ ), discontinuous permafrost $(30-80 \%$ of area, MAAT $<-1^{\circ} \mathrm{C}$ ), and sporadic permafrost $\left(<30 \%\right.$ of area, MAAT $>-1^{\circ} \mathrm{C}$ ) (e.g. Schrott, 1999; specifics on extent and temperature thresholds are intended as only rough guidelines and vary in the literature). On the continental to mountain range-scale, the role of air temperature is modified by oceanic influences. Permafrost, particularly in unconsolidated debris accumulations, is generally thought to be less extensive in maritime climates (e.g. Cheng and Dramis, 1992; Etzelmüller et al., 2003; Gruber and Haeberli, 2009; see also Figure 4.3). Comparatively mild winter temperatures and thick snow covers, insulating the subsurface on moderately inclined slopes during winter, result in warmer ground temperatures. Furthermore, the glaciation limit is lower in maritime settings owing to higher precipitation. Suitable locations for frozen taluses are consequently often occupied by glaciers or firn fields. Conversely, in continental climates the opposite is the case.

On the catchment scale, the influence of topography on incoming solar radiation and snow distribution increases in significance (domain topography). Incoming radiation levels govern the energy input into the ground (e.g. Hoelzle, 1992; Gruber et al., 2004; Lewkowicz and Ednie, 2004). Therefore, permafrost occurs at suitable altitudes more likely in shaded locations than on sun-exposed slopes. This difference, which results in aspect-dependent variations in distribution limits, is less pronounced in maritime climates (Figure 4.3), where the frequent cloud cover reduces short wave-radiation discrepancies between aspects. A sufficiently thick snow cover $(>60-80 \mathrm{~cm}$ ) decouples the ground from the atmosphere in terms of energy transfer (e.g. Keller, 1994; Hanson and Hoelzle, 2004; Luetschg et al., 2004;

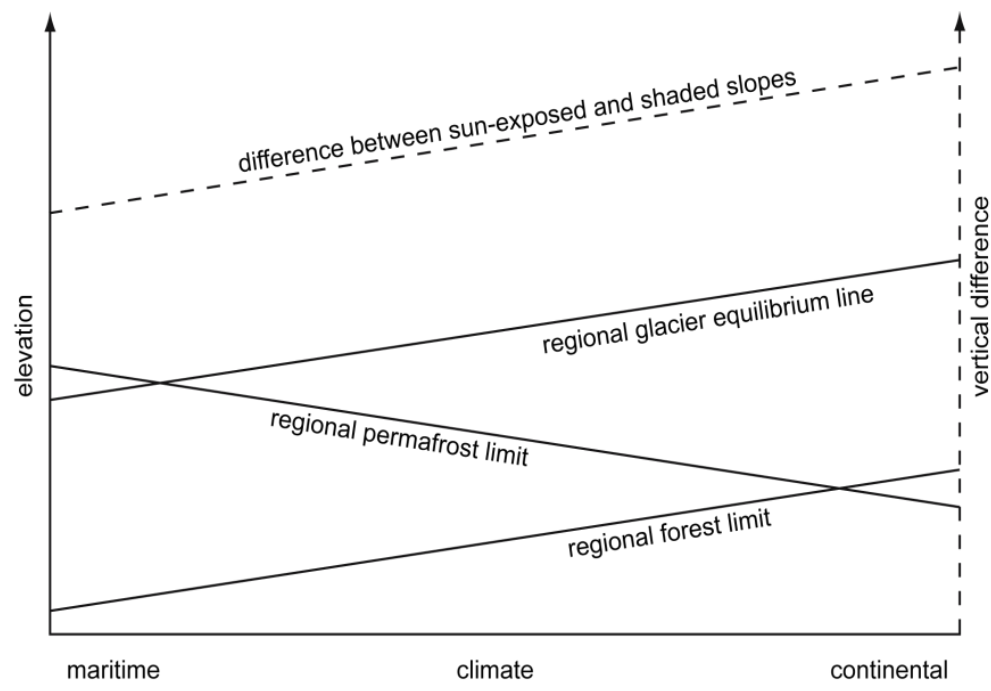

Figure 4.3

Relationship between permafrost distribution and other climatically-controlled limits as a function of continentality and elevation. The lines indicate trends, but their shape is simplified (e.g. glaciation limits rise exponentially with increasing continentality). Adapted from Gruber and Haeberli, 2009, p. 36. 
Zhang, 2005; Luetschg et al., 2008). The high air content of the snow pack reduces its thermal conductivity, insulating the subsurface from atmospheric influences during the winter months. The timing of the first snow (or accumulation by wind distribution) is especially critical for subsurface temperature development during winter and thus permafrost favourability. The establishment of an insulating snow cover in late summer/ early autumn prevents the ground from cooling and the summer warmth is retained in the subsurface material throughout winter. A thick snow cover lasting into spring/ early summer, on the other hand, shields the ground from warm spring/summer temperatures and shortens the period of energy transfer into the ground. Depending on timing, duration and thickness, the snow cover can thus have a warming or cooling effect on the ground thermal conditions and thus facilitate or hinder permafrost occurrence.

On the local scale, the thermal properties of the surface and subsurface material govern the heat transfer into the ground and therefore local permafrost distribution patterns. Especially coarse debris has been found to promote permafrost, as the air-filled interconnected voids between the blocks facilitate effective cooling both in summer and winter (e.g. Harris and Pedersen, 1998; Hanson and Hoelzle, 2004). The coarse micro relief impedes the formation of a closed snow cover during winter, leaving ventilation funnels. The denser cold winter air sinks through these openings into the ground, displacing the lighter warmer air and thus providing an effective cooling during the colder months (termed 'Balch effect'). The stable air stratification remains also during summer, since the cold air prevents the infiltration of warmer summer air at depth, and thus lessens the subsurface warming during the summer months. A similar ventilation effect, referred to as 'chimney effect', has been observed within taluses at slope scale (e.g. Delaloye and Lambiel, 2005): During the winter months, warm air rises within the talus slope and exits at the upper slope. As a consequence of the created pressure gradient, cold air is aspirated at the lower part of the scree slope, effectively cooling the subsurface material at the slope toe. In summer, the cold air accumulates within or drains from the slope foot due to its density, in both instances retarding subsurface warming. This ventilation effect, which creates negative annual temperature anomalies at the lower slope and positive annual temperature anomalies at the upper slope, is thought to be the reason why permafrost occurrences are often restricted to the lower talus areas (e.g. Haeberli, 1975; Lerjen et al., 2003; Lambiel and Pieracci, 2008). Fine-grained surface materials are generally unfavourable for permafrost, as their comparatively high water content acts as a source of latent heat, which hinders effective subsurface cooling (e.g. Hoelzle et al., 1999; Heggem et al., 2005). In the continental regions of Scandinavia, however, soil wetness has been found a permafrost promoting factor (Etzelmüller and Frauenfelder, 2009). The high water content of the active layer during summer supports the establishment of a dense vegetation cover. The biomass insulates the subsurface during the warm months but promotes cooling during the cold periods due to the high thermal conductivity of the frozen organic material (e.g. Seppälä, 2011). 


\subsubsection{Indicators, prospecting methods, and distribution modelling of alpine permafrost}

\section{Indicators}

Permafrost is a thermal state of subsurface material and hence generally not visible on the surface. Yet, active rock glaciers, perennial snow patches and ice walls or cold-based hanging glaciers, are surficial indicators of local permafrost occurrences. The reverse, however, is not valid: A lack of permafrost indicators in a climatically suitable region does not imply that permafrost is absent in taluses or rockwalls.

\section{$\underline{\text { Rock glaciers }}$}

Rock glaciers are the largest and most conspicuous permafrost indicators in alpine environments. They are 'lobate or tongue-shaped bodies of perennially frozen unconsolidated material supersaturated with interstitial ice and ice lenses that move downslope [...] by creep as a consequence of the deformation of ice contained in them' (Barsch, 1996, p. 4). Rock glaciers develop from thick debris accumulations underneath rockwalls (talus-derived rock glaciers, Figure $4.4 \mathrm{~B}$ ) or from glacial deposits (morainederived rock glaciers, Figure 4.4 C) (French, 2007). Their surface is commonly composed of coarse chaotically-dispersed frost-weathered blocks. Large rock glaciers typically show sequences of longitudinal and transversal ridges and furrows, created by compressive flow due to increased friction towards the margins or slope changes (Haeberli, 1985; Kääb et al., 1998; Kenner et al., 2014). Most rock glaciers in alpine environments are of Holocene Age, developed after the recession of the Last Glacial Maximum (LGM) glaciers, and hence thousands of years old (e.g. Kirkbride and Brazier, 1995; Frauenfelder et al., 2005).

Based on rock glaciers' ice content and movement, three activity states are differentiated (Haeberli, 1985; Barsch, 1996): Active rock glaciers contain a debris core supersaturated by ice and creep downslope with velocities in the order of centimetres to metres a year (e.g. Kääb, 2005; Delaloye et al., 2008; Janke et al., 2013). Inactive rock glaciers also contain ice; however, due to the reduction in interstitial ice (climatic inactivity) or decrease in slope or debris supply (dynamic inactivity) the internal friction of the ice-debris mixture exceeds the gravitational forcing and they ceased moving. Stagnant rock glaciers entirely free of ice are referred to as relict (or fossil) features. An exact differentiation between the different activity types is only possible by a combination of permafrost prospecting methods (see below) and deformation measurements (e.g. Kaufmann, 1998; Kääb and Vollmer, 2000; Kenner et al., 2014). Yet, morphological characteristics, such as convexity, steepness of the frontal lobe, and vegetation cover, can be used as general indicators of a feature's ice content and likely mobility (see Section 4.2 .1 for details). For simplicity, rock glaciers 
A
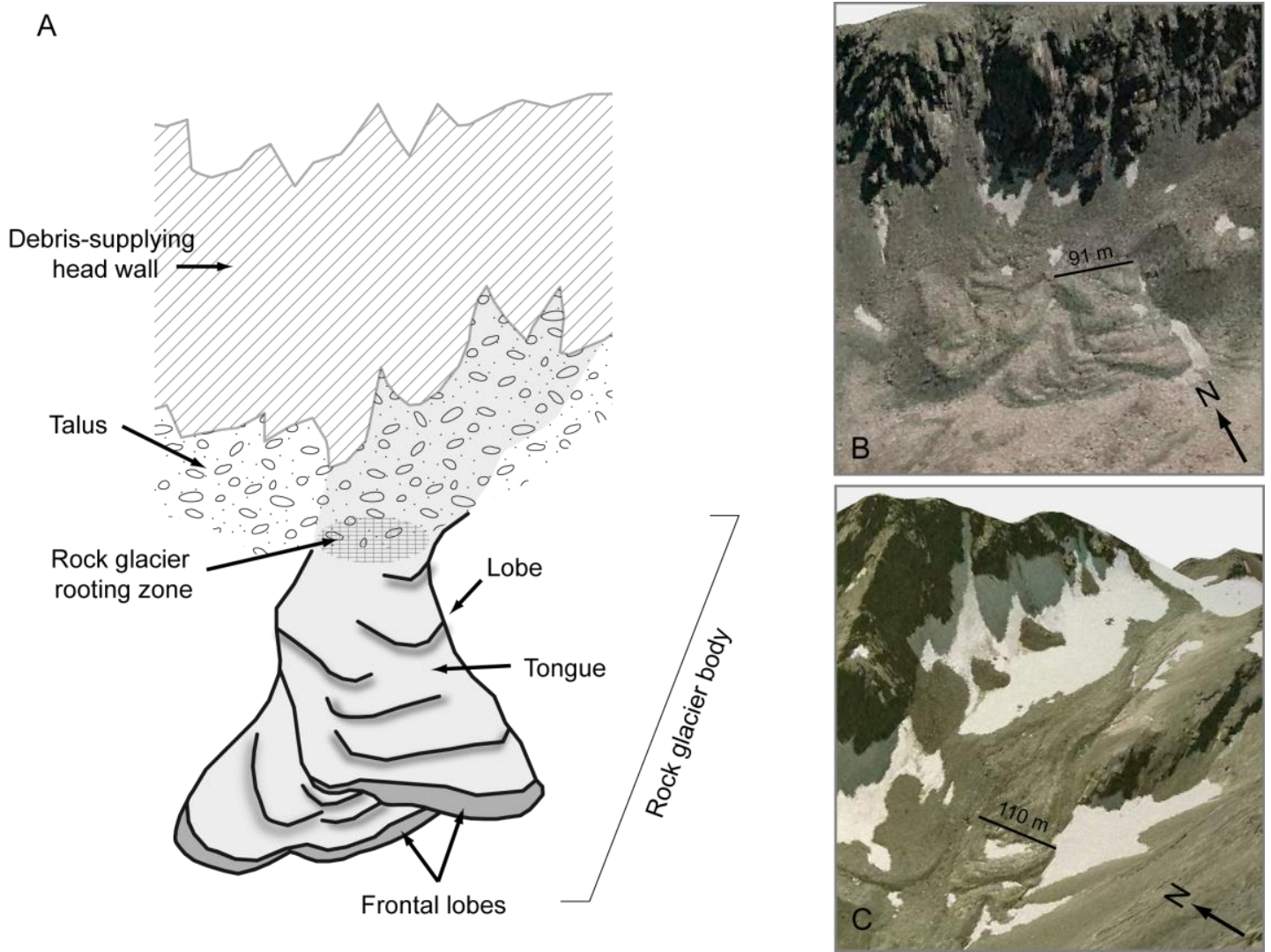

Figure 4.4

A) Schematic representation of an active talus-derived rock glacier in the Irishman Stream Valley, Ben Ohau Range (43.988 S, 170.050 E). B) Oblique view of the talus-derived rock glacier illustrated in A. C) Oblique view of a moraine-derived rock glacier of unknown activity close to Mt Glenmary (43.985 S, $169.884 \mathrm{E})$.

Images: 3D views of orthophotograph mosaic (Terralink, 2005-2008).

containing ice, i.e. active and inactive features, are also often collectively referred to as intact features, as opposed to ice-free relict rock glaciers.

The origin of rock glaciers is controversial. Some authors interpret rock glaciers purely as features of periglacial origin, as their movement results from the deformation of ice-debris mixtures, which conforms with the definition and characteristics of permafrost (e.g. Wahrhaftig and Cox, 1959; Haeberli, 1985; Barsch, 1996; Haeberli and Vonder Mühll, 1996; Haeberli et al., 2006). While members of this school of thought object to a glacial origin of rock glaciers and, therefore, the features' affiliation to the glacial domain, they acknowledge that rock glaciers' debris and ice may have originally been part of a glacial system, e.g. till, buried ice, or remnants of a former glacier. Alternatively, active rock glaciers might also be hydrologically linked to present glaciers. Other authors argue that rock glaciers can also develop from 'true' glaciers and represent a continuum in ice-debris ratios (e.g. Whalley, 1983; Whalley and Martin, 1992; Ackert, 1998). In-depth reviews of this discussion can be found in Berthling (2011) and Janke et al. (2013). Irrespective of the actual origin of the ice within rock glaciers, permafrost conditions must prevail at depth for 
the ice to be preserved over long periods (Haeberli, 2000). Therefore, rock glaciers are indicators for alpine permafrost occurrence. However, geneses of rock glaciers and potential connections to past or present glacial systems have to be considered when using rock glaciers for permafrost distribution estimates (cf. Section 4.2.2).

\section{Perennial snow patches, ice walls, and hanging glaciers}

Perennial snow patches are snow accumulations or firn fields that persist over consecutive years. Ground surface temperatures do not exceed $0^{\circ} \mathrm{C}$ at these locations even during the summer months, i.e. the permafrost table lies immediately at the surface (e.g. Haeberli, 1975; Ballantyne, 1978; Kneisel, 2004). Perennial snow patches are thus indicators for at least local permafrost occurrences. Where they are spatially clustered, extensive permafrost occurrences are likely (cf. Figure 4.4 B, C). Furthermore, the existence of perennial snow patches promotes the preservation of permafrost conditions in the subsurface material: Snow and ice at the surface prevents summer heat input, but allows the winter cold to penetrate into the ground (Haeberli and Vonder Mühll, 1996). Persistent meltwater input from the areas surrounding the perennial snow patch supports the growth of segregation ice at depth.

Ice walls and cold-based hanging glaciers are, similar to perennial snow patches, indicators for locations where the permafrost table lies directly at the surface of rock faces (e.g. Haeberli et al., 1997; Gruber and Haeberli, 2009). Their existence on steep to vertical cliffs would not be possible, if the temperature at these locations were above melting point during the summer months.

\section{Prospecting methods}

Excavations and drillings are direct and unambiguous methods to verify the presence of permafrost. These methods also provide valuable information on the stratigraphy and thermal state of the subsurface material. Furthermore, boreholes can be equipped with instruments to document subsurface temperature development through time (e.g. King et al., 1992). However, excavating and drilling is expensive, time-consuming, and especially in remote locations logistically difficult to accomplish. Hence, indirect, mostly geophysical, methods are often applied for permafrost investigations in alpine environments. Detailed summaries of the various methods and practices, such as measurements of the bottom temperature of the snow cover (BTS), electrical resistivity soundings, seismic refraction surveys, and ground penetrating radar (GPR), are provided by Vonder Mühll et al. (2002), Kneisel et al. (2008), Hauck and Kneisel (2008), and Harris et al. (2009). To date, it is not possible to utilise remotely sensed data for permafrost prospecting. However, imagery can be used for permafrost indicator mapping and derived parameters, such as altitude, slope, 
aspect, surface cover and soil wetness, employed for distribution modelling (cf. Etzelmüller et al., 2001a; Kääb, 2008).

The BTS method (bottom temperature of the winter snow cover, Haeberli, 1973) is based on the low thermal conductivity of a sufficiently thick snow cover $(>60-100 \mathrm{~cm})$, which insulates the subsurface from air temperature variations during the winter months (cf. Section 4.1.1 above). During that time, ground surface temperatures, i.e. the temperatures at the snow cover base, are mainly controlled by heat transfer from below and thus influenced by the presence or absence of permafrost. BTS temperatures above permafrost have been observed to stabilise towards the end of the winter season (i.e. before the onset of the snow melt) generally below - $3^{\circ} \mathrm{C}$ (e.g. Haeberli, 1973, 1978; King, 1983). At locations without permafrost, surface temperatures commonly level out above $-2^{\circ} \mathrm{C}$. From these observations, the BTS rule-of-thumb was derived, where $\mathrm{BTS}<-3^{\circ} \mathrm{C}$ indicate probable permafrost presence, BTS between $-2^{\circ} \mathrm{C}$ to $-3^{\circ} \mathrm{C}$ possible permafrost presence, and $\mathrm{BTS}>-2^{\circ} \mathrm{C}$ improbable permafrost presence. So far, these BTS thresholds have been successfully used in various regions for permafrost prospection (e.g. Swiss Alps: Hoelzle, 1992; Southern Norway: Isaksen et al., 2002; Yukon Territory, Canada: Lewkowicz \& Ednie, 2004; Austrian Alps: Otto et al., 2012; Southern Carpathians, Romania: Onaca, 2013). Ishikawa and Hirakawa (2000), however, suggest that the commonly used temperature thresholds might not be globally valid. Investigations into the potential regional variability of BTS thresholds have yet to be conducted. High BTS sample densities can be achieved by probing the ground with a thermistor attached to a long pole. Yet, the (additional) use of continuous measurements by means of miniature temperature data loggers buried a few centimetres below the surface is recommended (e.g. Hoelzle et al., 1999; Ishikawa, 2003; Brenning et al., 2005), as the continuous records allow better judgement of the reliability of measured BTS values, which can be significantly influenced by the temporal development of the winter snow cover (cf. Section 4.3.4).

Geophysical methods for permafrost prospecting are based on the differing physical properties of ice-cemented ground and unfrozen material (see Vonder Mühll et al., 2002, Kneisel et al., 2008, Hauck and Kneisel, 2008, or Harris et al., 2009, for details). Electrical resistivity tomography (ERT) surveys use an array of ground electrodes to inject a direct current (DC) into the ground and measure the electrical potential at depth between the electrodes. Ice is characterised by high electrical resistivity; values greater than $10 \mathrm{k} \Omega \mathrm{m}$ are typically indicative for permafrost (e.g. Hilbich et al., 2008; Lambiel and Pieracci, 2008; Scapozza et al., 2011). Electromagnetic (EM) induction methods also detect differences in electrical conductivity of subsurface material; however, they operate on voltage induced from a magnetic field and thus do not require galvanic coupling to the ground (e.g. Hauck et al., 2001; Maurer and Hauck, 2007). Refraction seismic techniques use the velocity of acoustic waves to map subsurface structures. The speed of wave propagation varies in materials according to their density and frozen ground $(2000-4000 \mathrm{~m} / \mathrm{s})$ can hence be differentiated 
from unfrozen material (e.g. active layer 400 - 1500 m/s) (e.g. Hausmann et al., 2007; Hilbich, 2010). Ground Penetrating Radar (GPR), a type of EM technique, registers the energy that is partially reflected as short radio waves pass through dielectric boundaries. GPR does not supply information on the type or thermal state of the subsurface material. However, the high vertical resolution of mapped reflectors can be used to delineate boundaries between materials and hence provide valuable complementary information to the findings of other prospecting methods (e.g. Hausmann et al., 2007; Maurer and Hauck, 2007; Otto et al., 2012).

\section{Distribution modelling}

Since alpine permafrost is largely invisible and has high spatial variability, the modelling of its distribution is one of the key interests in permafrost research. Current modelling approaches can be divided into two types: Empirical-statistical models, which are based on correlations between known permafrost occurrences and topoclimatic factors, and more sophisticated process-oriented models, which calculate ground temperatures by simulating energy fluxes between the atmosphere and subsurface material. Reviews of common methodologies and recent advances can be found in Etzelmüller et al. (2001b), Riseborough et al. (2008), Harris et al. (2009), and Etzelmüller (2013). The choice of modelling approach largely depends on the spatial scale of interest. Local-scale distribution estimates are desirable, given the high spatial variability of permafrost in alpine environments. However, the accuracy and spatial resolution of the available information on local climate or ground conditions often limit modelling attempts to generalised estimates.

Empirical-statistical distribution models relate known permafrost occurrences to topoclimatic factors, such as altitude, slope, aspect, mean annual air temperature, solar radiation, and vegetation cover. Positive statistical relationships are used to formulate rule-of-thumb guidelines for permafrost presence (e.g. Haeberli, 1975; Haeberli, 1996), to model the spatial distribution of indicators such as BTS or mean annual ground surface temperatures (e.g. Gruber and Hoelzle, 2001; Heggem et al., 2006; Abramov et al., 2008), or to calculate permafrost probabilities via regression analyses (e.g. Lewkowicz and Ednie, 2004; Heggem et al., 2005; Etzelmüller et al., 2006; Ridefelt et al., 2008; Boeckli et al., 2012b). GIS-based adaptions of Haeberli's $(1975,1996)$ topoclimatic distribution guidelines are widely used for regional estimates (e.g. Keller, 1992; Imhof, 1996; Allen et al., 2008; Sattler et al., 2011; Schrott et al., 2012). Other regional models focus on the distribution of visual indicators, such as rock glaciers, to derive lower distribution limits (e.g. Frauenfelder and Kääb, 2000; Lambiel and Reynard, 2001; Aoyama, 2005; Nyenhuis et al., 2005). In high-latitude maritime areas, the single parameter mean annual air temperature was found to adequately describe regional permafrost occurrences (e.g. Etzelmüller et al., 1998; 2007). Recently, Gruber (2012) presented a global predictive approach based on MAAT. Published 
estimates were used to calculate a global permafrost zonation index, which represents the probability of mean annual ground temperatures being below $0^{\circ} \mathrm{C}$ for a given MAAT. Empirical-statistical distribution models neglect energy exchange processes between the atmosphere and subsurface material as well as transient heat fluxes. This simplification brings the advantage that empirical-statistical distribution models can be easily applied even in areas with low density of climate observations. These models only require a limited number of input parameters and are reasonably reliable if calibrated well. However, due to the reliance on regional or local calibration, extrapolations in time or to non-calibrated areas might yield incorrect distribution estimates.

Process-oriented distribution models focus on energy fluxes on the local scale. Analytical approaches translate atmosphere-ground relationships into simplified mathematical models to compute ground temperatures (e.g. Heggem et al., 2006; Juliussen and Humlum, 2007; Gisnås et al., 2013). However, mountain environments are often too heterogeneous and relationships are too complex to be adequately resolved by analytic models. Numerical approaches, on the other hand, explicitly parameterise the individual energy balance components, such as net radiation, thermal conductivity of the subsurface material, and three-dimensional heat flow, and calculate thermal conditions at depth as well as their evolution through time (e.g. Stocker-Mittaz et al., 2002; Luetschg, 2005; Scherler et al., 2010). Their development assumes a sound understanding of local heat transfer functions and requires a large amount of precisely measured or computed data. In debris environments, the formulation of sufficiently accurate estimates of snow cover development, heat transfer within coarse materials, and the role of hydrothermal processes with the active layer remain key challenges for the development of spatially-distributed numerical models. Promising advances have been made, however, in numerical modelling of ground temperature distributions in steep rock walls (Gruber, 2005; Noetzli et al., 2007; Noetzli and Gruber, 2009), where the influence of superficial snow and debris is negligible. Based on physical principles and driven by climate parameters, process-oriented distribution models allow for spatio-temporal extrapolations. These models can thus be used for sensitivity studies, implementing information on climate change scenarios and utilising the output of high-resolution Regional Climate Models (RCMs) (e.g. Luetschg and Haeberli, 2005; Salzmann et al., 2007a, b; Jafarov et al., 2012; Scherler et al., 2013).

\subsubsection{Permafrost research in the Southern Alps}

Alpine permafrost research is a comparatively young scientific field. Its origins date back to the seminal paper of Wahrhaftig and Cox (1959) on rock glaciers in the Alaska Range as well as to early systematic work in the late 1960s and 1970s, particularly in the European Alps, the Himalaya, the Tien Shan, and the Canadian Rockies (for a summary see 
Gorbunov, 1978, and Haeberli et al., 2010). It is, therefore, not surprising that the presence of perennially frozen ground in the remote areas of New Zealand's Southern Alps went unnoticed by the scientific community for a long time. Soons (1962) noted in an early review of periglacial features in New Zealand that 'No features have been observed in the South Island which certainly indicate the occurrence of permafrost.' (p. 82 f.), and concludes from the lack of frost wedge structures that it 'seems doubtful whether periglacial conditions associated with the last glaciation were sufficiently intense to produce permafrost in the South Island' (p. 83). However, soon afterwards, and most likely facilitated by the advent of extensive aerial photograph coverage of the Southern Alps, rock glaciers received scientific attention (cf. review of periglacial research in New Zealand in Augustinus, 2002).

Early rock glacier research in New Zealand (McGregor, 1967; Birkeland, 1982) focused on the identification and dating of periods of rock glacier activity to supplement the Holocene glacial chronology. Chinn (1988) and Gellatly et al. (1988) included rock glaciers in their inventories of glacial features, but interpreted them, in contrast to the earlier studies, as being purely of glacial origin. Kirkbride and Brazier (1995) dated lobes of three talus-derived rock glaciers in a tributary of Jack Stream, Central Ben Ohau Range. The authors inferred a dual threshold model (climate and talus thickness) for their genesis, explaining the varying number of lobes developed by rock glaciers in proximity to each other. Activity of one of the rock glaciers was assessed by resistivity and creep measurements. Monitoring between 1989 and 1994 indicated maximum surface movement of $0.14 \mathrm{~m} \mathrm{a}^{-1}$ (Brazier et al., 1998). A rock glacier inventory for multiple mountain ranges was created by Jeanneret (1975), who mapped 27 active rock glaciers in selected areas in the Burnett Range, the Two Thumb Range, and the Craigieburn Range. Jeanneret (1975) noticed a decrease in the altitude of active rock glacier fronts towards the lower northern mountain ranges; an observation that Barsch (1996) found surprising, given the generally higher mean annual temperatures at lower latitude (cf. Cheng and Dramis, 1992). Barsch (1996) suspected an insufficient small sample size as well as potential misinterpretation of the rock glaciers' activity state as an explanation for this trend, but did not exclude Jeanneret's (1975) interpretation of a possible topographic control on the observed distribution pattern. Brazier et al. (1998) compiled an extensive rock glacier inventory for the Ben Ohau Range. The rock glaciers showed a strong vertical zonation of active and relict features, corresponding to temperature and regional precipitation gradients. Based on the distribution of active features, Brazier et al. (1998) formulated the first empirical distribution estimate for the Southern Alps, proposing that sporadic permafrost occurs in a narrow zone in the Southern Alps where mean annual temperature is below $-2^{\circ} \mathrm{C}$ and glacier equilibrium line altitudes exceed $2100 \mathrm{~m}$. The authors suggest an altitudinal distribution limit of approximately $2000 \mathrm{~m}$ a.s.l. This estimate conforms with an earlier statement by Gorbunov (1978) who also estimated that sporadic permafrost occurs in the Southern Alps above approximately $2000 \mathrm{~m}$. Although not clearly stated, it is assumed that Gorbunov's (1978) estimate was based on latitudinal and continentality 
considerations, since no empirical evidence was cited. Recently, Gruber (2012) used similar generalised distribution guidelines for a high-resolution $(<1 \mathrm{~km})$ global permafrost model based on mean annual air temperature (see above). Modelling results suggest that, depending on chosen parameter thresholds, in approximately $76 \mathrm{~km}^{2}-486 \mathrm{~km}^{2}$ of the Southern Alps' unglacierised area permafrost is possible. The coarse resolution of Gruber's (2012) distribution model provides only a very high-order estimate of the present permafrost extent. Similarly, the large grid size does not allow inference of meaningful altitudinal limits. For a regional spatially-distributed permafrost estimate, Allen et al. (2008) adapted Haeberli's $(1975,1996)$ topoclimatic distribution thresholds for steep slopes $\left(>20^{\circ}\right)$ to the climatic conditions in the Mt Cook region by adjusting the aspect-dependent elevation limits according to the difference in $0^{\circ} \mathrm{C}$ altitudes between the Swiss Alps and the Mt Cook region, acknowledging regional precipitation gradients by using a variable lapse rate. Allen et al. (2008) compared the model result with Brazier et al.'s (1998) rock glacier inventory and concluded that the model probably underestimates the actual permafrost extent in the Southern Alps. Results of a second model (Allen et al., 2009), aiming at estimating permafrost distribution in steep rockwalls by modelling the spatial distribution of mean annual rock temperatures as a function of incoming solar radiation, suggest that bedrock permafrost may occur in extremely shaded locations as low as $2000 \mathrm{~m}$ a.s.l. Allen et al. (2009) emphasise that derived distribution limits are based on data from steep rock faces $\left(>45^{\circ}\right)$ and might, therefore, not be valid for gentle slopes where snow and debris accumulations decouple the ground from direct atmospheric influences (cf. Section 4.1.1). A topoclimatic, spatially-distributed permafrost model for the Southern Alps' debris domain was so far pending. Reports, such as the excavation of frozen debris at several metre depth at the Ohau ski field at $\sim 1700 \mathrm{~m}$ a.s.l. (H. Purdie, pers. comm. September 2009), suggest that permafrost might be more extensive in the Southern Alps than previously thought. 


\subsection{METHODOLOGY}

The establishment of a regional permafrost distribution estimate for the Southern Alps is a key objective of this study. Permafrost distribution modelling was based on the statistical evaluation of a regional rock glacier inventory for the Canterbury Region. Logistic regression was used to identify characteristic topoclimatic conditions at the head area of presently active rock glaciers. Identified statistical relationships between permafrost presence, mean annual air temperature, and potential incoming solar radiation in snow-free months are subsequently utilised for estimating the potential contemporary permafrost extent. To accommodate for possible variations in variable relationships, three different model designs, including a geographically weighted logistic regression (GWLR) model, were tested. The following sections outline the procedures for mapping rock glaciers by aerial photo interpretation and for their classification according to activity status. Furthermore, the rationale for using rock glaciers for permafrost distribution modelling is explained, the statistical method 'logistic regression' introduced, and the different model designs and input data described.

\subsubsection{Rock glacier inventory}

Active rock glaciers occur in New Zealand's Southern Alps in high-altitude areas east of the Main Divide, where the climate is cold enough for the preservation of perennially frozen ground but too dry for glaciers to occupy suitable topoclimatic locations (cf. Haeberli, 1985; Humlum, 1998, see also Section 2.4). Existing rock glacier inventories for the Ben Ohau Range as well as for other selected areas in the Southern Alps have already been described in Section 4.1.3. Another data source is the Central South Island Glacial Geomorphology (CSIGG) map (Barrell et al., 2011), which gives the spatial extent of rock glaciers but does not differentiate between activity states.

With the exception of the CSIGG map, the existing rock glacier inventories only cover small areas in the Southern Alps. They are therefore of limited use for the deduction of a region-wide permafrost estimate that potentially acknowledges climatic gradients present across the Southern Alps (see Section 4.2.2 below). The area of interest for the present rock glacier survey was hence widened to the mountainous areas of the Canterbury Region. Since most of the eastern ranges of the Southern Alps are situated within Canterbury, the assessed rock glacier distribution is thought representative for the whole Southern Alps. Inferred permafrost distribution limits are, therefore, assumed to be valid also in alpine areas outside Canterbury, such as the Mt Aspiring region. 
The focus of this study lies on permafrost occurrences within debris slopes. Therefore, the distribution of talus-derived rock glaciers, which developed from ice-saturated debris accumulations beneath rockwalls, is of main interest for the inference of the potential contemporary permafrost extent. Climatic conditions in the rooting zone of talus-derived rock glaciers were favourable for permafrost formation prior to the onset of permafrost creep. Conditions are presumably still favourable for at least permafrost preservation in the case of presently active features (cf. Section 4.1.2). It is, therefore, plausible that permafrost is currently also present in non-creeping taluses, where topoclimatic conditions are similar to those in the head area of currently active features.

The formation of talus-derived rock glaciers is controlled by several factors, including climate, topography, and sediment supply (e.g. Kirkbride and Brazier, 1995; Frauenfelder, 2004). The features' size and shape can thus vary significantly depending on local conditions and stage of development (Figure 4.5). Ice-rich permafrost in talus slopes is thought to form in consequence to the incorporation of snow avalanche deposits or firn fields into the talus deposits and refreezing of melt water at lower depths (e.g. Haeberli and Vonder Mühll, 1996; Humlum, 2005). Ice-supersaturated debris becomes unstable once the shear stress, which is a function of ice content, thickness of talus deposits, and slope gradient, exceeds a critical limit (Barsch, 1996). The lower part of the talus slope creeps outwards and forms a first ridge (Figure $4.5 \mathrm{~A}$ ). These embryonic rock glaciers are commonly referred to as 'protalus ramparts' in permafrost literature (e.g. Haeberli, 1985; Scapozza et al., 2011; Scotti et al., 2013), a term sometimes used in non-permafrost literature for morphologically similar ramparts (pronival ramparts) formed by supranival debris supply (e.g. Ballantyne and Kirkbride, 1986; Shakesby, 1997). To avoid confusion, the term 'protalus rock glacier' (as suggested by Shakesby, 1997) is used in this thesis to refer to the initial permafrost creep ridges. Where topoclimatic conditions are suitable, the initial bulge moves further downslope and a more developed rock glacier with the characteristic furrow-and-ridges topography forms (Figure 4.5 B, C).

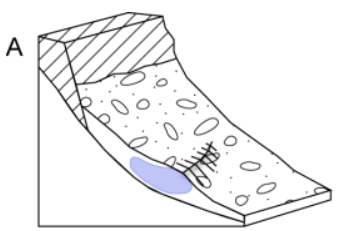

Protalus rock glacier

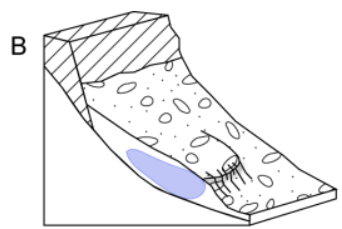

Single-lobe rock glacier

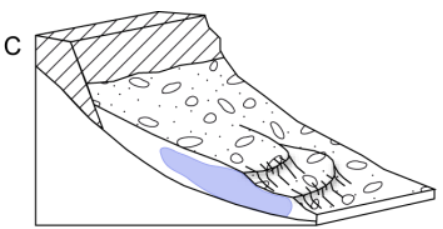

Multiple-lobe rock glacier

Time

Figure 4.5

Morphological model of talus-derived rock glacier development, modified after Haeberli, 1985, and Shakesby, 1997. 
Rock glaciers (in the following used for all permafrost creep features, i.e. talus-derived and moraine-derived rock glaciers, including protalus rock glaciers) in the Canterbury Region were mapped based on the Terralink (2005-2008) orthophoto mosaic and Google Earth imagery available at mid-2010. The landforms were recorded as point features in ArcMap 9.3 (ESRI, 2009b) at the approximate rock glacier initiation line (Figure 4.6, yellow circle). Humlum (1988, p.165) defines the initiation line of talus-derived rock glaciers as 'the level where a normal talus gives way to a rock glacier body below'. As such, Humlum's (1988) rock glacier initiation line altitude (RILA) is consistent with Barsch's (1996, p. 21) 'height of the rooting zone', where the rooting zone describes the slope area were permafrost creep initially started (cf. Figure $4.4 \mathrm{~A}$ ). This specific location can also be identified for moraine-derived rock glaciers. For intricate rock glacier complexes, a single representative point feature was mapped instead of multiple features with similar properties in proximity to each other (Figure 4.6, blue triangle). Additional to the spatial location of the rock glacier initiation line, rock glacier type, rock glacier complexity, rock glacier initiation line altitude (RILA), altitude of the rock glacier front, aspect of the rock glacier tongue, and, most importantly, the rock glacier's present activity state were recorded as supplementary attributes (Table 4.1).

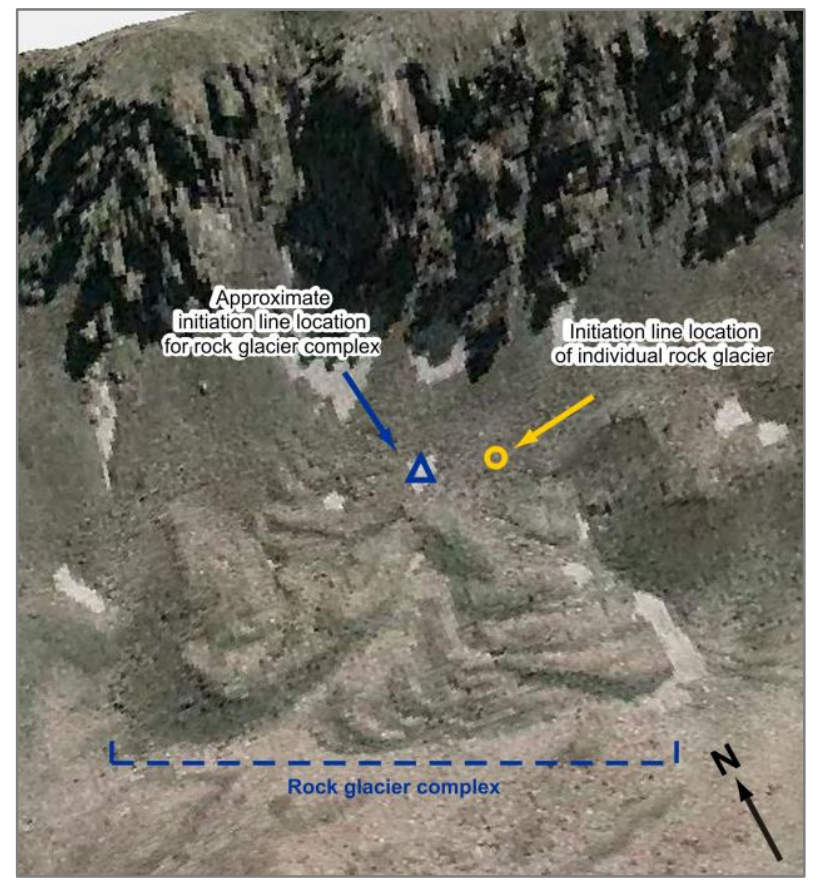

Figure 4.6

Examples of rock glacier initiation line locations. The yellow circle marks the approximate location of the initiation line of the single talus-derived rock glacier. The blue triangle marks the initiation line location which was actually mapped for this specific rock glacier complex at the head of the Irishman Stream Valley, Ben Ohau Range.

Image: 3D view of orthophotograph (Terralink, 2005-2008). 
Table 4.1 Summary of attributes mapped in conjunction with the rock glacier initiation line location.

\begin{tabular}{lll}
\hline Feature & Attributes & Subtypes \\
\hline Rock glacier initiation line $(\mathrm{p})$ & Type & $\begin{array}{c}\text { Talus-derived rock glacier; moraine-derived rock glacier, } \\
\text { protalus rock glacier } \\
\text { Single lobe; multiple lobes }\end{array}$ \\
& $\begin{array}{l}\text { Complexity } \\
\text { Initiation line altitude }[\mathrm{m}]\end{array}$ & \\
& $\begin{array}{l}\text { Altitude at front }[\mathrm{m}] \\
\text { Aspect }\left[{ }^{\circ}\right]\end{array}$ & \\
Activity & Active; inactive; relict \\
\hline
\end{tabular}

(p) point feature

Present-day rock glacier activity was exclusively assessed by imagery interpretation, using the morphological diagnostics listed in Table 4.2 to distinguish between active, inactive, and relict features. An accurate identification of rock glaciers' activity status would require both geophysical surveying to ascertain the presence of ice and deformation rate measurements to ascertain current mobility (cf. Section 4.1.2). Since both analyses are labour-intense procedures, rock glacier activity classifications based on the morphological criteria are common (e.g. Humlum, 1988; Brazier et al., 1998; Ikeda and Matsuoka, 2002; Nyenhuis, 2006; Lilleøren and Etzelmüller, 2011; Kellerer-Pirklbauer et al., 2012; Krainer and Ribis, 2012; Falaschi et al., 2014) and an accepted approach for regional rock glacier

Table 4.2 Visual diagnostics for rock glacier activity classification (after Barsch, 1996; Ikeda and Matsuoka, 2002; and Roer and Nyenhuis, 2007).

\begin{tabular}{|c|c|c|c|}
\hline Criteria & active rock glacier & inactive rock glacier & relict rock glacier \\
\hline Overall morphology & well-developed & well-developed & collapsed \\
\hline Cross profile & convex-up & signs of subsidence & subsided \\
\hline Surface relief & $\begin{array}{l}\text { transverse ridges and } \\
\text { furrows, frequently lateral } \\
\text { logitudinal ridges }\end{array}$ & $\begin{array}{l}\text { transverse ridges and } \\
\text { furrows, frequently lateral } \\
\text { logitudinal ridges }\end{array}$ & $\begin{array}{l}\text { outer ridges higher than } \\
\text { interior }\end{array}$ \\
\hline Frontal lobe & ramp with sharp edges & $\begin{array}{l}\text { less defined break, well } \\
\text { developed boulder apron at } \\
\text { foot }\end{array}$ & rounded ridge \\
\hline Frontal slope & $\begin{array}{l}\text { steep }\left(>35^{\circ}\right) \text {, lighter than } \\
\text { surrounding, exposing } \\
\text { fresh/unweathered material, } \\
\text { no vegetation visible }\end{array}$ & $\begin{array}{l}\text { gentler, partial or full } \\
\text { vegetation }\end{array}$ & $\begin{array}{l}\text { subdued, eroded, full } \\
\text { vegetation }\end{array}$ \\
\hline Upper surface & $\begin{array}{l}\text { fresh and unstable } \\
\text { boulders, no fine material, } \\
\text { commonly vegetation-free }\end{array}$ & $\begin{array}{l}\text { stable boulders, depressed, } \\
\text { partial or full vegetation }\end{array}$ & $\begin{array}{l}\text { stable boulders, weathered } \\
\text { surface, fine material in } \\
\text { gaps }\end{array}$ \\
\hline $\begin{array}{l}\text { Perennial snow patches in } \\
\text { vicinity }\end{array}$ & common & possible & absent \\
\hline
\end{tabular}


studies (cf. Barsch, 1996; Roer and Nyenhuis, 2007). However, discrimination between the activity classes based only on visual diagnostics is not always straight forward. Common issues are:

- Morphological differences between active and inactive rock glaciers are subtle and not easily detected in remotely-sensed imagery. Thus, the differentiation between active and inactive features involves higher levels of uncertainty than the differentiation between active and relict rock glaciers.

- The magnitude of subsidence occurring on a rock glacier in consequence to the melting of interstitial ice depends on the feature's original ice content (Ikeda and Matsuoka, 2002). Formerly ice-rich rock glaciers, which contained massive ice cores in the past, might show the characteristic subsided cross profile with prominent rounded lateral ridges once the ice has melted. Remnants of rock glaciers with lower ice content, on the other hand, might lack distinct signs of collapse and, in extreme cases, might still display a well-developed convex morphology (see Ikeda and Matsuoka, 2002, p. 155, for example).

- Continuous vegetation cover on rock glaciers has been found to be a reliable proxy for rock glacier immobility in the Central European Alps (e.g. Cannone and Gerdol, 2003; Burga et al., 2004). However, the absence of vegetation discernible in remotelysensed imagery is not an indicator for permafrost creep, as the development of a vegetation cover depends on several factors, including microclimate, duration of snow cover, water supply, and the presence of fine substrate where plants can develop (e.g. Burga et al., 2004). Furthermore, the link between extensive vegetation cover and relict rock glaciers is not globally valid. Active rock glaciers with forest cover have been reported from Canada (M. Hoelzle, pers. comm. July 2014) and Alaska (S. Eaves, pers. comm. August 2014).

The differentiation of protalus rock glaciers from landforms with similar morphology, such as pronival ramparts, moraines, or landslide deposits, is often challenging. Therefore, particular care was taken to only map features where both the appearance of the ridges as well as landform assemblies of the wider environment suggested a permafrost-related genesis. The probability of present-day ice within the identified protalus rock glaciers was again judged exclusively on visual criteria. Only ridges of conspicuous convexity were mapped as intact. 


\subsubsection{Present-day permafrost distribution estimate}

The choice of modelling approach for permafrost distribution estimates is restricted by the spatial scale, spatial accuracy, and quality of the available input data (cf. Section 4.1.2). In this study, rock glaciers are used as permafrost indicators. Given their slope-scale size and clear topoclimatic-influenced distribution pattern, rock glaciers allow the differentiation of permafrost suitable and permafrost unsuitable slopes and thus the evaluation of potential permafrost occurrence on the catchment scale.

The use of rock glaciers for permafrost distribution estimates traces back to Barsch (1978), who noted that 'the lower limit of active rock glaciers [...] seems to be of greater importance for the description of permafrost distribution than all climatically controlled equilibrium lines' (p. 351). Since then, the altitudinal distribution of rock glaciers has been used in several regional studies to infer present and past permafrost distribution limits (e.g. Stötter, 1994; Lambiel and Reynard, 2001; Aoyama, 2005; Nyenhuis et al., 2005). However, basing distribution estimates on mean or minimum rock glacier front altitudes is likely to lead to significant overestimating of the zone of potential permafrost occurrence within surrounding debris slopes due to the dynamic character of rock glaciers. Where topoclimatic conditions are especially suitable for permafrost creep, such as high supply of debris and high input of snow or refreezing meltwater, rock glaciers have been observed to export permafrost into technically permafrost unfavourable locations (e.g. Lugon and Delaloye, 2001). Similarly, the coarse boulder surface of rock glaciers facilitates cold-air ventilation (cf. Section 4.1.1) and permafrost might thus be preserved in localities well below the present-day permafrost limit (cf. Janke et al., 2012). More recent studies focus, therefore, on the identification of characteristic topoclimatic conditions at presently active rock glacier locations and use statistical relationships to spatially predict the extent of the contemporary permafrost distribution (e.g. Janke, 2005; Nyenhuis, 2006; Boeckli et al., 2012a).

In this study, logistic regression is used to relate mean annual air temperature (MAAT) and potential incoming solar radiation (PISR) to the location of active rock glaciers and thus modern permafrost occurrences. To avoid a probable overestimate of the permafrost favourable area due to the mobility of rock glaciers (cf. above), the statistical analysis is based on climatic conditions at the approximate rock glacier initiation line. The spatial accuracy of the mapped initiation line is thought sufficient to capture relevant variances in topoclimatic conditions at the rock glacier heads (cf. Figure 4.6). This is also thought valid for rock glacier complexes for which only a single representative point was mapped. Similarly, the identification of rock glacier activity based on imagery interpretation is thought adequately reliable to allow differentiation between probable and improbable permafrost sites. Given that topoclimatic conditions are, or have been up to recently, favourable for permafrost existence at the active rock glacier sites (perennially frozen debris reacts only 
slowly to atmospheric warming, e.g. Haeberli, 1992), it is assumed that permafrost potentially also presently exists in non-creeping taluses with similar climatic conditions (cf. Section 4.2.1). Based on this assumption, statistical relationships between permafrost presences and topoclimatic variables can be used to spatially extrapolate findings by calculating the probability of permafrost presence at a given location, using the spatially continuous input datasets MAAT and PISR as predictors. Since MAAT is controlled by elevation, the likelihood of permafrost presence as well as its areal extent (cf. Section 4.1.1) is expected to increase with altitude, allowing the delineation of catchment areas where conditions would be potentially suitable for contemporary permafrost presence.

A finer-scaled (e.g. slope foot vs. slope top) estimate of the potential permafrost distribution would be more suited for the analysis of the possible influence of permafrost on debris flow activity. However, the available data on permafrost presence (active rock glaciers) are inadequate for the inference of more localised predictions. Reliable slope-scale distribution models would require fine-scaled topoclimatic information as well as information on surface characteristics and annual snow cover distribution for both model development and spatial application (cf. Section 4.1.2).

Given the strong climatic gradients present across the Canterbury region, the predictive power of MAAT and PISR for present-day permafrost occurrences might vary spatially. For example, frequent cloud cover closer to the humid Main Divide might dampen the influence of incoming solar radiation compared to drier south-eastern areas (cf. Allen et al., 2008). To explore the potential presence of spatial trends in variable relationships, three different logistic regression models, including the reasonably new Geographically Weighted Regression method, were tested. The individual model designs as well as information on the input data used are described below. A general introduction to global and local regression models follows.

\section{Background to logistic regression models}

Logistic regression models are a type of generalised linear model which predicts the conditional probability for a dichotomous outcome variable $Y$ to occur (e.g. permafrost present (1), permafrost absent (0)) based on a set of explanatory variables $X$ (e.g. Brenning and Trombotto, 2006).

Depending on consideration of the spatial location of observations in the probability estimates, two types of logistic regression models can be distinguished (cf. Brunsdon et al., 1996; Fotheringham et al., 2002): Global logistic regression models assume that direction and strength of relationships between dependent (outcome) and independent (explanatory) variables, described by regression coefficients, are constant across space. Local logistic regression models, on the other hand, assume spatial non-stationarity in variable 
relationships and allow coefficient estimates to vary across space. Cartographic visualization of spatially varying relationships can highlight spatial trends and thus facilitate the identification of additional controls on the outcome variable or indicate suitable spatial subdivisions of model extents.

Both model types build on the same mathematical principle: Since the dichotomous outcome variable $\mathrm{Y}$ can take only one of two values (e.g. yes/ no, male/female), the relationship between $Y$ and an independent variable $X_{n}$ is 'S-shaped' (Figure 4.7). This violates the basic assumption of linear regression models that the relationship between predictor and dependent variable is linear. To overcome this violation, logistic regressions calculate conditional probabilities as the natural logarithm of the odds of $Y$ taking a specific value (referred to as logit or log-odds):

$$
\ln \left(\frac{P(Y=1)}{1-P(Y=1)}\right)=B_{0}+B_{1} X_{1}+B_{2} X_{2}+\cdots+B_{n} X_{n}
$$

where $P(Y=1)$ is the probability of outcome $Y$ taking the value $1, B_{0}$ the intercept, and $B_{n}$ the regression coefficient of the explanatory variable $X_{n}$ (representing the average relationship of all observations) (cf. Peng et al., 2002; Field, 2005). This way, the 'form' of the relationship becomes linear while the relationship itself stays non-linear. Solving for $P(Y=1)$, a multivariate global logistic regression model can thus be described by the equation:

$$
\begin{array}{ll} 
& P(Y=1)=\frac{1}{1+e^{-Z}} \\
\text { with } \quad & Z=B_{0}+B_{1} X_{1}+B_{2} X_{2}+\cdots+B_{n} X_{n}
\end{array}
$$

where $e$ is the base of the natural logarithm.

A local regression method of growing popularity is Geographically Weighted Regression (Brunsdon et al., 1996; Brunsdon et al., 1998; Fotheringham et al., 2002). Geographically Weighted Regression (GWR) models calculate a coefficient estimate $B_{n}$ for each variable $X_{n}$ at each observation location i. A multivariate logistic GWR model is thus a localised adaption of the global logistic regression model:

$$
\begin{array}{ll} 
& P\left(Y_{i}=1\right)=\frac{1}{1+e^{-Z_{i}}} \\
\text { with } \quad & Z_{i}=B_{0}\left(u_{i}, v_{i}\right)+\sum_{k} B_{k}\left(u_{i}, v_{i}\right) X_{k i}
\end{array}
$$

where $P\left(Y_{i}=1\right)$ is the probability of $Y$ taking the value 1 at location $i, B_{0}$ the intercept, $B_{k}$ the 


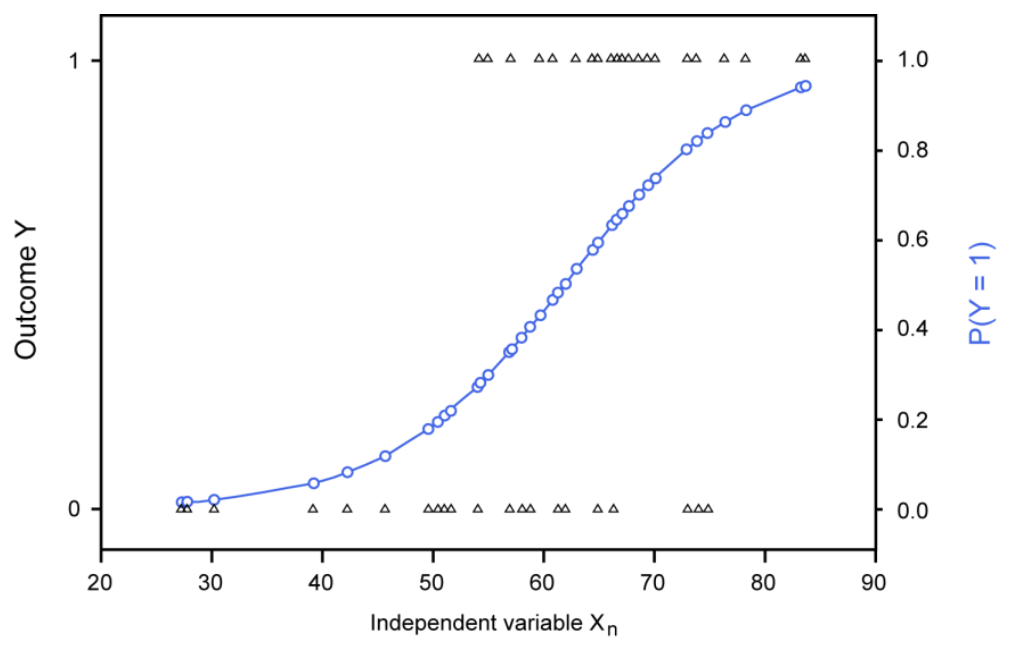

Figure 4.7

Example of the S-shaped relationship between the conditional probability of the outcome $Y$ being 1 and the continuous independent variable $X_{n}$ before logarithmic transformation of $P(Y=1)$. The triangles represent the actual observations, which can only take the outcome value 0 or 1. Source: Modified after Field, 2005, p. 265.

regression coefficient of the explanatory variable $X_{k}(k=1,2,3, \ldots, n), u_{i,}, v_{i}$ the coordinates at location $i$, and $e$ the base of the natural logarithm (cf. Brunsdon et al., 1996; Fotheringham et al., 2002).

Local regression coefficients $B_{k i}$ are calculated by employing a distance-decay-based weighting function, which gives more weight to observations closer to location $i$ than those further away (Brunsdon et al., 1998). The number of observations used for the coefficient estimate is defined by a spatial kernel, which can either be fixed (defined distance) or adaptive (defined number of observations). The choice of kernel depends on the spatial structure of the analysed dataset. For regularly distributed observations, a fixed distance is an appropriate analysis radius; for irregularly dispersed data, an adaptive kernel is recommended (Fotheringham et al., 2002).

The size of the spatial kernel, the so-called kernel bandwidth, has a large impact on the GWR model result (Fotheringham et al., 2002). Regression models run with large bandwidths use also a large number of observations for calculating the regression coefficients at location $i$ and thus have a similar smoothing (averaging) effect on calculated local coefficients as global regression models. Models run with small bandwidths, on the other hand, produce highly localised coefficient estimates and will thus display a high spatial variance in regression coefficients, which might disguise any existing trends in variable relationships. The appropriate kernel bandwidth for a given dataset is a trade-off between large sample bias and small sample variance and can be mathematically determined by goodness-of-fit calculations (Fotheringham et al., 2002).

The mathematical background to logistic regression, as well as information on procedures and interpretation, are extensively described in Hosmer and Lemeshow (2000), 
Menard (2002), Peng and So (2002), Peng et al. (2002), Field (2005), and Kleinbaum et al. (2010). Examples of global logistic regression analyses in the environmental science context include permafrost distribution studies (e.g. Lewkowicz and Ednie, 2004; Brenning and Trombotto, 2006), landslide susceptibility mapping (e.g. Ohlmacher and Davis, 2003; Nandi and Shakoor, 2010; Simon, 2012) and habitat modelling (e.g. Pereira and Itami, 1991). Detailed information on GWR is given in Brunsdon et al. (1996), Brunsdon et al. (1998), Fotheringham et al. (2002), and Wheeler and Tiefelsdorf (2005). Examples for the application of logistic GWR for geomorphologic and ecologic research questions can be found in Atkinson et al. (2003), Windle et al. (2010), Wimberly et al. (2008), and Erener and Düzgün (2010). Ridefelt et al. (2008) explored the use of logistic GWR for permafrost distribution modelling in northern Sweden.

\section{Model designs}

To explore spatial trends in the statistical relationship between rock glacier activity and the predictor variables mean annual air temperature (MAAT) and potential incoming solar radiation (PISR), three different model designs were tested:

- Permafrost model I (PFM I) uses global logistic regression to analyse variable relationships between permafrost presence, MAAT, and PISR based on active and relict rock glaciers mapped in the Canterbury Region.

- Permafrost model II (PFM II) also uses global logistic regression for relationship analysis, but coefficient estimates are calculated for each mountain range separately.

- Permafrost model III (PFM III) uses logistic GWR to identify spatial trends in variable relationships. Subregions, identified through this model, can subsequently be used for separate global regression models, similar to PFM II.

Splitting the area of application for the permafrost distribution estimate into meaningful subregions and employing region-specific distribution models has the potential to increase the spatial accuracy of the overall model result. It allows incorporating unobserved or unobservable variables into the model calibration without actually quantifying them (e.g. Ridefelt et al., 2008).

PFM I and PFM II were calculated in SPSS 18 (SPSS, 2009) and the 'stats' package in R (R Development Core Team, 2011). PFM III was calculated in GWR 4.0 (Nakaya et al., 2013). Additional model quality measure were computed in ROC-AUC (Schroeder, 2003). Moran's I test for spatial autocorrelation was performed in ArcGIS 9.3 (ESRI, 2009b). 


\section{Input data}

All regression models use the same input data: mapped active and relict rock glaciers, modelled mean annual air temperature at the rock glacier initiation line (MAAT, $\left[{ }^{\circ} \mathrm{C}\right]$ ), and modelled potential incoming solar radiation in snow-free months at the rock glacier initiation line (PISR, [kWh m$\left.{ }^{-2}\right]$ ).

Mapped active and relict talus-derived rock glaciers (including protalus rock glaciers) are used as dependent variable in the regression models, representing permafrost presence (1) and permafrost absence $(0)$ at the sample locations. Although per definition, inactive rock glaciers also indicate the presence of permafrost, their utilisation for predictive permafrost models is questionable. Firstly, the differentiation of inactive rock glaciers from active or relict features is generally difficult based on visual interpretation of remotely sensed imagery alone and thus inherently associated with high uncertainty (cf. Nyenhuis, 2006; also Section 4.2.1). Therefore, in practice, the category 'inactive' also comprises ambiguous cases, where visual characteristics do not quite fit either the active or the relict rock glacier description. Secondly, inactivity of rock glaciers can be due both to deteriorated climatic conditions or reduced sediment supply (climatic vs. dynamic inactivity, cf. Section 4.1.2). A differentiation between these two inactivity states is only possible by detailed field measurements of the local temperature regime and debris/ice supply conditions. While climatic inactive rock glaciers might be indicators for permafrost existence, as they still contain - albeit degrading - ice, they are inadequate for the analysis of permafrost favourable topoclimatic conditions. For these reasons, inactive rock glaciers were omitted from the regression analyses in the present study. This approach is supported by the modelling results of Nyenhuis (2006), who compared the predictive power of permafrost distribution models based on different combinations of active, inactive, and relict rock glaciers as input data. The model based on only active and relict rock glaciers achieved the highest predictive accuracy. Furthermore, where active rock glaciers occur nested in larger relict rock glaciers only the active rock glaciers were included in the regression analysis, as both features would be characterised by similar topoclimatic conditions and thus bias statistical relationship analyses.

Spatially-distributed information on mean annual air temperatures (MAAT, $\left[{ }^{\circ} \mathrm{C}\right]$ ) in the permafrost study regions (see next section) was modelled for the standard climate period $1971-2000$ by spatially interpolating and altitudinally extrapolating daily temperature data from nearby climate stations available in the National Climate Database (NIWA, 2010; listed in Appendix 6). Temperature data from the available stations was 1) lapsed to sea level, using a constant lapse rate of $-0.5^{\circ} \mathrm{C} / 100 \mathrm{~m}$ (BA5 method (Tait, 2010), conforming with Norton's (1985) empirical New Zealand-wide average lapse rate) and a $25 \mathrm{~m}$ DEM (Barringer et al., 2002) for elevation information, 2) interpolated between the stations to create a reference surface, and 3) extrapolated to the elevation of each grid point. For 
computational reasons (high data quantity over large areas), the analysis resolution was set to $100 \mathrm{~m}$. This generalisation was deemed acceptable, given that MAAT decreases only moderately with altitude. A significantly finer resolution of $15 \mathrm{~m}$ was chosen for the calculation of potential incoming solar radiation (PISR), which is characterised by a significantly higher spatial variability. Spatially-distributed PISR was calculated in ArcGIS (ESRI, 2009b) with the Spatial Analyst Extension tool 'Area Solar Radiation' and a $15 \mathrm{~m}$ DEM (Columbus et al., 2011a) as topographic base information. The underlying model accounts for both latitude and local viewshed and thus enables the identification of variations in insolation on a catchment scale. Information on the tool itself and employed algorithms are published in Fu and Rich (2000) and the ArcGIS online resources (ESRI, 2009a). Insolation sums $\left[\mathrm{kWh} \mathrm{m}^{-2}\right.$ ] were calculated for the snow-free period December to May (inferred from field observations in the Ben Ohau Range, cf. Section 4.3.4), since incoming shortwave radiation influences subsurface temperatures only in times of low albedo, i.e. when the ground is not covered by a reflective and insulating snow cover (e.g. Hoelzle, 1994). For lack of meteorological field data, default values representing general clear sky conditions were used as radiation parameter inputs (uniform diffuse radiation model, diffuse proportion 0.3 , and transmittivity 0.5 ). This means that the effect of clouds on radiation levels (lower transmittivity, higher diffuse proportion) was not parameterised in the calculations and incoming radiation might be overestimated in frequently overcast areas close to the Main Divide. 


\section{$4.3 \mid$ RESULTS}

This section presents the rock glacier inventory for Canterbury and the results of the inferred permafrost distribution estimate for the Southern Alps. Section 4.3.1 outlines characteristics of the rock glacier distribution in the Canterbury Region. Section 4.3.2 describes the results of the three model designs tested for model development and explains the reasoning for choosing a global regression approach for model training. Section 4.3.3 presents the application of the developed permafrost distribution model in the Southern Alps. The model results are evaluated by two independent permafrost indicator datasets in Section 4.3.4.

\subsubsection{Rock glacier inventory}

Rock glaciers occur in the Canterbury Region in the Inland Kaikoura Range, the Arthur's Pass region, the Lake Heron region, the Two Thumb Range, the Liebig-, Gamack-, and Hall ranges, the Ben Ohau Range, Neumann Range, and the Barrier Range. Based on this spatial clustering, seven study regions were delineated, which will serve as spatial units for the following regional comparison (Figure 4.8). The rock glacier study regions were named according to well-known mountain ranges or topographic features to assist the reader's spatial orientation. It shall be noted that the 'Liebig Range' study region includes besides the actual Liebig Range the Gamack Range and Hall Range. Similarly, the 'Ben Ohau Range' study region encompasses the adjacent Neumann Range. The rock glaciers mapped in the Inland Kaikoura Range are situated immediately east of the range's main ridge, which forms the administrative boundary to the neighbouring Marlborough Region. The search area was therefore expanded into the Marlborough Region for this study region, to include both the north-western and south-eastern flank of the Inland Kaikoura Range. However, rock glaciers were only found on the Canterbury side.

Overall, 386 rock glaciers were mapped in the Canterbury Region (the full inventory is listed in Electronic Appendix 3). The majority (87\%) of these are talus-derived rock glaciers with predominantly $(73 \%)$ multiple lobes (Figure 4.9). Twelve percent of the mapped features were interpreted as protalus rock glaciers, i.e. initial stages of permafrost creep. Moraine-derived rock glaciers were rare $(1 \%)$ in the investigated mountain ranges.

To assess the credibility of the established rock glacier inventory (which was created independently of previous studies), the dataset was compared to the regional inventories published by Brazier et al. (1998) and Barrell et al. (2011). Both published datasets were available in digital form (Brazier et al.'s (1998) published rock glacier list had been digitised 


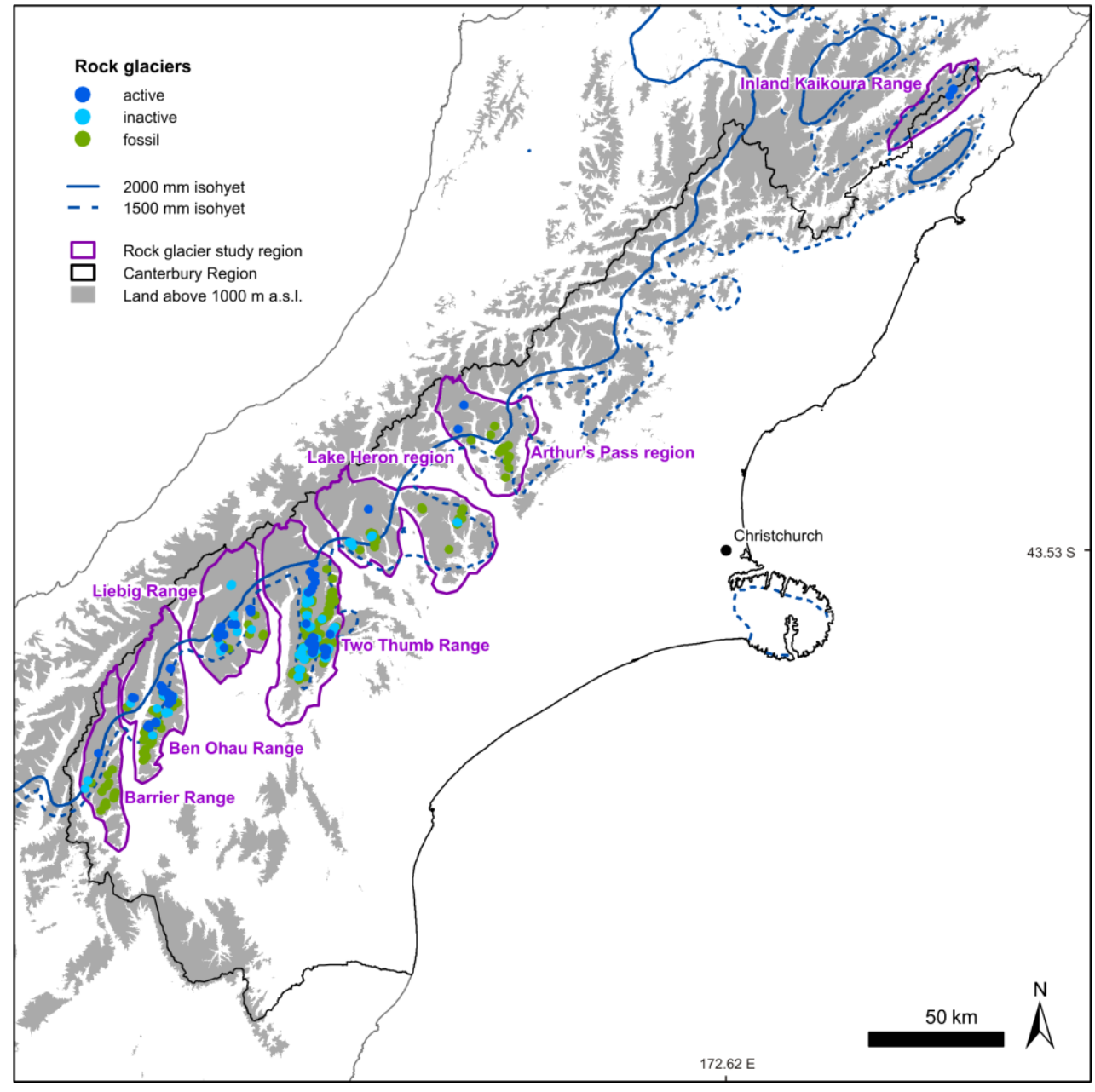

Figure 4.8

Rock glacier inventory for the Canterbury Region. The rock glacier distribution is characterised by a spatial offset from the Main Divide (identical to the north-western boundary of the Canterbury Region in map), which is best described by the $2000 \mathrm{~mm}$ isohyet (rainfall data: Tait, 2006, derived from NZ Metservice, 1985)).

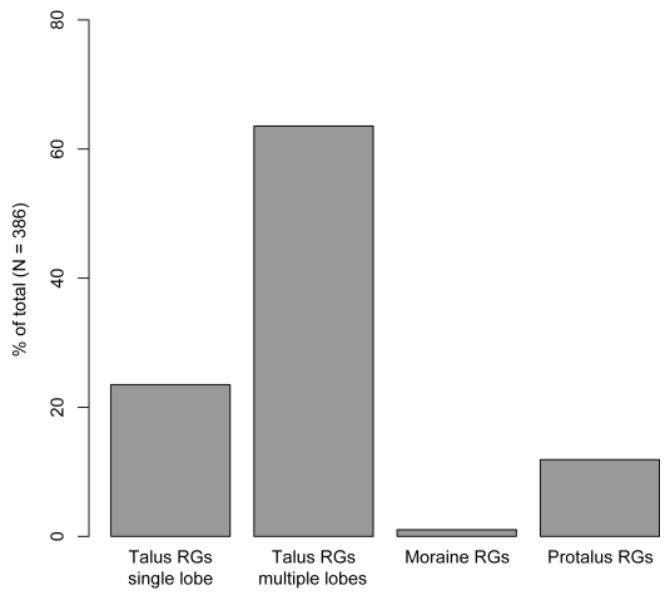

Figure 4.9

Rock glacier distribution according to rock glacier type. The majority of mapped rock glaciers were multi-lobe talus-derived features. 
by S. Allen (pers. comm. August 2009)). The published datasets could thus be easily compared with the mapped features within ArcMap. Information on the individual inventories, including properties mapped and spatial overlap with this study's inventory, is summarised in Table 4.3.

The comparison of the three inventories revealed a satisfactory agreement between the datasets, particularly in the mapping of active rock glaciers in the Ben Ohau Range (Brazier et al.'s (1998) dataset). Deviations primarily concerned the inclusion of landforms of similar morphology as rock glaciers into the published inventories. In the present study, only landforms whose morphology strongly suggested past, recent, or present creep of icesaturated debris were included in the inventory, aiming at reducing the potential bias introduced by mapping permafrost features solely by remotely-sensed imagery interpretation. Mapping criteria for the other inventories were defined more loosely or landforms classified differently. Brazier et al. (1998) tried to avoid a genetic classification of landforms (periglacial vs. glacial origin) and grouped talus-derived rock glaciers originating from cirque headwalls with other similar looking ridge-and-furrow features, such as moraine sequences or pronival ramparts, into the category of 'cirque-floor lobes'. Barrell et al. (2011) define rock glaciers as 'accumulation of angular rock debris with a wrinkled surface form that indicates downhill flow or creep, occurring in high mountain basins' (p. 79). The mapping of rock glaciers in this inventory appears to have been predominantly based on a 'wrinkled surface' and thus also includes small debris covered glaciers or moraine sequences.

Table 4.3 Comparison of this study's rock glacier dataset to published regional inventories.

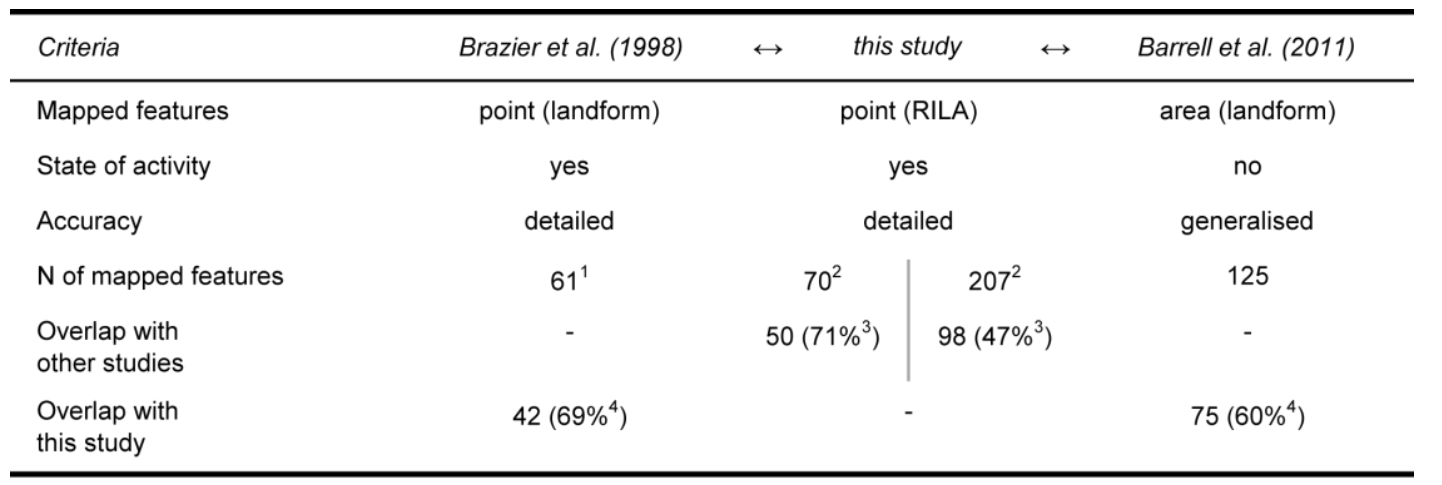

includes only rock glacier-related features of Brazier et al.'s (1998) inventory (codes T1, T2, CTM, CT)

2 number of features in area covered by the other inventory

3 percent of this study's features mapped in the other study

${ }^{4}$ percent of other study's features mapped in this study

\section{Distribution characteristics across the Canterbury District}

\section{Spatial distribution}

Rock glaciers occur predominantly in the drier southern parts of the investigated mountain ranges. The northern distribution boundary can be roughly described by the 
$2000 \mathrm{~mm}$ - isohyet (Figure 4.8). This value is higher than the northern distribution limit given by Brazier et al. (1998) for the Ben Ohau Range. However, it has to be noted that these two mean annual precipitation values were derived from different dataset and are thus most likely not directly comparable.

The number of rock glaciers mapped in the individual study regions varies significantly (Table 4.4). Signs of present and past permafrost creep were most abundant in the Two Thumb Range, followed by the Ben Ohau Range. Both of these ranges are high mountain ranges, extending comparatively far south (Figure 4.8). Situated in the rain shadow of the Main Divide, large areas of these ranges are characterised by low precipitation at high altitude and thus ideal for rock glacier development. A similar pattern is present when only considering intact rock glaciers. Besides the Two Thumb Range and Ben Ohau Range, the Liebig Range, situated in-between, also shows a comparatively high density of active and inactive rock glaciers; indicating that contemporary permafrost is likely to be most extensive in the central ranges of the Southern Alps.

Table 4.4 Rock glacier density according to study regions.

\begin{tabular}{lccccc}
\hline \multirow{2}{*}{ Region } & \multicolumn{2}{c}{$N$ RGs mapped } & & \multicolumn{2}{c}{$R G$ density [feature $/ 100 \mathrm{~km}^{2}$ ] } \\
\cline { 2 - 3 } \cline { 5 - 6 } \cline { 5 - 6 } total & intact & & total & intact \\
\hline Inland Kaikoura Range & 3 & 3 & & 1 & 1 \\
Arthur's Pass region & 16 & 2 & & 3 & 0 \\
Lake Heron region & 34 & 8 & & 3 & 1 \\
Two Thumb Range & 202 & 87 & & 17 & 7 \\
Liebig Range & 35 & 25 & & 4 & 3 \\
Ben Ohau Range & 76 & 38 & & 11 & 5 \\
Barrier Range & 20 & 3 & & 4 & 1 \\
\hline
\end{tabular}

\section{Activity}

Almost half $(43 \%)$ of the mapped rock glaciers were classified as intact, i.e. as permafrost creep features that presently still contain ice (Figure 4.10). A fifth of all rock glaciers $(20 \%)$ were thought to be active. The other quarter $(23 \%)$ were interpreted as having ceased moving in response to climate warming or decline in debris supply. However, their full forms suggested that these features still contain ice. The majority (57\%) of the mapped rock glaciers were classified as relict features that no longer contain ice.

The proportion of active, inactive, and relict features in the individual study regions varies significantly. Particularly noteworthy are the Liebig Range, where the majority of features were classified as active, and the Ben Ohau Range, where the number of intact and relict features is balanced. The Inland Kaikoura Range represents an unusual anomaly: All three 


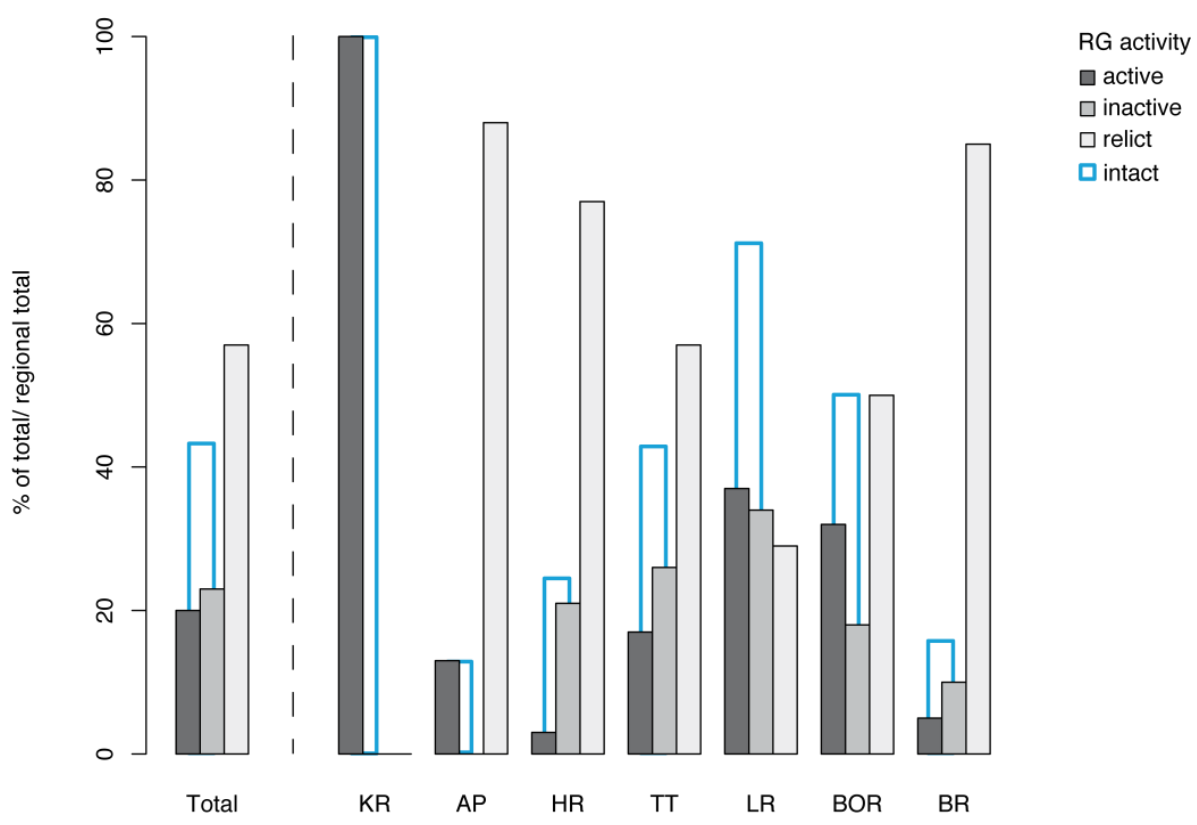

Figure 4.10

Rock glacier distribution according to activity status overall and differentiated by region. Almost half of all the mapped features were classified as intact, i.e. as presently still containing ice.

features mapped in this region were classified as active; no inactive or relict features were found. A possible explanation for the overall low number of rock glaciers and the complete lack of relict features in the Inland Kaikoura Range is the steep topography in this region (cf. Section 3.2.1). High erosion rates may have led to the removal or blanketing of fossil features at lower altitudes. Alternatively, suitable locations may have been occupied by true glaciers up to the recent geologic past. Several of the high-altitude south-east facing valleys below Tapuae-o-Uenuku (2885 m) still feature impressive debris-covered glaciers in their head areas.

\section{Altitude}

Based on the altitudinal centre of the mapped intact and relict rock glaciers (calculated as RILA minus half the altitudinal difference between RILA and rock glacier front), permafrost creep features in the Canterbury Region occur predominantly (95\%) between $1600 \mathrm{~m}$ and $2200 \mathrm{~m}$ a.s.l. (Figure 4.11). They are most abundant (26\%) between $1800 \mathrm{~m}$ and $1900 \mathrm{~m}$. A breakdown by study region, however, revealed that the altitudinal distribution varies across the Canterbury Region (Figure 4.12). While in the Inland Kaikoura Range, for example, rock glaciers occur only above $2300 \mathrm{~m}$, they are generally absent in this elevation zone in the similarly high Liebig Range. The altitudinal upper limit of rock glacier occurrence in the individual ranges strongly correlates with the local long-term glacier equilibrium line altitude as estimated by Lamont et al. (1999). Above this temperature-precipitation defined altitude, the annual amount of solid precipitation is sufficient for glaciation and hence 


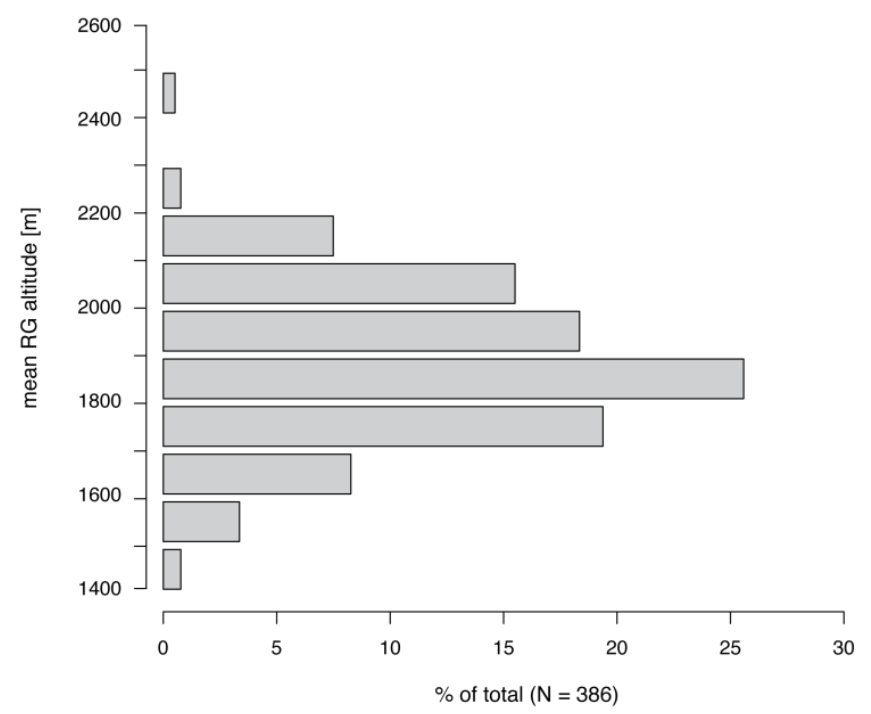

Figure 4.11

Rock glacier distribution according to mean rock glacier altitude. Rock glaciers are in the Canterbury Region most abundant between $1800 \mathrm{~m}$ and $1900 \mathrm{~m}$.

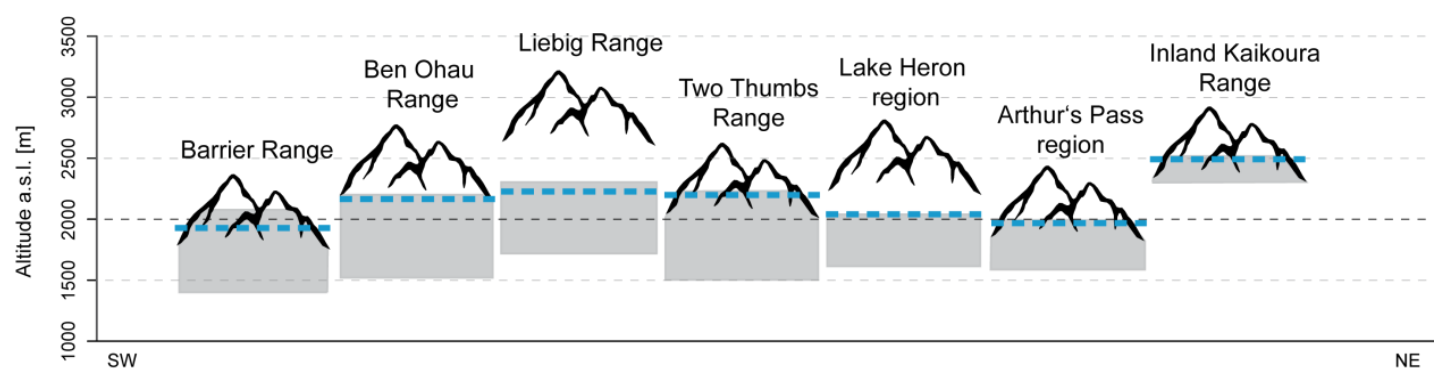

Figure 4.12

Altitudinal zone (grey bars) of rock glacier occurrence (based on mean RG altitude) in the individual study regions. The left mountain peak for each region symbolises the highest peak of the respective mountain range. The $2000 \mathrm{~m}$ altitude is highlighted as supplement for Figure 4.15. The blue dashed lines represent the approximate glacier equilibrium line altitudes (ELAs) in the individual study regions as estimated by Lamont et al. (1999). A clear relationship exists between the altitudinal upper limit of rock glacier occurrence and the local glacial equilibrium line altitude, which represents the lower boundary of the climatic zone where glaciers can exist.

suitable locations for rock glacier development are or have recently been (pre-20 ${ }^{\text {th }}$ century warming) occupied by permanent glaciers or permanent ice fields (cf. Humlum, 1998; Brenning, 2005a).

The analysis of the mean rock glacier altitude allowed the characterisation of altitudinal patterns in rock glacier distribution that also acknowledges the impressive lengths of some of the relict features. However, the focus of this study lies on characterisation of topoclimatic conditions at rock glacier initiation lines and the use of their spatial variation for modelling purposes. Mean annual air temperature (MAAT) is at a given latitude the climatic expression of elevation. It is therefore not surprising that initiation line altitude of the mapped rock 
glaciers (RILA) correlates strongly $(r=-.968, p=0.01)$ with the modelled MAAT values at these locations (Figure 4.13). The visible stratification between active and relict rock glaciers confirms the suitability of MAAT for differentiating between permafrost favourable and permafrost unfavourable locations. However, the pattern is not explicit with relict features also occurring at high altitude/ low MAAT locations. These deviating cases suggest the presence of an additional significant influence on permafrost distribution patterns. Alternatively, these cases might represent misclassified rock glaciers.

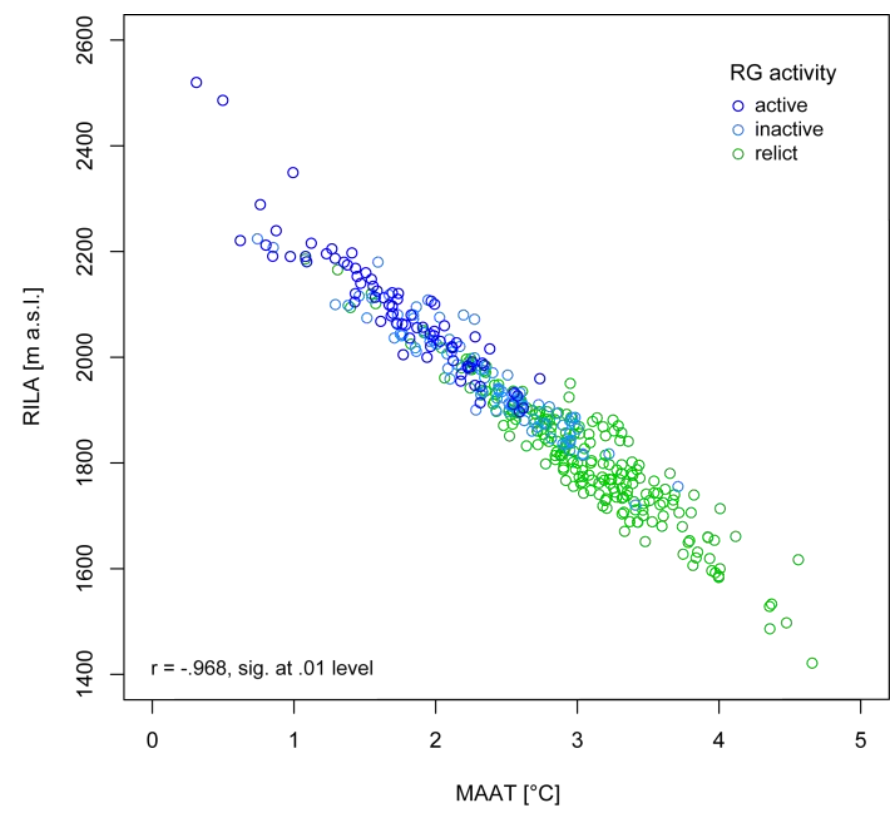

Figure 4.13

Relationship between modelled mean annual air temperature (MAAT) and rock glacier initiation line altitude (RILA) of the mapped rock glaciers $(N=386)$. A clear stratification is evident between active and relict features regarding the calculated MAAT at rock glacier head area.

\section{$\underline{\text { Aspect }}$}

More than two-thirds of the mapped rock glaciers face south (39\%) or south-east (29\%), i.e. are located on sun-avert slopes (Figure 4.14). A similar overall trend is visible in the individual inventory regions (Figure 4.15). However, focusing on the orientation of active features, clear differences exist between the individual regions that can only be partly explained by initiation line altitude. In the Two Thumb Range, active rock glaciers occur predominantly in southern to south-eastern aspects. In the Ben Ohau Range and Liebig Range, active features are also found at a similar altitude in south-western to western aspects. 
The aspect control on permafrost distribution patterns represents variations in the energy input into the ground by incoming solar radiation. A distinct relationship is visible between the orientation of mapped rock glaciers and the modelled potential energy input at the rock glacier initiation line (Figure 4.16). However, a differentiation between active and relict features based on PISR alone is not possible. This indicates that air temperature is the more significant predictor for permafrost occurrence. Yet, inclusion of information on insolation is likely to improve predictive models, as indicated by the clustering of active rock glaciers in sun-avert aspects in the regional rock glacier distribution diagrams (Figure 4.15) as well as the well-defined differentiation of active and relict rock glaciers by the two parameters combined (Figure 4.17).

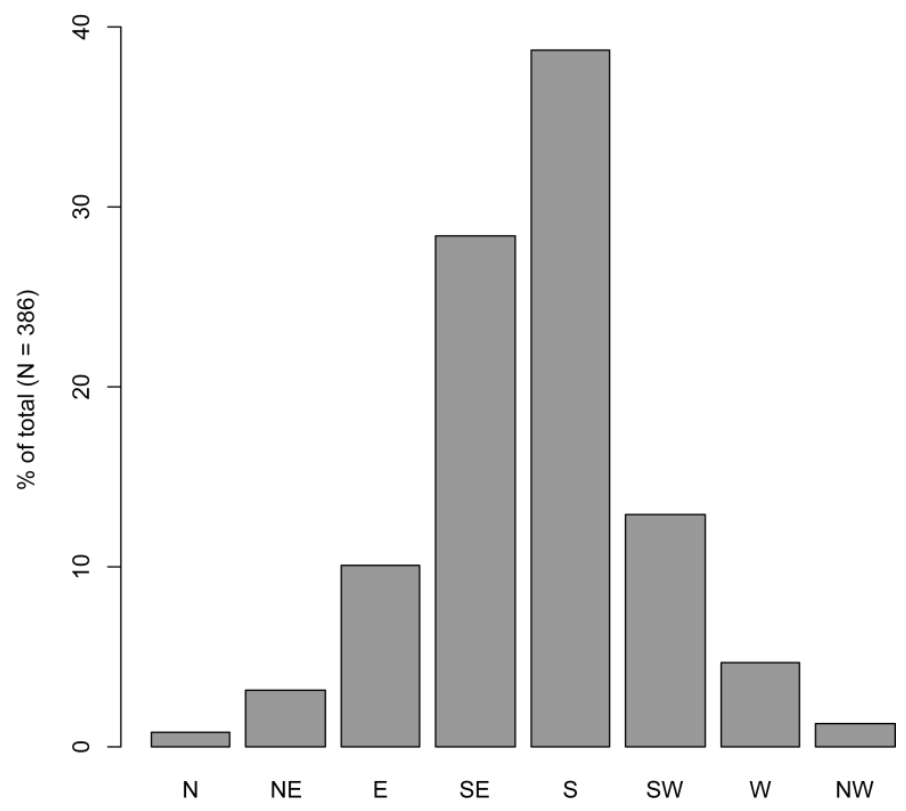

Figure 4.14

Rock glacier distribution according to aspect. Rock glaciers occur in the Canterbury Region predominantly in southern and south-eastern aspects. 

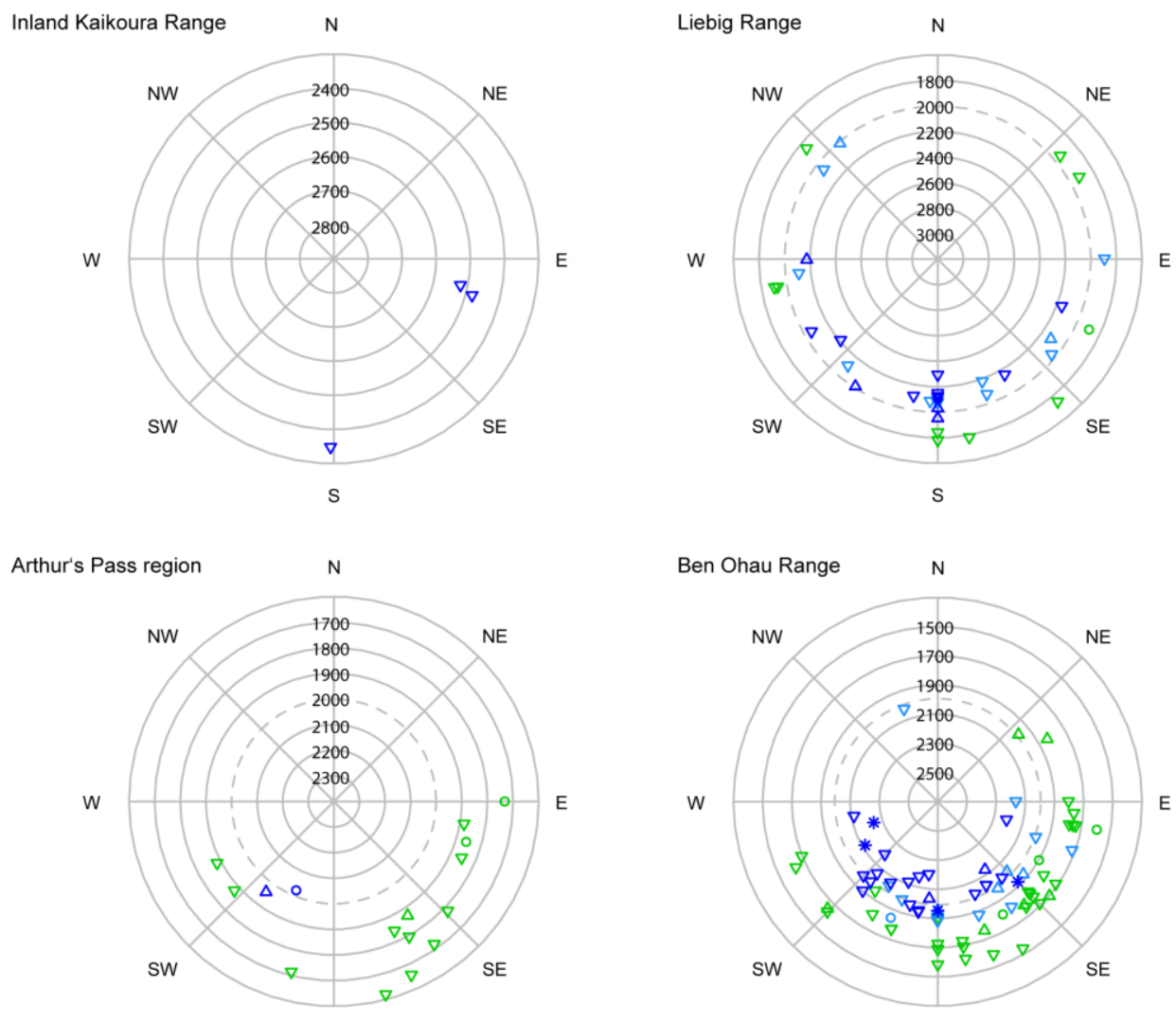

S
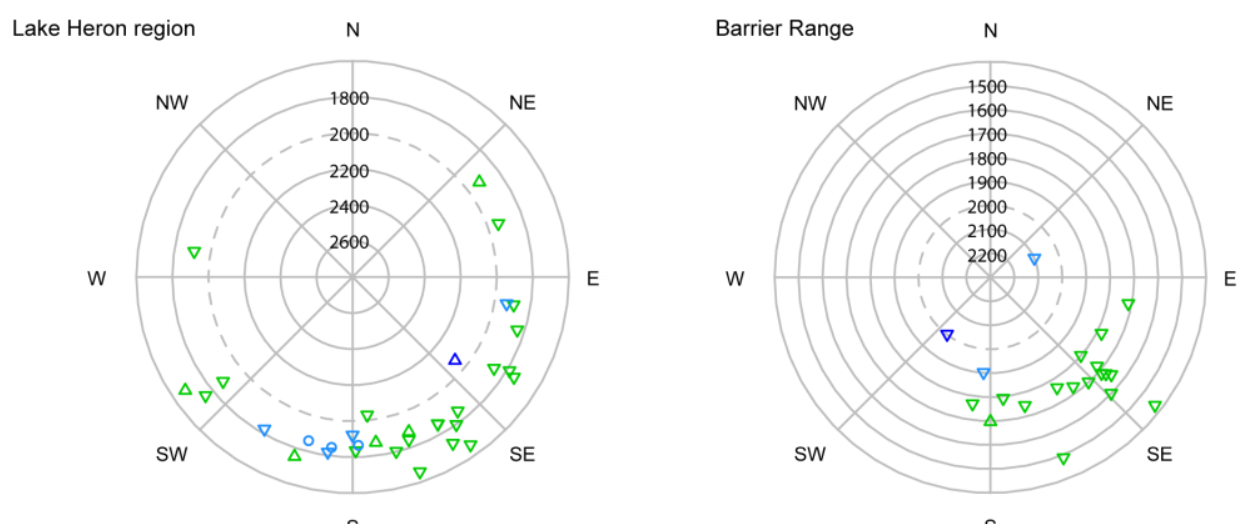

s

Two Thumb Range

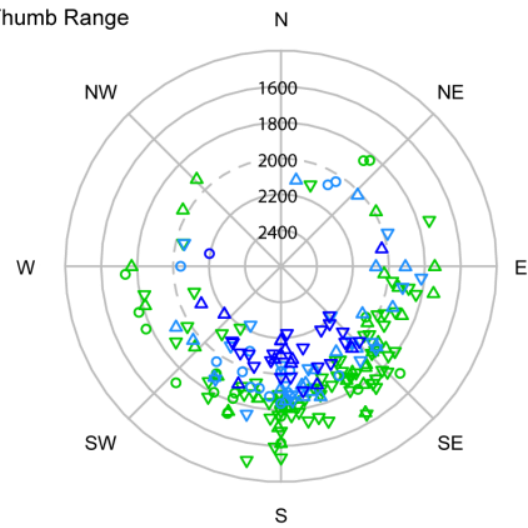

Rock glacier type

- Protalus rampart

$\Delta$ Talus-derived RG (single lobe)

$\nabla$ Talus-derived RG (multiple lobes)

* Moraine-derived RG

\section{Rock glacier activity}

active

inactive

relict

- 2000 m a.s.l.

Figure 4.15

Rock glacier distribution in study regions according to initiation line altitude (RILA) and aspect. The range of orientations in which active features occur varies between the study regions. 


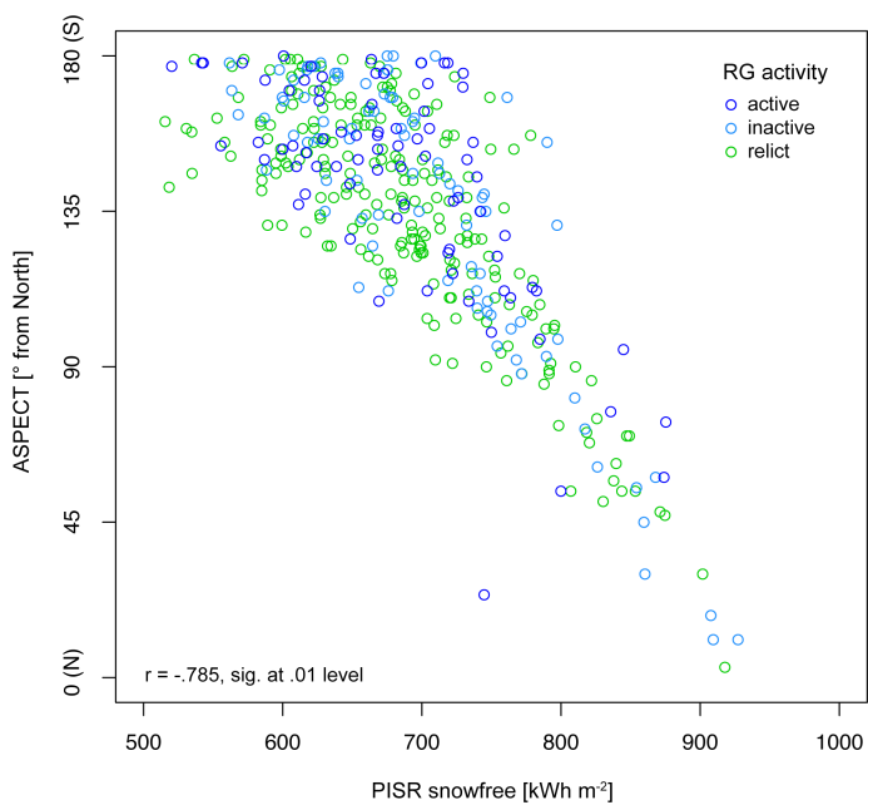

Figure 4.16

Relationship between the modelled potential incoming solar radiation (PISR) in snow-free months and rock glacier orientation $(\mathrm{N}=386)$.

The peculiar outlier at $745 \mathrm{kWh} \mathrm{m}^{-2}$ represents an active moraine-derived rock glacier below Mt Glenmary. Probably originating from dead-ice, the lateral moraine crept at this location outwards to both side, with the longer rock glacier tongue forming towards northwest.

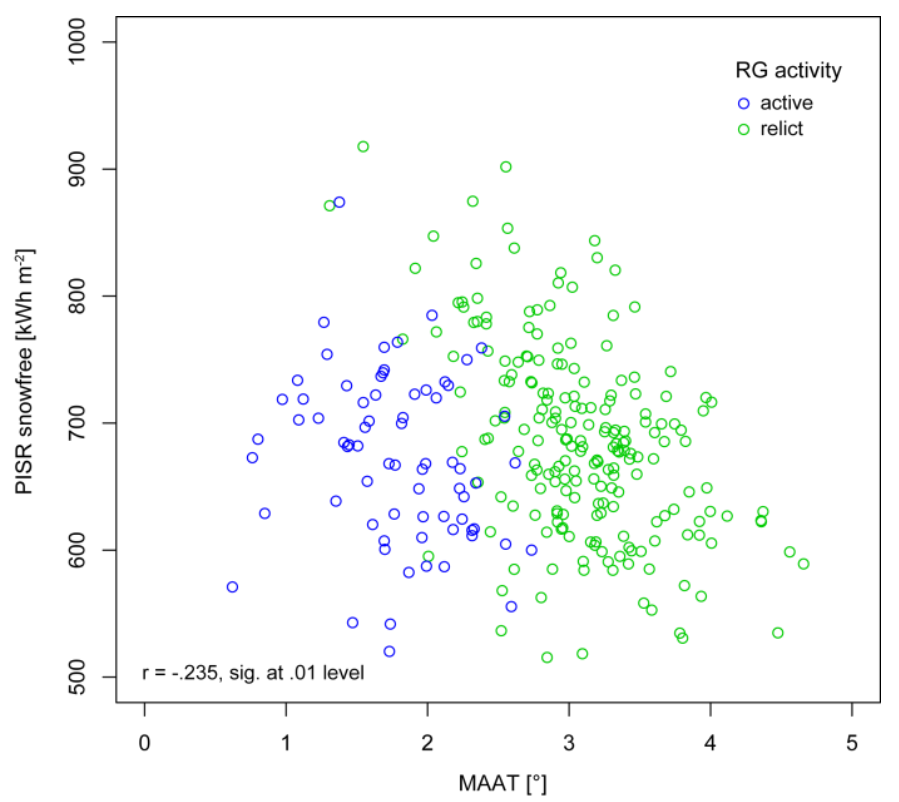

Figure 4.17

Relationship between modelled mean annual air temperature (MAAT) and modelled potential incoming solar radiation (PISR) in snow-free months for the active and relict talus-derived rock glaciers used for calibration of the permafrost distribution model $(N=280)$. A clear differentiation is evident between active and relict features, indicating the suitability of the two parameters for permafrost distribution modelling. 


\subsubsection{Regression models}

Three logistic regression models were tested to explore the potential presence of nonstationarity in the statistical relationship between active rock glaciers and the topoclimatic parameters MAAT and PISR and thus the possibility of spatial variance in the predictive power of the two topoclimatic parameters for permafrost occurrence. The three models are based on active and relict rock glaciers from the central Canterbury ranges only. The three active rock glaciers in the Inland Kaikoura Range were omitted from the analysis to avoid potential bias of the regression results, since no relict features were mapped in this region to allow a reasonable comparison of permafrost favourable and unfavourable topoclimatic conditions. Overall, a dataset of 280 active and relict rock glaciers was available for the regression analysis. Results of the three model designs are listed in Table 4.5. The individual model results are discussed in the following after a short introduction to common problems in logistic regressions, relevant for all three model designs, and model performance measures.

\section{Common problems in logistic regressions}

Logistic regression models are, like linear regression models, sensitive to correlation between predictor variables (Hosmer and Lemeshow, 2000; Field, 2005). The higher the correlation between the independent variables, the greater the number of equally well-fitting coefficient estimates for a given relationship. High numbers of possible coefficient estimates equate mathematically to a high standard error for calculated coefficients and thus reduce the statistical significance of the estimated relationship. Field (2005) states that bivariate predictor correlations greater than .80 are strong indicators that the output of a regression model will be influenced by multicollinearity. A more sophisticated measure for the presence of critical correlation levels is the variance inflation factor (VIF). VIF values greater than 10 are considered critical. Average VIF values greater than 1 indicate that multicollinearity might be biasing the regression output (e.g. Menard, 2002; Field, 2005).

Another common bias for logistic regression models is the number of events per predictor variable (EPV), which has been found to be an influential control on the confidence interval for calculated regression coefficients (e.g. Peduzzi et al., 1996; Vittinghoff and McCulloch, 2007). Hosmer and Lemeshow (2000) recommend as a rule-of-thumb 10 events per parameter as a sensible sample size, where 'events' equals responses of the less numerous variable value. More recent studies (e.g. Vittinghoff and McCulloch, 2007; Courvoisier et al., 2011) found that, although this guideline is helpful for highlighting potentially problematic models, it is not a definite threshold. Other factors, such as the number of predictors, overall 


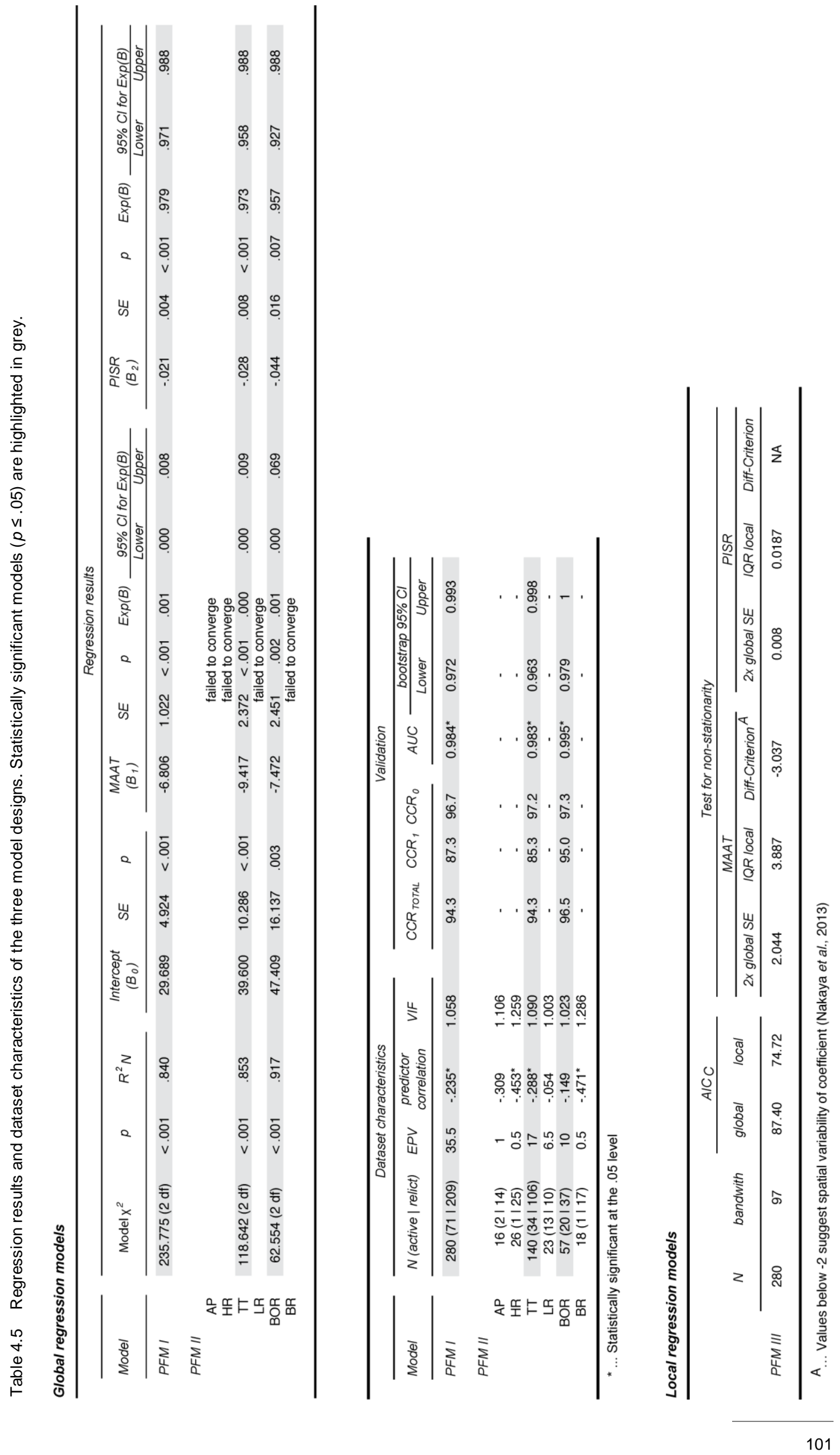


sample size, and collinearity between the predictor variables significantly influence the performance of regression models and can lower critical values well below the 10 EPV threshold.

A third common problem is that logistic regression models fail when an outcome variable can be perfectly or almost-perfectly predicted by one or a combination of several independent variables (e.g. Menard, 2002; Field, 2005). These situations, known as complete or quasi-complete separation, are more likely to occur in small sample populations (Peng and So, 2002). Although in theory, it is desirable to include variables with particularly high predictive power into the regression model, in practice, the lack of overlap in the distribution of predictor values between outcome groups means that an infinite number of valid curves can be fitted to the data (Figure 4.18). Such data structures render regression models unstable, which may result in non-convergence (i.e. no coefficient estimate achieved) or inflated standard errors for calculated coefficient estimates (Hosmer and Lemeshow, 2000).

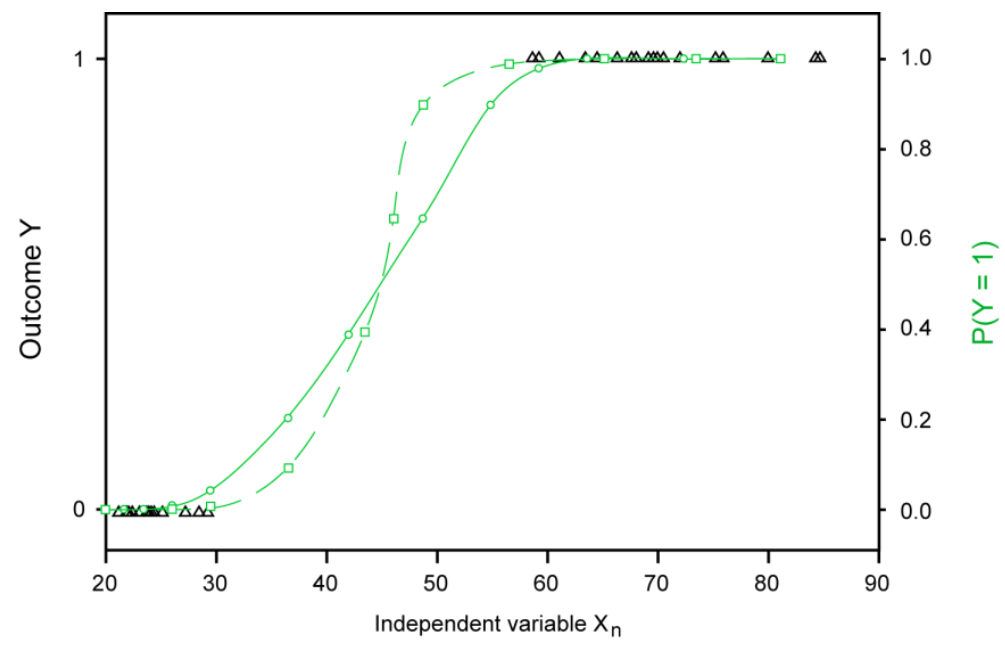

Figure 4.18

Example of complete separation in values of the predictor variable $X_{n}$ for the outcome $Y$. The green lines signify possible fitted curves, indicating multiple possible coefficient estimates for the relationship between $Y$ and $X_{n}$. Source: Modified after Field, 2005, p. 265.

\section{Model performance measures}

The performance of a logistic regression model can be evaluated by the model's discriminative ability, i.e. the model's ability to adequately predict the presence or absence of a certain event (e.g. Rykiel, 1996; Pearce and Ferrier, 2000; Harrell, 2001). Ideally, a model's discriminative ability is tested on a separate dataset (external validation). Hence, data-splitting is a popular validation technique for large datasets, where half, a third, or a fifth of the original data are withheld from model training and used for model validation 
(Steyerberg et al., 2001; Schroeder and Reineking, 2004). Data-splitting is only feasible in sufficiently large datasets, where the loss of training data is unlikely to jeopardise model fit. Harrell (2001) recommends 100 subjects in the less frequent outcome class (i.e. $100 \mathrm{EPV}$ ) for datasets to qualify for data-splitting. However, Steyerberg et al. (2001) consider samples with 40 EPV already suitable for data-splitting validation. For smaller datasets, resampling techniques, such as cross-validation and bootstrapping, are more appropriate (e.g. Fielding and Bell, 1997; Harrell, 2001; Schroeder and Reineking, 2004). These so-called internal validation procedures assess a model's predictive performance by calculating a mean validation criteria with confidence intervals for a given number of training- and test samples, randomly drawn from the whole dataset that was used for model development. For $k$-fold cross-validation, the dataset is split into k equal parts; $k-1$ parts are used to train the model which is then tested on the remaining part. In bootstrapping, a sample of $n$ cases is drawn with replacement from the original dataset for model training, while the rest of the dataset serves as test sample. Generally several hundred bootstrap samples are analysed for model validation, making bootstrapping the most efficient internal validation technique (Steyerberg et al., 2001).

A popular measure for spatial distribution models' discriminative ability is the area under the receiver operating characteristic (ROC) curve, known as AUC (cf. Pearce and Ferrier, 2000; Schroeder and Reineking, 2004; Lobo et al., 2008). The AUC denotes the probability that for a randomly drawn pair of presence/absence data, the model will predict a higher value for the presence case than for the absence case (Fielding and Bell, 1997). Based on the ROC curve, which plots sensitivity (correctly predicted event fraction) as a function of the commission error (1 - falsely predicted event fraction) (cf. Figure 4.21), the AUC score offers a single value for model comparison, independent of a defined cut-off value. This is an advantage over confusion-matrix based measures, such as the correct classification rate (CCR), which require the definition of a threshold above which a certain probability is evaluated as an event. Although this threshold is commonly held constant for model comparison within a single study, it might impede the comparison of model performance between independent studies. In the present study, models' predictive powers are compared by both, bootstrapped AUCs and correct classification rates (CCR) based on a cut-off value of 0.5 . All validation values were calculated using the freely available software program 'ROC Plotting and AUC Calculation Transferability Test' (Schroeder, 2003).

\section{PFM I}

PFM I represents the most basic model design analysed. Using global logistic regression on all mapped active and relict rock glaciers, PFM I analyses the regionally-averaged statistical relationship between permafrost presence and the predictor variables MAAT and PISR. 
The model's overall fit, as well as all coefficient estimates, were statistically highly significant $(p<.001$, Table 4.5), indicating that MAAT and PISR adequately predict the presence of active rock glaciers in the study regions. As expected, both MAAT $(B=-6.806)$ and PISR $(B=-.021)$ are negatively related to contemporary permafrost occurrence. In other words, the lower the mean annual air temperature and the lower the incoming solar radiation totals during the snow-free months at the rock glacier initiation line, the higher the probability that the mapped feature is presently still active. The large difference in magnitude between the two coefficient estimates stems from a difference in magnitude of the predictor values, and thus does not signify a significantly inferior predictive power of PISR as such. However, regression coefficients for standardised predictor values (Table 4.6) indicate that a unit change in MAAT has a larger effect on the probability of permafrost being present at a given location than a unit change in PISR. Moran's I analysis showed regression residuals are spatially independent (Moran's $I=0.059, p=.507$ ) and parameter estimates thus unbiased by spatial autocorrelation of observations.

Validation criteria suggest that PFM I achieves a high predictive accuracy (Table 4.5). The AUC score of 0.98 indicates an excellent discriminative ability between permafrost presence and absence according to Hosmer and Lemeshow (2000). This is also shown by the high overall correct classification rate (CCR $\mathrm{CROTAL}_{\text {TA }}$ ) of $94.3 \%$. However, the difference between correctly classified presence $\left(\mathrm{CCR}_{1}=87.3 \%\right)$ and correctly classified absence $\left(\mathrm{CCR}_{0}=96.7 \%\right)$ signals that the model performs better at predicting permafrost absence than permafrost presence (using the common cutoff-value of 0.5 ).

Table 4.6 Regression results for PFM I calculated with standardised predictor variables ZMAAT and ZPISR.

\begin{tabular}{|c|c|c|c|c|c|c|}
\hline Model $x^{2}$ & \multicolumn{3}{|c|}{$235.775(2 \mathrm{df}), p<.001$} & $\mathrm{CCR}_{\text {TOTAL }}$ & 264/280 & \\
\hline \multirow{3}{*}{$\mathrm{R}_{\mathrm{N}}^{2}$} & \multicolumn{3}{|l|}{.840} & $\mathrm{CCR}_{1}$ & $\begin{array}{c}202 / 209 \\
62 / 71\end{array}$ & $\begin{array}{l}96.1 \% \\
87.3 \%\end{array}$ \\
\hline & \multirow[b]{2}{*}{ B } & \multirow[b]{2}{*}{ SD } & \multirow[b]{2}{*}{$p$} & \multirow[b]{2}{*}{$\exp (B)$} & \multicolumn{2}{|c|}{$95 \% \mathrm{Cl}$ for $\exp \mathrm{b}$} \\
\hline & & & & & Lower & Upper \\
\hline Z MAAT & -5.286 & .793 & $<.001$ & .005 & .001 & .024 \\
\hline Z PISR & -1.556 & .330 & $<.001$ & 211 & 110 & 403 \\
\hline Constant & -3.405 & .540 & $<.001$ & .033 & & \\
\hline
\end{tabular}

\section{PFM II}

For PFM II, separate global regression models were fitted for the individual rock glacier study regions, aiming at identifying potential differences in the strength of variable relationships between the regions. 
Statistically significant model fits were only achieved for the Two Thumb Range (TT) and the Ben Ohau Range (BOR) (Table 4.5). These two regions are the only areas with EPV values above Hosmer and Lemeshow's (2000) critical threshold of 10 events per predictor variable. Collinearity statistics (VIF) are below critical levels for all datasets, suggesting that the events per variable and thus sample sizes are the main reason for failure of the four other regions' models.

Comparing the coefficient estimates for the Two Thumb Range and the Ben Ohau Range reveals differences in variable relationships between the two regions. Most noteworthy is the difference in the contribution of PISR for permafrost prediction with PISR being more influential in the Ben Ohau Range than in the Two Thumb Range. Differences also exist in model performance: The Ben Ohau Range model achieves higher scores for both AUC and overall correct classification rates than the Two Thumb Range model due to a better ability to predict permafrost occurrences $\left(\mathrm{CCR}_{1}\right)$.

\section{PFM III}

PFM III represents the local logistic regression model, calculated in GWR 4.0 (Nakaya et al., 2013) for all 280 active and relict rock glaciers of the southern Canterbury region (Table 4.5, Figure 4.19).

Localised regression models for the individual sample points were computed based on an adaptive kernel of 126 data points (cf. Section 4.2.2). This value was calculated in GWR 4.0 by $\mathrm{AIC}_{\mathrm{C}}$ (corrected Akaike Information Criterion) minimisation as the appropriate bandwidth for the given dataset of spatially clustered sample points.

The decrease in $\mathrm{AIC}_{\mathrm{C}}$ scores (a relative goodness-of-fit criterion accounting for model complexity, e.g. Harrell, 2001) of the local model on the global model by more than 3 points (Table 4.5) indicates a statistically significant improvement of performance of the local model that allows for spatial variance in variable relationships (Fotheringham et al., 2002). The presence of non-stationarity of statistical relationships in the analysed sample population is also suggested by a higher variance in local coefficient estimates than predicted by the global model (Charlton et al., 2003): The interquartile range (i.e. range within which $50 \%$ of cases lie) for the local coefficient estimates of both MAAT and PISR are significantly larger than two times the standard error (i.e. 1 standard deviation, range of approximately $68 \%$ of cases provided cases are normally distributed) of the respective global coefficient estimate (Table 4.5). Non-stationarity was statistically verified for the predictor MAAT; the respective test for PISR was inconclusive (Table 4.5).

Spatial mapping of the coefficient estimates revealed an increasing negative relationship with distance from the Main Divide for both predictors, displaying the strongest effect in the most distal southern Two Thumb Range (Figure 4.19 C, D). Statistical significance for 
coefficient estimates across the analysis region varied between the predictor variables. While MAAT estimates were at only five locations not statistically significant at the .05 level, non-significant PISR coefficient estimates were frequent (Figure 4.19).

Given the strong climatic gradients present in the Southern Alps perpendicular to the Main Divide (cf. Chapter 2), the observed pattern appears reasonable and might represent a real influence of one or several unaccounted controls, such as the dampening effect of cloud cover on PISR. However, recent critical analyses of GWR, triggered by the increasing popularity of the procedure for applied research, warn against rash interpretations of spatial
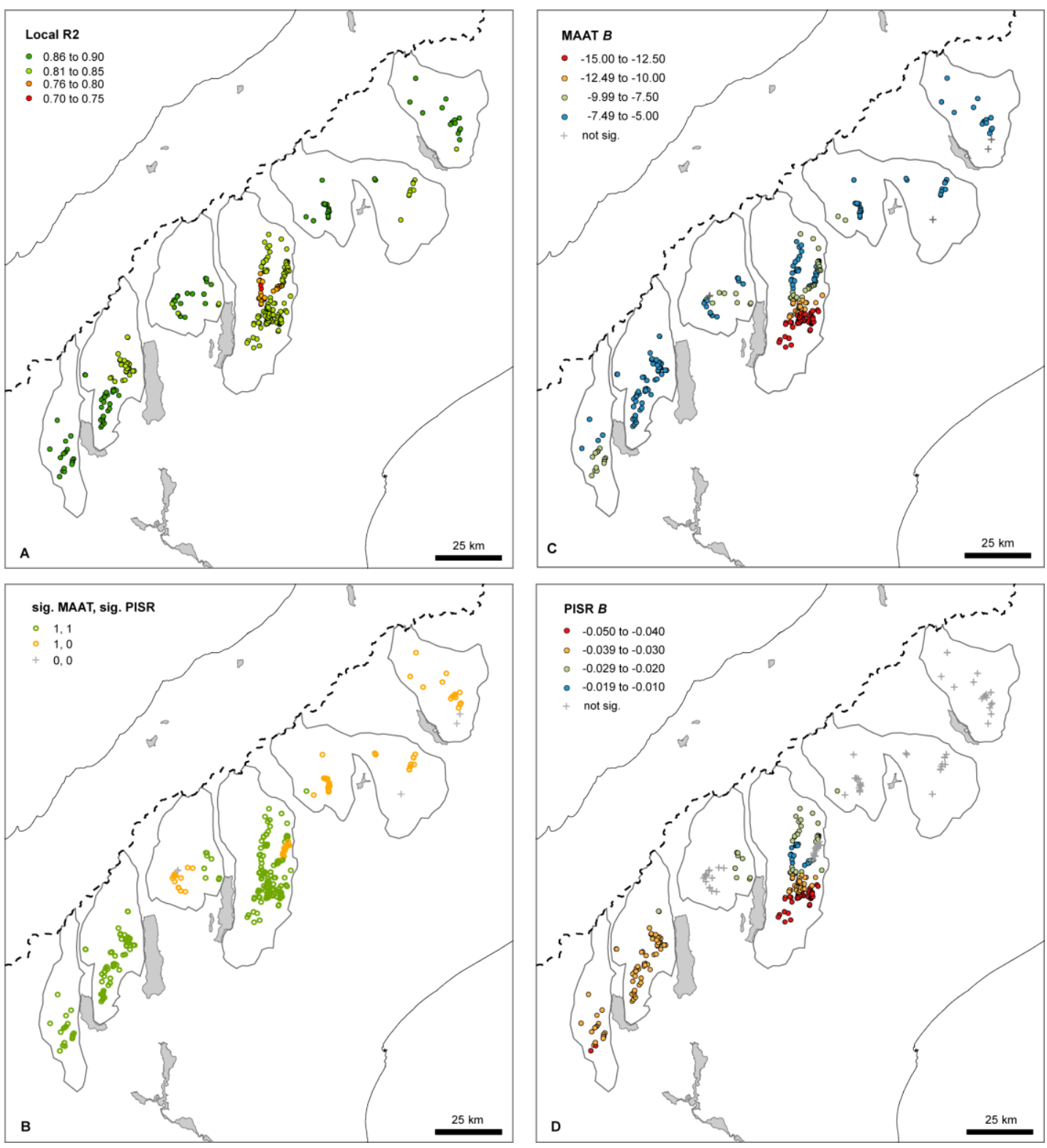

Figure 4.19

Results of PFM III: A) Local $\mathrm{R}^{2}$; B) Significance of coefficient estimates for MAAT and PISR at location $i$; $1=p \leq .05,0=p>.05$, inferred from absolute t-values $</> \pm 1.96$ (Fotheringham et al., 2002) ; C) Coefficient estimates for MAAT at location $i$; D) Coefficient estimates for PISR at location $i$. 
patterns of local GWR estimates (e.g. Jetz et al., 2005; Wheeler and Tiefelsdorf, 2005; Cho et al., 2010). A main concern is that parameters might be correlated on a local scale even if predictors are unrelated on the global scale. Resulting multicollinearity issues bias the local coefficient estimates and thus hamper any meaningful interpretation of spatial variance in calculated variable relationships (Wheeler and Tiefelsdorf, 2005).

Strong correlations between local coefficient estimates are indicative of multicollinearity problems in GWR calculations and highlight regions where results might be distorted by statistical artefacts (Wheeler, 2008). A scatterplot of the local coefficient estimates for MAAT and PISR reveals that local estimates for the southern Two Thumb Range, the Ben Ohau Range, and the Barrier Range are highly correlated (Figure 4.20). Estimates in these regions might, therefore, be significantly biased by multicollinearity and the calculated heterogeneity in variable relationships artificial. Similar is true for coefficient estimates in the Arthur's Pass region and eastern Lake Heron region. The counter-intuitive positive relationship between PISR and permafrost occurrence in these areas is already a strong indicator for statistical problems in the local data structure (Wheeler and Tiefelsdorf, 2005). Additionally, PISR coefficient estimates in these regions were statistically not significant on the .05 level (Figure 4.19 D), further highlighting these areas as problematic.

More thorough statistical analyses, so far not included in standard GWR programs, would be needed to further investigate the statistical stability of the indicated spatial nonstationarity in variable relationships. In view of the involved uncertainties, resulting to some extent from the novelty of local regression approaches, such further analyses were deemed impracticable.
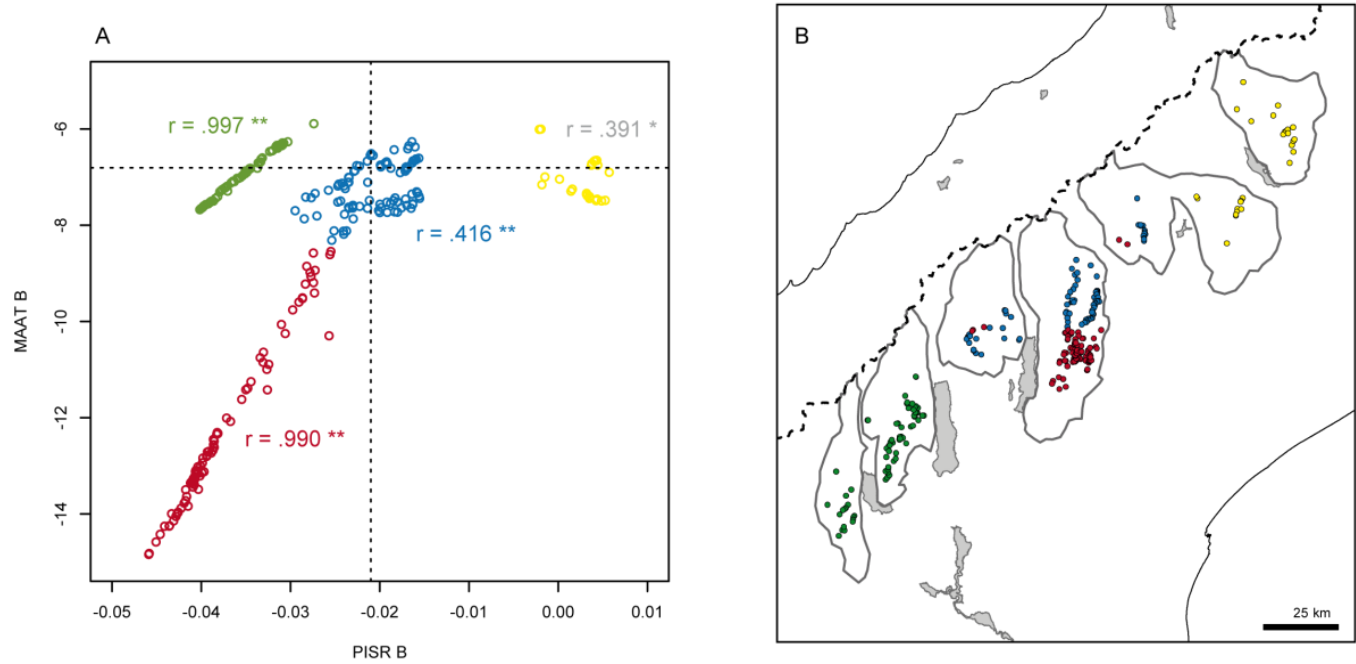

Figure 4.20

Scatterplot of local coefficient estimates for MAAT and PISR (Plate A), highlighting subsamples of high correlation and thus the presence of spatial structure effects in the local coefficient estimates. Pearson correlation coefficients are given for the individual subsamples, with ** denoting significance on .01 level and * significance on the .05 level. The identified subsamples are spatially visualised in Plate B, using a corresponding colour scheme. 


\section{Model comparison and conclusion}

The global regression model PFM I quantified the statistical relationship between the two predictor variables, MAAT and PISR, and permafrost occurrence averaged across all 280 sample points. The overall model as well as the predictive effect of both MAAT and PISR were statistically highly significant $(p<.001)$. Both predictors showed the expected negative relationship to permafrost presence, i.e. the lower modelled mean annual air temperature and the lower the potential incoming solar radiation, the higher the probability of permafrost at a given location. PFM I distinguished reasonably well between permafrost absence and permafrost presence; however, correct classification rates suggest that the model performed better at predicting locations without permafrost than locations with permafrost present.

Both PFM II and PFM III, representing more localised model approaches, suggested the presence of non-stationarity in the statistical relationships of MAAT and PISR with observed permafrost presence. While PFM II highlighted differences in relationship strengths between the study regions, PFM III suggested that the underlying spatial trend might run perpendicular to the Main Divide.

The two successful global regression models calculated as part of PFM II for the Two Thumb Range and the Ben Ohau Range produced different coefficient estimates $\left(T T: B_{\text {MAAT }}=-9.417, B_{\text {PISR }}=-.028 ;\right.$ BOR: $\left.B_{\text {MAAT }}=-7.472, B_{\text {PISR }}=-.044\right)$. Model performance of the Ben Ohau Range model exceeded the Two Thumb Range model with a notably higher correct classification of permafrost occurrences, indicating that the predictive power of MAAT and PISR varies between the two study regions. The good performance of the Ben Ohau Range model remains also when applied to the other ranges (Figure 4.21, Area Rest): Its ability to predict active rock glaciers is identical to PFM I $\left(\mathrm{CCR}_{1}=86.3 \%\right)$; however, it is slightly inferior in the correct classification of non-permafrost sites $\left(\mathrm{CCR}_{0}=92.4 \%\right.$ vs $97.1 \%)$.

Results of PFM III indicate an increase in predictive power of both MAAT and PISR with increasing distance from the Main Divide. The good predictive performance of the PFM II Ben Ohau model might be explained by fairly stationary coefficient estimates calculated by PFM III for the Ben Ohau Range and its wider surroundings. In contrast, local coefficient estimates for the Two Thumb Range, which extends the furthest from the Main Divide, show a higher variability. It has to be noted that the high density of data points in the Two Thumb range amplifies local variations, as the sample points used as input for the localised models are situated in comparatively short distance to the local regression point. High correlation of local coefficient estimates in both the Ben Ohau Range and Two Thumb Range suggests the presence of multicollinearity problems in the local subsamples used for model calibration. Without further analyses and corrective measures it can therefore not be 
excluded that the spatial heterogeneity in variable relationships indicated by PFM III is mainly the product of statistical artefacts.

Despite indications for spatial heterogeneity in the statistical relationships of MAAT and PISR with observed permafrost presence, results of PFM II and PFM III were not conclusive enough for warranting the delineation of subregions, which might improve the predictive accuracy of the permafrost distribution model. The permafrost extent in the Southern Alps was therefore in the following estimated according to the statistical relationships identified in the global regression model PFM I.

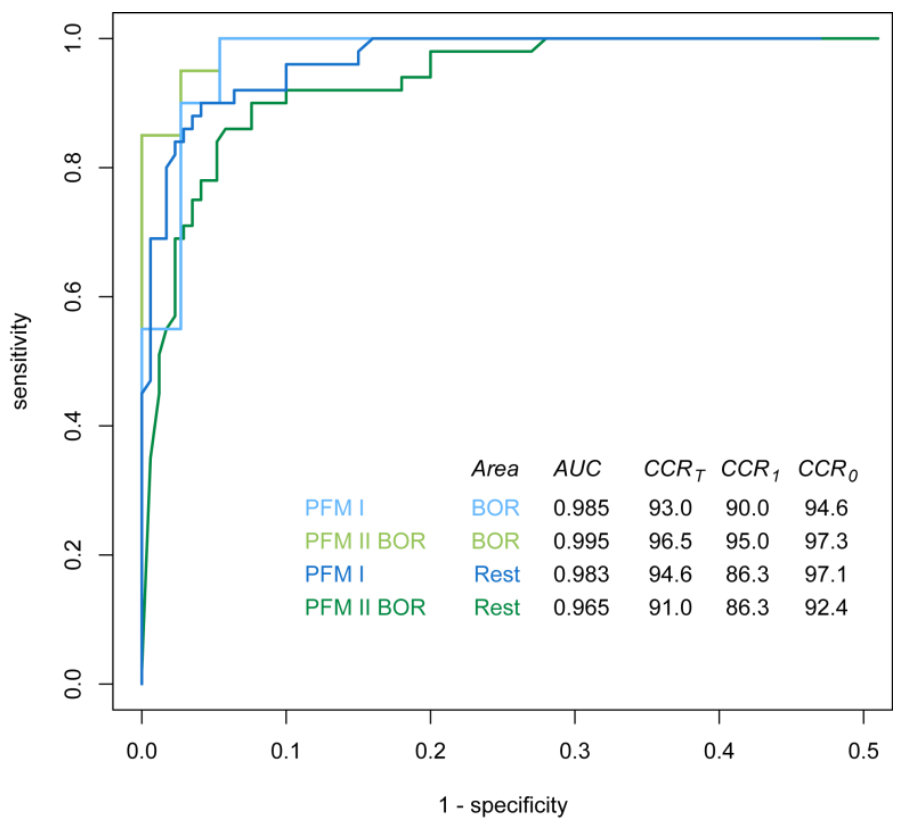

Figure 4.21

ROC curves of the models PFM I and PFM II BOR for the area Ben Ohau Range (BOR) and all other areas combined (Rest). Insert table shows AUC values, overall correct classification rate $\left(C_{C} R_{T}\right)$, correct classification rate of permafrost presence $\left(\mathrm{CCR}_{1}\right)$, and correct classification rate of permafrost absence $\left(\mathrm{CCR}_{0}\right)$ for the respective models.

The ability of the Ben Ohau Range model (PFM II BOR) to predict active rock glaciers in the remaining areas (Rest) is identical to the global overall model (PFM I), however, is slightly inferior in the correct classification of non-permafrost sites.

\subsubsection{Permafrost distribution estimate for the Southern Alps}

The potential extent of contemporary permafrost in seven study regions was modelled based on the statistical relationship between mean annual air temperature (MAAT, ${ }^{\circ} \mathrm{C}$ ), potential incoming solar radiation in snow-free months (PISR, $\mathrm{kWh} \mathrm{m}^{-2}$ ), and permafrost presence (initiation line of active rock glaciers), described in the global regression model PFM I (Section 4.3.2). It is thought that the developed distribution model is likely to be valid 
also outside the areas used for model training. However, for this general overview of the potential contemporary permafrost extent in the Southern Alps, permafrost distribution was only calculated for the seven permafrost study regions. Spatially-distributed conditional probabilities of permafrost presence were obtained by raster calculation in ArcGIS 9.3 (ESRI, 2009b) based on the following equation derived from PFM I:

$$
\begin{aligned}
& \text { P(PF present })=\frac{1}{1+e^{-(a+b * M A A T+c * P I S R)}} \\
& \text { where } \quad \begin{aligned}
\mathrm{a} & =29.68949 \\
\mathrm{~b} & =-6.80646 \\
\mathrm{c} & =-0.02097
\end{aligned}
\end{aligned}
$$

A probability threshold of 0.6 was chosen to discriminate between 'permafrost probable' $(P \geq 0.6)$ and 'permafrost improbable' $(P<0.6)$ locations and thus for delineating potential permafrost areas. This cut-off value is slightly more conservative than values used in other probability-based permafrost distribution estimates (e.g. Lewkowicz and Ednie, 2004; Janke, 2005; Ridefelt et al., 2008), but coincides with the optimal cut-off of 0.598 , computed by ROC-AUC (Schroeder, 2003) as the cut-off value at which PFM I's predictions achieve maximum correct classification rates for the analysed rock glacier inventory.

The potential contemporary permafrost extent in the seven permafrost study regions is illustrated in Figure 4.22 and Figure 4.23. Overall, in approximately $7 \%$ of the study regions, equalling $512 \mathrm{~km}^{2}$, topoclimatic conditions are evaluated as favourable for the presence of perennially frozen rock or debris (Table 4.7). Eliminating areas currently covered by glaciers, which are often at least partly warm-based in temperate climates and thus, as well as for practical considerations, generally considered permafrost exclusion areas (e.g. Bonnaventure et al., 2012; Gruber, 2012), reduces the modelled contemporary permafrost extent to $391 \mathrm{~km}^{2}$ (5.3\%). The highest percent permafrost area can be found in the Liebig Range, where permafrost occurrence is probable in $11 \%$ of the unglacierised land, followed by the Ben Ohau Range and Two Thumb Range with each slightly more than $6 \%$ area.

The proportional permafrost extent in the individual study regions is strongly linked to the proportion of respective land above $1500 \mathrm{~m}$ (Figure 4.24), highlighting the altitudinal control on permafrost occurrence via mean annual air temperature. Interestingly, topoclimatic conditions are either highly favourable for permafrost occurrence $(P \geq 0.9)$ or classified as not favourable $(P<0.6)$ in the majority of locations. In particular, likelihood values of 0.6 to 0.7 are comparatively rare, occurring largely as a thin spatial band around the lower rim of the modelled permafrost extent (cf. inset Figure 4.23). Their confined spatial 
Table 4.7 Modelled permafrost extent in the permafrost study regions.

\begin{tabular}{|c|c|c|c|c|}
\hline \multirow{2}{*}{ Region } & \multicolumn{2}{|c|}{ PF extent } & \multicolumn{2}{|c|}{ PF extent excl. glaciers ${ }^{*}$} \\
\hline & $\mathrm{km}^{2}$ & $\%$ & $\mathrm{~km}^{2}$ & $\%$ \\
\hline Inland Kaikoura Range & 22.8 & 5.1 & 22.8 & 5.1 \\
\hline Arthur's Pass region & 14.6 & 1.5 & 10.6 & 1.1 \\
\hline Lake Heron region & 79.0 & 4.6 & 58.1 & 3.4 \\
\hline Two Thumb Range & 117.9 & 7.5 & 98.7 & 6.3 \\
\hline Liebig Range & 166.3 & 16.3 & 110.6 & 10.9 \\
\hline Ben Ohau Range & 79.5 & 8.3 & 61.2 & 6.4 \\
\hline Barrier Range & 31.8 & 4.7 & 29.0 & 4.3 \\
\hline Overall & 511.9 & 7.0 & 391.05 & 5.32 \\
\hline
\end{tabular}

distribution allows the inference of mean lower limits of the modelled permafrost distribution (Table 4.8).

Lower distribution limits were calculated separately for the central ranges and the Inland Kaikoura Range (Table 4.8). In the central ranges, permafrost is probable above $1866 \mathrm{~m}$ on south-facing slopes and above $2120 \mathrm{~m}$ on north-facing slopes. The average lower boundary of permafrost occurrence in the central Southern Alps is $2000 \mathrm{~m}$. In the Inland Kaikoura Range, the calculated limits are higher: Permafrost is probable above $2062 \mathrm{~m}$ on southfacing slopes and above $2261 \mathrm{~m}$ on north-facing slopes. The mean lower limit in the Inland Kaikoura Range is $2147 \mathrm{~m}$.

Separate calculations for the central ranges and Inland Kaikoura Range were primarily motivated by the higher uncertainty in the modelled permafrost extent for the Inland Kaikoura Range. The region's three active rock glaciers had not been considered in the model's training to avoid a potential bias in the regression results due to the lack of information on permafrost unfavourable conditions in this region (cf. Section 4.3.2). The modelled extent for the Inland Kaikoura Range must consequently be interpreted with special caution. However, the comparison of the region's three active rock glaciers and the modelled permafrost distribution shows that all three features are situated at locations where permafrost presence was estimated to be highly probable (Figure 4.23). The application of the permafrost distribution model in the Inland Kaikoura Range appears, therefore, reasonable. Secondly, the differentiation between central ranges and the much further north situated Inland Kaikoura Range identified an increase in lower permafrost distribution limits towards the warmer top of the South Island. This increase fits the global permafrost distribution trend of increasing elevation limits with decreasing latitude (cf. Section 4.1.1). 


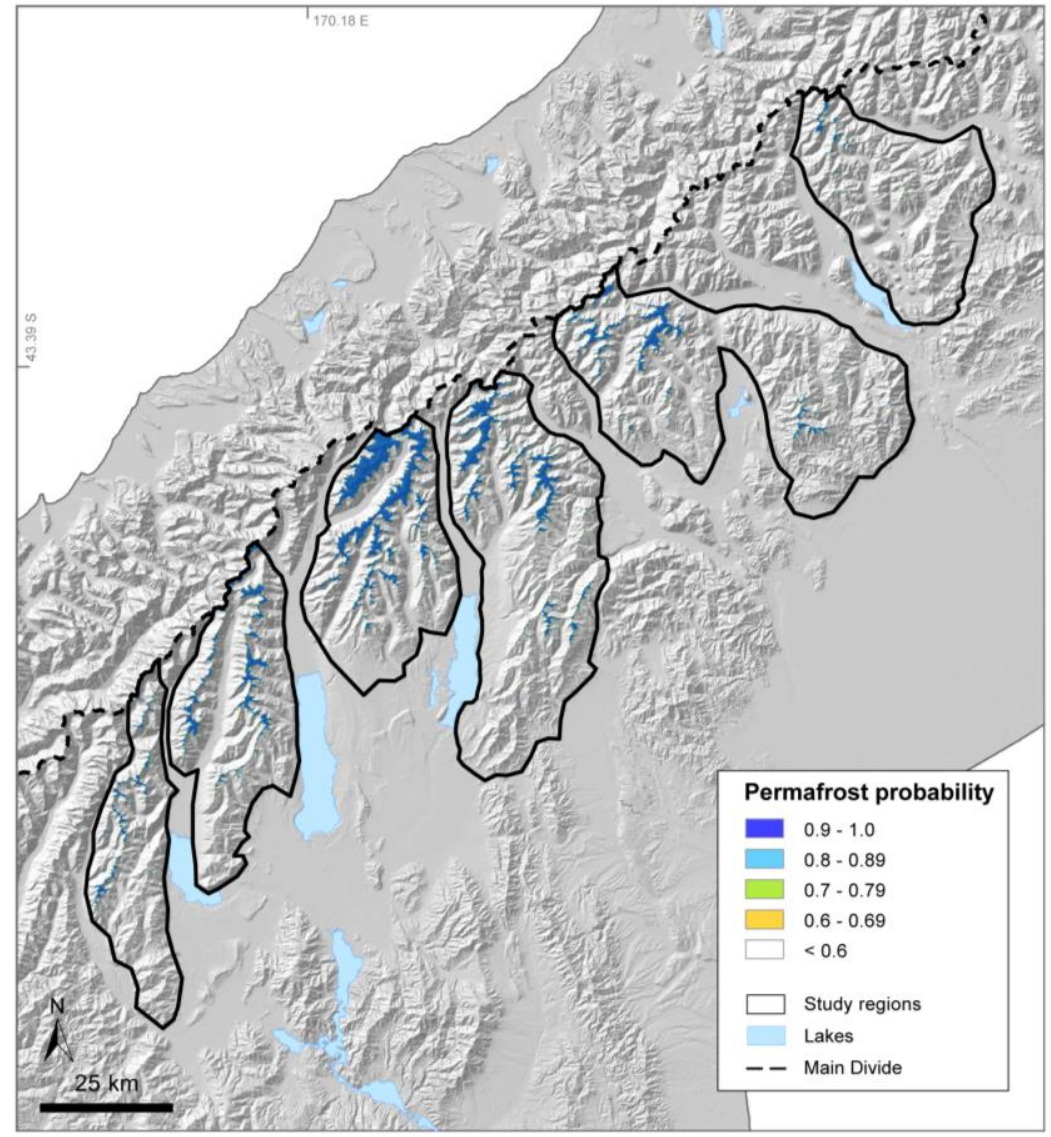

Figure 4.22

Permafrost probability map for the permafrost study regions, delineating the modelled contemporary permafrost extent in central Canterbury. Basemap: Hillshade of a 25 m DEM (Barringer et al., 2002).

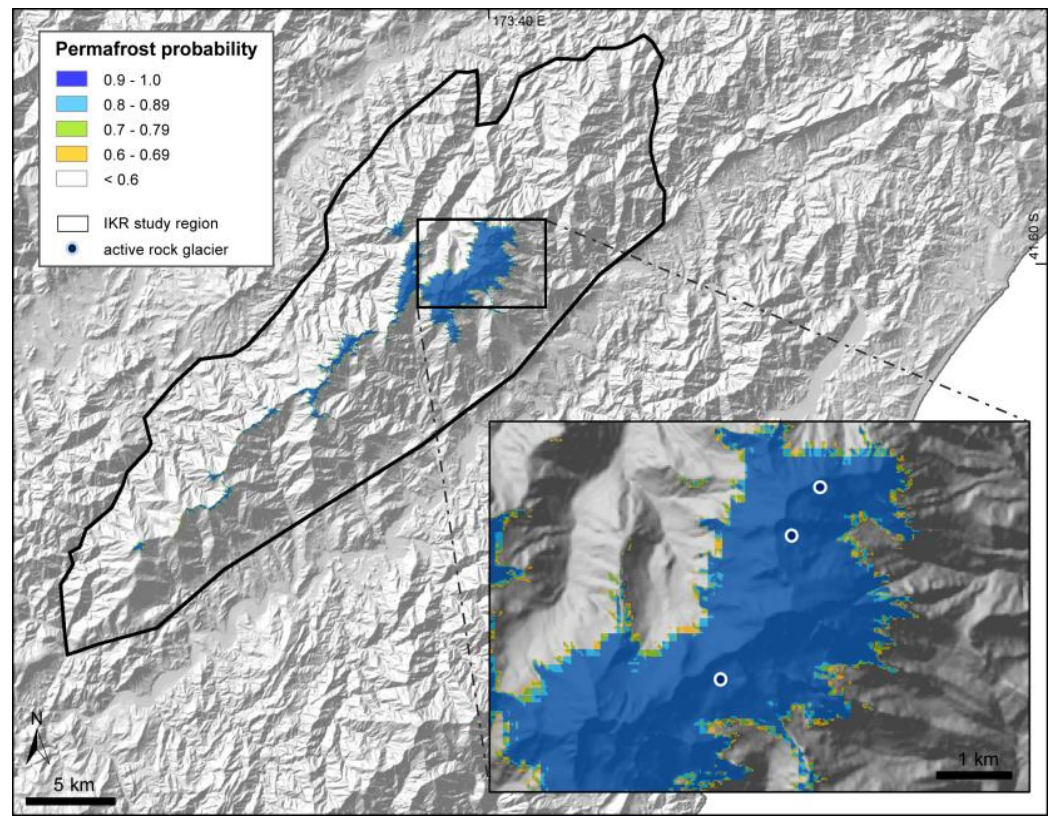

Figure 4.23

Permafrost probability map for the Inland Kaikoura Range delineating the modelled contemporary permafrost extent. Insert: The three active rock glaciers (circles) mapped in the vicinity of Tapuae-o-Uenuku are all situated well within the estimated permafrost zone. Basemap: Hillshade of a 25 m DEM (Barringer et al., 2002). 


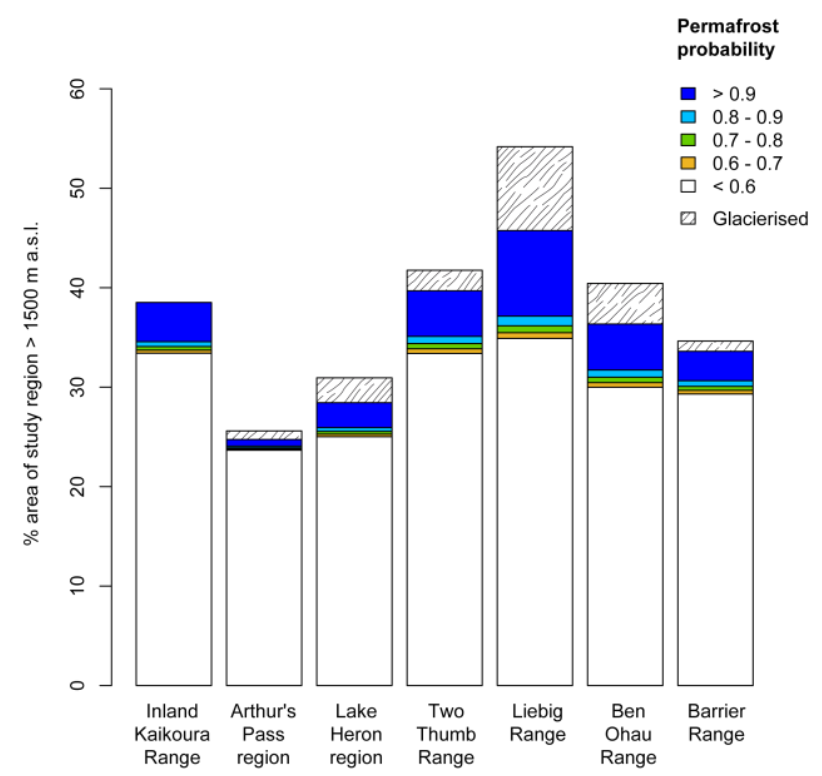

Figure 4.24

Extent of permafrost probability classes in the permafrost study regions. Column height represents percent area of land above $1500 \mathrm{~m}$ a.s.l. Marked proportions of potential permafrost areas are calculated for the central ranges of the Southern Alps as well as the Inland Kaikoura Range.

Table 4.8 Elevation summary for locations with permafrost probability between 0.6 and 0.7 according to aspect classes as well as averaged over all orientations, representing the approximate lower limit of the potential permafrost extent in the central Southern Alps and the Inland Kaikoura Range.

\begin{tabular}{|c|c|c|c|c|}
\hline \multirow[b]{3}{*}{ Aspect class } & \multicolumn{4}{|c|}{$\begin{array}{l}\text { Elevation }[\mathrm{m}] \text { of locations with } \\
\text { permafrost probability } 0.6-0.7\end{array}$} \\
\hline & \multicolumn{2}{|c|}{ Central ranges } & \multicolumn{2}{|c|}{ Inland Kaikoura R. } \\
\hline & $\min$ & mean & $\min$ & mean \\
\hline $\mathrm{N}$ & 1916 & 2120 & 2123 & 2261 \\
\hline NE & 1792 & 2075 & 1966 & 2213 \\
\hline$E$ & 1700 & 1985 & 1880 & 2137 \\
\hline SE & 1567 & 1896 & 1820 & 2085 \\
\hline$S$ & 1440 & 1866 & 1844 & 2062 \\
\hline SW & 1574 & 1925 & 1820 & 2075 \\
\hline W & 1672 & 2029 & 1832 & 2136 \\
\hline NW & 1890 & 2106 & 2001 & 2215 \\
\hline \multicolumn{2}{|c|}{$\begin{array}{l}\text { Mean lower limit of } \\
\text { permafrost distribution }\end{array}$} & $2000 \mathrm{~m}$ & & $2147 \mathrm{~m}$ \\
\hline
\end{tabular}




\subsubsection{Local evaluation of the permafrost distribution estimate}

The local validity of the modelled permafrost extent was evaluated by two independent datasets: 1) BTS data (bottom temperature of the winter snow cover, see Section 4.1.2 for background) derived from continuous ground surface temperature measurements at slopes in and around the head area of the Irishman Stream Valley, central Ben Ohau Range, and 2) perennial snow patch distribution in the wider vicinity of the Irishman Stream Valley.

The head area of the Irishman Stream Valley was selected as permafrost field site based on the presence of extensive high-altitude debris slopes of all orientations, the presence of active rock glaciers, indicating its location within the potential permafrost zone, and easy access by helicopter for logistical convenience. A preliminary permafrost distribution estimate, derived from the mean toe elevation of intact rock glaciers mapped in the Ben Ohau Range (see Appendix 7), was used to identify suitable locations for data logger placement and electrical resistivity soundings. Technical problems (cf. Section 4.4.2) prevented the successful completion of the resistivity surveys, and model results were, therefore, not verified by geophysical ground truthing.

\section{BTS data}

In March 2010, forty-four miniature data loggers $\left(\mathrm{HOBO}^{\circledR}\right.$ Pendant Temperature/Light Data loggers, $\mathrm{UA}-002-08 ; 0.5^{\circ} \mathrm{C}$ accuracy and $0.1^{\circ} \mathrm{C}$ resolution at $0^{\circ} \mathrm{C}$, Figure $4.26 \mathrm{~B}$ ) were placed in the head area of the Irishman Stream Valley, the Boundary Stream Valley, and a southern tributary of the Jack Stream Valley, referred to as Ferintosh Creek by Birkeland (1982), to continuously record ground surface temperatures (GST) at 6-hour intervals for the following 23 months (Figure 4.25). The loggers were buried a few centimetres below the surface to protect them from the influence of direct sunlight.

Continuous GST recordings allow evaluation of the development of ground surface temperatures throughout the winter season and thus enable an informed judgement on the reliability of inferred BTS values (see below). This was vital for the present study, as the applicability of the BTS method in New Zealand's Southern Alps had not been tested before. A primary concern was that the winter snowpack, affected by intermittent melt periods characteristic for New Zealand's alpine winter conditions, might be unable to decouple the subsurface from atmospheric influences long enough for ground surface temperatures to reach an equilibrium reflecting the thermal regime of the subsurface material (cf. Section 4.1.2). Similar has been observed in Iceland (Etzelmüller et al., 2007), preventing the use BTS measurements for permafrost prospecting in the Icelandic mountains. Furthermore, no information existed whether the empirical thresholds for BTS interpretations (BTS $<-3^{\circ} \mathrm{C}$ probable permafrost presence, BTS $-2^{\circ} \mathrm{C}$ to $-3^{\circ} \mathrm{C}$ possible 


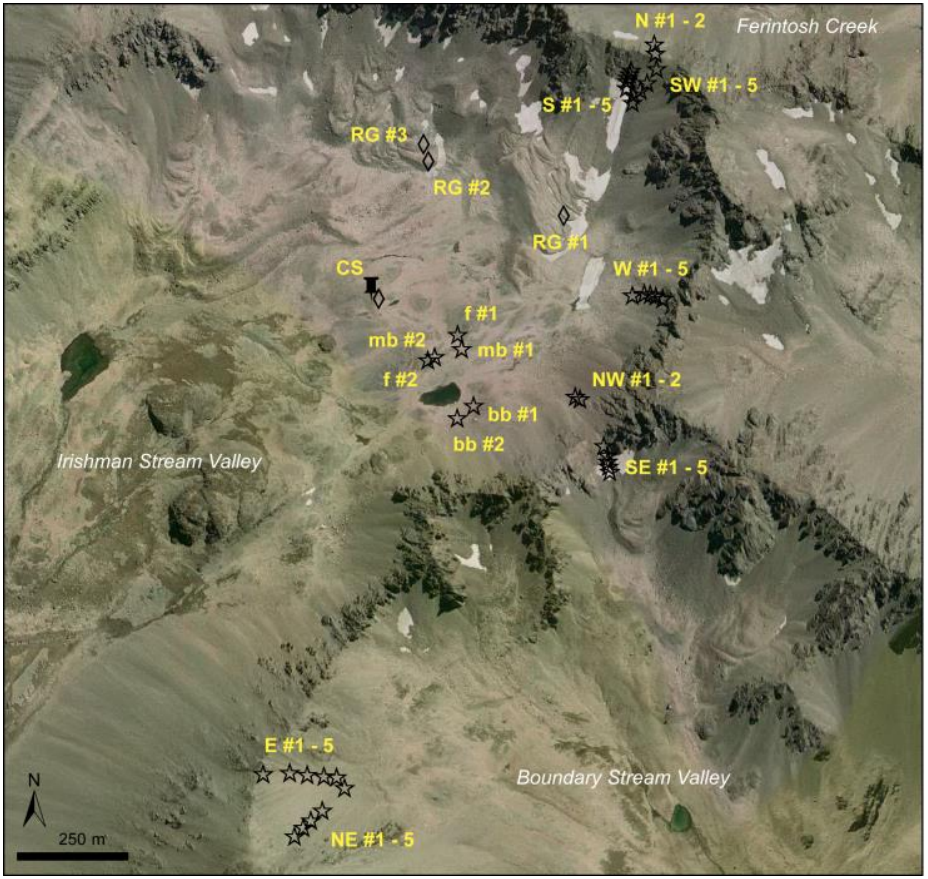

Temperature records

I Climate station

t5 Data loggers (GST)

$\diamond \quad$ Data loggers (snow depth)

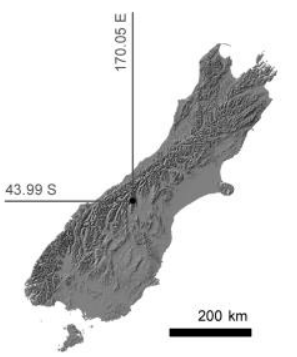

Figure 4.25

Continuous ground surface measurement sites in the central Ben Ohau Range. Site names include information on local characteristics: RG ... rock glacier; bb ... big boulders; mb ... medium-sized blocks; $f$... fine substrate; N, NE, E, SE, S, SW, W, NW ... orientation. Sites were numbered slope downwards.

permafrost presence, and $\mathrm{BTS}>-2^{\circ} \mathrm{C}$ improbable permafrost presence) derived in the European Alps, are also valid in New Zealand's Southern Alps.

To assess the applicability of the BTS method in New Zealand, three data loggers were placed on active rock glaciers in the Irishman Stream head area. Assuming that the morphological interpretation of these landforms as ice-containing was correct, temperature records were expected to exemplify the annual GST evolution above permafrost occurrences. Snow height development was monitored by mounting light-sensitive data loggers at $50 \mathrm{~cm}$ and $80 \mathrm{~cm}$ on a pole close to the GST measurement location (Figure 4.26). Further six data loggers were placed in different surface cover types (big boulders, medium blocks (fist-size), and fine-grained material (pebble/matrix mixture)) to investigate the influence of surface material on BTS inference.

The remaining thirty-four data loggers were distributed in longitudinal profiles on slopes of all eight aspect classes. The longitudinal setting was chosen to investigate potential slope-scale variations in permafrost occurrences as well as to increase the chance of observations crossing modelled permafrost limits. A reduced number of loggers were placed on north- and north-west facing slopes, as the preliminary distribution estimate suggested permafrost absence at these locations. 


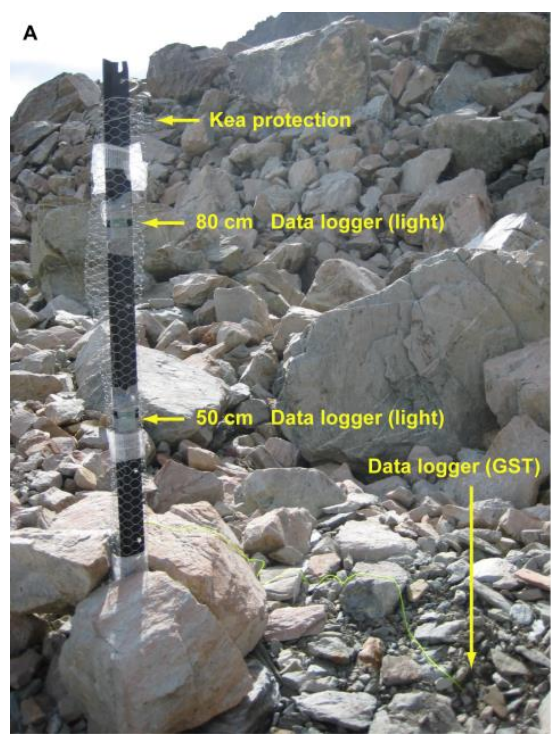

B

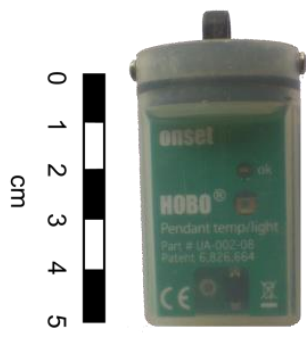

Figure 4.26

A) Data logger setup on rock glacier site RG \#2. Light-sensitive data loggers were mounted on a steel waratah a short distance from the GST measuring site. Tape and chicken wire were used to secure the loggers against keas. B) Example of a data logger used in this study. Image: K. Sattler, 2013.

GST data of the first winter season was retrieved in January 2011 during a service check. At that time, all data loggers could be relocated. One data logger ( $f \# 2)$ was malfunctioning and was therefore replaced. In February 2012, at the end of the 23 month measuring period, 40 of the 44 GST loggers could be recovered. Three of the loggers (SE \#1, W \#5, S \#5) are thought to have been lost by talus movement. The fourth logger, placed in the vicinity of the climate station, on the other hand, appears to have been removed by kea (inquisitive alpine parrots, endemic to New Zealand), who also demolished all cabling at the climate station. Air temperature records of the latter plummeted to unrealistic $-40^{\circ} \mathrm{C}$ in late December 2012 , placing the incident(s) around Christmas time.

\section{Interpretation of GST time series}

The seasonal evolution of ground surface temperatures is influenced by the onset of snow cover development, snow cover thickness, and the snow pack's water content (e.g. Ishikawa, 2003; Brenning et al., 2005; Zhang, 2005; Krummenacher et al., 2008). Temperature profiles can, therefore, be used to determine 1) if the snow height was sufficient to insulate the ground from atmospheric influences, 2) at what temperature the GST stabilised towards the end of the winter season (= BTS), and 3) whether the timing of snow cover development might have biased inferred BTS values.

Examples of three typical GST profiles are illustrated in Figure 4.27, profiles B, C, and D. All three profiles display a clear difference in temperature evolution between the snow-free 
and snow-covered season. However, temperature development contrasts significantly at the three sample locations during the winter months as a result of differing snow conditions above:

In profile B, GST remains generally positive until May, following, albeit dampened, the diurnal air temperature fluctuations (profile A). In May, GST drops below $0^{\circ} \mathrm{C}$; the ground freezes. Distinct capping of temperature fluctuations at $0^{\circ} \mathrm{C}$ indicates the presence of a thin snow cover until late May, which, due to its high albedo and emissivity, shields the subsurface from incoming radiation, but facilitates heat emission and thus ground cooling (e.g. Keller, 1994; Zhang, 2005). At the end of May, the GST profile stabilises, signalling that the snow depth has increased sufficiently to decouple the subsurface from atmospheric influence. The insulating effect of the snow pack is especially evident late September, when air temperature records show a significant cold spell. A corresponding thermal signal is absent in profile B: The GST remained more or less stable throughout spring at the so-called Winter Equilibrium Temperature (WEqT), i.e. the temperature represented by BTS measurements. At the end of October, preceded by a short period of slight gradual warming, GST suddenly increases to $0^{\circ} \mathrm{C}$, indicating the onset of meltwater percolating through the snow pack. The release of latent heat by meltwater refreezing at the still cold snow/ground interface as well as within the active layer holds the GST constant at freezing point (e.g. Hanson and Hoelzle, 2004; Zhang, 2005). This so-called 'zero-curtain effect' lasts until the snow cover has melted. After that, the GST follows again the daily variations in air temperatures again.

Profile C shows a close correspondence of GST and air temperature through May, indicating that snow cover developed at this location later than at the previous site. Similar to profile B, the GST curve significantly smoothes from late May onwards reflecting the development of a persistent snow cover. However, the negative GST does not stabilise but follows the air temperature with an approximate lag of seven days. As such, profile $\mathrm{C}$ clearly reflects the cold spell mid-September. The evident lack of insulation is likely the result of insufficient snow depth.

In profile D, GST remains at freezing point throughout the snow-covered season, indicating that melt-water is constantly present at this location during the winter months. This temperature profile was recorded close to the ridge of a north-facing slope ( $\mathrm{N} \# 1$, Figure 4.25). Wind exposure is likely to keep snow depth low at this site, which in combination with comparatively high incoming radiation might lead to the maintaining of water presence throughout the snowpack and active layer during the winter months. 


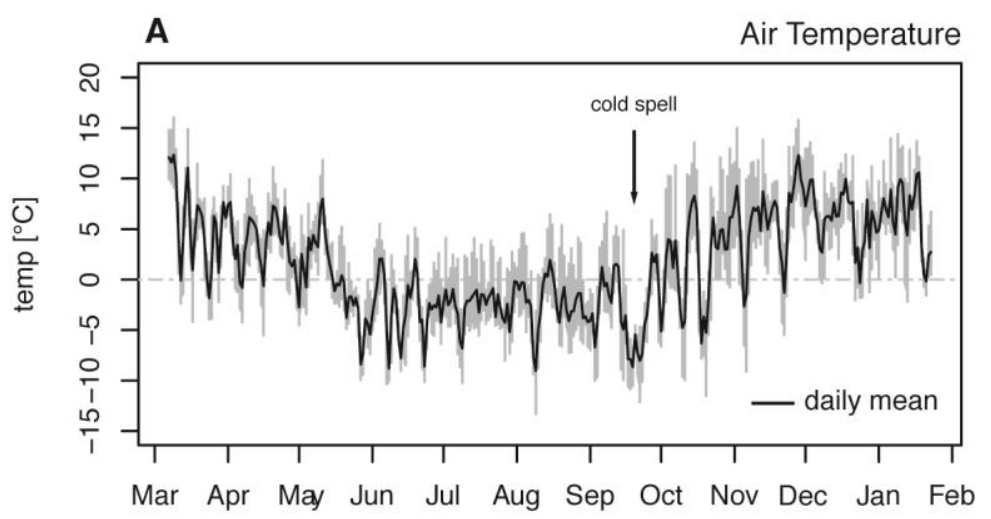

Figure 4.27

Examples of three ground surface temperature (GST) profile types $(B, C, D)$, and corresponding air temperatures recorded March 2010 - Feb 2011 in the Irishman Stream area, central Ben Ohau Range (A). Annotations in plate $B$ were adapted from Hoelzle et al. (2003) and Isaksen et al. (2002).

B

Type 1

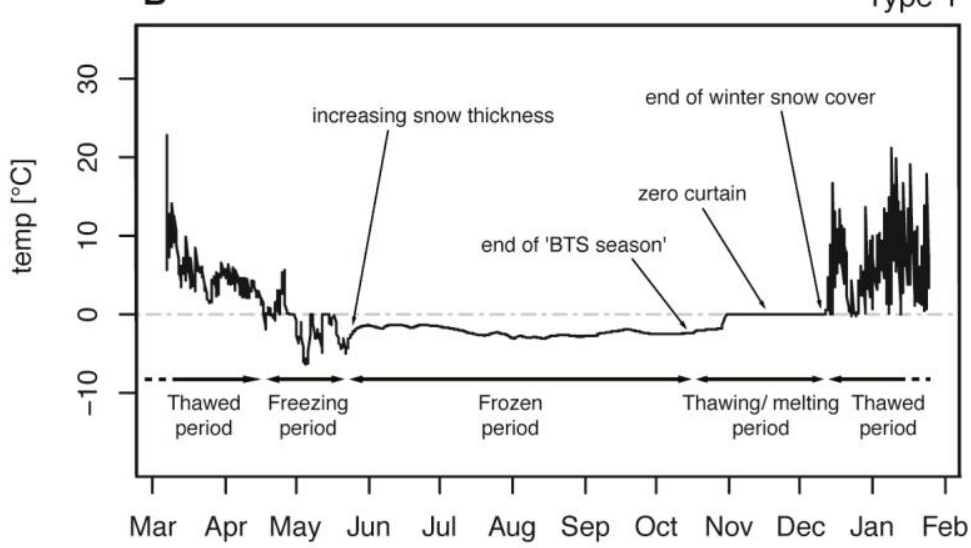

C

Type 2

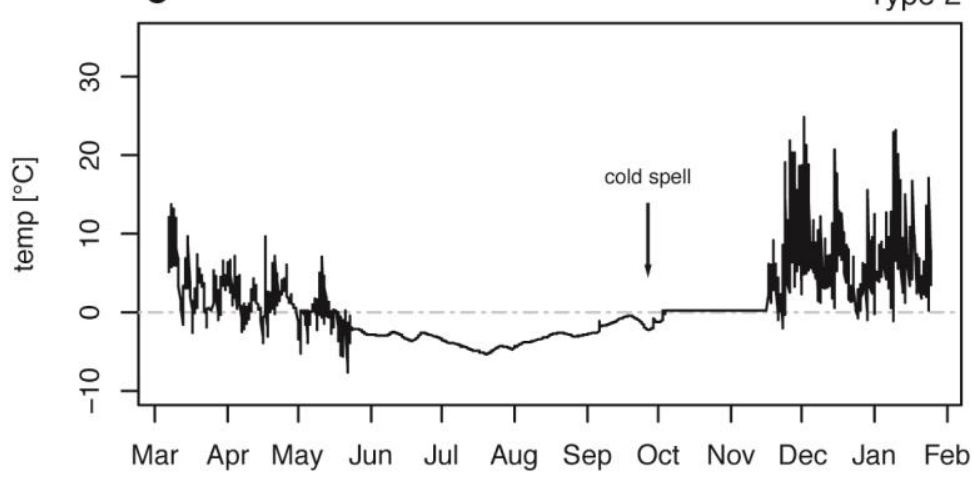

D

Type 3

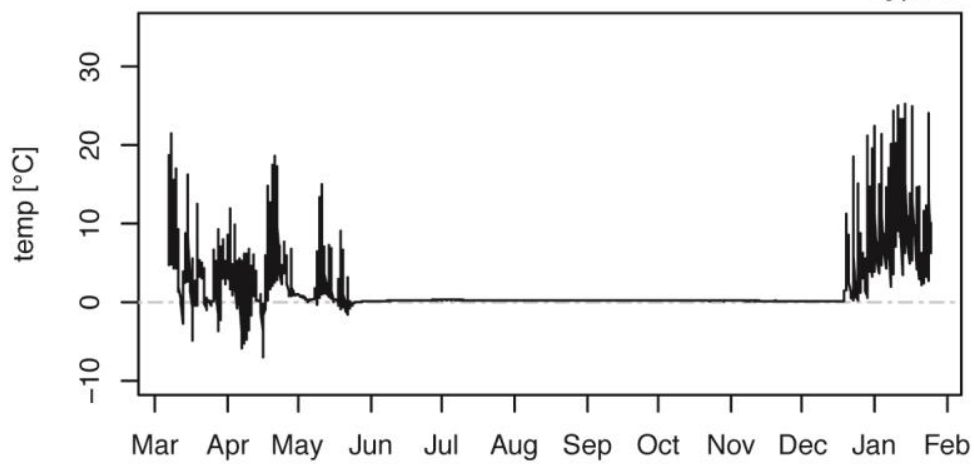




\section{BTS calculation and results}

Separated by winter season, the recorded GST time series (listed in Electronic Appendix 4) were categorised by visual inspection according to the three profile types outlined above. For sites classified as Type 1, i.e. where a sufficiently thick snow cover insulated the subsurface from air temperature influences, BTS values were calculated as the mean GST recorded between the $1^{\text {st }}$ and $14^{\text {th }}$ of September. This period captured the time shortly before the onset of warming in most profiles and was, therefore, thought representative for the Winter Equilibrium Temperature at the respective site. Furthermore, this period corresponds to the northern hemisphere's month of March, described by Brenning et al. (2005) as the most reliable time for BTS measurements. An average value was chosen to remove the bias of slight short-term variations visible in the profiles as well as to weaken the influence of warming at sites, where the thawing season had already begun early September.

Profile types and inferred BTS values at Type 1 sites for the two investigated winter seasons are presented in Figure 4.28. Differences in both overall profile type distribution and inferred BTS values indicate that snow conditions varied significantly at the measurement sites between the two winters. In winter 2010, the presence of meltwater at the ground surface held the GST at freezing level throughout the winter season (Type 3) at the majority of sites (19). At 14 sites, predominantly south-east to south-west orientated, snow cover height was sufficient for ground insulation. Snow height records at the rock glacier sites suggest that a snow pack of $>80 \mathrm{~cm}$ is necessary for decoupling the subsurface from atmospheric influences (Rock glacier \#1 and \#2 in EA 4). However, due to the limited height information, it is not clear whether the threshold lies at about $0.8 \mathrm{~m}$ or actually higher. Inferred BTS values ranged in 2010 between $-3^{\circ} \mathrm{C}$ and $0^{\circ} \mathrm{C}$. Only at one rock glacier site, GST evolution was decoupled from air temperature variations that year. The equilibrium temperature at this likely permafrost site was relatively warm at $-1.69^{\circ} \mathrm{C}$ and would, according to commonly used BTS thresholds, indicate permafrost absence. In winter 2011, snow depth did not reach the critical level at most of the south and southwest facing sites. The same was true for many other sites, resulting in Type 2 being the dominant profile type that season. The loss of BTS-interpretable sites in southern aspects was compensated by the presence of Type 1 sites around the tarn as well as on the east-facing slope that year. BTS values ranged in September 2011 between $-6^{\circ} \mathrm{C}$ and $0^{\circ}$. Sites with BTS records for both years showed significantly lower values in the second season. Two of the rock glacier test sites showed BTS-interpretable Type 1 profiles in winter 2011. At both sites, inferred equilibrium temperatures were below $-3^{\circ} \mathrm{C}$, suggesting permafrost presence at depth.

A comparison of the GST evolution during the two winter seasons at site $E \# 5$, which showed a Type 1 profile for both winters, reveals significant differences in the timing of the 

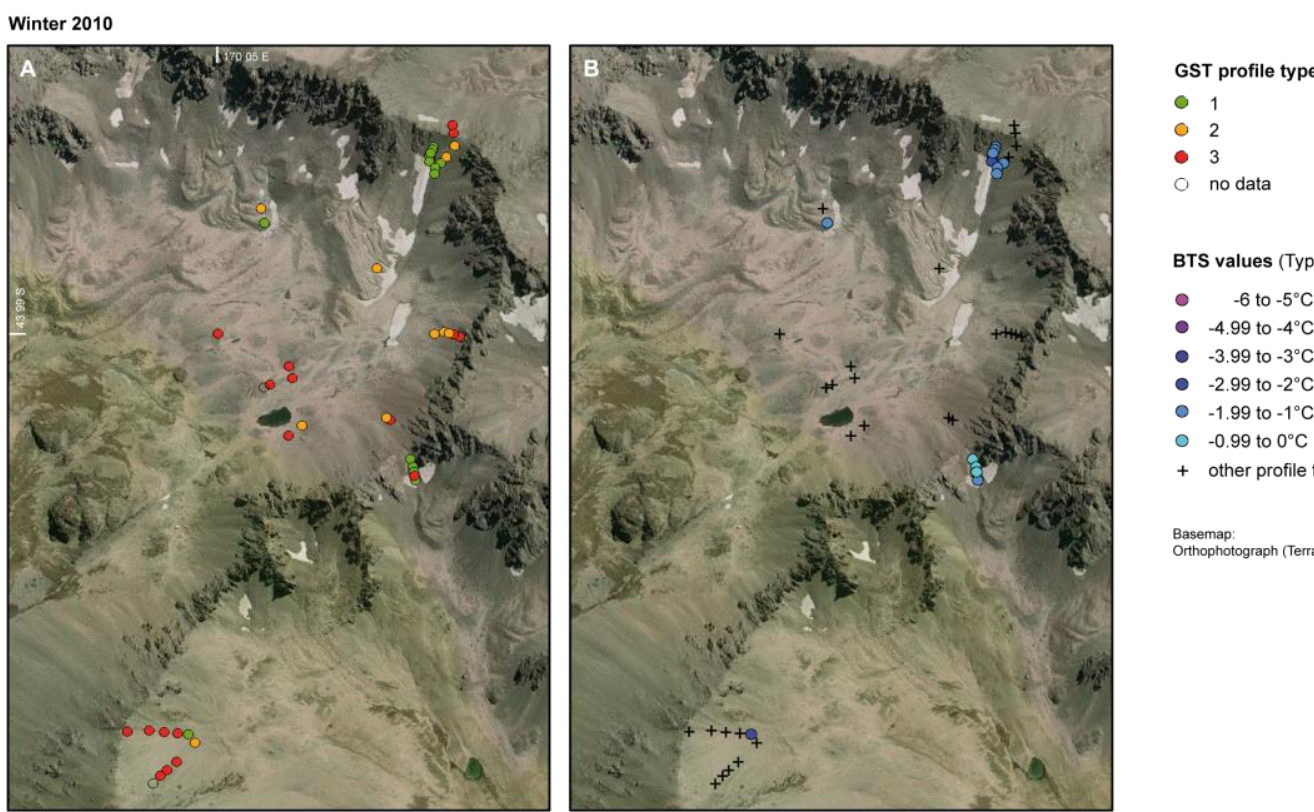
BTS values (Type 1 sites)
- -6 to $-5^{\circ} \mathrm{C}$
- -4.99 to $-4^{\circ} \mathrm{C}$
- -3.99 to $-3^{\circ} \mathrm{C}$
- -2.99 to $-2^{\circ} \mathrm{C}$
- -1.99 to $-1^{\circ} \mathrm{C}$
- -0.99 to $0^{\circ} \mathrm{C}$
+ other profile type/ no data
Basemap:
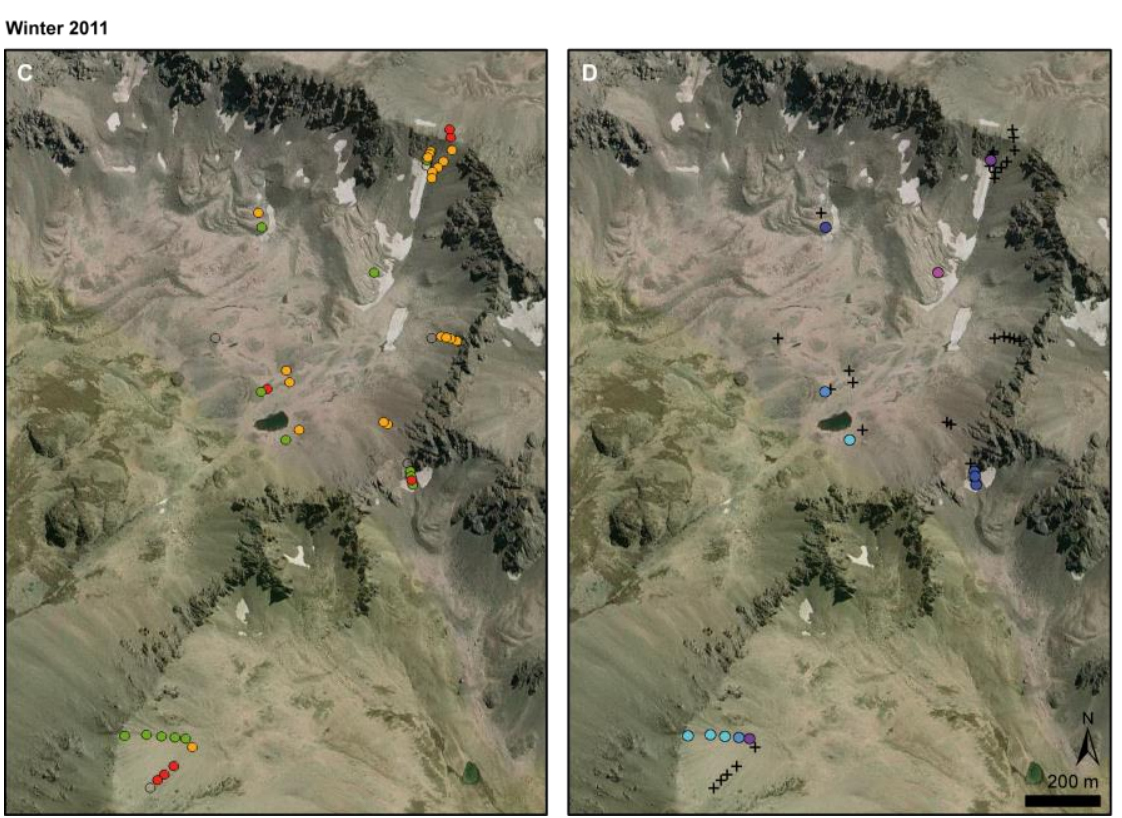

Figure 4.28

GST profile types and BTS values for the winter 2010 (A, B) and 2011 (C, D). BTS values were calculated for Type 1 GST profiles as the mean GST of the period $1^{\text {st }}$ to $14^{\text {th }}$ September of the respective year.

formation of an insulating snow cover between the two years to be the main control on observed deviations in BTS temperatures (Figure 4.29). In 2010, autumn GST first dropped into significant sub-zero temperatures at site $E \# 5$ in late April. Intermittent presence of a thin snow cover and thus probably short-term enhanced ground cooling is indicated by the GST being constant at $0^{\circ} \mathrm{C}$ for short intervals during that time. Approximately a month after the initial temperature drop, a thick snow cover developed at the site, shielding the ground surface from air temperature variations. As the subsurface had not much time to cool between temperature dropping below freezing and snow cover development, the subsurface 


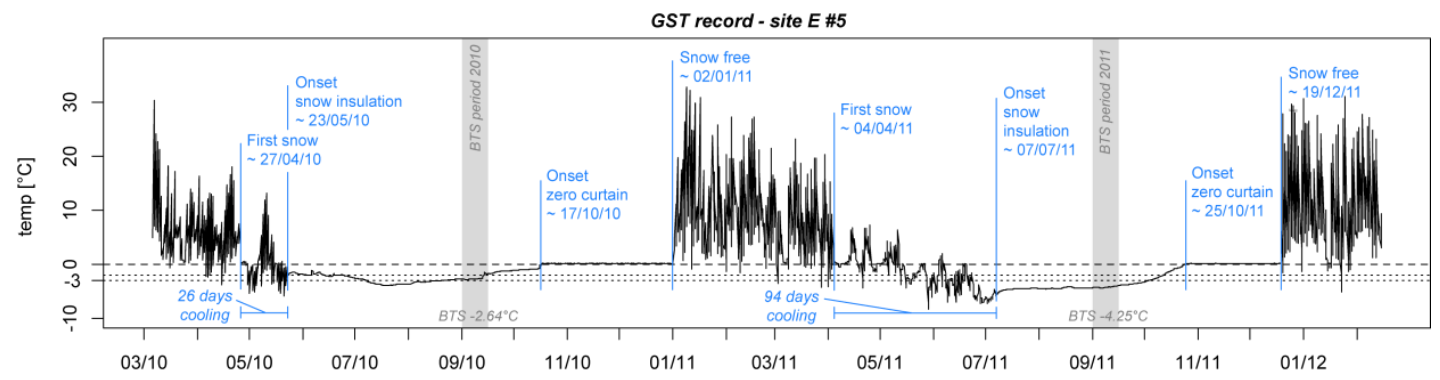

Figure 4.29

Twenty-three month record of GST development at site E \#5, illustrating the influence of snow cover conditions in early winter on GST development. Grey vertical bars signify BTS measurement periods; calculated BTS values are given at the bottom of the bars.

was insulated at relatively high temperatures. Starting at temperatures warmer than the equilibrium temperature, the GST decreased gradually until stabilising around $-3^{\circ} \mathrm{C}$ from July until mid-September. In the following year, winter 2011, ground freezing already started in early April. GST gradually decreased thereon, probably aided by the presence of a thin snow cover at times. An insulating snowpack only developed early July, giving the subsurface a long time to emit any stored heat. This is reflected by an initial warming of the GST to an equilibrium temperature of around $-4.5^{\circ} \mathrm{C}$ towards the end of July; a level significantly lower than the previous year.

The timing of snow cover development is thus critical for the interpretability of observed BTS values for permafrost mapping (cf. also Imhof et al., 2000; Brenning et al., 2005; Krummenacher et al., 2008). Brenning et al. (2005) consider years with thermal regimes affected by early snow cover development (winter 2010 this study) better suited for BTS interpretations than thermal regimes characterised by significant ground cooling prior to the development of an insulation snow cover (winter 2011 this study). However, given that the former is likely to produce warmer temperatures than the 'true' equilibrium temperature, Brenning et al. (2005) recommend adjusting inferred BTS values according to mean deviations from the long term average characteristic for the respective thermal regime. Such corrective measures are not possible in the present study, given the short period of GST records. Instead, the BTS values for the two winter seasons are interpreted as describing two 'endmember' distribution patterns, with the warmer 2010 temperatures representing conservative estimates of permafrost presence at the investigation sites and the colder 2011 values illustrating a more liberal approximation.

\section{Comparison of BTS data and modelled permafrost extent}

BTS values for each winter season were translated into qualitative statements about potential permafrost presence according to the European interpretation thresholds. Results are compared to the modelled permafrost extent in Figure 4.30. 

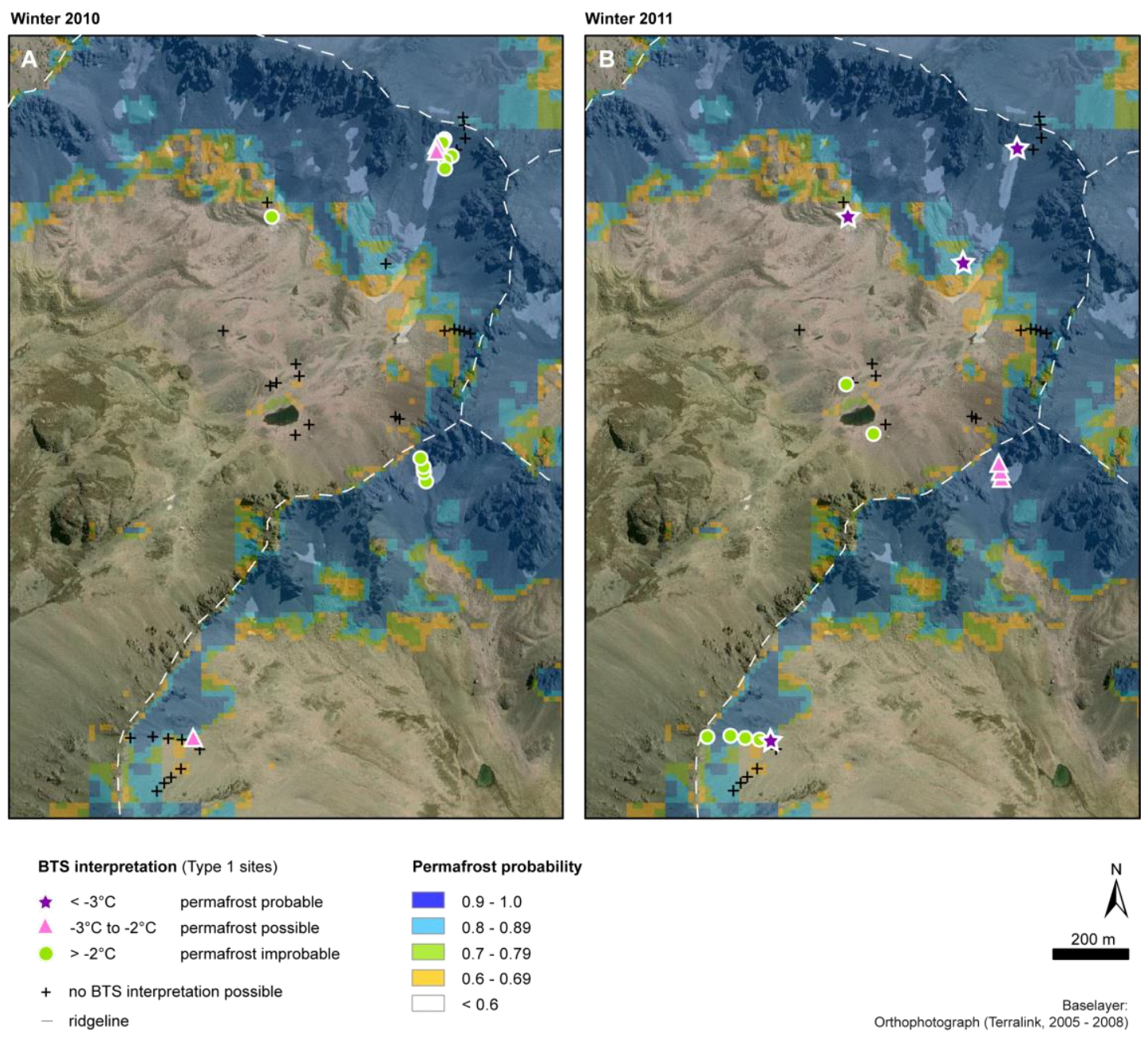

Figure 4.30

Comparison of the modelled permafrost extent and the distribution of determined BTS values for A) winter 2010 and B) winter 2011. Overall, there is a good agreement between the modelled potential permafrost extent and BTSindicated permafrost sites.

BTS values of the 2010 winter indicate the possible presence of permafrost at depth at only three sites (Figure 4.30 A). All of these sites lie within the modelled permafrost extent. Permafrost is possible at the lower two south-facing sites S \#4 and S \#5. The validity of predicted permafrost occurrence at these locations is supported by the proximity to a presumably perennial snow patch visible in the orthophotograph taken in February 2006. The third site of possible permafrost is site $E \# 5$, located at the foot of the east-facing slope. The permafrost model predicted a $77 \%$ likelihood of permafrost presence at this location, representing an occurrence at the estimated lower limit of the potential permafrost extent in the Southern Alps.

BTS values from 2011 confirm all the permafrost sites identified in the previous year. Additionally, permafrost presence is also indicated at the three lower sites on the southeastfacing slope as well as at the rock glacier test sites. With the exception of RG \#2, all 
indicated permafrost sites are within the modelled permafrost extent. Although the 2011 BTS values are likely biased towards lower temperatures and thus might incorrectly suggest the presence of permafrost for some sites, the indicated permafrost distribution pattern appears reasonable. Permafrost occurrence on the sun-avert south-eastern slope is plausible, and again supported by the presence of a long lasting snow patch, visible in the 2006 orthophotograph. Similarly, the localised occurrence of permafrost at the foot of the eastern slope is in accordance with observations in the European Alps (e.g. Lerjen et al., 2003; Lambiel and Pieracci, 2008), where permafrost lenses within talus slopes were often restricted to the lower areas (cf. Section 4.1.1).

Overall, the modelled potential permafrost distribution is thought to represent the BTSindicated permafrost extent reasonably well. The strong aspect control on permafrost occurrence, suggested by the model for the validation area, is supported by the distribution of the possible and probable permafrost sites. Even BTS data from 2011, which is thought to be biased towards lower equilibrium temperatures and thus might falsely suggest permafrost presence at some locations, did not indicate permafrost occurrence outside the modelled extent. The rock glacier site RG\#2 forms an exception: The permafrost model was consciously based on topoclimatic conditions at the head of active rock glaciers to avoid overestimating the potential permafrost extent due to the mobility of rock glaciers and their exceptional ability to preserve permafrost even in topoclimatic hostile locations (cf. Section 4.2.2). The presumably active rock glacier extending beyond the modelled lower distribution limit therefore confirms that the model represents the pursued conservative distribution estimate. The actual presence of ice within the rock glacier at site RG \#2, and thus the validity of the rock glacier classification by morphologic criteria, could not be confirmed by BTS data due to the warm equilibrium temperatures measured at this site in 2010. However, the presence of ice at depth at this location appears more likely than its absence, given that the BTS in $2010\left(-1.69^{\circ} \mathrm{C}\right)$ was significantly colder than at other as permafrost improbable indicated sites. BTS-indicated non-permafrost sites at locations for which high permafrost probabilities were predicted do not falsify the model results. These are rather an expression of the high local variability of permafrost, strongly influenced by thermal properties of the surface and subsurface material (cf. Section 4.1.1), which was not considered in the present distribution estimate.

\section{Perennial snow patch distribution}

Considering the late-summer date (13 February 2006) of the available orthophotograph for the Irishman Stream Valley (Terralink, 2005-2008), snow patches visible in the imagery are likely perennial, albeit their actual extent might not have been at its minimum that year. The data logger site $S \# 5$ is shown covered in snow in the 2006 imagery, but was located just above the snow patch extent in the years of the field visits. This suggests that the 
individual snow patches were more extensive in 2006 than in the following years. However, assuming that at least part of the visible snow patches remain throughout the years, their approximate location as well as density were considered suitable as a further independent permafrost indicator for validating the modelled potential permafrost distribution.

Figure 4.31 illustrates a satisfactory agreement between the modelled permafrost extent and the mapped snow patch distribution and thus suggests a reasonable model result. Only a few isolated patches are found outside potential permafrost zone. Most of these are on or close-by presumably active rock glaciers. As permafrost creep was not considered in the permafrost distribution model (cf. above), this discrepancy does not contradict the model's performance.

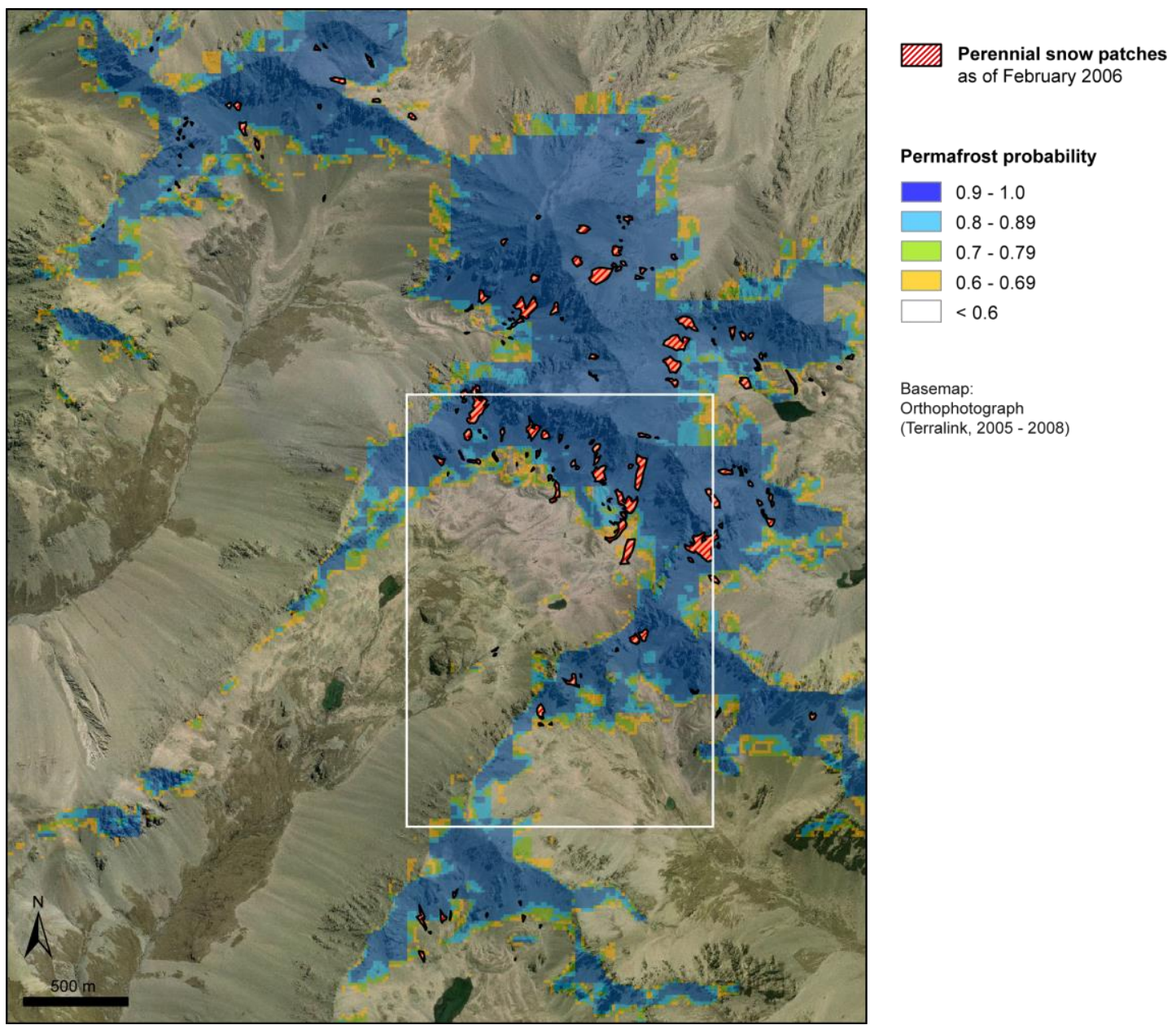

Figure 4.31

Comparison of modelled permafrost extent and late-summer snow patch distribution, as mapped in February 2006, in the wider vicinity of the Irishman Stream Valley head area. The white frame marks the extent visible in Figure 4.28 and Figure 4.30. The good agreement between the modelled permafrost extent and the mapped snow patch distribution suggest a reasonable model result. 


\subsection{Discussion}

This section discusses the findings of the rock glacier inventory and the derived permafrost distribution estimate in the context of published domestic and international literature (Section 4.4.1). It further reviews the applicability of the BTS method (bottom temperature of the winter snow cover) for permafrost mapping in New Zealand (Section 4.4.2).

\subsubsection{Rock glacier distribution and derived permafrost extent in the Southern Alps}

Rock glaciers are common landforms in the drier eastern ranges of the Southern Alps. The inventory for the Canterbury Region shows a spatial offset of the western (i.e. upper) rock glacier distribution limit to the Main Divide of approximately $20 \mathrm{~km}$ (Figure 4.8). This distribution limit corresponds well with the local glacial equilibrium line altitudes in the eastern ranges (Figure 4.12). The climatically-controlled vertical separation of active and relict features (Figure 4.13) is spatially manifested in a distinct east-west trend with active features occurring generally close to the higher western distribution margin, whereas relict features are frequent in the lower eastern areas. The observed patterns agree with the general characteristics of rock glacier distribution outlined, amongst others, in Haeberli (1985), Barsch (1996), and Humlum (1998).

A decrease in front altitudes of active rock glaciers towards the lower northern ranges, observed by Jeanneret (1975) in a small rock glacier inventory for selected areas in the central ranges of the Canterbury Region (cf. Section 4.1.3), was not confirmed in the present study. Front altitudes of active rock glaciers as well as of the overall dataset increase with decreasing latitude (Figure 4.32). Although the relationship is admittedly weak, the observed trend conforms with the global-scale permafrost distribution pattern governed by the decrease in mean annual air temperatures towards the poles (e.g. Cheng and Dramis, 1992; Haeberli et al., 1993). The altitudinal trend indicated by Jeanneret's (1975) dataset might, therefore, be due to the study's small sample size or biased by misclassification of relict landforms, as suggested by Barsch (1996). A topographic influence on rock glacier occurrence, discussed by Jeanneret (1975) as well as others (e.g. Brazier et al., 1998; Frauenfelder, 2004; Brenning and Azocar, 2010), is indicated in the Canterbury rock glacier inventory by differences in the lower distribution limits between the rock glacier study regions (Figure 4.32, cf. also Figure 4.12). The lower distribution limit lies significantly higher in the Liebig Range than in the neighbouring mountain ranges. A look at the topographic configuration of the Liebig Range investigation area reveals that large areas between 


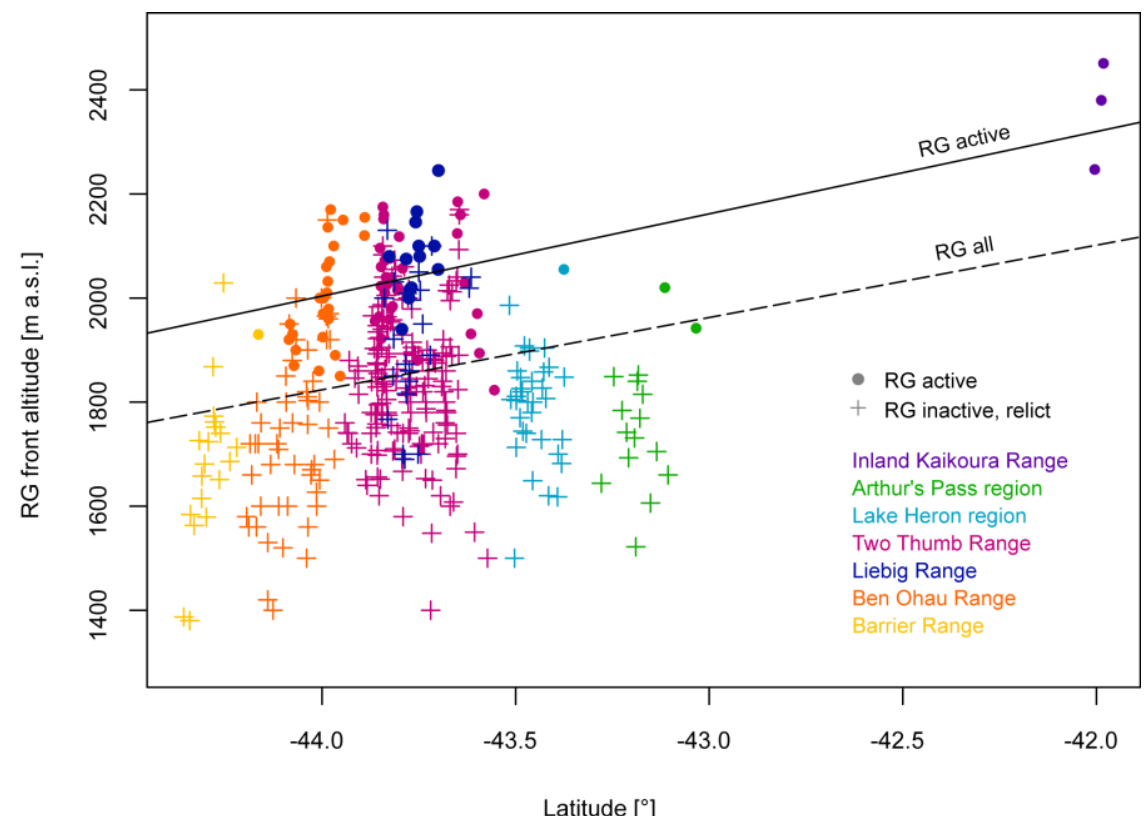

Figure 4.32

Relationship between rock glacier front altitude and latitude in the Canterbury Region for active features (circles) and intact and relict features (crosses). Front altitudes of both active rock glaciers (solid line, $r=.554$, sig at .01 level) as well as the overall dataset (dashed line, $r=.237$, sig at .01 level) increase towards north, conforming with a latitudinal trend in the general global permafrost distribution limits.

$1500 \mathrm{~m}$ and $1800 \mathrm{~m}$ a.s.I. are either gentle, glacially smoothed slopes without talus accumulations or very steep slopes. In both cases, the local topography is unsuitable for rock glacier development despite most likely suitable climatic conditions in the past.

The latitudinal control of mean annual air temperature and thus global permafrost distribution is also evident in the comparison of the Southern Alps' rock glacier distribution to other international datasets (Figure 4.33). Active rock glaciers occur in New Zealand at lower altitudes than in the Nepal Himalaya, but at higher elevations than in the subarctic northern Norway, Canada, or Alaska. Interestingly, distribution limits are significantly lower in the maritime Southern Alps than in the continental European Alps despite being located at comparable latitudes. A similar pattern is indicated by the North American datasets with Alaskan distribution limits being slightly lower than those in the further inland located southern Yukon Territory. These differences suggest the presence of an oceanic control on global permafrost distribution limits besides the well-acknowledged latitudinal control. A possible influence may be the effect of moderate annual temperature amplitudes characteristic for maritime climates (cf. NIWA, 2001; Sturman and Wanner, 2001) on the preservation of permafrost. Comparatively low summer maxima might significantly reduce ground warming and ice loss during the warm seasons (cf. Brazier et al., 1998), facilitating the existence of permanently frozen ground at lower altitudes. A global-scale oceanic control on permafrost distribution limits was occasionally suggested in the early literature (Cheng, 1983; Gorbunov, 1988) but has so far not been systematically investigated. Confirmation of 


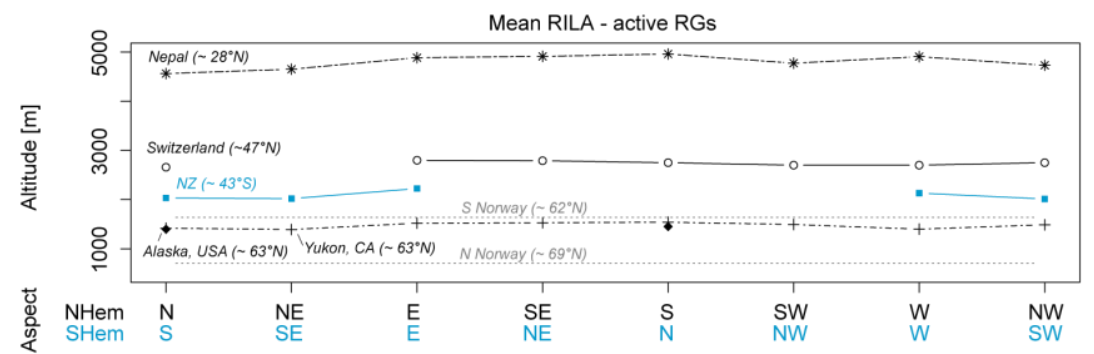

* Regmi, $2008(101 \mid \mathrm{na})$

- Haeberli, $1975(11 \mid 29)$

- NZ RG Inventory (78 | 386)

+ Page 2009 (178|na)

- Wahrhaftig \& Cox, 1959 (93|194)

Lilleøren \& Etzelmüller ( $\mathrm{N} 44$ | 188

$\mathrm{S} 6 \mid 23)$

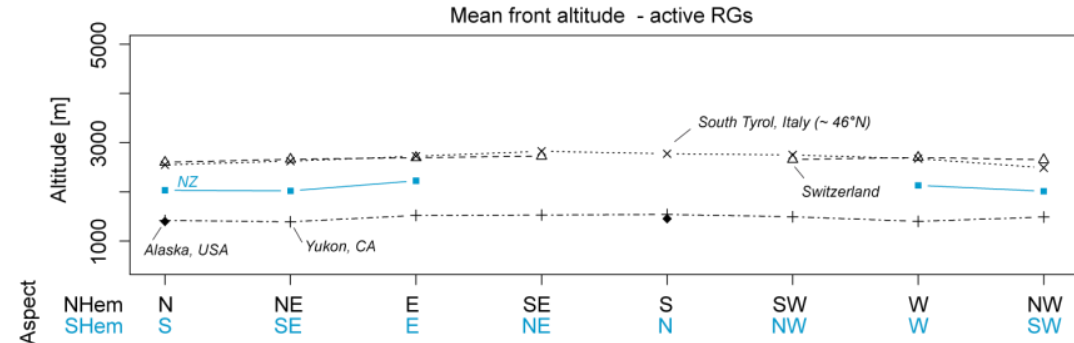

Nyenhuis, $2006(38 \mid 83)$

$\times$ Monreal \& Stoetter, $2010(240 \mid 1778)$

- NZ RG Inventory (78 | 386)

+ Page $2009(178 \mid \mathrm{na})$

- Wahrhaftig \& Cox, 1959 (93|194)

Figure 4.33

Altitudinal distribution limits of active rock glaciers according to aspect, taken from a selection of published international rock glacier inventories. Locations (inclusive approximate latitude) are given in the diagram. Respective sample populations are given in brackets in the legend with the first number describing the number of active rock glaciers and the second number the size of the overall rock glacier inventory.

lower altitudinal limits in maritime settings would not contradict the decrease in permafrost limits with increasing continentality across mountain ranges, as described in Section 4.1.1. It is likely that this more regional trend is also present in the Southern Alps. However, to test this would require a denser and spatially more extensive dataset of permafrost field observations (e.g. profile across the Southern Alps or along ranges with significant continentality gradients) than the available active rock glacier inventory, which only documents permafrost presence in a narrow band parallel to the Main Divide.

Modelled mean annual air temperatures at the rock glacier initiation line are above $0^{\circ} \mathrm{C}$ for all active rock glaciers mapped in the Canterbury Region (Figure 4.13). The existence of active rock glaciers in locations with positive MAAT has previously been described by Trombotto et al. (1997) and Brenning (2005b) in the Andes, by Birnie and Thom (1982) in the Falkland Islands Dependencies, and by Eyles (1978) in Iceland. The latter two citations refer to findings in maritime settings comparable to the Southern Alps. Such observations are, however, unusual. Rock glacier inventories from around the world indicate that active features generally occur at sites with a negative MAAT (Figure 4.34; cf. also Barsch, 1996; Humlum, 1998), contributing to the general guideline for first-order distribution estimates that significant permafrost occurrences have generally been preserved in areas where present-day MAAT does not exceed $0^{\circ} \mathrm{C}$ (cf. Section 4.1.1).

The presence of active rock glaciers at sites with positive MAAT may indicate that contemporary permafrost occurrences in the Southern Alps are not supported by presentday climatic conditions. Their preservation in seemingly permafrost-unsuitable conditions 


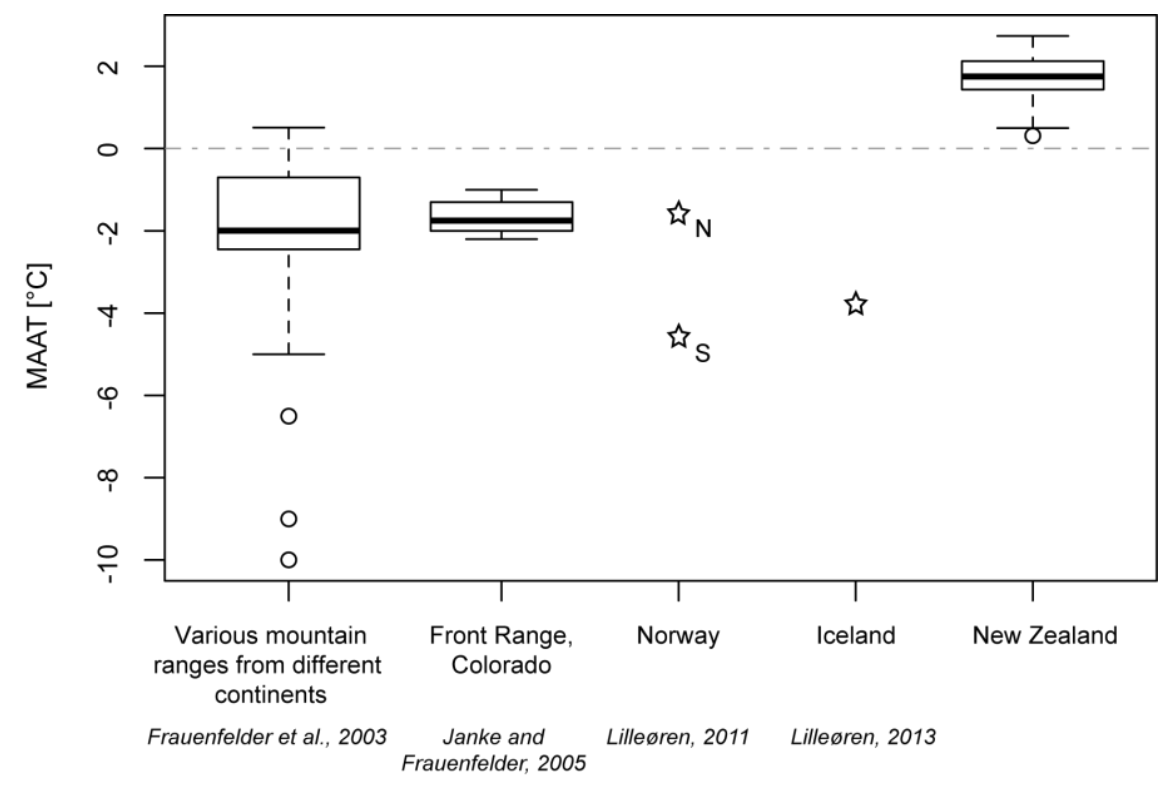

Figure 4.34

Comparison of modelled mean annual air temperature (MAAT) at active rock glacier sites in the Southern Alps to other international datasets. Modelled MAAT is positive for active rock glaciers mapped in the Southern Alps, whereas published temperatures for features in the other mountain ranges are generally negative.

The boxplots summarise temperature distributions of active rock glaciers; stars represent mean values of all the intact (i.e. active and inactive) talus-derived rock glaciers mapped in the respective inventories. The dataset compiled by Frauenfelder et al. (2003) includes rock glacier information from the European Alps, the Sierra Nevada, as well as from subarctic and arctic areas.

might be the result of the long lag and response time of ice-supersaturated debris accumulations to atmospheric warming (e.g. Haeberli, 1992; Romanovsky et al., 2010), the ground-cooling effect of coarse surface material characteristic for rock glaciers and taluses (cf. Section 4.1.1), and/ or reduced summer ice-loss due to maritime conditions (cf. above). The mobility of rock glaciers, which was in the present study inferred by morphological diagnostics but has been previously verified by Kirkbride and Brazier (1995) for a rock glacier in the Central Ben Ohau Range, might be an expression of permafrost warming. Increased deformation rates, registered for many rock glaciers in the European Alps in recent years, have been attributed to warming of internal ice to temperatures close to $0^{\circ} \mathrm{C}$ as well as the effect of increased melt-water percolation (e.g. Kääb et al., 2007; Roer et al., 2008). Recent observations as well as thermo-mechanic modelling suggest that rock glaciers react to atmospheric warming by increased deformation before transgressing into inactivity and further loss of ice by melt-out (Kääb et al., 2007). Alternatively, modelled mean annual air temperatures for alpine areas of the Southern Alps might overestimate the actual temperatures at rock glacier initiation areas due to the use of an inadequate lapse rate. The temperature lapse rate describes the change in temperature with increasing altitude. Lapse rates vary both spatially and interannually (e.g. Norton, 1985; Blandford et al., 2008; Doughty, 2013) and are influenced by the moisture content of the air as well as topographyinduced effects, such as temperature inversions with cold-air accumulation in alpine valleys 
or aspect-dependent warming of valley slopes (e.g. Rolland, 2003; Lewkowicz and Bonnaventure, 2011). Ideally, temperature lapse rates are derived from the analysis of low and high-altitude climate stations in the respective study region. However, given the low number of alpine climate stations in New Zealand, only limited information exists on the spatial distribution of temperature with elevation in the Southern Alps. In the present study, mean annual temperature calculations were based on a constant lapse rate of $0.5^{\circ} \mathrm{C} / 100 \mathrm{~m}$. This rate was derived by Anderson et al. (2006) from observations at the Franz Josef Glacier located at the West Coast. It corresponds to Norton's (1985) empirical New Zealand-wide average lapse rate and performed reasonably well predicting temperatures for an independent high-altitude record east of the Main Divide (Tait, 2010). Recent lapse rate calculations by Doughty (2013), based on temperature data from the climate station in the Irishman Stream Valley, Central Ben Ohau Range (Figure 4.25), for the period March 2010 to January 2011 , yielded a similar value of $0.54^{\circ} \mathrm{C} / 100 \mathrm{~m}$. However, this mean annual lapse rate was lowered by frequent winter valley inversions. Calculations by Allen et al. (2009) based on high-altitude climate stations closer to the main divide suggested a humid lapse rate of $0.6^{\circ} \mathrm{C} / 100 \mathrm{~m}$ for extrapolations near the Main Divide and $0.7^{\circ} \mathrm{C} / 100 \mathrm{~m}$ for the drier ranges further east. Similar values were used by Brazier et al. (1998) in their study on climatic characteristics of active rock glaciers in the Ben Ohau Range. The authors tested several lapse rates varying spatially according to the regional precipitation gradients. Employed lapse rates ranged from $0.6^{\circ} \mathrm{C} / 100 \mathrm{~m}$ for the wetter northern part to $0.8^{\circ} \mathrm{C} / 100 \mathrm{~m}$ for the drier southern part of the Ben Ohau Range. Brazier et al.'s (1998) lapse rates were for all scenarios higher than the value used in the present study. The higher lapse rates resulted in lower MAAT estimates at the rock glacier sites (Figure 4.35), which let Brazier et al. (1998) conclude that active rock glaciers, and thus contemporary permafrost, occur in the Southern Alps in areas where MAAT is below $-2^{\circ} \mathrm{C}$. Further research into the regional distribution of temperature variations with altitude in the Southern Alps is needed. Systematic studies into the spatial and temporal variation of lapse rates in the Southern Alps would significantly improve our current abilities to model annual temperature evolution at high elevation sites. Improved information would benefit many research fields, such as runoff modelling for alpine catchments, glacier sensitivity studies and frost-weathering studies (cf. Section 5.2.7, Question II) and help to answer the question if New Zealand's active rock glaciers exist de facto in areas with positive MAAT.

An advantage of empirical-statistical permafrost distribution models over processoriented analytical or numerical approaches is that uncertainties, such as the outlined lack of information on the likely altitude of the $0^{\circ} \mathrm{C}$ isotherm, do not negatively impact model results, provided 1) that model development is based on sound scientific assumptions (e.g. modelled MAAT is a valid predictor of rock glacier activity) and 2) that model training and model application are based on similar input data (e.g. data/ parameters used for MAAT extrapolations and grid size). Local evaluation of the established regional permafrost 


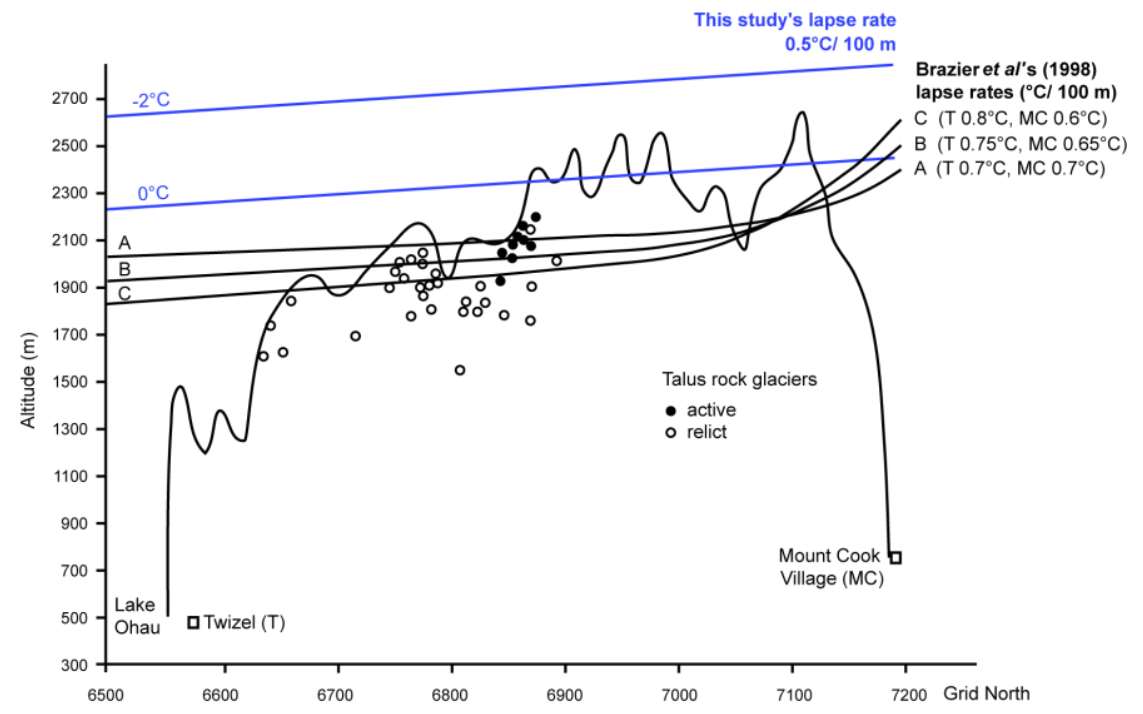

Figure 4.35

Profile of the Ben Ohau Range, illustrating the spatial and altitudinal distribution of active and fossil rock glaciers mapped by Brazier et al. (1998) (adapted from Brazier et al., 1998, p. 199). The present study's rock glaciers were not added to the graph, since the two inventories correspond largely (cf. Section 4.3.1). The black lines represent the possible range of the $-2^{\circ} \mathrm{C}$ isotherm according to the different lapse rate combinations employed by Brazier et al. (1998). The blue lines represent the altitudes of the $0^{\circ} \mathrm{C}$ and $-2^{\circ} \mathrm{C}$ - isotherm when using this study's constant lapse rate of $0.5^{\circ} \mathrm{C} / 100 \mathrm{~m}$.

The higher lapse rates used by Brazier et al. (1998) result in significantly lower MAAT estimates at the active rock glacier sites than if extrapolating by this study's lapse rate.

distribution estimate by independent BTS data and perennial snow patch distribution suggested that the calculated potential permafrost extent is reasonable (cf. Section 4.3.4). The modelled permafrost extent also agrees well with the potential permafrost extent calculated by Gruber (2012) based on cold variant assumptions, i.e. where isolated permafrost occurrences are also likely at sites with low positive MAAT (Figure 4.36). It is noted, however, that the two distribution estimates conform better in the southern Canterbury ranges (Figure 4.36 A-B) than in the more central ranges (Figure $4.36 \mathrm{C}-\mathrm{D}$ ). A possible explanation is differences in MAAT calculations between the two models (this study's spatially stationary vs. Gruber's (2012) spatially variable lapse rate). A comparison of the models' climate datasets would likely provide better insight into the observed deviation. The present study's permafrost distribution model is based on field observation (active and relict rock glaciers in the Southern Alps) and consequently might be assumed to be of higher credibility. The good agreement between the modelled permafrost extent and Gruber's (2012) cold-variant extent, therefore, indicates that the cold variant assumptions are more appropriate for the application of Gruber's (2012) model in New Zealand. A possible reason is the above-mentioned oceanic influence on the global-scale permafrost distribution, which might facilitate the preservation of permafrost at lower elevations. Comparison of Gruber's (2012) global permafrost zonation index to permafrost observations from other maritime mountain ranges, such as the Japanese Alps, might reveal a systematic underestimate of 
Barrier \& Ben Ohau Range
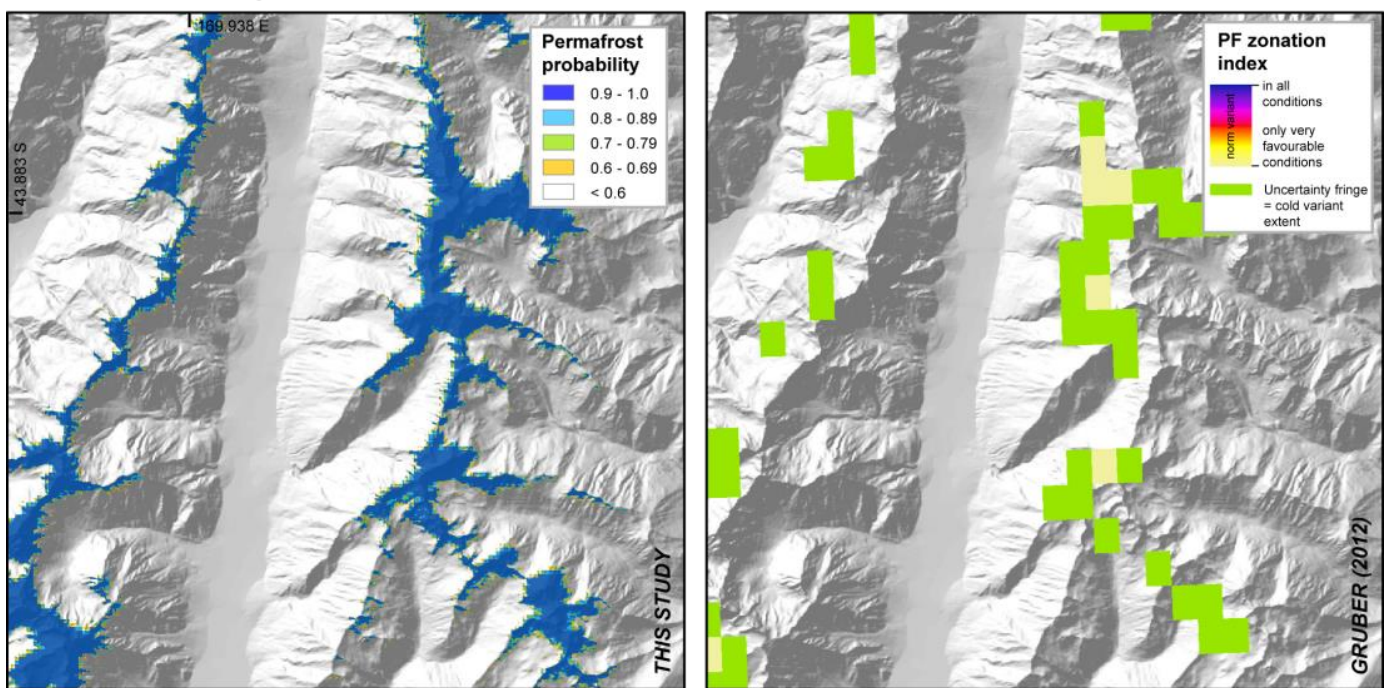

Liebig \& northern Two Thumb Range
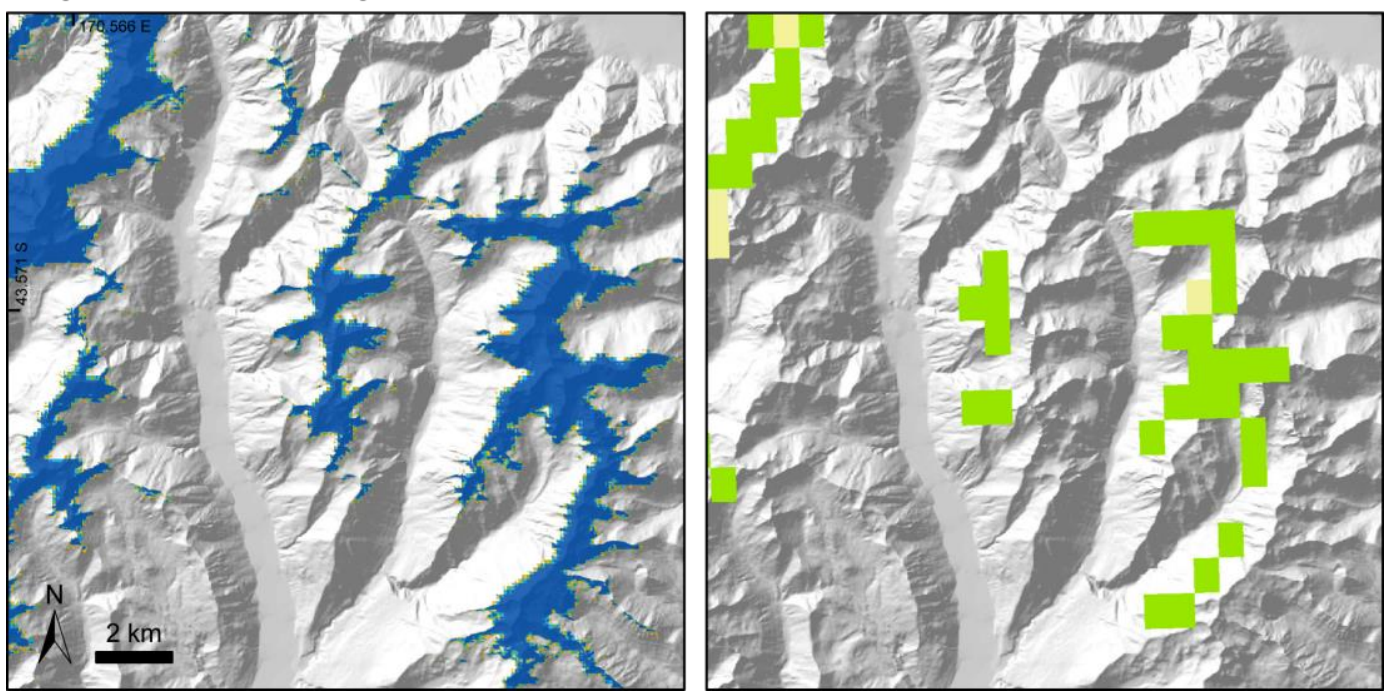

Figure 4.36

Comparison of the modelled potential permafrost extent in the central Ben Ohau Range (top) and the northern Two Thumb Range (bottom) to the model results by Gruber (2012). The modelled extent agrees well with the potential permafrost areas calculated by Gruber (2012) as part of the global permafrost zonation model based on mean annual air temperature and terrain ruggedness information. The slight offset to the west of mountain ridges in Gruber's dataset is possibly the result of a systematically error in the base datasets used in the calculation of the global permafrost zonation index (S. Gruber, pers. comm. March 2014).

the permafrost extent in maritime settings by Gruber's (2012) model. Such findings would further support the presence of an oceanic control on global permafrost distribution limits.

Model results suggest that topoclimatic conditions are in the central Southern Alps favourable for permafrost occurrence above approximately $2000 \mathrm{~m}$ a.s.l. $( \pm \sim 100 \mathrm{~m}$, cf. Table 4.8). This corresponds well with the distribution limits previously suggested by Brazier et al. (1998), Gorbunov (1978), and Allen et al. (2009) (cf. Section 4.1.3). Brazier et al. (1998) hypothesise that permafrost might be, however, less widespread than this altitudinal guideline suggests. The authors argue that greater incoming radiation may 
preclude permafrost presence in the shallow open cirques, characteristic for the southern parts of many of Canterbury's high-altitude ranges. In the present study, which included potential incoming radiation in the modelling process, no indication was found in support of this. The modelled permafrost extent in the Ben Ohau Range is also in the southern areas reasonably well described by the $2000 \mathrm{~m}$ contour line

The suggested lower permafrost distribution limit of approximately $2000 \mathrm{~m}$ a.s.l. in the central Southern Alps does not exclude the existence of permafrost at lower elevations, such as observed in the Ohau ski field at $\sim 1700 \mathrm{~m}$ a.s.I (cf. Section 4.1.3). The lower permafrost boundary was calculated based on the mean elevation of locations with predicted permafrost probability of 0.6 to 0.7 . Sites of this probability class were modelled for southern aspects in the central ranges as low as $1440 \mathrm{~m}$ a.s.l. (Table 4.8). Below the chosen probability threshold of 0.6 , topoclimatic conditions are assumed less favourable but should not be interpreted as prohibiting of isolated permafrost occurrences. Local conditions, such as coarse debris cover or long-lasting snow deposits, which were not considered in the present model, might facilitate permafrost presence even in locations where topoclimatic conditions appear unsuitable. Similarly, permafrost lenses might have been preserved since the last cold period under metres of debris, largely disconnected from modern-day climatic influences.

\subsubsection{Applicability of the BTS method for permafrost prospecting in New Zealand}

Results of the continuous surface temperature (GST) measurements in the central Ben Ohau Range suggest that the bottom temperature of the winter snow cover (BTS) can potentially be used for permafrost prospecting in New Zealand's Southern Alps (cf. Section 4.3.4). At many monitoring sites, snowpack conditions were dry enough during the two investigated winters for ground surface temperatures to reflect temperature development in the near-surface material (Type 1 and 2 profiles in Figure 4.28). However, at several of these sites, snowpack height was insufficient to decouple the subsurface from air temperature fluctuations and thus for the establishment of an equilibrium temperature towards the end of winter (Type 2 profiles). As a result, BTS values could only be inferred for approximately a third of the monitoring sites each year. The high spatial variability in GST profile types suggests that extensive BTS campaigns with thermistor probes (e.g. Isaksen et al., 2002; Julián and Chueca, 2007; Schöner et al., 2012) might not be feasible in the Southern Alps. While observations affected by an isothermal (i.e. wet) snow cover can be easily identified by a BTS value close to freezing point and disregarded, it is not possible to determine whether a probed BTS value reflects an atmospheric signal. Snow height at the time of BTS probing might be an adequate indicator whether the subsurface had been 
decoupled from atmospheric influences for a sufficient period (e.g. Schöner et al., 2012). However, this requires further information on BTS-critical snow heights in the Southern Alps as well as the verification of the end-of-winter snow height as a reliable Type-1 profile indicator also in New Zealand settings. The use of continuous temperature loggers is generally recommended, as their records give insight into the temperature evolution prior to the BTS 'period' and thus allow the evaluation of the BTS values' interpretability.

The two-year GST records demonstrated that inferred BTS values vary significantly interannually at a given site. The comparatively late development of a thick snow cover in winter 2011 facilitated effective ground cooling during autumn and early winter. BTS values for 2011 were consequently significantly cooler than the previous winter, when earlier snowpack development insulated the subsurface at relatively high temperatures. Longer time series (preferably five to ten years) would allow the identification of temperature development regimes as suggested by Brenning et al. (2005). Long-term records could be used to determine a 'likely' BTS value at the individual monitoring sites (e.g. long-term average) and enable the development of corrective measures for short-term GST monitoring records in the region.

The interpretation of BTS values at the monitoring sites (with respect to the likelihood of permafrost presence in the subsurface material) was based on the commonly used BTS rule-of-thumb (Hoelzle, 1992) derived in the European Alps. The validity of these thresholds in New Zealand's maritime climate could not be investigated due to technical problems preventing the verification of permafrost occurrence at the monitoring sites by electrical resistivity tomography (ERT). In March 2010 and January 2011, several transects were attempted along the miniature data logger profiles (Figure 4.25) as well as across the presumably active rock glaciers in the Irishman Steam Valley, using a 16 electrode GF Instruments ARES-Automatic Resistivity System (GF Instruments, n.d.) with 5 metre spacing and various array configurations. Thirty centimetre steel rods, hammered into the talus or placed in voids between boulders and filled with smaller blocks, were employed as electrodes. Readings were only successfully completed for a few partial transects; none covering a BTS monitoring site. Dry ground conditions towards the end of summer as well as insufficient contact between bigger blocks and electrodes at the talus footslopes likely impaired the coupling between the electrodes and the ground. An earlier survey date (January) in summer 2010/11 as well as watering of electrodes with salt water immediately before measurements did not significantly improve the number of successful readings. Ground truthing of permafrost occurrence at the BTS monitor sites was consequently abandoned. The use of water-saturated sponges in steel nets (Ishikawa, 2008) or porous pot electrodes (M. Cockcroft, pers. comm. November 2010), placements of electrodes into small holes drilled into rock (Kneisel and Hauck, 2008), or filling voids (where reasonable) with sand that is repeatedly watered before measurements might improve the contact between electrodes and ground material. All of these measures require time and equipment-intensive 
preparation of survey slopes prior to resistivity measurements. The Irishman Stream head area is recommended for future, more elaborate resistivity surveys because of its easy access by helicopter, the proximity of a tarn as in-field water source (see Figure 4.25), as well as the modelled and BTS-indicated high likelihood of permafrost presence within debris slopes. Combined with further GST records, results could provide valuable information on whether the empirical BTS 'rule-of-thumb' thresholds are valid in the Southern Alps. 


\subsection{SUMMARY}

Permafrost is defined as ground that remains at or below $0^{\circ} \mathrm{C}$ for at least two consecutive years. Permafrost occurrence in alpine environments is characterised by a high spatial variability as the steep mountain topography induces a strong spatial heterogeneity of controlling factors. At catchment to local scales, the dominant control of mean annual air temperature on permafrost distribution is modified by the amount of incoming solar radiation, snow distribution, and thermal properties of the surface and subsurface material.

The distribution of alpine permafrost in the Southern Alps was modelled at the catchment-scale based on the statistical evaluation of a regional rock glacier inventory for the Canterbury Region. Rock glaciers are the most conspicuous surface expressions of alpine permafrost and are readily identifiable in remotely sensed imagery by their characteristic furrow-and-ridge topography. Overall, 386 rock glaciers were mapped of which $20 \%$ were classified as active (containing ice, moving), $23 \%$ as inactive (containing ice, not moving), and $57 \%$ as relict features (no ice, not moving). Logistic regression was used to identify characteristic topoclimatic conditions at the head area of presently active talusderived rock glaciers. Climatic conditions at these locations were favourable for permafrost formation prior to the onset of permafrost creep and are presumably still favourable for at least permafrost preservation. It is, therefore, plausible that permafrost is currently also present in non-creeping taluses, where topoclimatic conditions are similar to those in the head area of currently active features. Identified statistical relationships between permafrost presences, mean annual air temperature, and potential incoming solar radiation in snow-free months were used to compute spatially-distributed conditional probabilities for permafrost occurrence. A probability threshold of 0.6 was chosen to discriminate between 'permafrost probable' $(P \geq 0.6)$ and 'permafrost improbable' $(P<0.6)$ locations and thus for delineating potential permafrost areas.

Based on the model results, permafrost occurrence is likely above $\sim 2000 \mathrm{~m}$ a.s.l. in the central Southern Alps and above $2150 \mathrm{~m}$ a.s.l. in the Inland Kaikoura Range. The increase in lower permafrost distribution limits towards the warmer north of the South Island conforms with the global permafrost distribution pattern of increasing altitudinal limits with decreasing latitude. The local validity of the modelled permafrost extent was evaluated by a two-year record of bottom temperatures of the winter snow cover (BTS), derived from continuous ground surface temperature measurements at a test site in the central Ben Ohau Range, and distribution of perennial snow patches in the wider vicinity of the test site. Both independent datasets support the modelled permafrost extent; the developed permafrost distribution estimate appears therefore reasonable.

The distribution of active rock glaciers in the Southern Alps suggests that the potential permafrost zone extends to lower elevations in the maritime New Zealand setting than in the 
continental European Alps despite comparable latitudes. A similar pattern was also indicated in North American datasets. These findings suggest an oceanic control on global permafrost distribution limits besides the well-acknowledged latitudinal control. Comparatively low summer maxima, characteristic for maritime climates, might significantly reduce ice loss during the warm season and thus facilitate the preservation of permafrost at significantly lower altitudes. Such global-scale oceanic influence on permafrost distribution has yet to be systematically investigated.

Continuous ground surface temperature measurements over two consecutive years indicate that snow pack conditions in the Southern Alps are potentially suitable for BTS measurements. However, the validity of the commonly used BTS thresholds for permafrost mapping has yet to be verified for New Zealand. Furthermore, corrective measures for interannual variations in BTS temperatures and guidelines for critical snow height have to be developed before extensive BTS campaigns with thermistor probes are practicable in the Southern Alps. 


\section{5| STATISTICAL ANALYSIS OF DEBRIS FLOW PRECONDITIONING FACTORS}

The literature review on factors controlling debris flow initiation (Section 3.1.2) highlighted the significant role of preconditioning factors on the spatial distribution and activity of debris flow systems. In this chapter, univariate and multivariate statistics are used to investigate the potential influence of periglacial and non-periglacial preconditioning factors on the distribution of debris flow systems and debris flow events mapped in the study areas (cf. Section 3.3). A short introduction to the utilised statistical methods, frequency ratio and logistic regression, is given in Section 5.1. Frequency ratios are used in this study to investigate spatial variations in debris flow system and event density according to slope, aspect, altitude, lithology, presence of Quaternary sediment reservoirs, neo-tectonic uplift rates, and permafrost occurrence within the initiation area (Section 5.2.1 - 5.2.6). Logistic regression is used to analyse the effect of environmental conditions on sediment reaccumulation in supply-limited systems, which is inferred by variations in debris flow systems' activity during the investigation period (Section 5.2.7). Regression models are utilised to answer seven specific research questions that investigate the potential influence of frost-weathering intensity, permafrost occurrence within rockwalls, topography, aspect, and lithology on supply-dependent debris flow activity. The structure of this chapter differs from the previous chapters, since it does not include a dedicated discussion section. Instead the statistical results are discussed along with the analyses. The chapter ends with a summary of key results in Section 5.3.

The statistical analysis focuses on the potential control of preconditioning factors on debris flow occurrence in the study areas. Triggering events, such as heavy rainfall and earthquakes, are not considered due to current challenges in their spatially-distributed parameterisation (cf. Section 1.1). For methodological reasons, it is assumed that every system encountered the same number and type of triggering events during the investigation period. This is of course an unrealistic assumption, as small-scale variations in rainfall triggers are known to occur (e.g. Beschta, 1983; Goodrich et al., 1995; Blijenberg, 1998). However, this generalisation allows a comparison of active and non-active debris flow 
systems with respect to environmental conditions within and above debris flow initiation areas, and hence the analysis of predisposing controls.

This study aims to identify the potential influence of periglacial preconditioning factors on debris flow activity in high-alpine areas. Many of the selected study areas have thus significant proportions of area above the limit of closed vegetation (upper limit of penalpine vegetation $\sim 1500 \mathrm{~m}$; Wardle, 1991, p. 77). Consequently, in-depth analyses of the potential influence of vegetation cover on slope stability or the effect of land use change or wild fire occurrence on debris flow activity were omitted. However, it is noted that the analysis of historical aerial photographs, used for debris flow event mapping, did not indicate incidences of deforestation or wild fires in the study areas during the investigation period. Yet, changes in vegetation cover prior to the documented period cannot be excluded as a potential influence on the observed debris flow activity in the study areas. In particular, the development of a notable number of new slide instabilities in the Mt Aspiring region (cf. Section 3.3.2) might be linked to a past change in vegetation cover or land use practice at these mid-altitude sites. A further factor not included in the present analysis is the geometry of slopes in and around debris flow initiation areas, as the currently available DEMs, derived from $20 \mathrm{~m}$ contour lines, do not adequately resolve the topography of hillslopes (cf. Section 3.2.3).

\subsection{Statistical METHODS}

\subsubsection{Frequency ratios}

In order to investigate the influence of a specific preconditioning factor on the initiation of debris flows, frequency ratios were calculated for the overall debris flow inventory $(N=1534)$, the active systems $(N=219)$, and the multiple event systems $(N=18)$.

Frequency ratio $(F R)$ is a simple quantitative measure for the statistical relationship between the occurrence of debris flows and a specific contributing factor (cf. Lee and Talib, 2005; Erener and Düzgün, 2010). It is calculated as the quotient of percent frequency distributions and can be computed for both categorical and continuous variables as:

$$
F R_{k}=\frac{D F_{k}}{A_{k}}
$$

where $F R_{k}$ is the frequency ratio for the influencing factor or factor subclass $k, D F_{k}$ the proportion of debris flows occurring in or at factor class $k$, and $A_{k}$ the proportion of the area with factor $\mathrm{k}$ present. Assuming that debris flow events are more common in areas with promoting conditions, a frequency ratio value greater than 1 , denoting a debris flow 
frequency above the study areas' overall average, indicates that the analysed factor or factor subcategory has a positive relationship with debris flow occurrence. A frequency ratio value lower than 1 , on the other hand, suggests an impeding control. In short, frequency ratios are the areally-normalised extension to the frequency distributions presented in Section 3.3.

Since frequency ratios are based on proportions, they are sensitive to the size of samples. Frequency ratios for small sample populations (e.g. the active system dataset, $\mathrm{N}=219$ ) are likely to display more extreme ratio values than those for larger populations (e.g. the overall debris flow inventory, $N=1534$ ), since the individual cases have a higher weight in percent frequency distributions within small populations. Frequency ratio values between different sized datasets should thus be compared with caution and interpretations based on the presence or absence of a positive statistical relationship rather than the actual ratio value. Despite these limitations, frequency ratios are a useful statistical tool to analyse events in relation to the spatial extent of a specific preconditioning factor and thus to identify process promoting or impeding conditions (cf. Lee and Sambath, 2006; Pradhan and Lee, 2010; Reis et al., 2012).

\subsubsection{Logistic regression}

Bivariate analyses, such as frequency ratio analyses, allow exploring the effect of individual factors on debris flow activity. The investigation of the influence of more than one factor on debris flow occurrence though requires a more sophisticated multivariate statistical approach such as logistic regression.

The mathematical background of logistic regression models as well as methodological aspects of their implementation have already been described in Chapter 4 in the context of the permafrost distribution estimate (see Section 4.2.2 and Section 4.3.2). Logistic regression was used in Chapter 4 to derive a predictive model that calculated the conditional probability of permafrost occurrence at a given location. The model was based on a selected set of local environmental conditions already known from literature to adequately predict permafrost presence. The objective of the present chapter is to identify the relevant preconditioning factors for debris flow activity from a set of potential, yet untested, influencing factors. Logistic regression will, therefore, be used in the following as an exploratory tool to assess the presence of statistically significant relationships between environmental variables and debris flow occurrence and to answer specific research questions. As the present study focuses only on a selected set of literature-based preconditioning factors and omits for process initiation equally important triggering events, it does not claim comprehensiveness. Consequently, it is not attempted to use logistic regression results for predicting the likelihood of debris flow activity in selected systems or to identify debris flow prone areas. 


\subsection{ANALYSIS OF PRECONDITIONING FACTORS}

The following sections describe the results of the statistical analysis of predisposing controls for debris flow activity in the Southern Alps. Sections 5.2.1 to 5.2.6 focus on the potential role of slope, aspect, altitude, lithology and Quaternary deposits, neo-tectonic uplift rates, and permafrost occurrence within the initiation area in the formation of debris flows. Promoting conditions are explored by frequency ratios, which were calculated separately for all the mapped debris flow systems (All systems) and systems that showed activity during the investigation period (Active systems). In both datasets, it was further distinguished between debris flow types (slide-initiated (SIT), runoff-generated (RIT), and slide-related $(\mathrm{COMB}))$. The frequency ratio values are included in tabular form within the respective sections. Extended versions of the tables, including debris flow counts for and areal extent of the individual factor classes, can be found in the Electronic Appendix 5. Section 5.2.7 explores the role of selected environmental factors on regolith recharge in supply-dependent debris flow systems, which was inferred from variations in debris flow systems' activity during the investigation period. Dependency on sediment availability for debris flow formation is common for runoff-generated debris flow systems, as events generally deplete available debris storages (cf. Section 3.1.2, active debris reservoirs). The sediment recharge analyses were, consequently, restricted to a sample of runoff-generated debris flow systems for which regolith-supplying contribution areas had been delineated (Section 3.2.3). Seven research questions guided the regression of mapped debris flow activity against frostweathering intensity, aspect, lithology, uplift rates (as a proxy for bedrock fracture density), and bedrock permafrost. Results of the regression models are included under the respective questions.

\subsubsection{Slope}

One of three main prerequisites of debris flow development is, besides material availability and sudden excessive water input, sufficient gravitational forcing within the initiation area. The initial examination of the debris flow inventory (cf. Section 3.3) showed that common slope gradients of debris flow initiation in the study areas are with $30^{\circ}$ to $40^{\circ}$ in agreement with observations of studies worldwide (cf. Corominas et al., 1996). Prevailing gradients do not vary greatly between the studied regions. However, significant differences in affected slope angles were observed between debris flow types. Slide-initiated (SIT) and slide-related (COMB) instabilities, which commonly occur in well-developed sediment accumulations, developed generally at less inclined locations than purely runoff-generated debris flows (RIT). This difference is also apparent when relating the number of debris flow 
systems to the slope classes' areal extent (Table 5.1). All debris flow types are overproportionately frequent in the slope categories $30^{\circ}$ to $40^{\circ}$. Slide-initiated and sliderelated debris flows are also exceptionally frequent below $30^{\circ}$, whereas runoff-generated debris flows are overproportionately numerous above $40^{\circ}$. Slope gradients exceptionally susceptible for debris flow development thus vary according to initiation type. Based on the low frequency ratios for debris flow systems at gradients below $20^{\circ}$ and the complete lack of debris flow events occurring in these categories during the investigation period, slope gradients below $20^{\circ}$ can be assumed to be process impeding.

In theory, debris flows do not develop on slopes above the angle of repose for loose sediment, which is commonly assumed to be $45^{\circ}$ (cf. Section 3.1.2). However, frequency distributions in Table 3.3 showed that $6 \%$ (109) of the mapped debris flow systems and $8 \%$ (19) of active debris flow systems originated in locations above this theoretical threshold. The conspicuous number of debris flows developing in theoretically unsuitable areas is likely related to the insufficient representation of hillslope topography in the $15 \mathrm{~m}$ DEM (Columbus et al., 2011a) utilised for the slope calculations. Surface gradients for the $15 \mathrm{~m}$ grid cells were computed in ArcMap 9.3 as the maximum rate of change in altitude in relation to its neighbouring cells (ESRI, 2009a). Consequently, cells representing concave slope breaks at the rock-debris interface show erroneously high values, since their calculation is based on the height difference to the adjacent rock cliffs. Slope values of runoff-generated debris flow systems that developed at the rock-debris interface are therefore biased towards higher values. Frequency ratios above one for runoff-generated systems (Table 5.1, All systems) and events (Table 5.1, Active systems) in the slope category ' $45^{\circ}$ to $50^{\circ}$ ' are likely the expression of the common occurrence of debris flows at the exit of rock channels onto taluses.

Table 5.1 Frequency ratios for slope categories according to initiation type and activity count. The green colouring indicates ratios greater than 1 with light green marking ratios of 1 to $<2$ and grass green $\geq 2$. An extended version of this table, including debris flow counts and areal extent of the individual slope classes, can be found in the Electronic Appendix 5.

\begin{tabular}{|c|c|c|c|c|}
\hline \multirow[b]{2}{*}{ Slope $\left[^{\circ}\right]$} & \multicolumn{4}{|c|}{ All systems } \\
\hline & TOTAL & SIT & RIT & COMB \\
\hline$\leq 10$ & 0.03 & - & 0.04 & - \\
\hline$>10-15$ & 0.05 & 0.15 & 0.04 & - \\
\hline$>15-20$ & 0.17 & 0.31 & 0.10 & 0.57 \\
\hline$>20-25$ & 0.33 & 1.30 & 0.18 & 0.49 \\
\hline$>25-30$ & 0.61 & 1.11 & 0.47 & 1.21 \\
\hline$>30-35$ & 1.16 & 1.40 & 1.09 & 1.48 \\
\hline$>35-40$ & 1.70 & 1.37 & 1.77 & 1.49 \\
\hline$>40-45$ & 1.72 & 0.61 & 1.98 & 0.86 \\
\hline$>45-50$ & 1.10 & 0.26 & 1.34 & 0.12 \\
\hline$>50-55$ & 0.59 & 0.30 & 0.71 & - \\
\hline$>55-60$ & 0.35 & - & 0.44 & - \\
\hline$>60$ & - & - & - & - \\
\hline
\end{tabular}

\begin{tabular}{|cccccc|}
\multicolumn{7}{|c|}{ Active systems } \\
\hline TOTAL & SIT & RIT & COMB & $>$ 1 EVENT \\
- & - & - & - & - \\
- & - & - & - & - \\
- & - & - & - & - \\
0.46 & 1.62 & 0.25 & 0.37 & 1.11 \\
0.60 & 1.28 & 0.45 & 0.73 & 0.73 \\
\hline 1.08 & 0.72 & 1.06 & 1.66 & 1.25 \\
\hline 1.79 & 1.58 & 1.82 & 1.81 & 1.63 \\
\hline 1.59 & 0.91 & 1.81 & 1.04 & 0.52 \\
\hline 1.10 & 0.65 & 1.37 & - & 1.11 \\
\hline 1.25 & 1.47 & 1.42 & - & 2.53 \\
\hline 0.49 & - & 0.67 & - & - \\
- & - & - & - & - \\
\hline
\end{tabular}


Interestingly, although debris flow initiation areas were not overproportionately frequent at gradients above $50^{\circ}$, a comparatively large number of these systems showed activity during the investigation period. This may indicate a higher susceptibility of systems originating at the rock/debris interface for debris flow formation. A closer look at the topographic location of the relevant debris flow systems revealed that almost two thirds of the predominately runoff-generated systems in the category $50^{\circ}$ to $55^{\circ}$ were located within $20 \mathrm{~m}$ of the rock/debris interface. In turn, a third of these systems were active during the investigation period. However, the higher susceptibility of these debris flow systems close to the rock/debris interface was not confirmed when comparing debris flow activity levels by the topographic classes debris, rock/debris interface, and rock (Figure 5.1). Debris flow systems located within $20 \mathrm{~m}$ of the mapped rock/debris interface (cf. Section 3.2.4) were not more frequently active during the investigation period than debris flow systems below (debris slopes) or within rock channels (rock).

High frequency ratios for slide-initiated active systems and multiple event systems in the slope category ' $50^{\circ}$ to $55^{\circ}$ ' are both based on only a single debris flow system in the Glacier Burn valley, Mt Aspiring region (MA-GB). This system formed initially between 1988 and 1998 in shallow, vegetated regolith on the catchment's steep north-facing slope and experienced reactivation in the subsequent period. As a result of the small number of active slide-initiated systems $(\mathrm{N}=31)$ and active multiple event systems $(\mathrm{N}=18)$, the proportional value of this single system in the respective samples is comparatively high (3\% and $6 \%$, respectively). Conversely, the proportional extent of the slope category ' $50^{\circ}$ to $55^{\circ}$ ' is with $2 \%$ only small, resulting in misleadingly high frequency ratio values.

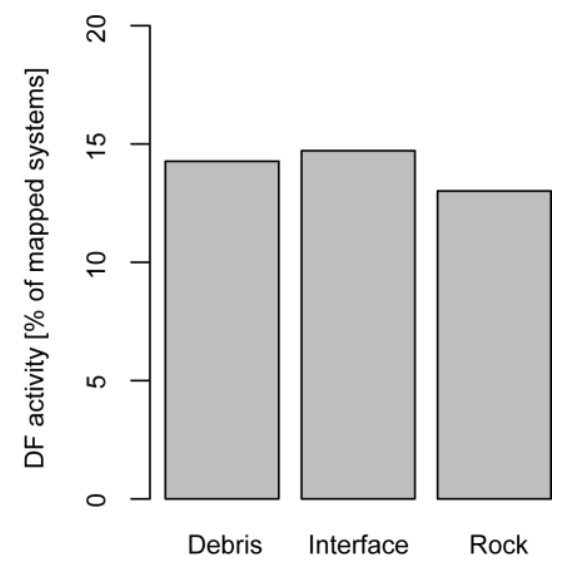

Figure 5.1

Debris flow activity, calculated as proportion of mapped systems showing activity during the investigation period, in the topographic categories debris, rock/debris interface, and rock wall. 


\subsubsection{Aspect}

The orientation of slopes has no direct influence on debris flow occurrence. However, especially in combination with altitude, aspect is a main control on other potentially influential factors, such as regolith production through rock weathering, past and present glacial and periglacial activity, or permafrost occurrence (cf. Section 3.1.2).

The initial examination of the debris flow inventory showed that both debris flow systems and observed events are particularly numerous in locations with south and south-east orientations, suggesting a higher tendency for mass-wasting processes in sun-avert locations. Relating debris flow counts to the areal extent of the individual aspect classes, however, does not confirm a strong spatial preference (Table 5.2). Although debris flow systems of all initiation types are more frequent than the expected value in southern aspect classes, the ratios are mostly only slightly above 1 and thus observed numbers are only slightly above the areal probability. Strong relationships, however, can be found for slideinitiated debris flow systems as well as slide-initiated events in the northwest and northern aspects. More than a third (37\%) of all slide-initiated systems emanated in these aspect classes. Excluding systems originating in relict sediment storages, such as moraines and landslide deposits, which might, due to their susceptibility to instabilities, bias process counts in certain aspect classes (cf. Section 5.2.4), the proportion of slide-initiated systems in northwest and northern aspects even increases to $41 \%$. A possible reason for this marked spatial clustering in northwards facing aspect classes is the distinct valley-slope asymmetry observed in more than half of the study areas (e.g. Denas Creek, Arthur's Pass region (AP-DC), Black Birch Stream valley, Mt Cook region (MC-BBS), Kay Creek tributary, Mt Aspiring region (MA-KCET)). Sun-avert valley flanks in these catchments are formed by steep rockwalls with active, presumably well-drained talus cones below, whereas the sunfacing valley sides are gentler sloping, largely without significant outcrops or slope breaks. These north-facing flanks are in many cases continuously blanketed by detritus up to the ridge crests. Closed vegetation cover in mid and lower ranges suggests advanced soil

Table 5.2 Frequency ratios for aspect categories according to initiation type and activity count. The green colouring indicates ratios greater than 1 with light green marking ratios of 1 to $<2$, grass green 2 to $<3$, and dark green $\geq 3$. An extended version of this table, including debris flow counts and areal extent of the individual aspect classes, can be found in the Electronic Appendix 5.

\begin{tabular}{|c|c|c|c|c|c|c|c|c|c|}
\hline \multirow[b]{2}{*}{ Aspect class } & \multicolumn{4}{|c|}{ All systems } & \multicolumn{5}{|c|}{ Active systems } \\
\hline & TOTAL & SIT & RIT & СOMB & TOTAL & SIT & RIT & СОMB & I >1 EVENT \\
\hline $\mathrm{N}$ & 0.96 & 1.50 & 0.87 & 1.17 & 0.87 & 1.95 & 0.75 & 0.37 & 1.12 \\
\hline $\mathrm{NE}$ & 0.84 & 0.49 & 0.90 & 0.73 & 0.69 & 0.97 & 0.70 & 0.28 & 2.09 \\
\hline$E$ & 0.74 & 0.49 & 0.70 & 1.24 & 0.50 & 0.55 & 0.37 & 1.25 & 0.47 \\
\hline SE & 1.00 & 1.21 & 0.97 & 1.07 & 1.09 & 0.50 & 1.09 & 1.73 & 1.73 \\
\hline$S$ & 1.23 & 0.64 & 1.33 & 1.02 & 1.36 & 0.20 & 1.57 & 1.37 & - \\
\hline sw & 1.05 & 1.15 & 1.04 & 1.01 & 0.81 & 0.76 & 0.88 & 0.44 & - \\
\hline W & 1.15 & 0.75 & 1.22 & 0.96 & 1.11 & 0.68 & 1.24 & 0.78 & 0.59 \\
\hline NW & 1.00 & 1.91 & 0.91 & 0.79 & 1.38 & 3.07 & 1.13 & 0.96 & 1.44 \\
\hline
\end{tabular}


development and hence, due to reduced permeability, slope conditions potentially susceptible to shallow landslides. Given that slide and slip-related instabilities are especially prone to short-term reactivation (cf. Section 3.4.2), it is not surprising that multiple events also show overproportionate frequencies in the sun-facing aspect classes. The exceptionally high frequency ratio in the north-east aspect category is again due to the small overall number systems with multiple debris flow events.

A structural control cannot be eliminated as a reason for the observed valley-asymmetry without detailed field investigation. However, given that the asymmetry can be observed to a varying degree in all west-east trending study areas and thus in different geologic terranes, a past climatic control of aspect-constrained periglacial weathering (cf. Currey, 1964; Leslie and McGlone, 1973; Siegmund and Hall, 2000; Niu et al., 2005) seems more likely. During periglacial periods (i.e. cold-climate conditions after the LGM), higher insolation levels would have resulted in deeper active-layer thicknesses of permafrost soils and increased water availability on sun-facing slopes. This would have led to more effective weathering and gelifluction at these locations and hence to the production of a gentle slope profile over time. During the summer period, the increased sediment input from sun-facing slopes likely forced the valley drainage towards the opposite valley sides, causing lateral erosion and maintenance of a steep slope gradient at the opposite sun-avert valley flanks.

\subsubsection{Altitude}

Elevation above sea level is, similar to aspect, a topographic factor that does not directly affect debris flow occurrence. However, elevation is a main control on other, predominantly climate-related influential factors, such as type and amount of precipitation, duration and intensity of frost weathering, vegetation cover, presence of glaciers, and permafrost occurrence (cf. Section 3.1.2).

The initial examination of the debris flow inventory showed that debris flows occur in the study areas at a wide range of elevations. They are most abundant in the mid-altitude classes between $1200 \mathrm{~m}$ and $1700 \mathrm{~m}$. Frequency ratios incorporating the areal extent of the individual altitudinal zones confirm the overproportionate presence of debris flows in the midranges (Table 5.3). Given that the potentially influencing altitude-related environmental limits, such as permafrost occurrence (mean lower limit of permafrost distribution $2000 \mathrm{~m}$; cf. Section 4.3.3), and the limit of closed vegetation cover ( $1500 \mathrm{~m}$; Wardle, 1991) are located at higher elevations, a climate-related influence on the observed pattern seems unlikely. However, increased regolith production due to intense frost weathering above the debris flow initiation areas (above $\sim 1700 \mathrm{~m}$, according to Hales and Roering's (2009) frost-cracking intensity model; see Section 5.2 .7 for details), cannot be excluded as a 
Table 5.3 Frequency ratios for altitude categories according to initiation type and activity count. The green colouring indicates ratios greater than 1 with light green marking ratios of 1 to $<2$, grass green 2 to $<3$, and dark green $\geq 3$. An extended version of this table, including debris flow counts and areal extent of the individual altitude classes, can be found in the Electronic Appendix 5.

\begin{tabular}{|c|c|c|c|c|c|c|c|c|c|c|}
\hline \multirow[b]{2}{*}{ Altitude [m a.s.I.] } & \multicolumn{4}{|c|}{ All systems } & \multicolumn{6}{|c|}{ Active systems } \\
\hline & TOTAL & SIT & RIT & COMB & TOTAL & SIT & RIT & COMB & 1 & EVENT \\
\hline$>2400-2500$ & - & - & - & - & - & - & - & - & 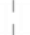 & - \\
\hline$>2300-2400$ & - & - & - & - & - & - & - & - & 1 & - \\
\hline$>2200-2300$ & 0.27 & - & 0.34 & - & - & - & - & - & 1 & - \\
\hline$>2100-2200$ & 0.45 & - & 0.57 & - & - & - & - & - & 1 & - \\
\hline$>2000-2100$ & 0.48 & - & 0.61 & - & 0.31 & - & 0.42 & - & 1 & - \\
\hline$>1900-2000$ & 0.69 & - & 0.87 & - & 0.56 & - & 0.76 & - & 1 & - \\
\hline$>1800-1900$ & 0.76 & 0.38 & 0.87 & 0.30 & 0.63 & 0.63 & 0.67 & 0.36 & 1 & - \\
\hline$>1700-1800$ & 0.87 & 0.54 & 0.93 & 0.73 & 0.88 & - & 1.08 & 0.68 & 1 & - \\
\hline$>1600-1700$ & 1.16 & 1.55 & 1.10 & 1.27 & 0.77 & 1.28 & 0.62 & 1.10 & & 0.55 \\
\hline$>1500-1600$ & 0.96 & 0.68 & 1.01 & 0.90 & 0.87 & - & 1.18 & - & 1 & 0.59 \\
\hline$>1400-1500$ & 1.19 & 0.70 & 1.23 & 1.31 & 1.25 & 0.38 & 1.48 & 0.88 & 1 & - \\
\hline$>1300-1400$ & 1.53 & 1.80 & 1.42 & 2.07 & 1.90 & 2.84 & 1.56 & 2.80 & & 1.40 \\
\hline$>1200-1300$ & 1.61 & 2.35 & 1.53 & 1.44 & 2.35 & 3.59 & 1.90 & 3.61 & & 4.64 \\
\hline$>1100-1200$ & 1.38 & 0.94 & 1.31 & 2.35 & 1.47 & 0.52 & 1.80 & 0.59 & & 2.68 \\
\hline$>1000-1100$ & 1.21 & 2.16 & 0.94 & 2.28 & 1.33 & 2.01 & 0.90 & 3.08 & & 3.47 \\
\hline$>900-1000$ & 0.81 & 3.04 & 0.46 & 1.33 & 0.29 & 1.01 & - & 1.16 & & 1.73 \\
\hline$>800-900$ & 0.53 & 2.63 & 0.33 & - & 1.58 & 7.46 & 0.72 & - & & 3.21 \\
\hline$>700-800$ & 0.17 & 0.85 & 0.11 & - & - & - & - & - & & - \\
\hline$>600-700$ & - & - & - & - & - & - & - & - & 1 & - \\
\hline $500-600$ & - & - & - & - & - & - & - & - & 1 & - \\
\hline
\end{tabular}

possible control on the observed debris flow distribution pattern. A closer examination of the respective debris flow systems suggests that the high abundance of systems at mid-ranges is at least to some degree dataset-specific, as some study areas with exceptionally high debris flow densities or counts (e.g. Middlehead Stream valley, Seaward Kaikoura Range (KR-MHS), Castle Hill - Foggy Stream valleys, Arthur's Pass region (AP-CHFS), Enys Stream valley, Arthur's Pass region (AP-ES), and Upper Stony Creek tributary, Mt Aspiring region (MA-USCT)) have large proportions of land area in these altitudinal classes. The overproportionate abundance of debris flows of all initiation types at $1600 \mathrm{~m}$ to $1700 \mathrm{~m}$ can be explained by extensive zones of debris immediately below the rock/debris interface (e.g. Kay Creek tributary, Mt Aspiring region (MA-KCET)), rock outcrops (e.g. Forest Creek, Two Thumb Range (TT-FC)), or moraines (e.g. Stony Stream valley, Mt Cook region (MC-SSV)). Frequency ratios for the different debris flow types reflect previous observations with respect to slope gradients (cf. above). Slide-initiated (SIT) and slide-related (COMB) systems occur overproportionately in the lower altitudinal classes, whereas runoff-generated debris flow systems (RIT) originate above spatial probability at higher altitudes. Although valley floor elevations vary significantly between study areas, it can be assumed that slopes at lower elevations are generally gentler, allowing for sediment to accumulate and for soil to develop and consequently providing the environment for slide instabilities to occur. Frequency ratios for debris flow events largely reflect the patterns observed in the general debris flow inventory. Overall, based on areal frequencies, altitude and related environmental parameters appear not to have a substantial influence on debris flow occurrence in the study areas. Local topography and the presence of certain geomorphic 
features, such as talus/rock interfaces, rock outcrops, or moraines, seem of greater importance for debris flow development.

\subsubsection{Lithology \& Quaternary deposits}

Empirical evidence for a lithological control on debris flow activity is unusual (cf. Section 3.1.2). So far only a few studies have established a process-based link between the spatial variations in debris flow occurrence and rock types (e.g. Ballantyne, 1986; Griffiths et al., 2004). Rock mass strength as a property of rock lithology is likely to be the dominant aspect of lithological control on debris flow occurrence. Rock mass strength is affected by bedding, foliation, fracture spacing, and orientation and determines the local topography by imparting control on the susceptibility of bedrock to weathering and failure (e.g. Sass, 2005b; Moore et al., 2009; see also Section 5.2.5). As such, rock mass strength influences not only the spatial distribution of debris flows by conditioning steepness of slopes and the extent and grain-size composition of debris reservoirs, but also affects weatheringcontrolled sediment reaccumulation in supply-limited debris flow systems.

Information on bedrock geology in the study areas was sourced from the digital vector version of New Zealand's national geological map QMAP (Quarter-million-scale map), sheets 13 (Kaikoura; Rattenbury et al., 2006), 15 (Aoraki; Cox and Barrell, 2007), and 18 (Wakatipu; Turnbull, 2000). Lithologies were differentiated according to the QMAP's rock group attribute, allowing for a generalised classification of the study areas' geological environments. In the following, capitalisation is used to differentiate QMAP's rock groups (e.g. Argillite) from the lithological unit (e.g. argillite), which might be only the predominant part of the respective rock group (e.g. argillite generally occurs interbedded with sandstone). For clarity, the QMAP rock groups Schist and Metavolcanic have been replaced by the terms Greyschist and Greenschist, which are more commonly used terms for these Otago Schist units (e.g. Craw, 1984; Mortimer and Roser, 1992).

Most of the study areas are located within the non-metamorphosed regions of the Torlesse Composite terrane (cf. Section 2.2). Therefore, it is not surprising that the overwhelming majority $(78 \%)$ of the mapped debris flow systems originated in either Greywacke or Sandstone (Figure 5.2). The areal bias in the frequency counts is evident when calculating debris flow densities for the individual rock groups (Figure 5.3). The number of debris flow systems in Greywacke only is close to the overall average density of debris flows in the study areas. Argillite and Sandstone, on the other hand, show above average debris flow densities.

The number of debris flow events within the rock groups is generally proportional to the number of systems in the respective category (Figure 5.2). Only in Argillite is the relative 


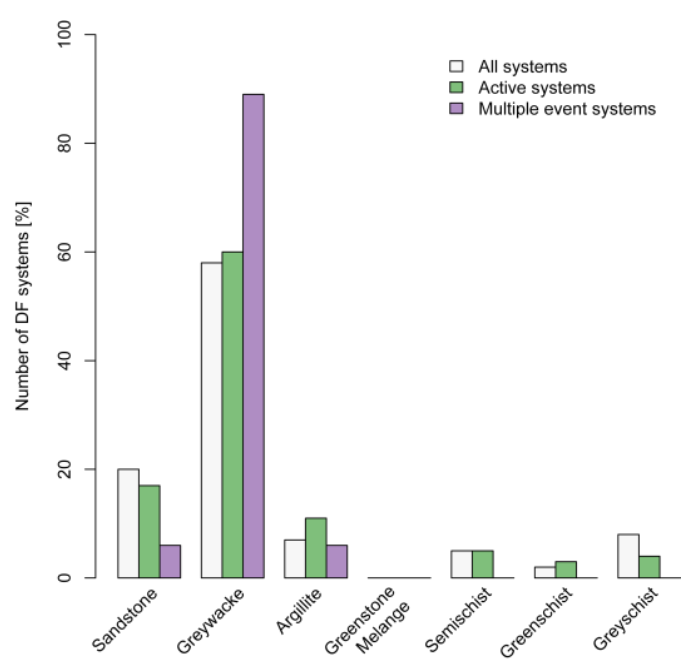

Figure 5.2

Frequency of debris flow systems and events in the individual lithology classes.

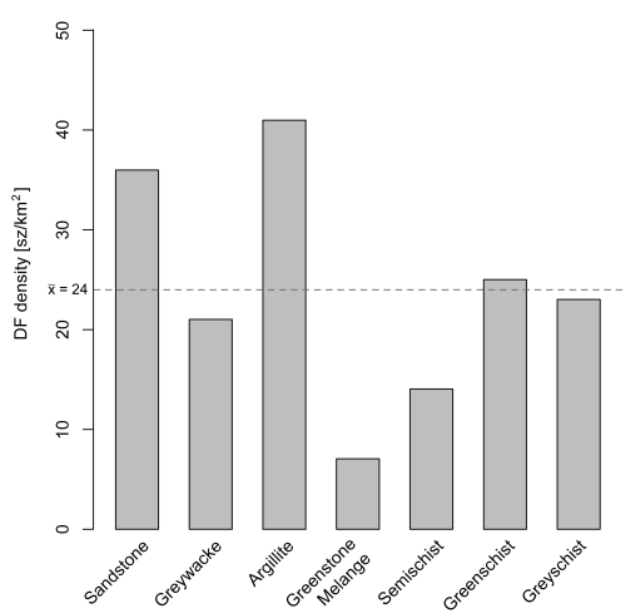

Figure 5.3

Debris flow density (overall inventory) in the individual lithology classes. The dashed line marks the overall mean debris flow density $(\bar{X})$ of 24 systems per $\mathrm{km}^{2}$.

number of events found to be markedly above the general inventory counts, suggesting a comparatively high debris flow activity in this generally weathering-susceptible geologic formation (see below). Conversely, in Greyschist (moderate-grade pelitic metamorphic rock, textural zone IV, Turnbull, 2000; corresponds to Craw's (1984) 'grey pelitic schist') the relative event count is below the mapped systems' count, which might indicate an impeding environment for debris flow occurrence. Multiple events occurred predominantly in Greywacke.

The exceptional propensity of Argillite for debris flow development is also evident in the rock group's high frequency ratios (Table 5.4). Both runoff-generated systems and events are overproportionately present in this class. The rock group Argillite occurs in the study areas only in the Camp Creek catchment, northern Two Thumb Range (TT-CC). The study area's topography is dominated by extensive colluvial blankets and large debris taluses

Table 5.4 Frequency-ratio values for lithology classes according to initiation type and activity count. The green colouring indicates ratios greater than 1 with light green marking ratios of 1 to $<2$, grass green 2 to $<3$, and dark green $\geq 3$. An extended version of this table, including debris flow counts and areal extent of the individual lithology classes, can be found in the Electronic Appendix 5.

\begin{tabular}{|c|c|c|c|c|c|c|c|c|c|}
\hline \multirow[b]{2}{*}{ Lithology class } & \multicolumn{4}{|c|}{ All systems } & \multicolumn{5}{|c|}{ Active systems } \\
\hline & TOTAL & SIT & RIT & COMB & TOTAL & SIT & RIT & COMB & | >1 EVENT \\
\hline Sandstone & 1.56 & 1.53 & 1.51 & 2.01 & 1.33 & 0.76 & 1.46 & 1.16 & 0.44 \\
\hline Greywacke & 0.90 & 0.97 & 0.89 & 0.86 & 0.92 & 1.09 & 0.87 & 1.02 & 1.37 \\
\hline Argillite & 1.78 & 0.16 & 2.07 & 1.08 & 2.88 & - & 3.76 & 0.93 & 1.40 \\
\hline Semischist & 0.59 & 0.17 & 0.72 & 0.08 & 0.59 & - & 0.73 & 0.48 & 1 \\
\hline GS Melange & 0.31 & 0.76 & 0.29 & - & 0.53 & 3.77 & - & - & 1 \\
\hline Greenschist & 1.08 & 1.80 & 1.03 & 0.84 & 2.21 & 4.47 & 1.72 & 2.56 & - \\
\hline Greyschist & 1.01 & 1.50 & 0.89 & 1.48 & 0.44 & 1.18 & 0.23 & 0.90 & 1 \\
\hline
\end{tabular}


below proportionally moderate rock walls. Cox and Barrell (2007) report alternating sequences of thickly bedded (>10 m) black argillitic siltstone and greywacke sandstone for this region with siltstone (argillite) being the dominant rock. The finer-grained argillite is less competent than the adjacent sandstone beds and hence commonly more fractured and sheared than the latter (Whitehouse and Pearce, 1992). Particularly in the proximity to faults (T. Little, pers. comm. August 2013), as is the case in the Camp Creek study area, which is crossed perpendicular by an unnamed inactive fault (see Appendix 1), the well-indurated and technically hard argillite can consequently be highly susceptible to weathering and failure. The conspicuous debris abundance in the catchment is therefore most likely the expression of the particularly weathering-susceptible local geology. High regolith supply, combined with the steep topography of the glacial trough, appears to create an ideal environment for runoff-generated debris flows, expressed by both high system density and high activity levels.

Other rock groups, where frequency ratios indicate overproportionately high debris flow densities, are Sandstone, Greenschist, and Greyschist. High ratios stem primarily from exceptional counts of slide-initiated (SIT) or slide-related (COMB) systems in these classes. To eliminate a potential bias in debris flow counts by the presence of slip-prone Quaternary sediment reservoirs, frequency ratios were recalculated including classes of distinct debrisflow relevant Quaternary deposits (Table 5.5). Landslide deposits and moraines, are commonly poorly consolidated, of restricted permeability, and hence susceptible to slope failures (cf. Turnbull, 2000; Sattler, 2008). Similarly, relict rock glaciers and taluses represent seemingly supply-unlimited sediment reservoirs and might, as, for example, the relict taluses in in the Middlehead Stream valley, Seaward Kaikoura Range (KR-MHS), be characterised

Table 5.5 Frequency ratios for Quaternary deposits and lithology classes separately according to process type and activity count. The green colouring indicates ratios greater than 1 with light green marking ratios of 1 to $<2$, grass green 2 to $<3$, and dark green $\geq 3$. An extended version of this table, including debris flow counts and areal extent of the individual factor classes, can be found in the Electronic Appendix 5.

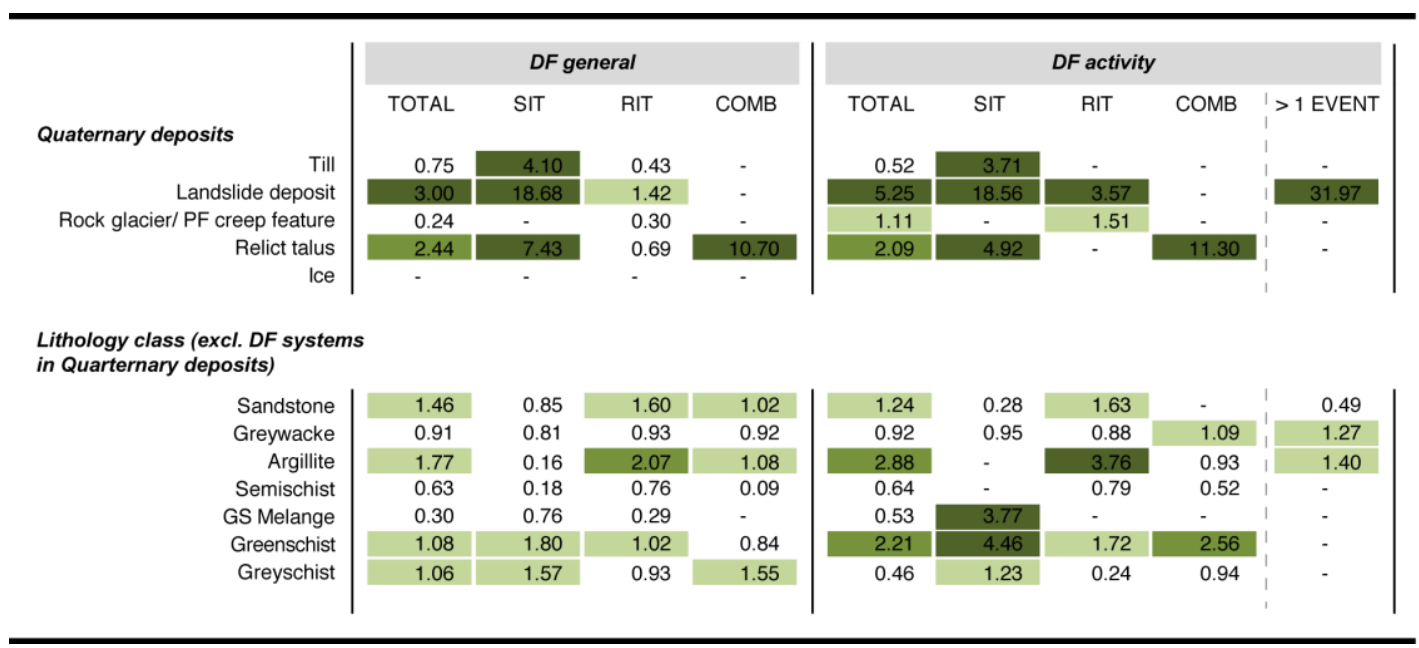


by a large number of instabilities. The extent of Quaternary deposits in the study areas (see maps in Appendix 1) was mapped based on coloured orthophotographs (Terralink, 20052008), utilising where available information from the Central South Island Glacial Geomorphology map (Barrell et al., 2011). The extent of present-day glaciation, mapped from Terralink's (2005-2008) orthophoto mosaic, was included in the calculations for completeness.

Frequency ratios for the Quaternary deposits confirm their exceptional propensity for slide-initiated and slide-related debris flow development (Table 5.5). Almost a fifth (18\%) of all debris flow systems mapped as slide-initiated or slide-related originated in the areally comparatively low represented Quaternary deposits. System and event ratios are especially high for landslide deposits and relict taluses. These values are based on the landslide area in the Black Birch Stream valley, Mt Cook region (MC-BBS), and the relict taluses in the Kaikoura ranges (lower Dart Stream valley (KR-LDS), Middlehead Stream valley (KR-MHS)), which have already been described in Section 3.2.1 due to the extraordinary debris flow densities observed in these locations. Both slide-initiated debris flow systems and events are also overproportionately frequent in glacial deposits. Debris flow systems emanating from intact or relict permafrost creep features, on the other hand, are rare. Given that rock glacier debris is generally coarse, well drained and in most cases situated at low to moderate angles, the formation of debris flows within these sediment storages is unlikely. However, where rock glacier fronts extend into steep terrain, such as on the western flank of the Stony Stream Valley, Mt Cook region (MC-SSV), the large sediment bodies can become unstable and form an active sediment source for debris flows. All three debris flow systems mapped within rock glacier deposits originated from this particular relict rock glacier in the Stony Stream Valley. Two out of the three runoff-generated systems showed activity during the investigation period, indicating high process susceptibility under specific circumstances.

Excluding the debris flow systems originating from Quaternary deposits has only a slight effect on the frequency ratios in individual rock groups (Table 5.5). The initial overproportionate high count of potentially slide-related systems (COMB) in Sandstone is no longer observed when excluding debris flow systems emanating from relict taluses. However, high ratios remain for both runoff-generated debris flow systems and events in Argillite, slide-initiated (SIT) and slide-related (COMB) systems and events in Greenschist and Greyschist, as well as for slide-initiated (SIT) events in Greenstone Melange (a narrow fault-bounded geologic unit, consisting of blocks of varying lithology embedded in a serpentinite matrix; Turnbull, 2000).

Otago's greenschists and greyschists are both moderate-grade metamorphic rocks (textural zone IV) of similar metamorphic history but formed from different parent rocks (volcanic vs. non-volcanic sedimentary rock; Craw, 1984). The rock groups Greenschist and Greyschist both occur in the Upper Stony Creek tributary, Mt Aspiring region (MA-USCT). 
The catchment's topography is influenced by the basement rocks' foliation, with steep scarp slopes occurring on the western flank and comparatively long dip slopes prevalent on the eastern flank. The distribution of debris flow systems within the catchment indicates a topographic and geologic favourability of the dip slopes for debris flow formation; the majority of debris flow systems ( $80 \%$ ) and events (93\%) originated on these eastern slopes. Greenschist occurs in a small area $\left(1 \mathrm{~km}^{2}\right)$ in the eastern upper part of the catchment (see Appendix 1). Out of the 24 debris flow systems mapped in this relatively small area, 7 systems showed activity during the investigation period, resulting in exceptionally high frequency ratios for this lithology class. Interestingly, all of the seven events occurred between 1984 and 1998, whereas in the remaining catchment, only two other events were mapped for this period. Conversely, in the subsequent period 1998 to 2006, multiple events occurred in Greyschist and none in Greenschist. Aerial photograph coverage for the Upper Stony Stream tributary is the shortest of all study areas (cf. Figure 3.9) and hence conclusions about debris flow activity in this catchment are significantly impaired. A lithological control on the spatial variance in debris flow events is possible. Although the degree of foliation and orientation appear to be similar in the two rock classes (cf. Craw, 1984; Turnbull, unpublished QMAP field sheet), differences in geochemical composition (such as more easily erodible primary minerals in greenschist, cf. Craw, 1984), combined with the location of Greenschist outcrops close to the ridge crest, might favour regolith production and hence debris flow development in this area. Alternatively, a locallyrestricted high-intensity rainfall event between 1984 and 1998 might have triggered the high number of debris flow events observed in the Greenschist terrain. With critical debris storages depleted, debris supply might have been insufficient for the development of debris flows in the subsequent investigation period.

The high frequency ratio for slide-initiated events in Greenstone Melange is due to the lithology class' small extent $\left(0.6 \mathrm{~km}^{2}\right)$, inflating the ratio (based on a single event) out of proportion. Turnbull (2000) describes the Greenstone Melange, especially if fractured, as a weak lithology prone to erosion. However, the small spatial extent of the geologic unit and the corresponding low overall debris flow system count (4) prevents a reasonable analysis.

\subsubsection{Neo-tectonic uplift rates}

Fractures can significantly reduce the effective strength of rock walls (Selby, 1980, 1982; Hoek, 1983) and hence promote regolith production (Molnar et al., 2007). The spacing and orientation of fractures is thought to be more important than intact rock mass strength in bedrock's susceptibility to instabilities (Augustinus, 1992; Sass, 2005b; Stewart, 2007; Moore et al., 2009). Bedrock in the Southern Alps is generally deformed and heavily fractured (e.g. Whitehouse and McSaveney, 1990; Owens, 1992) due to significant tectonic 
deformation in the geologic past. Information on the in situ rock mass strength and fracture density in the individual study areas and therefore on the local propensity of bedrock to regolith production was not available. However, in an attempt to roughly parameterise this geomorphically influential rock attribute, neo-tectonic uplift rates are assumed to be a proxy for the amount of tectonic strain experienced by the local bedrock since its formation. Rock situated in high-uplift areas such as at the Southern Alps' axial ranges is assumed to be more fractured (cf. observations by Augustinus, 1992; Owens, 1992) and hence to a higher degree susceptible to mass-wasting than bedrock in tectonically more stable regions (cf. Molnar et al., 2007). Furthermore, landscapes subjected to high contemporary uplift rates are characterised by high relief. Gravitational processes, such as rockfalls, landslides, and subsequently debris flows, are comparatively more frequent in these regions, as hillslopes strive towards a new equilibrium (e.g. Whitehouse, 1987; Crozier et al., 1992; Hovius et al., 1997).

Information on neo-tectonic uplift rates in the Southern Alps was derived from a digitised version of Wellman's (1979) uplift map for the South Island (Figure 5.4). This generalised sketch of uplift isolines, inferred from dated marine benches, river terraces, lake shores, and geomorphologic deduction, is the only dataset currently available that covers all study regions. Despite considerable spatial as well as data-inherent inaccuracies (Wellman (1979) estimates value errors to be at least $25 \%$, attributed to methodological uncertainties of the applied inference techniques), the pattern correlates well with more recent findings such as exhumation rates (F. Herman, pers. comm., June 2011; see Figure 5.4), GPS measurements (Beavan et al., 2010), and local estimates (e.g. Van Dissen and Yeats, 1991). Since the present study focuses on a qualitative to semi-quantitative comparison of debris flow environments in the individual study areas, the use of the South Island-wide dataset was preferred to newer but spatially restricted estimates.

Frequency ratios for the individual uplift classes only partly confirm increased debris flow occurrence in neo-tectonically active regions (Table 5.6). Both systems and events are overproportionately numerous in areas of the highest uplift category $\left(7 \mathrm{~mm} \mathrm{a}^{-1}\right)$ and slightly below areal probability in tectonically stable areas $\left(<1 \mathrm{~mm} \mathrm{a}^{-1}\right)$. However, the pattern does not apply for the intermediate uplift classes. Areas with estimated uplift rates of 5 to $6 \mathrm{~mm} \mathrm{a}^{-1}$ show low debris flow frequencies, whereas areas subjected to moderate uplift of estimated 3 to $4 \mathrm{~mm} \mathrm{a}^{-1}$ show again high frequency ratios.

The study areas subjected to comparatively high uplift rates $\left(7 \mathrm{~mm} \mathrm{a}^{-1}\right)$ are situated in the Kaikoura ranges. As mentioned in Section 3.2.1, these catchments are characterised by a high relief and, in response to the ongoing vertical uplift, drainage lines are deeply incised into the bedrock. Although both debris flow systems and events are overproportionately frequent in these areas, the frequency ratios are only moderately above average. 


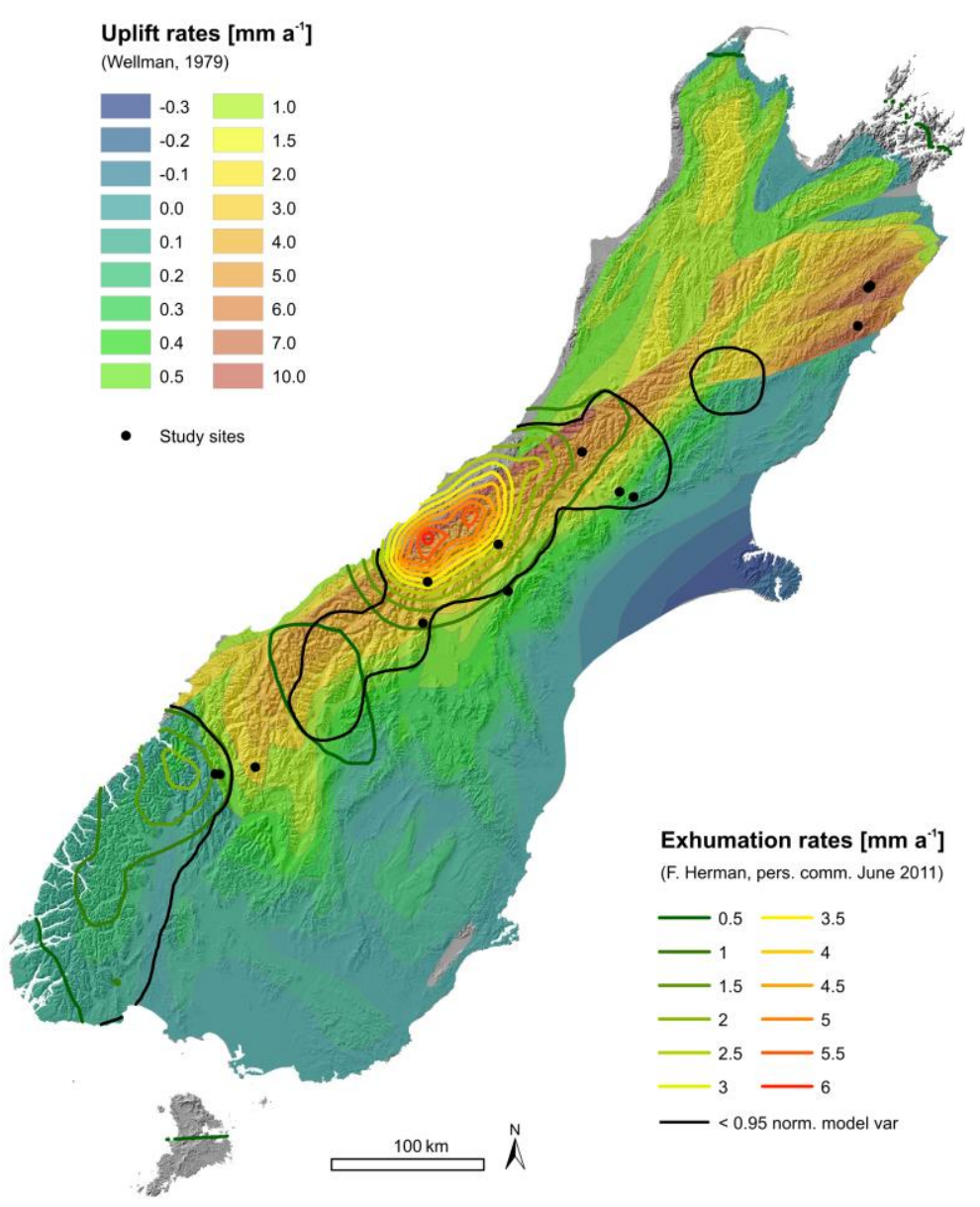

Figure 5.4

Uplift rates for New Zealand's South Island after Wellman (1979) overlain by modelled exhumation rates for the last $1 \mathrm{Ma}$ (F. Herman, pers. comm. June 2011).

The high ratio for slide-related systems (COMB) is mainly attributed to the high process densities in undercut relict taluses. Low frequency ratios for the uplift category of $6 \mathrm{~mm} \mathrm{a}^{-1}$ are based on only three debris flow systems close to the exit of the lower Dart Stream, Inland Kaikoura Range (KR-LDS), and are thus not indicative. However, the equally low ratio of debris flow systems in the uplift category of $5 \mathrm{~mm} \mathrm{a}^{-1}$ is based on a statistically meaningful sample of 63 debris flow systems in the Denas Creek catchment, Arthur's Pass region (AP-DC). This glaciated catchment is characterised by steep rockwalls with well-developed debris accumulations (cf. Appendix 1). Runoff-generated debris flow systems originating at the rock/debris interface are comparatively frequent. However, this is not represented in the system frequency ratio or spatial density (cf. Figure 3.15) due to the study area's extensive bedrock extent. Over a period of five decades, not a single event was identified in this Greywacke catchment, despite the seemingly suitable conditions. Measured and modelled 
Table 5.6 Frequency ratios for uplift rate categories according to process type and activity count. The green colouring indicates ratios greater than 1 with light green marking ratios of 1 to $<2$, grass green 2 to $<3$, and dark green $\geq 3$. An extended version of this table, including debris flow counts and areal extent of the individual uplift classes, can be found in the Electronic Appendix 5.

\begin{tabular}{|c|c|c|c|c|c|c|c|c|c|}
\hline \multirow{2}{*}{$\begin{array}{l}\text { Uplift rate } \\
{\left[\mathrm{mm} \mathrm{a}^{-1}\right]}\end{array}$} & \multicolumn{4}{|c|}{ All systems } & \multicolumn{5}{|c|}{ Active systems } \\
\hline & TOTAL & SIT & RIT & COMB & TOTAL & SIT & RIT & СОМB & | >1 EVENT \\
\hline $0-<1$ & 0.81 & 0.47 & 0.83 & 0.94 & 0.89 & 0.91 & 0.87 & 0.97 & 1.23 \\
\hline 1 & - & - & - & - & - & - & - & - & 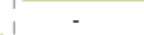 \\
\hline 2 & 1.06 & 1.88 & 0.97 & 0.99 & 0.79 & 1.19 & 0.65 & 1.17 & 1 \\
\hline 3 & 2.15 & 0.27 & 2.54 & 1.03 & 1.74 & - & 2.36 & - & i \\
\hline 4 & 1.19 & 2.33 & 1.12 & 0.68 & 2.20 & 2.53 & 2.23 & 1.66 & 3.74 \\
\hline 5 & 0.57 & - & 0.72 & - & - & - & - & - & 1 \\
\hline 6 & 0.33 & - & 0.27 & 1.02 & - & - & - & - & 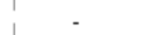 \\
\hline 7 & 1.62 & 1.61 & 1.57 & 2.06 & 1.39 & 0.80 & 1.54 & 1.22 & 0.46 \\
\hline
\end{tabular}

exhumation rates as well as interpolated uplift rates from GPS measurements suggest that uplift rates in this region might be lower than estimated by Wellman (1979) (cf. Tippett and Kamp, 1993; Houlié and Stern, 2012; F. Hermann, pers. comm. June 2011, Figure 5.4). Given the discrepancies in published uplift values, results for this category are, therefore, considered not indicative.

The high frequency ratios observed in the moderate uplift categories ( 3 to $4 \mathrm{~mm} \mathrm{a}^{-1}$ ) reflect debris flow observations in the Camp Creek valley, northern Two Thumb Range (TT-CC), and the Black Birch Stream valley, Mt Cook region (MC-BBS). Both of these catchments have been identified in the previous section as debris flow hot spots in the context of lithology (Argillite) and Quaternary sediment storages (landslide deposit). Similarly, elevated frequencies of slide-initiated and slide-related systems in areas with estimated uplift rates of $2 \mathrm{~mm} \mathrm{a}^{-1}$ can be attributed to the presence of the steep side moraine in the Stony Stream Valley, Mt Cook region (MC-SSV), as well as to the presence of extensive soil-covered rectilinear slopes, the expression of the local structural geology (cf. Section 3.2.1), at the eastern flank of the Upper Stony Stream tributary, Mt Aspiring region (MA-USCT).

Overall, no clear indications for a link between debris flow activity and neo-tectonic uplift rates were found. Although the frequency ratios for the end member categories confirm the expected pattern of high debris flow activity in high uplift areas and vice versa, the overall results are inconclusive. Whether uplift rates are really a useful proxy for the density of rock fractures remains unknown.

\subsubsection{Permafrost}

The presence of permafrost within sediment storages is thought to increase the susceptibility for slide instabilities during the warm seasons as the permafrost table acts as an aquiclude and thus as a potential failure plane during rainfall events or rapid snowmelt 
(see Section 3.1.2). Permafrost similarly affects runoff-generated systems, where the presence of ice at depth can impede the infiltration of surface runoff, promoting liquefaction of the overlying active-layer material.

The potential permafrost extent in the study areas was modelled based on the statistical relationship between the occurrence of active rock glaciers and the environmental parameters mean annual air temperature (MAAT) and potential incoming solar radiation (PISR) (cf. Chapter 4). Although modelling results have not been verified outside the Ben Ohau Range, for the purpose of this analysis, it is assumed that the determined relationship is also valid in other areas of the Southern Alps. Local conditional probabilities were calculated from similar data sets used for model calibration, i.e. a $100 \mathrm{~m}$ MAAT and a $15 \mathrm{~m}$ PISR raster surface (see Section 4.2.2). A probability value of 0.6 was used again as the cut-off value for the potential contemporary permafrost extent (cf. Section 4.3.3).

Based on the permafrost estimate, approximately $10 \%$ of the study areas are presently potentially underlain by permafrost (Table 5.7). Significant permafrost extent is modelled for Denas Creek, Arthur's Pass region (AP-DC), Camp Creek, Two Thumb Range (TT-CC), Forest Creek, Two Thumb Range (TT-FC), Stony Stream valley, Mt Cook region (MC-SSV), as well as all the study areas in the Mt Aspiring region (see maps in Appendix 8). Only the Castle Hill - Foggy Stream catchments, Arthur's Pass region (AP-CHFS), are located entirely outside the estimated permafrost zone.

Overall, $6 \%$ of all mapped debris flow systems emanated in potential permafrost areas (Table 5.7). Despite inferred permafrost occurrences in more than half of all the study areas, marked numbers of systems originating in potential permafrost areas were only observed in

Table 5.7 Modelled permafrost extent (excl. present-day glacier extent) in the individual study areas.

\begin{tabular}{|c|c|c|c|c|c|}
\hline \multirow[b]{2}{*}{ Study area } & \multicolumn{2}{|c|}{ PF extent } & \multicolumn{3}{|c|}{$D F$ within PF zone } \\
\hline & ha & $\%$ & $\mathrm{~N}$ & $\%$ & $\mathrm{~N}$ active \\
\hline TSV & 6 & 1.8 & 2 & 3.4 & - \\
\hline LDS & 4 & 1.4 & - & - & - \\
\hline MSV & 6 & 2.5 & - & - & - \\
\hline DC & 65 & 13.5 & 2 & 3.2 & - \\
\hline ES & 9 & 1.3 & 2 & 1.7 & - \\
\hline CHFS & - & - & - & - & - \\
\hline $\mathrm{CC}$ & 53 & 18.6 & 29 & 24.4 & 3 \\
\hline FC & 186 & 22.3 & 21 & 17.4 & 1 \\
\hline BBS & 4 & 0.9 & - & - & - \\
\hline SSV & 127 & 20.4 & 36 & 22.8 & 3 \\
\hline USCT & 70 & 10.9 & 2 & 1.3 & - \\
\hline GB & 97 & 14.7 & - & - & - \\
\hline KCET & 72 & 16.0 & 1 & 1.1 & - \\
\hline Total & 697 & 10.5 & 95 & 6.2 & 7 \\
\hline
\end{tabular}




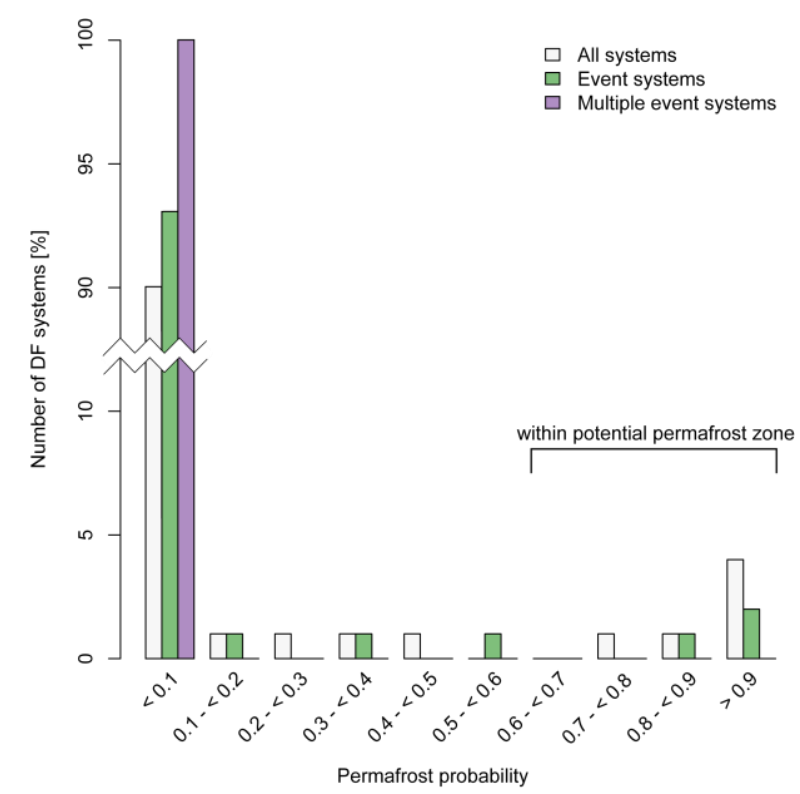

Figure 5.5

Percent frequency distribution of mapped debris flow systems and events in the individual permafrost probabilitv classes.

the two study areas in the Two Thumb Range and the Stony Stream valley, Mt Cook region (MC-SSV). Seven of these systems (7\%), all originating in locations where topoclimatic conditions are highly favourable for permafrost presence $(P \geq 0.8)$ showed activity during the investigation period (Figure 5.5). Multiple events systems were absent within the modelled permafrost zone.

According to the permafrost distribution estimate, permanently frozen ground occurs in the Southern Alps approximately above 2000 m a.s.l. (cf. Section 4.3.3). Significant proportions of this elevational zone are comprised of steep rockwalls or exposed bedrock. These areas are commonly unsuitable for debris flow development due to the lack of significant debris accumulations. To eliminate resulting biases, the extent of the rock areas (cf. Section 3.2.4) as well as present-day glaciers were excluded from the analysed area. Consequently, runoff-generated debris flows emanating from small debris accumulations within rock channels were also excluded. This reduced the number of debris flow systems used in the frequency ratio analysis from 1534 to 1395 systems.

Frequency ratios for the modelled permafrost categories showed no substantial indication of increased susceptibility for debris flow formation in potentially permafrost-underlain areas (Table 5.8). Both slide-initiated (SIT) and slide-related (COMB) debris flow systems occur without exception well below the estimated lower permafrost boundary, suggesting that active-layer instabilities might be rare in the Southern Alps. Runoff-generated debris flow systems (RIT), on the other hand, show slightly above average frequencies in areas of high 
Table 5.8 Frequency ratios for permafrost probability categories according to initiation type and activity count. The green colouring indicates ratios greater than 1 . An extended version of this table, including debris flow counts and areal extent of the individual permafrost classes, can be found in the Electronic Appendix 5.

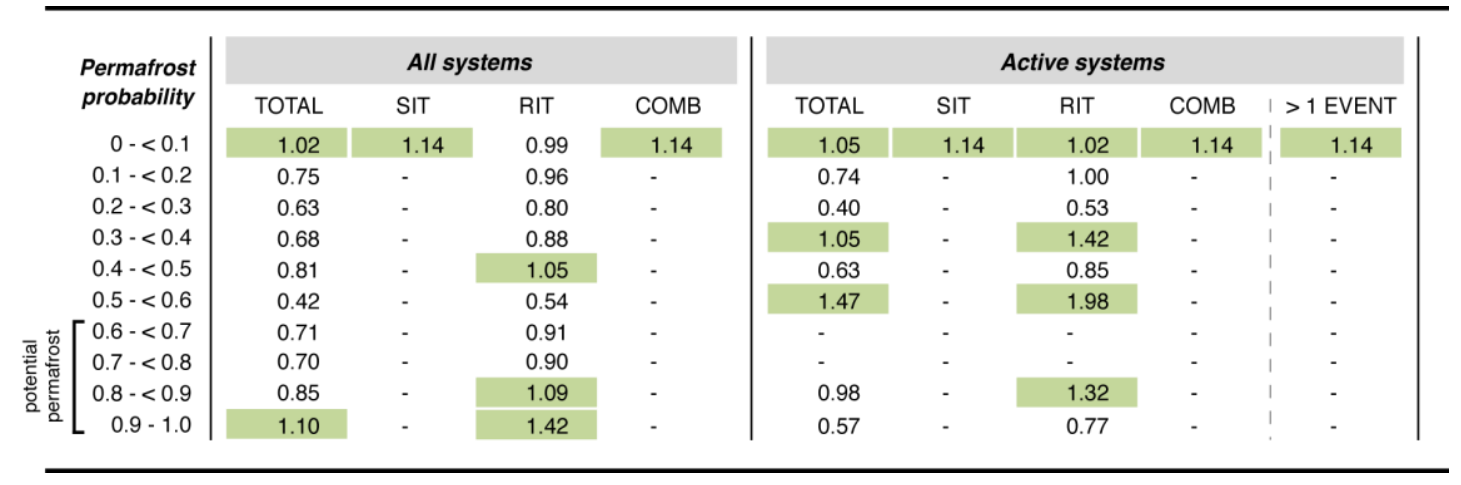

permafrost probability ( $\geq 0.8$ ). Compared to the categories' spatial extent, events occurred overproportionately frequent in the probability class 0.8 to $<0.9$ and 0.5 to $<0.6$. However, the marked frequency ratios in these two classes are based on only two events per category. The significance of the observed activity in these two critical classes (i.e. in areas with high probability of permafrost occurrence and areas close to the estimated lower boundary of the permafrost distribution, which is thought to be particularly sensitive to atmospheric warming) is therefore questionable.

\subsubsection{Regolith recharge}

In supply-limited debris flow systems, the availability of sediment for event initiation varies through time (cf. Section 3.1.2). Sediment storages have to be refilled by means of mass movements or, although likely less effective, by in situ weathering of present debris, before another event can occur. None of the mapped debris flow systems showed signs of soil creep, permafrost creep, or landslides (i.e. instabilities on surrounding slopes, excluding failures at debris flow channel flanks) contributing sediment to the source area. Hence rockfall is assumed to be the dominant regolith supply mechanism for the analysed debris flow systems. Frost-weathering intensity, lithology, effective rock mass strength, and permafrost presence are known preparatory factors for rockfall activity in high alpine areas (e.g. Luckman, 1976; Marquínez et al., 2003; Sass, 2005b). These factors can positively affect sediment recharge rates in debris flow catchments and hence promote debris flow occurrence.

The possible role of sediment recharge in explaining the spatial variation of debris flow activity was explored by using logistic regression. The analysis was based on the 404 contribution areas of runoff-generated supply-limited debris flow systems, mapped semiautomatically from a $15 \mathrm{~m}$ DEM (see Section 3.2.3; details of the contribution areas are 
listed in Electronic Appendix 2). The activity of debris flow systems during the investigation period was used as the dependent input variable $(0=$ no event, $1=\operatorname{event}(\mathrm{s}))$. For the purpose of this analysis, the presence or absence of debris flow activity was assumed to express differences in sediment recharge rates between debris flow systems. Ordinal regression analyses, based on the actual number of events in the debris flow systems during the investigation period, were waived, since the sample size was with 404 observations (59 events, 345 non-events) at critical levels for multivariate regression analyses (cf. EPV discussion in Section 4.3.2).

The overall significance of logistic regression models as well as the correct classification rate of events $\left(\mathrm{CCR}_{1}\right)$ were used to answer the following research questions:

I. Are size and steepness of debris flow contribution areas statistically significant controls for the spatial variation in debris flow activity observed during the investigation period?

II. Are debris flow events more likely to occur in debris flow systems with contribution areas exposed to comparatively high levels of frost weathering?

III. Are debris flow events more likely to occur in southeast to southwest-facing locations because frost weathering is more intense in sun-avert locations?

IV. Is regolith production higher, and are debris flow events thus more likely, in certain lithologies?

V. Does the susceptibility of certain lithologies to frost weathering affect the likelihood of debris flow formation?

VI. Does the level of neo-tectonic uplift, as a proxy for fracture density, affect the susceptibility of certain lithologies to frost weathering and thus the likelihood of debris flow formation?

VII. Is regolith production higher, and are debris flow events thus more likely, in debris flow systems with contribution areas within the permafrost zone?

For each of these questions, the underlying objective, data input, statistical results, and interpretation are presented in the following subsections. All logistic regression models were calculated in SPSS 18 (SPSS, 2009). 


\section{Are size and steepness of debris flow contribution areas statistically significant controls for the spatial variation in debris flow activity observed during the investigation period?}

Debris flow systems with large contribution areas have a higher potential to produce large amounts of sediment than those with smaller contribution areas. The topography within the contribution area can influence how much material accumulates at the catchment's exit, which often represent the initiation area of runoff-generated debris flows (cf. Section 3.1.1). In contribution areas with pronounced rock protrusions, debris might be stored above the catchment's exit and is thus not available for debris flow initiation.

To investigate the potential influence of contribution areas' size and topography on debris flow occurrence, a logistic regression model was run, including all 404 catchment samples. The predictor variables, standardised size of the contribution areas, standardised percentage of area above $40^{\circ}$ inclination, as well as an interaction term, were entered blockwise into the regression model (for details on performing logistic regression in SPSS see Field, 2005). Percentage area above $40^{\circ}$ slope was computed based on a slope raster derived from a $15 \mathrm{~m}$ DEM (Columbus et al., 2011a).

The overall fit of the individual model steps lacked statistical significance, indicating that neither the size of the contribution area nor its topography has an effect on the odds of a debris flow event occurring in a given debris flow system during the investigation period. Multicollinearity statistics (listed in Appendix 9) did not indicate critical correlations between the predictor variables, which might have resulted in a devaluation of the individual parameters' explanatory power.

\section{Are debris flow events more likely to occur in debris flow systems with contribution areas exposed to comparatively high levels of frost weathering?}

Frost action is an efficient weathering mechanism and a key factor in regolith production in high-alpine areas (cf. Section 3.1.2). It comprises mechanical processes that weaken the coherence of solid rock but does not include the actual kinetic process of particle removal (e.g. rockfall). However, it can be assumed that in areas of intense frost weathering, more material is available to be delivered by mass movements into the debris flow source areas. Consequently, increased regolith recharge rates are expected to result in higher debris flow activity.

The analysis of the potential influence of frost-weathering intensities on debris flow activity provided an opportunity to compare the two competing frost-weathering hypotheses currently discussed in literature, volumetric ice expansion and segregation ice growth, in their explanatory power of (debris flow inferred) spatial variations in regolith production. In the following, the two mechanisms are introduced first and the respective datasets used in 
this analysis described. After the presentation of the analysis results, the value of the two frost-weathering intensity datasets for debris flow analyses is reviewed.

\section{Volumetric ice expansion}

Traditionally, the $9 \%$ volumetric expansion of water freezing in pores and cracks has been viewed as the dominant mechanism of mechanical breakdown of rocks in cold environments (Hall, 2006; Harris et al., 2009). The forming ice increases the tensional stress at existing crack tips and causes crack propagation (Walder and Hallet, 1986; French, 2007). Alternatively, the progressive inward freezing of ice increases the pressure of water trapped inside the crack and leads to crack enlargement caused by hydro-fracturing (Prick, 2003; Matsuoka and Murton, 2008). Subsequent thaw releases the separated rock fragments from the rock mass and promotes rockfall (Sass, 2005a). Long-term monitoring in the Swiss Alps showed cumulative widening and resulting permanent opening of cracks by repetitive freezing and thawing (Matsuoka, 2008). Complementary rockfall monitoring documented the efficacy of crack opening in the production of rock fragments up to pebble size. However, the actual ability of expanding ice to mechanically disintegrate solid rock to levels seen in natural environments has long been doubted (e.g. White, 1976; Walder and Hallet, 1985, 1986). Critical pressures are only reached in closed (i.e. hydraulically unconnected) systems with very high saturation levels ( 90\%) and where freezing occurs rapidly from all sides; conditions uncommon in natural environments (Prick, 2003; Matsuoka and Murton, 2008). Frost weathering by volumetric expansion might thus operate only within a few centimetres of the rock surface, where pores and cracks are water filled and rapid freezing occurs, and might produce only small debris fragments (Matsuoka and Murton, 2008; Girard et al., 2013).

A simple model for parameterising frost weathering by volumetric expansion is calculating the spatial distribution of frost cycle counts. Assuming that repetitive freezing and thawing enlarges cracks, thereby weakening the rock mass and promoting rockfall, rock faces subjected frequently to freeze/thaw cycles are expected to produce more debris than rock faces subjected to fewer cycles. Matsuoka and Murton (2008) dismiss such approaches as oversimplified, as they disregard vital parameters, such as moisture availability, the extent of frost-thaw penetration into the rock, as well as the duration of the individual cycles. Furthermore, air temperature does not equal rock temperature, since the latter is influenced by lithology (especially surface albedo) and aspect (Gruber et al., 2004; Hall et al., 2005). Due to these constraints, mechanically effective frost cycles are significantly fewer than the number of times atmospheric temperature drops below freezing point (Fahey and Lefebure, 1988; Matsuoka et al., 1998). However, the mean number of annual frost cycles can be easily calculated from interpolated daily minimum and maximum air temperatures. Its 
spatial distribution can help to identify areas which are potentially subjected to significant freezing and hence frost weathering.

The spatial distribution of the mean annual frost cycles in the study areas was calculated for the standard climate period $1971-2000$ by altitudinally extrapolating daily minimum and maximum air temperature from a near climate station (see Appendix 6 for list of stations). Building on Delunel et al. (2010), a frost cycle was counted when:

$$
\frac{T_{\min }}{T_{\max }}<0
$$

where $T_{\min }$ and $T_{\max }$ are minimum and maximum temperature of a given day. The climate data were derived from the National Climate Database (NIWA, 2010; climate stations are listed in Appendix 6). A 15m DEM (Columbus et al., 2011a) and a spatially constant lapse rate of $0.5^{\circ} \mathrm{C} / 100 \mathrm{~m}$ (cf. Section 4.2.2) were used for the altitudinal extrapolation. An example of the model output is given in Figure 5.6. Model results for all the study areas are included in Appendix 8.

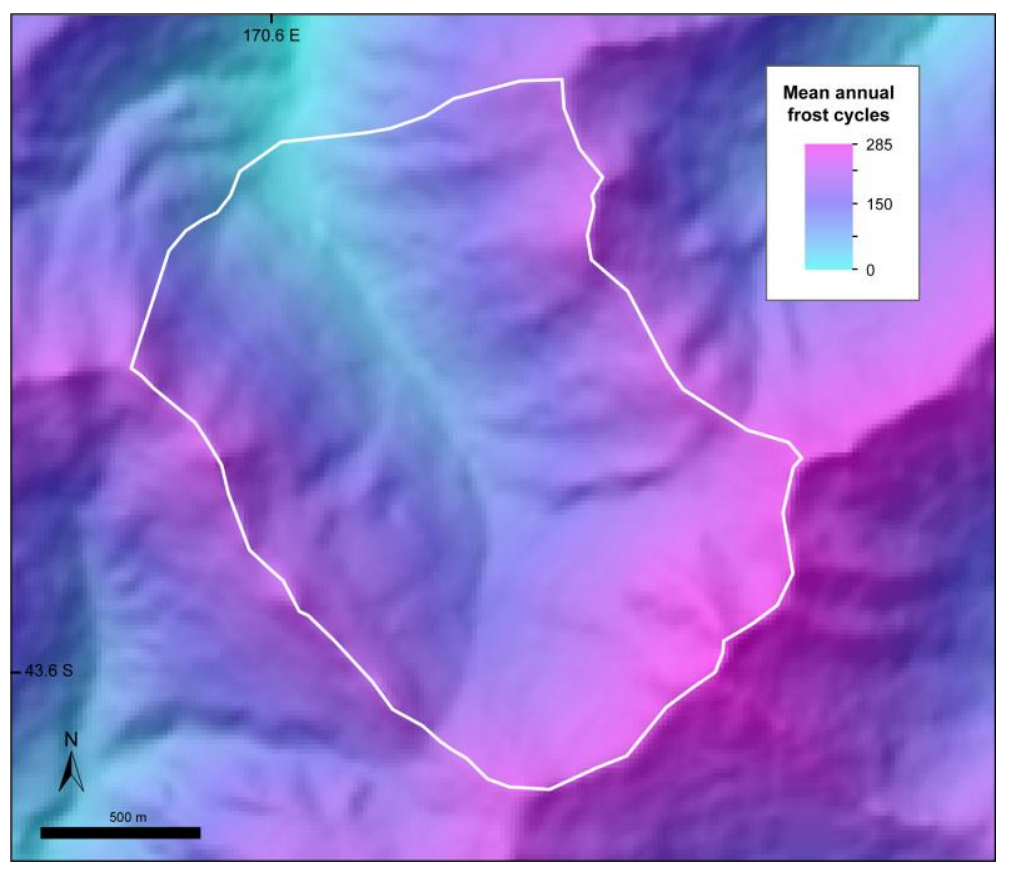

Figure 5.6

Spatial distribution of mean annual frost cycles in the Camp Creek Valley, northern Two Thumb Range. Basemap: Hillshade of a 15m DEM (Columbus et al., 2011a) 


\section{Segregation ice growth}

Laboratory experiments as well as field observations suggest ice segregation as the actual cause for effective bedrock fracturing in cold environments (e.g. Coutard and Francou, 1989; Hallet et al., 1991; Murton et al., 2006; Amitrano et al., 2012; Girard et al., 2013). In ice-filled pores and cracks, liquid water exists even at temperatures significantly below zero in the form of nanometer-scale films at the ice/rock interface (Dash et al., 1995). The thickness of these films is a function of temperature. Thin films adjacent to the ice surface create a pressure deficit, inducing the migration of liquid water to the ice front where it accretes (Walder and Hallet, 1985). Intermolecular forces, repelling the growing ice from the surrounding rock, create critical levels of stress in the surrounding rock and culminate in small, but progressive fracture propagation at the crack tip (Walder and Hallet, 1985; Hales and Roering, 2007). Segregation ice growth is thought to be most efficient where moisture-containing rock is subjected to absolute temperatures between $-3^{\circ} \mathrm{C}$ and $-10^{\circ} \mathrm{C}$ for extended periods (Hallet et al., 1991; Anderson, 1998). At this optimal thermal range, referred to as 'frost cracking window' (Anderson, 1998; Hales and Roering, 2007), the low temperatures induce significant temperature gradients while the viscosity of water is still sufficiently low for migration.

Frost weathering by segregation ice growth was implemented in the present study by Hales and Roering's (2007, 2009) frost-cracking intensity model, which estimates frost-cracking intensities as a function of mean annual air temperature (MAAT) and annual temperature variations $\left(T_{a}\right)$. Details on the model setup are described in Hales and Roering (2007). In short, the model is based on calculations of rock temperatures through time and rockwall depth for a given MAAT and $\mathrm{T}_{\mathrm{a}}$. The modelled temperature gradients within the rockwall are used as a proxy for frost-cracking intensity, since the greater the gradient, the more efficient the delivery of water to the freezing front, resulting in faster ice growth and hence more intense frost cracking. Temperature gradients are summed at every location of the depth profile over the course of an annual temperature cycle to quantify the rate of ice segregation growth and subsequently frost-cracking intensity. General assumptions underlying the calculations are that 1) segregation ice growth is most effective at rock temperatures between $-3^{\circ} \mathrm{C}$ and $-8^{\circ} \mathrm{C}$, 2) free water is available from either the surface during thawing or as unfrozen groundwater at depth, 3) annual air temperatures vary sinusoidally around the MAAT, and 4) that air temperatures are representative of rock temperatures. The model does not consider rock mass strength, porosity or saturation of bedrock. Hales and Roering (2009) calculated depth-integrated frost-cracking intensities for MAATs between $-4^{\circ} \mathrm{C}$ and $+3^{\circ} \mathrm{C}$ (Figure 5.7) to generalise the depth-dependent model predictions for spatial modelling in the Craigieburn Range, New Zealand (i.e. the range where this study's Enys Stream Valley study area is situated). The authors assumed an annual temperature cycle $\left(\mathrm{T}_{\mathrm{a}}\right)$ of $\pm 6^{\circ} \mathrm{C}$, consistent with annual variations observed at climate stations in the Craigieburn Range. Highest frost-cracking intensities are predicted for areas 


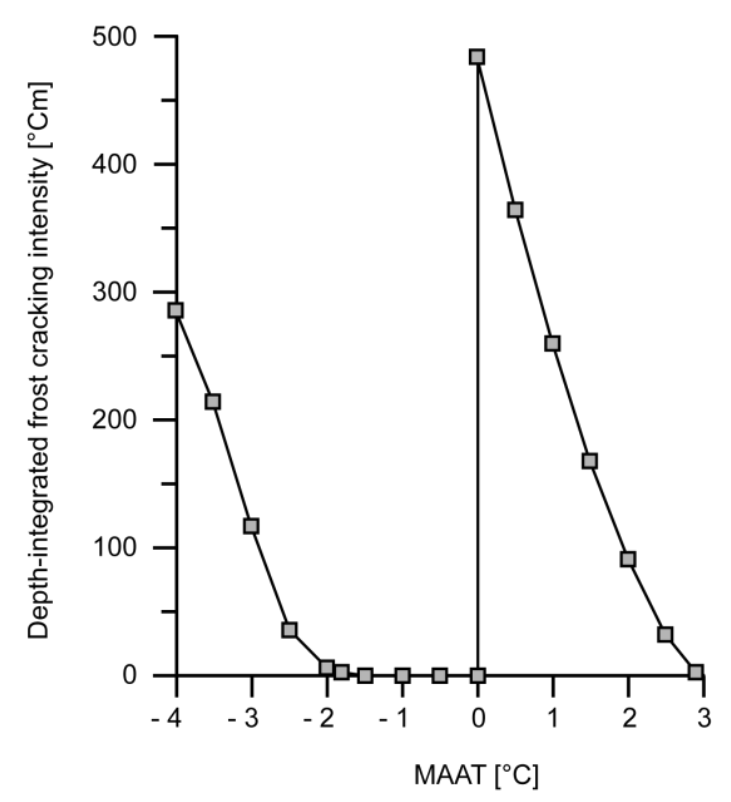

Figure 5.7

Predicted depth-integrated frost-cracking intensity values for a range of MAAT, based on annual temperature variations $\left(T_{a}\right)$ of $6^{\circ} \mathrm{C}$ (after Hales and Roering, 2009, p. 248)

with MAAT just above $0^{\circ} \mathrm{C}$ (Figure 5.7). At these locations, annual temperature oscillations allow rock to efficiently cool to significant depths, but are still warm enough to sustain free water for most of the year (Hales and Roering, 2007, 2009). At moderately negative MAAT areas, rock classifies as warm permafrost (cf. Gruber et al., 2004; Allen et al., 2009) and water is only available to the system during thawing periods within the active layer. Depthintegrated annual frost-cracking intensities are, therefore, low between MAAT $0^{\circ} \mathrm{C}$ and $-2^{\circ} \mathrm{C}$. At MAAT below $-2^{\circ} \mathrm{C}$, predicted intensities increase again due to the presence of optimal frost-cracking temperatures $\left(-3^{\circ} \mathrm{C}\right.$ to $\left.-8^{\circ} \mathrm{C}\right)$ at depth during times of water availability.

The spatial distribution of frost-cracking intensities in the study areas was calculated by converting spatially-distributed mean annual air temperatures, calculated for the standard climate period 1971-2000 by extrapolating mean daily temperatures from a near climate station (see Appendix 6 for list of stations), to frost-cracking intensities based on Figure 5.7. The analysis of annual temperature variations at climate stations close to the individual study areas (Table 5.9) showed that a $T_{a}$ (annual temperature variation) of $6^{\circ} \mathrm{C}$ is representative for most of the study regions. Only at the Kaikoura climate station, $T_{a}$ is with $4.25^{\circ} \mathrm{C}$ markedly lower, representing the maritime climate at the coast. Since $T_{a}$ controls the amount of time that rock temperatures remain within the critical frost-cracking window (Hales and Roering, 2007), the use of a $T_{a}$ of $6^{\circ} \mathrm{C}$ for the estimate of frost-cracking intensities in the maritime-influenced Kaikoura ranges likely overestimates the amount of frost cracking. However, given that two of the three affected study areas are situated in the Inland Kaikoura Range and, therefore, at some distant to the sea, the use of a more 
continental $\mathrm{T}_{\mathrm{a}}$ of $6^{\circ} \mathrm{C}$ seems appropriate also for the Kaikoura study sites. Figure 5.8 shows an example of the model output. Results are not spatially extensive since frost cracking is only predicted for areas with MAAT $\leq 3^{\circ} \mathrm{C}$. Model results for all the study areas are included in Appendix 8.

Table 5.9 Mean annual temperature cycles $\left(T_{a}\right)$, calculated for the period 1971-2000, at climate stations close to the study areas. Climate data is derived from the Cliflo database (NIWA, 2010). Numbers in brackets refer to Cliflo station IDs.

\begin{tabular}{llr}
\hline Study region & Climate station & Ta $\left.{ }^{\circ} \mathrm{C}\right]$ \\
\hline Kaikoura ranges & Kaikoura AWS (4506) & 4.25 \\
Arthur's Pass region & Craigieburn Forest (4651) & 5.75 \\
Two Thumb range & Lake Tekapo Airport (4970) & 6.75 \\
Mt Cook region & Mt Cook/ Hermitage (18125) & 6.3 \\
Mt Aspiring region & Queenstown (5446) & 6.3 \\
\hline
\end{tabular}

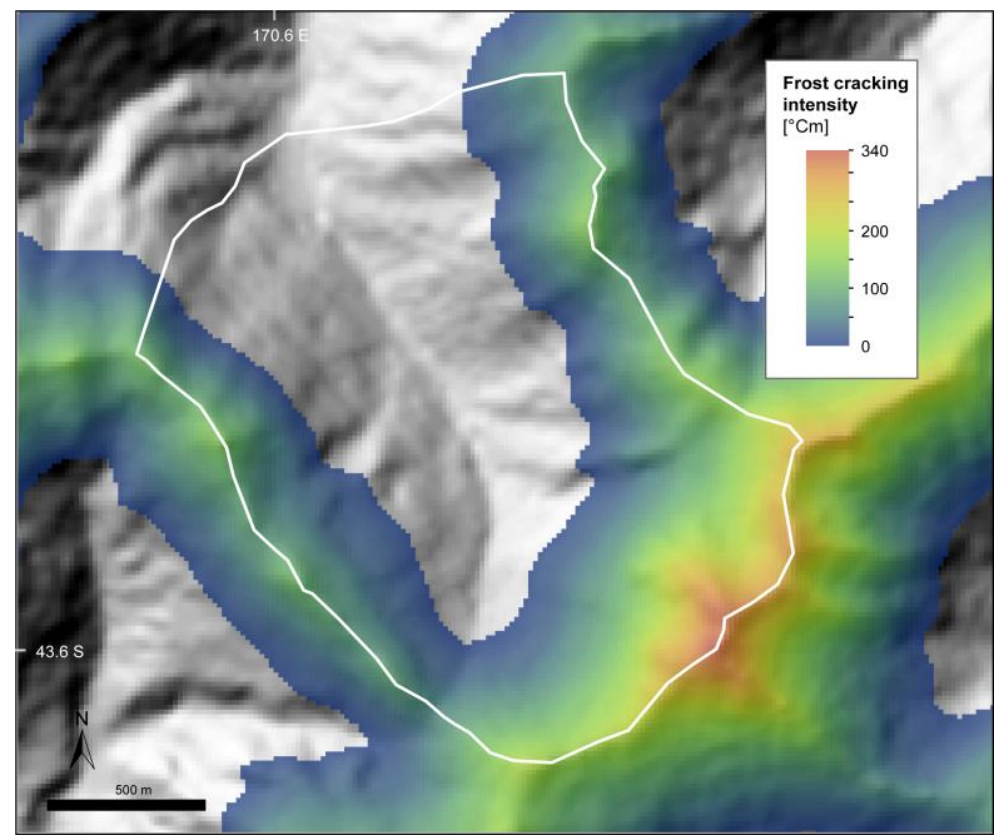

Figure 5.8

Spatial distribution of frost-cracking intensity in the Camp Creek Valley, northern Two Thumb Range. Basemap: Hillshade of a 15m DEM (Columbus et al., 2011a)

\section{Analysis}

For each contribution area, the standardised mean and standardised sum of mean annual freeze-thaw cycles and frost-cracking intensities were calculated. Both the sum and 
mean were chosen, since it was initially not known which parameter would describe frostweathering activity levels best. While the mean intensity controls for the influence of catchment size, it is strongly biased by the frequency of values within the contribution area and might lead to underestimating frost-weathering activity within the corresponding area. The spatially aggregated sum, on the other hand, can be interpreted as the expression of the catchment's total sediment supply potential, but does not account for catchment size.

An initial regression model based on all 404 catchments, using activity in the debris flow systems during the investigation period as dependent and the four frost-weathering parameters as independent variables, was overall not statistically significant, i.e. no relationship between debris flow activity and any of the frost-weathering parameters could be detected in the sample population.

To investigate the potential presence of regional variations in the relationship, the catchments were grouped into three analysis regions: North, Central, and South (Table 5.10). The regression model was rerun for each analysis region separately. Analysis of the individual study regions was not undertaken, since the number of events in the 'central' ranges was too limited for regression analysis (cf. critical EPV, Section 4.3.2).

Only the model for the region 'South', i.e. the Mt Aspiring region, produced a statistically significant result (Table 5.11). This indicates that regional differences exist within the dataset regarding the strength of the relationship between frost-weathering activity and debris flow occurrence. Out of the four predictors analysed, the sum of the mean annual number of frost cycles explained variations in debris flow activity best. The probability of an event occurring during the investigation period in the Mt Aspiring region increases with the number of frost cycles experienced in the contribution area. Multicollinearity measures (VIF, see Section 4.3.2 for background) were not at critical levels (Appendix 9). However, VIF values indicated that regression results might be biased by correlation between parameters. Repeating the regression for each predictor individually (to remove potential multicollinearity effects), did

Table 5.10 Activity counts, according to debris flow study regions and grouped analysis regions.

\begin{tabular}{|c|c|c|c|c|c|c|c|}
\hline \multirow[b]{2}{*}{ Study region } & \multicolumn{2}{|c|}{ active } & \multirow[b]{2}{*}{ Total } & \multirow[b]{2}{*}{ Analysis region } & \multicolumn{2}{|c|}{ active } & \multirow[b]{2}{*}{ Total } \\
\hline & no & yes & & & no & yes & \\
\hline Kaikoura ranges & 80 & 15 & 95 & North & 80 & 15 & 95 \\
\hline Arthur's Pass region & 56 & 7 & 63 & & & & \\
\hline Two Thumb Range & 26 & 6 & 32 & Central & 139 & 17 & 156 \\
\hline Mt Cook region & 57 & 4 & 61 & & & & \\
\hline Mt Aspiring region & 126 & 27 & 153 & South & 126 & 27 & 153 \\
\hline Total & 345 & 59 & 404 & Total & 345 & 59 & 404 \\
\hline
\end{tabular}


Table 5.11 Results of the logistic regression for the analysis region 'South' using debris flow systems' activity during the investigation period as dependent variable and the spatially aggregated sum and mean values of calculated frost-cracking intensities $(\mathrm{FCl})$ and the mean annual frost cycles (Fcyc) as independent variables.

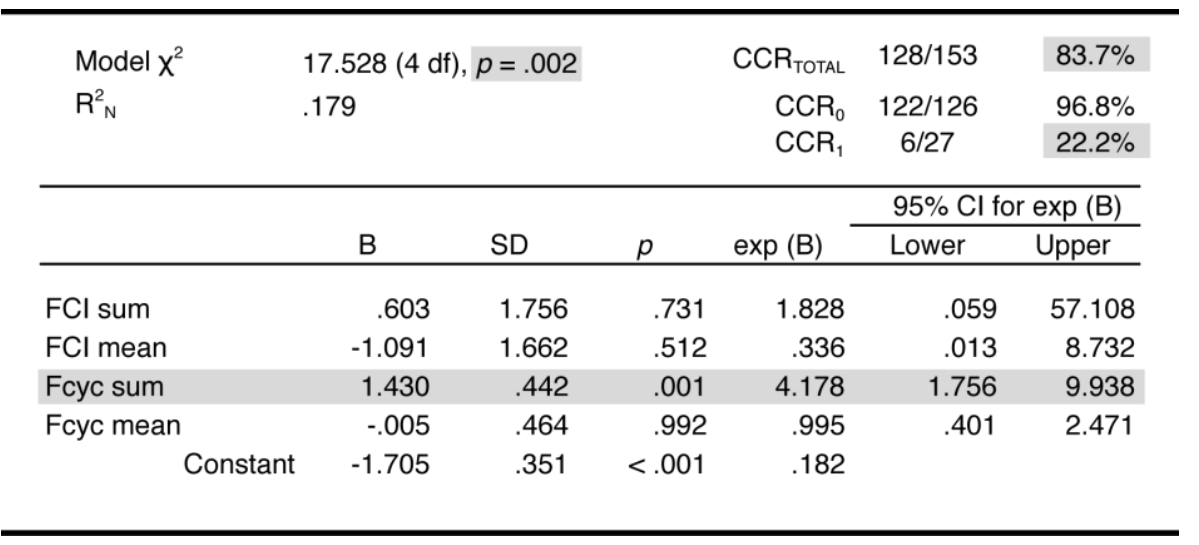

not yield a different result. The sum of mean annual frost cycles remained the only statistically significant predictor for variations in the observed debris flow activity in the Mt Aspiring region ( $p<.001 ; \mathrm{CCR}_{1}$ remained at 22.2\%). The acceptable performance of this rudimentary parameter as a predictor for debris flow activity during the investigation period is to some extent surprising, given that freeze-thaw related volumetric expansion of ice within rockwalls is thought to be of minor importance in regolith production (e.g. White, 1976; Walder and Hallet, 1985; 1986; cf. above). Controlling for size of the contribution area did not improve the model's explanatory power. Small catchments with comparatively high frost-weathering activity do not appear to be more prone to debris flow formation than large areas with lower frost-weathering levels, or vice versa.

The data available for this study do not allow deductions to be made about whether debris flow activity is independent of frost-weathering activity in the North and Central regions or whether the available sample populations are too small or unbalanced in numbers of event vs. non-event cases (see Question V for example, where reducing number of nonevents resulted in a statistically significant estimate) to detect the relationship. Factors, such as rock type, fracture density, or debris reservoirs' water saturation capacities, might attenuate the relationship and impede its identification. Alternatively, debris flow events might have gone unmapped in these regions due to a lack in number or quality of aerial photographs or due to difficulties in identifying events in steep channelised debris flow systems, reducing the number of events for statistical testing.

\section{Evaluation of the two frost-weathering intensity datasets}

Laboratory experiments and field observations strongly point towards segregation ice growth as the dominant mechanism of frost weathering in cold environments (cf. above). 
Hales and Roering's $(2007,2009)$ frost-cracking intensity model represents a first attempt to implement the theoretical principles of segregation ice growth in a spatial model. The authors' aim was to model the complicated physics of segregation ice growth using readily accessible parameters. The frost-cracking intensity model is consequently (and necessarily) a strong simplification of the complicated interactions governing segregation ice growth in bedrock, not considering influential parameters such as bedrock properties, rock temperatures, or local water availability (c.f. Anderson et al., 2013). Yet, the model's basic assumptions have been shown to facilitated a spatially-distributed regional-scale application: Hales and Roering (2009) modelled the distribution of present and past frost-cracking intensities across the Craigieburn Range, Southern Alps. Their calculated altitudinal patterns related well to the spatial distribution of presently active scree slopes and paleo-scree slopes, respectively. Delunel et al. (2010) reported a good correlation between mean catchment frost-cracking intensities calculated for 'Little Ice Age' conditions and catchmentwide ${ }^{10} \mathrm{Be}$ denudation rates. In the present study, however, the parameters quantifying potential frost cracking by segregation ice growth in the debris flow contribution areas according to Hales and Roering's $(2007,2009)$ model were not statistically significant predictors of observed variations in debris flow activity. Instead, the expected frost-related control was indicated by the predictive power of mean annual freeze-thaw cycles, i.e. the parameter representing the theoretically less effective process for regolith production.

A possible reason for the absence of a statistically significant relation between modelled frost-cracking intensities and debris flow activity is the comparatively small number of contribution areas for which significant frost-cracking activity was modelled. A comparison of the available sample sizes for the frost-cycle and frost-cracking analyses (Table 5.12) reveals that, due to the spatial restriction of the intense frost-cracking zone to higher elevations, the number of catchments available for the frost-cracking analysis is much smaller than for the frost-cycle analysis. Strategically increasing the sample population by contribution areas within the frost-cracking zone might strengthen the statistical signal and disclose the suspected relationship.

Table 5.12 Activity counts according to debris flow study regions for frost-cracking intensity data and frost cycle data.

\begin{tabular}{|c|c|c|c|c|}
\hline \multirow[b]{2}{*}{ Region } & \multicolumn{2}{|c|}{$\begin{array}{c}\text { Frost cracking intensity } \\
\text { active }\end{array}$} & \multicolumn{2}{|c|}{$\begin{array}{c}\boldsymbol{N} \text { frost cycles } \\
\text { active }\end{array}$} \\
\hline & no & yes & no & yes \\
\hline Kaikoura ranges & 11 & 2 & 80 & 15 \\
\hline Arthur's Pass region & 8 & 0 & 56 & 7 \\
\hline Two Thumb Range & 23 & 5 & 26 & 6 \\
\hline Mt Cook region & 22 & 0 & 57 & 4 \\
\hline Mt Aspiring region & 27 & 9 & 126 & 27 \\
\hline Total & 91 & 16 & 345 & 59 \\
\hline
\end{tabular}


The predictive power of mean annual frost cycles suggests that the parameter is capable of representing geomorphically relevant spatial variations in frost-weathering activity, even though empirical observations on bedrock fracturing in cold environments indicate volumetric ice expansion does not contribute significantly to regolith production. A possible explanation for the predictive performance of mean annual frost cycles is the similarity of calculated values to modelled frost-cracking intensities, which are thought to represent the more realistic frost-action control (Figure 5.9). Both model approaches are strong simplifications of the factors governing the respective frost-weathering mechanisms, not considering important influences such as water availability, rock temperature, or length of uninterrupted frost periods. Calculations are in both models exclusively based on temperature data, parameterising the most basic characteristic of frost action, i.e. the increase of frostweathering activity with altitude (cf. maps in Appendix 8). Consequently, the spatial trends represented by the two datasets are comparable; the two frost-weathering models provide in their present design similar information for logistic regression analyses. This similarity demonstrates a current inability to transfer theoretical knowledge of bedrock weathering in cold environments into suitable catchment-scale models. More sophisticated frostweathering models are needed, which are ideally physically-based and implement local-scale estimates of rock temperatures, water availability, and bedrock properties through time (see recommendations in Section 6.4).

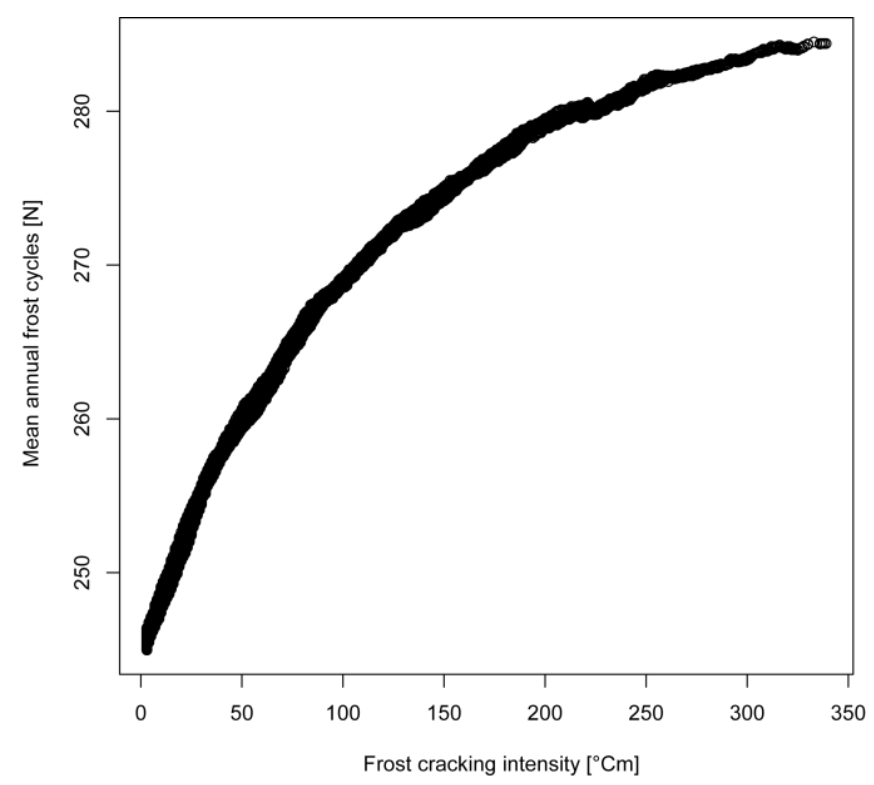

Figure 5.9

Relationship between modelled frost-cracking intensities and mean annual frost cycles for highaltitude locations (37,112 sample points) in the Camp Creek catchment, Two Thumb Range. The two parameters show a strong exponential relationship, relaying similar information to regression models. 


\section{Is frost weathering more intense in sun-avert locations and are debris flow events thus more likely to occur in southeast to southwest-facing locations?}

The orientation of rockwalls has been found to be a significant control on frost-weathering efficacy in the European Alps (e.g. Coutard and Francou, 1989; Sass, 2005b; cf. Section 3.1.2). Sun-avert locations receive less incoming solar radiation than rockwalls facing towards the sun (e.g. Gruber et al., 2003). The lower short-wave radiation totals affect the thermal regime of sun-avert rockwalls, resulting in longer and more intense frost at depth as well as more constant water supply due to longer lasting snow cover and lower evaporation (cf. Coutard and Francou, 1989). All these conditions promote segregation ice growth and are hence thought to enhance frost-driven breakdown of bedrock and subsequently debris production in sun-avert locations.

Frost-cracking intensity within the contribution areas, the parameter representing frostweathering activity by segregation ice growth, was not found to be a significant predictor of debris flow occurrence in the study areas. Therefore, the analysis of a potential aspectdependent control on frost-induced regolith production was based on the summed annual frost cycle data for the Mt Aspiring region. The influence of rockwall orientation on regolith production is fundamentally based on the concept of segregation ice growth as the cause for effective bedrock fracturing. Theoretically, debris flow activity predictions based on freezethaw frequencies should, therefore, not result in a statistically significant improvement when combined with aspect information. However, as noted above, the spatial variation in annual frost cycles appears to capture geomorphically relevant frost-related conditions. Including information on the dominant orientation of debris flow contribution areas, might, therefore, improve the correct classification of active and inactive debris flow systems.

To increase sample sizes, aspect classes were grouped into northern and southern aspect categories (Table 5.13), omitting systems with predominantly west and east orientated contribution areas. The predictors, standardised sum of the mean annual frost cycles, aspect category, and the interaction term, were included into the regression model via a forced blockwise entry. This allows isolating the effect of each term on the model's explanatory power. The southern category was used as base category for comparing the influence of the two categorical predictors.

The exclusion of predominantly west and east orientated contribution areas $(\mathrm{N}=44)$ from the analysis significantly reduced the percentage of correctly classified event systems $\left(\mathrm{CCR}_{1}\right)$ predicted by the mean annual frost cycle sum from $22 \%$ to $9 \%$ (Table 5.14 , Block I). Adding information about the contribution areas' orientation as a further predictor did not improve the model's $\mathrm{CCR}_{1}$ (Table 5.14, Block II). However, adding the interaction term, which controls for the number of frost cycles when comparing debris flow activity in southand north-facing systems, represented a statistically significant improvement of the model's explanatory power and raised the $\mathrm{CCR}_{1}$ for events to $17 \%$ (Table 5.14, Block III). 
Table 5.13 Activity counts in the Mt Aspiring region according to individual and grouped aspect classes.

\begin{tabular}{|c|c|c|c|c|c|c|c|}
\hline \multirow[b]{2}{*}{ Aspect class } & \multicolumn{2}{|c|}{ active } & \multirow[b]{2}{*}{ Total } & \multirow{2}{*}{$\begin{array}{l}\text { Grouped } \\
\text { aspect class }\end{array}$} & \multicolumn{2}{|c|}{ active } & \multirow[b]{2}{*}{ Tota } \\
\hline & no & yes & & & no & yes & \\
\hline NW & 20 & 3 & 23 & & & & \\
\hline $\mathrm{N}$ & 4 & 4 & 8 & North & 28 & 9 & 37 \\
\hline $\mathrm{NE}$ & 4 & 2 & 6 & & & & \\
\hline$E$ & 8 & 1 & 9 & not considered & & & \\
\hline SE & 31 & 10 & 41 & & & & \\
\hline$S$ & 13 & 4 & 17 & South & 58 & 14 & 72 \\
\hline SW & 14 & 0 & 14 & & & & \\
\hline W & 32 & 3 & 35 & not considered & & & \\
\hline Total & 126 & 27 & 153 & Total & 86 & 23 & 109 \\
\hline
\end{tabular}

Table 5.14 Results of the logistic regression model, exploring the orientation-dependent effect of frost weathering on debris flow activity in the Mt Aspiring region. The predictors were entered into the model by forced blockwise entry: Block I - standardised sum of mean annual frost cycles (Fcyc sum); Block II - aspect class with South as base category (South vs. North); Block III - interaction term, controlling aspect class for frost-weathering level (South vs. North by Fcyc sum) .

\begin{tabular}{|c|c|c|c|c|c|c|c|}
\hline \multirow[t]{6}{*}{ BLOCKI } & Model $x^{2}$ & \multicolumn{3}{|c|}{$7.602(1 \mathrm{df}), p=.006$} & $\mathrm{CCR}_{\text {TOTAL }}$ & $85 / 109$ & $78.0 \%$ \\
\hline & $\mathrm{R}_{\mathrm{N}}^{2}$ & \multicolumn{3}{|l|}{.105} & $\mathrm{CCR}_{0}$ & $83 / 86$ & $96.5 \%$ \\
\hline & & \multirow[b]{2}{*}{ B } & \multirow[b]{2}{*}{$\mathrm{SD}$} & \multirow[b]{2}{*}{$p$} & \multirow[b]{2}{*}{$\exp (B)$} & \multicolumn{2}{|c|}{$95 \% \mathrm{Cl}$ for $\exp (\mathrm{B})$} \\
\hline & & & & & & Lower & Upper \\
\hline & Fcyc sum & 1.106 & .417 & .008 & 3.021 & 1.333 & 6.846 \\
\hline & Constant & -1.241 & .246 & $<.001$ & .289 & & \\
\hline \multirow[t]{8}{*}{ BLOCK II } & Block $x^{2}$ & \multirow{2}{*}{\multicolumn{2}{|c|}{$\begin{array}{r}.925(1 \mathrm{df}), p=.336 \\
8.530(2 \mathrm{df}), p=.014\end{array}$}} & & $\mathrm{CCR}_{\text {TOTAL }}$ & $85 / 109$ & $78.0 \%$ \\
\hline & Model $\mathrm{X}^{2}$ & & & & $\mathrm{CCR}_{0}$ & \multirow{2}{*}{$\begin{array}{c}83 / 86 \\
2 / 23\end{array}$} & $96.5 \%$ \\
\hline & $\mathrm{R}_{\mathrm{N}}^{2}$ & \multicolumn{2}{|l|}{.117} & & $\mathrm{CCR}_{1}$ & & $8.7 \%$ \\
\hline & & \multirow[b]{2}{*}{ B } & \multirow[b]{2}{*}{ SD } & \multirow[b]{2}{*}{$p$} & \multirow[b]{2}{*}{$\exp (\mathrm{B})$} & \multicolumn{2}{|c|}{$95 \% \mathrm{Cl}$ for $\exp (\mathrm{B})$} \\
\hline & & & & & & Lower & Upper \\
\hline & Fcyc sum & 1.186 & .441 & .007 & 3.275 & 1.381 & 7.770 \\
\hline & South vs. North & .504 & .522 & .334 & 1.656 & .595 & 4.609 \\
\hline & Constant & -1.413 & .313 & $<.001$ & .243 & & \\
\hline \multirow[t]{9}{*}{$B L O C K I I I$} & Block $x^{2}$ & \multirow{2}{*}{\multicolumn{2}{|c|}{$\begin{array}{r}3.880(1 \mathrm{df}), p=.049 \\
12.409(3 \mathrm{df}), p=.006\end{array}$}} & & $\mathrm{CCR}_{\text {TOTAL }}$ & $85 / 109$ & $82.6 \%$ \\
\hline & Model $X^{2}$ & & & & $\mathrm{CCR}_{0}$ & \multirow{2}{*}{$\begin{array}{c}86 / 86 \\
4 / 23\end{array}$} & $100.0 \%$ \\
\hline & $\mathrm{R}_{\mathrm{N}}^{2}$ & \multicolumn{2}{|l|}{.167} & & $\mathrm{CCR}_{1}$ & & $17.4 \%$ \\
\hline & & \multirow[b]{2}{*}{ B } & \multirow[b]{2}{*}{ SD } & \multirow[b]{2}{*}{$p$} & \multirow[b]{2}{*}{$\exp (B)$} & \multicolumn{2}{|c|}{$95 \% \mathrm{Cl}$ for $\exp (\mathrm{B})$} \\
\hline & & & & & & Lower & Upper \\
\hline & Fcyc sum & .782 & .503 & .120 & 2.185 & .815 & 5.862 \\
\hline & South vs. North & 1.058 & .658 & .108 & 2.882 & .794 & 10.461 \\
\hline & $\begin{array}{l}\text { South vs. North } \\
\text { by Fcyc sum }\end{array}$ & 2.913 & 1.675 & .082 & 18.405 & .691 & 490.443 \\
\hline & Constant & -1.395 & .304 & $<.001$ & .248 & & \\
\hline
\end{tabular}


The estimate for the interaction term coefficient was with $p=.082$ slightly above the commonly adopted significance threshold of the 95\% confidence interval ( $p \leq .05)$. This means that the chance of the coefficient being entirely random is 1 in 12 as compared to the generally accepted chance of 1 in 20 . Both block and model chi-square were statistically significant $(p \leq .05)$, indicating that including the interaction term into the model represented a statistically significant improvement to Block II of the model. This, as well as the notable improvement in $\mathrm{CCR}_{1}$, suggests that the general orientation of debris flow systems has an effect on sediment recharge via frost weathering. The inflated standard error of the interaction term indicates numeric problems, possibly caused by an unfavourable data structure (cf. Section 4.3.2), which might reduce the significance of the coefficient estimate. Multicollinearity statistics did not indicate significant correlation between the individual predictors (cf. Appendix 9).

Accepting the slightly lower confidence level for the interaction term's coefficient estimate, the results suggest that at a given level of frost-weathering intensity, debris flows were more likely to occur in sun-avert debris flow systems than in sun-facing systems. Assuming that the spatial variation in debris flow activity during the investigation period expresses differences in sediment recharge rates, frost-induced regolith production appears to be more intense in sun-avert locations. This is in accordance with the observations in the European Alps (e.g. Coutard and Francou, 1989; Sass, 2005b).

\section{Is regolith production higher, and are debris flow events thus more likely, in certain lithologies?}

The potential effect of lithology on debris flow density and event formation has already been to some extent addressed in Section 5.2.4. Frequency ratios showed that both runoffgenerated (i.e. supply-limited) debris flow systems and debris flow events occurred above average in Argillite, Sandstone, and Greenschist.

The study areas' dominant lithology types are all fairly susceptible to mechanical weathering (cf. Whitehouse and Pearce, 1992; Turnbull, 2000; Cox and Barrell, 2007). New Zealand sandstones, including the subtype greywacke, are generally hard rocks with high intact rock mass strength due to a high quartz content (Coates, 2002; Stewart, 2007). However, as a consequence of past tectonic deformation, they are commonly closely fractured, which significantly reduces their effective strength and makes them susceptible to weathering and gravitational erosion. Fine-grained lithologies, such as argillite, are innately less competent and tend to physically weather more rapidly on atmospheric exposure, forming clay-rich minerals that further reduce the rock mass' effective strength (Whitehouse and Pearce, 1992; Cox and Barrell, 2007). Rock mass strength of metamorphic rocks, such as greyschist and greenschist, is strongly anisotropic. It generally decreases with metamorphic grade due to increasing mica grain size, but effective strength can vary locally, 


\begin{tabular}{|c|c|c|c|c|c|c|c|}
\hline \multirow[b]{2}{*}{ Lithology class } & \multicolumn{2}{|c|}{ active } & \multirow[b]{2}{*}{ Total } & \multirow[b]{2}{*}{ Rock type } & \multicolumn{2}{|c|}{ active } & \multirow[b]{2}{*}{ Tota } \\
\hline & no & yes & & & no & yes & \\
\hline Argillite & 10 & 5 & 15 & & & & \\
\hline Greywacke & 158 & 33 & 191 & Sedimentary & 248 & 53 & 301 \\
\hline Sandstone & 80 & 15 & 95 & & & & \\
\hline Greenstone Melange & 3 & 0 & 3 & not included & & & \\
\hline Semischist & 25 & 0 & 25 & not included & & & \\
\hline Greyschist & 58 & 3 & 61 & Metamorphic & 69 & 6 & 75 \\
\hline Greenschist & 11 & 3 & 14 & & & & \\
\hline Total & 345 & 59 & 404 & Total & 317 & 59 & 376 \\
\hline
\end{tabular}

depending on schistosity, cleavage, and the presence of quartz veins (Turnbull, 2000; Cox and Barrell, 2007).

The regression-based analysis of the lithological influence on regolith production in the delineated debris flow contribution areas was again based on rock group data from the vector version of the QMAP (cf. Section 5.2.4) at the location of the initiation areas. A frequency distribution of events in the seven lithological sub-categories revealed that the analysed runoff-generated debris flow systems in Greenstone Melange and Semischist did not experience activity during the investigation period (Table 5.15). These classes were hence excluded from the analysis, and the regression model was run with a reduced sample population of 376 debris flow systems. The lithology class Greyschist, which previously showed the lowest overall frequency ratio for active systems (Table 5.5), was used as the base category for the categorical predictor comparison.

The overall fit of the model was statistically significant, i.e. information on lithology in the contribution areas improved the model's power in explaining variations in observed debris flow activity (Table 5.16). However, the correct classification rate of events $\left(\mathrm{CCR}_{1}\right)$ did not improve above the base model which uses the majority of outcomes (here non-event, i.e. $\mathrm{CCR}_{0}=100 \%$ and $\mathrm{CCR}_{1}=0 \%$ ) as classification criteria (see e.g. Peng and So, 2002, or Field, 2005, for details on the interpretation of logistic regression results). Lithology on its own thus appears to have only an inferior control on sediment production, as it lacks any predictive power for debris flow events observed in the study areas.

Regression coefficients suggest statistically significant differences between lithologies in the likelihood of debris flow activity during the investigation period (Table 5.16). Based on the odds ratio $(\exp (B)$, a measure for the effect size of categorical data, cf. Field, 2005), compared to an event occurring in Greyschist, it was:

- almost 10 times more likely that an event occurred in Argillite, 
- 4 times more likely that an event occurred in Greywacke,

- almost 4 times more likely that an event occurred in Sandstone.

Probabilities of debris flow occurrence in Greenschist were not statistically significant different from those in Greyschist on the 0.05 confidence level. However, the relationship is with $p=.059$ only slightly above the cut-off threshold. Given the small sample size, which might reduce the parameter's explanatory power, it can be assumed that the indicated higher likelihood of events occurring during the investigation period in Greenschist than in Greyschist is valid. Multicollinearity statistics were not at critical levels (Appendix 9), but values indicated that regression results might be biased by multicollinearity.

Based on the odd ratios as well as the lack of events in Semischist and Greenstone Melange, lithologies can be ranked according to event likelihood as follows:

Argillite $>$ Greenschist $>$ Greywacke $>$ Sandstone $>$ Greyschist $>$ Semischist/Melange .

This ranking largely supports the results of the frequency ratio analysis in Section 5.2.4, indicating that Argillite and Greenschist are more susceptible to debris flow formation.

Eight of the delineated debris flow contribution areas stretched over two lithology classes. Therefore, the regression model was repeated, using the predominant lithology in the contribution area as independent variable. Interestingly, minor changes in the data set (three cases changed from Argillite to Greywacke, of which two showed activity during the investigation period) rendered the whole model statistically not significant. This change in outcome is thought to reflect again the limited size of the sample population. To increase sample sizes, contribution areas were grouped according to their principle type into sedimentary rock and metamorphic rock (Table 5.15). This differentiation appeared sensible,

Table 5.16 Results of the logistic regression using debris flow systems' activity during the investigation period as dependent variable and lithology in the debris flow initiation area as independent variable.

\begin{tabular}{|c|c|c|c|c|c|c|}
\hline Model $x^{2}$ & \multicolumn{3}{|c|}{$10.501(4 \mathrm{df}), p=.033$} & $\mathrm{CCR}_{\text {TOTAL }}$ & $317 / 376$ & $84.3 \%$ \\
\hline \multirow[t]{3}{*}{$R^{2}{ }_{N}$} & \multicolumn{3}{|l|}{.047} & $\mathrm{CCR}_{0}$ & $317 / 317$ & $100.0 \%$ \\
\hline & \multirow[b]{2}{*}{$\mathrm{B}$} & \multirow[b]{2}{*}{ SD } & \multirow[b]{2}{*}{$p$} & \multirow[b]{2}{*}{$\exp (B)$} & \multicolumn{2}{|c|}{$95 \% \mathrm{Cl}$ for $\exp (\mathrm{B})$} \\
\hline & & & & & Lower & Upper \\
\hline Lithology (overall) & & & .080 & & & \\
\hline Greyschist vs. Argillite & 2.269 & .807 & .005 & 9.667 & 1.989 & 46.972 \\
\hline Greyschist vs. Greywacke & 1.396 & .622 & .025 & 4.038 & 1.193 & 13.672 \\
\hline Greyschist vs. Greenschist & 1.663 & .880 & .059 & 5.273 & .939 & 29.600 \\
\hline Greyschist vs. Sandstone & 1.288 & .656 & .049 & 3.625 & 1.003 & 13.101 \\
\hline Constant & -2.962 & .592 & $<.001$ & .052 & & \\
\hline
\end{tabular}


since the literature review on variations in rock mass strength in the study areas (see above) did not produce clear indications for existing patterns (apart from the exceptional weathering susceptibility of argillite). The regression model was rerun, using sedimentary rock as the base category for the effect comparison.

The differentiation between sedimentary rock and metamorphic rock in the debris flow contribution areas was a statistically significant predictor for variation in debris flow activity in the study areas (Table 5.17). However, the differentiation explained less variance in the outcome variable (event/ non-event) than the model based on the individual lithology groups $\left(R_{N}^{2}=.022\right.$ compared to $R_{N}^{2}=.047$ in Table 5.16). Similar to the previous model, the correct classification rate did not improve beyond the base model. Nonetheless, the model indicated a statistically significant relationship between the type of geology and debris flow activity, suggesting that the odds for an event occurring during the investigation period are lower in areas with metamorphic basement rock than in areas with sedimentary rock. Multicollinearity measures did not signify a correlation between the two geology types (Appendix 9).

Table 5.17 Results of the logistic regression using debris flow systems' activity during the investigation period as dependent variable and the principal type of lithology in the debris flow initiation area as independent variable.

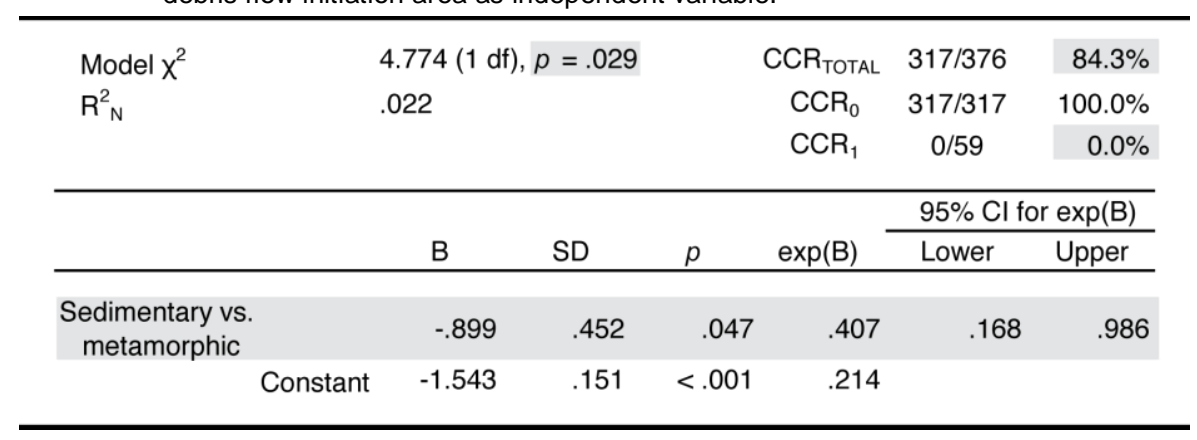

\section{Does the susceptibility of certain lithologies to frost weathering affect the likelihood of debris flow formation?}

The susceptibility of rock to frost weathering and its subsequent effect on regolith production rates within debris flow contribution areas is thought to be the dominant component of the lithological control on debris flow activity in cold environments (cf. Section 3.1.2). Laboratory experiments demonstrated significant differences in regolith production between sedimentary and crystalline rocks (e.g. André, 2003; Migon, 2006). The efficacy of rock disintegration by segregation ice growth is expected to be higher in porous or heavily fractured rock due to the favourable conditions for water migrating towards the freezing front (cf. Walder and Hallet, 1985; Hales and Roering, 2007). Controlling for frost- 
weathering activity in the regression analysis may, therefore, strengthen the statistical signal of a lithological control on debris flow activity in the study areas.

The analysis of the potential effect of lithologies' susceptibility to frost weathering on debris flow activity was initially restricted to the Mt Aspiring region, where a statistically significant relationship between frost-weathering intensity and debris flow occurrence had been established (cf. Question II). The rock types represented in the Mt Aspiring region are Greyschist, Greenschist, Greywacke, and Greenstone Melange (Table 5.18), allowing metamorphic and sedimentary rocks to be compared. Since debris flow systems situated in Greenstone Melange did not show activity during the investigation period, this category was omitted from the analysis, reducing the sample population to 150. The predictors, standardised sum of the mean annual frost cycles, lithology, and the interaction term, were entered via forced blockwise entry into the regression model. Greyschist was again used as the base category for the comparison.

Including lithology alongside frost weathering in the regression model provided a statistically significant improvement of the model's explanatory power (Table 5.19, Block II, $p=.001)$. However, the additional information did not improve the correct classification of events beyond that of using frost weathering alone (Table 5.19, Block I). Differences between the lithologies in the likelihood of debris flow formation during the investigation period reflect the findings above: It was more likely that debris flows occurred in Greywacke terrain than in Greyschist. No statistically significant difference was detected between Greyschist and Greenschist. Adding interaction terms into the model, which control for the level of frost weathering when comparing debris flow activity in the different lithologies, did not yield a statistically significant improvement of the model's explanatory power (Table 5.19, Block III). The lack of statistical significance of the interaction terms suggests that the local bedrock's susceptibility to frost weathering does not affect debris flow activity in the Mt Aspiring region. However, variance inflation factors (VIFs) indicated critical levels of multicollinearity between the predictor variables (Appendix 9). Standard errors might, consequently, be inflated, reducing the statistical significance of variable relationships.

Table 5.18 Activity counts in the Mt Aspiring region according to lithology classes.

\begin{tabular}{|c|c|c|c|}
\hline \multirow[b]{2}{*}{ Lithology class } & \multicolumn{2}{|c|}{ active } & \multirow[b]{2}{*}{ Total } \\
\hline & no & yes & \\
\hline Greyschist & 58 & 3 & 61 \\
\hline Greenschist & 11 & 3 & 14 \\
\hline Greywacke & 54 & 21 & 75 \\
\hline Greenstone Melange & 3 & 0 & 3 \\
\hline Total & 126 & 27 & 153 \\
\hline
\end{tabular}


Table 5.19 Results of the logistic regression, exploring the lithology-dependent effect of frostweathering activity on debris flow occurrence in the Mt Aspiring region. The predictors were entered via forced blockwise entry into the model: Block I - standardised sum of mean annual frost cycles (Fcyc sum), Block II - lithology class with Greyschist as contrast class, and Block III - interaction term controlling lithology class for frostweathering activity.

\begin{tabular}{|c|c|c|c|c|c|c|c|}
\hline \multirow[t]{6}{*}{ BLOCKI } & \multirow{4}{*}{$\begin{array}{l}\text { Model } X^{2} \\
R^{2}{ }_{N}\end{array}$} & \multirow{2}{*}{\multicolumn{3}{|c|}{$\begin{array}{l}16.112(1 \mathrm{df}), p<.001 \\
.167\end{array}$}} & \multirow{3}{*}{$\begin{array}{r}\mathrm{CCR}_{\text {TOTAL }} \\
\mathrm{CCR}_{0} \\
\mathrm{CCR}_{1}\end{array}$} & \multirow{2}{*}{$\begin{array}{c}125 / 150 \\
119 / 123 \\
6 / 27\end{array}$} & \multirow{3}{*}{$\begin{array}{l}83.3 \% \\
96.7 \% \\
22.2 \%\end{array}$} \\
\hline & & & & & & & \\
\hline & & \multirow[b]{2}{*}{$\mathrm{B}$} & \multirow[b]{2}{*}{ SD } & \multirow[b]{2}{*}{$p$} & & $95 \% \mathrm{Cl}$ for $\exp (\mathrm{B})$ & \\
\hline & & & & & $\exp (B)$ & Lower & Upper \\
\hline & Fcyc sum & 1.368 & .360 & $<.001$ & 3.927 & 1.937 & 7.959 \\
\hline & Constant & -1.475 & .229 & $<.001$ & .229 & & \\
\hline \multirow[t]{10}{*}{ BLOCK II } & Block $x^{2}$ & \multirow{2}{*}{\multicolumn{2}{|c|}{$\begin{array}{l}13.132(2 \mathrm{df}), p=.001 \\
29.244(3 \mathrm{df}), p<.001\end{array}$}} & & $\mathrm{CCR}_{\text {TOTAL }}$ & \multirow{3}{*}{$\begin{array}{c}125 / 150 \\
119 / 123 \\
6 / 27\end{array}$} & $83.3 \%$ \\
\hline & $a^{2}$ & & & & $\mathrm{CCR}_{0}$ & & $96.7 \%$ \\
\hline & $\mathrm{R}_{\mathrm{N}}^{2}$ & \multicolumn{2}{|l|}{.290} & & $\mathrm{CCR}_{1}$ & & $22.2 \%$ \\
\hline & & & & & & \multicolumn{2}{|c|}{$95 \% \mathrm{Cl}$ for $\exp (\mathrm{B})$} \\
\hline & & B & SD & $p$ & $\exp (B)$ & Lower & Upper \\
\hline & Fcyc sum & 1.513 & .436 & .001 & 4.540 & 1.933 & 10.663 \\
\hline & Lithology (overall) & & & .008 & & & \\
\hline & Greyschist vs. Greywacke & 2.068 & .681 & .002 & 7.911 & 2.082 & 30.067 \\
\hline & Greyschist vs. Greenschist & .960 & .969 & .322 & 2.611 & .391 & 17.452 \\
\hline & Constant & -2.871 & .614 & $<.001$ & .057 & & \\
\hline \multirow[t]{12}{*}{ BLOCK III } & Block $x^{2}$ & \multirow{2}{*}{\multicolumn{2}{|c|}{$\begin{array}{r}3.692(2 \mathrm{df}), p=.158 \\
32.935(5 \mathrm{df}), p<.001\end{array}$}} & & $\mathrm{CCR}_{\text {TOTAL }}$ & \multirow{3}{*}{$\begin{array}{c}126 / 150 \\
119 / 123 \\
7 / 27\end{array}$} & $84.0 \%$ \\
\hline & Model $\mathrm{X}^{2}$ & & & & $\mathrm{CCR}_{0}$ & & $96.7 \%$ \\
\hline & $\mathrm{R}^{2}{ }_{\mathrm{N}}$ & \multicolumn{2}{|l|}{.323} & & $\mathrm{CCR}_{1}$ & & $25.9 \%$ \\
\hline & & \multirow[b]{2}{*}{ B } & \multirow[b]{2}{*}{ SD } & \multirow[b]{2}{*}{$p$} & \multirow[b]{2}{*}{$\exp (B)$} & \multicolumn{2}{|c|}{$95 \% \mathrm{Cl}$ for $\exp (\mathrm{B})$} \\
\hline & & & & & & Lower & Upper \\
\hline & $\begin{array}{l}\text { Fcyc sum } \\
\text { Litholoav (overall) }\end{array}$ & -.356 & 1.638 & $\begin{array}{l}.828 \\
.009\end{array}$ & .701 & .028 & 17.379 \\
\hline & Greyschist vs. Greywacke & 2.267 & .800 & .005 & 9.654 & 2.011 & 46.347 \\
\hline & Greyschist vs. Greenschist & .080 & 1.719 & .963 & 1.083 & .037 & 31.478 \\
\hline & $\begin{array}{l}\text { Lithology (overall) } \\
\text { by Fcyc sum }\end{array}$ & & & .314 & & & \\
\hline & $\begin{array}{l}\text { Greyschist vs. Greywacke } \\
\text { by Fcyc sum }\end{array}$ & 2.014 & 1.745 & .248 & 7.496 & .245 & 229.016 \\
\hline & $\begin{array}{l}\text { Greyschist vs. Greenschist } \\
\text { by Fcyc sum }\end{array}$ & 3.399 & 2.247 & .130 & 29.926 & .366 & 2447.139 \\
\hline & Constant & -3.051 & .745 & $<.001$ & .047 & & \\
\hline
\end{tabular}

Omitting the contribution areas in Greenstone Melange and Semischist, which lacked any activity during the investigation period, from the overall sample population $(\mathrm{N}=404)$ and consequently reducing the number of non-event cases, rendered the relationship between frost weathering and debris flow activity for the whole data set statistically significant. Therefore, the above model was repeated for this larger dataset of 376 contribution areas (= overall sample population minus Greenstone Melange and Semischist). In contrast to the Mt Aspiring dataset, the inclusion of an interaction term controlling for frost-action in differences between lithology classes did improve the model's explanatory power (Table 5.20, Block III, $p=.007$ ). However, also in this larger dataset, none of the interaction 
terms indicated a statistically significant relationship between lithology and debris flow formation.).

To increase sample sizes describing differences in lithology, rock types were again grouped into sedimentary and metamorphic rocks (cf. Table 5.15). The model was rerun for

Table 5.20 Results of the logistic regression, exploring the lithology-dependent effect of frostweathering activity on debris flow occurrence in all study areas. The predictors were entered via forced blockwise entry into the model: Block I - standardised sum of mean annual frost cycles (Fcyc sum), Block II - lithology class with Greyschist as contrast class, and Block III - interaction term controlling lithology class for frost-weathering activity.

\begin{tabular}{|c|c|c|c|c|c|c|c|}
\hline \multirow[t]{6}{*}{ BLOCK I } & Model $X^{2}$ & \multicolumn{2}{|c|}{$5.548(1 \mathrm{df}), p=.019$} & & \multirow{2}{*}{$\begin{array}{r}\mathrm{CCR}_{\text {TOTAL }} \\
\mathrm{CCR}_{0} \\
\mathrm{CCR}_{1}\end{array}$} & \multirow{2}{*}{$\begin{array}{c}316 / 376 \\
316 / 317 \\
0 / 59\end{array}$} & \multirow{2}{*}{$\begin{array}{r}84.0 \% \\
99.7 \% \\
0.0 \%\end{array}$} \\
\hline & $\mathrm{R}_{\mathrm{N}}^{2}$ & .025 & & & & & \\
\hline & & \multirow[b]{2}{*}{$\mathrm{B}$} & \multirow[b]{2}{*}{ SD } & \multirow[b]{2}{*}{$p$} & \multirow[b]{2}{*}{$\exp (B)$} & \multicolumn{2}{|c|}{$95 \% \mathrm{Cl}$ for $\exp (\mathrm{B})$} \\
\hline & & & & & & Lower & Upper \\
\hline & Fcyc sum & .308 & .133 & .021 & 1.361 & 1.048 & 1.767 \\
\hline & Constant & -1.695 & .144 & $<.000$ & .184 & & \\
\hline \multirow[t]{12}{*}{ BLOCK II } & Block $x^{2}$ & \multirow{2}{*}{\multicolumn{2}{|c|}{$\begin{array}{r}9.378(4 \mathrm{df}), p=.052 \\
14.926(5 \mathrm{df}), p=.011\end{array}$}} & & $\mathrm{CCR}_{\text {TOTAL }}$ & \multirow{3}{*}{$\begin{array}{c}316 / 376 \\
316 / 317 \\
0 / 59\end{array}$} & $84.0 \%$ \\
\hline & IViodel X & & & & $\mathrm{CCR}_{0}$ & & $99.7 \%$ \\
\hline & $\mathrm{R}_{\mathrm{N}}^{2}$ & .067 & & & $\mathrm{CCR}_{1}$ & & $0.0 \%$ \\
\hline & & & & \multirow[b]{2}{*}{$p$} & \multirow[b]{2}{*}{$\exp (\mathrm{B})$} & \multicolumn{2}{|c|}{$95 \% \mathrm{Cl}$ for $\exp (\mathrm{B})$} \\
\hline & & B & $\mathrm{SD}$ & & & Lower & Upper \\
\hline & Fcyc sum & .277 & .131 & .035 & 1.319 & 1.019 & 1.706 \\
\hline & Lithology (overall) & & & .107 & & & \\
\hline & Greyschist vs. Argillite & 2.143 & .811 & .008 & 8.522 & 1.739 & 41.756 \\
\hline & Greyschist vs. Greywacke & 1.353 & .623 & .030 & 3.871 & 1.141 & 13.130 \\
\hline & Greyschist vs. Greenschist & 1.538 & .884 & .082 & 4.654 & .823 & 26.325 \\
\hline & Greyschist vs. Sandstone & 1.153 & .662 & .081 & 3.168 & .866 & 11.587 \\
\hline & Constant & -2.906 & .593 & $<.000$ & .055 & & \\
\hline \multirow[t]{17}{*}{ BLOCK III } & Block $x^{2}$ & \multirow{2}{*}{\multicolumn{2}{|c|}{$\begin{array}{l}14.262(4 \mathrm{df}), p=.007 \\
29.188(9 \mathrm{df}), p=.001\end{array}$}} & & $\mathrm{CCR}_{\text {TOTAL }}$ & $367 / 376$ & $84.6 \%$ \\
\hline & Model $\mathrm{X}^{2}$ & & & & $\mathrm{CCR}_{0}$ & \multirow{2}{*}{$\begin{array}{r}313 / 317 \\
5 / 59\end{array}$} & $98.7 \%$ \\
\hline & $R^{2}{ }_{N}$ & \multicolumn{2}{|l|}{.129} & & $\mathrm{CCR}_{1}$ & & $8.5 \%$ \\
\hline & & \multirow[b]{2}{*}{$\mathrm{B}$} & \multirow[b]{2}{*}{ SD } & \multirow[b]{2}{*}{$p$} & \multirow[b]{2}{*}{$\exp (B)$} & \multicolumn{2}{|c|}{$95 \% \mathrm{Cl}$ for $\exp (\mathrm{B})$} \\
\hline & & & & & & Lower & Upper \\
\hline & Fcyc sum & -.356 & 1.638 & .828 & .701 & .028 & 17.379 \\
\hline & Lithology (overall) & & & .232 & & & \\
\hline & Greyschist vs. Argillite & 2.069 & .974 & .034 & 7.917 & 1.173 & 53.420 \\
\hline & Greyschist vs. Greywacke & 1.491 & .771 & .053 & 4.443 & .981 & 20.127 \\
\hline & Greyschist vs. Greenschist & .080 & 1.719 & .963 & 1.083 & .037 & 31.478 \\
\hline & Greyschist vs. Sandstone & 1.387 & .797 & .082 & 4.004 & .840 & 19.081 \\
\hline & $\begin{array}{l}\text { Lithology (overall) } \\
\text { by Fcyc sum }\end{array}$ & & & .092 & & & \\
\hline & $\begin{array}{l}\text { Greyschist vs. Argillite } \\
\text { by Fcyc sum }\end{array}$ & 1.429 & 1.852 & .440 & 4.173 & .111 & 157.320 \\
\hline & $\begin{array}{l}\text { Greyschist vs. Greywacke } \\
\text { by Fcyc sum }\end{array}$ & 1.004 & 1.654 & .544 & 2.730 & .107 & 69.851 \\
\hline & $\begin{array}{l}\text { Greyschist vs. Greenschist } \\
\text { by Fcyc sum }\end{array}$ & 3.399 & 2.247 & .130 & 29.926 & .366 & 2447.139 \\
\hline & $\begin{array}{l}\text { Greyschist vs. Sandstone } \\
\text { by Fcyc sum }\end{array}$ & .143 & 1.675 & .932 & 1.154 & .043 & 30.735 \\
\hline & Constant & -3.051 & .745 & $<.000$ & .047 & & \\
\hline
\end{tabular}


the data set of 376 contribution areas, using the sedimentary rock class as the base category for the effect comparison.

Adding information on the basement geology type resulted in a statistically significant improvement above the univariate regression model (Table 5.21, Block II). However, including the additional information did not improve the model's correct classification of events. The difference between the two rock types concerning the likelihood of events decreased in statistical significance just beyond the $95 \%$ confidence threshold. The effect of the interaction term, on the other hand, was statistical significant at the 0.05 level (Table 5.21, Block III). Interestingly, the direction of the difference in the susceptibility of lithology classes towards debris flows is opposite that for the rock type predictor alone: At

Table 5.21 Results of the logistic regression, exploring the lithology-dependent effect of frostweathering activity on debris flow occurrence in all study areas. The predictors were entered via forced blockwise entry into the model: Block I - standardised sum of mean annual frost cycles (Fcyc sum), Block II - lithology type with sedimentary rock as contrast class, and Block III - interaction term controlling lithology type for frostweathering activity.

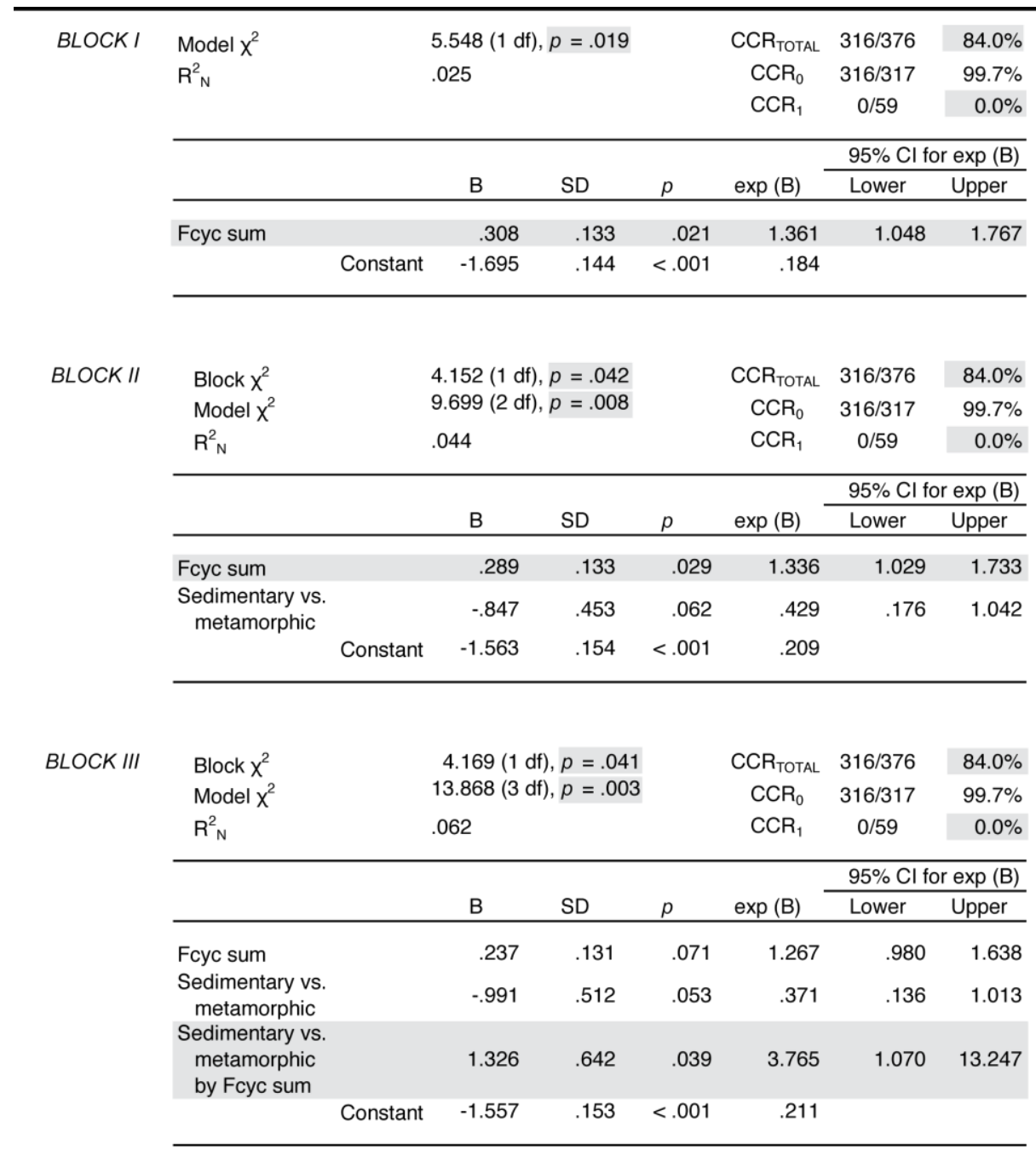


similar frost-weathering levels, the odds for an event occurring during the investigation period were higher in metamorphic rock than in sedimentary rock. Yet, this statistical significant relationship did not increase the correct classification rate of events. The higher susceptibility of metamorphic rock to frost weathering is not confirmed in the Mt Aspiring dataset (Table 5.22, Block III), where both Greenschist and Greyschist occur and statistical signals of frost- as well as lithological controls had already been established (Table 5.19). For this smaller dataset, the block, including the interaction term, did not yield a statistically significant improvement in explanatory power. Given the lack of improvement in $\mathrm{CCR}_{1}$ in the large dataset as well as the lack of a respective relation in the Mt Aspiring dataset, the suggested higher susceptibility of metamorphic rock to frost weathering is unsupported and might not be genuine. Multicollinearity measures were not at critical levels for either model (Appendix 9).

Table 5.22 Results of the logistic regression, analysing the lithology-dependent effect of frostweathering activity on debris flow occurrence in the Mt Aspiring region. The predictors were entered via forced blockwise entry into the model: Block I, standardised sum of mean annual frost cycles (Fcyc sum) is identical to Block I in Table 5.19, Block II - lithology type with sedimentary rock as contrast class, and Block III - interaction term controlling lithology type for frost-weathering activity.

\begin{tabular}{|c|c|c|c|c|c|c|c|c|}
\hline \multirow[t]{8}{*}{ BLOCK II } & Block $x^{2}$ & & \multirow{2}{*}{\multicolumn{3}{|c|}{$\begin{array}{l}12.181(1 \mathrm{df}), p<.001 \\
28.293(2 \mathrm{df}), p<.001\end{array}$}} & $\mathrm{CCR}_{\text {TOTAL }}$ & $124 / 150$ & $82.7 \%$ \\
\hline & Model $x^{2}$ & & & & $28.293(2 \mathrm{df}), p<.001$ & $\mathrm{CCR}_{0}$ & $120 / 123$ & $97.6 \%$ \\
\hline & $\mathrm{R}_{\mathrm{N}}^{2}$ & & \multicolumn{3}{|l|}{.282} & $\mathrm{CCR}_{1}$ & $4 / 27$ & $14.8 \%$ \\
\hline & & & \multirow[b]{2}{*}{ B } & \multirow[b]{2}{*}{ SD } & \multirow[b]{2}{*}{$p$} & \multirow[b]{2}{*}{$\exp (\mathrm{B})$} & \multicolumn{2}{|c|}{$95 \% \mathrm{Cl}$ for $\exp (\mathrm{B})$} \\
\hline & & & & & & & Lower & Upper \\
\hline & Fcyc sum & & 1.613 & .430 & $<.001$ & 5.020 & 2.159 & 11.670 \\
\hline & $\begin{array}{l}\text { Sedimentary vs. } \\
\text { metamorphic }\end{array}$ & & -1.773 & .567 & .002 & .170 & .056 & .516 \\
\hline & & Constant & -.790 & .286 & .006 & .454 & & \\
\hline \multirow[t]{9}{*}{ BLOCK III } & Block $x^{2}$ & & \multirow{3}{*}{\multicolumn{2}{|c|}{$\begin{array}{r}.012(1 \mathrm{df}), p=.912 \\
28.305(3 \mathrm{df}), p<.001 \\
.282\end{array}$}} & & $\mathrm{CCR}_{\text {TOTAL }}$ & $124 / 150$ & $83.3 \%$ \\
\hline & Model $x^{2}$ & & & & & $\mathrm{CCR}_{0}$ & \multirow{2}{*}{$\begin{array}{c}120 / 123 \\
5 / 27\end{array}$} & $97.6 \%$ \\
\hline & $\mathrm{R}_{\mathrm{N}}^{2}$ & & & & & $\mathrm{CCR}_{1}$ & & $18.8 \%$ \\
\hline & & & \multirow[b]{2}{*}{ B } & \multirow[b]{2}{*}{ SD } & \multirow[b]{2}{*}{$p$} & \multirow[b]{2}{*}{$\exp (B)$} & \multicolumn{2}{|c|}{$95 \% \mathrm{Cl}$ for $\exp (\mathrm{B})$} \\
\hline & & & & & & & Lower & Upper \\
\hline & Fcyc sum & & 1.659 & .600 & .006 & 5.252 & 1.621 & 17.022 \\
\hline & $\begin{array}{l}\text { Sedimentary vs. } \\
\text { metamorphic }\end{array}$ & & -1.764 & .570 & .002 & .171 & .056 & .523 \\
\hline & $\begin{array}{l}\text { Sedimentary vs. } \\
\text { metamorphic } \\
\text { by Fcyc sum }\end{array}$ & & -.096 & .869 & .912 & .908 & .165 & 4.985 \\
\hline & & Constant & -.784 & .293 & .007 & .457 & & \\
\hline
\end{tabular}


VI. Does the level of neo-tectonic uplift, as a proxy for fracture density, affect the susceptibility of certain lithologies to frost weathering and thus the likelihood of debris flow formation?

Rock fractures, created by tectonic deformation of rock masses, can significantly reduce the effective strength of rockwalls as well as promote the mechanical breakdown by segregation ice growth (e.g. Augustinus, 1992; Sass, 2005b; Walder and Hallet, 1985; cf. Section 5.2.5 and the previous subsection). Debris flow contribution areas located within heavily fractured rock masses are therefore expected to experience higher debris reaccumulation rates and subsequently higher debris flow activity. Given the lack of information on rock mass strength and fracture density of the study areas' basement rocks, neo-tectonic uplift rates are used as a proxy for the degree of tectonic straining rock masses experienced in the past and hence for fracture density (cf. Section 5.2.5). Although this link is admittedly a very rough generalisation and simplification of geologic processes, it allows a tentative parameterisation of a geological attribute important for denudation processes in high alpine areas and its implementation in more complex multivariate statistical analyses. However, any positive relationship has to be viewed in the context of a general gravitational influence. Regions subjected to significant neo-tectonic uplift are generally characterised by high relief and intense gravitational mass-wasting, as hillslopes adjust to changing stress conditions within the uplifted rock masses (e.g. Clarke and Burbank, 2010).

The analysis of the explanatory power of estimated neo-tectonic uplift rates for variations in debris flow activity was restricted to debris flow systems in Greywacke, as Greywacke was the only investigated rock group that also included adequate variations in uplift rates (Table 5.23). Information on estimated uplift rates in the study areas was again taken from Wellman (1979) (cf. Section 5.2.5).

Table 5.23 Sample count for all study areas according lithology class and uplift rate.

\begin{tabular}{|c|c|c|c|c|c|c|c|c|c|}
\hline \multirow[b]{2}{*}{ Lithology } & \multicolumn{8}{|c|}{ uplift rate $\left[\mathrm{mm} \mathrm{a}^{-1}\right]$} & \multirow[b]{2}{*}{ Total } \\
\hline & 0.2 & 0.5 & 2.0 & 3.0 & 4.0 & 5.0 & 6.0 & 7.0 & \\
\hline Argillite & - & - & - & 9 & 6 & - & - & - & 15 \\
\hline Greywacke & 31 & 88 & 9 & 4 & 27 & 32 & - & - & 191 \\
\hline Melange & - & 3 & - & - & - & - & - & - & 3 \\
\hline Greenschist & - & - & 14 & - & - & - & 2 & 93 & 109 \\
\hline Sandstone & - & - & - & - & - & - & - & - & 0 \\
\hline Greychist & - & - & 61 & - & - & - & - & - & 61 \\
\hline Semischist & - & - & 21 & - & 4 & - & - & - & 25 \\
\hline$\overline{\text { Total }}$ & 31 & 91 & 105 & 13 & 37 & 32 & 2 & 93 & 404 \\
\hline
\end{tabular}


The model result showed that the estimated uplift rate was a statistically significant predictor of debris flow occurrence in Greywacke catchments during the investigation period (Table 5.24). However, the effect was opposite to what was expected: According to the model output, the odds for an event occurring during the investigation period decreased with increasing uplift rates. The reason for this unexpected finding is thought to be related to biases in the sample population rather than a true relationship. A cross tabulation of event/non-event counts per uplift category and study areas (Table 5.25) reveals that events were overproportionately numerous in comparatively tectonically stable areas with uplift rates below $1 \mathrm{~mm} \mathrm{a}^{-1}$. The complete lack of events in Greywacke catchments subjected to comparatively high present-day uplift (Denas Creek (DC) and four debris flow systems in Camp Creek (CC)) is thought to effectively bias the coefficient estimate towards a negative relationship, which might not be present in a different sample population. Alternatively, the negative relationship might be the expression of unknown factors, which may also be able to explain the unexpected absence of debris flow events in the Denas Creek catchment, Arthur's Pass Region (cf. Section 5.2.5).

Table 5.24 Result of the logistic regression, exploring the effect of uplift rates on general sediment production in greywacke catchments.

\begin{tabular}{|c|c|c|c|c|c|c|}
\hline Model $x^{2}$ & \multicolumn{3}{|c|}{$13.997(1 \mathrm{df}), p<.001$} & $\mathrm{CCR}_{\text {TOTAL }}$ & $158 / 191$ & $82.7 \%$ \\
\hline \multirow[t]{3}{*}{$\mathrm{R}_{\mathrm{N}}^{2}$} & \multicolumn{3}{|l|}{.117} & $\mathrm{CCR}_{0}$ & $158 / 158$ & $100.0 \%$ \\
\hline & \multirow[b]{2}{*}{$\mathrm{B}$} & \multirow[b]{2}{*}{$\mathrm{SD}$} & \multirow[b]{2}{*}{$p$} & \multirow[b]{2}{*}{$\exp (B)$} & \multicolumn{2}{|c|}{$95 \% \mathrm{Cl}$ for $\exp (\mathrm{B})$} \\
\hline & & & & & Lower & Upper \\
\hline Uplift rate & -.489 & .162 & .002 & .613 & .447 & .841 \\
\hline Constant & -.927 & .244 & $<.001$ & .396 & & \\
\hline
\end{tabular}

Table 5.25 Activity count for study areas in greywacke according to study area and uplift rate. The first number states the debris flow systems mapped in the study area in the respective uplift category. The second number gives the number of systems that showed activity during the investigation period.

\begin{tabular}{|c|c|c|c|c|c|c|c|}
\hline \multirow[b]{2}{*}{ Study area } & \multicolumn{6}{|c|}{ uplift rate $\left[\mathrm{mm} \mathrm{a}^{-1}\right]$} & \multirow[b]{2}{*}{ Total } \\
\hline & 0.2 & 0.5 & 2.0 & 3.0 & 4.0 & 5.0 & \\
\hline $\mathrm{DC}$ & - & - & - & - & - & 3210 & 32 \\
\hline CHFS & 2417 & - & - & - & - & - & 31 \\
\hline $\mathrm{CC}$ & - & - & - & 410 & - & - & 4 \\
\hline $\mathrm{FC}$ & - & $12 \mid 1$ & - & - & - & - & 13 \\
\hline BBS & - & - & - & - & $24 \mid 3$ & - & 27 \\
\hline SSV & - & - & $8 \mid 1$ & - & - & - & 9 \\
\hline GB & - & $15 \mid 9$ & - & - & - & - & 24 \\
\hline KCET & - & $39 \mid 12$ & - & - & - & - & 51 \\
\hline Total & 2417 & $66 \mid 22$ & $8 \mid 1$ & 410 & $24 \mid 3$ & 3210 & 191 \\
\hline
\end{tabular}


In view of the doubtful, albeit statistical significant, result of the univariate regression, a multivariate regression using the same data input for analysing the effect of present-day uplift on Greywacke's susceptibility to frost weathering was omitted.

\section{Is regolith production higher, and are debris flow events thus more likely, in debris flow systems with contribution areas within the permafrost zone?}

Sass (2005b) observed significantly higher denudation rates in supposed permafrost locations than at lower altitudes. His observations are supported by laboratory experiments (Murton et al., 2001; Murton et al., 2006), which simulated segregation ice growth in at depth permanently frozen chalk blocks. The experiments showed that intense frost-induced fracturing by segregation ice growth occurred at the base of the active layer and just beneath the permafrost table. Assuming that similar processes occur in natural rockwalls with permafrost at depth, a causal link between rockfall activity and permafrost-enhanced frost weathering is likely. Increased regolith production rates in debris flow systems with contribution areas within the permafrost zone are expected to result in higher debris flow activity than in systems at lower altitudes.

Information on the estimated permafrost extent in the mapped debris flow contribution areas was derived from the permafrost dataset described in Section 5.2.6. Out of the 404 debris flow systems analysed, almost $20 \%$ had contribution areas within or extending into the modelled permafrost zone (Table 5.26). Roughly the same percentage (18\%) of these systems showed activity during the investigation period.

To investigate the potential effect of permafrost within debris flow contribution area on regolith production and hence on the odds of debris flow occurrence, three parameters were calculated for each of the 404 debris flow contribution areas: 1) a binary variable indicating the general presence or absence of permafrost in the catchment area (PF present), 2) percentage of the contribution area potentially underlain by permafrost (PF percent), and

Table 5.26 Activity count according to permafrost presence in the debris flow contribution areas for all study regions. Figures in brackets give proportion of events/ non-events within permafrost category.

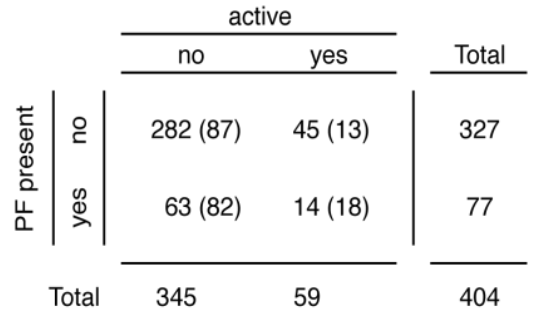


3) the spatially aggregated sum of permafrost probability in the contribution area (PF prob sum). The three predictors were entered in a single block into the regression model. For the categorical predictor PF present, the absence of permafrost was chosen as base category for effect comparison. The continuous variables were entered in standardised form into the regression model.

The model, including all three parameters, produced a statistically significant result (Table 5.27). The two variables PF present and PF percent were both statistically significant predictors of variations in the debris flow occurrence. However, the coefficient estimates indicated opposite relationships between permafrost presence and debris flow formation. Debris flow events were six times more likely to occur in debris flow systems within the modelled permafrost zone than outside $(\exp (B)$ of PF present). Yet, the odds of a debris flow event occurring during the investigation period decreased with increasing extent of permafrost in the contribution areas (PF percent). Univariate regression models for the two predictors did not reproduce the indicated relationships (i.e. models were not statistically significant). The statistical results on the effect of bedrock permafrost on debris flow formation are, therefore, inconclusive.

In summary, there is no indication in the present dataset that regolith production and hence the odds for debris flow occurrence are higher in debris flow systems with contribution areas within the potential permafrost zone. A possible explanation for the absence of the expected relationship may be the unwarranted use of the established permafrost distribution estimate for this analysis. Inferred from rock glaciers, the distribution estimate is thought primarily valid for the debris domain. Permafrost presence in bedrock, which is governed by slightly different climatic controls (see e.g. Gruber and Haeberli, 2007, or Noetzli et al., 2007, for details), might be therefore not well represented in the established permafrost distribution model.

Table 5.27 Results of the logistic regression, analysing the effect of permafrost in the contribution areas on debris flow occurrence. The regression was calculated for the whole sample dataset $(N=404)$. The standardised predictors, proportion of contribution area potentially underlain by permafrost (PF percent), and the aggregated sum of permafrost probability (PF prob sum), and the categorical predictor presence or absence of permafrost (PF present) were all entered as one block into the model. Multicollinearity measures were close to but not at critical levels (Appendix 9).

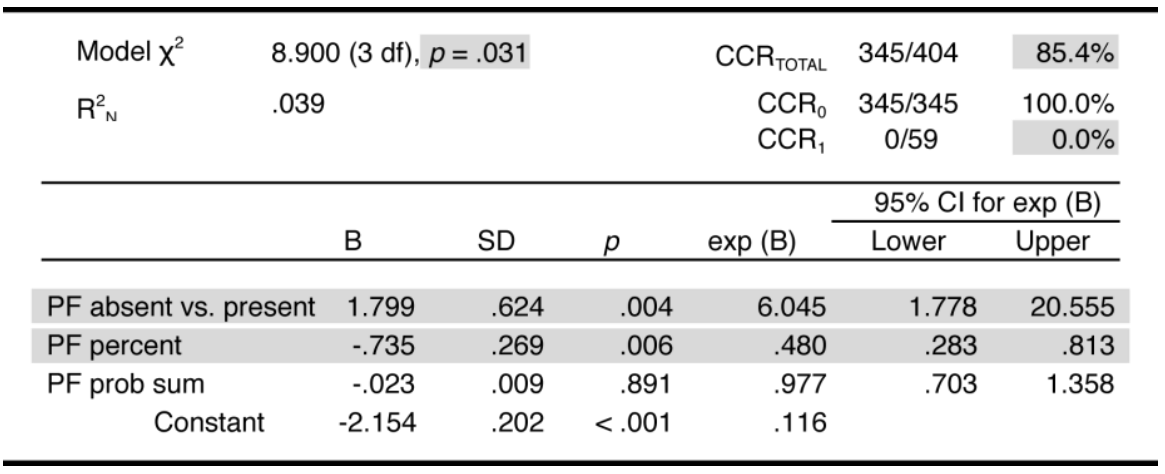




\subsection{SUMMARY}

Frequency ratios and logistic regression models were used to investigate the potential control of periglacial and non-periglacial preconditioning factors on the distribution of debris flow systems and debris flow events in the study areas. Overall, this study's findings are largely consistent with the main controls for debris initiation outlined in literature (cf. Section 3.1.2). A tabular summary of the findings is presented in Table 5.28.

Results of the statistical analyses suggest a periglacial influence on debris flow activity is present at high altitudes where enhanced regolith production in the debris flow contribution areas occurs as a result of intense frost weathering. A statistically significant relationship was detected in the Mt Aspiring region, where the odds for a debris flow event occurring during the investigation period increased with the number of frost cycles experienced in the contribution area. The size of the contribution area appears to be of minor importance in this context. Debris flow systems with small contribution areas subjected to comparatively high frost cycle counts did not show a higher tendency for event formation than systems with larger contribution areas subjected to fewer frost cycles. Frost-induced regolith production (inferred from variations in debris flow activity) appears to be more efficient in sun-avert locations than in sun-facing locations. This is in agreement with observations in the European Alps (e.g. Coutard and Francou, 1989; Sass, 2005b).

Segregation ice growth within bedrock is thought to be the dominant weathering mechanism in cold environments. Higher efficacy of frost weathering in sun-avert locations supports the superiority of frost weathering by segregation ice growth above frost weathering by volumetric ice expansion. It was therefore surprising that the parameters representing frost weathering by segregation ice growth were not statistically significant predictors of variations in the observed debris flow activity. The absence of a statistically significant relationship is possibly the result of an insufficiently small sample population. The good performance of the frost cycle parameter, which in theory is an inadequate measure of frostweathering activity, suggests that the parameter, nonetheless, captures regolith-production relevant variations in frost-weathering levels.

Table 5.28 Findings of the statistical analysis of factors influencing debris flow activity in the Southern Alps Blue colouring signifies periglacial or periglacial-related influences.

\begin{tabular}{|c|c|c|c|}
\hline & Promoting Factors & No influence detected & Inconclusive statistical results \\
\hline Spatial distribution & $\begin{array}{l}\text { Slope } \\
\text { Quaternary deposits } \\
\text { Lithology }\end{array}$ & $\begin{array}{l}\text { Aspect } \\
\text { Altitude } \\
\text { Permafrost }\end{array}$ & Uplift rate ( rock fractures) \\
\hline Sediment recharge & $\begin{array}{l}\text { Frost weathering } \\
\text { Aspect }\end{array}$ & Catchment topography & $\begin{array}{l}\text { Lithology } \\
\text { Uplift rate ( rock fractures) } \\
\text { Permafrost }\end{array}$ \\
\hline
\end{tabular}


No indication was found that permafrost within sediment reservoirs increases the susceptibility for slope instabilities. Similarly, the potential presence of permanently frozen bedrock within the debris flow contribution areas does not appear to increase regolith production rates and hence debris flow activity. However, it has to be noted that the information on the potential permafrost extent was inferred from rock glaciers and is, therefore, primarily thought valid for the debris domain. The use of the developed model for predicting bedrock permafrost might thus be unwarranted.

The analysis of non-periglacial controls confirmed the cardinal role of catchment topography and the presence of Quaternary deposits in the distribution of debris flow systems and consequently events. Debris flows developed generally at slope gradients above $20^{\circ}$ with critical slope ranges varying according to debris flow initiation mechanisms. An initiation-type dependent pattern was also evident in the altitudinal distribution of debris flows. Slide-initiated and slide-related debris flows generally occur in well-developed sediment accumulations, which are characterised by gentler slope gradients and are frequently located close to the valley floor. Examples for such sediment accumulations are Quaternary sediments, such as landslide deposits, moraines, and relict taluses, which showed an exceptional propensity for debris flow formation as well as reactivation during the investigation period. A topographic control due to aspect-constrained relief development is also suspected in the notable frequency of slide instabilities on north-facing slopes.

A lithologic control on debris flow activity was amongst other things suggested by a conspicuous density of debris flow systems and events in argillitic bedrock. Extensive colluvium, pointing to high local weathering rates, in combination with steep topography appeared to form the ideal setting for debris flow formation in the relevant study area. Regression of debris flow activity against lithology types confirmed a high susceptibility of argillitic geology to debris flow formation with debris flow events being most likely during the investigation period in Argillite, followed by Greenschist, Greywacke, Sandstone and lastly Greyschist. However, differentiating merely between lithology classes in the regression analyses did not result in the correct prediction of debris flow events. This supports the common assumption that lithology alone is not a key factor in debris flow formation. Yet, lithology type is known to be a factor in bedrock-weathering efficacy and consequently regolith production by frost action in high alpine areas. However, linking lithology and frost-weathering intensity in regression analyses did not reveal any statistically significant relationships. An attempt to improve the available geologic information by including neotectonic uplift rates as a proxy for rock fracturing, an important criterion in the weathering susceptibility of bedrock, was unsuccessful. In sum, none of the investigated lithologies could be identified as particularly susceptible to frost weathering. 


\section{6| CONCLUSIONS}

This study investigated the influence of permafrost and intensive frost weathering on debris flow activity in New Zealand's Southern Alps. The motivation for this research was to contribute to the knowledge of predisposing factors of debris flow activity in periglacial areas. It was argued in the introduction that a better understanding of debris flow controls in high mountain areas is needed for the identification of signs of debris flow response to changing climatic conditions, a topical issue given contemporary and anticipated effects of global warming at high altitudes. This thesis contributes towards a better understanding of debris flow preconditioning factors by providing empirical evidence in support of the promoting effect of intense frost weathering on debris flow formation. It further demonstrates the potential and limitations of a regional debris flow inventory for identifying periglacial and nonperiglacial controls on debris flow initiation. The main findings of this study are summarised in Section 6.1 by addressing the three research questions outlined in Section 1.2. Section 6.2 discusses methodological aspects of the analyses by reviewing the datasets used in this study. Implications of the study's findings are outlined in Section 6.3, followed by recommendations for further research in Section 6.4. The chapter concludes with a final remark in Section 6.5.

\subsection{MAIN FINDINGS}

Three central research questions, outlined in Section 1.2, guided this research. The main findings of this study can be summarised by addressing these questions:

\section{1) Are debris flow systems within the permafrost zone more active than those at} lower altitudes?

The potential permafrost extent in the Southern Alps was modelled based on topoclimatic conditions derived at active rock glacier sites in the Canterbury Region. Model results suggest that conditions are favourable for permafrost occurrence above $\sim 2000 \mathrm{~m}$ a.s.I. in the central Southern Alps and above $\sim 2150$ m a.s.l. in the Kaikoura Ranges. 
This research found no indication that the presence of permafrost within sediment reservoirs in debris flow initiation areas or within the regolith-supplying rockwalls above the debris flow initiation areas promotes debris flow formation. Slide-initiated or slide-related debris flow systems occurred in the study areas without exception well below the modelled permafrost zone, suggesting that active-layer instabilities might be rare in the Southern Alps. Runoff-generated debris flow systems originating in potential permafrost areas were neither more frequent nor showed higher activity than systems at lower altitudes. Statistical results on the promoting effect of permafrost within bedrock on frost-weathering efficiency and, consequently, regolith supply for debris flow formation were inconclusive.

\section{2) Are debris flow systems subjected to intense frost-weathering regimes more active than those at lower altitudes?}

Regression of debris flow activity in supply-dependent debris flow systems against spatial variations in modelled frost-weathering intensities in the regolith contributing areas suggested a promoting effect of frost action on debris flow formation. The likelihood for a debris flow event occurring during the investigation period increased with the degree of frost weathering experienced in the contribution area. The statistical relationship was strongest in the Mt Aspiring region where almost a quarter of the active debris flow systems were correctly classified based on the level of frost weathering in the contribution area. Furthermore, in the Mt Aspiring region, debris flow events were more likely to occur at similar frost-weathering levels in sun-avert than sun-facing locations. This observation supports the general assumption that bedrock fracturing by segregation ice growth is more effective in sun-avert locations. Variations in lithologies' susceptibility to frost weathering (thought to be the main pathway of a lithological influence on debris flow activity in supplylimited systems) were not demonstrated in this study.

\section{3) Which non-periglacial preconditioning factors influence debris flow activity in} the Southern Alps?

The spatial distribution of debris flow systems and events in the study areas appeared strongly linked to the topographic configuration of catchments and the availability of readily mobilised sediment. Debris flows generally developed at locations where slope gradients exceeded $20^{\circ}$, with common slope ranges varying between debris flow types. The frequent occurrence of slide-initiated debris flow systems on north-facing slopes was also primarily attributed to a topographic control. Sun-facing slopes are generally the gentler slopes in the markedly asymmetric east-west facing valleys of the Southern Alps, providing the topographic and climatic conditions for slide-susceptible soils to develop. Debris flows initiated by shallow landsliding were therefore preferentially found on the north-facing slopes. 
Quaternary deposits, such as landslide deposits, moraines, and undercut relict taluses, were favoured locations for debris flow formation in the study areas. The abundant sediment availability at these locations promoted the formation of debris flows as well as frequent reactivation of debris flow systems. A strong link to sediment availability is also suspected in the conspicuous density of debris flow systems and events in argillitic bedrock. Particularly weak local geology presumably led to the formation of extensive taluses in the respective steep glacially formed valley with material being easily mobilised during strong rainfall events. Regression of debris flow activity in supply-limited systems also indicated a high likelihood of debris flow formation in argillite. However, lithological information could not explain overall spatial variations in debris flow activity. Consequently, lithology alone is not thought to be an influential factor for debris flow formation.

\subsection{Methodological ASPECTS OF THE INVESTIGATION OF DEBRIS FLOW PRECONDITIONING FACTORS}

This section focuses on methodological considerations underlying the statistical analyses conducted in this research. As statistical models are often only as good as the data they are based on, this section critically reviews the informative value of the available datasets describing environmental conditions in the study areas as well as of the established debris flow inventory. The section further evaluates the value of the statistical methods frequency ratios and logistic regression in the analysis of predisposing controls.

\section{Informative value of the datasets describing predisposing factors}

A principal challenge in the statistical analysis of debris flow preconditioning factors is the discrepancy in spatial scale between the local-scale factors affecting debris flow formation and the generally regional-scale datasets describing these factors (cf. Section 1.1). Field observations of slope gradients in debris flow initiation areas, sediment availability, or geotechnical properties of the parent rock may be available for selected sites (e.g. Blijenberg, 1998). However, such level of detail is presently not achievable for a statistically representative regional-scale debris flow inventory. Analyses of large debris flow inventories, therefore, have to rely on generalised representations or approximations of environmental variables and thus on cross-scale inference of cause-effect relationships. The transformation of point observations into continuous gridded datasets (e.g. DEM, MAAT), the computation of derivatives from elevation raster (e.g. slope, aspect), or the aggregation of data to common domains (rock groups) inevitably affects the informative value of explanatory variables at a given location. Such generalisations and estimations may weaken 
or disguise relationships between investigated processes and environmental controls (e.g. Goodchild, 2011; Rougier and Beven, 2013).

In the present study, the evaluation of debris flow preconditioning factors was exclusively based on remotely-sensed imagery (mapping of debris flow systems, debris flow events, and rock glaciers), regional-scale thematic datasets (temperature interpolations, geologic maps), and freely available terrain data (contour-derived $15 \mathrm{~m}$ and $25 \mathrm{~m}$ DEMs). No additional localscale information was collected for selected debris flow systems and calculated parameters were not validated at debris flow sites. The available information was found sufficient to identify meaningful patterns in the spatial distribution of debris flow systems (cf. Section 5.2.1-5.2.6). Frequency ratios highlighted certain spatial settings, such as slope classes or abundant sediment reservoirs, which appeared particularly susceptible to debris flow formation and allowed qualitative statements on whether a factor or factor class promoted debris flow activity. The available datasets were, however, only of limited value for investigating potential environmental controls on debris flow activity in supply-limited debris flow systems, which are strongly related to the reaccumulation of regolith at the debris flow initiation zones (cf. Section 5.2.7).

The coarse resolution of the available terrain datasets represented a significant methodological limitation for the sediment recharge analyses. Contour-derived fifteen metre grid cells, the finest resolution currently available among New Zealand-wide DEMs, were found too coarse to adequately resolve the slope characteristics of dissected rockwalls or hillslopes for the computer-assisted delineation of a sufficiently large number of debris flow contribution areas. In consequence, only a comparatively small number of debris flow systems were available for the regression analyses. This likely reduced the explanatory power of several of the regression models, particularly in cases where the sample population was further split for investigating the influence of categorical parameters such as rock types. Recalculation of the contribution areas based on a high-resolution (e.g. $1 \mathrm{~m}$ ) LiDAR (Light Detection and Ranging) dataset is likely to significantly increase the number of analysis units. The more detailed representation of hillslope topography in LiDAR datasets is expected to improve the output of the automated delineation of debris flow contribution areas by increasing the number of delineated features as well as requiring less manual postprocessing (cf. Section 3.2.3). LiDAR data is currently not available for the study areas, but, given the current trends in land surveying in New Zealand, will probably be obtainable in the foreseeable future. Improved terrain information would also allow better constraining of critical slope values for the different debris flow mechanisms (cf. Section 5.2.1), information particularly valuable for hazard assessments and susceptibility mapping (e.g. Van Westen et al., 2008; Petschko et al., 2014).

The statistically significant relationship between debris flow activity and frost-weathering intensities in the contribution areas suggests that spatially-distributed frost-weathering 
intensity estimates, computed by simple model approaches utilising DEM data and temperature records, can be utilised for evaluating the effect of frost-weathering on debris flow activity. However, given the conceptual simplicity of existing models (cf. Section 5.2.7, Question II), a more sophisticated model would likely improve the currently weak and inconsistent statistical relationship of what is expected to be one of the strongest controls on debris flow activity in high-alpine areas (cf. Section 3.1.2 or Section 5.2.7, Question II). This study's finding that, subjected to comparable frost action, sun-avert debris flow systems were more likely to produce a debris flow event during the investigation period than sunfacing systems, implies that already the inclusion of aspect in the frost-weathering estimates may provide a significant improvement in the informative value of frost-weathering intensity datasets for debris flow analyses. Ideally, a sophisticated spatially-distributed frostweathering intensity model would be physically-based, parameterising the relevant controls on segregation ice growth in bedrock, such as rock temperature, water availability, and geotechnical properties of bedrock (see recommendations in Section 6.3). Such model would also allow variations in lithologies' susceptibility to frost weathering to be incorporated into debris flow activity analyses. The high-level information on bedrock characteristics in the study areas published in New Zealand's QMAP series did not permit addressing the potential, most likely frost-related, geologic control on debris flow activity in the analysed debris flow systems. An attempt to supplement the available geologic information by including information on neo-tectonic uplift rates as a proxy for the degree of rock fracturing was ineffective.

The permafrost distribution model developed as part of this study provided a catchmentscale estimate of the potential extent of contemporary permafrost in the study areas. The derived information has to be considered only a rough appraisal of the likely permafrost occurrences in the study areas, since local conditions, such as scree size (significantly influencing the distribution of permafrost on the hillslope scale), were not considered in the predictive model. However, the spatially-distributed information on the potential permafrost extent did allow a first-order comparison of debris flow densities within and outside the modelled permafrost extent. Results of this comparison suggested the absence of a relationship between the presence of permafrost at debris flow initiation zones and debris flow occurrence.

The developed permafrost distribution model was inferred from topoclimatic conditions at active rock glacier sites and, thus, results are strictly speaking only valid for evaluating permafrost occurrence in debris slopes. The inconclusive statistical results relating bedrock permafrost to sediment reaccumulation in supply-limited debris flow systems may therefore be linked to an unwarranted use of the model for predicting permafrost presence within debris-supplying rockwalls. Information derived from dedicated empirical bedrock permafrost models, such as developed by Allen et al. (2009) for steep rock slopes close to the Southern Alps' Main Divide, may be more appropriate for investigating a potential predisposing 
influence. An extension of Allen et al.'s (2009) study to a regional-scale model could be combined with this thesis' distribution model to an improved debris-bedrock permafrost model, similar to the approach recently presented by Boeckli et al. (2012) for the European Alps. Alternatively, sophisticated frost-weathering models based on rock temperature evolution through time could provide the necessary spatial information on the distribution of permanently frozen rock slopes.

\section{Informative value of the debris flow inventory}

A further challenge to statistical analyses of debris flow preconditioning factors is the temporal representativeness of the debris flow event dataset. This study's debris flow inventory, documenting debris flow occurrences during the past five to six decades (depending on the study site), has to be considered only a snapshot of debris flow activity in the study areas (cf. Section 3.4.1). The surprisingly low number of active debris flow systems (14\% of mapped systems), the low count (18) of multiple event systems, and calculated minimum average recurrence intervals of 16 to 21 years, suggest that the average return period for many of the investigated debris flow systems is longer than debris flow reactivations being captured during the investigation period. It is, therefore, unknown how well the established debris flow event dataset represents the spatial variability of debris flow activity in the study areas. Similarly, it is unknown whether the debris flow systems that showed activity during the investigation period actually represent debris flow systems particularly susceptible to debris flow formation, which was the main assumption for the sediment recharge regression models. Established patterns and trends may be valid in the present dataset, but might not hold in a longer-term inventory. Furthermore, this study focused exclusively on factors preconditioning debris flow activity. The spatial and temporal distribution of rainfall trigger events, which certainly influenced the observed debris flow event distributions, was omitted from considerations owing to the current challenges in spatially-distributed rainfall modelling (cf. Section 1.1). For similar reasons, episodes of potentially heightened regolith production in supply-limited systems due to seismicallyinduced rockfalls (cf. Section 3.1.2) were not considered. A more holistic approach would be able to segregate the role of hydrological and - if applicable - seismic triggers in the observed spatial and temporal distribution of debris flow events.

The temporal limitation of the debris flow event dataset raises the question of whether the available information is adequate for characterising debris flow activity in the study areas and for inferring preconditioning controls for debris flow initiation. It may be argued that the debris flow event dataset is incomplete as it fails to capture common debris flow recurrence intervals, which would allow an unambiguous differentiation of particularly active from less active debris flow systems. Including hydro-meteorological information into the statistical analysis of environmental controls might be seen essential in order to isolate the role of 
preconditioning factors from triggering events. Furthermore, this study assumes stationarity in influencing factors over time. While this assumption is reasonable for factors relating to topography and geology, it might not be valid for climate-related factors, such as regolith production by frost action or the temporal frequency of rainfall triggers. Research by Salinger et al. (1993) and Salinger and Mullan (1999) indicate that mean surface temperatures in New Zealand's South Island as well as rainfall at the South Island's West Coast significantly increased since the 1940s. Observed changes are most likely due to a combination of both shifts in Pacific atmospheric circulation (cf. Section 2.3) and human-induced warming (Mullan et al., 2001; Dean and Stott, 2009). Such climatic changes may obstruct or even prevent the characterisation of baseline debris flow activity in the study areas, where common debris flow return periods seem to exceed the time scale of significant changes in climatic conditions. The value of the debris flow inventory as a baseline for future climate change impact studies, as hypothesised in the introduction, is therefore questionable. Yet, the limitations of the established debris flow event dataset should be considered in the context of what is currently achievable. Aerial photograph series represent presently the only source of information for regional debris flow inventories due to their spatially detailed timelapse documentation of the land surface over large areas. Event records may be extended into the pre-aerial survey times by absolute and relative dating of debris flow scars or deposits at selected sites (e.g. radiocarbon dating, lichenometry, schmidt hammer exposureage dating, cosmogenic nuclides dating, or optically stimulated luminescence (OSL) dating; see Lang et al., 1999, Goudie, 2006, or Schneuwly-Bollschweiler et al., 2013, for details on the individual methods). However, large populations of debris flow systems, necessary for statistical evaluation of preconditioning factors, are hardly realisable when using direct dating methods for debris flow event identification (cf. Matthews et al. (2009), example for radiocarbon dating of debris flow deposits). Dendrochronology, increasingly applied in the European Alps to establish long-term debris flow datasets on an annual to seasonal scale (e.g. Schneuwly-Bollschweiler and Stoffel, 2012), is not applicable for reconstructing activity at the present study's investigation sites due to the general absence of trees at the areas of interest. Furthermore, the magnitude of events in geomorphologically simple debris flow systems, such as analysed in the present study, would likely be too small to cause datable damages on surrounding trees. New generations of high-resolution satellites (e.g. WorldView, GeoEye, Quickbird), providing annual imagery even for remote parts such as the Southern Alps, will improve debris flow event mapping in future. The extension of this study's debris flow event inventory based on future satellite imagery would increase the dataset's representativeness and likely provide more information on common debris flow recurrence intervals in the study areas. A longer-term event dataset, however, would be to a higher degree affected by uncertainty arising from variability and long-term changes in influencing factors over time. The increase in informative value of a 'more complete' dataset with respect to debris flow recurrence intervals might therefore be counteracted by a 
decrease in the representativeness of datasets describing environmental influences through time. Including information on changes in temperature and rainfall patterns would be pivotal for the statistical evaluation of such longer-term debris flow event inventories.

\section{Choice of statistical methods}

Frequency ratio and logistic regression were chosen for the statistical evaluation of debris flow preconditioning factors based on their common use in geosciences for the investigation of spatial patterns of environmental phenomena (e.g. Jomelli et al., 2003; Brenning and Trombotto, 2006; Lee and Pradhan, 2007; Erener and Düzgün, 2010; Simon, 2012). Frequency ratios proved a simple but valuable measure that related debris flow system counts to the spatial extent of the investigated factors. They provided an extension to the initial description of the debris flow inventory by frequency distributions (Section 3.3.1-3.3.3) by setting numeric trends into the context of the environmental characteristics of the study areas. Frequency ratios highlighted situations that appeared favourable for debris flow formation and thus facilitated a qualitative evaluation of debris flow preconditioning factors. The utility of logistic regression for the analysis of predisposing debris flow controls, on the other hand, has yet to be further tested. Many of the inconclusive regression models in this study were thought primarily due to inadequately small sample populations. However, logistic regression models assume a linear relationship between events and predictor variables which might not be adequate for some relationships. The use of generalised additive models (GAM; Hastie and Tibshirani, 1990), a semi-parametric nonlinear extension to general linear models recently adopted in geomorphological distribution modelling (e.g. Brenning, 2009; Goetz et al., 2011; Petschko et al., 2014), might achieve stronger statistical parameter relationships. Generalised additive models might, therefore, be better suited for the investigation of predisposing debris flow controls. 


\section{$6.3 \mid$ IMPLICATIONS OF FINDINGS}

This study provided empirical evidence for the role of periglacial and non-periglacial predisposing factors in debris flow formation. Results emphasise the importance of considering basic and variable susceptibility of debris flow systems in activity analyses, particularly in studies that attribute observed spatial trends in debris flow activity to global warming. However, this research also highlighted that our current understanding of debris flow preconditioning factors is rudimentary and inadequate for any meaningful implementation in climate change impact studies. So far, regional-scale data on debris flow activity and potential environmental controls allow mainly qualitative statements on whether certain environmental factors influence debris flow formation. Yet, more quantitative information on relationships is needed to advance knowledge. Quantitative measures would facilitate the relative ranking of predisposing controls and thus identification of the most critical factors, values, or parameter combinations. Such information could be utilised in regional-scale hazard assessments, designs of hazard control measures, and climate change impact scenarios.

One of the challenges in quantifying the role of predisposing factors in debris flow initiation is the necessary use of regional-scale datasets for inferring local-scale influences. The success of this cross-scale inference heavily relies on the informative value of regionalscale datasets. Several of the present study's statistical analyses were likely negatively impacted by lack in detail or accuracy of the spatial data. For some parameters, information might be significantly improved by the collection of additional or more detailed data. New technologies, such as LiDAR or Unmanned Aerial Vehicles (UAVs or 'drones'), have the potential for delivering high-resolution geometric or visual information on topography and sediment availability for a large number of debris flow systems. Such developments could help to overcome logistic challenges in collecting site-specific data for large debris flow inventories. Other limitations, such as uncertainties in frost-weathering intensities and local permafrost presence, signify current gaps in knowledge and skills. The improvement of the frost-weathering intensity and permafrost distribution datasets therefore require the development of new spatially-distributed models (see recommendations below). This study's findings suggest that in order to improve our current knowledge on debris flow predisposing controls it is necessary to take a step back and focus research efforts on the spatial parameterisation of the individual influencing factors. New or improved base information can be utilised in future exploratory studies similar to the present research and remaining limitations reassessed in an ongoing, systematic, and sustained manner. The low number of published studies systematically investigating debris flow preconditioning factors suggests that related objectives might often be perceived as unpromising, especially in view of the still unresolved challenges in spatially-distributed modelling of hydrological trigger events. 
However, increasing research efforts trying to evaluate debris flow systems' response to climate change should ideally be matched by equal efforts to advance our knowledge of the system itself.

A surprising finding of this research was that return periods in runoff-generated supplylimited systems, the most numerous type of debris flow systems in the Southern Alps, are likely longer than reactivations being captured during the investigated period of five to six decades. This was unexpected given that the Southern Alps, with their steep topography, frequent extreme rainfall events, and high denudation rates, were thought to provide the ideal environment for debris flows. Debris flow recurrence intervals of several decades raise the question of whether New Zealand's Southern Alps are a suitable geographic location for further research into debris flow preconditioning factors in high-alpine areas. Based on this study's findings, debris flow event catalogues for Southern Alps sites derived from aerial photographs likely offer a temporally incomplete snapshot of debris flow activity. Consequently, the inventories provide only partial information on the spatial distribution of debris flow events. Misinterpretations of spatial variations in debris flow activity might decrease the statistical significance of analyses and complicate the identification of predisposing controls. Extending debris flow inventories into the past by dating deposits or into the future by forthcoming satellite imagery might allow characterising spatial variations in debris flow activity by spatial trends in recurrence intervals. However, debris flow activity documented in longer-term inventories is more likely to be affected by variability in trigger events caused by longer-term climate oscillations (e.g. Interdecadal Pacific Oscillation) and gradual global-warming related changes, such as shifts in intense frost action or permafrost degradation. Therefore, isolating predisposing controls from climatic and climate-related signals, a currently unresolved challenge, would be essential for the meaningful analysis of these longer-term debris flow inventories. In view of the temporal limitations of Southern Alps' debris flow inventories, other mountainous areas might be better suited for future studies on debris flow predisposing factors. Debris flow recurrence intervals of only a few years have been reported in the European Alps (e.g. Van Asch and Van Steijn, 1991; Van Steijn, 1996; Blijenberg, 1998; Jomelli et al., 2004). Such short return periods might require only a few decades of aerial photographs for identifying especially active debris flow systems. Furthermore, better temporal resolution of imagery and a denser network of highaltitude climate stations in the European Alps may aid the isolation of hydro-meteorological influences in observed spatial patterns. However, also in European settings, challenges related to the spatial parameterisation of potential environmental controls have yet to be overcome. 


\subsection{RECOMMENDATIONS FOR FUTURE RESEARCH}

This study identified several research needs, and recommended new or alternative approaches throughout the text. In the following, two topics are highlighted where future research has the potential to contribute to the field of periglacial geomorphology. The first recommendation aims at advancing our knowledge of regolith production by frost action in high-alpine debris flow systems; the second focuses on the potential of BTS (bottom temperature of the winter snow cover) for furthering our knowledge on permafrost distribution in New Zealand's Southern Alps.

Development of a sophisticated spatially-distributed frost-weathering intensity model. Currently available frost-weathering intensity models (Section 5.2.7, Question II) are based on outdated assumptions (e.g. number of freeze-thaw cycles) or oversimplify relevant controls on frost-related bedrock weathering (e.g. predicting segregation ice growth solely based on MAAT). New generations of frost-weathering intensity models, ideally processoriented, implementing information on rock temperatures, water availability, and bedrock's geotechnical properties through time, are needed for more accurately predicting spatial variations in frost action. Long-term monitoring of rock temperatures (e.g. Gruber et al., 2003; Allen et al., 2009) and related bedrock cracking levels inferred from acoustic emissions (e.g. Amitrano et al., 2012; Girard et al., 2013), could contribute valuable field data for the development of a more advanced frost-cracking intensity model. The extension of monitoring efforts into different lithologies may allow the assessment of differences in lithologies' susceptibility to frost weathering. Seismic refraction surveys, a novel approach for assessing bedrock fracture density at hillslope scale (e.g. Clarke and Burbank, 2011), may offer the necessary quantitative measure of effective rock mass strength for a meaningful implementation of lithology in frost-weathering intensity models. Assuming that frost action is the dominant control on near-surface bedrock failure in alpine environments, improved frost-weathering models should provide better approximations of spatial variations in regolith production. The use of such datasets is therefore expected to result in stronger explanatory links between frost-weathering intensity and debris flow activity. Furthermore, new generation physically-based models will provide better frost-action estimates under warming conditions for climate change impact assessments.

Validating BTS thresholds in the Southern Alps and developing New Zealandspecific BTS application guidelines. This research provided the first evidence that the bottom temperature of the winter snow cover (BTS) can potentially be used for permafrost prospecting in the maritime Southern Alps (Section 4.3.4). However, the validity of the commonly used BTS interpretation thresholds (BTS rule-of-thumb, Hoelzle, 1992), derived in the European Alps, has yet to be verified in New Zealand. Resurveying the Irishman Stream BTS sites by electrical resistivity tomography (ERT), using improved talus-suited ground 
coupling devices, such as pot electrodes, wet sponges in steel nets, or electrodes placed into scree blocks, is encouraged. Information on the actual presence or absence of permafrost at these sites would allow the critical evaluation of the European thresholds. Such information would not only be of value for permafrost research in New Zealand but also worldwide as the BTS rule-of-thumb has not been systematically evaluated outside the European Alps. Furthermore, corrective measures for significant interannual variation in BTS temperatures as well as guidelines for critical snow heights for BTS probing will have to be established before areally extensive BTS campaigns by thermistor probes will be viable in the Southern Alps. Long-term (five to ten years) monitoring of ground surface temperatures (GST) by miniature data loggers would provide information on the likely magnitude of yearto-year variations in BTS temperatures. Derived average deviations from the long-term mean could subsequently be used for correcting BTS campaign values according to whether complementary continuous GST records indicated a particularly 'warm' or 'cold' BTS year (cf. Brenning et al., 2005). Correcting for interannual variability will be essential for a reliable application of BTS in the Southern Alps. End-of-winter equilibrium temperatures in the Irishman Stream suggested that permafrost temperatures may be comparatively warm. The thermal signal of permafrost presence measurable at the ground-snowpack interface, may, therefore, be weak and easily overshadowed by the influence of an early or late snowpack evolution on winter ground temperatures. Measures to correct for interannual variability in BTS temperatures are likely site-specific and their assessment should therefore be repeated for any new application region. Critical snow heights for BTS probing, in contrast, are probably more universal. The installation of poles above long-term monitoring sites, equipped with light or temperature sensors in decimetre intervals, would facilitate the concurrent recording of GST and snow depth evolution through time. Relations between end-of-winter snow height and BTS-interpretable temperature profiles may allow the inference of a critical snow height for BTS probing in New Zealand settings.

The reliable application of BTS for permafrost mapping in the Southern Alps would represent a cost- and time-efficient technique to collect field information on likely permafrost presence and absence on a local scale. Such data would represent a valuable addition to the limited number of rock glaciers currently available for the development of a Southern Alps-wide empirical-statistical permafrost distribution model. However, given the comprehensive prerequisite investigations required to facilitate a South Island-wide application of BTS, the future feasibility of an extensive BTS dataset for large-scale permafrost distribution modelling seems unlikely. Yet, advancing the BTS method for selected climatically reasonably consistent regions, such as the central Ben Ohau Range or northern Two Thumb Range, would facilitate the development of empirical hillslope-scale permafrost distribution models for these areas. BTS measurements by probing or continuous GST monitoring have the potential to provide large datasets for the development of such models, which is likely to benefit the statistical evaluation of topoclimatic controls. 
Additionally, the local scale of BTS information would allow the effect of surface conditions to be incorporated in statistical analyses. Given that scree sizes can be roughly mapped from remotely sensed imagery, this information could be incorporated in predictive distribution models. Resulting probability maps may be able to reliably resolve differences in permafrost likelihood between upper and lower slope areas and would therefore be better suited for investigating the possible influence of permafrost presence on debris flow initiation. Lastly, BTS campaigns could provide further information on the likely lower limits of contemporary permafrost in the Southern Alps. Such field-based information would be valuable for further investigating the potentially lowering effect of maritime climate on permafrost distribution limits.

\subsection{CONCLUDING REMARKS}

This thesis has met its primary aim of providing empirical evidence that periglacial conditions promote debris flow formation in high alpine areas. Statistical results indicate higher activity in debris flow systems where regolith production in the debris-supplying contribution areas is likely enhanced by intense frost weathering. However, no indication was found in this study that permafrost within the debris flow initiation areas or within the rockwalls above positively affect debris flow development. Other non-periglacial factors found to promote debris flow formation were local topography and the presence of Quaternary sediment reservoirs.

This study's findings show the importance of identifying predisposing environmental controls in debris flow studies, especially when investigating potential implications of climate change in alpine areas. However, our current understanding of debris flow preconditioning is rudimentary and inadequate to make predictions. Two major challenges in the quantification of predisposing controls have been identified: the establishment of representative debris flow datasets and adequate spatially-distributed parameterisation of predisposing controls. Improving environmental parameter datasets will likely strengthen the statistical relationship of suspected influences on debris flow formation and, subsequently, will aid the quantification of relationships for applied research fields, such as climate change impact studies. 


\section{REFERENCES}

Abram NJ, Mulvaney R, Vimeux F, Phipps SJ, Turner J, and England MH. 2014. Evolution of the Southern Annular Mode during the past millennium. Nature Climate Change, 4(7): 564-569. DOI: 10.1038/nclimate2235.

Abramov A, Gruber S, and Gilichinsky D. 2008. Mountain permafrost on active volcanoes: Field data and statistical mapping, Klyuchevskaya volcano group, Kamachatka, Russia. Permafrost and Periglacial Processes, 19(3): 261-277. DOI: $10.1002 /$ ppp.622.

Ackert JRP. 1998. A rock glacier/debris-covered glacier system at Galena Creek, Absaroka Mountains, Wyoming. Geografiska Annaler: Series A, Physical Geography, 80(3-4): 267-276. DOI: 10.1111/j.0435-3676.1998.00042.x.

Ahnert F. 1998. Introduction to geomorphology, Arnold, London, 352 p.

Allen S, Owens I, and Huggel C. 2008. A First Estimate of Mountain Permafrost Distribution in the Mount Cook Region of New Zealand's Southern Alps. In Proceedings of the Ninth International Conference on Permafrost. Vol. 1. Kane DL and Hinkel KM (eds), Institute of Northern Engineering, University of Alaska, Fairbanks, pp. 37-42.

Allen SK, Gruber S, and Owens IF. 2009. Exploring Steep Bedrock Permafrost and its Relationship with Recent Slope Failures in the Southern Alps of New Zealand. Permafrost and Periglacial Processes, 20(4): 345-356. DOI: 10.1002/ppp.658.

Amitrano D, Gruber S, and Girard L. 2012. Evidence of frost-cracking inferred from acoustic emissions in a high-alpine rock-wall. Earth and Planetary Science Letters, 341-344: 86-93. DOI: 10.1016/j.epsl.2012.06.014.

Anderson B, Lawson W, Owens I, and Goodsell B. 2006. Past and future mass balance of 'Ka Roimata o Hine Hukatere' Franz Josef Glacier, New Zealand. Journal of Glaciology, 52 (179): 597-607. DOI: 10.3189/172756506781828449.

Anderson RS. 1998. Near-surface thermal profiles in alpine bedrock: Implications for the frost weathering of rock. Arctic and Alpine Research, 30(4): 362-372. DOI: $10.2307 / 1552008$.

Anderson RS, Anderson SP, and Tucker GE. 2013. Rock damage and regolith transport by frost: an example of climate modulation of the geomorphology of the critical zone. Earth Surface Processes and Landforms, 38(3): 299-316. DOI: 10.1002/esp.3330.

André M-F. 2003. Do periglacial landscapes evolve under periglacial conditions? Geomorphology, 52(1-2): 149-164. DOI: 10.1016/s0169-555x(02)00255-6.

Aoyama M. 2005. Rock glaciers in the northern Japanese Alps: palaeoenvironmental implications since the Late Glacial. Journal of Quaternary Science, 20(5): 471-484. DOI: $10.1002 / j q s .935$.

Arblaster JM and Meehl GA. 2006. Contributions of External Forcings to Southern Annular Mode Trends. Journal of Climate, 19(12): 2896-2905. 
Atkinson PM, German SE, Sear DA, and Clark MJ. 2003. Exploring the relations between riverbank erosion and geomorphological controls using geographically weighted logistic regression. Geographical Analysis, 35(1): 58-82.

DOI: 10.1353/geo.2002.0028.

Augustinus P. 1992. The influence of rock mass strength on glacial valley cross-profile morphometry: A case study from the Southern Alps, New Zealand. Earth Surface Processes and Landforms, 17(1): 39-51. DOI: 10.1002/esp.3290170104.

Augustinus P. 1995. Rock mass strength and the stability of some glacial valley slopes. Zeitschrift für Geomorphologie, 39(1): 55-68.

Augustinus P. 2002. Periglacial research in New Zealand: a review. South African Journal of Science, 98(1-2): 64-70.

Bacon SN, Chinn TJ, Van Dissen RJ, Tillinghast SF, Goldstein HL, and Burke RM. 2001. Paleo-equilibrium line altitude estimates from late Quaternary glacial features in the Inland Kaikoura Range, South Island, New Zealand. New Zealand Journal of Geology and Geophysics, 44(1): 55-67. DOI: 10.1080/00288306.2001.9514922.

Ballantyne CK. 1978. The Hydrologic Significance of Nivation Features in Permafrost Areas. Geografiska Annaler: Series A, Physical Geography, 60(1/2): 51-54.

Ballantyne CK. 1986. Landslides and slope failures in Scotland: a review. Scottish Geographical Magazine, 102(3): 134-150. DOI: 10.1080/00369228618736667.

Ballantyne CK and Kirkbride MP. 1986. The characteristics and significance of some lateglacial protalus ramparts in upland Britain. Earth Surface Processes and Landforms, 11: 659-671. DOI: 10.1002/esp.3290110609.

Bardou E. 2011. Influence of the connectivity with permafrost on the debris-flow triggering in high-alpine environment. Italian Journal of Engineering and Geology, 11(3): 13-21. DOI: 10.4408/IJEGE.2011-03.B-002.

Barrell DJA, Cox Sc, and Greene S. 2009. Otago Alluvial Fans Project: Supplementary maps and information on fans in selected areas of Otago. GNS Science Consultancy Report 2009/052, Lower Hutt, New Zealand.

Barrell DJA, Andersen BG, and Denton GH. 2011. Glacial geomorphology of the central South Island, New Zealand. GNS Science Monograph, Nr. 27, GNS Science, Lower Hutt, 81 p. + map (5 sheets) + legend (1 sheet)

Barringer JRF, Pairman D, and McNeill SJ. 2002. Development of a high-resolution digital elevation model for New Zealand. Landcare Research Contract Report LC0102/170, prepared for Foundation for Research, Science \& Technology, $33 \mathrm{p}$.

Barsch D. 1978. Rock glaciers as indicators of discontinuous Alpine permafrost. An example from Swiss Alps. In Proceedings of the Third International Conference on Permafrost, National Research Council of Canada, Ottowa, pp. 349 - 352.

Barsch D. 1988. Rockglaciers. In Advances in Periglacial Geomorphology. Clark MJ (ed), Wiley, Chichester, pp. 69-90.

Barsch D. 1996. Rockglaciers - Indicators for the Present and Former Geoecology in High Mountain Environments, Springer-Verlag, Berlin, $319 \mathrm{p}$.

Beavan J, Denys P, Denham M, Hager B, Herring T, and Molnar P. 2010. Distribution of present-day vertical deformation across the Southern Alps, New Zealand, from 10 years of GPS data. Geophysical Research Letters, 37(L16305). DOI: $10.1029 / 2010 \mathrm{gl044165.}$

Beniston M. 2003. Climatic change in mountain regions: A review of possible impacts. Climatic Change, 59(1-2): 5-31. DOI: 10.1023/a:1024458411589.

Berryman KR, Cochran UA, Clark KJ, Biasi GP, Langridge RM, and Villamor P. 2012. Major Earthquakes Occur Regularly on an Isolated Plate Boundary Fault. Science, 336(6089): 1690-1693. DOI: 10.1126/science.1218959. 
Berthling I. 2011. Beyond confusion: Rock glaciers as cryo-conditioned landforms. Geomorphology, 131(3-4): 98-106. DOI: 10.1016/j.geomorph.2011.05.002.

Berthling I and Etzelmüller B. 2011. The concept of cryo-conditioning in landscape evolution. Quaternary Research, 75(2): 378-384. DOI: 10.1016/j.yqres.2010.12.011.

Berti M, Genevois R, Simoni A, and Tecca PR. 1999. Field observations of a debris flow event in the Dolomites. Geomorphology, 29(3-4): 265-274. DOI: 10.1016/s0169$555 \times(99) 00018-5$.

Beschta RL. 1983. Channel changes following storm-induced hillslope erosion in the upper Kowai Basin, Torlesse Range, New Zealand. Journal of Hydrology, New Zealand, 22(2): 93-111.

Beylich AA and Sandberg O. 2005. Geomorphic Effects of the Extreme Rainfall Event of 20-21 July, 2004 in the Latnjavagge Catchment, Northern Swedish Lapland. Geografiska Annaler: Series A, Physical Geography, 87(3): 409-419. DOI: 10.1111/j.0435-3676.2005.00267.x.

Birkeland PW. 1982. Subdivision of Holocene glacial deposits, Ben-Ohau-Range, New Zealand, using relative-dating methods. Geological Society of America Bulletin, 93(5): 433-449. DOI: 10.1130/0016-7606(1982)93<433:SOHGDB>2.0.CO;2

Birnie RV and Thom G. 1982. Preliminary observations on two rock glaciers in South Georgia, Falkland Islands Dependencies. Journal of Glaciology, 28(99): 377-386.

Blair T and McPherson J. 2009. Processes and Forms of Alluvial Fans. In Geomorphology of Desert Environments. Parsons A and Abrahams A (eds), Springer Science+Business Media B.V., pp. 413-467. DOI: 10.1007/978-1-4020-5719-9_14

Blandford TR, Humes KS, Harshburger BJ, Moore BC, Walden VP, and Ye H. 2008. Seasonal and synoptic variations in near-surface air temperature lapse rates in a mountainous basin. Journal of Applied Meteorology and Climatology, 47(1): 249-261. DOI: 10.1175/2007jamc1565.1.

Blijenberg H. 1998. Rolling Stones? Triggering and frequency of hillslope debris flows in the Bachelard Valley, southern French Alps. Nederlandse Geografische Studies, Nr. 246, Faculteit Ruimtelijke Wetenschappen Universiteit Utrecht, 223 p.

Bockheim J and Tarnocai C. 1998. Nature, occurrence and origin of dry permafrost. In Proceedings of the Seventh International Conference on Permafrost. 55, Centre d'Etudes Nordiques, Universite Laval, Quebec, Yellowknife, Canada, pp. 57-63.

Boeckli L, Brenning A, Gruber S, and Noetzli J. 2012a. Permafrost distribution in the European Alps: calculation and evaluation of an index map and summary statistics. The Cryosphere, 6(4): 807-820. DOI: 10.5194/tc-6-807-2012.

Boeckli L, Brenning A, Gruber S, and Noetzli J. 2012b. A statistical approach to modelling permafrost distribution in the European Alps or similar mountain ranges. The Cryosphere, 6(1): 125-140. DOI: 10.5194/tc-6-125-2012.

Bollschweiler M and Stoffel M. 2010. Tree rings and debris flows: Recent developments, future directions. Progress in Physical Geography, 34(5): 625-645. DOI: $10.1177 / 0309133310370283$.

Bommer C, Fitze P, and Schneider H. 2012. Thaw-Consolidation Effects on the Stability of Alpine Talus Slopes in Permafrost. Permafrost and Periglacial Processes, 23(4): 267-276. DOI: 10.1002/ppp.1751.

Bonnaventure PP, Lewkowicz AG, Kremer M, and Sawada MC. 2012. A permafrost probability model for the southern Yukon and northern British Columbia, Canada. Permafrost and Periglacial Processes, 23(1): 52-68. DOI: 10.1002/Ppp.1733.

Bovis MJ. 1993. Hillslope geomorphology and geotechnique. Progress in Physical Geography, 17(2): 173-189. DOI: 10.1177/030913339301700205. 
Bovis MJ and Jakob M. 1999. The role of debris supply conditions in predicting debris flow activity. Earth Surface Processes and Landforms, 24(11): 1039-1054. DOI: 10.1002/(SICI)1096-9837(199910)24:11<1039::AID-ESP29>3.0.CO;2-U.

Bowman E and Davies T. 2008. The recognition and identification of debris flow hazards for proposed development sites in New Zealand. In Proceedings of the 18th NZGS Geotechnical Symposium on Soil-Structure Interaction. Chin C (ed), Auckland, 6 p.

Brayshaw D and Hassan MA. 2009. Debris flow initiation and sediment recharge in gullies. Geomorphology, 109(3-4): 122-131. DOI: 10.1016/j.geomorph.2009.02.021.

Brazier V, Kirkbride MP, and Owens IF. 1998. The relationship between climate and rock glacier distribution in the Ben Ohau Range, New Zealand. Geografiska Annaler: Series A, Physical Geography, 80A(3-4): 193-207. DOI: 10.1111/j.0435-3676.1998.00037.x.

Brenning A. 2005a. Geomorphological, hydrological and climatic significance of rock glaciers in the Andes of Central Chile (33-35 $\left.{ }^{\circ} \mathrm{S}\right)$. Permafrost and Periglacial Processes, 16(3): 231-240. DOI: 10.1002/ppp.528.

Brenning A. 2005b. Climatic and geomorphological controls of rock glaciers in the Andes of Central Chile: Combining statistical modelling and field mapping. Unpublished PhD thesis, Humboldt-Universitat zu Berlin, Germany, $153 \mathrm{p}$.

Brenning A. 2009. Benchmarking classifiers to optimally integrate terrain analysis and multispectral remote sensing in automatic rock glacier detection. Remote Sensing of Environment, 113(1): 239-247. DOI: 10.1016/j.rse.2008.09.005.

Brenning A and Trombotto D. 2006. Logistic regression modeling of rock glacier and glacier distribution: Topographic and climatic controls in the semi-arid Andes. Geomorphology, 81(1-2): 141-154. DOI: 10.1016/j.geomorph.2006.04.003.

Brenning A and Azocar GF. 2010. Statistical Analysis of Topographic and Climatic Controls and Multispectral Signatures of Rock Glaciers in the Dry Andes, Chile (27 degrees33 degrees S). Permafrost and Periglacial Processes, 21(1): 54-66. DOI: 10.1002/ppp.670.

Brenning A, Gruber S, and Hoelzle M. 2005. Sampling and statistical analyses of BTS measurements. Permafrost and Periglacial Processes, 16(4): 383-393. DOI: $10.1002 / p p p .541$.

Brook MS, Kirkbride MP, and Brock BW. 2008. Temporal constraints on glacial valley crossprofile evolution: Two Thumb Range, central Southern Alps, New Zealand. Geomorphology, 97(1-2): 24-34. DOI: 10.1016/j.geomorph.2007.02.036.

Brunsden D. 1979. Mass movements. In Process in Geomorphology. Embleton C and Thornes J (eds), Arnold, London, pp. 131-186.

Brunsdon C, Fotheringham AS, and Charlton ME. 1996. Geographically Weighted Regression: A Method for Exploring Spatial Nonstationarity. Geographical Analysis, 28(4): 281-298. DOI: 10.1111/j.1538-4632.1996.tb00936.x.

Brunsdon C, Fotheringham S, and Charlton M. 1998. Geographically Weighted RegressionModelling Spatial Non-Stationarity. Journal of the Royal Statistical Society Series $D$ The Statistician, 47(3): 431-443. DOI: 10.1111/1467-9884.00145.

Burga CA, Frauenfelder R, Ruffet J, Hoelzle M, and Kääb A. 2004. Vegetation on Alpine rock glacier surfaces: a contribution to abundance and dynamics on extreme plant habitats. Flora, 199(6): 505-515. DOI: 10.1078/0367-2530-00179.

Burrows CJ. 1980. Radiocarbon dates for post-Otiran glacial activity in the Mount Cook region, New Zealand. New Zealand Journal of Geology and Geophysics, 23(2): 239-248. DOI: 10.1080/00288306.1980.10424209. 
Caine N. 1980. The rainfall intensity-duration control of shallow landslides and debris flows Geografiska Annaler: Series A, Physical Geography, 62(1-2): 23-27. DOI: $10.2307 / 520449$.

Cannone N and Gerdol R. 2003. Vegetation as an ecological indicator of surface instability in rock glaciers. Arctic, Antarctic, and Alpine Research, 35(3): 384-390. DOI: 10.1657/1523-0430(2003)035[0384:Vaaeio]2.0.Co;2.

Carrara A, Crosta G, and Frattini P. 2008. Comparing models of debris-flow susceptibility in the alpine environment. Geomorphology, 94(3-4): 353-378. DOI: 10.1016/j.geomorph.2006.10.033.

Carrivick J, Manville V, and Cronin S. 2009. A fluid dynamics approach to modelling the 18th March 2007 lahar at Mt. Ruapehu, New Zealand. Bulletin of Volcanology, 71(2): 153-169. DOI: 10.1007/s00445-008-0213-2.

Carson MA and Kirby M. 1972. Hillslope Form and Process, Cambridge University Press, Cambridge, pp. 475.

Charlton M, Fotheringham S, and Brunsdon C. 2003. GWR 3 - Software for Geographically Weighted Regression, Manual, Spatial Analysis Research Group, Department of Geography, University of Newcastle upon Tyne, 21 p.

Chater AM and Sturman AP. 1998. Atmospheric conditions influencing the spillover of rainfall to lee of the Southern Alps, New Zealand. International Journal of Climatology, 18(1): 77-92.

DOI: 10.1002/(sici)1097-0088(199801)18:1<77::aid-joc218>3.0.co;2-m.

Chen J-C. 2011. Variability of impact of earthquake on debris-flow triggering conditions: case study of Chen-Yu-Lan watershed, Taiwan. Environmental Earth Sciences, 64(7): 1787-1794. DOI: 10.1007/s12665-011-0981-4.

Cheng G. 1983. Vertical and horizontal zonation of high-altitude permafrost. In Proceedings of the Fourth International Conference on Permafrost, National Academy Press, Fairbanks, Alaska, pp. 139 - 144.

Cheng $G$ and Dramis F. 1992. Distribution of mountain permafrost and climate. Permafrost and Periglacial Processes, 3(2): 83-91. DOI: 10.1002/ppp.3430030205.

Chiarle M, lannotti S, Mortara G, and Deline P. 2007. Recent debris flow occurrences associated with glaciers in the Alps. Global and Planetary Change, 56(1-2): 123-136. DOI: 10.1016/j.gloplacha.2006.07.003.

Chinn T. 1988. Glaciers and the glacier inventory. New Zealand Alpine Journal, 41: 92-97.

Chinn T. 1995. Glacier Fluctuations in the Southern Alps of New Zealand Determined from Snowline Elevations. Arctic and A/pine Research, 27(2): 187-198.

DOI: $10.2307 / 1551901$.

Chinn T. 2001. Distribution of the glacial water resources of New Zealand. Journal of Hydrology, New Zealand, 40(2): 139-187.

Chinn T, Fitzharris BB, Willsman A, and Salinger MJ. 2012. Annual ice volume changes 1976-2008 for the New Zealand Southern Alps. Global and Planetary Change, 92-93(0): 105-118. DOI: 10.1016/j.gloplacha.2012.04.002.

Cho SH, Lambert DM, and Chen Z. 2010. Geographically weighted regression bandwidth selection and spatial autocorrelation: an empirical example using Chinese agriculture data. Applied Economics Letters, 17(8): 767-772.

DOI: $10.1080 / 13504850802314452$.

Christensen JH, Hewitson B, Busuioc A, Chen A, Gao X, Held I, Jones R, Kolli RK, Kwon WT, Laprise R, Magaña Rueda V, Mearns L, Menéndez CG, Räisänen J, Rinke A, Sarr A, and Whetton P. 2007. Regional Climate Projections. In Climate Change 2007: The Physical Science Basis. Contribution of Working Group I to the Fourth Assessment Report of the Intergovernmental Panel on Climate Change. Solomon S, 
Qin D, Manning M, Chen Z, Marquis M, Averyt KB, Tignor M, and Miller HL (eds), Cambridge University Press, Cambridge, pp. 235-336.

Clarke BA and Burbank DW. 2010. Bedrock fracturing, threshold hillslopes, and limits to the magnitude of bedrock landslides. Earth and Planetary Science Letters, 297(3-4): 577-586. DOI: 10.1016/j.epsl.2010.07.011.

Clarke BA and Burbank DW. 2011. Quantifying bedrock-fracture patterns within the shallow subsurface: Implications for rock mass strength, bedrock landslides, and erodibility. Journal of Geophysical Research, 116: F04009. DOI: 10.1029/2011JF001987.

Clow D, Schrott L, Webb R, Campbell D, Torizzo A, and Dornblaser M. 2003. Ground water occurrence and contributions to streamflow in an alpine catchment, Colorado Front Range. Ground Water, 41(7): 937-950. DOI: 10.1111/j.1745-6584.2003.tb02436.x.

Coates G. 2002. The Rise and Fall of the Southern Alps, Canterbury University Press, Christchurch, $80 \mathrm{p}$.

Columbus J, Sirguey P, and Tenzer R. 2011a. 15m DEM for New Zealand. www.koordinates.com (last accessed: 05/01/2014).

Columbus J, Sirguey P, and Tenzer R. 2011b. A free, fully assessed 15-m DEM for New Zealand. Survey Quarterly(66): 16-19.

Corominas J, Remondo J, Farias P, Estevao M, Zézere J, Díaz deTerán J, Dikau R, Schrott L, Moya J, and González A. 1996. Debris Flow. In Landslide Recognition. Dikau R, Brunsden D, Schrott L, and Ibsen M-L (eds), John Wiley \& Sons, Chichester, pp. 161-181.

Costa JE. 1984. Physical geomorphology of debris flows. In Developments an Applications of Geomorphology. Costa JE and Fleisher PJ (eds), Springer-Verlag, Berlin, pp. 268 - 317.

Courvoisier DS, Combescure C, Agoritsas T, Gayet-Ageron A, and Perneger TV. 2011. Performance of logistic regression modeling: beyond the number of events per variable, the role of data structure. Journal of Clinical Epidemiology, 64(9): 993-1000. DOI: 10.1016/j.jclinepi.2010.11.012.

Coussot P and Meunier M. 1996. Recognition, classification and mechanical description of debris flows. Earth-Science Reviews, 40(3-4): 209-227. DOI: 10.1016/0012-8252(95)00065-8.

Coutard J-P and Francou B. 1989. Rock Temperature Measurements in Two Alpine Environments: Implications for Frost Shattering. Arctic and Alpine Research, 21(4): 399-416.

Cowan HA and McGlone MS. 1991. Late Holocene displacements and characteristic earthquakes on the Hope River segment of the Hope Fault, New Zealand. Journal of the Royal Society of New Zealand, 21(4): 373-384.

DOI: $10.1080 / 03036758.1991 .10420834$.

Cox SC and Barrell DJA. 2007. Geology of the Aoraki area, 1: 250 000. Geological Map 15, GNS Science, Lower Hutt, 1 sheet $+71 \mathrm{p}$.

Craw D. 1984. Lithologic variations in Otago Schist, Mt Aspiring area, northwest Otago, New Zealand. New Zealand Journal of Geology and Geophysics, 27(2): 151-166. DOI: 10.1080/00288306.1984.10422524.

Cronin SJ, Hodgson KA, Neall VE, Palmer AS, and Lecointre JA. 1997. 1995 Ruapehu lahars in relation to the late Holocene lahars of Whangaehu River, New Zealand. New Zealand Journal of Geology and Geophysics, 40(4): 507-520. DOI: 10.1080/00288306.1997.9514780.

Crozier MJ. 1997. The climate-landslide couple: a Southern Hemisphere perspective. Paläoklimaforschung Paleoclimate Research, 19: 333-354. 
Crozier MJ. 1999. Prediction of rainfall-triggered landslides: a test of the Antecedent Water Status Model. Earth Surface Processes and Landforms, 24(9): 825-833. DOI: 10.1002/(sici)1096-9837(199908)24:9<825::aid-esp14>3.0.co;2-m.

Crozier MJ. 2010. Deciphering the effect of climate change on landslide activity: A review. Geomorphology, 124(3-4): 260-267. DOI: 10.1016/j.geomorph.2010.04.009.

Crozier MJ and Preston NJ. 1999. Modelling changes in terrain resistance as a component of landform evolution in unstable hill country. In Process Modelling and Landform Evolution. Lecture Notes in Earth Sciences. Hergarten S and Neugebauer H (eds), Springer Berlin Heidelberg, pp. 267-284. DOI: 10.1007/BFb0009730.

Crozier MJ, Gage M, Pettinga J, M. S, and Wasson R. 1992. The stability of hillslopes. In Landforms of New Zealand. Soons JM and Selby MJ (eds), Longman Paul, Auckland, pp. 63-90.

Cruden DM and Varnes DJ. 1996. Landslide types and processes. In Landslides Investigation and Mitigation, Special Report 247. Turner AK and Schuster RL (eds), Transportation Research Board, US National Research Council, Washington, DC, pp. 36-75.

Currey DR. 1964. A Preliminary Study of Valley Asymmetry in the Ogotoruk Creek Area, Northwestern Alaska. Arctic, 17(2): 84-98.

Dash J, Fu H, and Wettlaufer J. 1995. The premelting of ice and its environmental consequences. Reports on Progress in Physics, 58(1): 115. DOI: $10.1088 / 0034-4885 / 58 / 1 / 003$.

Davies T and McSaveney M. 2008. Principles of sustainable development on fans. Journal of Hydrology, New Zealand, 47(1): 43 - 65.

De Scally FA and Owens IF. 2004. Morphometric controls and geomorphic responses on fans in the Southern Alps, New Zealand. Earth Surface Processes and Landforms, 29(3): 311-322. DOI: 10.1002/esp.1022.

De Scally FA, Owens IF, and Louis J. 2010. Controls on fan depositional processes in the schist ranges of the Southern Alps, New Zealand, and implications for debris-flow hazard assessment. Geomorphology, 122(1-2): 99-116. DOI: 10.1016/j.geomorph.2010.06.002.

Dean SM and Stott PA. 2009. The Effect of Local Circulation Variability on the Detection and Attribution of New Zealand Temperature Trends. Journal of Climate, 22(23): 6217-6229. DOI: 10.1175/2009JCLI2715.1.

Decaulne A, SÆEmundsson P, and Petursson O. 2005. Debris Flow Triggered by Rapid Snowmelt: A Case Study in the Gleidarhjalli Area, Northwestern Iceland. Geografiska Annaler: Series A, Physical Geography, 87(4): 487-500. DOI: 10.1111/j.0435-3676.2005.00273.x.

Del Longo M, Finzi E, Galgaro A, Godio A, Luchetta A, Pellegrini GB, and Zambiano R. 2001. Responses of the Val d'Arcia small Dolomitic Glacier (Mount Pelmo, Eastern Alps) to Recent Climatic Changes. Geomorphological and Geophysical Study. Geografia Fisica e Dinamica Quaternaria, 24: 43-55.

Delaloye R and Lambiel C. 2005. Evidence of winter ascending air circulation throughout talus slopes and rock glaciers situated in the lower belt of alpine discontinuous permafrost (Swiss Alps). Norsk Geografisk Tidsskrift, 59(2): 194-203. DOI: 10.1080/00291950510020673.

Delaloye R, Perruchoud E, Avian M, Kaufmann V, Bodin X, Hausmann H, Ikeda A, Kääb A, Kellerer-Pirklbauer A, and Krainer K. 2008. Recent interannual variations of rock glacier creep in the European Alps. In Proceedings of the 9th International Conference on Permafrost, Institute of Northern Engineering, University of Alaska, Fairbanks, pp. 343-348. 
Delunel R, van der Beek PA, Carcaillet J, Bourlès DL, and Valla PG. 2010. Frost-cracking control on catchment denudation rates: Insights from in situ produced $10 \mathrm{Be}$ concentrations in stream sediments (Ecrins-Pelvoux massif, French Western Alps). Earth and Planetary Science Letters, 293(1-2): 72-83.

DOI: 10.1016/j.epsl.2010.02.020.

Dennis A. 2012. Mountains - South Island mountains. Te Ara - the Encyclopedia of New Zealand. www.teara.govt.nz/en/mountains/page-1 (last accessed: 31/05/2013).

DiBiase RA, Heimsath AM, and Whipple KX. 2012. Hillslope response to tectonic forcing in threshold landscapes. Earth Surface Processes and Landforms, 37(8): 855-865. DOI: 10.1002/esp.3205.

Doughty AM. 2013. Inferring past climate from moraine evidence using glacier modelling. Unpublished PhD thesis, Victoria University of Wellington, New Zealand, $217 \mathrm{p}$.

Erener A and Düzgün H. 2010. Improvement of statistical landslide susceptibility mapping by using spatial and global regression methods in the case of More and Romsdal (Norway). Landslides, 7(1): 55-68. DOI: 10.1007/s10346-009-0188-x.

ESRI. 2009a. ArcGIS Desktop 9.3 Help. www.webhelp.esri.com/arcgisdesktop/9.3 (last accessed: 06/01/2013).

ESRI. 2009b. ArcGIS 9.3.1 for Desktop, Environmental Systems Research Institute, Redlands, CA.

Etzelmüller B. 2013. Recent Advances in Mountain Permafrost Research. Permafrost and Periglacial Processes, 24(2): 99-107. DOI: 10.1002/ppp.1772.

Etzelmüller B and Frauenfelder R. 2009. Factors Controlling the Distribution of Mountain Permafrost in the Northern Hemisphere and Their Influence on Sediment Transfer. Arctic, Antarctic and Alpine Research, 41(1): 48-58.

DOI: 10.1657/1938-4246(08-026)[etzelmueller]2.0.co;2.

Etzelmüller B, Berthling I, and Sollid JL. 1998. The distribution of permafrost in Southern Norway; a GIS approach. In Proceedings of the Seventh International Conference on Permafrost, Centre d'Etudes Nordiques, Universite Laval, Quebec, Yellowknife, Canada, pp. 251-257.

Etzelmüller B, Odegard RS, Berthling I, and Sollid JL. 2001a. Terrain parameters and remote sensing data in the analysis of permafrost distribution and periglacial processes: Principles and examples from southern Norway. Permafrost and Periglacial Processes, 12(1): 79-92. DOI: 10.1002/ppp384.

Etzelmüller B, Hoelzle M, Heggem ESF, Isaksen K, Mittaz C, Vonder Mühll D, Odegard RS, Haeberli W, and Sollid JL. 2001b. Mapping and modelling the occurrence and distribution of mountain permafrost. Norsk Geografisk Tidsskrift, 55(4): 186-194. DOI: $10.1080 / 00291950152746513$.

Etzelmüller B, Berthling I, and Sollid JL. 2003. Aspects and concepts on the geomorphological significance of Holocene permafrost in southern Norway. Geomorphology, 52(1-2): 87-104. DOI: 10.1016/S0169-555X(02)00250-7.

Etzelmüller B, Heggem ESF, Sharkhuu N, Frauenfelder R, Kääb A, and Goulden C. 2006. Mountain permafrost distribution modelling using a multi-criteria approach in the Hovsgol area, northern Mongolia. Permafrost and Periglacial Processes, 17(2): 91-104. DOI: 10.1002/ppp.554.

Etzelmüller B, Farbrot H, Gudmundsson A, Humlum O, Tveito OE, and Björnsson H. 2007. The regional distribution of mountain permafrost in Iceland. Permafrost and Periglacial Processes, 18(2): 185-199. DOI: 10.1002/ppp.583.

Eyles N. 1978. Rock glaciers in Esjufjöll Nunatak area, south-east Iceland. Joekull, 28: $53-60$. 
Fahey BD and Lefebure TH. 1988. The freeze-thaw weathering regime at a section of the Niagara escarpment on the Bruce Peninsula, Southern Ontario, Canada. Earth Surface Processes and Landforms, 13(4): 293-304. DOI: 10.1002/esp.3290130403.

Falaschi D, Castro M, Masiokas M, Tadono T, and Ahumada AL. 2014. Rock Glacier Inventory of the Valles Calchaquíes Region ( $\left.25^{\circ} S\right)$, Salta, Argentina, Derived from ALOS Data. Permafrost and Periglacial Processes, 25(1): 69-75. DOI: $10.1002 / p p p .1801$.

Felderer A. 2008. Erhebung und Abschätzung von geomorphologischen Gefahrenpotentialen durch Gletscherrückgang und Permafrostdegradation im Naturpark Rieserferner-Ahrn. Unveröffentlichte Diplomarbeit, Universität Wien, Austria, 148 p. (in German).

Field AP. 2005. Discovering statistics using SPSS (and sex, drugs and rock'n'roll), Sage Publications, London, $779 \mathrm{p}$.

Fielding $\mathrm{AH}$ and Bell JF. 1997. A review of methods for the assessment of prediction errors in conservation presence/absence models. Environmental Conservation, 24(1): 38-49. DOI: $10.1017 / \mathrm{s} 0376892997000088$.

Fitzsimons JJ and Veit H. 2001. Geology and geomorphology of the European Alps and the Southern Alps of New Zealand - A comparison. Mountain Research and Development, 21(4): 340-349.

Fotheringham S, Charlton M, and Brunsdon C. 2002. Geographically Weighted Regression: The Analysis of Spatially Varying Relationships, John Wiley \& Sons Ltd., Chichester, $282 \mathrm{p}$.

Frauenfelder R. 2004. Regional-scale Modelling of the Occurrence and Dynamics of Rockglaciers and the Distribution of Paleopermafrost. Unpublished PhD thesis, University of Zuerich, Switzerland, $137 \mathrm{p}$.

Frauenfelder R and Kääb A. 2000. Towards a palaeoclimatic model of rock-glacier formation in the Swiss Alps. Annals of Glaciology, 31(1): 281-286. DOI: $10.3189 / 172756400781820264$.

Frauenfelder R, Haeberli W, and Hoelzle M. 2003. Rockglacier occurrence and related terrain parameters in a study area of the Eastern Swiss Alps. In Proceedings of the Eight International Conference on Permafrost. Phillips M, Springman SM, and Arenson LU (eds), Swets and Zeitlinger, pp. 253-258.

Frauenfelder R, Laustela M, and Kääb A. 2005. Relative age dating of Alpine rockglacier surfaces. Zeitschrift für Geomorphologie, 49(2): 145-166.

French H. 2007. The periglacial environment, John Wiley \& Sons Ltd., Chichester, 458 p.

French $\mathrm{H}$ and Thorn CE. 2006. The changing nature of periglacial geomorphology. Géomorphologie: relief, processus, environnement, 3/2006: 165-174. DOI: $10.4000 /$ geomorphologie. 119 .

Fu P and Rich PM. 2000. The Solar Analyst 1.0 Manual. Helios Environmental Modeling Institute (HEMI). http://citeseerx.ist.psu.edu/viewdoc/download; jsessionid 063D78F145F3244277FE555E1BBF4AC9?doi=10.1.1.98.1271\&rep=rep1\&type=pdf (last accessed: 18/02/14).

García-Ruiz JM, Arnáez J, Gómez-Villar A, Ortigosa L, and Lana-Renault N. 2013. Firerelated debris flows in the Iberian Range, Spain. Geomorphology, 196(0): 221-230. DOI: 10.1016/j.geomorph.2012.03.032.

Gellatly AF, Chinn TJH, and Röthlisberger F. 1988. Holocene glacier variations in New Zealand: A review. Quaternary Science Reviews, 7(2): 227-242.

DOI: 10.1016/0277-3791(88)90008-X. 
GF Instruments. n.d. ARES - Automatic resistivity system. http://www.gfinstruments.cz/index.php?menu=gi\&cont=ares_ov (last accessed: 20/03/2014).

Girard L, Gruber S, Weber S, and Beutel J. 2013. Environmental controls of frost cracking revealed through in situ acoustic emission measurements in steep bedrock. Geophysical Research Letters, 40(9): 1748-1753. DOI: 10.1002/Grl.50384.

Gisnås K, Etzelmüller B, Farbrot H, Schuler TV, and Westermann S. 2013. CryoGRID 1.0: Permafrost Distribution in Norway estimated by a Spatial Numerical Model. Permafrost and Periglacial Processes, 24(1): 2-19. DOI: 10.1002/ppp.1765.

Glade T. 1997. The temporal and spatial occurrence of rainstorm-triggered landslide events in New Zealand - An investigation into the frequency, magnitude and characteristics of landslide events and their relationship with climatic and terrain characteristics. Unpublished PhD thesis, Victoria University of Wellington, New Zealand, $392 \mathrm{p}$.

Glade T. 2000. Modeling landslide-triggering rainfalls in different regions in New Zealand: The soil water status model. Zeitschrift für Geomorphologie, 122: 63-84.

Glade T. 2003. Landslide occurrence as a response to land use change: a review of evidence from New Zealand. Catena, 51(3-4): 297-314. DOI: 10.1016/s0341-8162(02)00170-4.

Glade T. 2005. Linking debris-flow hazard assessments with geomorphology. Geomorphology, 66(1-4): 189-213. DOI: 10.1016/j.geomorph.2004.09.023.

GNS. 2004. New Zealand Active Fault Database. http://data.gns.cri.nz/af/index.jsp (last accessed: 09/02/2013).

Godt JW and Coe JA. 2007. Alpine debris flows triggered by a 28 July 1999 thunderstorm in the central Front Range, Colorado. Geomorphology, 84(1-2): 80-97. DOI: 10.1016/j.geomorph.2006.07.009.

Goetz JN, Guthrie RH, and Brenning A. 2011. Integrating physical and empirical landslide susceptibility models using generalized additive models. Geomorphology, 129(3-4): 376-386. DOI: 10.1016/j.geomorph.2011.03.001.

Goodchild MF. 2011. Scale in GIS: An overview. Geomorphology, 130(1-2): 5-9. DOI: 10.1016/j.geomorph.2010.10.004.

Goodrich DC, Faurès J-M, Woolhiser DA, Lane LJ, and Sorooshian S. 1995. Measurement and analysis of small-scale convective storm rainfall variability. Journal of Hydrology, 173(1): 283-308.

Goodwin C and Tarboton D. 2003. Morphometric properties. In Encyclopedia of Geomorphology. Goudie A and Panizza M (eds), Routledge, London, pp. 696-698.

Gorbunov A. 1978. Permafrost investigations in high-mountain regions. Arctic and Alpine Research, 10(2): 283-294. DOI: 10.2307/1550761.

Gorbunov A. 1988. The alpine permafrost zone of the USSR. In Proceedings of the Fifth International Conference on Permafrost. 1. Senneset K (ed), Tapir Publishers, Trondheim, Trondheim, Norway, pp. 154-158.

Gordon RA. 2012. Applied Statistics for the Social and Health Sciences, Routledge, New York, $1016 \mathrm{p}$.

Goudie AS. 2006. The Schmidt Hammer in geomorphological research. Progress in Physical Geography, 30(6): 703-718. DOI: 10.1177/0309133306071954.

Greenwood J, Norris J, and Wint J. 2004. Assessing the contribution of vegetation to slope stability. Proceedings of the Institution of Civil Engineers-Geotechnical Engineering, 157(4): 199-207. 
Griffiths GA. 1981. Some suspended sediment yields from South Island catchments, New Zealand. JAWRA Journal of the American Water Resources Association, 17(4): 662-671. DOI: 10.1111/j.1752-1688.1981.tb01274.x.

Griffiths GM and McSaveney MJ. 1983. Distribution of mean annual precipitation across some steepland regions of New Zealand New Zealand Journal of Science, 26: $197-209$

Griffiths PG, Webb RH, and Melis TS. 2004. Frequency and initiation of debris flows in Grand Canyon, Arizona. Journal of Geophysical Research, 109(F04002). DOI: 10.1029/2003jf000077.

Gruber S. 2005. Mountain Permafrost: Transient Spatial Modelling, Model Verification and the Use of Remote Sensing. Unpublished PhD thesis, Universität Zürich, Switzerland, $121 \mathrm{p}$.

Gruber S. 2012. Derivation and analysis of a high-resolution estimate of global permafrost zonation. The Cryosphere, 6: 221-233. DOI: 10.5194/tc-6-221-2012.

Gruber S and Hoelzle M. 2001. Statistical modelling of mountain permafrost distribution: Local calibration and incorporation of remotely sensed data. Permafrost and Periglacial Processes, 12(1): 69-77. DOI: 10.1002/ppp374.

Gruber S and Haeberli W. 2007. Permafrost in steep bedrock slopes and its temperaturerelated destabilization following climate change. Journal of Geophysical Research, 112(F02S18). DOI: 10.1029/2006jf000547.

Gruber S and Haeberli W. 2009. Mountain Permafrost. In Permafrost Soils. Soil Biology 16, Springer-Verlag, Berlin-Heidelberg, pp. 33-44. DOI: 10.1007/978-3-540-69371-0

Gruber S and Peckham S. 2009. Land-Surface Parameters and Objects in Hydrology. In Developments in Soil Science. Tomislav H and Hannes IR (eds), Elsevier, pp. 171-194. DOI: 10.1016/s0166-2481(08)00007-x.

Gruber S, Peter M, Hoelzle M, Woodhatch I, and Haeberli W. 2003. Surface temperatures in steep alpine rock faces - A strategy for regional-scale measurement and modelling. In Proceedings of the Eight International Conference on Permafrost. Phillips M, Springman SM, and Arenson LU (eds), A.A. Balkeman, pp. 325-330.

Gruber S, Hoelzle M, and Haeberli W. 2004. Rock-wall temperatures in the Alps: modelling their topographic distribution and regional differences. Permafrost and Periglacial Processes, 15(3): 299-307. DOI: 10.1002/Ppp.501.

Guzzetti F, Peruccacci S, Rossi M, and Stark CP. 2007. Rainfall thresholds for the initiation of landslides in central and southern Europe. Meteorology and Atmospheric Physics, 98(3): 239-267. DOI: 10.1007/s00703-007-0262-7.

Guzzetti F, Peruccacci S, Rossi M, and Stark C. 2008. The rainfall intensity-duration control of shallow landslides and debris flows: an update. Landslides, 5(1): 3-17. DOI: 10.1007/s10346-007-0112-1.

Haeberli W. 1973. Die Basis-Temperatur der winterlichen Schneedecke als möglicher Indikator für die Verbreitung von Permafrost in den Alpen. Zeitschrift für Gletscherkunde und Glaziologie, 9(1-2): 221-227. (in German).

Haeberli W. 1975. Untersuchungen zur Verbreitung von Permafrost zwischen Flüelapass und Piz Grialetsch (Graubünden). Mitteilungen der Versuchsanstalt für Wasserbau, Hydrologie und Glaziologie, Vol. 17, Eidgenössische Technische Hochschule Zürich, Zürich, 221 p. (in German).

Haeberli W. 1978. Special aspects of high mountain permafrost methodology and zonation in the Alps. In Proceedings of the Third International Conference on Permafrost, National Research Council of Canada, Ottowa, pp. 378-384. 
Haeberli W. 1985. Creep of mountain permafrost: internal structure and flow of alpine rock glaciers. Mitteilungen der Versuchsanstalt für Wasserbau und Glaziologie, Vol. 77, ETH Zürich, 119 p.

Haeberli W. 1992. Possible effects of climate change on the evolution of Alpine Permafrost. Catena Supplement, 22: 23-35.

Haeberli W. 1996. Die "Permafrost-Fausregeln" der VAW/ETHZ - einige grundsätzliche Bemerkungen. In Simulation der Permafrostverbreitung in den Alpen mit geographischen Informationssystemen. Haeberli W, Hoelzle M, Dousse JP, Ehrler C, Gardaz JM, Imhof M, Keller F, Kunz P, Lugon R, and Reynard E (eds), vdf Hochschulverlag an der ETH, Zürich, pp. 13-18. (in German).

Haeberli W. 2000. Modern Research Perspectives Relating to Permafrost Creep and Rock Glaciers: A Discussion. Permafrost and Periglacial Processes, 11(4): 290-293. DOI: 10.1002/1099-1530(200012)11:4<290::aid-ppp372>3.0.co;2-0.

Haeberli W and Vonder Mühll D. 1996. On the characteristics and possible origins of ice in rock glacier permafrost. Zeitschrift für Geomorphologie, Suppl. Bd. 104: 43-57.

Haeberli W and Gruber S. 2009. Global Warming and Mountain Permafrost. In Permafrost Soils. Soil Biology 16, Springer Berlin Heidelberg, pp. 205-218.

DOI: 10.1007/978-3-540-69371-0.

Haeberli W, Rickenmann R, Zimmermann M, and Rosli U. 1991. Murgänge. In Ursachenanalyse der Hochwasser 1987 - Ergebnisse der Untersuchungen. Mitteilungen des Bundesamtes für Wasserwirtschaft, Bern, pp. 77-88. (in German).

Haeberli W, Harris SA, Guodong C, and Gorbunov AP. 1993. Mountain Permafrost and Climatic Change. Permafrost and Periglacial Processes, 4(2): 165-174. DOI: $10.1002 /$ ppp.3430040208.

Haeberli W, Wegmann M, and Vonder Mühll D. 1997. Slope stability problems related to glacier shrinkage and permafrost degradation in the Alps. Eclogae Geologicae Helvetiae, 90(3): 407-414.

Haeberli W, Hallet B, Arenson L, Elconin R, Humlun O, Kääb A, Kaufmann V, Ladanyi B, Matsuoka N, Springman S, and Vonder Mühll D. 2006. Permafrost creep and rock glacier dynamics. Permafrost and Periglacial Processes, 17(3): 189-214. DOI: 10.1002/ppp.561.

Haeberli W, Noetzli J, Arenson L, Delaloye R, Gärtner-Roer I, Gruber S, Isaksen K, Kneisel C, Krautblatter M, and Phillips M. 2010. Mountain permafrost: development and challenges of a young research field. Journal of Glaciology, 56(200): 1043-1058. DOI: $10.3189 / 002214311796406121$.

Hales TC and Roering JJ. 2005. Climate-controlled variations in scree production, Southern Alps, New Zealand. Geology, 33(9): 701-704. DOI: 10.1130/G21528.1.

Hales TC and Roering JJ. 2007. Climatic controls on frost cracking and implications for the evolution of bedrock landscapes. Journal of Geophysical Research, 112(F02033). DOI: 10.1029/2006jf000616.

Hales TC and Roering JJ. 2009. A frost "buzzsaw" mechanism for erosion of the eastern Southern Alps, New Zealand. Geomorphology, 107(3-4): 241-253.

DOI: 10.1016/j.geomorph.2008.12.012.

Hall K. 2006. Perceptions of rock weathering in cold regions : a discussion on space and time attributes of scale. Géomorphologie : relief, processus, environnement, 3: 187-196. DOI: 10.4000/geomorphologie.146.

Hall K and Thorn C. 2011. The historical legacy of spatial scales in freeze-thaw weathering: Misrepresentation and resulting misdirection. Geomorphology, 130(1-2): 83-90.

DOI: 10.1016/j.geomorph.2010.10.003. 
Hall K, Lindgren BS, and Jackson P. 2005. Rock albedo and monitoring of thermal conditions in respect of weathering: some expected and some unexpected results. Earth Surface Processes and Landforms, 30(7): 801-811. DOI: 10.1002/esp.1189.

Hallet B, Walder JS, and Stubbs CW. 1991. Weathering by segregation ice growth in microcracks at sustained sub-zero temperatures: verification from an experimental study using acoustic emissions. Permafrost and Periglacial Processes, 2(4): 283-300. DOI: 10.1002/ppp.3430020404.

Hancox GT, Perrin ND, and Dellow GD. 1997. Earthquake-induced landsliding in New Zealand and implications for MM intensity and seismic hazard assessment. GNS Science Consultancy Report 43601B, Lower Hutt, New Zealand.

Hancox GT, Cox S, Turnbull I, and Crozier M. 2003. Reconnaissance studies of landslides and other ground damage caused by the Mw7. 2 Fiordland earthquake of 22 August 2003. GNS Science Report 2003/30, Lower Hutt, New Zealand.

Hancox GT, Dellow GD, McSaveney M, Scott MB, and Villamor P. 2004. Reconnaissance studies of landslides caused by the $M_{L} 5.4$ Lake Rotoehu earthquake and swarm of July 2004. GNS Science Report 2004/4, Lower Hutt, New Zealand.

Hanson S and Hoelzle M. 2004. The thermal regime of the active layer at the Murtèl rock glacier based on data from 2002. Permafrost and Periglacial Processes, 15(3): 273-282. DOI: 10.1002/ppp.499.

Harrell FE. 2001. Regression modeling strategies: with applications to linear models, logistic regression, and survival analysis. Springer Series in Statistics, Springer, New York, $568 \mathrm{p}$.

Harris C. 2005. Climate Change, Mountain Permafrost Degradation and Geotechnical Hazard. In Global Change and Mountain Regions. Advances in Global Change Research. Huber UM, Bugmann HKM, and Reasoner MA (eds), Springer Netherlands, pp. 215-224.

Harris C, Arenson LU, Christiansen HH, Etzemüller B, Frauenfelder R, Gruber S, Haeberli W, Hauck C, Hoelzle M, Humlum O, Isaksen K, Kääb A, Kern-Lütschg MA, Lehning M, Matsuoka N, Murton JB, Nozli J, Phillips M, Ross N, Seppälä M, Springman SM, and Mühll DV. 2009. Permafrost and climate in Europe: Monitoring and modelling thermal, geomorphological and geotechnical responses. EarthScience Reviews, 92(3-4): 117-171. DOI: 10.1016/j.earscirev.2008.12.002.

Harris SA and Pedersen DE. 1998. Thermal regimes beneath coarse blocky materials. Permafrost and Periglacial Processes, 9(2): 107-120.

DOI: 10.1002/(sici)1099-1530(199804/06)9:2<107::aid-ppp277>3.0.co;2-g.

Hastie TJ and Tibshirani RJ. 1990. Generalized Additive Models. Monograph on Statistics and Applied Probability, Vol. 43, CRC Press, Boca Raton, 352 p.

Hauck C and Kneisel C (eds). 2008. Applied geophysics in periglacial environments. Cambridge University Press, Cambridge, 240 p.

Hauck C, Guglielmin M, Isaksen K, and Vonder Mühll D. 2001. Applicability of frequencydomain and time-domain electromagnetic methods for mountain permafrost studies. Permafrost and Periglacial Processes, 12(1): 39-52. DOI: 10.1002/Ppp383.

Hausmann H, Krainer K, Brückl E, and Mostler W. 2007. Internal structure and ice content of Reichenkar rock glacier (Stubai Alps, Austria) assessed by geophysical investigations. Permafrost and Periglacial Processes, 18(4): 351-367. DOI: $10.1002 / p p p .601$.

Hayward JA. 1980. Hydrology and stream sediment from Torlesse Stream catchment. Tussock Grasslands and Mountain Lands Insitute - Special Publication, No.17, 236p. 
Heggem E, Juliussen H, and Etzelmüller B. 2005. Mountain permafrost in Central-Eastern Norway. Norwegian Journal of Geography, 59: 94-108.

DOI: $10.1080 / 00291950510038377$.

Heggem ESE, Etzenmüller B, Anarmaa S, Sharkhuu N, Goulden CE, and Nandinsetseg B. 2006. Spatial distribution of ground surface temperatures and active layer depths in the Hovsgol area, northern Mongolia. Permafrost and Periglacial Processes, 17(4): 357-369. DOI: 10.1002/ppp.568.

Henderson R and Thompson S. 1999. Extreme rainfalls in the Southern Alps of New Zealand. Journal of Hydrology, New Zealand, 38(2): 309-330.

Herman F and Braun J. 2006. Fluvial response to horizontal shortening and glaciations: A study in the Southern Alps of New Zealand. Journal of Geophysical Research, 111(F01008). DOI: 10.1029/2004jf000248.

Hilbich C. 2010. Time-lapse refraction seismic tomography for the detection of ground ice degradation. The Cryosphere, 4(3): 243-259. DOI: 10.5194/tc-4-243-2010.

Hilbich C, Hauck C, Hoelzle M, Scherler M, Schnudel L, Völksch I, Vonder Mühll DV, and Mäusbacher R. 2008. Monitoring mountain permafrost evolution using electrical resistivity tomography: a 7-year study of seasonal, annual, and long-term variations at Schilthorn, Swiss Alps. Journal of Geophysical Research, 113(F01S90). DOI: 10.1029/2007jf000799.

Hodgson KA and Manville VR. 1999. Sedimentology and flow behavior of a rain-triggered lahar, Mangatoetoenui Stream, Ruapehu volcano, New Zealand. Geological Society of America Bulletin, 111(5): 743-754.

DOI: 10.1130/0016-7606(1999)111<0743:Safboa>2.3.Co;2.

Hoek E. 1983. Strength of jointed rock masses. Geotechnique, 3: 187-223. DOI: $10.1680 /$ geot.1983.33.3.187.

Hoelzle M. 1992. Permafrost occurrence from BTS measurements and climatic parameters in the eastern Swiss Alps. Permafrost and Periglacial Processes, 3(2): 143-147. DOI: $10.1002 / p p p .3430030212$.

Hoelzle M. 1994. Permafrost und Gletscher im Oberengadin - Grundlagen und Anwendungsbeispiele für automatisierte Schätzverfahren. Mitteilungen der Versuchsanstalt fuer Wasserbau, Hydrologie und Glaziologie, Nr. 132, ETH Zürich, $121 \mathrm{p}$.

Hoelzle M, Wegmann M, and Krummenacher B. 1999. Miniature temperature dataloggers for mapping and monitoring of permafrost in high mountain areas: First experience from the Swiss Alps. Permafrost and Periglacial Processes, 10(2): 113-124. DOI: 10.1002/(Sici)1099-1530(199904/06)10:2<113::Aid-Ppp317>3.0.Co;2-A.

Hoelzle M, Haeberli W, and Stocker-Mittaz C. 2003. Miniature ground temperature data logger measurements 2000-2002 in the Murtel-Corvatsch area, Eastern Swiss Alps. In Proceedings of the Eight International Conference on Permafrost. Phillips M, Springman SM, and Arenson LU (eds), A.A. Balkeman, pp. 419-424.

Holzer TL, Hanks TC, and Youd TL. 1989. Dynamics of Liquefaction During the 1987 Superstition Hills, California, Earthquake. Science, 244(4900): 56-59. DOI: 10.1126/science.244.4900.56.

Hosmer DW and Lemeshow S. 2000. Applied logistic regression, John Wiley \& Sons, 373 p.

Houlié N and Stern T. 2012. A comparison of GPS solutions for strain and SKS fast directions: Implications for modes of shear in the mantle of a plate boundary zone. Earth and Planetary Science Letters, 345-348: 117-125. DOI: 10.1016/j.epsl.2012.06.029.

Hovius N, Stark CP, and Allen PA. 1997. Sediment flux from a mountain belt derived by landslide mapping. Geology, 25(3): 231-234. DOI: 10.1130/0091-7613(1997)025<0231:sffamb>2.3.co;2. 
Hübl J, Kienholz H, and Loipersberger A. 2002. DOMODIS - Documentation of Mountain Disasters. Schriftenreihe 1. Handbuch 1, Internationale Forschungsgesellschaft INTERPRAEVENT, Klagenfurt, $42 \mathrm{p}$.

Hufschmidt G. 2008. The evolution of risk from landslides: concepts and applications for communities in New Zealand. Unpublished PhD thesis, Victoria University of Wellington, New Zealand, $503 \mathrm{p}$.

Huggel C, Clague JJ, and Korup O. 2012. Is climate change responsible for changing landslide activity in high mountains? Earth Surface Processes and Landforms, 37(1): 77-91. DOI: 10.1002/esp.2223.

Humlum O. 1988. Rock glacier appearance level and rock glacier initiation line altitude - a methodological approach to the study of rock glaciers Arctic and Alpine Research, 20(2): 160-178. DOI: 10.2307/1551495.

Humlum O. 1998. The climatic significance of rock glaciers. Permafrost and Periglacial Processes, 9(4): 375-395.

DOI: 10.1002/(Sici)1099-1530(199810/12)9:4<375::Aid-Ppp301>3.3.Co;2-S.

Humlum O. 2005. Holocene permafrost aggradation in Svalbard. Geological Society, London, Special Publications, 242(1): 119-129.

DOI: 10.1144/gsl.sp.2005.242.01.11.

Hungr O. 2000. Analysis of debris flow surges using the theory of uniformly progressive flow. Earth Surface Processes and Landforms, 25(5): 483-495.

DOI: 10.1002/(sici)1096-9837(200005)25:5<483::aid-esp76>3.0.co;2-z.

Hungr O. 2005. Classification and terminology. In Debris-flow Hazards and Related Phenomena. Jakob M and Hungr O (eds), Springer Verlag, Berlin-Heidelberg, pp. 9-23.

Hungr O, Evans SG, Bovis MJ, and Hutchinson JN. 2001. A review of the classification of landslides of the flow type. Environmental \& Engineering Geoscience, 7(3): 221-238.

Hungr O, McDougall S, and Bovis M. 2005. Entrainment of material by debris flows. In Debris-flow Hazards and Related Phenomena. Jakob M and Hungr O (eds), Springer Verlag, Berlin-Heidelberg, pp. 135-158.

Hutchinson JN. 1988. General Report: Morphological and geotechnical parameters of landslides in relation to geology and hydrogeology. In Proceedings of the Fifth International Symposium on Landslides. Vol. 1. Bonnard C (ed), A.A. Balkema, pp. 3-36.

Ikeda A and Matsuoka N. 2002. Degradation of talus-derived rock glaciers in the Upper Engadin, Swiss Alps. Permafrost and Periglacial Processes, 13(2): 145-161. DOI: $10.1002 / p p p .413$.

Imaizumi F, Sidle RC, and Kamei R. 2008. Effects of forest harvesting on the occurrence of landslides and debris flows in steep terrain of central Japan. Earth Surface Processes and Landforms, 33(6): 827-840. DOI: 10.1002/esp.1574.

Imhof M. 1996. Modelling and verification of the permafrost distribution in the Bernese Alps (Western Switzerland). Permafrost and Periglacial Processes, 7(3): 267-280. DOI: 10.1002/(sici)1099-1530(199609)7:3<267::aid-ppp221>3.3.co;2-c.

Imhof M, Pierrehumbert G, Haeberli W, and Kienholz H. 2000. Permafrost investigation in the Schilthorn massif, Bernese Alps, Switzerland. Permafrost and Periglacial Processes, 11(3): 189-206.

DOI: 10.1002/1099-1530(200007/09)11:3<189::Aid-Ppp348>3.0.Co;2-N.

Innes JL. 1982. Debris flow activity in the Scottish highlands. Unpublished PhD thesis, University of Cambridge, United Kingdom, 638 p.

Innes JL. 1983. Debris flows. Progress in Physical Geography, 7: 469-501. DOI: $10.1177 / 030913338300700401$. 
Isaksen K, Hauck C, Gudevang E, Ødegård RS, and Sollid JL. 2002. Mountain permafrost distribution in Dovrefjell and Jotunheimen, southern Norway, based on BTS and DC resistivity tomography data. Norsk Geografisk Tidsskrift, 56(2): 122-136.

DOI: $10.1080 / 002919502760056459$.

Ishikawa M. 2003. Thermal regimes at the snow-ground interface and their implications for permafrost investigation. Geomorphology, 52(1-2): 105-120. DOI: 10.1016/S0169-555X(02)00251-9.

Ishikawa M. 2008. ERT imaging for frozen ground detection. In Applied Geophysics in Periglacial Environments. Kneisel C and Hauck C (eds), Cambridge University Press, Cambridge, pp. 109-117.

Ishikawa M and Hirakawa K. 2000. Mountain permafrost distribution based on BTS measurements and DC resistivity soundings in the Daisetsu Mountains, Hokkaido, Japan. Permafrost and Periglacial Processes, 11(2): 109-123.

DOI: 10.1002/1099-1530(200004/06)11:2<109::Aid-Ppp343>3.0.Co;2-O.

ITT Cooperation. 2009. ENVI 4.7 software, White Plains, NY.

Iverson RM. 1997. The physics of debris flows. Reviews of Geophysics, 35(3): 245-296. DOI: $10.1029 / 97 \mathrm{rg} 00426$.

Iverson RM. 2003a. The debris-flow rheology myth. In Debris-flow hazard mitigation: Mechanics, Prediction, and Assessment. Rickenmann D and Chen C (eds), Millpress, Rotterdam, pp. 303-314.

Iverson RM. 2003b. Debris flow. In Encyclopedia of Geomorphology. Goudie A (ed), Routledge, London, pp. 225.

Iverson RM. 2005. Debris-flow mechanics. In Debris-flow Hazards and Related Phenomena. Springer Praxis Books. Jakob M and Hungr O (eds), Springer Verlag, BerlinHeidelberg, pp. 105-134. DOI: 10.1007/3-540-27129-5_6

Iverson RM, Reid ME, and LaHusen RG. 1997. Debris-flow mobilization from landslides. Annual Review of Earth and Planetary Sciences, 25: 85-138. DOI: 10.1146/annurev.earth.25.1.85.

Jafarov EE, Marchenko SS, and Romanovsky VE. 2012. Numerical modeling of permafrost dynamics in Alaska using a high spatial resolution dataset. The Cryosphere, 6(3): 613-624. DOI: 10.5194/tc-6-613-2012.

Jakob M. 2003. Weathering-limited and transport-limited. In Encyclopedia of Geomorphology. Goudie A (ed), Routledge, London, pp. 1114-1115.

Jakob $\mathrm{M}$ and Weatherly H. 2003. A hydroclimatic threshold for landslide initiation on the North Shore Mountains of Vancouver, British Columbia. Geomorphology, 54(3-4): 137-156. DOI: 10.1016/s0169-555x(02)00339-2.

Jakob M and Hungr O (eds). 2005. Debris-flow hazards and related phenomena. Springer, Berlin-Heidelberg, $781 \mathrm{p}$.

Jakob M, Bovis M, and Oden M. 2005. The significance of channel recharge rates for estimating debris-flow magnitude and frequency. Earth Surface Processes and Landforms, 30(6): 755-766. DOI: 10.1002/esp.1188.

Janke J. 2005. The occurrence of alpine permafrost in the Front Range of Colorado. Geomorphology, 67(3-4): 375-389. DOI: 10.1016/j.geomorph.2004.11.005.

Janke $\mathrm{J}$ and Frauenfelder R. 2008. The relationship between rock glacier and contributing area parameters in the Front Range of Colorado. Journal of Quaternary Science, 23(2): 153-163. DOI: 10.1002/jqs.1133.

Janke JR, Williams MW, and Evans Jr A. 2012. A comparison of permafrost prediction models along a section of Trail Ridge Road, Rocky Mountain National Park, Colorado, USA. Geomorphology, 138(1): 111-120.

DOI: 10.1016/j.geomorph.2011.08.029. 
Janke JR, Regmi NR, Giardino JR, and Vitek JD. 2013. Rock Glaciers. In Treatise on Geomorphology. Shroder JF (ed), Academic Press, San Diego, pp. 238-273. DOI: 10.1016/B978-0-12-374739-6.00211-6

Jeanneret F. 1975. Blockgletscher in den Südalpen Neuseelands. Zeitschrift für Geomorphologie, 19(1): 83-94. (in German).

Jetz W, Rahbek C, and Lichstein JW. 2005. Local and global approaches to spatial data analysis in ecology. Global Ecology and Biogeography, 14(1): 97-98. DOI: 10.1111/j.1466-822X.2004.00129.x.

Johnson AM and Rodine JR. 1984. Debris flows. In Slope instability. Brunsden D and Prior DB (eds), Wiley, Chichester, pp. 257-361.

Jomelli V, Brunstein D, Chochillon C, and Pech P. 2003. Hillslope debris-flow frequency since the beginning of the 20th century in the Massif des Ecrins (French Alps). In Debris-flow hazard mitigation: Mechanics, Prediction, and Assessment. Rickenmann D and Chen C (eds), Millpress, Rotterdam, pp. 127-137.

Jomelli V, Pech P, Chochillon C, and Brunstein D. 2004. Geomorphic Variations of Debris Flows and Recent Climatic Change in the French Alps. Climatic Change, 64(1): 77-102. DOI: 10.1023/B:CLIM.0000024700.35154.44.

Jomelli V, Brunstein D, Grancher D, and Pech P. 2007. Is the response of hillslope debris flows to recent climate change univocal? A case study in the Massif des Ecrins (French Alps). Climatic Change, 85(1-2): 119-137.

DOI: $10.1007 / \mathrm{s} 10584-006-9209-0$.

Julián A and Chueca J. 2007. Permafrost distribution from BTS measurements (Sierra de Telera, Central Pyrenees, Spain): assessing the importance of solar radiation in a mid-elevation shaded mountainous area. Permafrost and Periglacial Processes, 18(2): 137-149. DOI: 10.1002/ppp.576.

Juliussen $\mathrm{H}$ and Humlum O. 2007. Towards a TTOP ground temperature model for mountainous terrain in central-eastern Norway. Permafrost and Periglacial Processes, 18(2): 161-184. DOI: 10.1002/Ppp.586.

Kääb A. 2005. Remote sensing of mountain glaciers and permafrost creep. Schriftenreihe Physische Geographie, Glaziologie und Geomorphologie, Nr. 48, Geographisches Institut der Universität Zürich, 264 p.

Kääb A. 2008. Remote sensing of permafrost-related problems and hazards. Permafrost and Periglacial Processes, 19(2): 107-136. DOI: 10.1002/ppp.619.

Kääb A and Vollmer M. 2000. Surface Geometry, Thickness Changes and Flow Fields on Creeping Mountain Permafrost: Automatic Extraction by Digital Image Analysis. Permafrost and Periglacial Processes, 11(4): 315-326.

DOI: 10.1002/1099-1530(200012)11:4<315::aid-ppp365>3.0.co;2-j.

Kääb A, Gudmundsson A, and Hoelzle M. 1998. Surface deformation of creeping permafrost. Photogrammetric investigations on rockglacier Murtèl, Swiss Alps. In Proceedings of the Seventh International Conference on Permafrost, Centre d'Etudes Nordiques, Universite Laval, Quebec, Yellowknife, Canada, pp. 531-537.

Kääb A, Frauenfelder R, and Roer I. 2007. On the response of rockglacier creep to surface temperature increase. Global and Planetary Change, 56(1-2): 172-187. DOI: doi:10.1016/j.gloplacha.2006.07.005.

Kaitna R, Schneuwly-Bollschweiler M, Sausgruber T, Moser M, Stoffel M, and Rudolf-Miklau F. 2013. Susceptibility and Triggers for Debris Flows: Emergence, Loading, Release and Entrainment. In Dating Torrential Processes on Fans and Cones. Advances in Global Change Research. Schneuwly-Bollschweiler M, Stoffel M, and Rudolf-Miklau F (eds), Springer Netherlands, pp. 33-49. DOI: 10.1007/978-94-007-4336-6_3 
Kaufmann V. 1998. Deformation analysis of the Doesen rock glacier (Austria). In Proceedings of the Seventh International Conference on Permafrost. Collection Nordicana No 55, Centre d'Etudes Nordiques, Universite Laval, Quebec, Yellowknife, Canada, pp. 551-556.

Keefer DK. 1984. Landslides caused by earthquakes. Geological Society of America Bulletin, 95(4): 406-421. DOI: 10.1130/0016-7606(1984)95<406:Icbe>2.0.co;2.

Keller F. 1992. Automated mapping of mountain permafrost using the program PERMAKART within the geographical information system Arc/Info. Permafrost and Periglacial Processes, 3(2): 133 - 138. DOI: 10.1002/ppp.3430030210.

Keller F. 1994. Interaktionen zwischen Schnee und Permafrost. Mitteilungen der Versuchsanstalt für Wasserbau, Hydrologie und Glaziologie, Nr. 127, Zürich, 145 p. (in German)

Kellerer-Pirklbauer A, Lieb GK, and Kleinferchner H. 2012. A new rock glacier inventory of the eastern European Alps. Austrian Journal of Earth Sciences, 105(2): 78-93.

Kenner R, Bühler Y, Delaloye R, Ginzler C, and Phillips M. 2014. Monitoring of high alpine mass movements combining laser scanning with digital airborne photogrammetry. Geomorphology, 206: 492-504. DOI: 10.1016/j.geomorph.2013.10.020.

Kerr T. 2009. Precipitation distribution in the Lake Pukaki catchment, New Zealand. Unpublished PhD Thesis, Canterbury University, New Zealand, 376 p.

Kienholz H. 1995. Gefahrenbeurteilung und -bewertung - auf dem Weg zu einem Gesamtkonzept. Schweizer Zeitschrift für Forstwesen, 146(9): 701 - 725. (in German).

King L. 1983. High Mountain Permafrost in Scandinavia. In Proceedings of the Fourth International Conference on Permafrost, National Academy Press, Fairbanks, Alaska, pp. 612-617.

King L, Gorbunov AP, and Evin M. 1992. Prospecting and Mapping of Mountain Permafrost and Associated Phenomena. Permafrost and Periglacial Processes, 3(2): 73-81. DOI: $10.1002 / p p p .3430030204$.

Kirkbride M and Brazier V. 1995. On the sensitivity of Holocene talus-derived rock glaciers to climate change in the Ben Ohau Range, New Zealand. Journal of Quaternary Science, 10(4): 353-365. DOI: 10.1002/Jqs.3390100405.

Kirkbride M and Matthews D. 1997. The role of fluvial and glacial erosion in landscape evolution: The Ben Ohau Range, New Zealand. Earth Surface Processes and Landforms, 22(3): 317-327.

DOI: 10.1002/(Sici)1096-9837(199703)22:3<317::Aid-Esp760>3.0.Co;2-I.

Kleinbaum DG, Klein M, and Pryor ER. 2010. Logistic Regression: A Self-Learning Text, Springer, New York, $701 \mathrm{p}$.

Kleinhans MG, Markies H, de Vet SJ, in 't Veld AC, and Postema FN. 2011. Static and dynamic angles of repose in loose granular materials under reduced gravity. Journal of Geophysical Research, 116(E11004). DOI: 10.1029/2011je003865.

Kneisel C. 2004. New insights into mountain permafrost occurrence and characteristics in glacier forefields at high altitude through the application of 2D resistivity imaging. Permafrost and Periglacial Processes, 15(3): 221-227. DOI: 10.1002/ppp.495.

Kneisel C. 2010. The nature and dynamics of frozen ground in alpine and subarctic periglacial environments. The Holocene, 20(3): 423-445.

DOI: $10.1177 / 0959683609353432$.

Kneisel C and Hauck C. 2008. Electrical methods. In Applied Geophysics in Periglacial Environments. Kneisel C and Hauck C (eds), Cambridge University Press, Cambridge, pp. 3-27. 
Kneisel C, Hauck C, Fortier R, and Moorman B. 2008. Advances in geophysical methods for permafrost investigations. Permafrost and Periglacial Processes, 19(2): 157-178. DOI: $10.1002 / p p p .616$.

Knight $\mathrm{J}$ and Harrison S. 2009. Periglacial and paraglacial environments: a view from the past into the future. In Periglacial and Paraglacial Processes and Environments. Knight $J$ and Harrison S (eds), The Geological Society, London, pp. 1-4. DOI: $10.1144 / \mathrm{sp} 320.2$

Korup O. 2005. Distribution of landslides in southwest New Zealand. Landslides, 2(1): 43-51. DOI: 10.1007/s10346-004-0042-0.

Koscielny M, Cojean R, and Thenevin I. 2009. Debris flow hazards due to land use changes above source areas in torrent catchments: case study of Les Arcs (Savoie, France). WIT Transactions on Ecology and the Environment, 124: 161-170. DOI: $10.2495 / \mathrm{rm} 090151$.

Krainer K and Ribis M. 2012. A rock glacier inventory of the Tyrolean Alps (Austria). Austrian Journal of Earth Sciences, 105(2): 32-47.

Krummenacher B, Mihajlovic D, Nussbaum A, and Staub B (eds). 2008. 20 Jahre Furggentälti: Permafrostuntersuchungen auf der Gemmi. Geographica Bernensia, Nr. 80. Geographisches Institut der Universität Bern, 113 p.

Lachenbruch AH. 1968. Permafrost. In Encyclopedia of Geomorphology. Fairbridge RW (ed), Reinhold, New York, pp. 833 - 838.

Lambiel C and Reynard E. 2001. Regional modelling of present, past and future potential distribution of discontinuous permafrost based on a rock glacier inventory in the Bagnes - Hérémence area (Western Swiss Alps). Norsk Geografisk Tidsskrift, 55(4): 219-223. DOI: 10.1080/00291950152746559.

Lambiel C and Pieracci K. 2008. Permafrost distribution in talus slopes located within the alpine periglacial belt, Swiss Alps. Permafrost and Periglacial Processes, 19(3): 293-304. DOI: 10.1002/Ppp.624.

Lamont GN, Chinn TJ, and Fitzharris BB. 1999. Slopes of glacier ELAs in the Southern Alps of New Zealand in relation to atmospheric circulation patterns. Global and Planetary Change, 22(1-4): 209-219. DOI: 10.1016/S0921-8181(99)00038-7.

Lang A, Moya J, Corominas J, Schrott L, and Dikau R. 1999. Classic and new dating methods for assessing the temporal occurrence of mass movements. Geomorphology, 30(1-2): 33-52. DOI: 10.1016/S0169-555X(99)00043-4.

Larsen IJ, Pederson JL, and Schmidt JC. 2006. Geologic versus wildfire controls on hillslope processes and debris flow initiation in the Green River canyons of Dinosaur National Monument. Geomorphology, 81(1-2): 114-127.

DOI: 10.1016/j.geomorph.2006.04.002.

Larsson S. 1982. Geomorphological Effects on the Slopes of Longyear Valley, Spitsbergen, after a Heavy Rainstorm in July 1972. Geografiska Annaler: Series A, Physical Geography, 64(3/4): 105-125.

Lee S and Talib JA. 2005. Probabilistic landslide susceptibility and factor effect analysis. Environmental Geology, 47(7): 982-990. DOI: 10.1007/s00254-005-1228-z.

Lee $S$ and Sambath T. 2006. Landslide susceptibility mapping in the Damrei Romel area, Cambodia using frequency ratio and logistic regression models. Environmental Geology, 50(6): 847-855. DOI: 10.1007/s00254-006-0256-7.

Lee $S$ and Pradhan B. 2007. Landslide hazard mapping at Selangor, Malaysia using frequency ratio and logistic regression models. Landslides, 4(1): 33-41. DOI: 10.1007/s10346-006-0047-y. 
Lerjen M, Kääb A, Hoelzle M, and Haeberli W. 2003. Local distribution pattern of discontinuous mountain permafrost. A process study at Fluela Pass, Swiss Alps. In Proceedings of the Eight International Conference on Permafrost. Springman S and Arenson L (eds), A.A. Balkeman, pp. 21-25.

Leslie DM and McGlone MS. 1973. Relict periglacial landforms at Clarks Junction, Otago. New Zealand Journal of Geology and Geophysics, 16(3): 575-583.

DOI: $10.1080 / 00288306.1973 .10431380$.

Lewin J and Warburton J. 1994. Debris Flows in an Alpine Environment. Geography, 79(2): 98-107.

Lewkowicz AG and Ednie M. 2004. Probability mapping of mountain permafrost using the BTS method, Wolf Creek, Yukon Territory, Canada. Permafrost and Periglacial Processes, 15(1): 67-80. DOI: 10.1002/Ppp.480.

Lewkowicz AG and Harris C. 2005. Morphology and geotechnique of active-layer detachment failures in discontinuous and continuous permafrost, northern Canada. Geomorphology, 69(1-4): 275-297. DOI: 10.1016/j.geomorph.2005.01.011.

Lewkowicz AG and Bonnaventure PP. 2011. Equivalent Elevation: A New Method to Incorporate Variable Surface Lapse Rates into Mountain Permafrost Modelling. Permafrost and Periglacial Processes, 22(2): 153-162. DOI: 10.1002/ppp.720.

Lilleøren KS and Etzelmüller B. 2011. A regional inventory of rock glaciers and ice-cored moraines in Norway. Geografiska Annaler: Series A, Physical Geography, 93A(3): 175-191. DOI: 10.1111/j.1468-0459.2011.00430.x.

Lilleøren KS, Etzelmüller B, Gärtner-Roer I, Kääb A, Westermann S, and Guð̃mundsson Á. 2013. The Distribution, Thermal Characteristics and Dynamics of Permafrost in Tröllaskagi, Northern Iceland, as Inferred from the Distribution of Rock Glaciers and Ice-Cored Moraines. Permafrost and Periglacial Processes, 24(4): 322-335. DOI: 10.1002/ppp.1792.

Lin J-C, Petley D, Jen C-H, Koh A, and Hsu M-L. 2006. Slope movements in a dynamic environment-A case study of Tachia River, Central Taiwan. Quaternary International, 147(1): 103-112. DOI: 10.1016/j.quaint.2005.09.011.

Lindsay J. 2010. Whitebox Geospatial Analysis Tools Tutorial Series, Tutorial 3: Streams and Watershed Extraction, The Centre for Hydrogeomatics, The University of Guelph, Guelph, pp. 15.

LINZ. 2013. NZ Mainland Ice Polygons (Topo, 1:50k). http://data.linz.govt.nz/layer/287-nzmainland-ice-polygons-topo-150k/ (last accessed: 13/10/2013).

Lobo JM, Jiménez-Valverde A, and Real R. 2008. AUC: a misleading measure of the performance of predictive distribution models. Global Ecology and Biogeography, 17(2): 145-151. DOI: 10.1111/j.1466-8238.2007.00358.x.

Lorente A, García-Ruiz JM, Beguería S, and Arnáez J. 2002. Factors explaining the spatial distribution of hillslope debris flows - A case study in the Flysch Sector of the Central Spanish Pyrenees. Mountain Research and Development, 22(1): 32-39. DOI: 10.1659/0276-4741(2002)022[0032:fetsdo]2.0.co;2.

Lorrey A, Fowler AM, and Salinger J. 2007. Regional climate regime classification as a qualitative tool for interpreting multi-proxy palaeoclimate data spatial patterns: A New Zealand case study. Palaeogeography Palaeoclimatology Palaeoecology, 253(3-4): 407-433. DOI: 10.1016/J.Palaeo.2007.06.011.

Loye A, Jaboyedoff M, and Pedrazzini A. 2009. Identification of potential rockfall source areas at a regional scale using a DEM-based geomorphometric analysis. Natural Hazards and Earth System Sciences, 9(5): 1643-1653.

DOI: 10.5194/nhess-9-1643-2009. 
Luckman BH. 1976. Rockfalls and rockfall inventory data: Some observations from surprise valley, Jasper National Park, Canada. Earth Surface Processes, 1(3): 287-298. DOI: 10.1002/esp.3290010309.

Luetschg M. 2005. A Model an Field Analysis if the Interaction between Snow Cover and Alpine Permafrost. Schriftenreihe Physische Geographie - Glaziologie und Geodynamik, Nr. 47, Geographisches Institut der Universität Zürich, 204 p.

Luetschg M and Haeberli W. 2005. Permafrost evolution in the Swiss Alps in a changing climate and the role of the snow cover. Norsk Geografisk Tidsskrift, 59(2): 78-83. DOI: $10.1080 / 00291950510020583$.

Luetschg M, Stoeckli V, Lehning M, Haeberli W, and Ammann W. 2004. Temperatures in two boreholes at Fluela Pass, Eastern Swiss Alps: the effect of snow redistribution on permafrost distribution patterns in high mountain areas. Permafrost and Periglacial Processes, 15: 283-297. DOI: 10.1002/ppp.500.

Luetschg M, Lehning M, and Haeberli W. 2008. A sensitivity study of factors influencing warm/thin permafrost in the Swiss Alps. Journal of Glaciology, 54(187): 696-704. DOI: $10.3189 / 002214308786570881$.

Lugon R and Delaloye R. 2001. Modelling alpine permafrost distribution, Val de Réchy, Valais Alps (Switzerland). Norsk Geografisk Tidsskrift, 55(4): 224 - 229. DOI: 10.1080/00291950152746568.

Marchi L, Arattano M, and Deganutti AM. 2002. Ten years of debris-flow monitoring in the Moscardo Torrent (Italian Alps). Geomorphology, 46(1-2): 1-17. DOI: 10.1016/S0169-555x(01)00162-3.

Marchi L, Chiarle M, and Mortara G. 2008. Climate changes and debris flows in periglacial areas in the Italian Alps. In Proceedings of the International Conference on Hydrological Changes and Management - From Headwaters to the Ocean: Hydrological Change and Water Management-Hydrochange 2008. Taniguchi M, Burnett WC, Fukushima Y, Haigh M, and Umezawa Y (eds), CRC Press/ Balkema, Leiden, Kyoto, Japan, pp. 111-115.

Marquínez J, Menéndez Duarte R, Farias P, and JiméNez Sánchez M. 2003. Predictive GIS-Based Model of Rockfall Activity in Mountain Cliffs. Natural Hazards, 30(3): 341-360. DOI: 10.1023/B:NHAZ.0000007170.21649.e1.

Matsuoka N. 2008. Frost weathering and rockwall erosion in the southeastern Swiss Alps: Long-term (1994-2006) observations. Geomorphology, 99(1-4): 353-368. DOI: 10.1016/j.geomorph.2007.11.013.

Matsuoka N and Murton J. 2008. Frost weathering: recent advances and future directions. Permafrost and Periglacial Processes, 19(2): 195-210. DOI: 10.1002/ppp.620.

Matsuoka N, Hirakawa K, Watanabe T, Haeberli W, and Keller F. 1998. The role of diurnal, annual and millennial freeze-thaw cycles in controlling alpine slope instability. In Proceedings of the Seventh International Conference on Permafrost. Collection Nordicana No 55, Centre d'Etudes Nordiques, Universite Laval, Quebec, Yellowknife, Canada, pp. 711-717.

Matthews JA, Dahl SO, Dresser PQ, Berrisford MS, Lie O, Nesje A, and Owen G. 2009. Radiocarbon chronology of Holocene colluvial (debris-flow) events at Sletthamn, Jotunheimen, southern Norway: a window on the changing frequency of extreme climatic events and their landscape impact. The Holocene, 19(8): 1107-1129. DOI: $10.1177 / 0959683609344674$.

Maurer $\mathrm{H}$ and Hauck C. 2007. Geophysical imaging of alpine rock glaciers. Journal of Glaciology, 53(180): 110-120. DOI: 10.3189/172756507781833893.

McColl S. 2012. Paraglacial Rockslope Stability Unpublished PhD thesis, University of Canterbury, New Zealand, $260 \mathrm{p}$. 
McGregor V. 1967. Holocene moraines and rock glaciers in the central Ben Ohau Range, south Canterbury, New Zealand. Journal of Glaciology, 6: 737-748.

McGreevy JP. 1981. Some perspectives on frost shattering. Progress in Physical Geography, 5(1): 56-75. DOI: 10.1177/030913338100500103.

McRoberts EC and Morgenstern NR. 1974. The Stability of Thawing Slopes. Canadian Geotechnical Journal, 11(4): 447-469. DOI: 10.1139/t74-052.

McSaveney MJ and Davies TRH. 2005. Engineering for debris flows in New Zealand. In Debris-flow Hazards and Related Phenomena. Jakob M and Hungr O (eds), Springer Verlag, Berlin-Heidelberg, pp. 635-658.

McSaveney MJ and Beetham RD. 2006. The potential for debris-flows from Karaka stream at Thames, Coromandel. GNS Science Consultancy Report 2006/014, Lower Hutt, New Zealand.

McSaveney MJ, Davis T, and Gough J. 1995. Natural hazard assessment for Mt Cook/ Aoraki Village and environs. Report 49500D.11 prepared for Department of Conservation and Mount Cook Village Development Steering Committee, GNS Science, Lower Hutt, New Zealand.

McSaveney MJ, Beetham RD, and Leonard GS. 2005. The 18 May 2005 debris flow disaster at Matata: Causes and mitigation suggestions. GNS Science Consultancy Report 2005/71, Lower Hutt, New Zealand.

Menard S. 2002. Applied Logistic Regression Analysis. Sage University Papers Series on Quantitative Applications in the Social Sciences, SAGE Publications, Thousand Oaks, $128 \mathrm{p}$.

Migon P. 2006. Granite landscapes of the world, Oxford University Press Oxford, New York, $416 \mathrm{p}$.

Mikoš M, Fazarinc R, and Ribičič M. 2006. Sediment production and delivery from recent large landslides and earthquake-induced rock falls in the Upper Soča River Valley, Slovenia. Engineering Geology, 86(2-3): 198-210.

DOI: $10.1016 /$ j.enggeo.2006.02.015.

Milne FD and Davies MCR. 2007. Control of soil properties on the Scottish debris flow geohazard and implications of projected climate change. In Landslides and Climate Change: Challenges and Solutions. Mclnnes R, Jakeways J, Fairbank $\mathrm{H}$, and Mathie E (eds), Taylor \& Francis Group, London, pp. 121-127.

Molnar P, Anderson RS, and Anderson SP. 2007. Tectonics, fracturing of rock, and erosion. Journal of Geophysical Research, 112(F03014). DOI: 10.1029/2005JF000433.

Monreal M and Stötter J. 2010. Alpine permafrost: a rock glacier inventory of South Tyrol based on laser-scanning data. In Challenges for Mountain Regions - Tackling Complexity. Borsdorf A, Grabherr G, Heinrich K, Scott B, and Stötter J (eds), Böhlau, Vienna, pp. 40-47.

Moore JR, Sanders JW, Dietrich WE, and Glaser SD. 2009. Influence of rock mass strength on the erosion rate of alpine cliffs. Earth Surface Processes and Landforms, 34(10): 1339-1352. DOI: 10.1002/esp.1821.

Mortimer N. 2004. New Zealand's Geological Foundations. Gondwana Research, 7(1): 261-272. DOI: 10.1016/S1342-937x(05)70324-5.

Mortimer N and Roser BP. 1992. Geochemical evidence for the position of the CaplesTorlesse boundary in the Otago Schist, New Zealand. Journal of the Geological Society, 149(6): 967-977. DOI: 10.1144/gsjgs.149.6.0967. 
Mullan AB, Salinger MJ, Thompson CS, and Porteous AS. 2001. The New Zealand Climate: present and future. In The effects of climate change and variation in New Zealand: An assessment using the CLIMPACTS system. Warrick RA, Kenny GJ, and Harman JJ (eds), The International Global Change Institute (IGCI), University of Waikato, Hamilton, pp. 11-31.

Mullan B, Wratt D, Dean S, Hollis M, Allan S, Williams T, Kenny G, and Environment Mft. 2008. Climate Change Effects and Impacts Assessment: A Guidance Manual for Local Government in New Zealand. 2nd edition, Ministry for the Environment, Wellington, pp. 149.

Murton JB, Coutard JP, Lautridou JP, Ozouf JC, Robinson DA, and Williams RBG. 2001. Physical modelling of bedrock brecciation by ice segregation in permafrost. Permafrost and Periglacial Processes, 12(3): 255-266. DOI: 10.1002/ppp.390.

Murton JB, Peterson R, and Ozouf J-C. 2006. Bedrock Fracture by Ice Segregation in Cold Regions. Science, 314(5802): 1127-1129. DOI: 10.1126/science.1132127.

Nakaya T, Charlton M, Lewis P, Fotheringham S, and Brunsdon C. 2013. GWR 4.0 Application for Geographically Weighted Regression Modelling.

Nandi A and Shakoor A. 2010. A GIS-based landslide susceptibility evaluation using bivariate and multivariate statistical analyses. Engineering Geology, 110(1-2): 11-20. DOI: 10.1016/j.enggeo.2009.10.001.

Nater P, Arenson L, and Springman S. 2008. Choosing Geotechnical Parameters for Slope Stability Assessments in Alpine Permafrost Soils. In Proceedings of the Ninth International Conference on Permafrost. Vol. 2. Kane DL and Hinkel KM (eds), Institute of Northern Engineering, University of Alaska, Fairbanks, pp. 1261-1266.

Neall VE. 2003. Lahar. In Encyclopedia of Geomorphology. Goudie A (ed), Routledge, London, pp. 597-599.

Niu F, Cheng G, Ni W, and Jin D. 2005. Engineering-related slope failure in permafrost regions of the Qinghai-Tibet Plateau. Cold Regions Science and Technology, 42(3): 215-225. DOI: 10.1016/j.coldregions.2005.02.002.

NIWA. 2001. Overview of New Zealand Climate - Mountainous/ Alpine regions, Mount Cook. http://www.niwa.co.nz/education-and-training/schools/resources/climate/overview /map_alpine (last accessed: 07/12/2013).

NIWA. 2010. National Climate Database. http://cliflo.niwa.co.nz/ (last accessed: 18/02/14).

Noetzli J and Gruber S. 2005. Alpiner Permafrost - ein Überblick. Jahrbuch des Vereins zum Schutz der Bergwelt, 70: 111-121. (in German).

Noetzli $\mathrm{J}$ and Gruber S. 2009. Transient thermal effects in Alpine permafrost. The Cryosphere, 3(1): 85-99. DOI: 10.5194/tc-3-85-2009.

Noetzli J, Gruber S, Kohl T, Salzmann N, and Haeberli W. 2007. Three-dimensional distribution and evolution of permafrost temperatures in idealized high-mountain topography. Journal of Geophysical Research, 112(F02S13). DOI: $10.1029 / 2006 j f 000545$.

Norris RJ and Cooper AF. 2001. Late Quaternary slip rates and slip partitioning on the Alpine Fault, New Zealand. Journal of Structural Geology, 23(2-3): 507-520. DOI: 10.1016/S0191-8141(00)00122-X.

Norton D. 1985. A multivariate technique for estimating New Zealand temperature normals. Weather and climate, 5(2): 64-74.

Nyenhuis M. 2006. Permafrost und Sedimenthaushalt in einem alpinen Geosystem. Bonner Geographische Abhandlungen, Nr. 116, Asgard-Verlag, Bonn, 228 p. (in German).

Nyenhuis M, Hoelzle M, and Dikau R. 2005. Rock glacier mapping and permafrost distribution modelling in the Turtmanntal, Valais, Switzerland. Zeitschrift für Geomorphologie NF, 49(3): 275-292. 
NZ metservice. 1985. Climatic map series. Part 6: annual rainfall (digitised version including expert interpolation). New Zealand Meteorological Service Miscellaneous Publication 175, New Zealand Meteorological Service, Wellington.

Ohlmacher GC and Davis JC. 2003. Using multiple logistic regression and GIS technology to predict landslide hazard in northeast Kansas, USA. Engineering Geology, 69(3-4): 331-343. DOI: 10.1016/s0013-7952(03)00069-3.

Onaca AL, Urdea P, and Ardelean AC. 2013. Internal Structure and Permafrost Characteristics of the Rock Glaciers of Southern Carpathians (Romania) Assessed by Geoelectrical Soundings and Thermal Monitoring. Geografiska Annaler: Series A, Physical Geography, 95(3): 249-266. DOI: 10.1111/geoa.12014.

Otto J-C, Keuschnig M, Goetz J, Marbach M, and Schrott L. 2012. Detection of mountain permafrost by combining high resolution surface and subsurface information - an example from the Glatzbach catchment, Austrian Alps. Geografiska Annaler: Series A, Physical Geography, 94(1): 43-57. DOI: 10.1111/j.1468-0459.2012.00455.x.

Owens IF. 1992. A Note on the Mount Cook Rock Avalanche of 14 December 1991. New Zealand Geographer, 48(2): 74-78. DOI: 10.1111/j.1745-7939.1992.tb00386.x.

Page A. 2009. A topographic and photogrammetric study of rock glaciers in the southern Yukon Territory. Unpublished PhD thesis, University of Ottawa, Canada, $160 \mathrm{p}$.

Page MJ, Trustrum NA, and Dymond JR. 1994. Sediment budget to assess the geomorphic effect of a cyclonic storm, New Zealand. Geomorphology, 9(3): 169-188. DOI: $10.1016 / 0169-555 \times(94) 90061-2$.

Paterson BR. 1996. Slope instability along State Highway 73 through Arthur's pass, South Island, New Zealand. New Zealand Journal of Geology and Geophysics, 39(3): 339-351. DOI: 10.1080/00288306.1996.9514718.

Pearce $\mathrm{J}$ and Ferrier S. 2000. Evaluating the predictive performance of habitat models developed using logistic regression. Ecological Modelling, 133(3): 225-245. DOI: 10.1016/S0304-3800(00)00322-7.

Peduzzi P, Concato J, Kemper E, Holford TR, and Feinstein AR. 1996. A simulation study of the number of events per variable in logistic regression analysis. Journal of Clinical Epidemiology, 49(12): 1373-1379. DOI: 10.1016/s0895-4356(96)00236-3.

Pellerin D. 2001. Rates of revegetation of gullies in coastal British Columbia: implications for sediment production. Unpublished MSc thesis, University of British Columbia, Canada, $126 \mathrm{p}$.

Peng C-YJ and So T-SH. 2002. Logistic Regression Analysis and Reporting: A Primer. Understanding Statistics, 1(1): 31-70. DOI: 10.1207/s15328031us0101_04.

Peng C-YJ, Lee KL, and Ingersoll GM. 2002. An introduction to logistic regression analysis and reporting. Journal of Educational Research, 96(1): 3-14.

DOI: $10.1080 / 00220670209598786$.

Pereira JMC and Itami RM. 1991. GIS-based habitat modeling using logistic multipleregression - A study of the MT Graham Red Squirrel Photogrammetric Engineering and Remote Sensing, 57(11): 1475-1486.

Petschko H, Brenning A, Bell R, Goetz J, and Glade T. 2014. Assessing the quality of landslide susceptibility maps - case study Lower Austria. Natural Hazards and Earth System Sciences, 14(1): 95-118. DOI: 10.5194/nhess-14-95-2014.

Péwé TL. 1983. Alpine Permafrost in the Contiguous United States: A Review. Arctic and Alpine Research, 15(2): 145-156. DOI: 10.2307/1550917.

Phillips CJ and Davies TRH. 1991. Determining rheological parameters of debris flow material. Geomorphology, 4(2): 101-110. DOI: 10.1016/0169-555X(91)90022-3.

Pierson TC. 1980a. Erosion and deposition by debris flows at Mt Thomas, North Canterbury, New Zealand. Earth Surface Processes, 5: 22-247. DOI: 10.1002/esp.3760050302. 
Pierson TC. 1980b. Debris flows: An important process in high country gully erosion. Journal of Tussock Grasslands \& Mountain Lands Institute - Review, 39: 3-14.

Pierson TC. 1981. Dominant particle support mechanisms in debris flows at Mt Thomas, New Zealand, and implications for flow mobility. Sedimentology, 28(1): 49-60. DOI: 10.1111/j.1365-3091.1981.tb01662.x.

Pierson TC. 1986. Flow behavior of channelized debris flows, Mount St. Helens, Washington. In Hillslope Processes. Abrahams AD (ed), Allen and Unwin, Boston, pp. 269-296.

Pierson TC, Janda RJ, Thouret J-C, and Borrero CA. 1990. Perturbation and melting of snow and ice by the 13 November 1985 eruption of Nevado del Ruiz, Colombia, and consequent mobilization, flow and deposition of lahars. Journal of Volcanology and Geothermal Research, 41(1-4): 17-66. DOI: 10.1016/0377-0273(90)90082-q.

Pradhan B and Lee S. 2010. Delineation of landslide hazard areas on Penang Island, Malaysia, by using frequency ratio, logistic regression, and artificial neural network models. Environmental Earth Sciences, 60(5): 1037-1054. DOI: 10.1007/s12665-009-0245-8.

Preston N. 1996. Spatial and temporal changes in terrain resistance to shallow translational regolith landsliding. Unpublsihed MSc Thesis, University of Wellington, New Zealand, $110 \mathrm{p}$.

Prick A. 2003. Frost and frost-weathering. In Encyclopedia of Geomorphology. Goudie A (ed), Routledge, London, pp. 412-415.

R Development Core Team. 2011. R: A language and environment for statistical computing, $\mathrm{R}$ Foundation for Statistical Computing, Vienna, Austria.

Rapp A. 1960. Recent Development of Mountain Slopes in Kaerkevagge and Surroundings, Northern Scandinavia. Geografiska Annaler, 42(2/3): 65-200.

Rattenbury MS, Townsend DB, and Johnston MR. 2006. Geology of the Kaikoura area, 1: 250 000. Geological Map 13, GNS Science, Lower Hutt, New Zealand, 1 sheet $+70 \mathrm{p}$.

Rebetez M, Lugon R, and Baeriswyl PA. 1997. Climatic change and debris flows in high mountain regions: the case study of the Ritigraben torrent (Swiss Alps). Climatic Change, 36(3): 371-389. DOI: 10.1023/A:1005356130392.

Regmi D. 2008. Rock glacier distribution and the lower limit of discontinuous mountain permafrost in the Nepal Himalaya. In Proceedings of the Ninth International Conference on Permafrost. Vol. 2. Kane DL and Hinkel KM (eds), Institute of Northern Engineering, University of Alaska, Fairbanks, pp. 1475-1480.

Reid LM and Page MJ. 2003. Magnitude and frequency of landsliding in a large New Zealand catchment. Geomorphology, 49(1-2): 71-88.

DOI: 10.1016/s0169-555x(02)00164-2.

Reis S, Yalcin A, Atasoy M, Nisanci R, Bayrak T, Erduran M, Sancar C, and Ekercin S. 2012. Remote sensing and GIS-based landslide susceptibility mapping using frequency ratio and analytical hierarchy methods in Rize province (NE Turkey). Environmental Earth Sciences, 66(7): 2063-2073. DOI: 10.1007/s12665-011-1432-y.

Renwick JA and Thompson D. 2006. Climate Variability: The Southern Annular Mode and New Zealand climate. Water \& Atmosphere, 14(2): 24-25.

Rickenmann D. 1999. Empirical relationships for debris flows. Natural Hazards, 19(1): 47-77. DOI: 10.1023/A:1008064220727

Rickenmann D and Zimmermann M. 1993. The 1987 debris flows in Switzerland: documentation and analysis. Geomorphology, 8(2-3): 175-189.

DOI: 10.1016/0169-555x(93)90036-2. 
Ridefelt H, Etzelmüller B, Boelhouwers J, and Jonasson C. 2008. Statistic-empirical modelling of mountain permafrost distribution in the Abisko region, sub-Arctic northern Sweden. Norsk Geografisk Tidsskrift, 62(4): 278-289.

DOI: 10.1080/00291950802517890.

Rieger D. 1999. Bewertung der naturräumlichen Rahmenbedingungen für die Entstehung von Hangmuren - Möglichkeiten zur Modellierung des Murpotentials. Münchener Geographische Abhandlungen, A 51, Institut für Geographie der Universität München, München, 149 p. (in German)

Riley KL, Bendick R, Hyde KD, and Gabet EJ. 2013. Frequency-magnitude distribution of debris flows compiled from global data, and comparison with post-fire debris flows in the western U.S. Geomorphology, 191(0): 118-128.

DOI: 10.1016/j.geomorph.2013.03.008.

Riseborough D, Shiklomanov N, Etzelmüller B, Gruber S, and Marchenko S. 2008. Recent advances in permafrost modelling. Permafrost and Periglacial Processes, 19(2): 137-156. DOI: 10.1002/Ppp.615.

Rist A. 2007. Hydrothermal processes within the active layer above alpine permafrost in steep scree slopes and their influence on slope stability. Unpublished PhD Thesis, University of Zurich, Switzerland, $168 \mathrm{p}$.

Roer I and Nyenhuis M. 2007. Rockglacier activity studies on a regional scale: comparison of geomorphological mapping and photogrammetric monitoring. Earth Surface Processes and Landforms, 32(12): 1747-1758. DOI: 10.1002/esp.1496.

Roer I, Haeberli W, Avian M, Kaufmann V, Delaloye R, Lambiel C, and Kääb A. 2008. Observations and Considerations on Destabilizing Active Rock Glaciers in the European Alps. In Proceedings of the Ninth International Conference on Permafrost. Vol. 2. Kane DL and Hinkel KM (eds), Institute of Northern Engineering, University of Alaska, Fairbanks, pp. 1505-1510.

Rolland C. 2003. Spatial and seasonal variations of air temperature lapse rates in Alpine regions. Journal of Climate, 16(7): 1032-1046.

DOI: 10.1175/1520-0442(2003)016<1032:Sasvoa>2.0.Co;2.

Romanovsky VE, Smith SL, and Christiansen HH. 2010. Permafrost thermal state in the polar Northern Hemisphere during the international polar year 2007-2009: a synthesis. Permafrost and Periglacial Processes, 21(2): 106-116.

DOI: 10.1002/ppp.689.

Rougier JC and Beven KJ. 2013. Model and data limitations: the sources and implications of epistemic uncertainty. In Risk and Uncertainty Assessment for Natural Hazards. Sparks RSJ and Hill LJ (eds), Cambridge University Press, New York, pp. 40-63.

Rykiel EJ. 1996. Testing ecological models: the meaning of validation. Ecological Modelling, 90(3): 229-244. DOI: 10.1016/0304-3800(95)00152-2.

Salinger MJ and Mullan AB. 1999. New Zealand climate: temperature and precipitation variations and their links with atmospheric circulation 1930-1994. International Journal of Climatology, 19(10): 1049-1071.

DOI: 10.1002/(sici)1097-0088(199908)19:10<1049::aid-joc417>3.0.co;2-z.

Salinger MJ, Hay J, McGann R, and Fitzharris B. 1993. Southwest Pacific temperatures: Diurnal and seasonal trends. Geophysical Research Letters, 20(10): 935-938. DOI: 10.1029/93GL01113.

Salinger MJ, Renwick JA, and Mullan AB. 2001. Interdecadal Pacific Oscillation and South Pacific climate. International Journal of Climatology, 21(14): 1705-1721. DOI: 10.1002/joc.691.

Salzmann N, Frei C, Vidale P-L, and Hoelzle M. 2007a. The application of Regional Climate Model output for the simulation of high-mountain permafrost scenarios. Global and Planetary Change, 56(1-2): 188-202. DOI: 10.1016/J.Gloplacha.2006.07.006. 
Salzmann N, Notzli J, Hauck C, Gruber S, Hoelzle M, and Haeberli W. 2007b. Ground surface temperature scenarios in complex high-mountain topography based on regional climate model results. Journal of Geophysical Research(F02S12): 1-10. DOI: $10.1029 / 2006 j f 000527$.

Sappington JM, Longshore KM, and Thompson DB. 2007. Quantifying Landscape Ruggedness for Animal Habitat Analysis: A Case Study Using Bighorn Sheep in the Mojave Desert. The Journal of Wildlife Management, 71(5): 1419-1426. DOI: 10.2193/2005-723.

Sass O. 2005a. Spatial patterns of rockfall intensity in the northern Alps. Zeitschrift für Geomorphologie, Suppl. Bd. 138: 51-65.

Sass O. 2005b. Temporal Variability of Rockfall in the Bavarian Alps, Germany. Arctic, Antarctic, and Alpine Research, 37(4): 564-573.

DOI: 10.1657/1523-0430(2005)037[0564:tvorit]2.0.co;2.

Sass O, Heel M, Leistner I, Stöger F, Wetzel K-F, and Friedmann A. 2012. Disturbance, geomorphic processes and recovery of wildfire slopes in North Tyrol. Earth Surface Processes and Landforms, 37(8): 883-894. DOI: 10.1002/esp.3221.

Sassa K and Wang $\mathrm{CH}$. 2005. Mechanism of landslide-triggered debris flows: Liquefaction phenomena due to the undrained loading of torrent deposits. In Debris-flow Hazards and Related Phenomena. Jakob M and Hungr O (eds), Springer-Verlag, BerlinHeidelberg, pp. 81-104.

Sattler K. 2008. Murgangaktivität und Permafrostverbreitung in einem periglazialen Hochgebirgsraum - eine Fallstudie im Schnalstal, Südtirol. Unveroeffentlichte Diplomarbeit, Universität Wien, Oesterreich, 145 p. (in German).

Sattler K, Keiler M, Zischg A, and Schrott L. 2011. On the Connection between Debris Flow Activity and Permafrost Degradation: A Case Study from the Schnalstal, South Tyrolean Alps, Italy. Permafrost and Periglacial Processes, 22(3): 254-265. DOI: $10.1002 / p p p .730$.

Scapozza C, Lambiel C, Baron L, Marescot L, and Reynard E. 2011. Internal structure and permafrost distribution in two alpine periglacial talus slopes, Valais, Swiss Alps. Geomorphology, 132(3-4): 208-221. DOI: 10.1016/j.geomorph.2011.05.010.

Scherler M, Hauck C, Hoelzle M, and Salzmann N. 2013. Modeled sensitivity of two alpine permafrost sites to RCM-based climate scenarios. Journal of Geophysical Research, 118(2): 780-794. DOI: 10.1002/jgrf.20069.

Scherler M, Hauck C, Hoelzle M, Stähli M, and Völksch I. 2010. Meltwater infiltration into the frozen active layer at an alpine permafrost site. Permafrost and Periglacial Processes, 21(4): 325-334. DOI: 10.1002/ppp.694.

Schneuwly-Bollschweiler M and Stoffel M. 2012. Hydrometeorological triggers of periglacial debris flows in the Zermatt valley (Switzerland) since 1864. Journal of Geophysical Research, 117: F02033. DOI: 10.1029/2011jf002262.

Schneuwly-Bollschweiler M, Stoffel M, and Rudolf-Miklau F (eds). 2013. Dating Torrential Processes on Fans and Cones: Methods and Their Application for Hazard and Risk Assessment. Advances in Global Change Research, 47. Springer Netherlands, $455 \mathrm{p}$.

Schöner W, Boeckli L, Hausmann H, Otto J-C, Reisenhofer S, Riedl C, and Seren S. 2012. Spatial Patterns of Permafrost at Hoher Sonnblick (Austrian Alps)-Extensive Fieldmeasurements and Modelling Approaches. Austrian Journal of Earth Sciences, 105(2): 154-168.

Schroeder B. 2003. ROC Plotting and AUC Calculation Transferability Test. http://lec.wzw.tum.de/index.php?id=67\&L=1 (last accessed: 29/06/2014). 
Schroeder B and Reineking B. 2004. Validierung von Habitatmodellen. In Habitatmodelle Methodik, Anwendung, Nutzen. UFZ-Berichte. Dormann CF, Blascke T, Lausch A, Schroeder B, and Soendergerath D (eds), UFZ-Eigenverlag Leipzig, pp. 47-56.

Schrott L. 1999. Typische und atypische Permafrostvorkommen - Klimatische Bedingungen, geomorphologische Indikatoren und Prospektionsmethoden. In Lebensraum Blockhalde. Möseler BM and Molenda R (eds), Selbstverlag des Naturhistorischen Vereins der Rheinlande und Westfalens, Bonn, pp. 13-26. (in German).

Schrott L, Otto J-C, and Keller F. 2012. Modelling alpine permafrost distribution in the Hohe Tauern region, Austria. Austrian Journal of Earth Sciences, 105(2): 169-183.

Scotti R, Brardinoni F, Alberti S, Frattini P, and Crosta GB. 2013. A regional inventory of rock glaciers and protalus ramparts in the central Italian Alps. Geomorphology, 186(0): 136-149. DOI: 10.1016/j.geomorph.2012.12.028.

Selby MJ. 1976. Slope Erosion due to Extreme Rainfall: A Case Study from New Zealand. Geografiska Annaler: Series A, Physical Geography, 58(3): 131-138. DOI: $10.2307 / 520925$.

Selby MJ. 1980. A rock mass strength classification for geomorphic purposes: with tests from Antarctica and New Zealand. Zeitschrift für Geomorphologie NF, 24(1): 31-51.

Selby MJ. 1982. Controls on the stability and inclinations of hillslopes formed on hard rock. Earth Surface Processes and Landforms, 7(5): 449-467.

DOI: $10.1002 /$ esp.3290070506.

Selby MJ. 1993. Hillslope materials and processes, Oxford University Press, Oxford, pp. 451.

Seppälä M. 2011. Synthesis of studies of palsa formation underlining the importance of local environmental and physical characteristics. Quaternary Research, 75(2): 366-370. DOI: 10.1016/j.yqres.2010.09.007.

Sevruk B and Mieglitz K. 2002. The effect of topography, season and weather situation on daily precipitation gradients in 60 Swiss valleys. Water science and technology, 45(2): 41-48.

Shakesby RA. 1997. Pronival (protalus) ramparts: a review of forms, processes, diagnostic criteria and palaeoenvironmental implications. Progress in Physical Geography, 21(3): 394-418. DOI: 10.1177/030913339702100304.

Sharp RP and Nobles L. 1953. Mudflow of 1941 at wrightwood, Southern California. Geological Society of America Bulletin, 64(5): 547-560.

DOI: 10.1130/0016-7606(1953)64[547:moawsc]2.0.co;2.

Sidle RC. 2005. Influence of forest harvesting activities on debris avalanches and flows. In Debris-flow Hazards and Related Phenomena. Jakob M and Hungr O (eds), Springer-Verlag, Berlin-Heidelberg, pp. 387-409.

Sidle RC and Ochiai H. 2006. Landslides: Processes, Prediction, and Land Use. Water Resources Monograph, 18, American Geophysical Union, Washington, DC, $312 \mathrm{p}$

Siegmund $\mathrm{M}$ and Hall K. 2000. A study of valley-side slope asymmetry based on the application of GIS analysis: Alexander Island, Antarctica. Antarctic Science, 12(4): 471-476.

Simon N. 2012. Developing a Systematic Approach to Susceptibility Mapping for Landslides in Natural and Artificial Slopes in an Area Undergoing Land Use Change, Kota Kinabalu, Sabah, Malaysia. Unpublished PhD thesis, Victoria University of Wellington, $526 \mathrm{p}$.

Sinclair MR, Wratt DS, Henderson RD, and Gray WR. 1997. Factors Affecting the Distribution and Spillover of Precipitation in the Southern Alps of New Zealand-A Case Study. Journal of Applied Meteorology, 36(5): 428-442.

DOI: 10.1175/1520-0450(1997)036<0428:fatdas>2.0.co;2. 
Sirguey P. 2014. AORAKI2013, surveying the height of Aoraki/Mt Cook. http://www.otago.ac.nz/surveying/research/geodetic/otago061558.html (last accessed: 24/06/2014).

Skermer N, Rawlings G, and Hurley A. 2002. Debris-flow defence at Aoraki Mount Cook Village, New Zealand. Quarterly Journal of Engineering Geology and Hydrogeology, 35: 19-24. DOI: 10.1144/qjegh.35.1.19.

Soons JM. 1962. A survey of periglacial features in New Zealand. In Land and Livelihood, Geographical Essays in Honour of George Jobberns, New Zealand Geographical Society, Christchurch, pp. 74-87.

Soons JM and Price LW. 1990. Periglacial phenomena in New Zealand. Permafrost and Periglacial Processes, 1(2): 145-159.

SPSS I. 2009. PASW Statistics for Windows, Version 18.0, SPSS Inc., Chicago.

Stewart S. 2007. Rock mass strength and deformability of unweathered closely jointed New Zealand Greywacke. Unpublished PhD thesis, University of Canterbury, New Zealand, $472 \mathrm{p}$.

Steyerberg EW, Harrell Jr FE, Borsboom GJ, Eijkemans M, Vergouwe Y, and Habbema JDF. 2001. Internal validation of predictive models: efficiency of some procedures for logistic regression analysis. Journal of Clinical Epidemiology, 54(8): 774-781. DOI: 10.1016/S0895-4356(01)00341-9.

Stiny J. 1931. Die geologischen Grundlagen der Verbauung der Geschiebeherde in Gewässern, Springer Verlag, Wien, 121 p. (in German).

Stocker-Mittaz C, Hoelzle M, and Haeberli W. 2002. Modelling Alpine Permafrost Distribution Based on Energy-Balance Data: a First Step. Permafrost and Periglacial Processes, 13: 271-282. DOI: 10.1002/Ppp.426.

Stoffel $\mathrm{M}$ and Huggel C. 2012. Effects of climate change on mass movements in mountain environments. Progress in Physical Geography, 36(3): 421-439.

DOI: $10.1177 / 0309133312441010$.

Stoffel M, Bollschweiler M, and Hassler G-R. 2006. Differentiating past events on a cone influenced by debris-flow and snow avalanche activity - a dendrogeomorphological approach. Earth Surface Processes and Landforms, 31(11): 1424-1437. DOI: 10.1002/esp.1363.

Stötter J. 1994. Veränderungen der Kryoshäre in Vergangenheit und Zukunft sowie Folgeerscheinungen - Untersuchungen in ausgewählten Hochgebirgsräumen im Vinschgau. Unveröffentlichte Habilitationsschrift, Ludwig-Maximilians-Universität, Germany, 264 p. (in German).

Sturman A and Wanner H. 2001. A Comparative Review of the Weather and Climate of the Southern Alps of New Zealand and the European Alps. Mountain Research and Development, 21(4): 359-369.

DOI: 10.1659/0276-4741(2001)021[0359:Acrotw]2.0.Co;2.

Sutherland R, Eberhart-Phillips D, Harris RA, Stern T, Beavan J, Ellis S, Henrys S, Cox S, Norris RJ, Berryman KR, Townend J, Bannister S, Pettinga J, Leitner B, Wallace L, Little TA, Cooper AF, Yetton M, and Stirling M. 2007. Do great earthquakes occur on the Alpine Fault in central South Island, New Zealand? In A Continental Plate Boundary: Tectonics at South Island, New Zealand. Geophysical Monograph 175, American Geoscience Union, Washington, DC, pp. 235-251. DOI: 10.1029/175gm 12

Tait A. 2010. Comparison of two interpolation methods for daily maximum and minimum temperatures for New Zealand - Stage 3: Comparison with independent high elevation temperature data, Unpublished manuscript, $14 \mathrm{p}$.

Tait A, Henderson R, Turner R, and Zheng X. 2006. Thin plate smoothing spline interpolation of daily rainfall for New Zealand using a climatological rainfall surface. International Journal of Climatology, 26(14): 2097-2115. DOI: 10.1002/joc.1350. 
Takahashi T. 1980. Debris flow on a prismatic open channel. Journal of the Hydraulics Division (ASCE), 106(3): 381-396.

Takahashi T. 1981. Estimation of potential debris flows and their hazardous zones: Soft counter measures for a disaster. Journal of Natural Disaster Science, 3(1): 57 - 89.

Takahashi T. 2007. Debris Flow - Mechanics, Prediction and Countermeasures, Taylor \& Francis, London, $448 \mathrm{p}$.

Terralink. 2005-2008. Colour orthophotograph mosaic, Wellington, New Zealand.

Thurston LL. 2009. An integrated approach to alluvial fan research. Unpublished BSc thesis, Unviersity of Otago, New Zealand, $125 \mathrm{p}$.

Tippett JM and Kamp PJJ. 1993. Fission Track Analysis of the Late Cenozoic Vertical Kinematics of Continental Pacific Crust, South Island, New Zealand. Journal of Geophysical Research, 98(B9): 119-16. DOI: 10.1029/92jb02115.

Tognacca C. 1999. Beitrag zur Untersuchung der Entstehungsmechanismen von Murgängen. Unveroeffentlichte Doktorarbeit, ETH Zuerich, Schweiz, 260 p. (in German).

Trombotto D, Buk E, and Hernández J. 1997. Short Communication Monitoring of Mountain Permafrost in the Central Andes, Cordon del Plata, Mendoza, Argentina. Permafrost and Periglacial Processes, 8(1): 123-129.

DOI: 10.1002/(SICl)1099-1530(199701)8:1<123::AID-PPP242>3.0.CO;2-M.

Turnbull IM. 2000. Geology of the Wakatipu area, 1: 250 000. Geological Map 18, GNS Science, Lower Hutt, New Zealand.

Turnbull IM, Thomson R, and Read SAL. 1975. Shotover River Sediment Source Survey Geological Report. Unpublished Engineering Report EG227, GNS Science, Lower Hutt, $16 \mathrm{p}$.

Turnbull IM, Allibone AH, and Jongens R. 2010. Geology of the Fjordland area, 1: 250000. Geological Map 17, GNS Science, Lower Hutt, New Zealand, 1 map sheet + 97 p.

Van Asch TWJ and Van Steijn H. 1991. Temporal patterns of mass movements in the French Alps. Catena, 18(5): 515-527. DOI: 10.1016/0341-8162(91)90052-Y.

Van Dissen R and Yeats RS. 1991. Hope fault, Jordan thrust, and uplift of the Seaward Kaikoura Range, New Zealand. Geology, 19(4): 393-396.

DOI: 10.1130/0091-7613(1991)019<0393:hfjtau>2.3.co;2.

Van Everdingen R (ed) 2005. Multi-language glossary of permafrost and related ground-ice terms. National Snow and Ice Data Center/World Data Center for Glaciology, Boulder, Colorado.

Van Steijn H. 1996. Debris-flow magnitude-frequency relationships for mountainous regions of Central and Northwest Europe. Geomorphology, 15(3-4): 259-273. DOI: 10.1016/0169-555X(95)00074-F.

Van Steijn H, Bertran P, Francou B, Texier J-P, and Hétu B. 1995. Models for the genetic and environmental interpretation of stratified slope deposits: Review. Permafrost and Periglacial Processes, 6(2): 125-146. DOI: 10.1002/ppp.3430060210.

Van Westen CJ, Castellanos E, and Kuriakose SL. 2008. Spatial data for landslide susceptibility, hazard, and vulnerability assessment: An overview. Engineering Geology, 102(3-4): 112-131. DOI: 10.1016/j.enggeo.2008.03.010.

Vanmaercke M, Kettner AJ, Van Den Eeckhaut M, Poesen J, Mamaliga A, Verstraeten G, Rãdoane M, Obreja F, Upton P, Syvitski JPM, and Govers G. 2014. Moderate seismic activity affects contemporary sediment yields. Progress in Physical Geography. DOI: 10.1177/0309133313516160. 
Varnes DJ. 1978. Slope movement types and processes. In Landslides, Analysis and Control. Transportation Research Board, Special Report 176. Schuster RL and Krizek RJ (eds), National Academy of Science, Washington, DC, pp. 11-33.

Vittinghoff $E$ and McCulloch CE. 2007. Relaxing the Rule of Ten Events per Variable in Logistic and Cox Regression. American Journal of Epidemiology, 165(6): 710-718. DOI: 10.1093/aje/kwk052.

Vonder Mühll D, Hauck C, and Gubler H. 2002. Mapping of mountain permafrost using geophysical methods. Progress in Physical Geography, 26: 643. DOI: 10.1191/0309133302pp356ra.

Wahrhaftig C and Cox A. 1959. Rock glaciers in the Alaska Range. Geological Society of America Bulletin, 70(4): 383-436.

DOI: 10.1130/0016-7606(1959)70[383:rgitar]2.0.co;2.

Walder $\mathrm{J}$ and Hallet B. 1985. A theoretical model of the fracture of rock during freezing. Geological Society of America Bulletin, 96(3): 336-346.

DOI: 10.1130/0016-7606(1985)96<336:Atmotf>2.0.Co;2.

Walder $\mathrm{J}$ and Hallet B. 1986. The Physical Basis of Frost Weathering: Toward a More Fundamental and Unified Perspective. Arctic and Alpine Research, 18(1): 27-32. DOI: $10.2307 / 1551211$.

Warburton J. 2007. Sediment budgets and rates of sediment transfer across cold environments in Europe: A commentary. Geografiska Annaler: Series A, Physical Geography, 89(1): 95-100. DOI: 10.1111/j.1468-0459.2007.00310.x.

Wardle P. 1991. Vegetation of New Zealand, Cambridge University Press, Cambridge, pp. 672.

Welcker C. 2011. Bulking debris flow initiation and impacts. Unpublished PhD thesis, University of Idaho, USA, $178 \mathrm{p}$.

Wellman HW. 1979. An uplift map for the South Island of New Zealand, and a model for the uplift of the Southern Alps. The Royal Society of New Zealand Bulletin, 18: 13-20.

Welsh A and Davies T. 2011. Identification of alluvial fans susceptible to debris-flow hazards. Landslides, 8(2): 183-194. DOI: 10.1007/s10346-010-0238-4.

Whalley W. 1983. Rock glaciers-permafrost features or glacial relics. In Proceedings of the Fourth International Conference on Permafrost, National Academy Press, Fairbanks, Alaska, pp. 1396-1401.

Whalley WB and Martin HE. 1992. Rock glaciers : II models and mechanisms. Progress in Physical Geography, 16(2): 127-186. DOI: 10.1177/030913339201600201.

Wheeler D. 2008. Visualizing and Diagnosing Output from Geographically Weighted Regression Models. Technical Report 08-02, Department of Biostatistics, Emory University, $39 \mathrm{p}$.

Wheeler D and Tiefelsdorf M. 2005. Multicollinearity and correlation among local regression coefficients in geographically weighted regression. Journal of Geographical Systems, 7(2): 161-187. DOI: 10.1007/s10109-005-0155-6.

White SE. 1976. Is Frost Action Really Only Hydration Shattering? A Review. Arctic and Alpine Research, 8(1): 1-6. DOI: 10.2307/1550606.

Whitehouse IE. 1982. Erosion on Sebastopol, Mt Cook, New Zealand, in the last 85 years. New Zealand Geographer, 38: 77-80. DOI: 10.1111/j.1745-7939.1982.tb00996.x.

Whitehouse IE. 1985. The frequency of high-intensity rainfalls in the Central Southern Alps, New Zealand. Journal of the Royal Society of New Zealand, 15(2): 213-226.

Whitehouse IE. 1987. Geomorphology of a compressional plate boundary, Southern Alps, New Zealand. In International Geomorphology. Gardiner V (ed), John Wiley \& Sons Ltd, Chichester, pp. 897-924. 
Whitehouse IE. 1988. Geomorphology of the central Southern Alps, New Zealand: the interaction of plate collision and atmospheric circulation. Zeitschrift für Geomorphologie, Suppl Bd. 69: 105-116.

Whitehouse IE and McSaveney M. 1990. Geomorphic appraisals for development on two steep, active alluvial fans, Mt Cook, New Zealand. In Alluvial fans: a field approach. Rachocki A and Church M (eds), John Wiley \& Sons Ltd., Chichester, pp. 369-384.

Whitehouse IE and McSaveney MJ. 1992. Assessment of Geomorphic Hazards along an Alpine Highway. New Zealand Geographer, 48(1): 27-32.

DOI: 10.1111/j.1745-7939.1992.tb00378.x.

Whitehouse IE and Pearce AJ. 1992. Shaping the mountains of New Zealand. In Landforms of New Zealand. Soons JM and Selby MJ (eds), Longman Paul, Auckland, pp. 144-160.

Wieczorek G. 1996. Landslide triggering mechanisms. In Landslides Investigation and Mitigation. Transportation Research Board, Special Report 247. Turner AK and Schuster RL (eds), US National Research Council Washington, DC, pp. 76-90.

Wieczorek GF and Glade T. 2005. Climatic factors influencing occurrence of debris flows. In Debris-flow Hazards and Related Phenomena. Jakob M and Hungr O (eds), Springer Verlag, Berlin-Heidelberg, pp. 325-362.

Williams GP and Guy HP. 1971. Debris avalanches - A geomorphic hazard. In Proceedings of the 1st Annual Geomorphology Symposia Series, State University of New York, Binghamton, pp. 25-46.

Wilson JP and Gallant JC. 2000. Terrain Analysis: Principles and Applications, John Wiley \& Sons, New York, 479 p.

Wimberly MC, Yabsley MJ, Baer AD, Dugan VG, and Davidson WR. 2008. Spatial heterogeneity of climate and land-cover constraints on distributions of tick-borne pathogens. Global Ecology and Biogeography, 17(2): 189-202.

DOI: 10.1111/j.1466-8238.2007.00353.x.

Windle MJS, Rose GA, Devillers R, and Fortin MJ. 2010. Exploring spatial non-stationarity of fisheries survey data using geographically weighted regression (GWR): an example from the Northwest Atlantic. Ices Journal of Marine Science, 67(1): 145-154.

DOI: 10.1093/icesjms/fsp224.

Wondzell SM and King JG. 2003. Postfire erosional processes in the Pacific Northwest and Rocky Mountain regions. Forest Ecology and Management, 178(1-2): 75-87. DOI: 10.1016/s0378-1127(03)00054-9.

Zhang TJ. 2005. Influence of the seasonal snow cover on the ground thermal regime: An overview. Reviews of Geophysics, 43(4). DOI: 10.1029/2004rg000157.

Zimmermann M. 1990. Periglaziale Murgänge. Mitteilungen der Versuchsanstalt fuer Wasserbau, Hydrologie und Glaziologie der ETH Zuerich, 108: 89-107. (in German).

Zimmermann M and Haeberli W. 1992. Climatic change and debris flow activity in highmountain areas. A case study in the Swiss Alps. Catena Supplement, 22: 59-72.

Zimmermann M, Mani P, and Romang H. 1997a. Magnitude-frequency aspects of alpine debris flows. Eclogae Geologicae Helvetiae, 90(3): 415-420.

Zimmermann M, Mani P, Gamma P, Gsteiger P, Heiniger O, and Hunziker G. 1997b. Murganggefahr und Klimaänderung - ein GIS-basierter Ansatz. Schlussbericht NFP 31, vdf Hochschulverlag an der ETH Zürich, Zürich, 161 p. (in German).

Zischg A, Curtaz M, Galuppo A, Lang K, Mayr V, Riedl C, and Schoeneich P. 2011. Chapter 2: Permafrost and debris-flows. In Hazards related to permafrost and to permafrost degradation. PermaNET project, State-of-the-art report 6.2. Schoeneich P, Dall'Amico M, Deline P, and Zischg A (eds), pp. 29-66. 


\section{APPENDICES}

APPENDIX 1: Debris FloW INVENTORY IN MAPS (SECTION 3.3) 

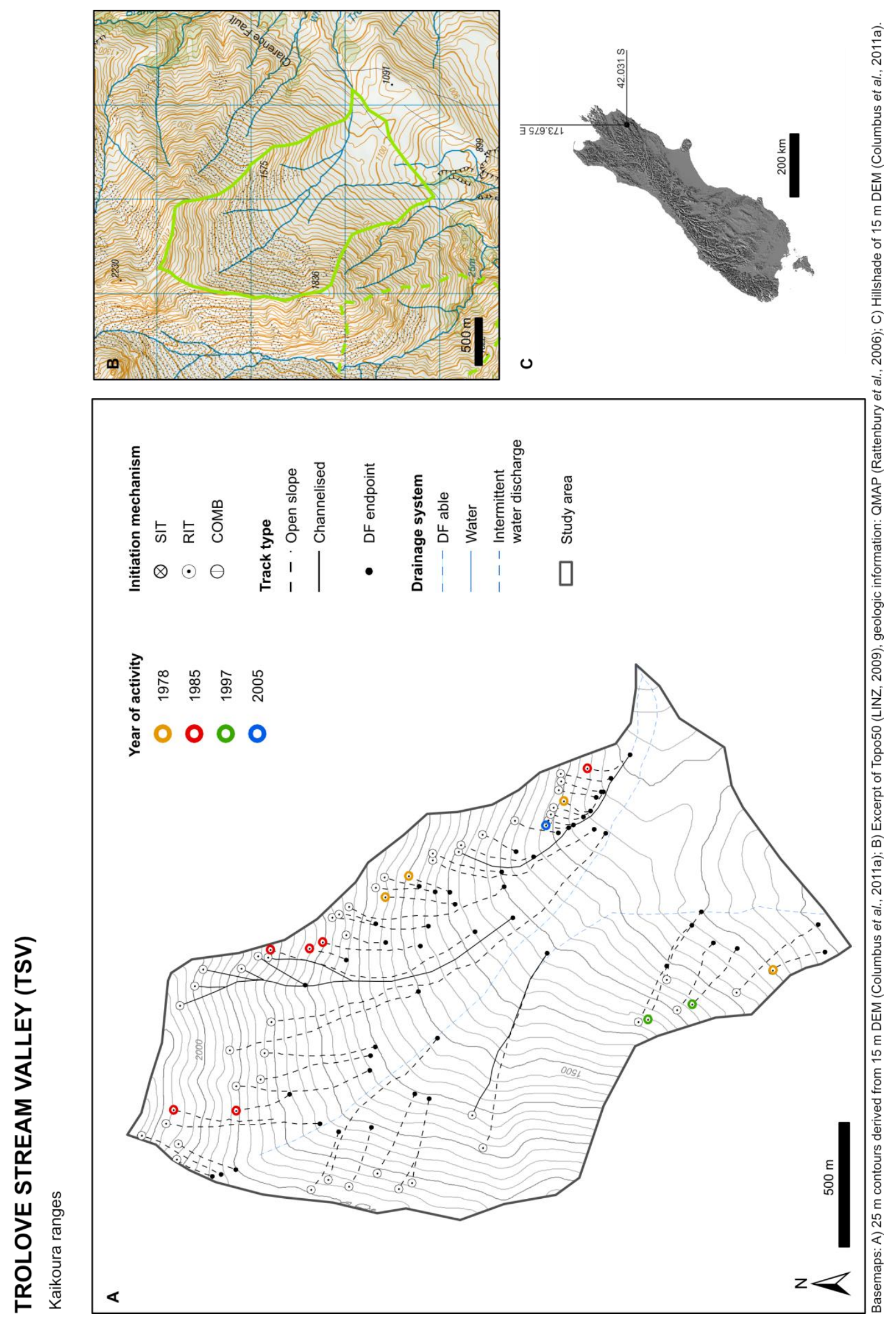

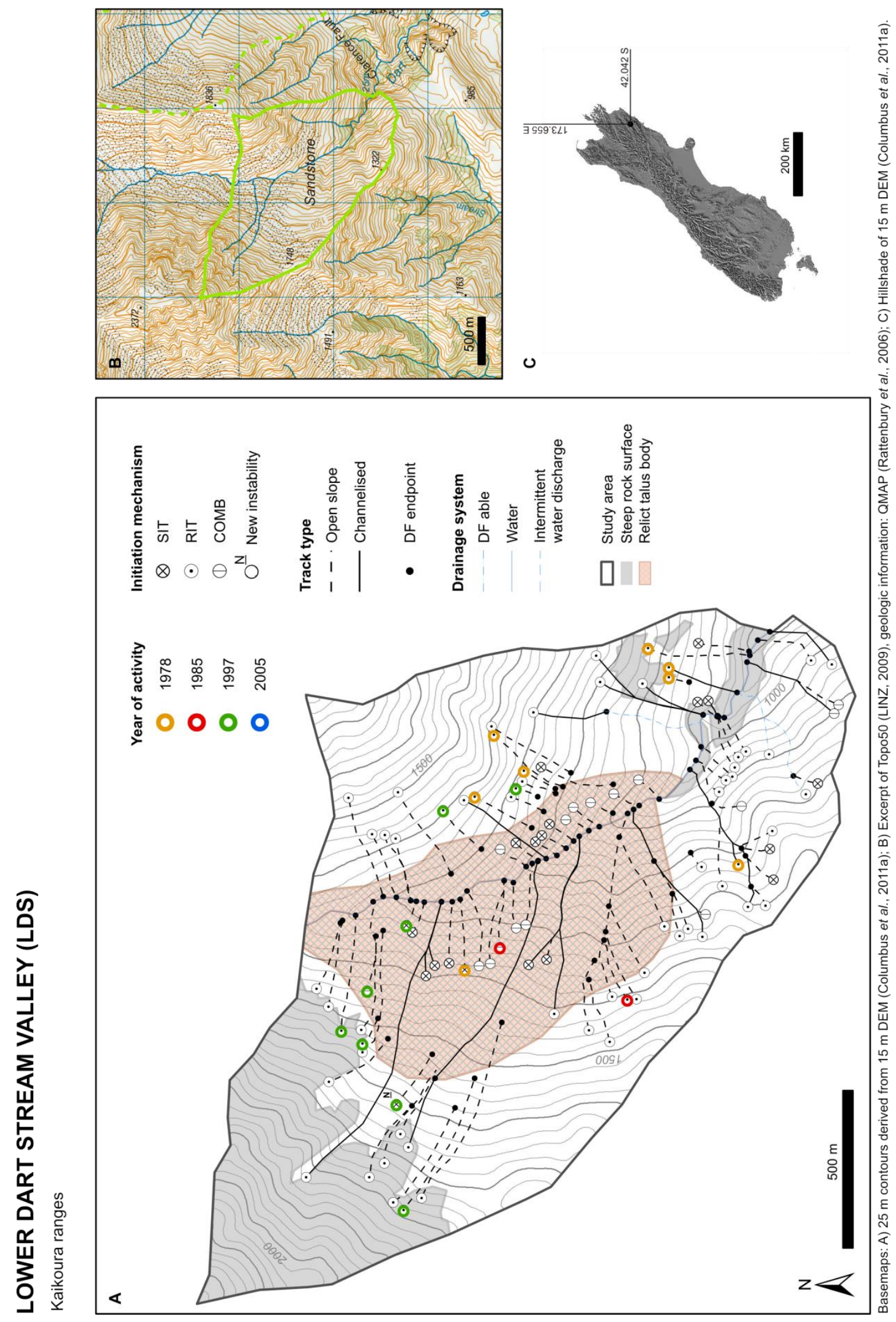

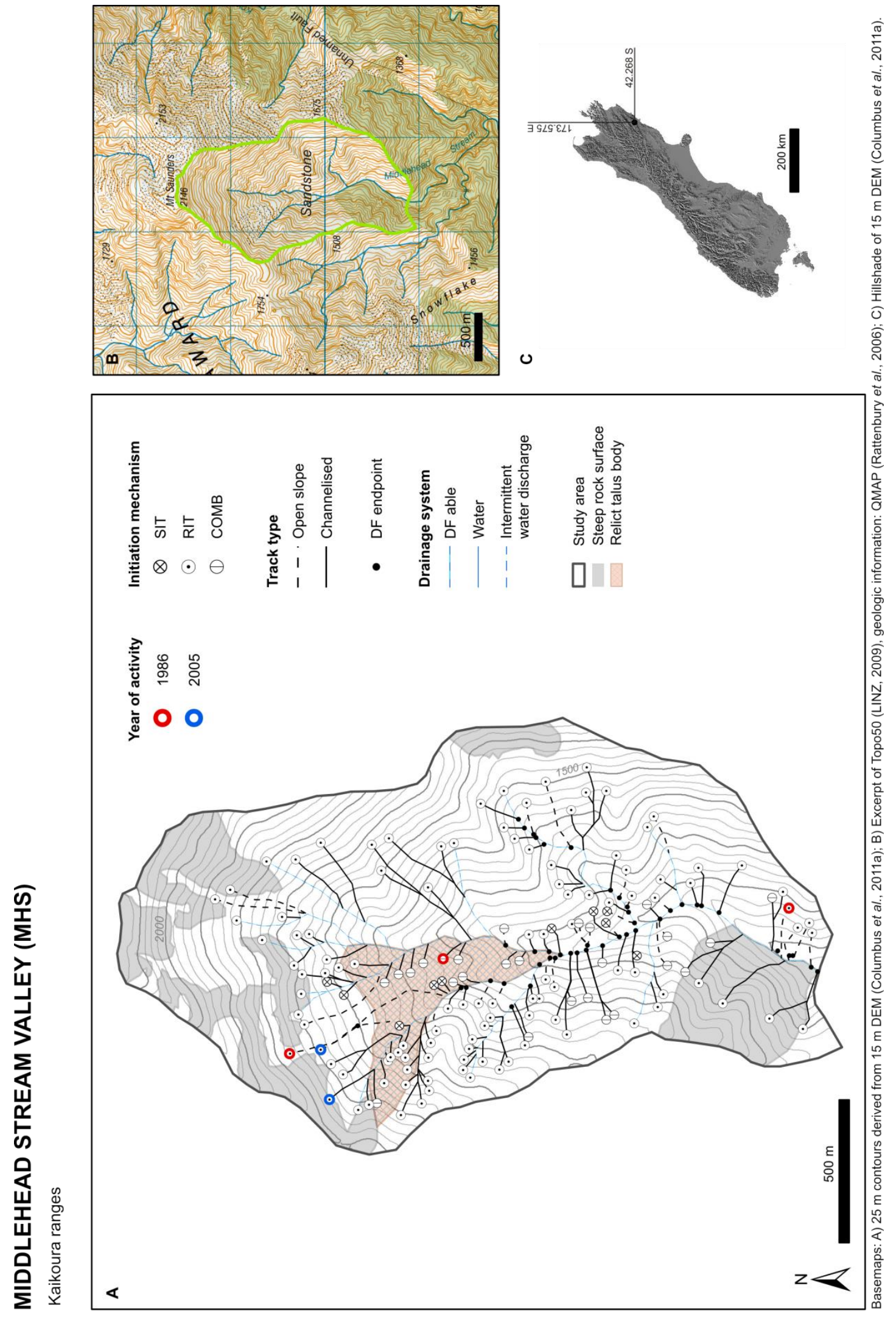


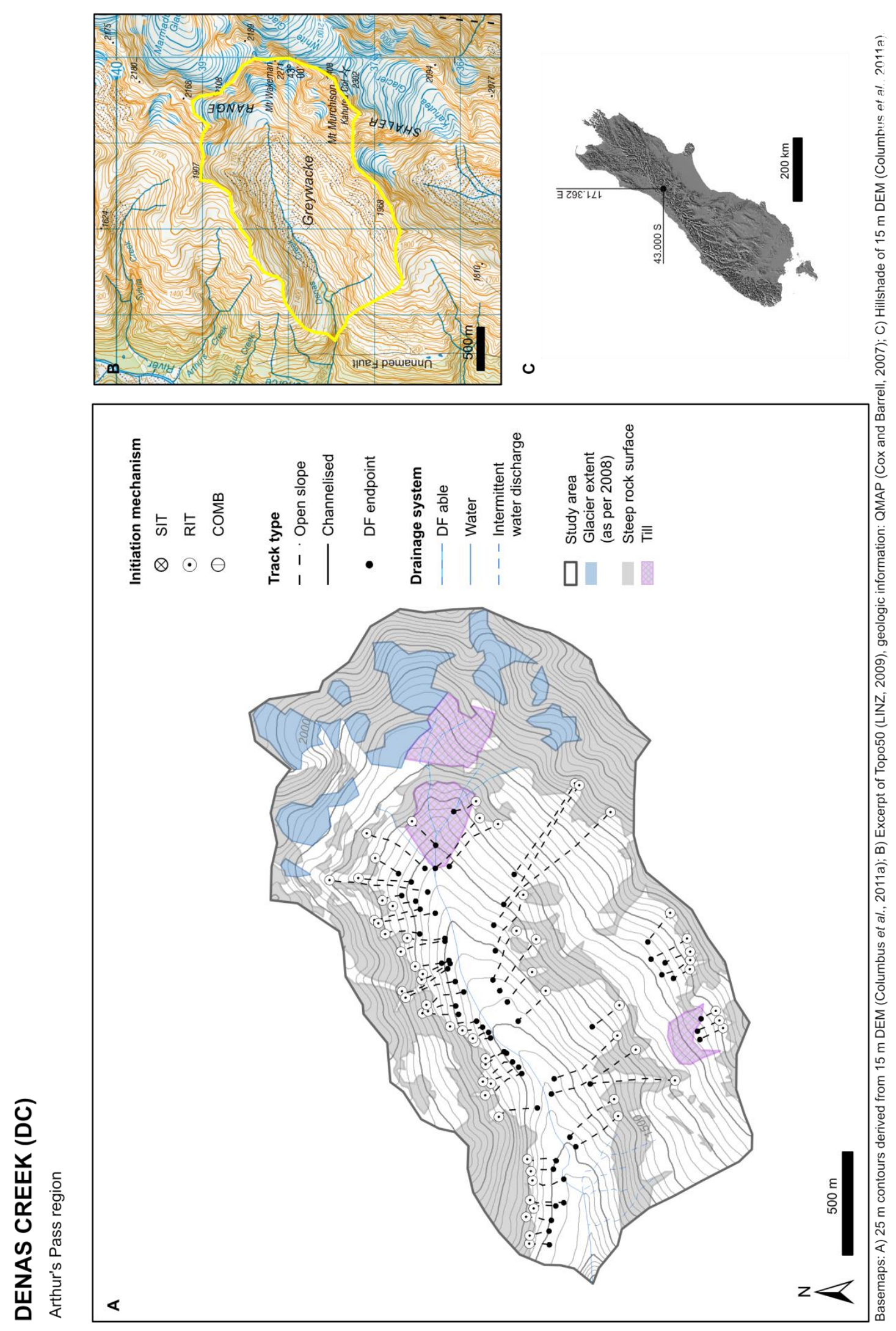



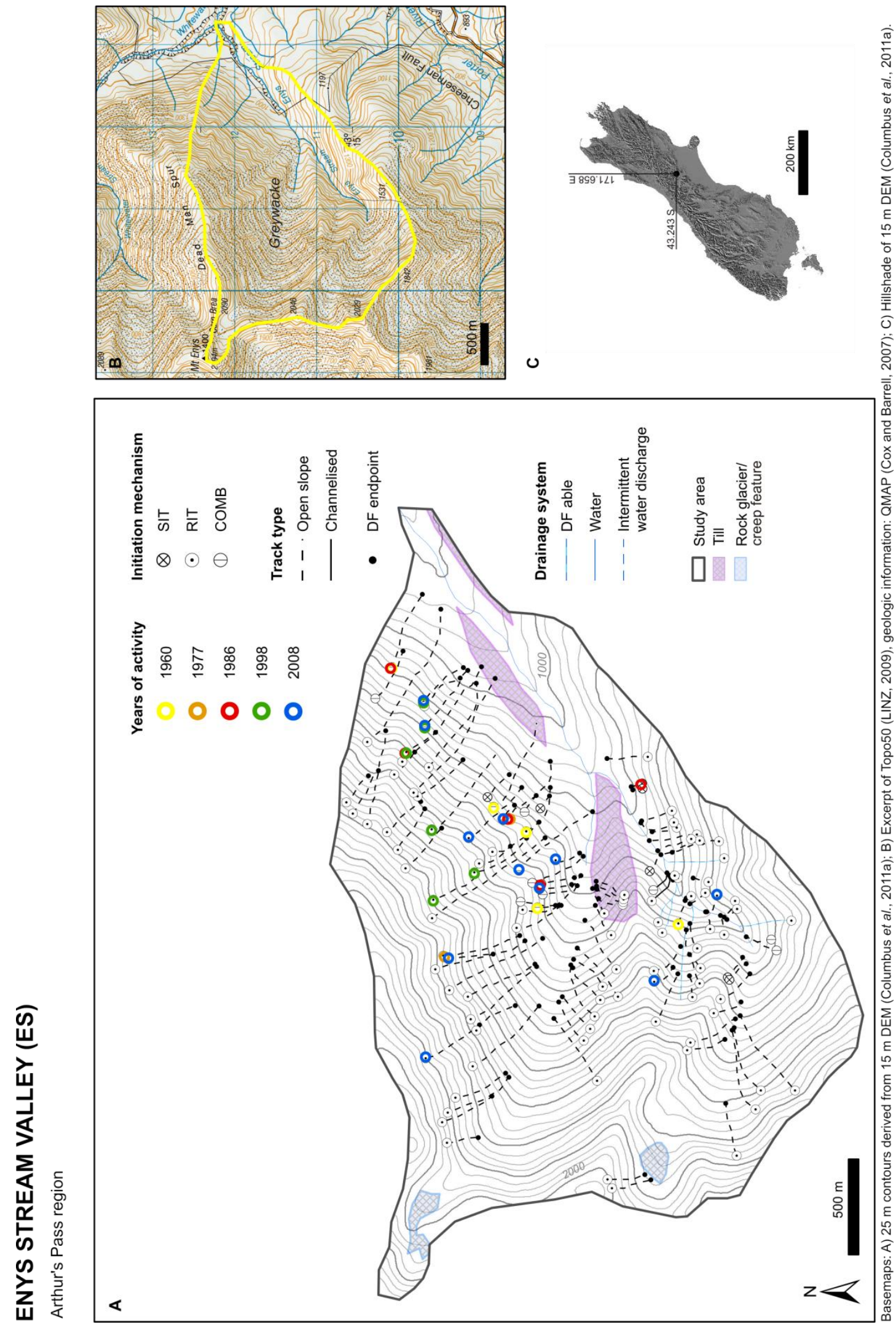

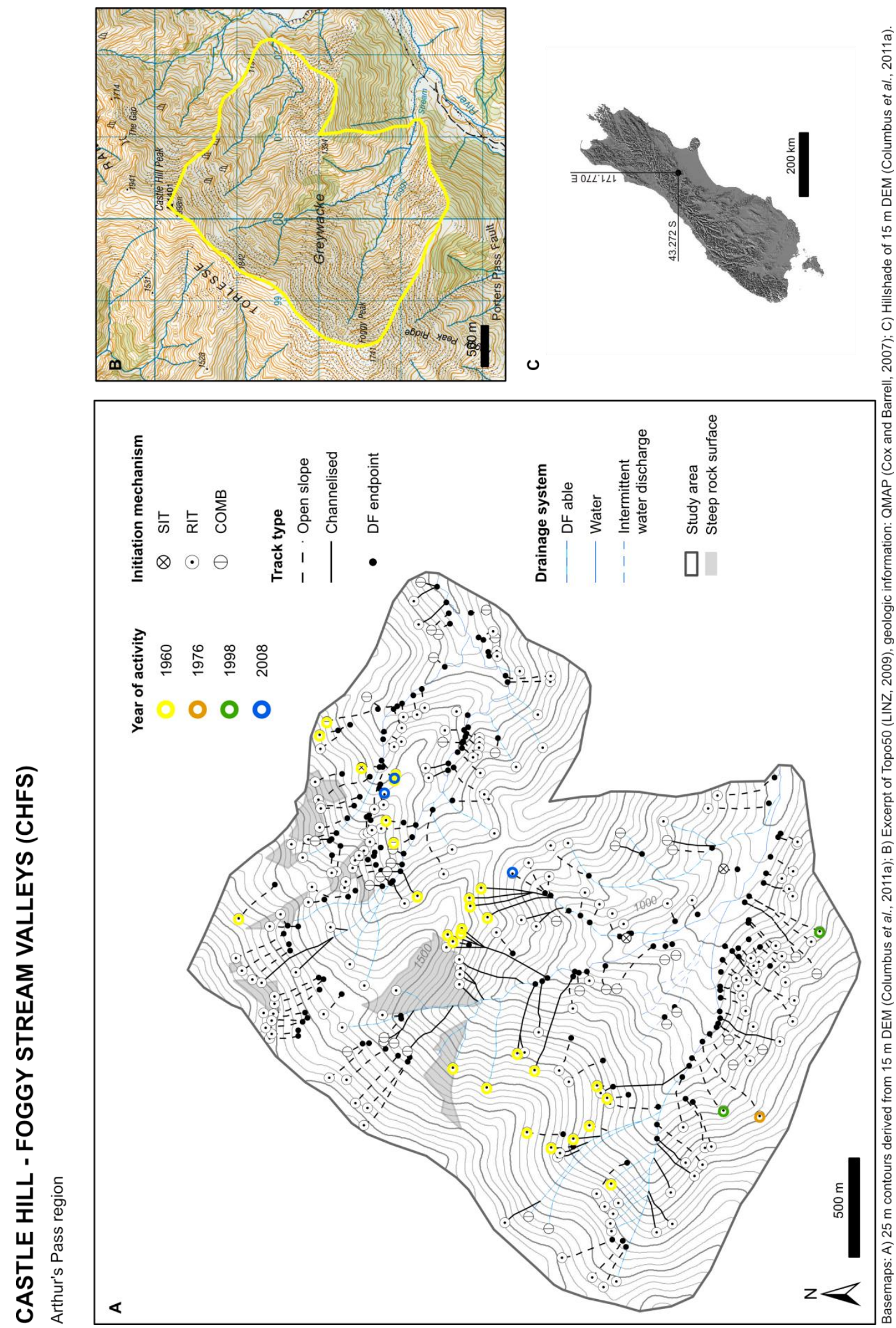


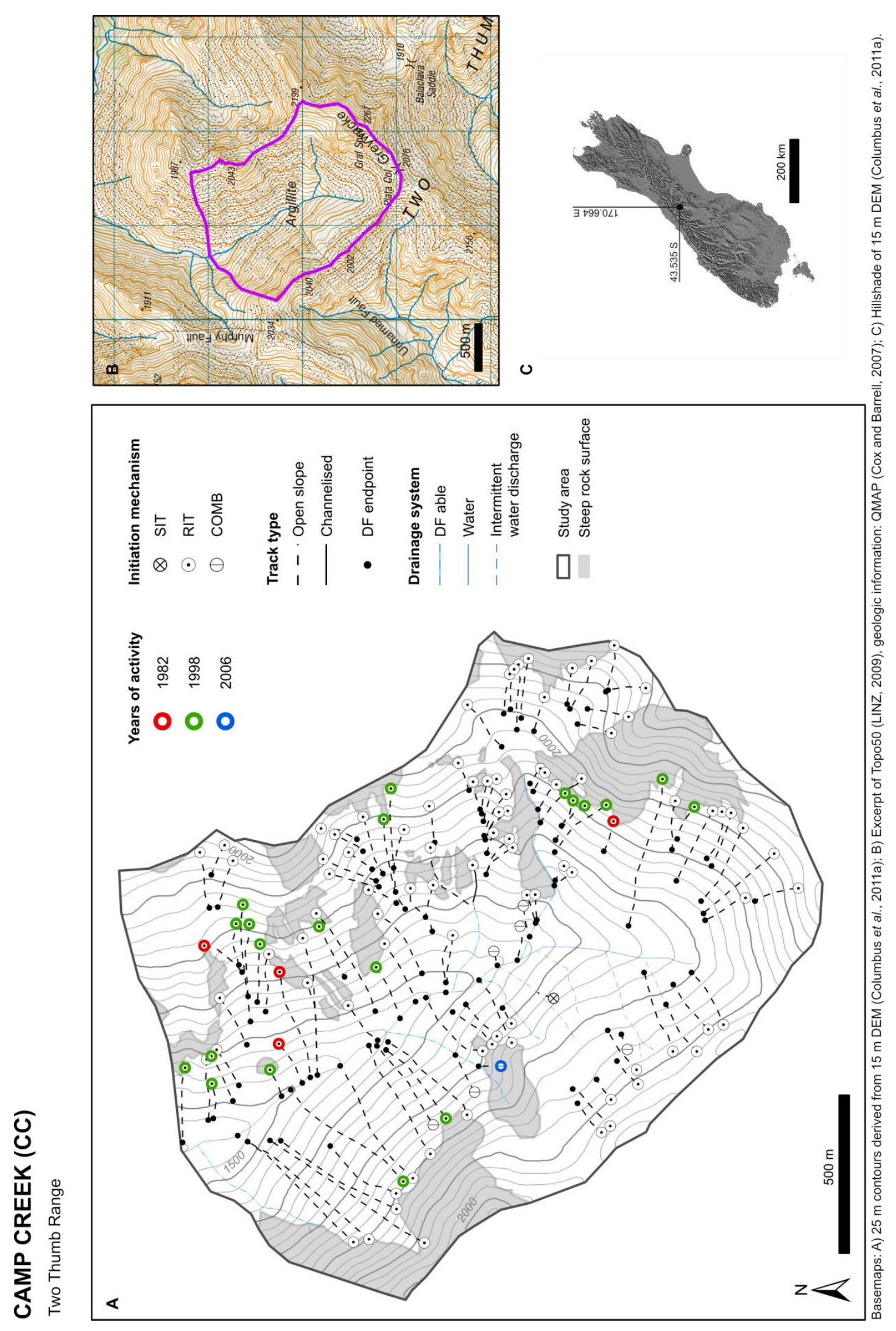




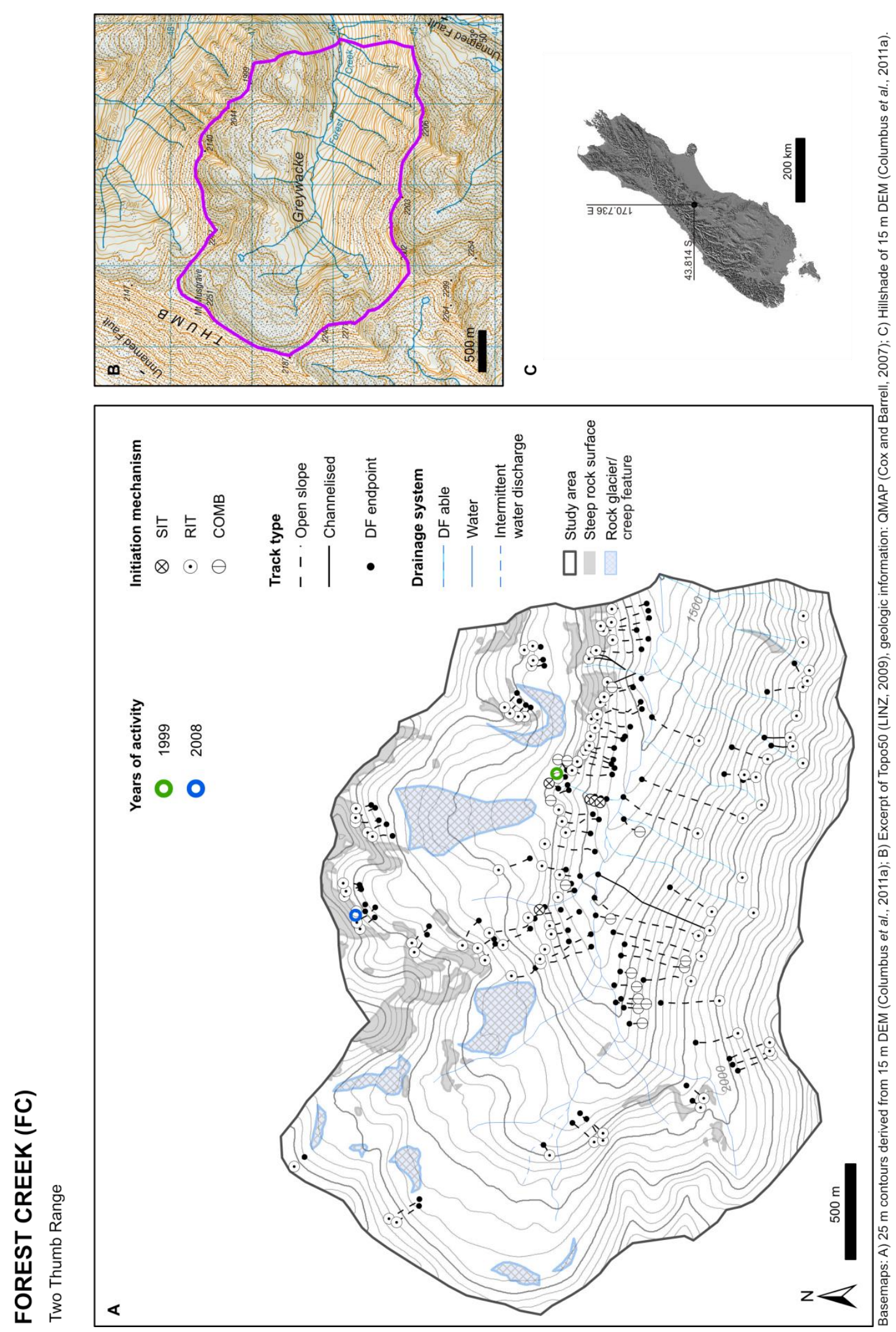




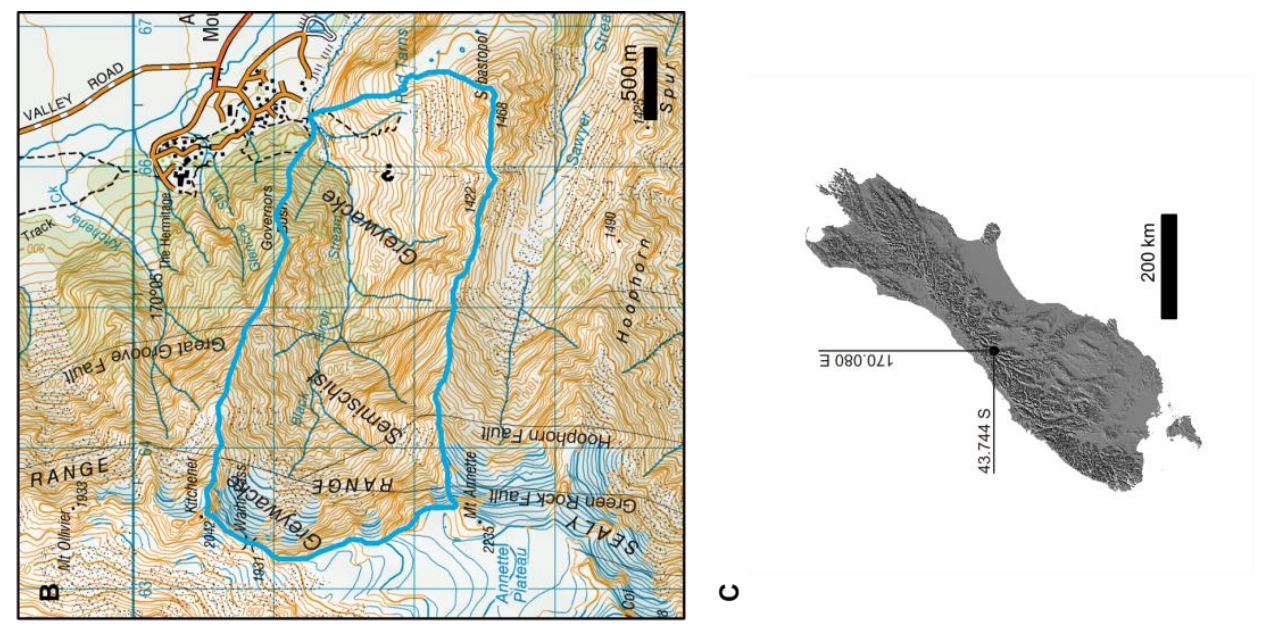

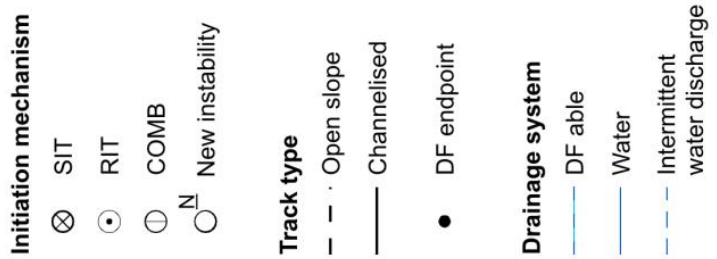

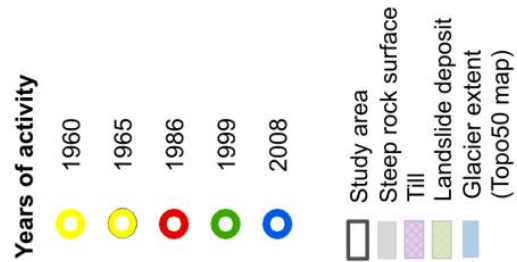
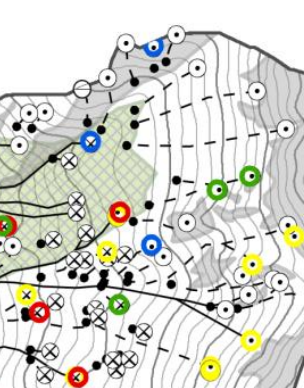

- 0.8
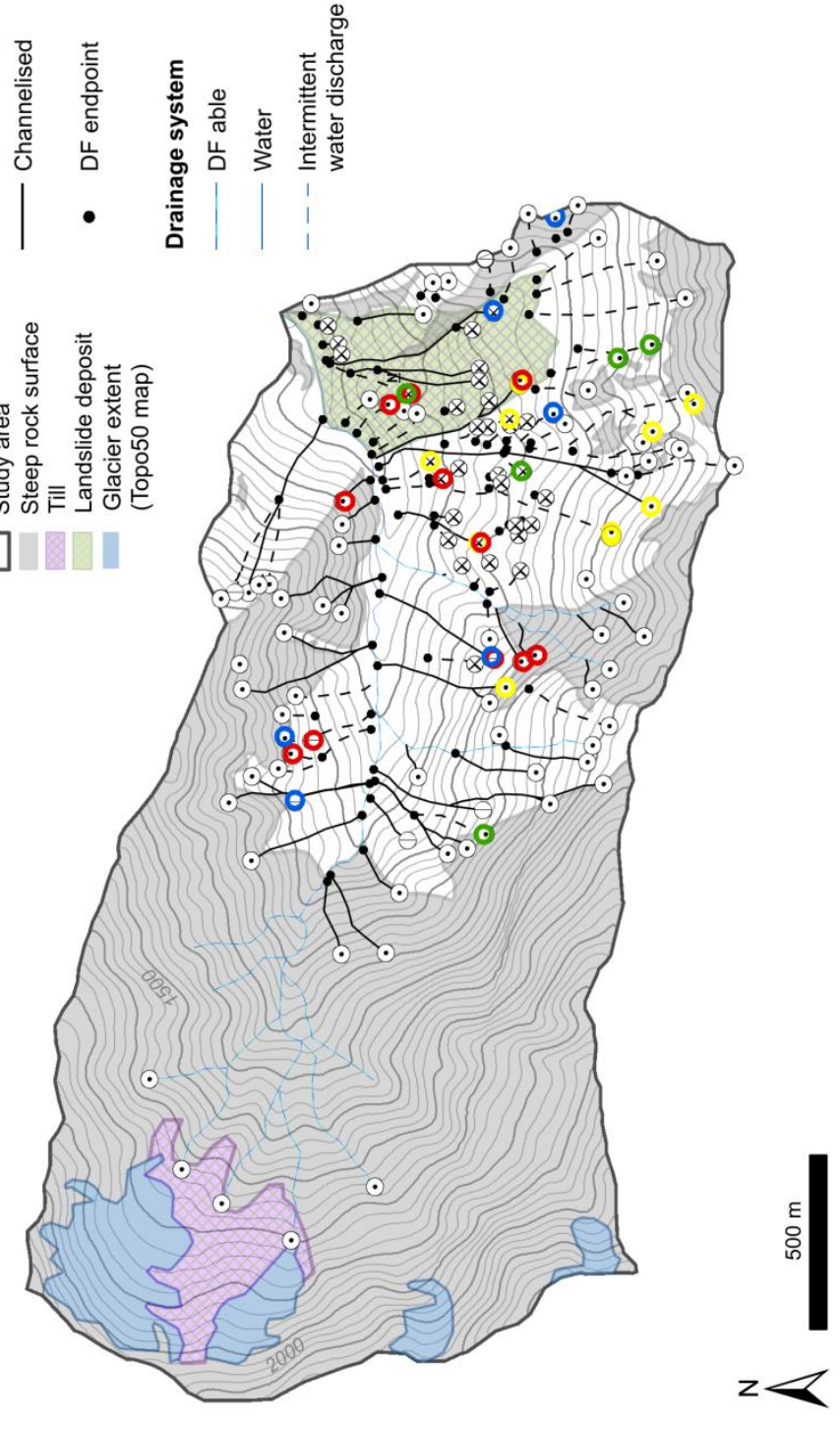

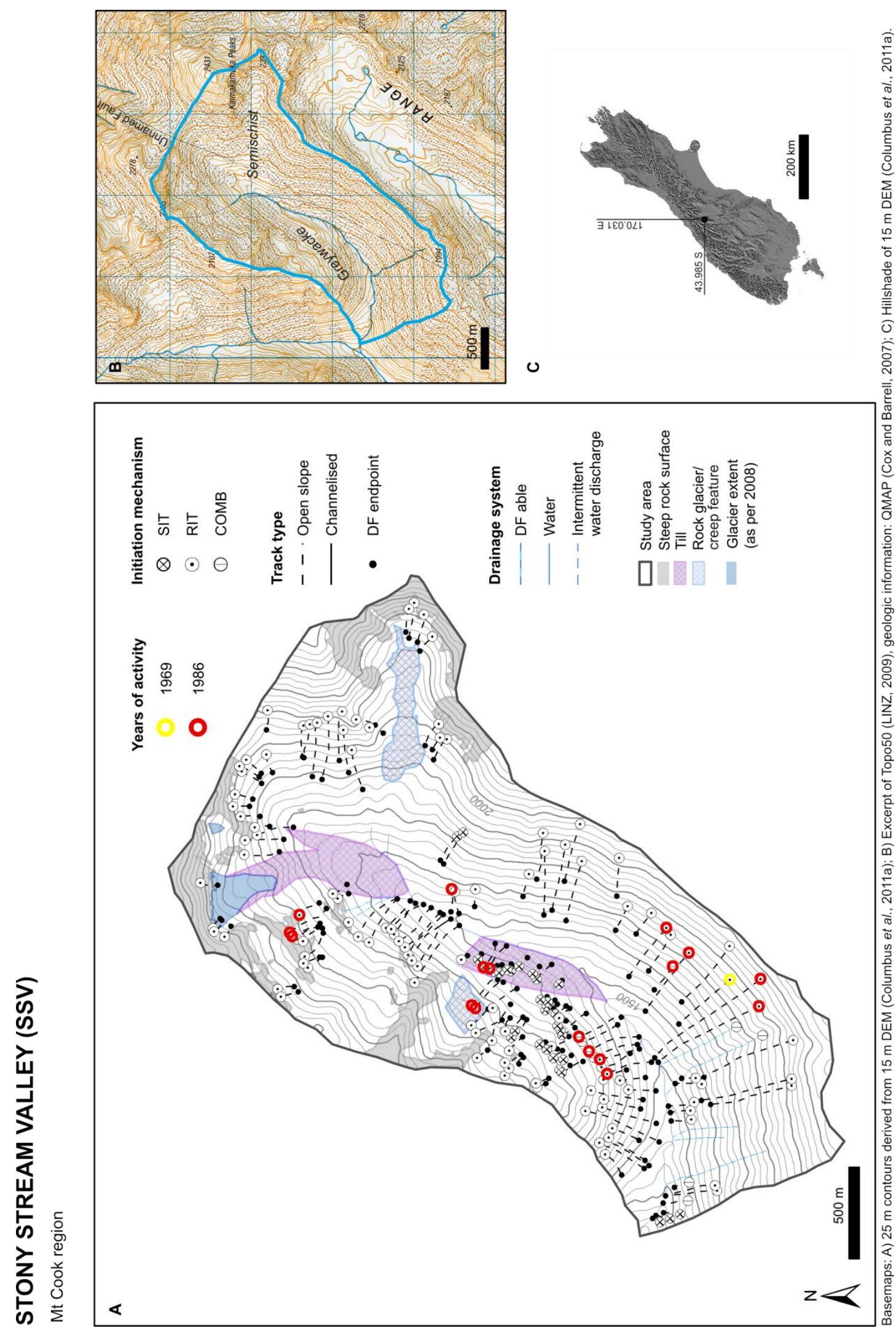

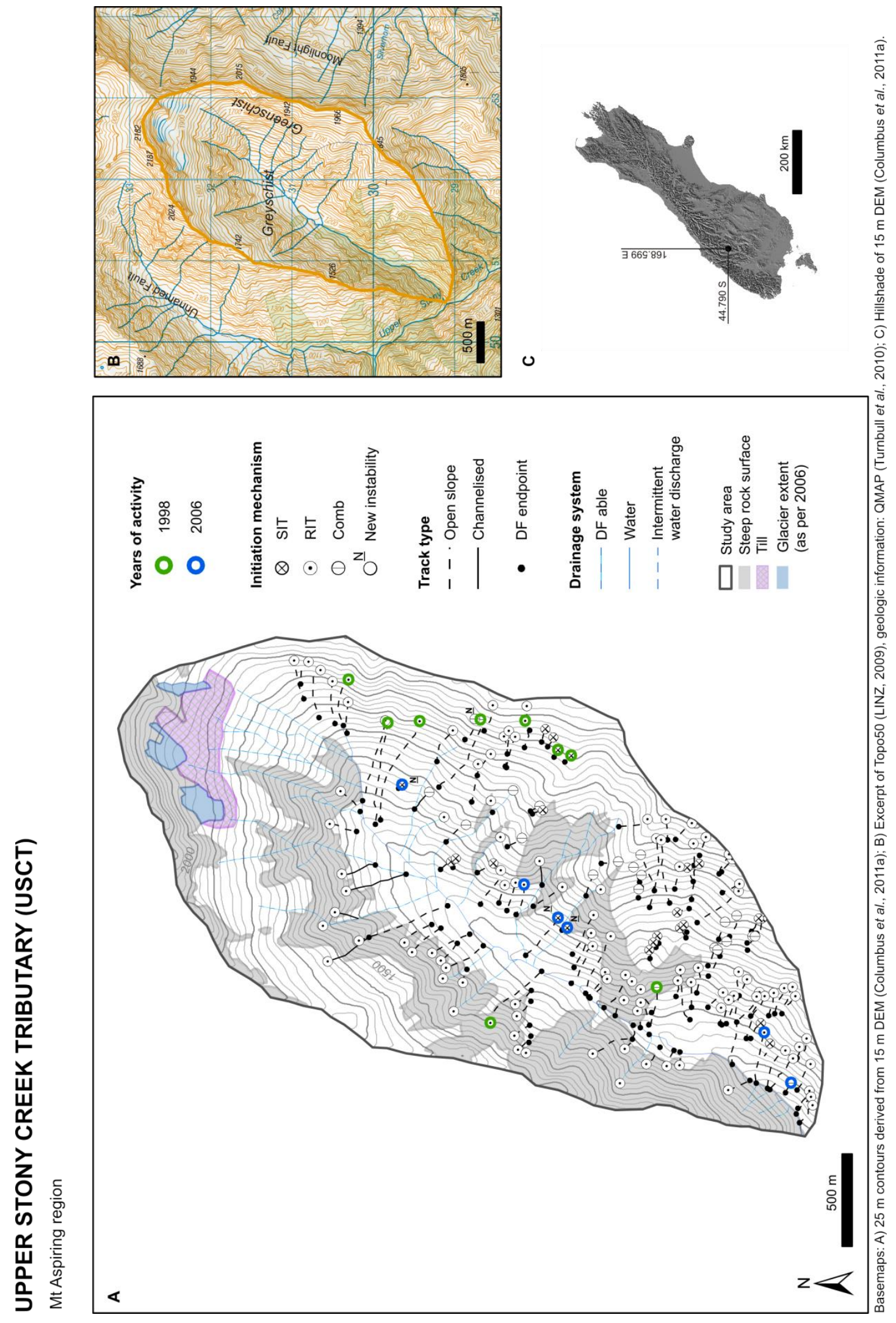


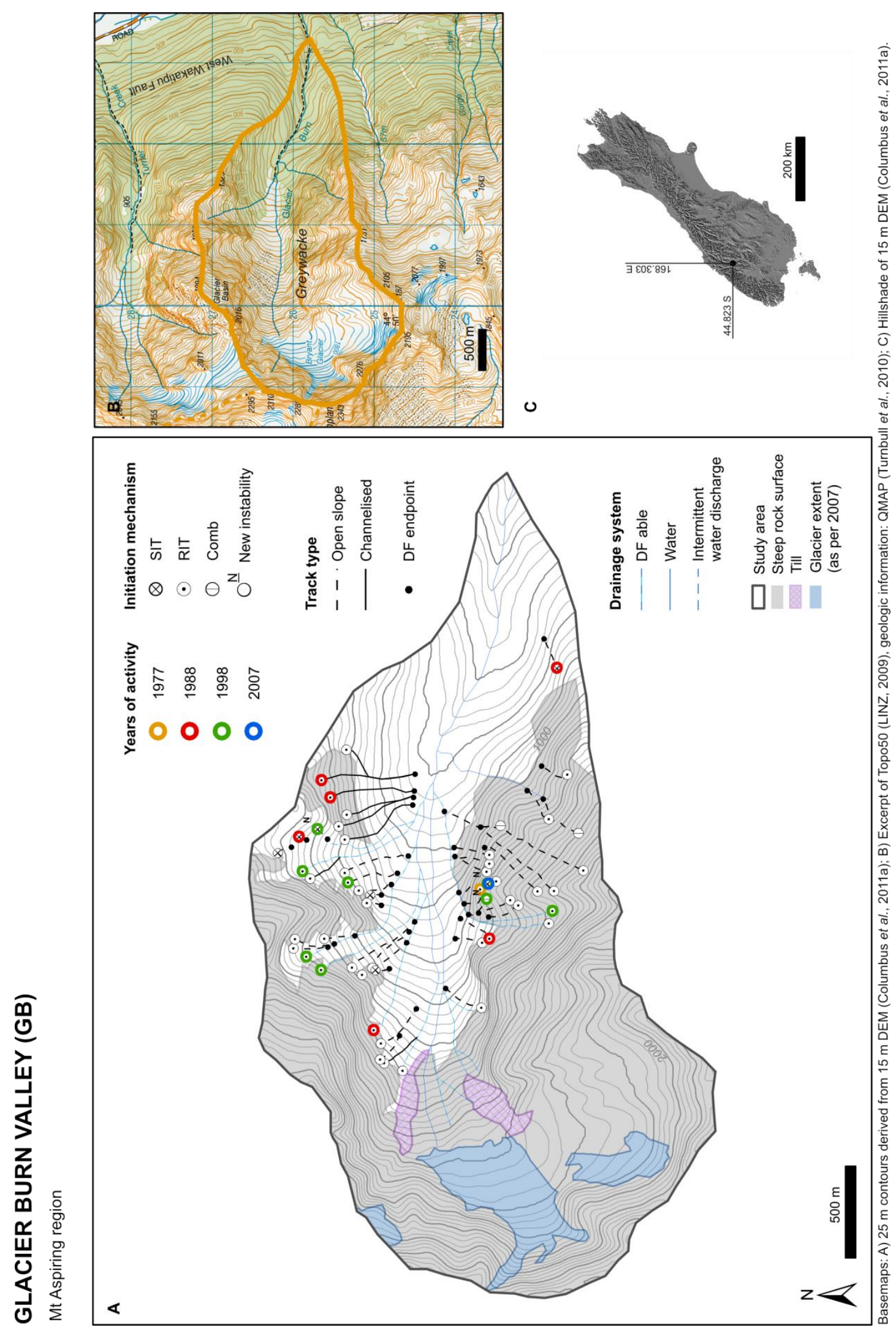



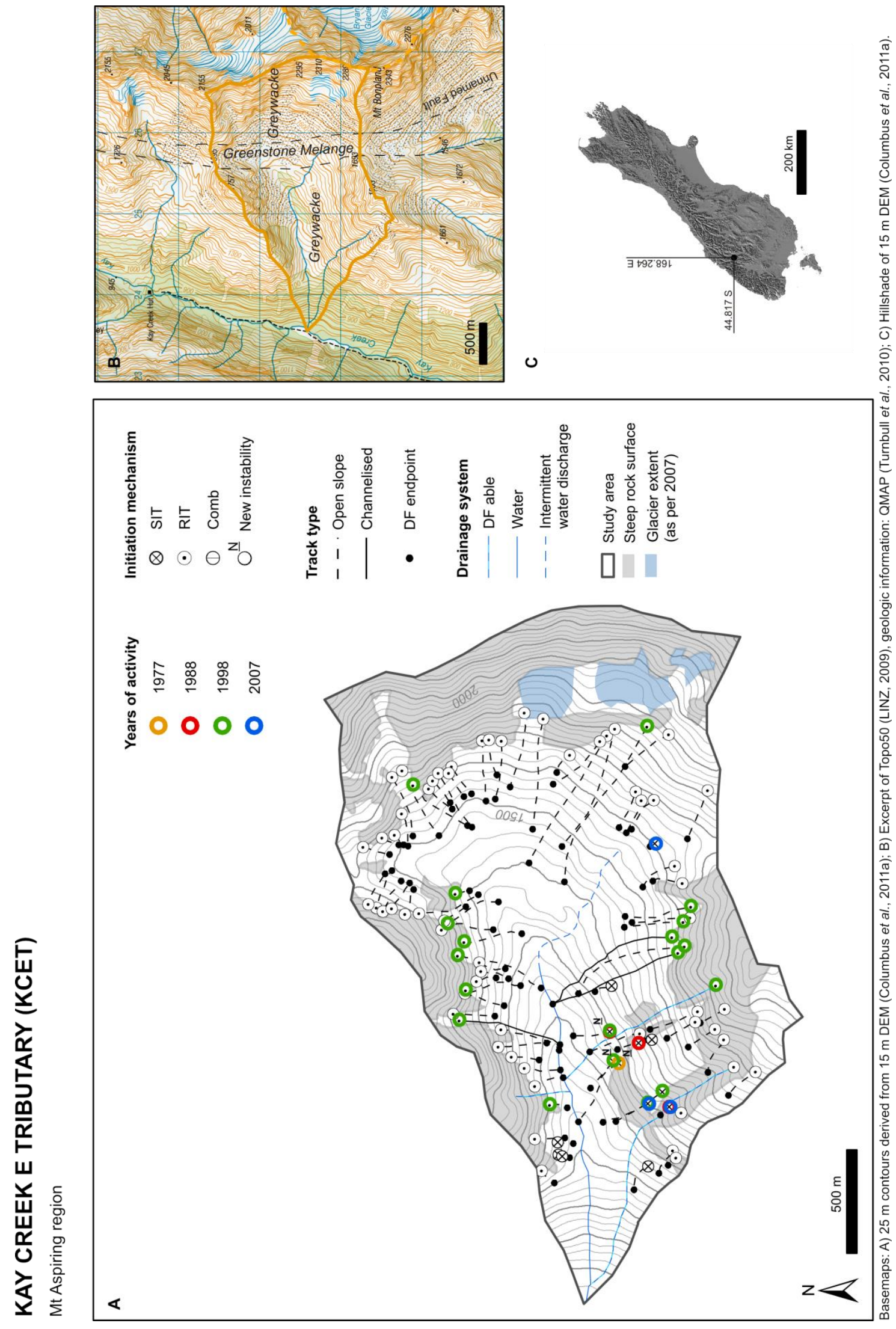


\section{APPENDIX 2: LIST OF AERIAL PHOTOGRAPHS USED FOR DEBRIS FLOW EVENT MAPPING (SECTION 3.2.2)}

\begin{tabular}{|c|c|c|c|c|c|c|c|c|}
\hline Region & Study area & Year & Photo $^{1}$ & Colour $^{2}$ & Scale & Source $^{3}$ & Quality $^{4}$ & No $G P s^{5}$ \\
\hline \multirow[t]{15}{*}{ Kaikoura ranges } & Trolove Stream valley & 1966 & 2033404020 & $\mathrm{~b} / \mathrm{w}$ & $1: 87500$ & GNS & 2 & 84 \\
\hline & & 1978 & 5052 D28 & $b / w$ & 1:25000 & GNS & 1 & 131 \\
\hline & & 1985 & 8452 B31 & $b / w$ & 1:50000 & NZArch & 2 & 75 \\
\hline & & 1997 & 418371 & $b / w$ & 1:50000 & NZASurv & 1 & 99 \\
\hline & & 2005 & OP mosaic & c & - & DoC & 1 & \\
\hline & Dart Stream valley (lower part) & 1966 & 2033404020 & $\mathrm{~b} / \mathrm{w}$ & 1:87500 & GNS & 2 & 84 \\
\hline & & 1978 & 2034404020 & $b / w$ & 1:25000 & GNS & 1 & 140 \\
\hline & & 1985 & 2035404020 & $\mathrm{~b} / \mathrm{w}$ & 1:50000 & NZArch & 2 & 75 \\
\hline & & 1997 & 2036404020 & $b / w$ & 1:50000 & NZASurv & 1 & 99 \\
\hline & & 2005 & 2037404020 & c & - & DoC & 1 & \\
\hline & Middlehead Stream valley & 1967 & 2033500026 & $b / w$ & 1:87500 & GNS & 2 & 135 \\
\hline & & 1974 & 3723 A6 & $b / w$ & 1:23900 & NZArch & 3 & - \\
\hline & & 1986 & 8533 E23 & $\mathrm{b} / \mathrm{w}$ & 1:25000 & NZArch & 1 & 135 \\
\hline & & 1997 & 418437 & $b / w$ & 1:50000 & NZASurv & 3 & 153 \\
\hline & & 2005 & OP mosaic & c & - & DoC & 1 & \\
\hline \multirow[t]{19}{*}{ Arthur's Pass region } & Denas Creek & 1959 & 1063274015 & $b / w$ & $1: 44500$ & GNS & 1 & 62 \\
\hline & & 1964 & 150837261 & $b / w$ & 1: 67500 & GNS & 1 & 67 \\
\hline & & 1977 & $5060 \mathrm{E} 3$ & $b / w$ & 1: 44000 & NZArch & 2 & 75 \\
\hline & & 1986 & $8584 \mathrm{E} 4$ & $b / w$ & 1: 50000 & NZArch & 2 & 76 \\
\hline & & 1998 & 506167 & $b / w$ & 1:50000 & NZASurv & 1 & 84 \\
\hline & & 2008 & OP mosaic & c & - & DoC & 1 & \\
\hline & Enys Stream valley & 1948 & 168612 & $\mathrm{~b} / \mathrm{w}$ & $1: 24600$ & NZArch & 1 & 52 \\
\hline & & & 168613 & $b / w$ & $1: 24600$ & NZArch & 1 & 29 \\
\hline & & 1960 & 1063274730 & $b / w$ & 1:44500 & GNS & 1 & 134 \\
\hline & & 1977 & $5060 \mathrm{H} 10$ & $b / w$ & 1:44000 & NZArch & 2 & 135 \\
\hline & & 1986 & $8584 \mathrm{H} 10$ & $b / w$ & 1:50000 & NZArch & 2 & 101 \\
\hline & & 1998 & 506238 & $\mathrm{~b} / \mathrm{w}$ & 1:50000 & NZASurv & 1 & 113 \\
\hline & & 2008 & OP mosaic & c & - & DoC & 1 & \\
\hline & Castle Hill - & 1948 & $168619-21$ & $b / w$ & $1: 24600$ & GNS & 1 & 179 \\
\hline & Foggy Stream valleys & 1960 & 1063276037 & $\mathrm{~b} / \mathrm{w}$ & 1:44500 & GNS & 1 & 265 \\
\hline & & 1976 & $2956 \mathrm{H} 1-10$ & $b / w$ & 1: 10000 & NZArch & 2 & 139 \\
\hline & & 1986 & $8584 \mid 10$ & $b / w$ & 1:50000 & NZArch & 2 & 135 \\
\hline & & 1998 & $12542 \mathrm{~A} 1$ & $\mathrm{~b} / \mathrm{w}$ & 1:50000 & NZArch & 2 & 134 \\
\hline & & 2008 & OP mosaic & c & - & DoC & 1 & \\
\hline \multirow[t]{12}{*}{ Two Thumb Range } & Camp Creek & 1964 & 1580372623 & $\mathrm{~b} / \mathrm{w}$ & 1: 67500 & NZArch & 1 & 92 \\
\hline & & 1982 & 8039 E9 & $\mathrm{b} / \mathrm{w}$ & 1:50000 & NZArch & 2 & 81 \\
\hline & & 1986 & 8595 A18 & $\mathrm{b} / \mathrm{w}$ & 1:50000 & NZArch & 2 & 79 \\
\hline & & 1998 & 506593 & $\mathrm{~b} / \mathrm{w}$ & 1:50000 & NZASurv & 1 & 103 \\
\hline & & 2006 & OP mosaic & c & - & DoC & 1 & \\
\hline & Forest Creek & 1957 & 101825007 & $b / w$ & 1: 44500 & NZArch & 1 & 70 \\
\hline & & & 101825016 & $\mathrm{~b} / \mathrm{w}$ & 1: 44501 & NZArch & 1 & 52 \\
\hline & & 1964 & 1580373022 & $\mathrm{~b} / \mathrm{w}$ & 1: 67500 & NZArch & 3 & 107 \\
\hline & & 1980 & $5664 \mathrm{~A} 1$ & $b / w$ & 1:25000 & NZArch & 1 & 113 \\
\hline & & 1986 & 8595 E19 & $\mathrm{b} / \mathrm{w}$ & 1:50000 & NZArch & 2 & 119 \\
\hline & & 1999 & 613554 & $\mathrm{~b} / \mathrm{w}$ & 1:50000 & & 1 & 139 \\
\hline & & 2008 & OP mosaic & c & - & DoC & 1 & \\
\hline \multirow[t]{12}{*}{ Mt Cook region } & Black Birch Stream valley & 1954 & $2311 / 2$ & $\mathrm{~b} / \mathrm{w}$ & & GNS & 1 & 104 \\
\hline & & 1960 & $10612715 \mathrm{~A} / 2$ & $b / w$ & 1: 44500 & GNS & 1 & 136 \\
\hline & & 1965 & 1580372440 & $b / w$ & 1: 67500 & NZArch & 2 & 138 \\
\hline & & 1986 & 8595 D16 & $b / w$ & 1:50000 & NZAM & 1 & 81 \\
\hline & & 1999 & 614662 & $b / w$ & 1:50000 & NZAM & 1 & 140 \\
\hline & & 2008 & OP mosaic & c & - & DoC & 1 & \\
\hline & Stony Stream valley ( $E$ fork) & 1960 & 1061271617 & $\mathrm{~b} / \mathrm{w}$ & $1: 44500$ & NZArch & 1 & 121 \\
\hline & & & 1061271618 & $\mathrm{~b} / \mathrm{w}$ & 1: 44501 & NZArch & 2 & 34 \\
\hline & & 1969 & $2085 \mathrm{C} 12$ & $\mathrm{~b} / \mathrm{w}$ & 1: 87000 & NZArch & 3 & 80 \\
\hline & & 1986 & 8595 G14 & $\mathrm{b} / \mathrm{w}$ & 1:50000 & NZArch & 2 & 78 \\
\hline & & 1999 & 613639 & $\mathrm{~b} / \mathrm{w}$ & 1:50000 & NZASurv & 1 & 134 \\
\hline & & 2006 & OP mosaic & c & - & DoC & 1 & \\
\hline
\end{tabular}

1 Photo ID refers to Survey No - Run No - Photo No or in case of NZSurv photos only to Photo No, OP mosaic refers to excerpt of the Terralink (2005-2008) orthophotograph mosaic

2 Colour of airphoto: black \& white (b/w), multicolour (c)

${ }^{3}$ Source of airphoto hard copy: GNS Science (GNS), New Zealand Archives (NZArch), NZ Aerial Survey (NZASurv),

Department of Conservation (DoC), Otago Regional Council (ORC)

${ }^{4}$ Ranking of airphoto quality $(1=$ good, $2=$ moderate, $3=$ bad $)$

5 Number of ground points used for georeferencing 


\begin{tabular}{|c|c|c|c|c|c|c|c|c|}
\hline Region & Study area & Year & Photo & Colour & Scale & Source & Quality & No GPS \\
\hline \multirow{14}{*}{ Mt Aspiring region } & Upper Stony Creek & 1966 & 2016398528 & $b / w$ & 1: 87500 & NZArch & 3 & 65 \\
\hline & $\mathrm{NE}$ tributary & 1984 & $8426 \mathrm{H} 9$ & $\mathrm{~b} / \mathrm{w}$ & 1: 50000 & NZArch & 2 & 115 \\
\hline & & 1998 & 611062 & c & 1: 50000 & NZASurv & 1 & 123 \\
\hline & & 2006 & OP mosaic & c & - & ORC & 1 & \\
\hline & Glacier Burn valley & 1966 & 2016398521 & $\mathrm{~b} / \mathrm{w}$ & 1: 87500 & NZArch & 2 & 55 \\
\hline & & 1977 & 5062 A8 & $b / w$ & 1: 25000 & NZArch & 1 & 87 \\
\hline & & 1988 & 8996 E 17 & $b / w$ & 1: 50000 & NZArch & 2 & 93 \\
\hline & & 1998 & 610963 & c & 1: 50000 & NZASurv & 1 & 75 \\
\hline & & 2007 & OP mosaic & & & ORC & 1 & \\
\hline & Kay Creek E tributary & 1966 & 2016398521 & $\mathrm{~b} / \mathrm{w}$ & 1: 87500 & NZArch & 2 & 55 \\
\hline & & 1977 & 5062 A 6 & $\mathrm{~b} / \mathrm{w}$ & 1: 25000 & NZArch & 1 & 68 \\
\hline & & 1988 & 8996 E 17 & $b / w$ & 1: 50000 & NZArch & 2 & 93 \\
\hline & & 1998 & 610964 & c & 1: 50000 & NZASurv & 1 & 76 \\
\hline & & 2007 & OP mosaic & c & - & ORC & 1 & \\
\hline
\end{tabular}




\section{APPENDIX 3: REGIONAL CHARACTERISTICS OF DEBRIS FLOW ACTIVITY IN THE STUDY AREAS (SECTION 3.3.1)}

\section{A 3.1 Initiation type}
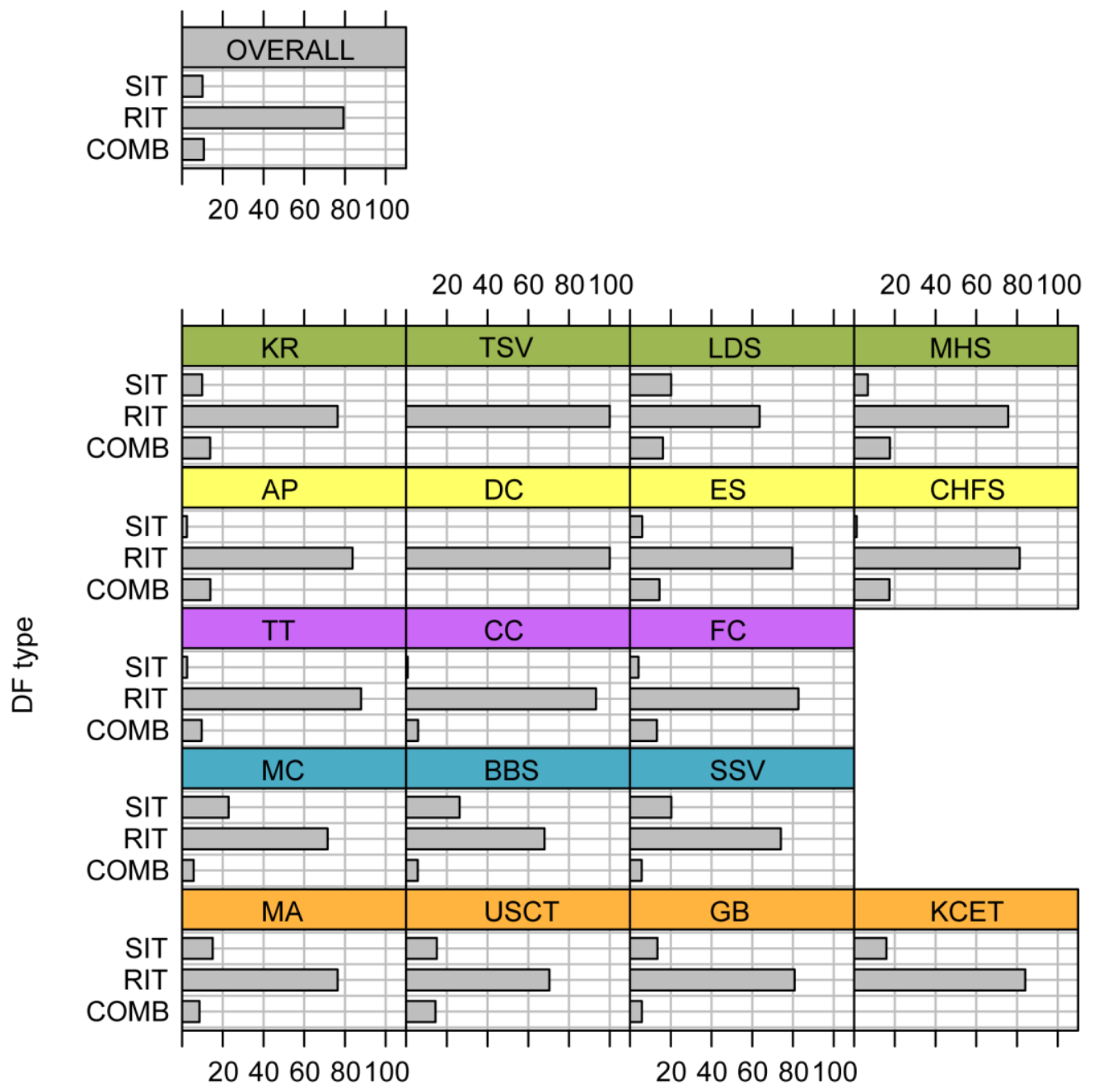

$\%$ of DF systems 
A 3.2 Regolith supply conditions
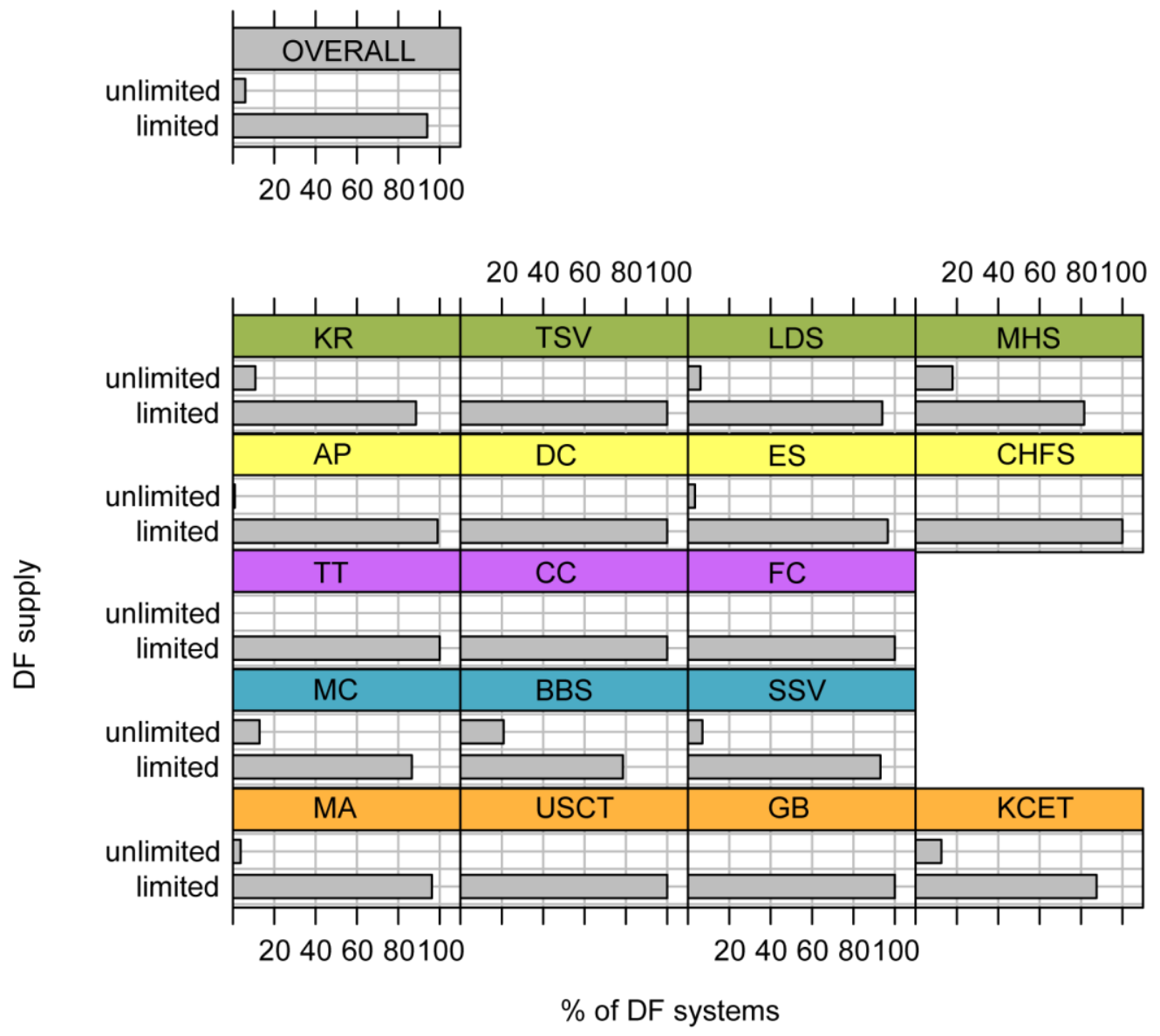


\section{A 3.3 Aspect}
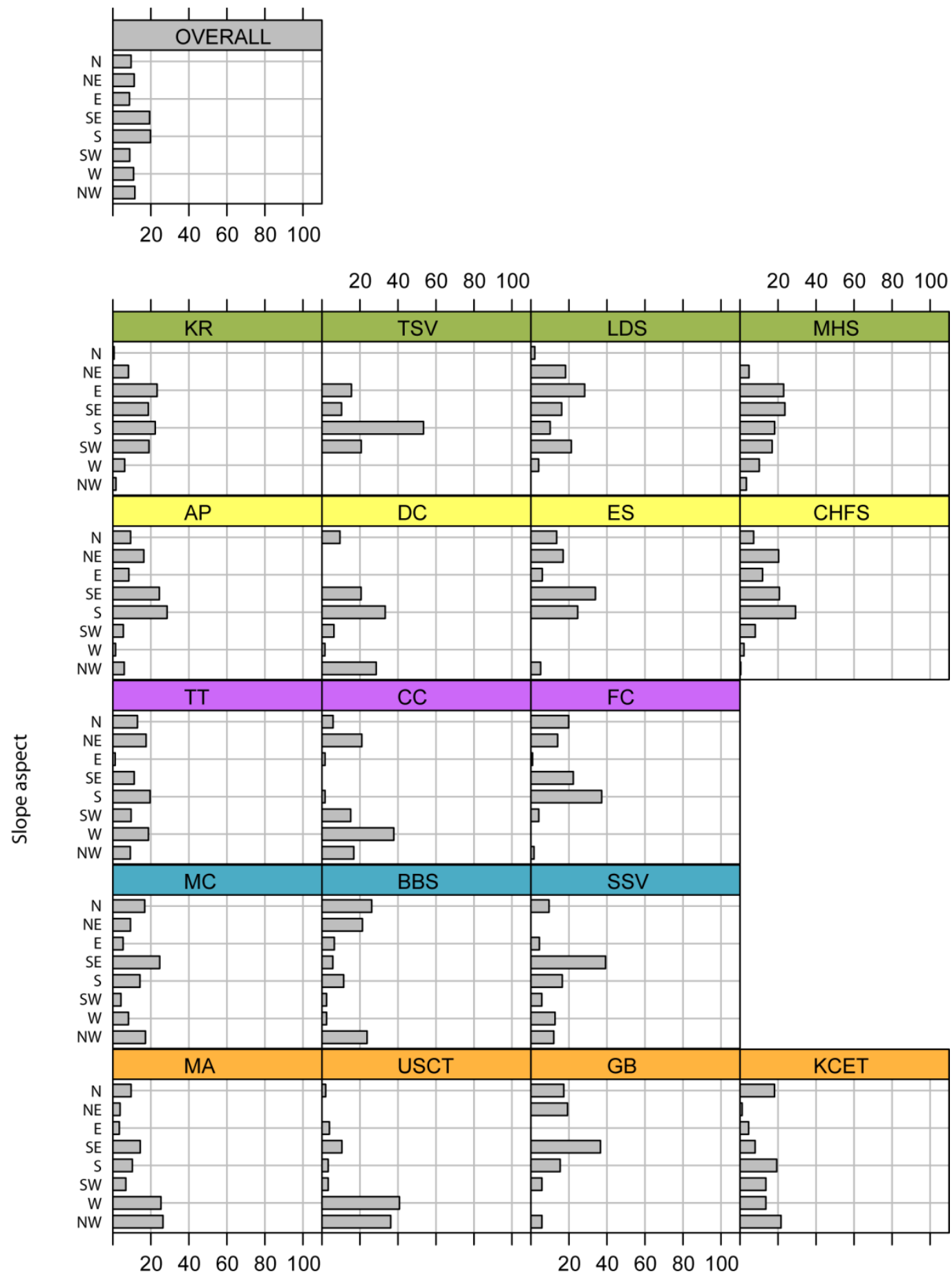

$\%$ of DF systems 
A 3.4 Slope
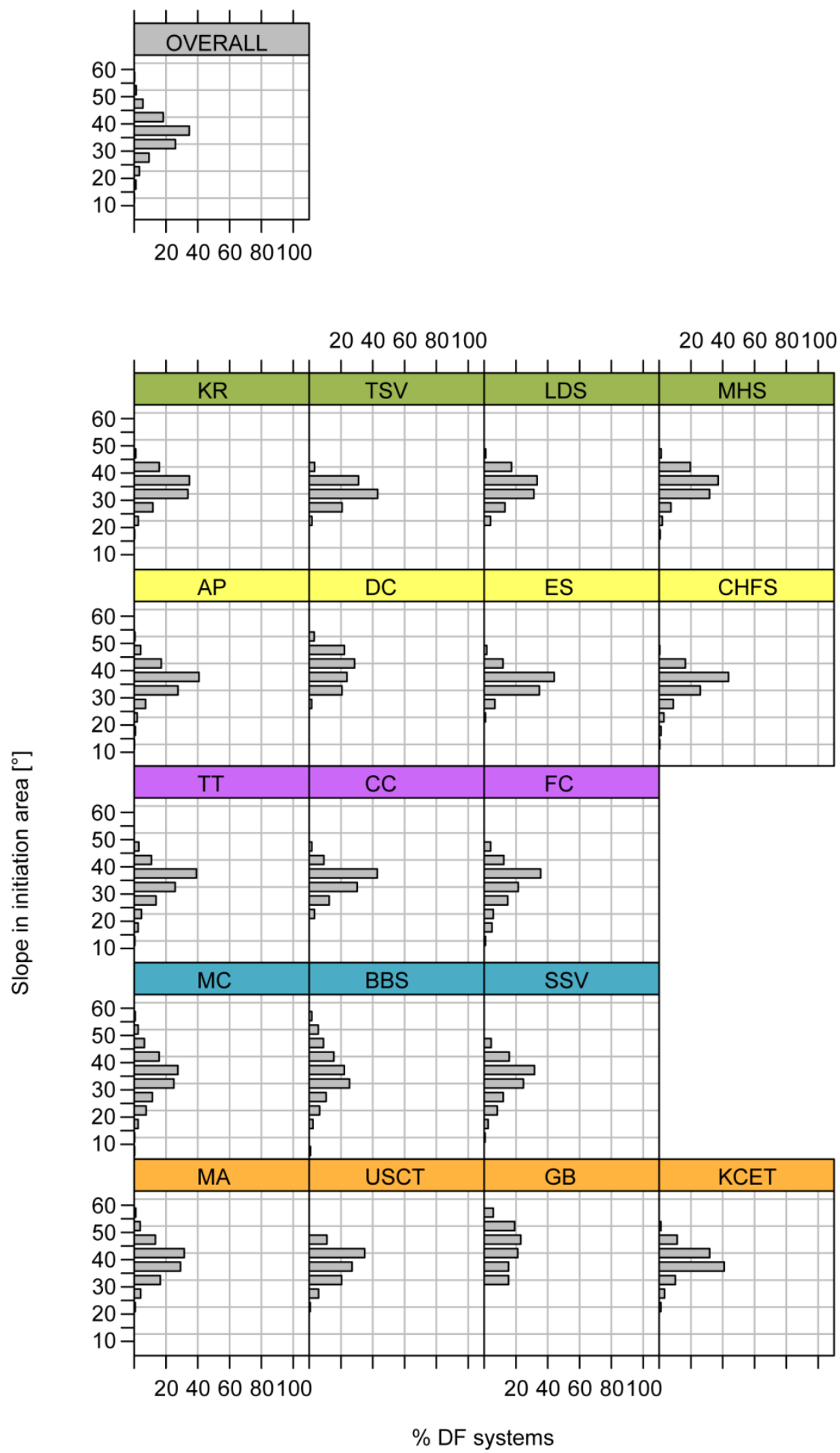
A 3.5 Altitude above sea level
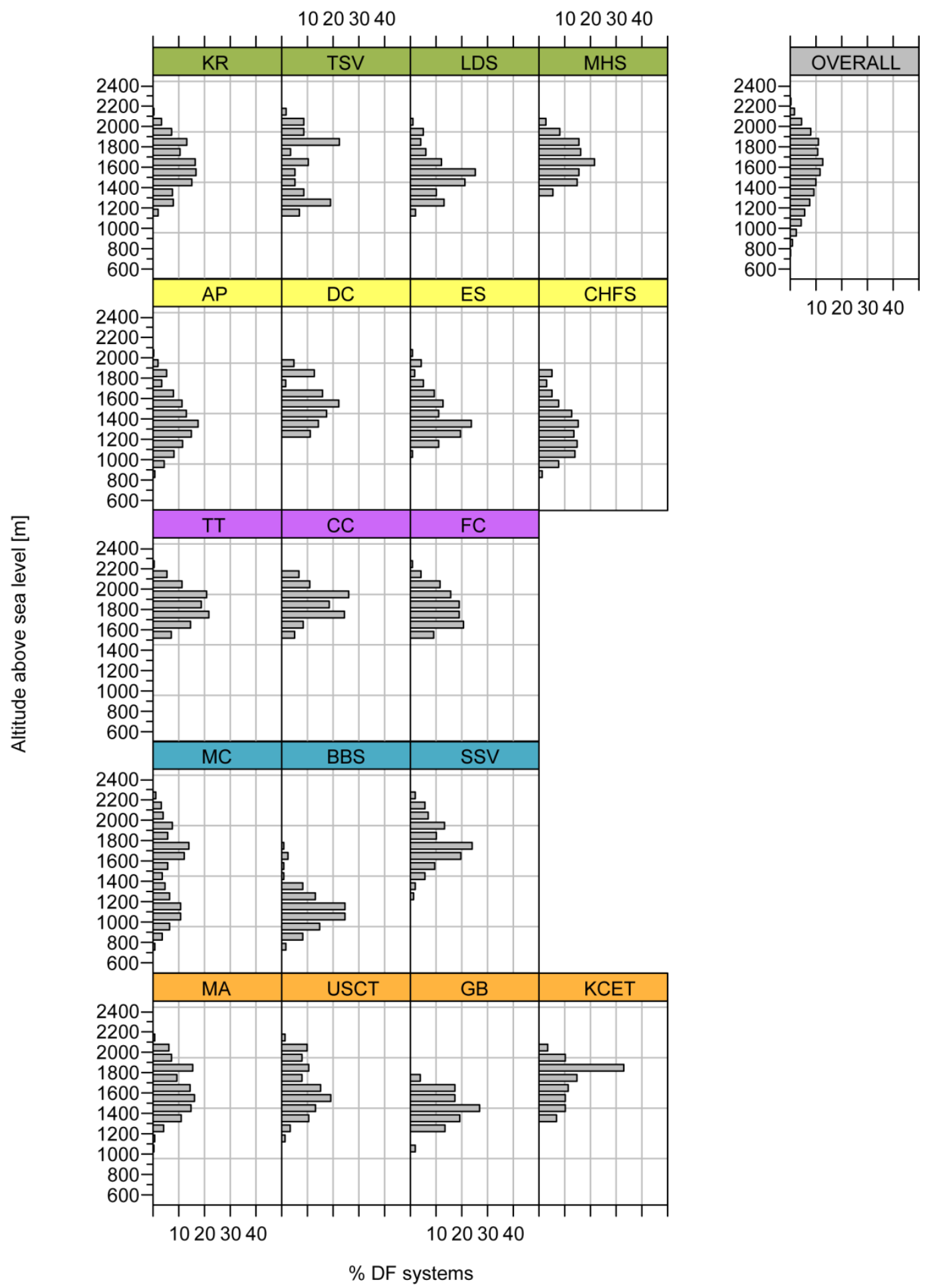
A 3.6 Altitude above catchment exit (relative altitude)

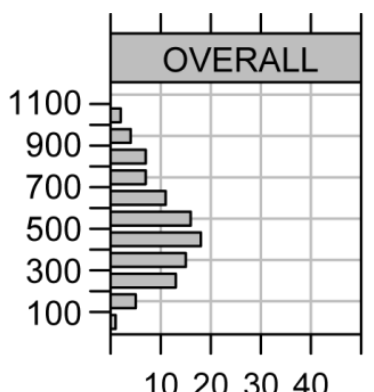

10203040

10203040

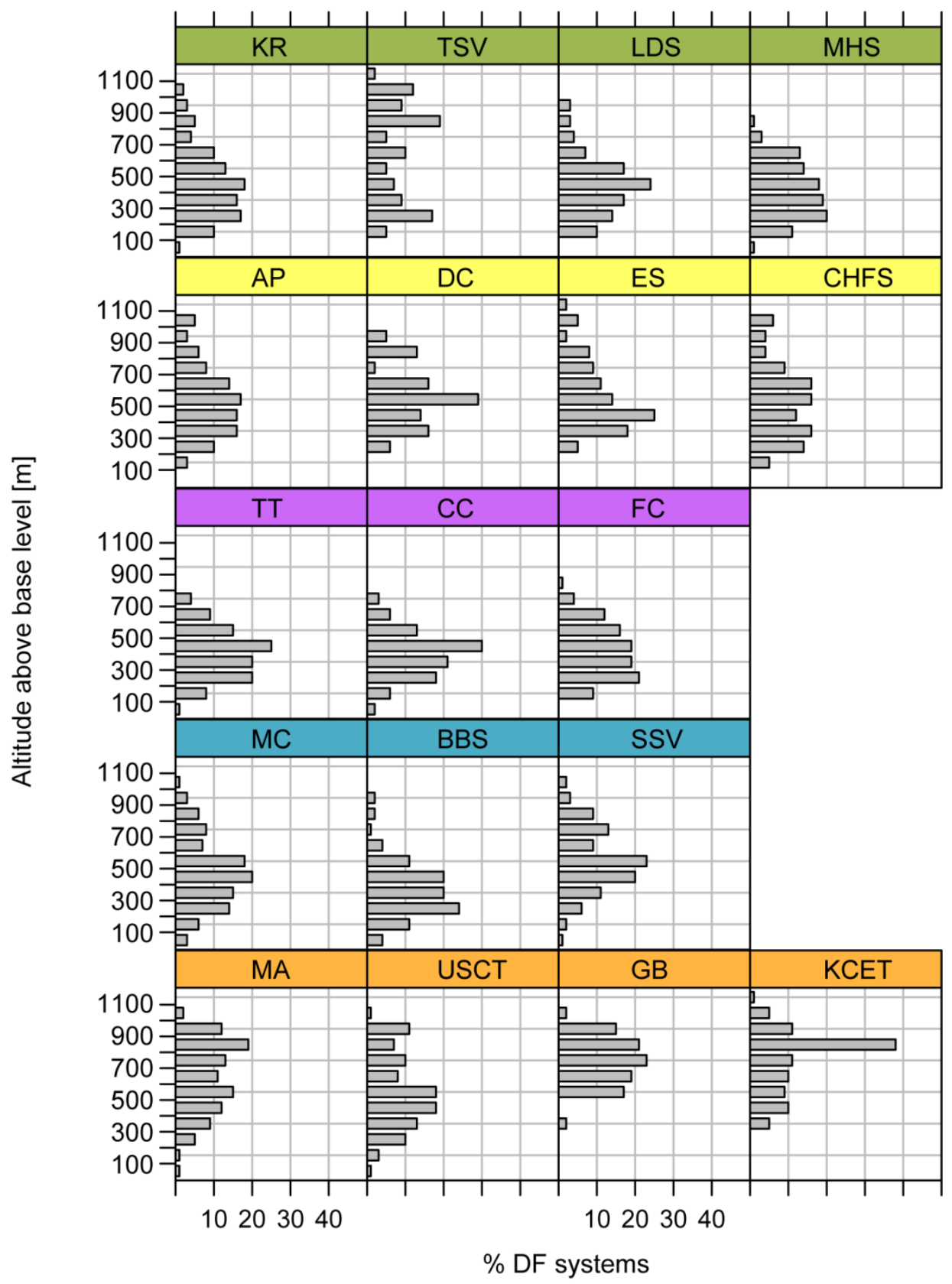


A 3.7 Altitude and sediment (rock/debris) distribution

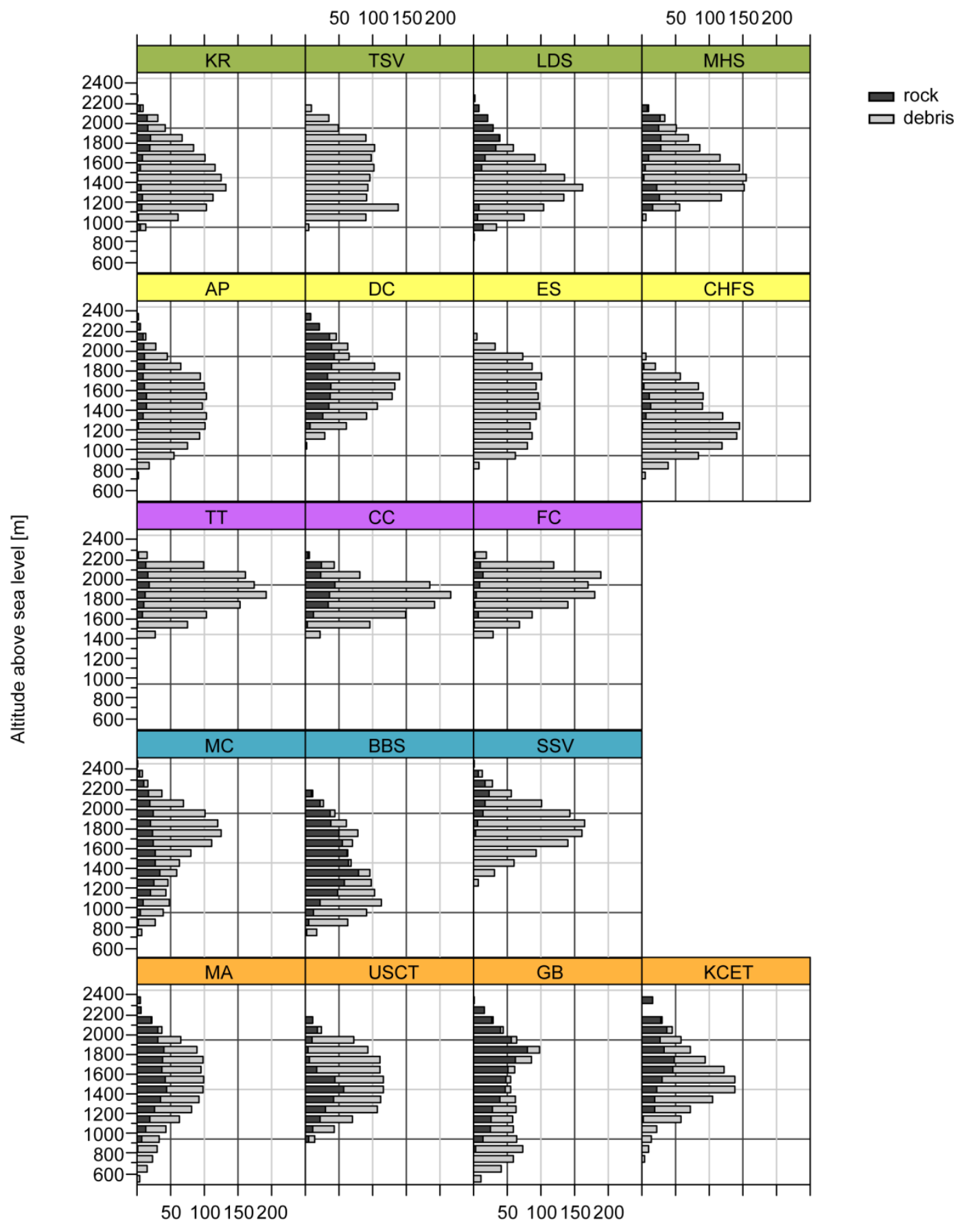

$\%$ of study area 


\section{APPENDIX 4: DEBRIS FLOW ACTIVITY IN STUDY AREAS THROUGH TIME (SECTION 3.3.2)}
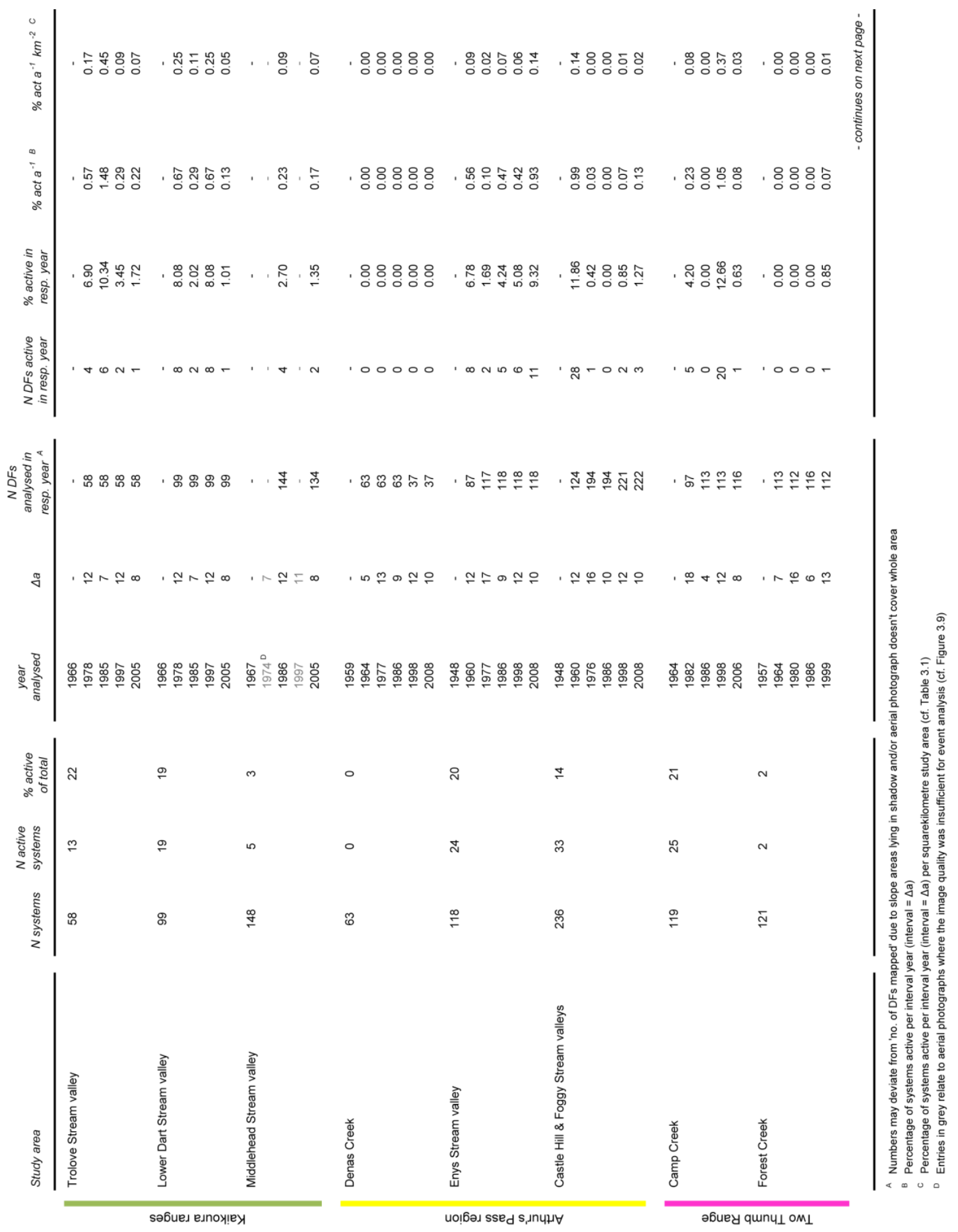


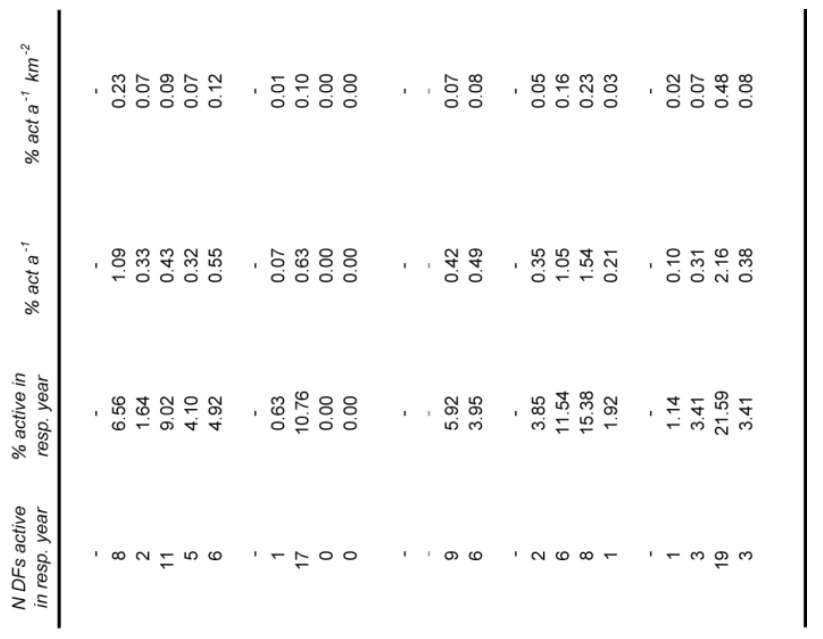

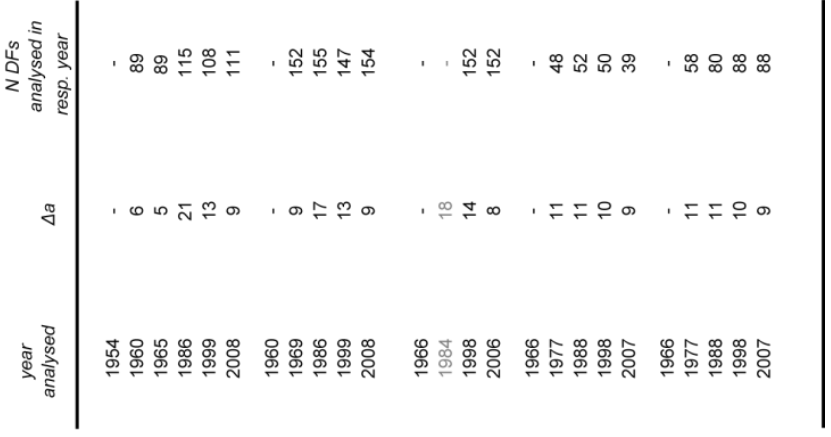
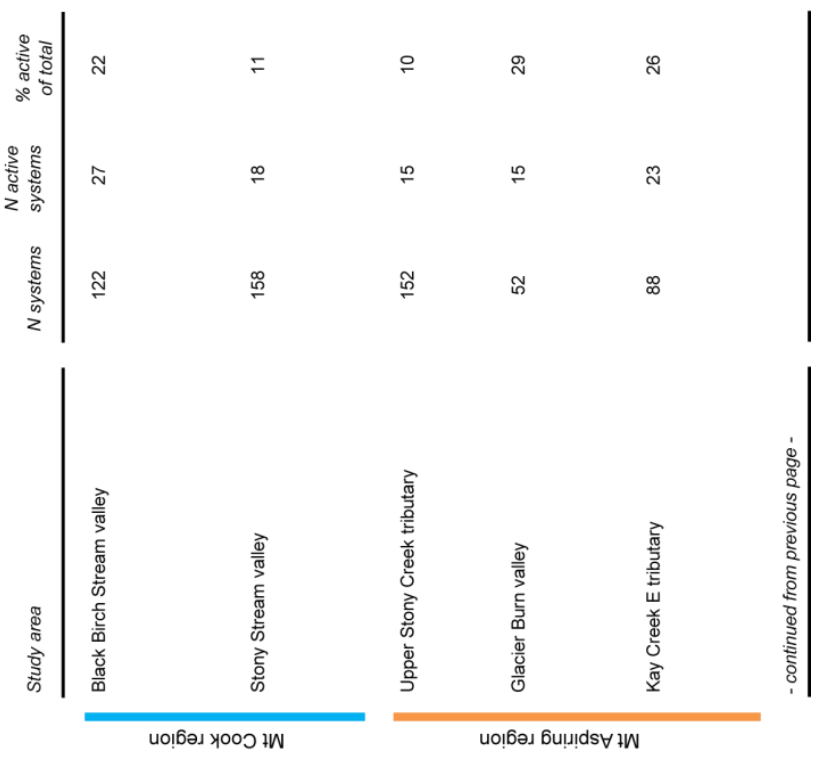


\section{APPENDIX 5: REGIONAL CHARACTERISTICS OF DEBRIS FLOW EVENTS IN THE STUDY AREAS (SECTION 3.3.2)}

A 5.1 Initiation type
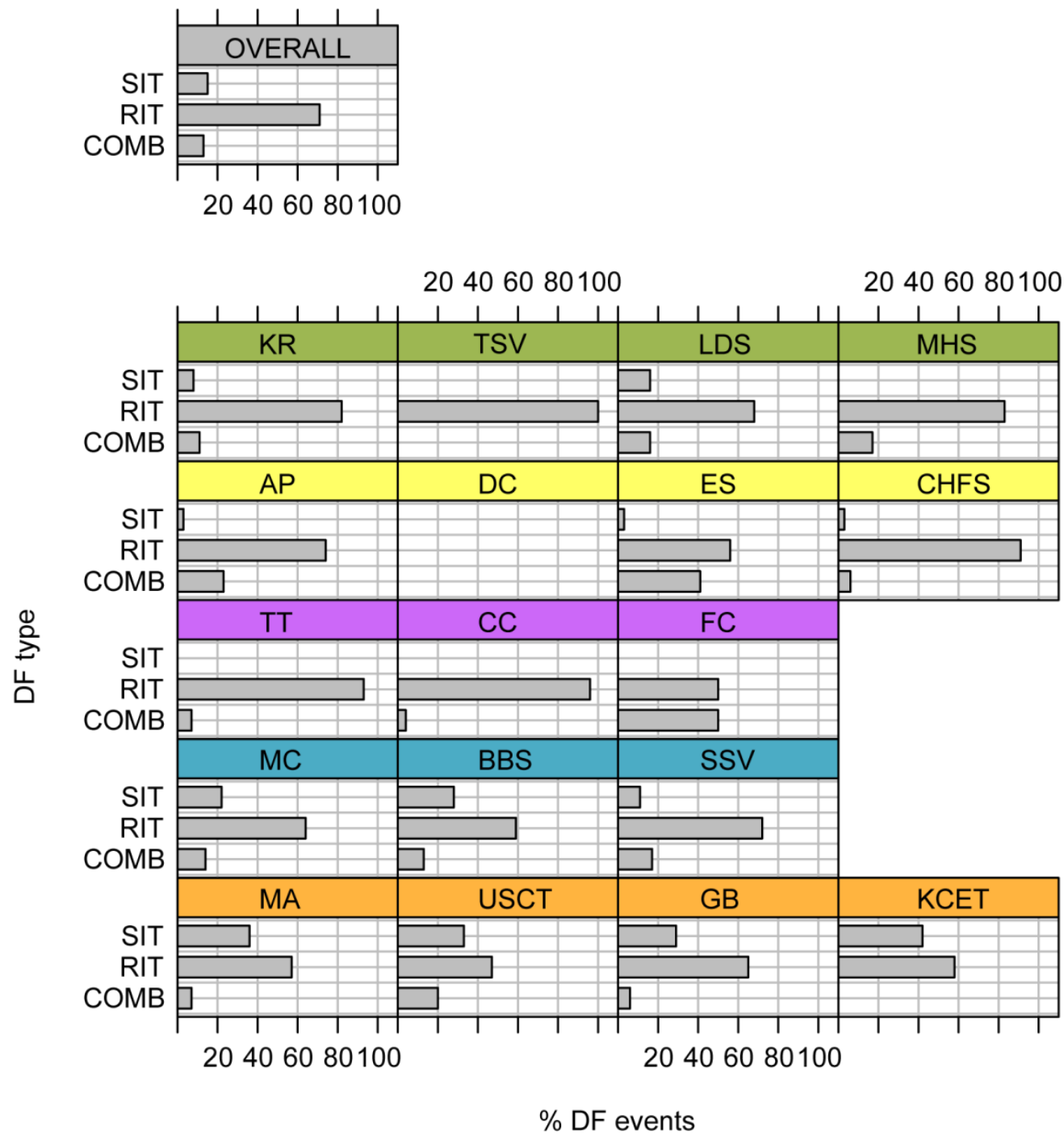


\section{A 5.2 Regolith supply conditions}
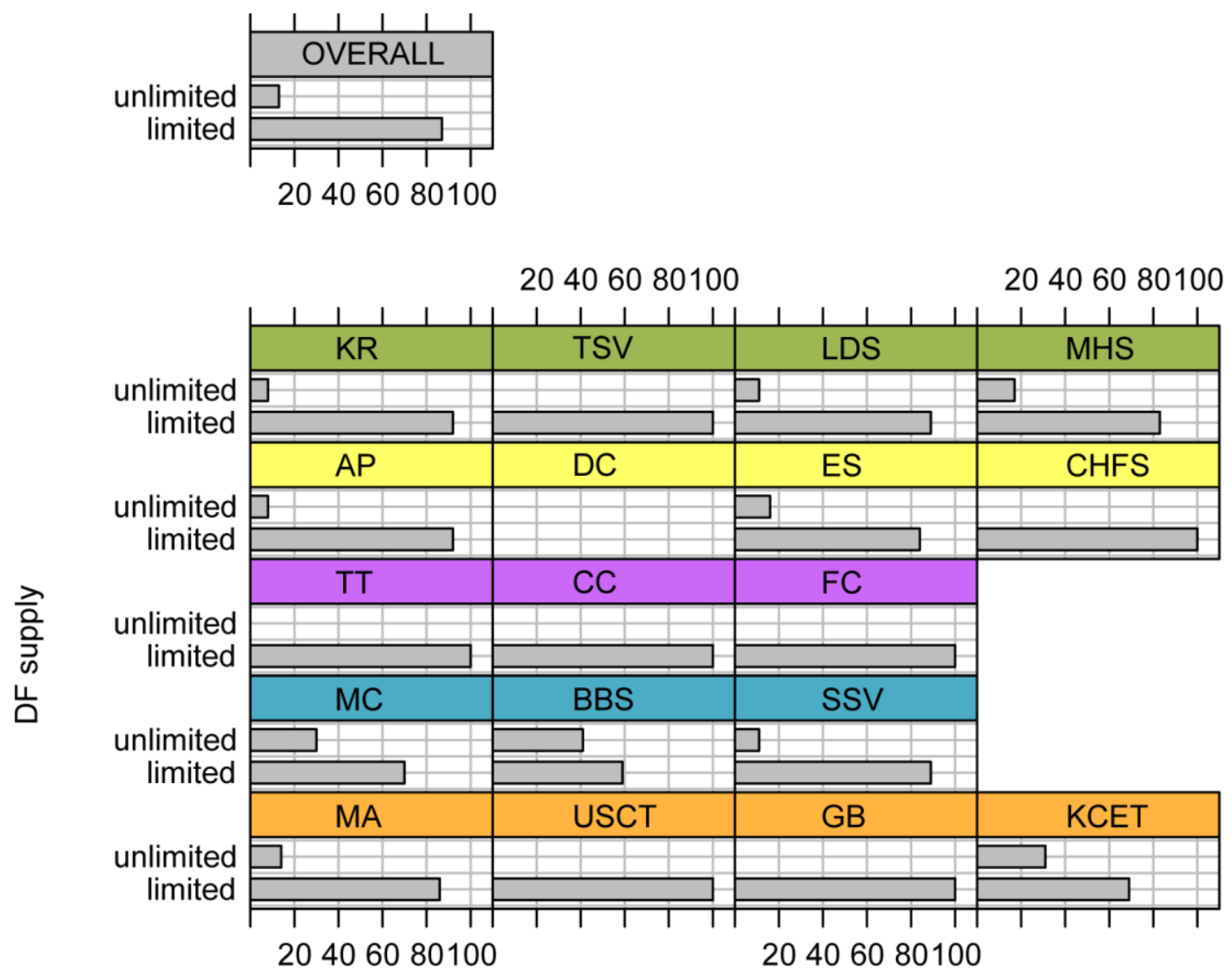

\% DF events 
A 5.3 Aspect
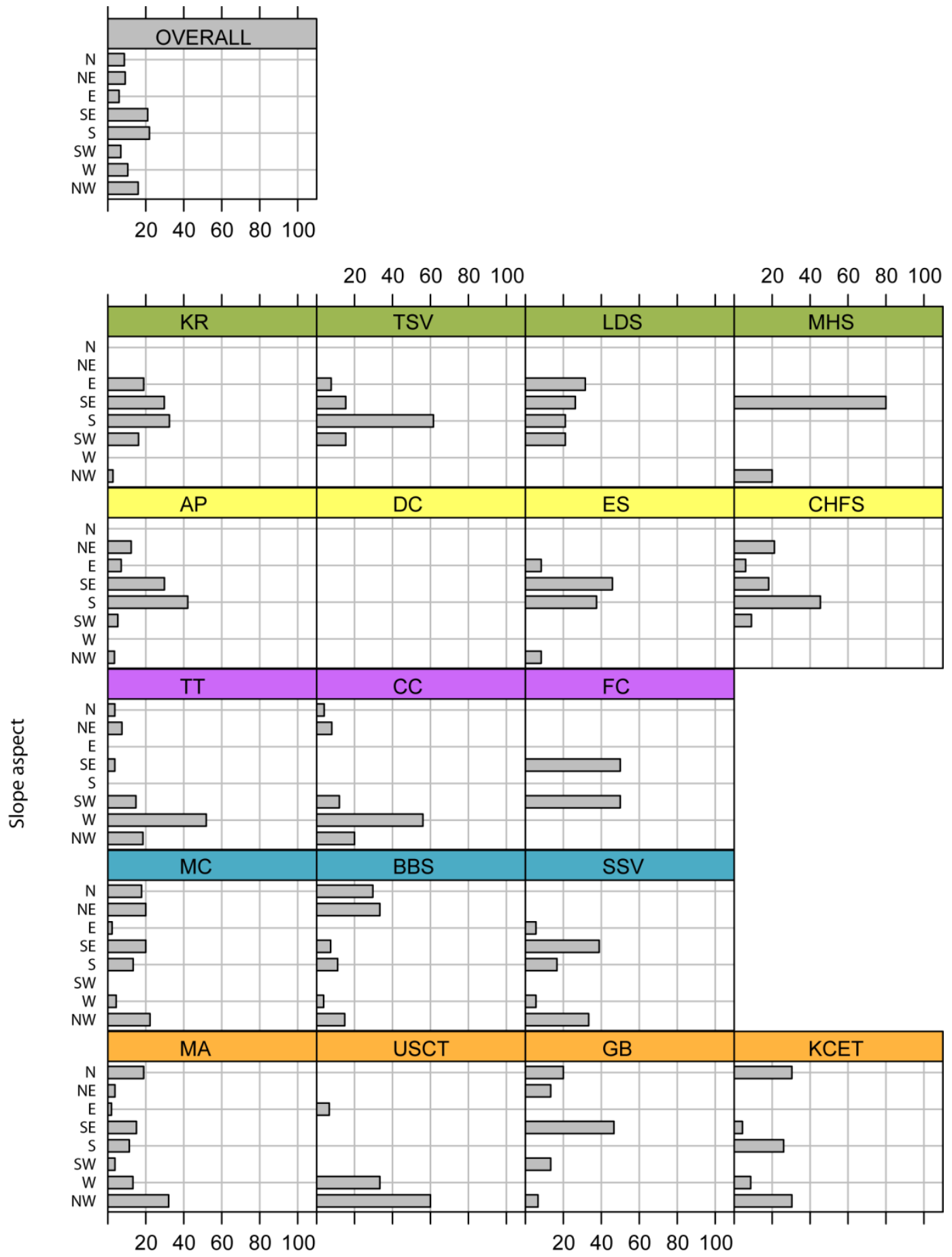

$\%$ of DF systems 


\section{A 5.4 Slope}
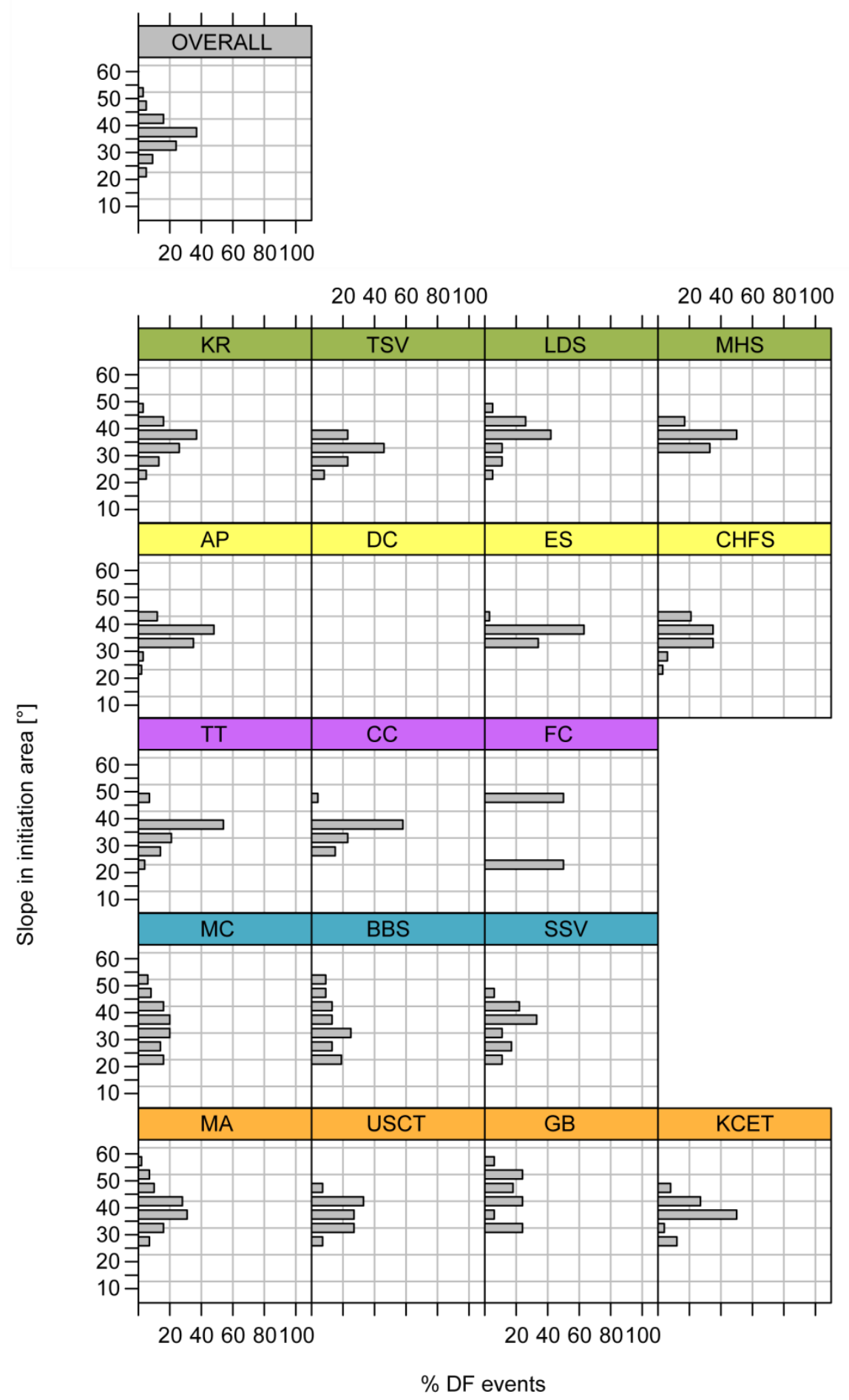
A 5.5 Altitude above sea level
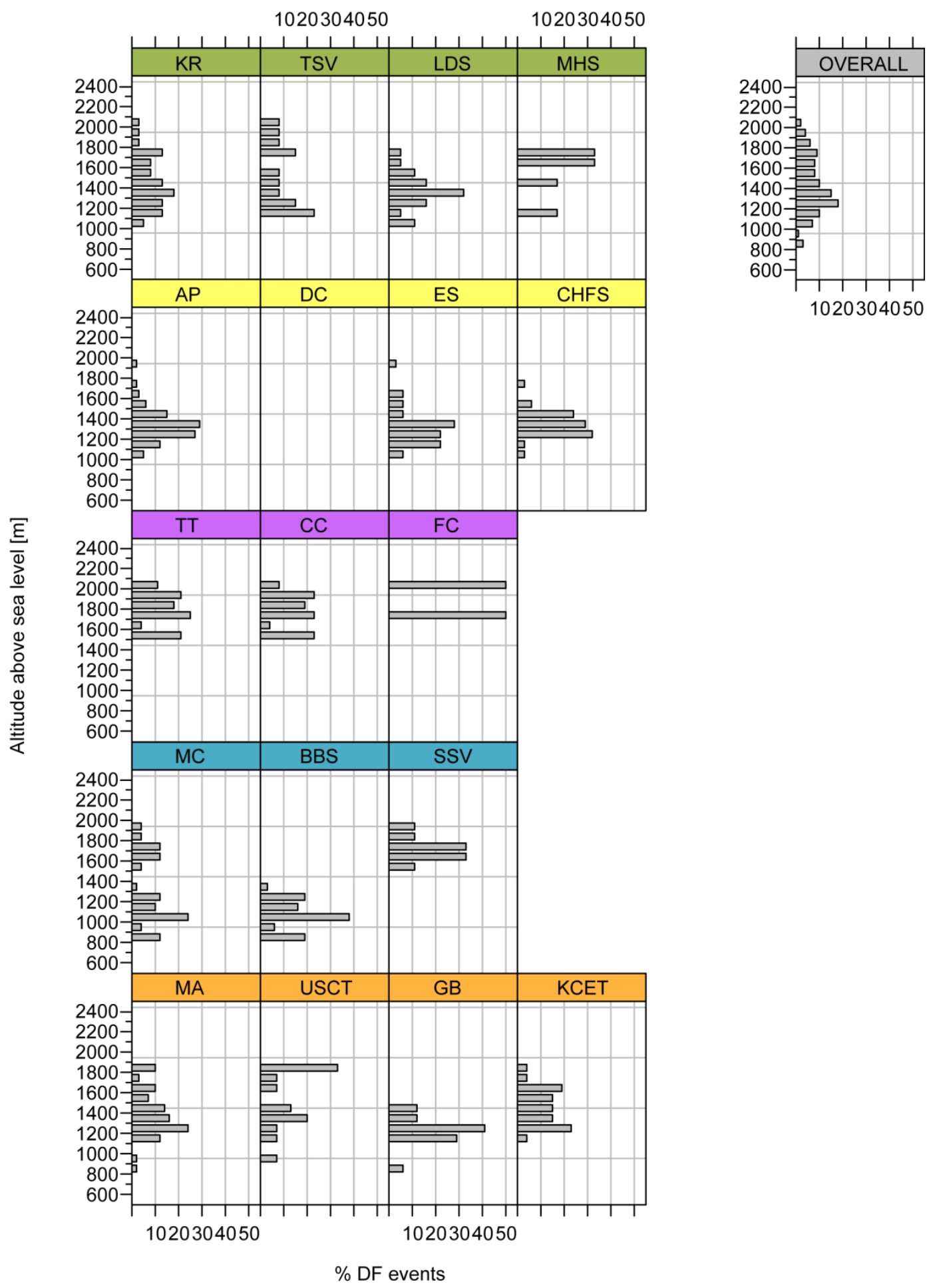
A 5.6 Altitude above catchment exit (relative altitude)
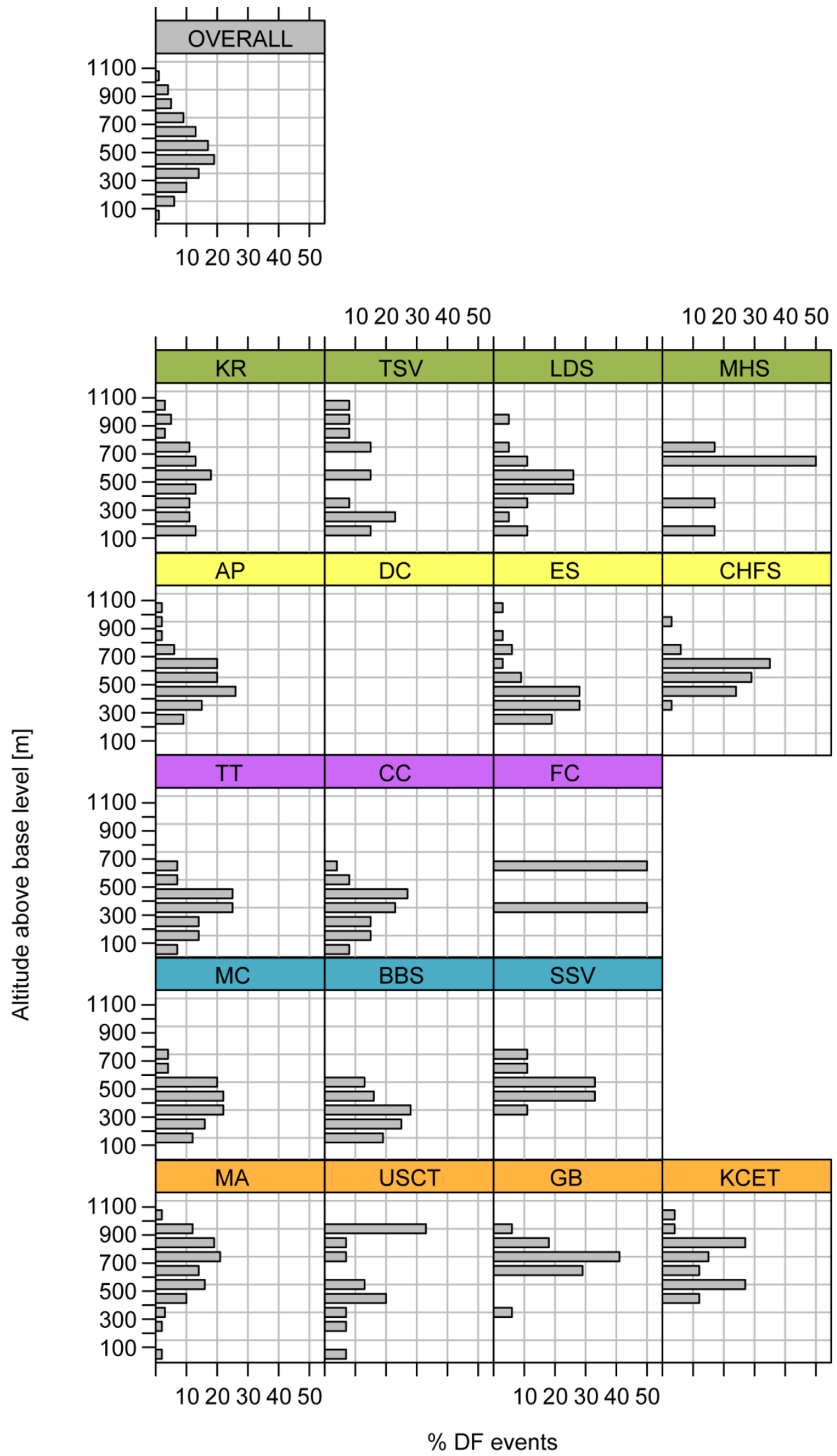


\section{APPENDIX 6: ClimATE STATIONS USED FOR TEMPERATURE INTERPOLATIONS (SECTION 4.2.2, 5.2.6, AND 5.2.7)}

The following tables list climate stations used in this study for temperature calculations. Table A4.1 specifies climate stations close to the debris flow study areas (Agent \# refers to National Climate Database ID (NIWA, 2010). Since the network of temperature-recording climate stations is sparse in the Southern Alps, nearby stations are identical for study areas of a given region. Climate stations are consequently grouped according to region. The stations highlighted in grey were used for frost-weathering intensity calculations (Section 5.2.7) for the study area noted in the last column. Mean annual temperature surfaces for the prediction of permafrost in the individual study areas (Section 5.2.6 and 5.2.7) were calculated by inter- and extrapolating between all the stations listed for the respective region. These regional lists are excerpts of Table A4.2 which lists all the South Island climate stations that were available for the calculation of mean annual temperature surfaces for the training and application of the permafrost distribution model (Section 4.2.2). Data from climate stations closest to the location of interest were denoted the highest weight in the calculations.

\begin{tabular}{|c|c|c|c|c|c|c|c|c|}
\hline $\begin{array}{l}\text { Table A4.1 } \\
\text { Region }\end{array}$ & Station name & Agent\# & Start date & End date ${ }^{A}$ & Latitude & Longitude & Altitude $[\mathrm{m}]$ & $\begin{array}{c}\text { Frost-weathering } \\
\text { calculations }^{8}\end{array}$ \\
\hline \multirow[t]{9}{*}{ Kaikoura ranges } & Blenheim & 4331 & 28/02/1947 & $31 / 08 / 1985$ & -41.51 & 173.95 & 4 & \\
\hline & Blenheim Aero AWS & 4326 & 7/09/1990 & active & -41.52 & 173.87 & 35 & \\
\hline & Blenheim Aero & 4322 & $31 / 12 / 1971$ & $31 / 03 / 1987$ & -41.52 & 173.87 & 40 & \\
\hline & Grassmere Salt Works & 4420 & $31 / 12 / 1971$ & 27/02/2014 & -41.73 & 174.15 & 2 & \\
\hline & Molesworth & 4461 & $31 / 12 / 1949$ & $30 / 01 / 1993$ & -42.09 & 173.26 & 890 & \\
\hline & Kaikoura AWS & 4506 & 14/01/1982 & active & -42.42 & 173.69 & 105 & \\
\hline & Kaikoura Weather Station & 4507 & $31 / 12 / 1971$ & 18/09/1991 & -42.42 & 173.69 & 105 & ISV, LUS, MHSS \\
\hline & Hanmer Forest & 4458 & $31 / 12 / 1971$ & $31 / 03 / 1995$ & -42.52 & 172.85 & 387 & \\
\hline & Hanmer Forest EWS & 11234 & 3/05/1995 & active & -42.53 & 172.85 & 363 & \\
\hline \multirow[t]{7}{*}{ Arthur's Pass region } & Mt Philistine Ews & 38103 & $14 / 04 / 2010$ & active & -42.88 & 171.53 & 1655 & \\
\hline & Arthurs Pass & 4513 & $11 / 04 / 1978$ & $30 / 04 / 2014$ & -42.94 & 171.56 & 738 & \\
\hline & Arthurs Pass Ews & 25821 & 2/08/2005 & active & -42.94 & 171.56 & 738 & \\
\hline & Craigieburn Forest & 4651 & $31 / 12 / 1963$ & $31 / 08 / 2013$ & -43.15 & 171.71 & 914 & CHFS, ES, DC \\
\hline & Harper River & 4657 & 9/12/1987 & $31 / 12 / 2007$ & -43.21 & 171.46 & 533 & \\
\hline & Lake Coleridge & 4670 & $1 / 08 / 1917$ & $30 / 08 / 1996$ & -43.37 & 171.53 & 364 & \\
\hline & Methven Cws & 36645 & 24/12/2008 & active & -43.64 & 171.65 & 313 & \\
\hline Two Thumb Range & Tasman Saddle Aws & 4578 & 2/06/1985 & $30 / 10 / 1987$ & -43.51 & 170.34 & 2310 & \\
\hline \multirow{7}{*}{ \& Mt Cook region } & Mt Cook EWS & 18125 & $1 / 02 / 2000$ & active & -43.74 & 170.10 & 765 & BBS \\
\hline & Mt Cook The Hermitage & 4591 & $30 / 04 / 1929$ & $29 / 02 / 2000$ & -43.73 & 170.09 & 765 & BBS \\
\hline & Peel Forest & 4772 & 11/09/1973 & $30 / 04 / 2014$ & -43.91 & 171.26 & 286 & \\
\hline & Lake Tekapo Air Safaris & 4970 & $31 / 12 / 1927$ & $30 / 04 / 2014$ & -44.00 & 170.44 & 762 & $\mathrm{CC}, \mathrm{FC}, \mathrm{SSV}$ \\
\hline & Twizel & 4995 & $3 / 02 / 1972$ & $31 / 05 / 1986$ & -44.25 & 170.09 & 457 & \\
\hline & Twizel & 4997 & 28/10/1991 & $1 / 07 / 2002$ & -44.26 & 170.10 & 457 & \\
\hline & Twizel Substation & 4996 & $31 / 03 / 1985$ & $31 / 12 / 1991$ & -44.28 & 170.10 & 451 & \\
\hline \multirow{8}{*}{ Mt Aspiring region } & Albert Burn & 35098 & 25/01/2008 & active & -44.38 & 168.93 & 1280 & \\
\hline & Lake Hawea & 5218 & $31 / 12 / 1971$ & $31 / 05 / 1988$ & -44.61 & 169.24 & 350 & \\
\hline & Milford Sound & 4107 & $31 / 12 / 1933$ & active & -44.67 & 167.92 & 3 & \\
\hline & Wanaka Park Hq & 5217 & 6/09/1990 & $31 / 01 / 1994$ & -44.70 & 169.14 & 305 & \\
\hline & Wanaka & 5223 & 11/08/1972 & $30 / 08 / 1990$ & -44.71 & 169.15 & 314 & \\
\hline & Wanaka Aero Aws & 7426 & 6/05/1992 & active & -44.72 & 169.24 & 352 & \\
\hline & Queenstown Aero & 5450 & $31 / 12 / 1971$ & 26/10/1995 & -45.02 & 168.74 & 349 & \\
\hline & Queenstown & 5446 & $31 / 08 / 1871$ & $30 / 04 / 2014$ & -45.04 & 168.66 & 329 & USCT, GB, KCET \\
\hline
\end{tabular}


Table A4.2

\begin{tabular}{|c|c|c|c|c|}
\hline Station name & Agent \# & Latitude & Longitude & Altitude $[\mathrm{m}]$ \\
\hline Nelson Aero & 4241 & -41.299 & 173.226 & 2 \\
\hline Blenheim & 4331 & -41.511 & 173.954 & 4 \\
\hline Blenheim Aero & 4322 & -41.520 & 173.872 & 40 \\
\hline Blenheim Aero AWS & 4326 & -41.523 & 173.865 & 35 \\
\hline Grassmere Salt Works & 4420 & -41.729 & 174.145 & 2 \\
\hline Molesworth & 4461 & -42.088 & 173.258 & 890 \\
\hline Reefton Ews & 3925 & -42.117 & 171.860 & 198 \\
\hline Kaikoura AWS & 4506 & -42.421 & 173.691 & 105 \\
\hline Kaikoura Weather Station & 4507 & -42.421 & 173.691 & 105 \\
\hline Hanmer Forest & 4458 & -42.522 & 172.854 & 387 \\
\hline Hanmer Forest EWS & 11234 & -42.534 & 172.851 & 363 \\
\hline Hokitika Aero & 3909 & -42.720 & 170.990 & 39 \\
\hline Hokitika South & 3907 & -42.730 & 170.960 & 4 \\
\hline Balmoral Forest & 4532 & -42.866 & 172.749 & 198 \\
\hline Mt Philistine Ews & 38103 & -42.883 & 171.532 & 1655 \\
\hline Ross & 3913 & -42.893 & 170.809 & 15 \\
\hline Arthurs Pass & 4513 & -42.940 & 171.560 & 738 \\
\hline Arthurs Pass Ews & 25821 & -42.943 & 171.563 & 738 \\
\hline Harihari N.Z.F.S. & 4044 & -43.144 & 170.553 & 45 \\
\hline Craigieburn Forest & 4651 & -43.150 & 171.710 & 914 \\
\hline Harper River & 4657 & -43.210 & 171.460 & 533 \\
\hline Okarito & 4053 & -43.219 & 170.166 & 2 \\
\hline Franz Josef Ews & 24926 & -43.365 & 170.134 & 80 \\
\hline Lake Coleridge & 4670 & -43.370 & 171.530 & 364 \\
\hline Franz Josef T.H.C. & 4059 & -43.380 & 170.180 & 122 \\
\hline Franz Josef & 4060 & -43.390 & 170.180 & 155 \\
\hline Fox Glacier Main Rd & 4069 & -43.466 & 170.017 & 152 \\
\hline Christchurch Aero & 4843 & -43.490 & 172.540 & 37 \\
\hline Mt Potts Ews & 37002 & -43.505 & 170.926 & 2128 \\
\hline Mt Potts Ews & 37002 & -43.505 & 170.926 & 2128 \\
\hline Tasman Saddle Aws & 4578 & -43.510 & 170.340 & 2310 \\
\hline Methven Cws & 36645 & -43.640 & 171.652 & 313 \\
\hline Mueller Hut Ews & 38102 & -43.722 & 170.065 & 1818 \\
\hline Mt Cook The Hermitage & 4591 & -43.730 & 170.090 & \\
\hline Mt Cook Ews & 18125 & -43.740 & 170.100 & 765 \\
\hline Haast & 4095 & -43.860 & 169.010 & 4 \\
\hline Haast Aws & 4097 & -43.860 & 169.010 & 5 \\
\hline Haast Correlation & 9999 & -43.860 & 169.010 & 5 \\
\hline Peel Forest & 4772 & -43.908 & 171.259 & 286 \\
\hline Jackson Bay AWS & 16625 & -43.975 & 168.617 & 2 \\
\hline Lake Tekapo Air Safaris & 4970 & -44.000 & 170.440 & 762 \\
\hline Twizel & 4995 & -44.250 & 170.090 & 457 \\
\hline Temuka & 5075 & -44.250 & 171.285 & 24 \\
\hline Twizel & 4997 & -44.260 & 170.100 & 457 \\
\hline Twizel Substation & 4996 & -44.280 & 170.100 & 451 \\
\hline Albert Burn & 35098 & -44.381 & 168.926 & 1280 \\
\hline Adair & 5088 & -44.433 & 171.165 & 85 \\
\hline Tara Hills Aws & 5212 & -44.528 & 169.890 & 488 \\
\hline Omarama Tara Hills & 5211 & -44.529 & 169.888 & 488 \\
\hline Benmore Power Stn & 5113 & -44.569 & 170.190 & 253 \\
\hline Lake Hawea & 5218 & -44.610 & 169.240 & 350 \\
\hline Milford Sound & 4107 & -44.670 & 167.920 & 3 \\
\hline Milford Correlation & 9998 & -44.670 & 167.920 & 3 \\
\hline Wanaka Park Hq & 5217 & -44.700 & 169.140 & 305 \\
\hline Wanaka & 5223 & -44.710 & 169.150 & 314 \\
\hline Wanaka Aero Aws & 7426 & -44.720 & 169.240 & 352 \\
\hline Waimate & 5102 & -44.741 & 171.036 & 64 \\
\hline Ikawai & 5041 & -44.873 & 170.939 & 70 \\
\hline Oamaru Airport & 5141 & -44.976 & 171.083 & 30 \\
\hline Queenstown Aero & 5450 & -45.024 & 168.735 & 349 \\
\hline Queenstown & 5446 & -45.037 & 168.663 & 329 \\
\hline Lauder EWS & 5535 & -45.040 & 169.684 & 376 \\
\hline Ophir 2 & 5544 & -45.106 & 169.611 & 305 \\
\hline Murchison Mtns Ews & 35614 & -45.222 & 167.630 & 1140 \\
\hline Manapouri Aero AWS & 5430 & -45.535 & 167.642 & 209 \\
\hline Lumsden AWS & 5496 & -45.748 & 168.449 & 187 \\
\hline Lumsden AWS & 5496 & -45.748 & 168.449 & 187 \\
\hline Tapanui & 5686 & -45.944 & 169.257 & 180 \\
\hline Gore & 5778 & -46.115 & 168.887 & 123 \\
\hline Winton 2 & 5768 & -46.157 & 168.328 & 44 \\
\hline
\end{tabular}




\section{APPENDIX 7:}

\section{PRELIMINARY PERMAFROST DISTRIBUTION ESTIMATE FOR THE IRISHMAN StREAM VALLEY, CENTRAL BEN OHAU RANGE (SECTION 4.3.4)}

The placement of miniature temperature data loggers for ground surface temperature monitoring was based on a preliminary permafrost distribution estimate for the head area of the Irishman Stream catchment and surrounding slopes. This preparatory estimate was derived from the mean toe elevation (per aspect class) of intact rock glaciers mapped in the Ben Ohau Range. Black symbols and white labels mark the logger location and corresponding site name.

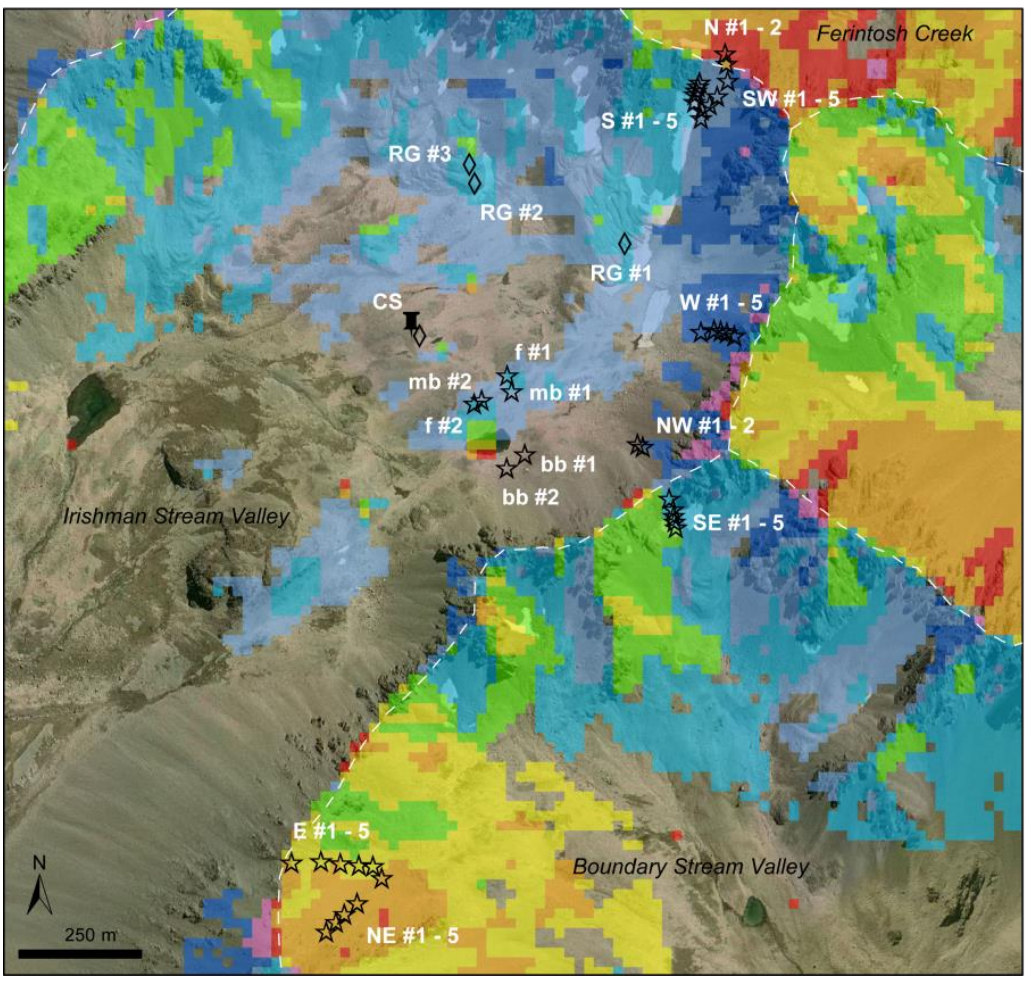

Preliminary permafrost extent according to aspect class

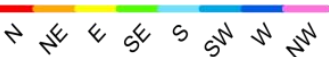

Logger locations

$\mp$ Climate station

Data loggers (GST)

$\diamond \quad$ Data loggers (snow depth)

-- Ridgeline

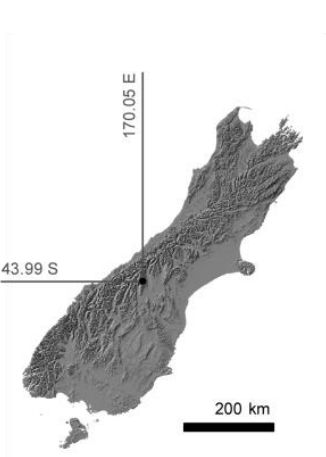


APPENDIX 8:

MODELLED PERMAFROST EXTENT AND FROST-WEATHERING

INTENSITIES IN THE STUDY AREAS (SECTION 5.2.6 AND 5.2.7) 

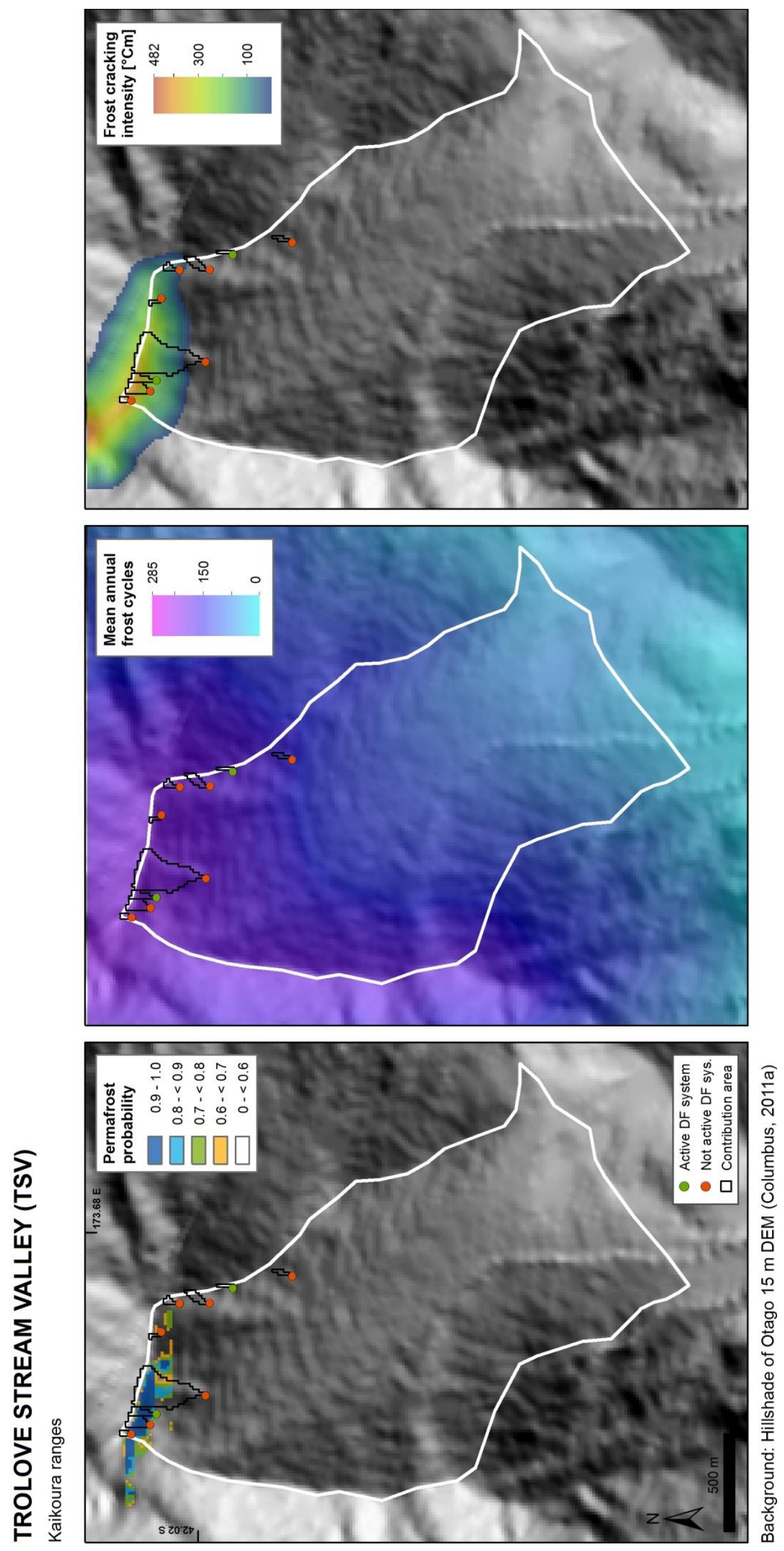

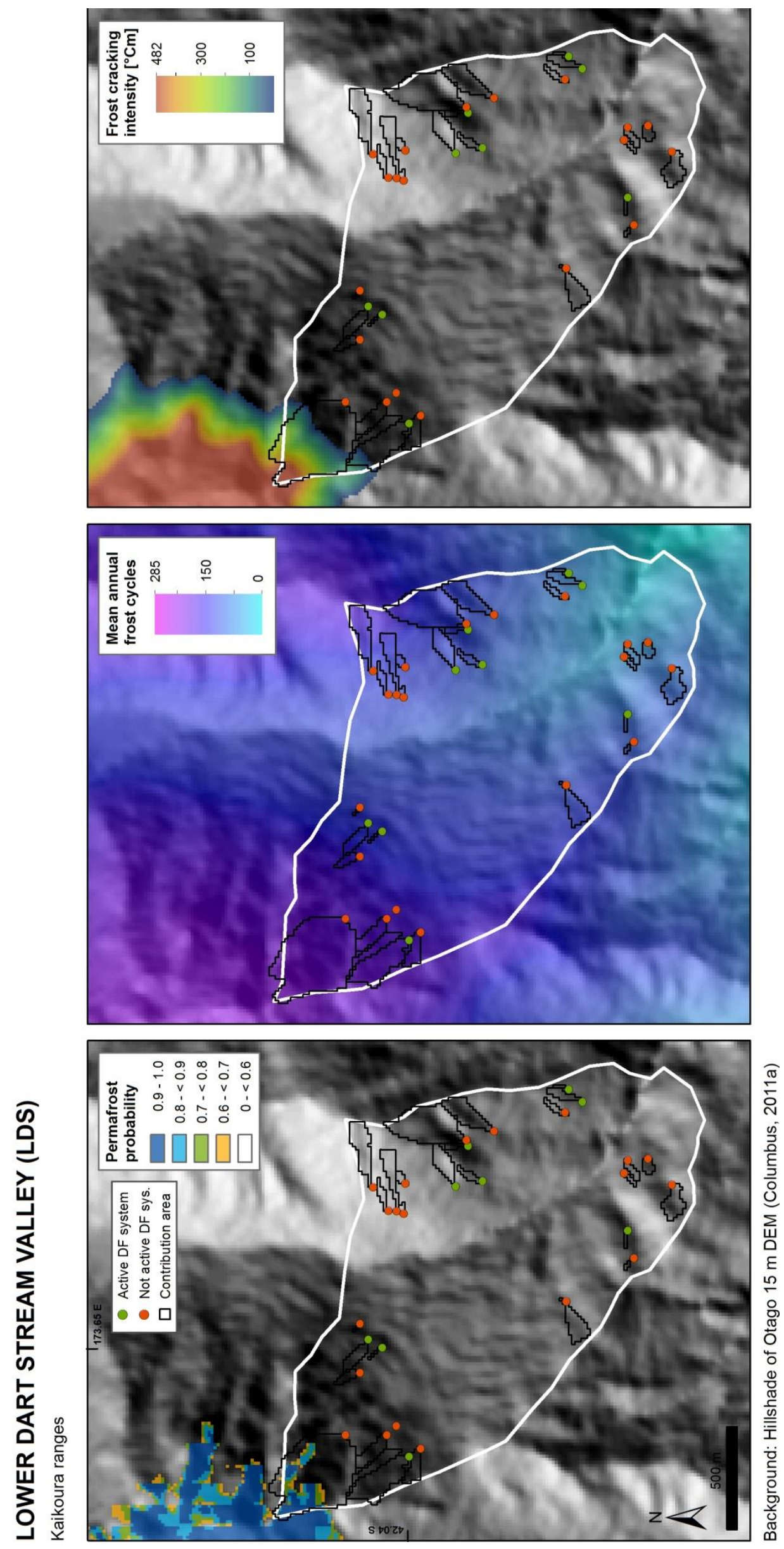

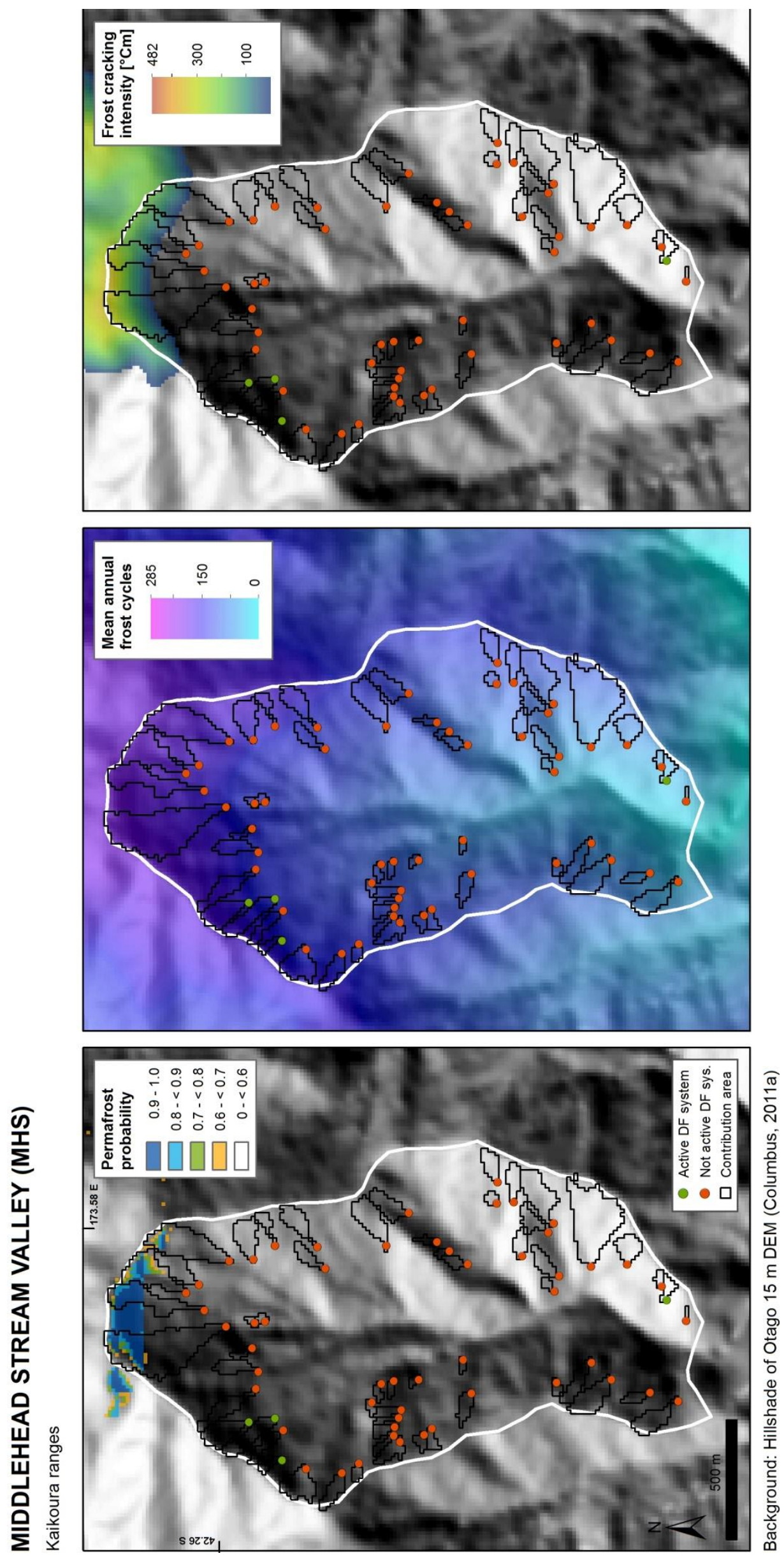

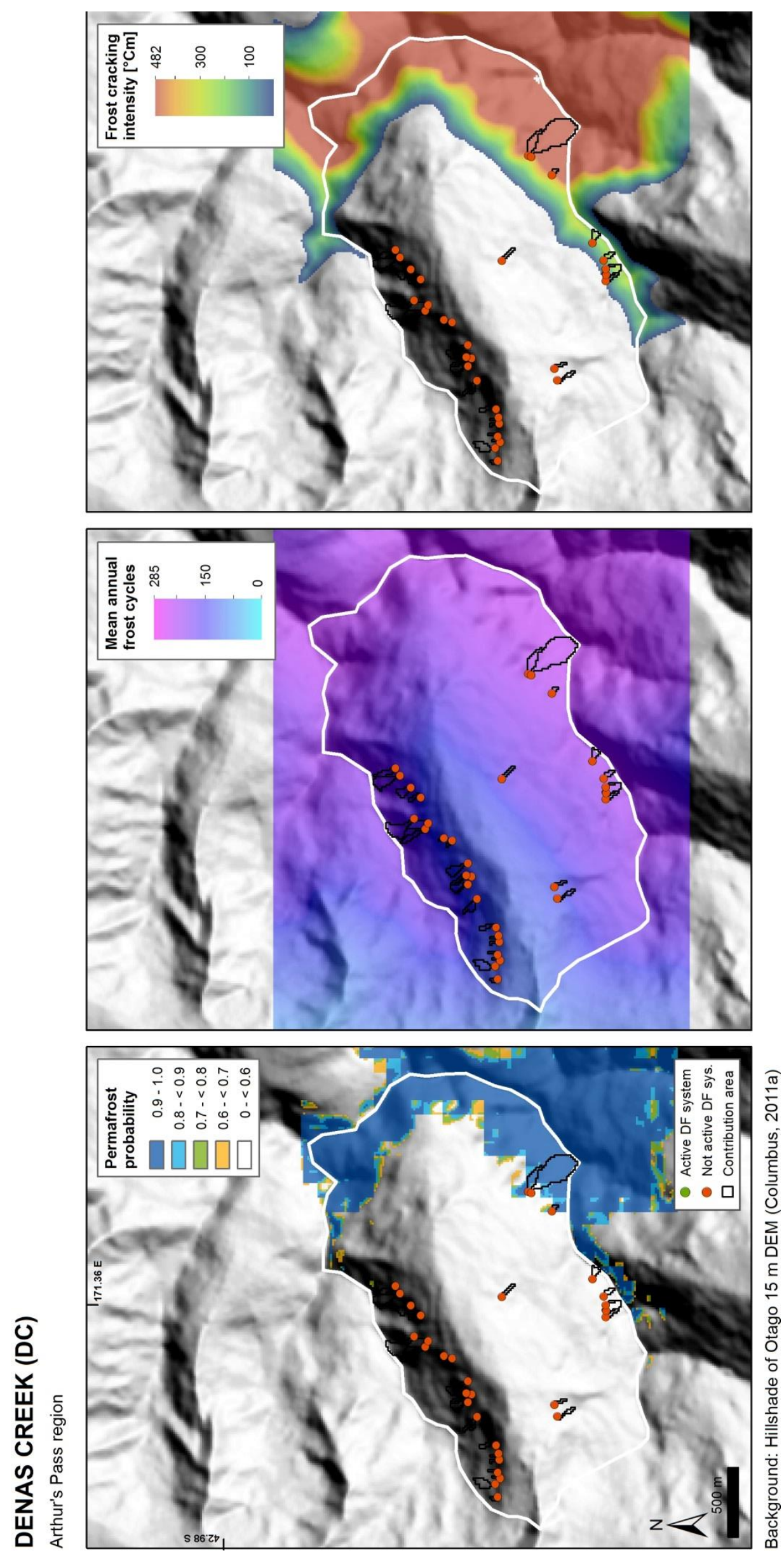

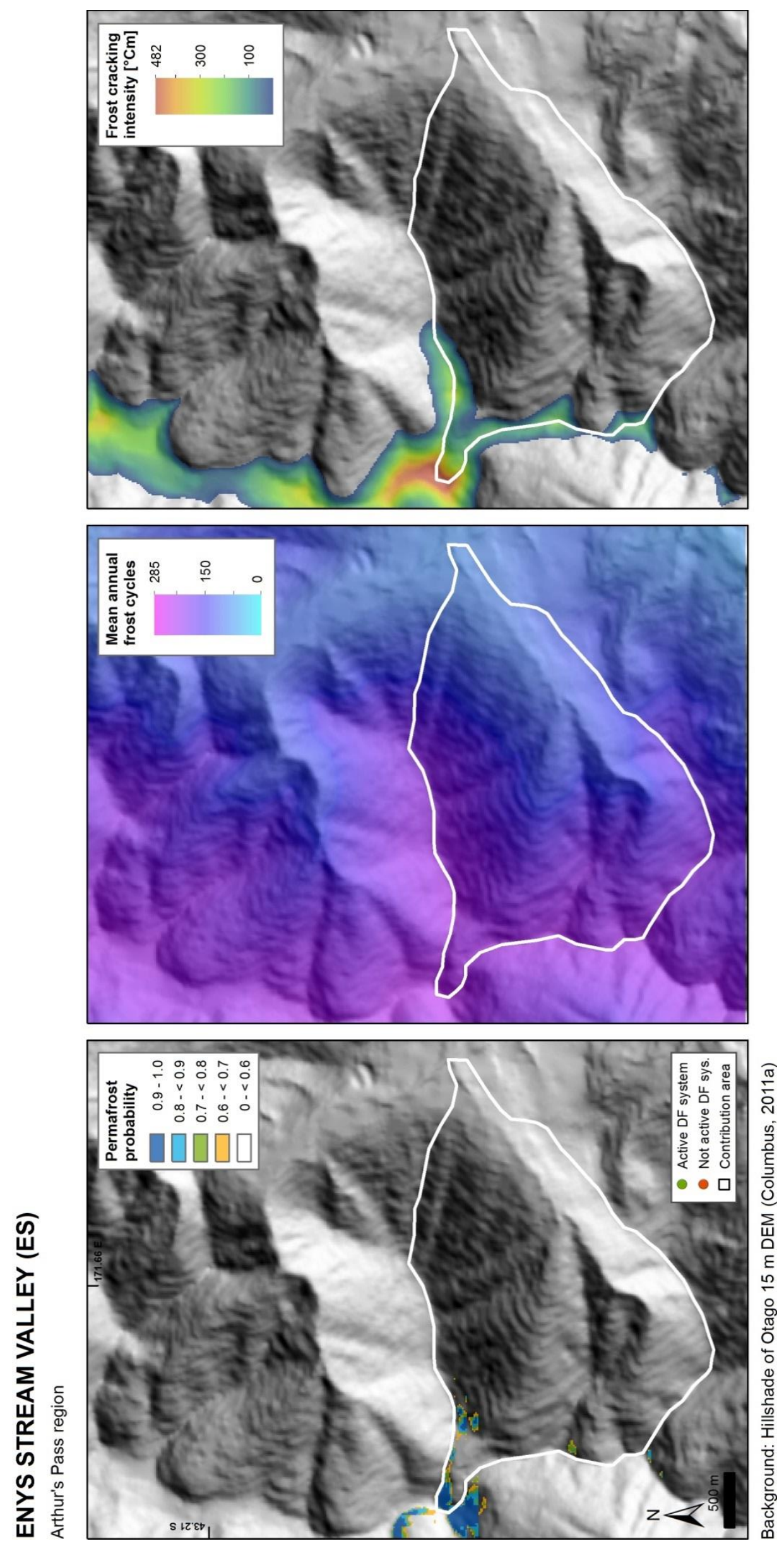

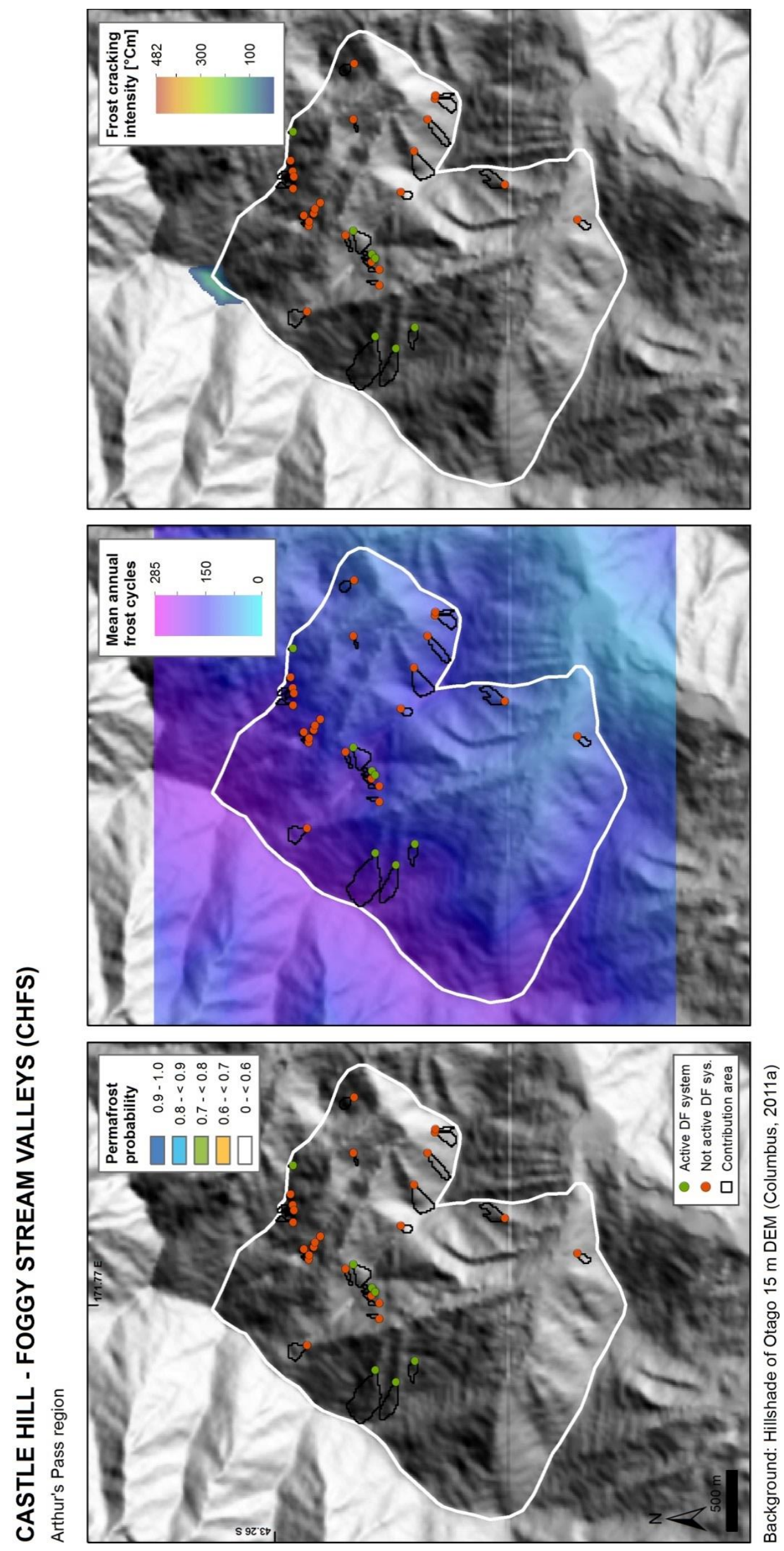

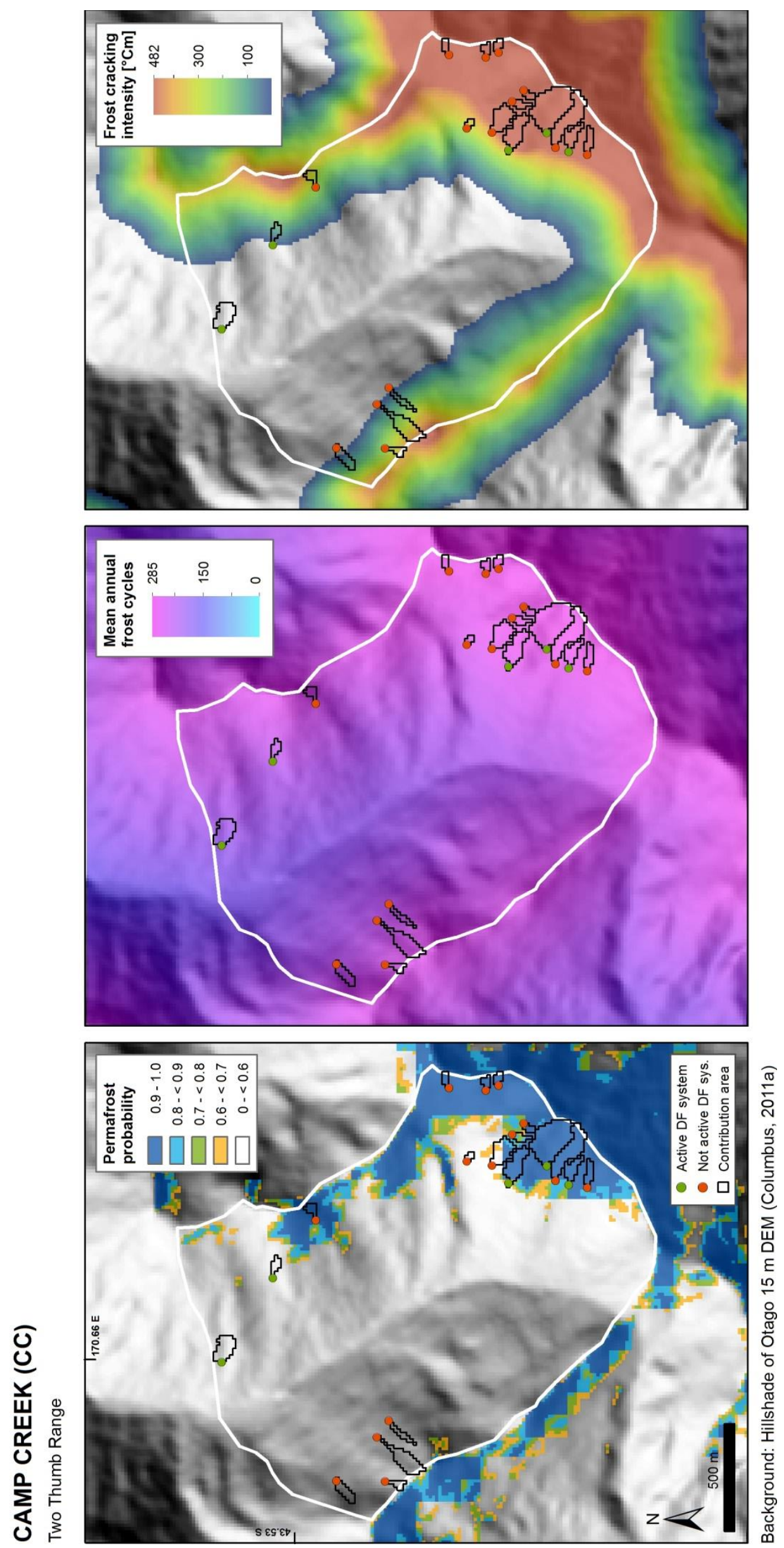

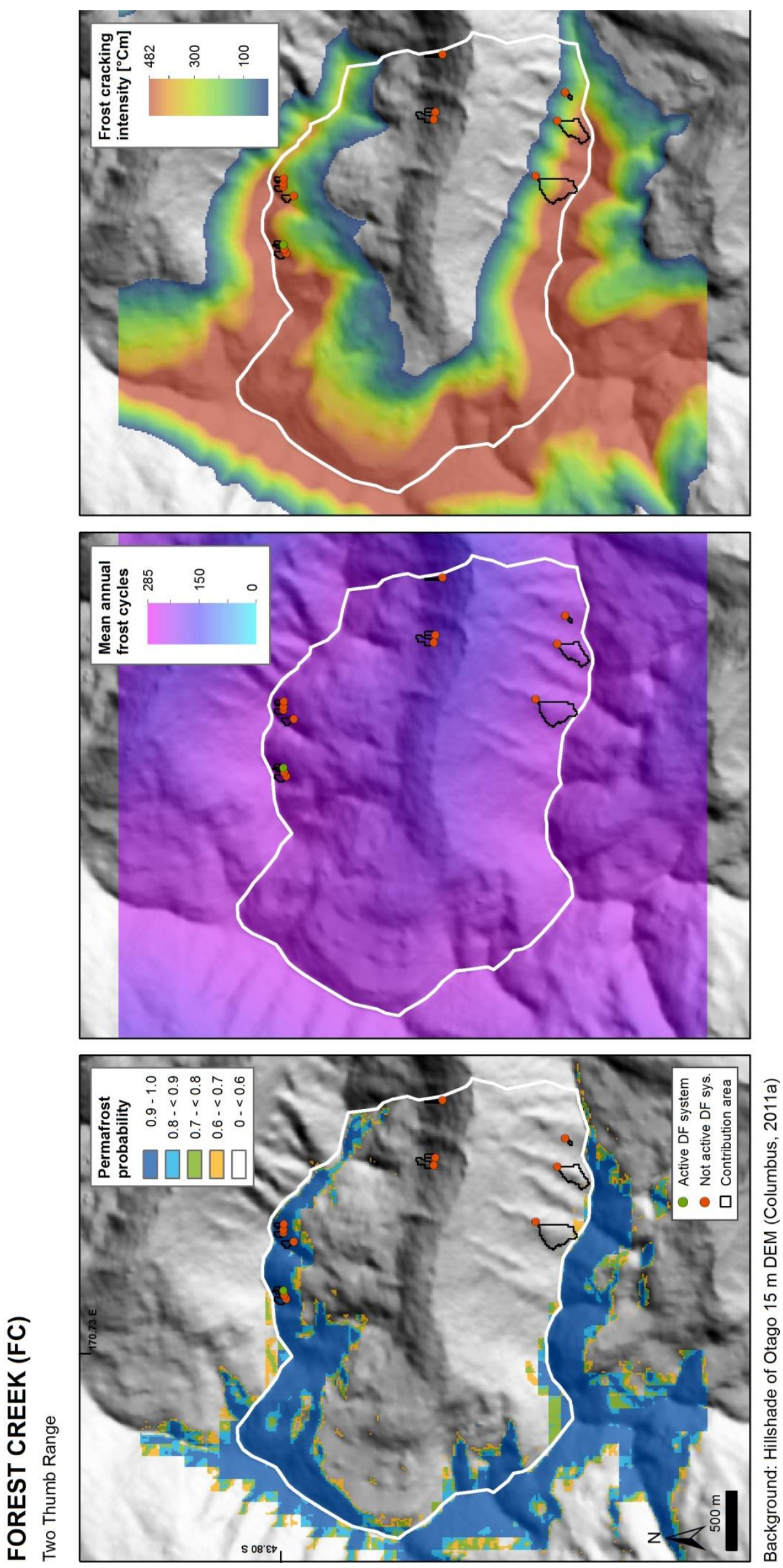

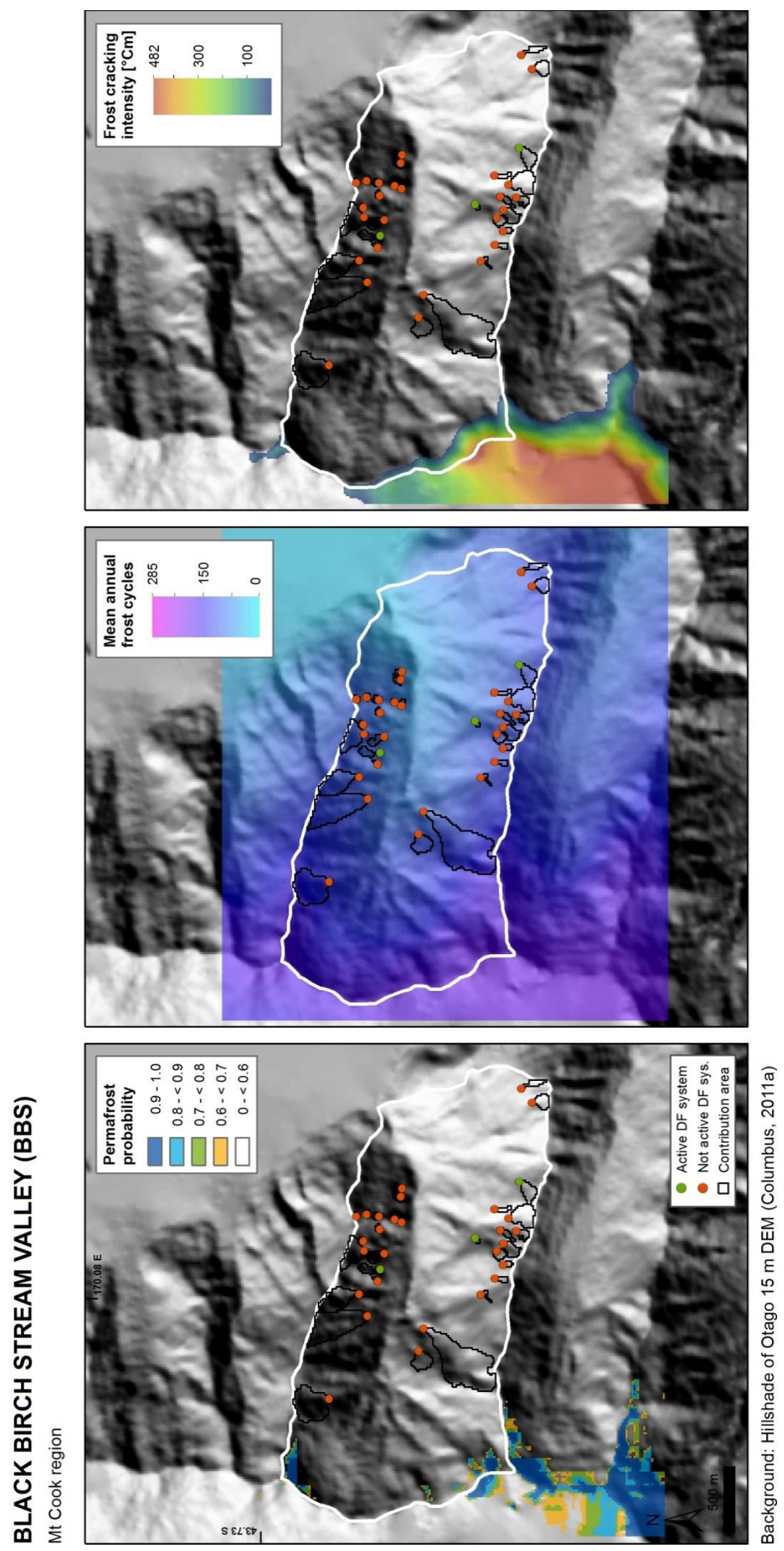

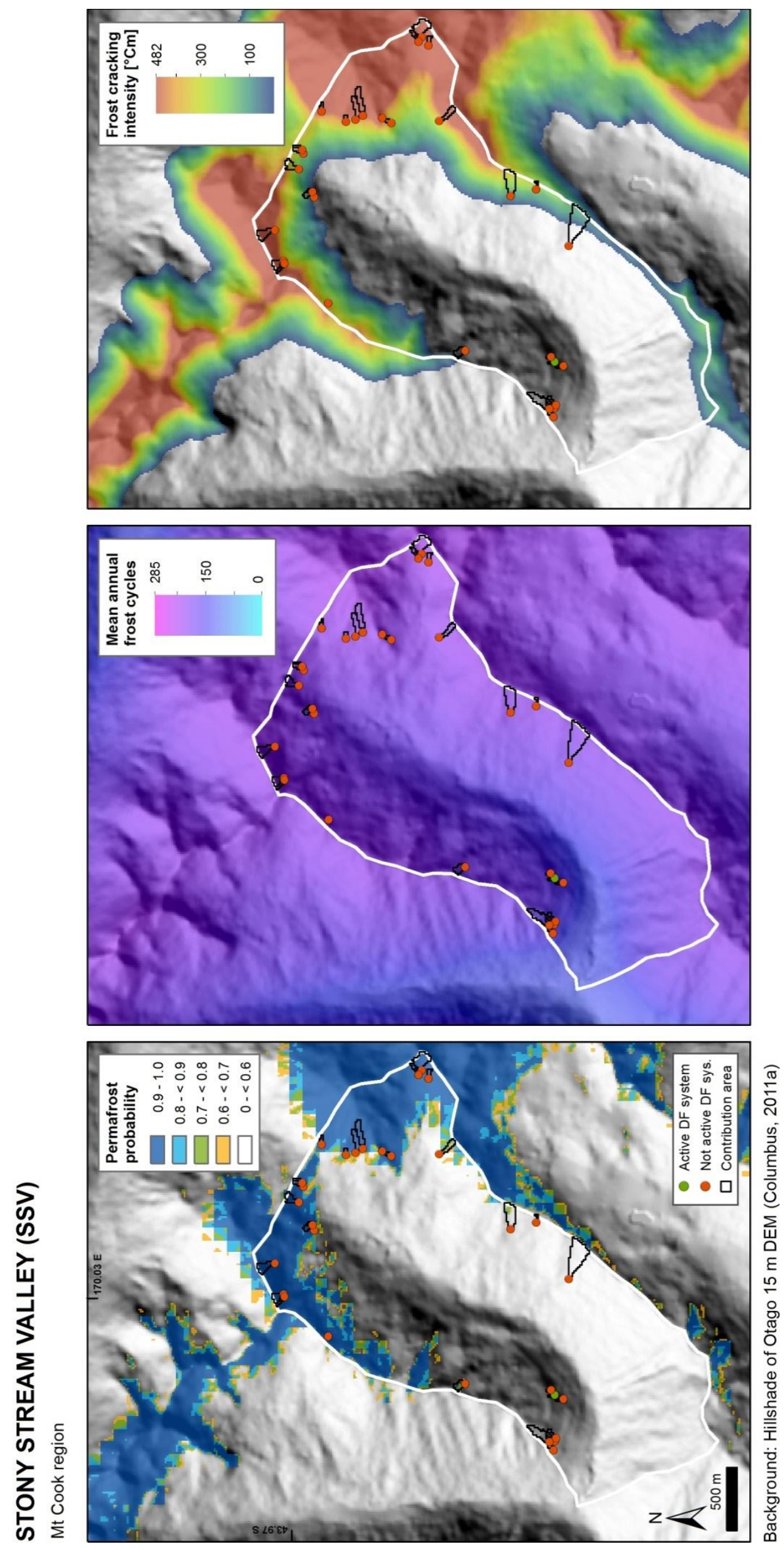

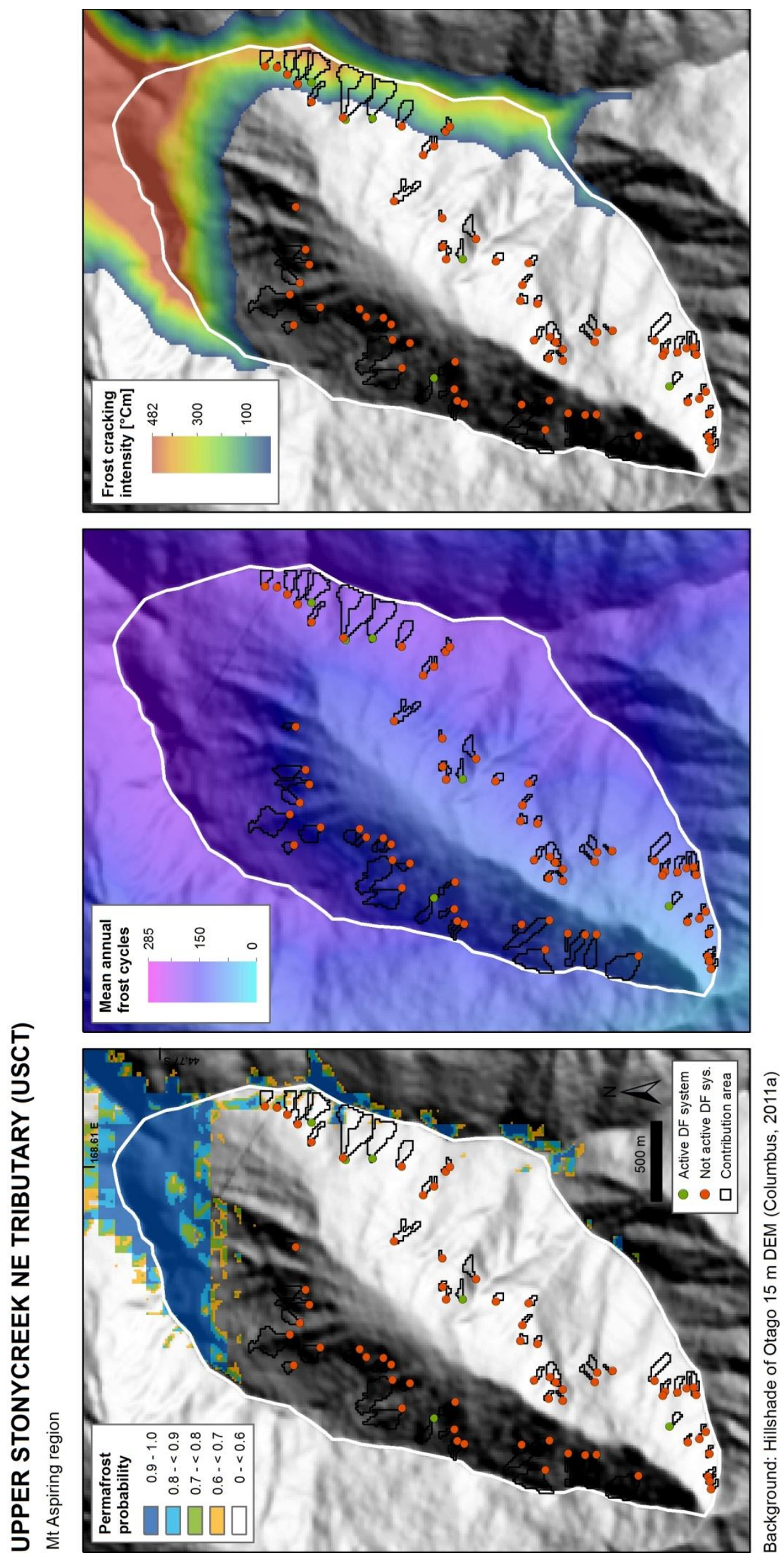

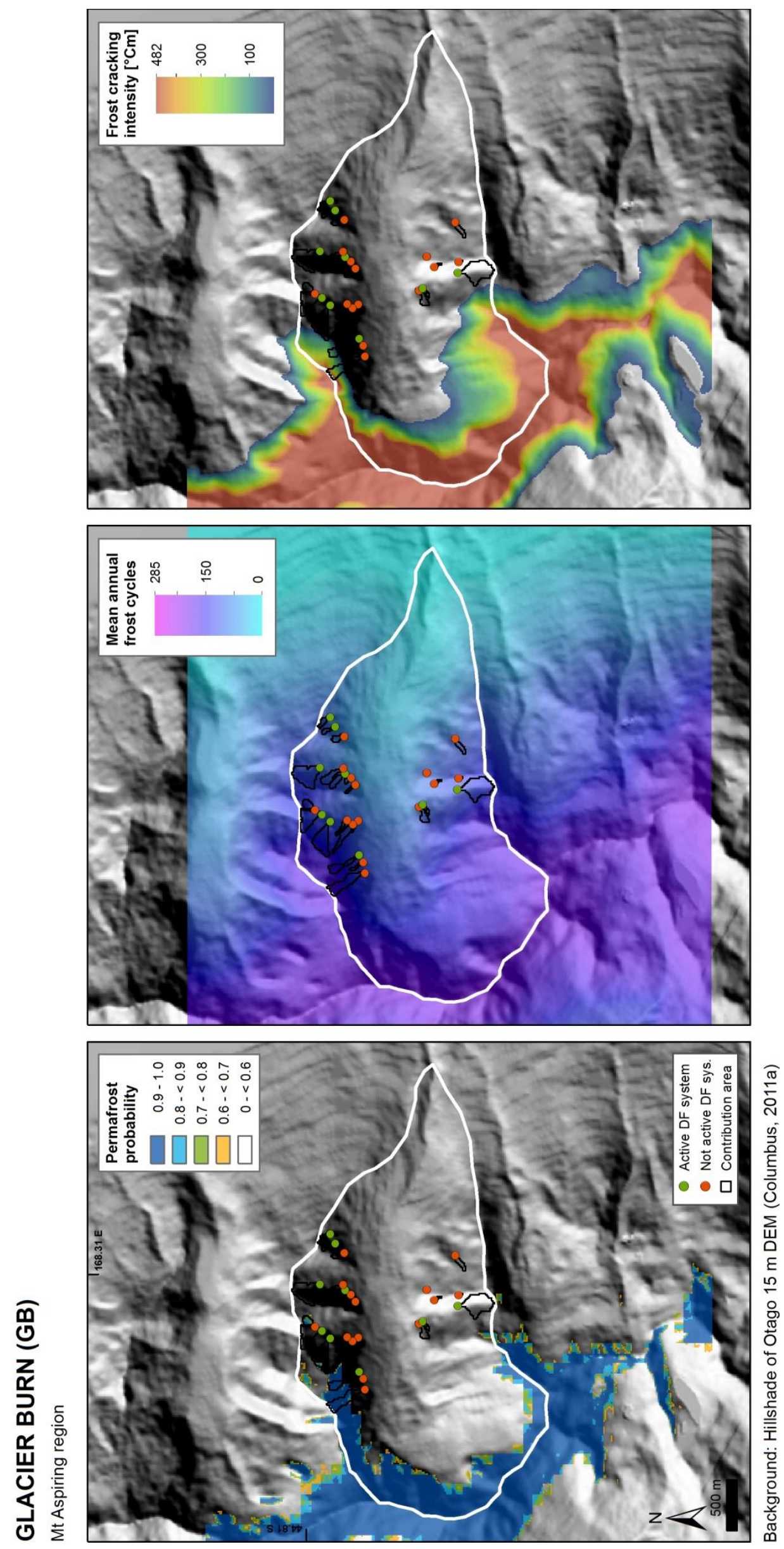

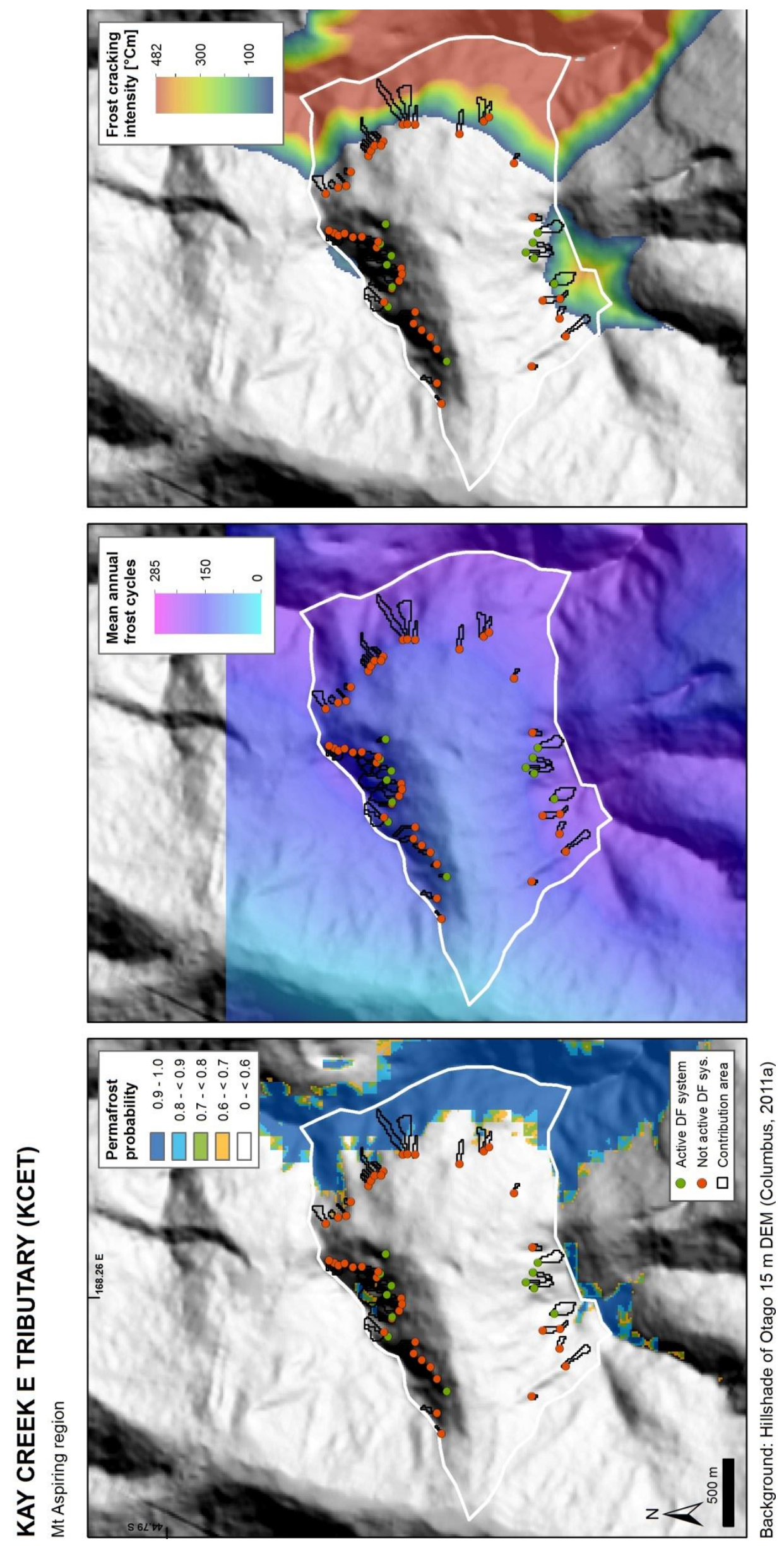


\section{APPENDIX 9: VARIANCE INFLATION FACTORS FOR REGRESSION ANALYSES}

The variance inflation factor (VIF) is a measure for multicollinearity between predictors in a regression model (e.g. Field, 2005; Gordon, 2012). A VIF values greater than 10 is considered critical. Average VIF values markedly above 1 indicate that multicollinearity might be biasing the regression model.

Variance inflation factors for the regression models in Section 5.2.7:

\section{Question I - Topography}

\begin{tabular}{ll} 
Parameter & VIF \\
\hline Area & 1.014 \\
Area slope $>40^{\circ}$ & 1.014
\end{tabular}

Question II - Frost weathering

Table 5.11

\begin{tabular}{ll} 
Parameter & VIF \\
\hline FCI sum & 4.583 \\
FCI mean & 4.686 \\
Fcyc sum & 1.379 \\
Fcyc mean & 1.540
\end{tabular}

Question III - Frost weathering \& aspect

\begin{tabular}{lll} 
Table 5.14 & Parameter & VIF \\
\cline { 2 - 3 } & Fcyc sum & 1.012 \\
& South vs North & 1.012
\end{tabular}

Question IV - Lithology

Table 5.16

\begin{tabular}{lc} 
Parameter & VIF \\
\hline Argillite & 1.036 \\
Greywacke & $\infty 1$ \\
Greenschist & 1.033 \\
Sandstone & 1.119 \\
Greychist & 1.105
\end{tabular}

\section{Question V - Lithology \& Frost weathering}

\begin{tabular}{lll} 
Table 5.19 & Parameter & VIF \\
\cline { 2 - 3 } & Fcyc sum & 1.051 \\
& Greywacke & 1.123 \\
& Greenschist & 1.171 \\
& Greyschist & $\infty$ \\
Table 5.20 & & \\
& Parameter & VIF \\
\cline { 2 - 3 } & Fcyc sum & 1.027 \\
& Argillite & 1.041 \\
& Greywacke & $\infty$ \\
& Greenschist & 1.038 \\
& Sandstone & 1.134 \\
& Greychist & 1.108 \\
& & \\
Table 5.21 & Parameter & VIF \\
\cline { 2 - 3 } & Fcyc sum & 1.004 \\
& Sedimentary vs. & 1.004 \\
& metamorphic rock & \\
& & \\
Table 5.22 & Parameter & VIF \\
\cline { 2 - 3 } & Fcyc sum & 1.000 \\
& Sedimentary vs. & 1.000 \\
& metamorphic rock &
\end{tabular}

Question VII - Permafrost

Table 5.27

\begin{tabular}{ll} 
Parameter & VIF \\
\hline PF pres & 4.952 \\
PF perc & 4.343 \\
PF sum & 1.488
\end{tabular}

$\overline{1 . . .}$ an infinite large VIF indicates perfect correlation with another predictor variable (cf. Gordon, 2012) 